Prepared in cooperation with U.S. Army Corps of Engineers and U.S. Fish and Wildlife Service

\title{
Spatial Variation in Population Dynamics of Northern Great Plains Piping Plovers
}

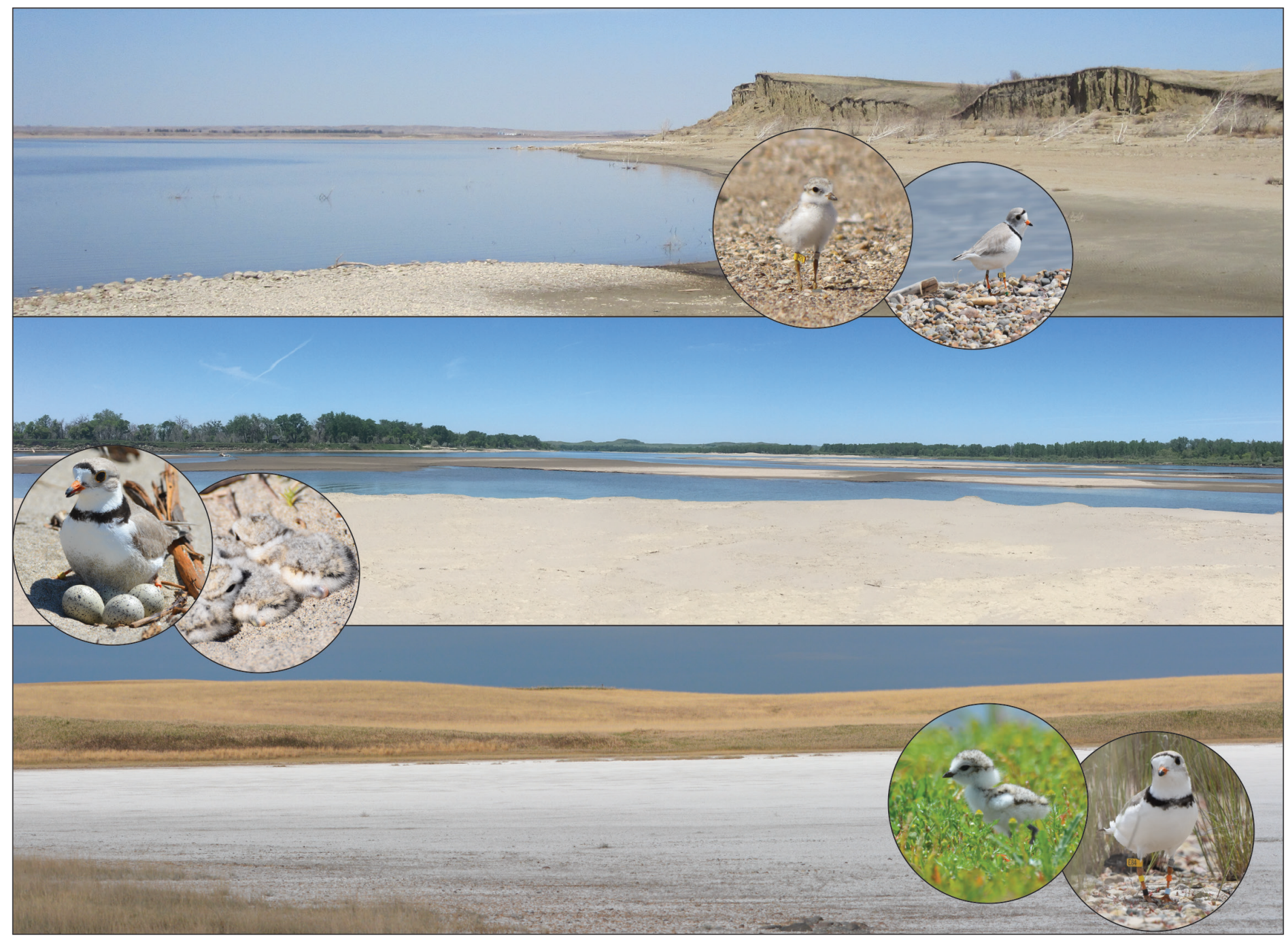

Open-File Report 2020-1152 


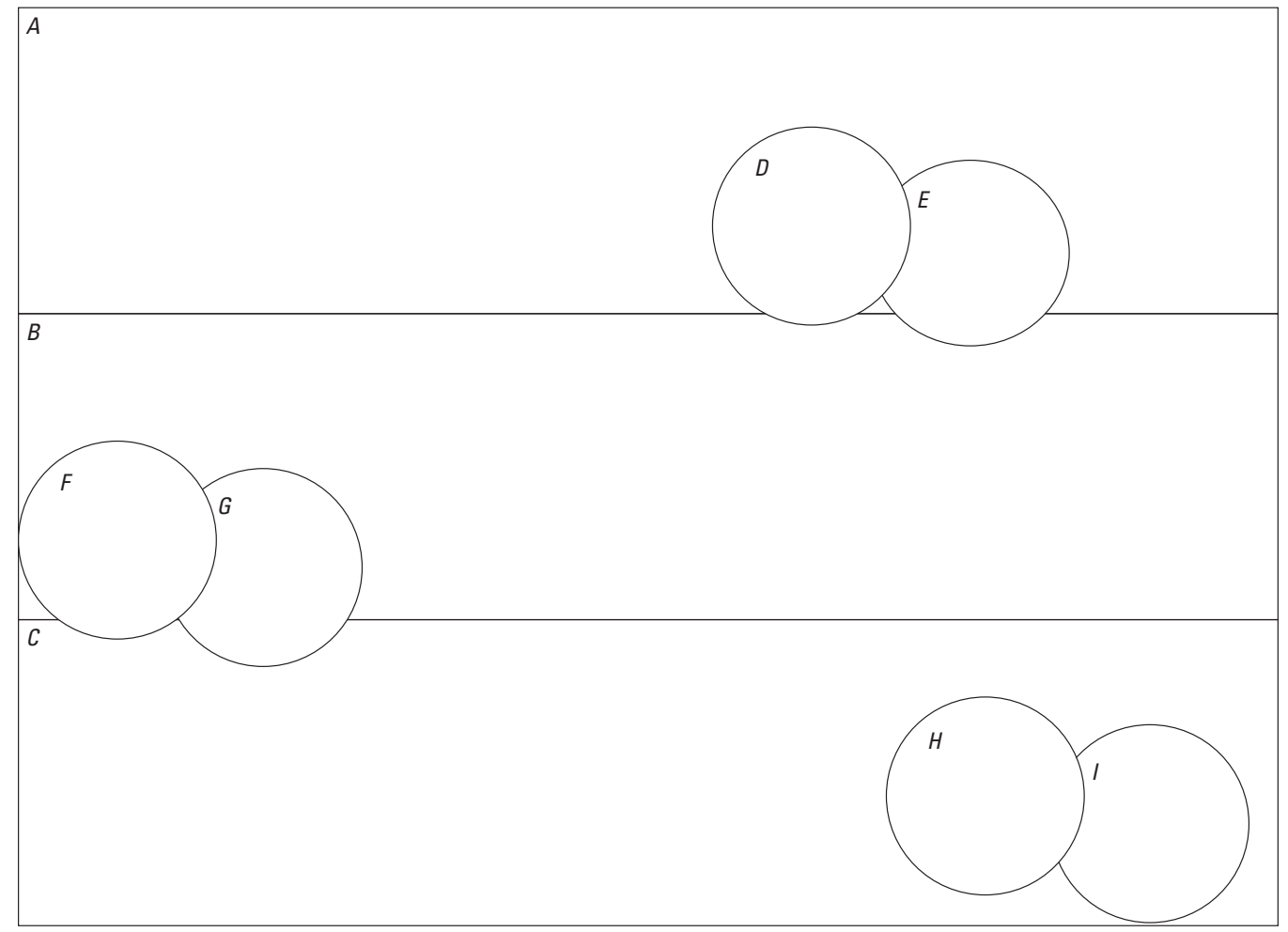

Front cover: $\quad A$, Typical reservoir habitat shoreline devoid of vegetation with cobble substrate and distant bluffs visible on Lake Sakakawea. $B$, Bare sand serves as the primary nesting substrate for piping plovers on the Garrison Reach of the Missouri River. $C$, An expansive salt flat with sparse vegetation on an alkali wetland used as nesting habitat by piping plovers. $D, A$ 14-day-old plover chick banded with a yellow alphanumeric flag stands on cobble substrate typical on reservoirs. $E$, A banded adult piping plover on cobble and pebble substrates seen on reservoir habitats. $F$, An adult piping plover standing over eggs on sand substrate typical on the riverine habitat type. $G$, Recently hatched chicks in nest bowl on the Garrison Reach of the Missouri River. H, Young piping plover chick in a field of vegetation on an alkali wetland. I, A banded adult piping plover stands amongst vegetation which is more prevalent on the alkali wetland habitat type.

Back cover: Two U.S. Geological Survey research technicians walk across a sparsely vegetated sandbar towards the Missouri River carrying spotting scopes and tripods in order to resight piping plovers. 


\section{Spatial Variation in Population Dynamics of Northern Great Plains Piping Plovers}

By Rose J. Swift, Michael J. Anteau, Kristen S. Ellis, Megan M. Ring, Mark H. Sherfy, Dustin L. Toy, and David N. Koons

Prepared in cooperation with U.S. Army Corps of Engineers and U.S. Fish and Wildlife Service

Open-File Report 2020-1152 


\section{U.S. Geological Survey, Reston, Virginia: 2021}

For more information on the USGS - the Federal source for science about the Earth, its natural and living resources, natural hazards, and the environment—visit https://www.usgs.gov or call 1-888-ASK-USGS.

For an overview of USGS information products, including maps, imagery, and publications, visit https://store.usgs.gov/.

Any use of trade, firm, or product names is for descriptive purposes only and does not imply endorsement by the U.S. Government.

Although this information product, for the most part, is in the public domain, it also may contain copyrighted materials as noted in the text. Permission to reproduce copyrighted items must be secured from the copyright owner.

Suggested citation:

Swift, R.J., Anteau, M.J., Ellis, K.S., Ring, M.M., Sherfy, M.H., Toy, D.L., and Koons, D.N., 2021, Spatial variation in population dynamics of northern Great Plains piping plovers: U.S. Geological Survey Open-File Report 2020-1152, 211 p., https://doi.org/10.3133/ofr20201152.

Associated data:

Swift, R.J., Anteau, M.J., Ring, M.M., Toy, D.L., and Sherfy, M.H., 2019, Renesting propensity, intervals, and reproductive success data for the Northern Great Plains Piping Plover, a threatened shorebird species 2014-2016: U.S Geological Survey data release, https://doi.org/10.5066/P9VAS8P7.

Swift, R.J., Anteau, M.J., Ellis, K.S., Ring, M.M., Sherfy, M.H., Toy, D.L., and Koons, D.N., 2020, Spatial variation in population dynamics of Northern Great Plains piping plovers, 2014-2019: U.S. Geological Survey data release, https://doi.org/10.5066/P96PSOBO.

ISSN 2331-1258 (online) 


\section{Acknowledgments}

This study was mostly funded by the U.S. Army Corps of Engineers' Missouri River Recovery Program, Omaha District. We also received logistical support from the U.S. Army Corps of Engineers' Garrison Project Office. We are also thankful for in-kind support and collaboration from the U.S. Fish and Wildlife Service National Wildlife Refuge (NWR) System (Arrowwood NWR, Audubon NWR/Wetland Management District [WMD], Lostwood NWR/WMD, Crosby WMD, Medicine Lake NWR, Northeast Montana WMD, Long Lake NWR/WMD) and Ecological Services Program, and The Nature Conservancy (John E. Williams Preserve, North Dakota).

We are also grateful for financial and technical support from the U.S. Geological Survey (USGS) Northern Prairie Wildlife Research Center. We particularly appreciate the contributions of Colin Dovichin, Erin Roche, Terry Shaffer, Marsha Sovada, Jennifer Stucker, Hillary Wagner, and Mark Wiltermuth in formulating the ideas and analyses presented here. The hard work and dedication of greater than 125 seasonal field technicians who collected and archived the data are especially noteworthy. We also want to thank the greater than 700 observers from other Federal and State agencies, nonprofits, and the public that reported banded piping plovers across their entire range. Max Post van der Burg and Brian Tangen provided detailed technical reviews of earlier drafts of this document which greatly improved this report. All capture and handling methods used in this study were in accordance with protocols approved by the Institutional Animal Care and Use Committee and within guidelines of an approved study plan by the USGS Northern Prairie Wildlife Research Center Animal Care and Use Committee. 



\section{Contents}

Acknowledgments ……...................................................................................................................

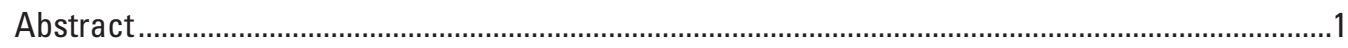

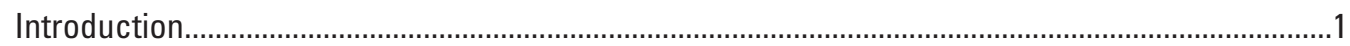

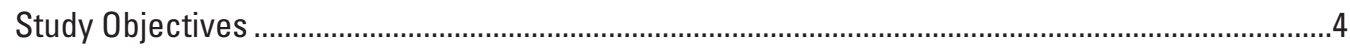

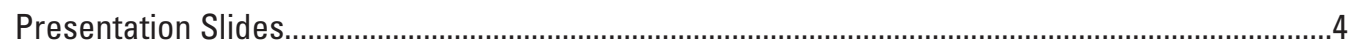

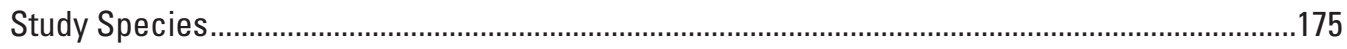

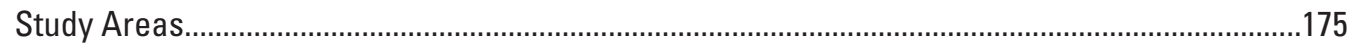

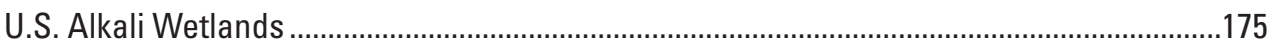

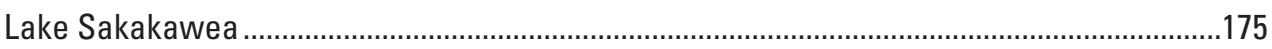

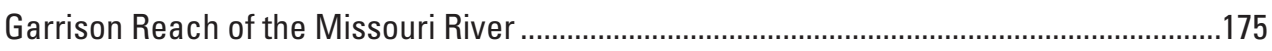

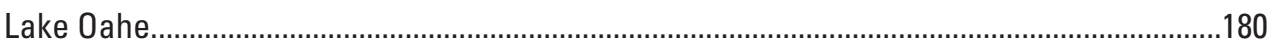

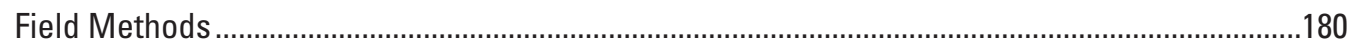

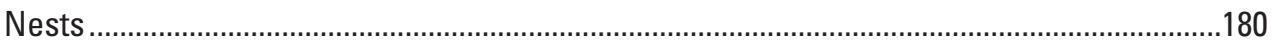

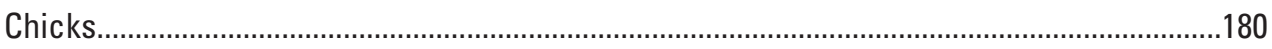

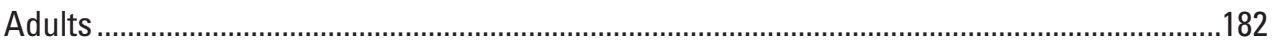

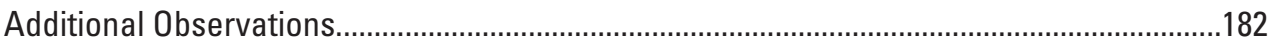

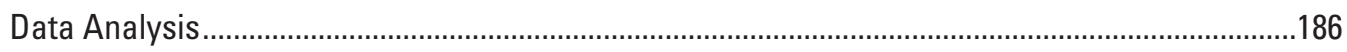

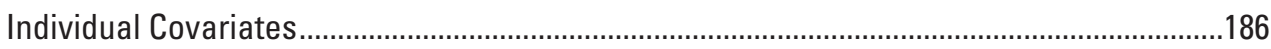

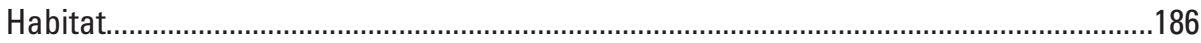

Reproductive Success .......................................................................................... 186

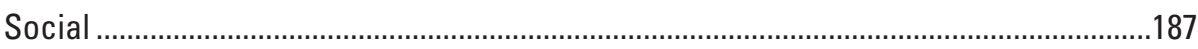

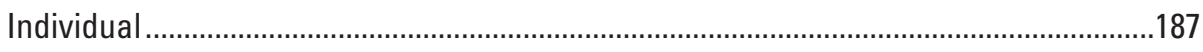

Renesting Propensity and Reproductive Success .............................................................188

Natal Survival and Dispersal Probabilities .......................................................................

Adult Survival and Breeding Dispersal Probabilities............................................................191

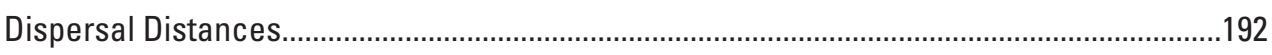

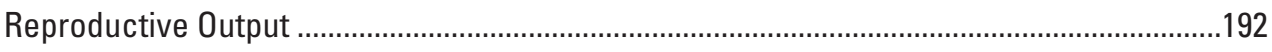

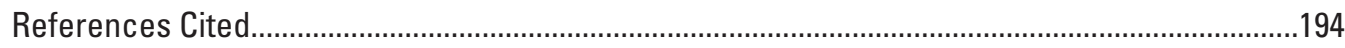

Appendix 1. Summary of Piping Plover Demographic Rates ....................................................201

\section{Figures}

1. Map showing northern Great Plains piping plover breeding focal study area in North Dakota, South Dakota, and Montana

2. Map showing piping plover breeding study areas based on four management units in North Dakota, South Dakota, and Montana monitored from 2014 to 2019.........176

3. Map showing approximate boundaries of the regions based on managers or wetland management districts of the U.S. Alkali Wetlands study area, North Dakota and Montana.

4. Map showing non-U.S. Geological Survey reported observations of piping plovers banded by the U.S. Geological Survey. 


\section{Tables}

1. Mean and standard deviation of the Standardized Precipitation-

Evapotranspiration Index from May through July for each region in the

U.S. Alkali Wetlands study area, North Dakota and Montana

2. Total wetlands visited by joint U.S. Geological Survey and U.S. Fish and

Wildlife Service crews for each region in the U.S. Alkali Wetlands study area, North Dakota and Montana

3. Mean and standard deviation main-stem reservoir pool elevations for May through July for Lake Sakakawea and Lake Oahe in 2014-19 and historical data, North Dakota and South Dakota

4. Total number of segments visited by U.S. Geological Survey crews for each management unit on the Missouri River, North Dakota and South Dakota, 2014-19

5. Mean and standard deviation main-stem outflow from the Garrison Dam for May through July for the Garrison Reach of the Missouri River, North Dakota, 2014-19.

6. Number of piping plover nests found in each management unit, North Dakota, South Dakota, and Montana, 2014-19.

7. Use of predator exclosures on a subset of piping plover nests in the U.S. Alkali Wetlands study area, North Dakota and Montana, 2014-16...

8. Number of uniquely marked piping plover chicks banded, natal recruits observed as adults, and chicks observed during the nonbreeding season hatched on the four management units, North Dakota, South Dakota, and Montana, 2014-17

9. Totals of piping plover adults captured and banded for the first time and unique identifiable resights by management unit, North Dakota, South Dakota, and Montana, 2014-19.

10. Unique observations of piping plovers in the management units that were originally banded in other breeding areas, United States and Canada, 2014-19

11. Unique individual piping plover resights and total reported observations per nonbreeding season, United States, Mexico, and the Caribbean, 2014-20

12. Unique observations of piping plovers reported by non-U.S. Geological Survey observers during the breeding season, United States and Canada, 2014-19.

13. A priori hypotheses about variables affecting renesting propensity and renest reproductive success

14. A priori hypotheses about variables affecting hatch-year annual survival and dispersal probabilities

15. A priori hypotheses about variables affecting adult annual survival and dispersal probabilities

16. A priori hypotheses about variables affecting natal dispersal and interannual adult breeding movement distances. 


\section{Conversion Factors}

U.S. customary units to International System of Units

\begin{tabular}{rrr}
\hline Multiply & By & To obtain \\
\hline & Flow rate & \\
\hline cubic foot per second $\left(\mathrm{ft}^{3} / \mathrm{s}\right)$ & 0.02832 & cubic meter per second $\left(\mathrm{m}^{3} / \mathrm{s}\right)$ \\
\hline
\end{tabular}

International System of Units to U.S. customary units

\begin{tabular}{llll}
\hline & Multiply & By & To obtain \\
\hline & Length & & \\
meter $(\mathrm{m})$ & 3.281 & foot (ft) & \\
kilometer $(\mathrm{km})$ & 0.6214 & mile (mi) & \\
meter $(\mathrm{m})$ & 1.094 & yard (yd) & \\
\hline
\end{tabular}

\section{Abbreviations}

\begin{tabular}{|c|c|}
\hline AHY & adult, 2 years and older \\
\hline ALK & U.S. Alkali Wetlands management unit \\
\hline $\mathrm{Cl}$ & confidence or credible interval \\
\hline GRR & Garrison Reach of the Missouri River management unit \\
\hline HY & hatch year \\
\hline MASL & meter above sea level \\
\hline MRS & $\begin{array}{l}\text { Missouri River management units (Lake Sakakawea, the Garrison Reach of the } \\
\text { Missouri River, and Lake Oahe) }\end{array}$ \\
\hline NGP & northern Great Plains \\
\hline NON & $\begin{array}{l}\text { transient or presumed nonbreeding individuals resighted in at least three } \\
\text { management units during one breeding season }\end{array}$ \\
\hline $\mathrm{OAH}$ & Lake Oahe management units \\
\hline PRISM & Parameter-elevation Regressions on Independent Slopes Model \\
\hline$r$ & correlation coefficient \\
\hline RSseg & reproductive success of segment \\
\hline SAK & Lake Sakakawea management unit \\
\hline USACE & U.S. Army Corps of Engineers \\
\hline USFWS & U.S. Fish and Wildlife Service \\
\hline USGS & U.S. Geological Survey \\
\hline MD & wetland management district \\
\hline
\end{tabular}





\title{
Spatial Variation in Population Dynamics of Northern Great Plains Piping Plovers
}

\author{
By Rose J. Swift, ${ }^{1}$ Michael J. Anteau, ${ }^{1}$ Kristen S. Ellis, ${ }^{1}$ Megan M. Ring, ${ }^{1}$ Mark H. Sherfy, ${ }^{1}$ Dustin L. Toy, ${ }^{1}$ and \\ David N. Koons²
}

\section{Abstract}

Metapopulation dynamics are determined not only by within-patch birth and death processes but also by betweenpatch movements of individuals (emigration and immigration). To conserve and manage a species that has a metapopulation structure, defined by local populations that are distributed among patches of suitable habitat, we need to understand each of these vital rates. For the federally listed northern Great Plains Charadrius melodus (Ord, 1824) (piping plover), managers assumed a metapopulation structure consisting of four breeding groups with low, balanced dispersal, which resulted in low extinction risk in a simulation-based viability study. The degree to which the northern Great Plains piping plover breeding population functions as a metapopulation depends on the rate of movement amongst breeding areas. Sources of variation in survival, dispersal probabilities, and dispersal distances were examined for hatch-year and adult piping plovers breeding in the northern Great Plains from 2014 to 2019 focusing on four manage-ment units (U.S. Alkali Wetlands, Lake Sakakawea, Garrison Reach of the Missouri River, and Lake Oahe). Additionally, renesting probabilities, renest reproductive success, and reproductive output were investigated from 2014 to 2016 in each of these areas to understand within-patch productivity. This report includes two major sections: (1) a presentation that includes the context, results, and implications of the study, followed by a detailed text methodology, and (2) an appendix that provides synthesized estimates of piping plover vital rates from throughout their range. River and alkali wetland habitats seem to be of higher quality than reservoir habitats, although alkali wetland habitats have lower annual survival, lower reproductive output, and lower fidelity probabilities than riverine habitats. Habitat availability drove dispersal probabilities and dispersal distances for hatch-year and adult piping plovers. Renesting propensity and renest reproductive success were generally low, suggesting that renesting is an uncommon and unproductive strategy to replace most lost reproductive attempts. Estimates indicated high connectivity between

\footnotetext{
1U.S. Geological Survey.
}

${ }^{2}$ Colorado State University. the U.S. Alkali Wetlands and the northern river units (Lake Sakakawea, Garrison Reach, Lake Oahe) of the Missouri River, suggesting that the assumed metapopulation structure and population viability may need to be reassessed.

\section{Introduction}

Local populations distributed among patches of suitable habitat are commonly referred to as metapopulations (Olivieri and others, 1990; Hanski, 1998). Metapopulation dynamics are the result of interacting processes at the local (in other words, environmental conditions) and regional (for example, spatiotemporal arrangement of patchy habitat) scales (Levins, 1969; Hanski, 1998; Hanski and Gilpin, 1991). The degree of spatial structure and connectivity of a metapopulation will have important implications for gene flow and population dynamics (Hanski, 1998). A metapopulation structure is typically thought to confer resilience to local perturbations or environmental variability, promote population persistence through reduced synchrony, and aid in the reestablishment of extirpated populations through immigration and recolonization events (Levins, 1969; McGowan and others, 2014; Roche and others, 2016). Ultimately, metapopulations dynamics will be affected by the demography (survival and productivity) of the population within a patch and the connectivity (dispersal) among habitat patches.

Dispersal is a fundamental life-history trait that allows colonization of patches and can buffer declining populations through immigration (Greenwood and Harvey, 1982). In birds, two general categories of dispersal movements are acknowledged: natal dispersal, which is defined as the movement from natal areas to an individual's first breeding territory, and breeding dispersal, which is defined as the movement of individuals between successive breeding territories (Greenwood and Harvey, 1982). Dispersal to new areas affects the potential for colonization of new favorable habitats, range expansion, and gene flow, making it a critical factor in conservation planning. Breeding dispersal distances tend to be lower for abundant generalist species and greater for species that specialize on patchily distributed habitats (Paradis and others, 1998; Martin and Fahrig, 2018). The abundance, availability, and 
distribution of resources and competitors across the landscape likely also affect dispersal probabilities and distance (Paradis and others, 1998).

Understanding of population structure and dispersal can improve success of conservation and management of a species. Successful recovery strategies must consider movements of individuals and their ability to disperse to available nesting sites, particularly in fragmented landscapes or where habitat is patchy (Amarasekare, 2004; Cox and Kesler, 2012). Dispersal probabilities and distances travelled will affect the likelihood of recolonization or genetic flow. Therefore, understanding metapopulation dynamics through dispersal probabilities and dispersal distances is critical for identifying the locations of potential conservation sites for species recovery and planning.

The Charadrius melodus (Ord, 1824) (piping plover) is a small migratory shorebird endemic to North America with breeding populations in the Atlantic coast, Great Plains, and Great Lakes regions. Federally listed primarily because of habitat loss and low reproductive output, piping plover breeding biology is studied throughout their range (U.S. Fish and Wildlife Service, 2003, 2009). Piping plovers breeding in the U.S. northern Great Plains (NGP; fig. 1) are patchily distributed on riverine sandbars, reservoir shorelines, and dry margins of wetlands in the Prairie Pothole Region commonly referred to as the "U.S. Alkali Wetlands" (Gaines and Ryan, 1988; Anteau and others, 2012a, b). Because piping plovers do not occupy all available, suitable habitat, metapopulation theory has often been used to explain connectivity within and among breeding groups (McGowan and others, 2014; Catlin and others, 2016). However, piping plover management has generally been specific to a subpopulation or a management unit. An understanding of piping plover metapopulation dynamics through estimates of productivity and connectivity could improve management of this imperiled species. To understand metapopulation dynamics, we assessed withinpopulation productivity (annual survival and reproductive output) and among-population connectivity (dispersal). 


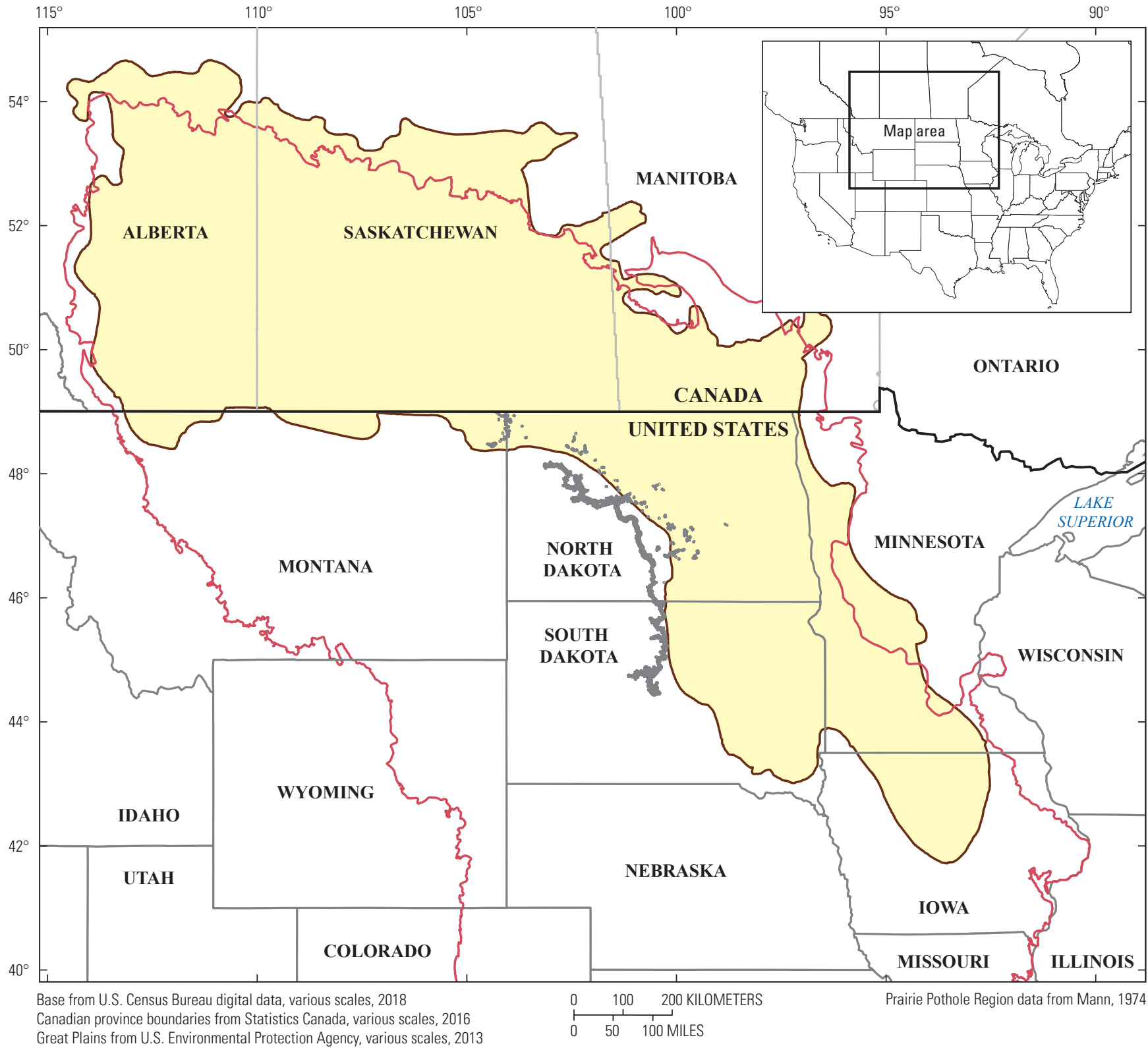

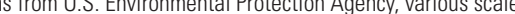

U.S. Alkali Wetlands from U.S. Fish and Wildlife Service, various scales, 2020

North American Datum of 1983

\section{EXPLANATION}

Prairie Pothole Region

Piping plover focal study area

Northern Great Plains boundary

Figure 1. Northern Great Plains piping plover breeding focal study area in North Dakota, South Dakota, and Montana. 


\section{Study Objectives}

The degree of connectivity was estimated for piping plovers among four management units of the NGP. Movements or dispersal can occur within a breeding season because of a renesting decision or between breeding seasons. Additionally, dispersal decisions are innately different for hatch-year birds, breeding for the first time, than those for adults with prior breeding experience. We investigated the parameters (habitat availability, individual characteristics, social factors, and reproductive success) for their effect on demographic variation (renesting, survival, dispersal, and movement distance decisions) for piping plovers on the four management units (U.S. Alkali Wetlands, Lake Sakakawea, the Garrison Reach of the Missouri River, and Lake Oahe; fig. 2). The following are the study objectives:

1. Estimate probabilities of natal and adult movements for piping plovers among northern Missouri River and the U.S. Alkali Wetlands breeding areas.

2. Estimate probabilities of hatch-year and adult survival for piping plovers in the northern Missouri River and the U.S. Alkali Wetlands breeding areas.

3. Examine the effect of environmental, individual, and social factors on natal survival and dispersal probabilities (natal dispersal and natal fidelity) for piping plovers.

4. Examine the effect of environmental, individual, reproductive success, and social factors on adult annual survival and breeding dispersal probabilities (emigration, immigration, and breeding fidelity) for piping plovers.

5. Identify environmental, individual, and social factors that affect natal dispersal and interannual adult breeding dispersal distances for piping plovers.

6. Identify environmental, individual, and temporal factors that affect the likelihood of initiating a renest (renest propensity) and of renest reproductive success for piping plovers.

7. Estimate reproductive output in the northern Missouri River and the U.S. Alkali Wetlands breeding areas for piping plovers.

\section{Presentation Slides}

This section includes presentation slides and text for each slide that explains and expounds on what is shown on each slide. Text in brackets defines abbreviations and provides additional information specific to each slide. All abbreviations are defined on the slides or in the slide text except for MRS, ALK, SAK, GRR, OAH, and NON because of space limitations on the slides and to avoid cluttering the slide text. See the "Abbreviations" section of this report for those definitions. All photographs are by the U.S. Geological Survey and are in the public domain. 


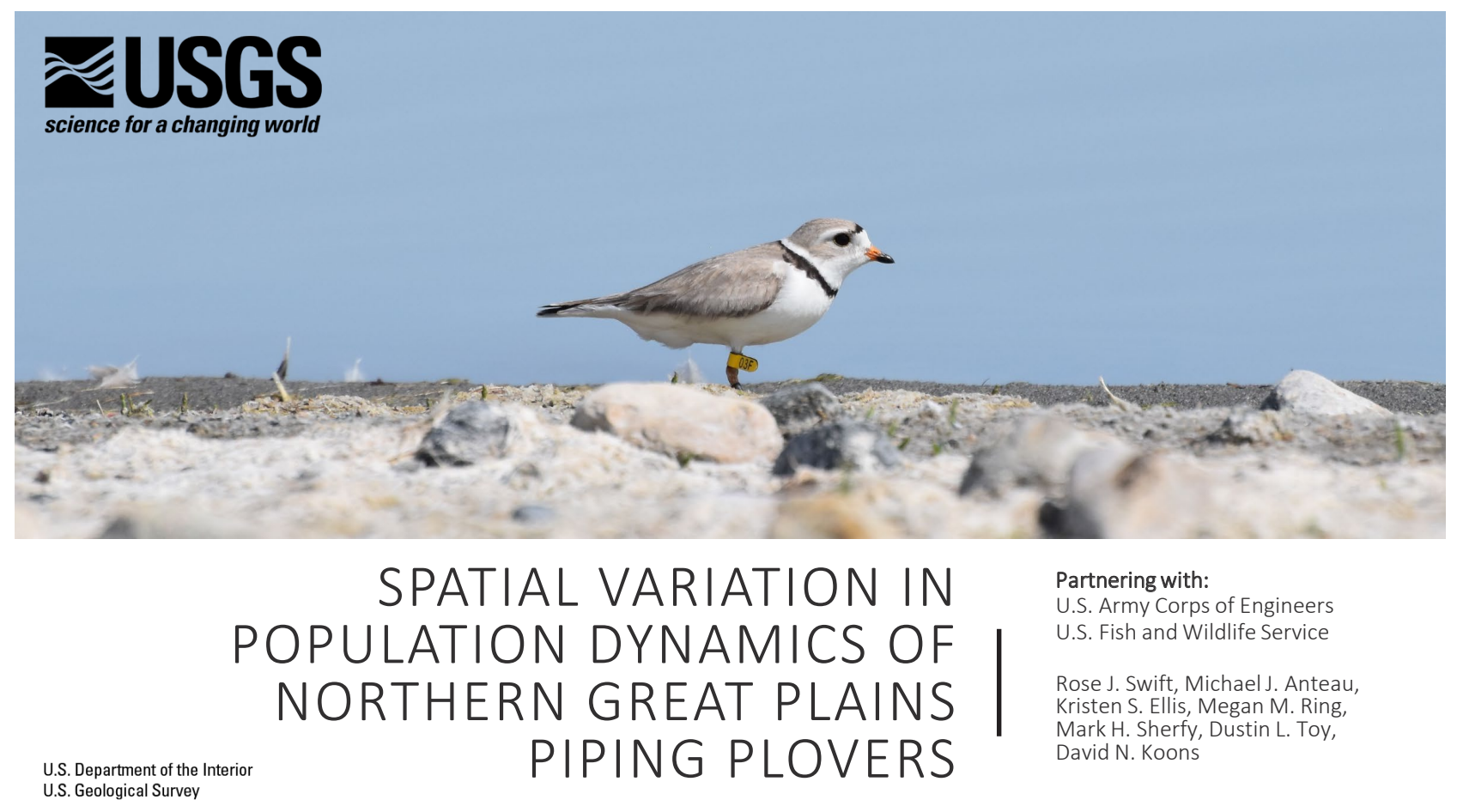

This presentation provides the context, results, and implications of the study. 


\section{Listed Objectives:}

1. Estimate probabilities of natal and adult movements for piping plovers among northern Missouri River and the U.S. Alkali Wetlands breeding areas

2. Estimate probabilities of hatch-year and adult survival for piping plovers in the northern Missouri River and the U.S. Alkali Wetlands breeding areas

3. Examine the effect of environmental, individual, and social factors on natal survival and dispersal probabilities (natal dispersal and natal fidelity) for piping plovers

4. Examine the effect of environmental, individual, reproductive success, and social factors on adult annual survival and breeding dispersal probabilities (emigration, immigration, and breeding fidelity) for piping plovers

5. Identify environmental, individual, and social factors that affect natal dispersal and interannual adult breeding dispersal distances for piping plovers

6. Identify environmental, individual, and temporal factors that affect the likelihood of initiating a renest (renest propensity) and of renest reproductive success for piping plovers

7. Estimate reproductive output in the northern Missouri River and the U.S. Alkali Wetlands breeding areas for piping plovers

\section{₹USGS}

The degree of connectivity was estimated for piping plovers among four management units of the U.S. northern Great Plains (NGP). Movements or dispersal can occur within a breeding season because of a renesting decision or between breeding seasons. Additionally, dispersal decisions are innately different for hatch-year birds, breeding for the first time, than those for adults with prior breeding experience. The parameters (habitat availability, individual characteristics, social factors, and reproductive success) were investigated for their influence on demographic variation (renesting, survival, dispersal, and movement distance decisions) for piping plovers on the U.S. Alkali Wetlands (ALK), Lake Sakakawea (SAK), the Garrison Reach of the Missouri River (GRR), and Lake Oahe (OAH). The objectives agreed on by the U.S. Geological Survey (USGS), U.S. Army Corps of Engineers (USACE), and U.S. Fish and Wildlife Service (USFWS) are listed. 


\section{Outline:}

\section{Background \& Explanations}

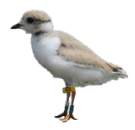

Hatch-year survival and natal dispersal influence recruitment

- Does hatch-year survival vary for chicks hatched in different habitats?

- How are the different units connected via natal dispersal?

- What factors influence natal dispersal distance?

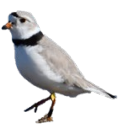

Adult survival and breeding dispersal influence population structure

- Does annual adult survival vary across different habitats?

- How are the different units connected via adult dispersal?

- What factors influence adult dispersal distance?

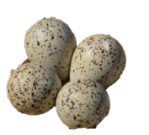

Can renesting be an effective reproductive strategy and how does it influence conservation of piping plovers?

- What factors influence renesting propensity?

- How much do renests contribute to the population?

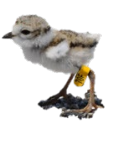

Is reproductive success high enough to account for unbalanced dispersal?

- How many fledglings per pair were produced?

- How many fledglings are needed for a stationary population?

- Are any populations at any management units growing?

\section{₹USGS}

\section{Conclusions}

This presentation is divided into six sections that provide (1) background into the study species, system, and questions; (2) estimates of hatch-year annual survival, natal dispersal, and natal dispersal distance; (3) estimates of adult annual survival, breeding dispersal, and dispersal distance; (4) understanding renesting propensity and renest reproductive success; (5) estimates of reproductive output and calculations of reproductive output required for a stable population; and (6) an overview of the major takeaways, conclusions, and management implications. The subsequent text methodology (beginning with the "Study Species" section) provides detailed field and analytical methods, and appendix 1 provides summary vital rate tables for piping plovers. 


\title{
Metapopulation dynamics
}

\author{
Need to understand not only within-patch birth and death rates, \\ but also between-patch movements
}

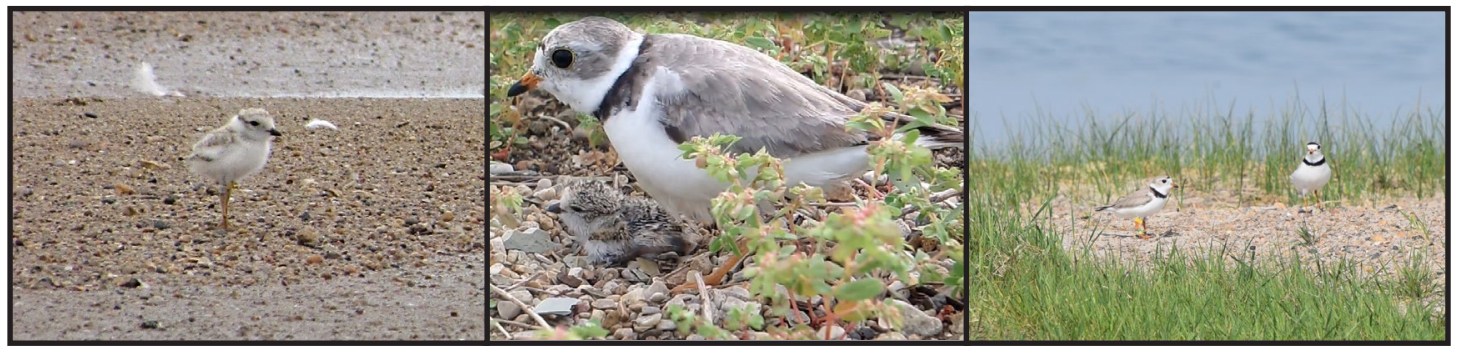

\section{‡USGS}

Substantial interest (for example, Olivieri and others, 1990; Hanski, 1998; Dail and Madsen, 2011) exists in the dynamics of metapopulations, defined as local populations distributed among patches of suitable habitat (Levins, 1969; Hanski and Gilpin, 1991). A metapopulation structure can often result from a patchy distribution of suitable nesting habitat. Metapopulation dynamics are determined not only by within-patch birth and death processes but also by between-patch movements of individuals. 


\section{Survival}

\section{Annual survival of breeding adults has the largest potential effect on abundance and population growth rates}

\section{Hatch-year annual survival influences recruitment and the population of breeding adults in future years}

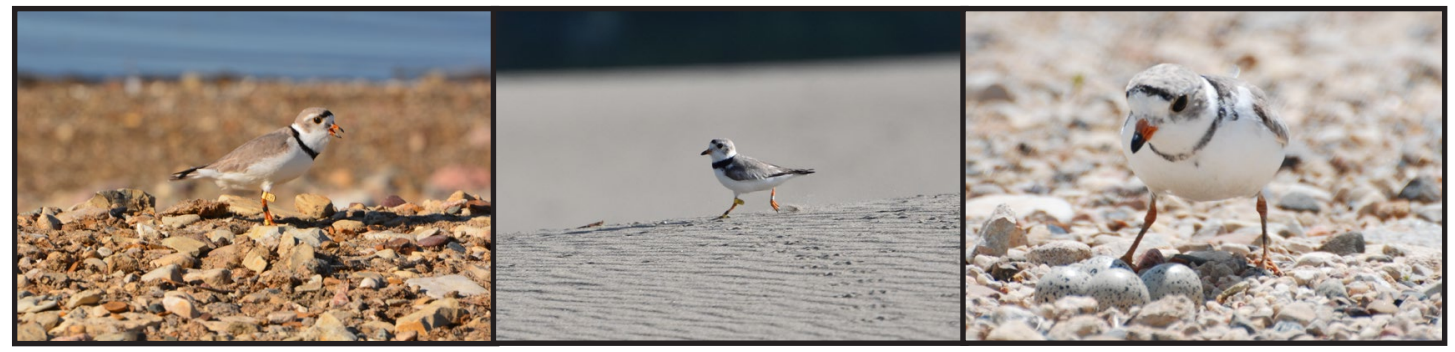

\section{‡USGS}

Life history theory predicts that population growth at asymptotic conditions should be more sensitive to changes in annual survival probability of adults than fertility or juvenile survival (Heppell and others, 2000; Sæther and Bakke, 2000; but see Hodgson and others, 2006). Survival of breeding adults has the greatest effect on population growth in most species of birds, including piping plovers, so ensuring wildlife managers understand factors that affect variation in annual survival is critically important (Larson and others, 2000; Plissner and Haig, 2000; Sæther and Bakke, 2000; Calvert and others, 2006; Roche and others, 2010). Piping plovers have a limited potential for growth (because they are a clutch-size determinant species that only lays four eggs), so even in years when habitat is readily available for breeding, survival can be critical for population growth. 


\section{Dispersal}

\section{Dispersal is a fundamental life-history strategy that affects individual fitness, gene flow, and population structure}

\section{Emigration and immigration can be important influences on population growth rates}

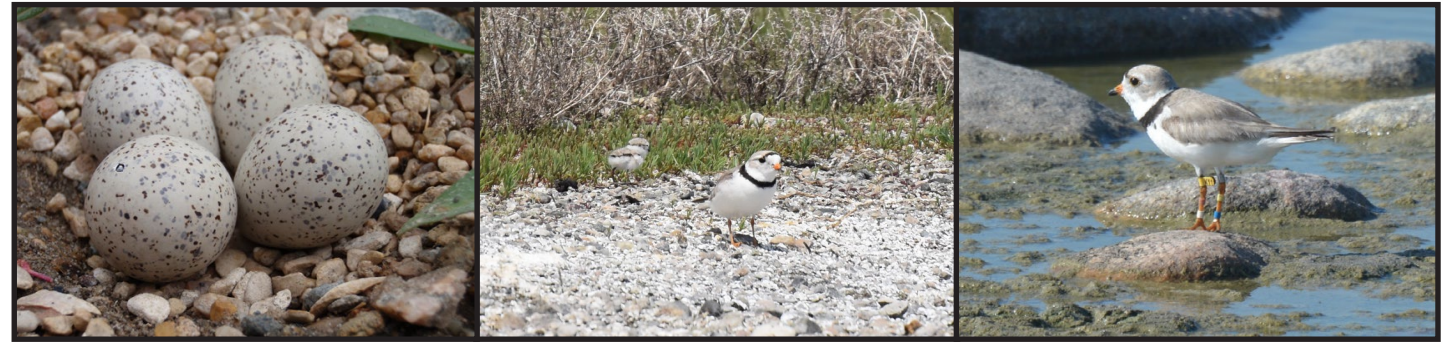

\section{₹USGS}

Understanding dispersal among breeding areas of piping plovers is important for their conservation because it informs the potential effects of conservation actions or stressors at one breeding area that may affect abundances at another area. Natal and breeding dispersal are driven by several selection pressures, including conspecific competition, individual characteristics, reproductive success, and spatiotemporal variation in habitat. Most studies focus on dispersal probabilities, but the distance traveled can also affect survival, success, and even metapopulation dynamics. Dispersal is a critical life history strategy that has important conservation implications, particularly for at-risk species with active recovery efforts. 


\section{Piping Plover Charadrius melodus}

- Northern Great Plains (NGP): Federally threatened

- Small, short-distance migratory shorebird

- Breeds in open, unvegetated habitats

\#USGS

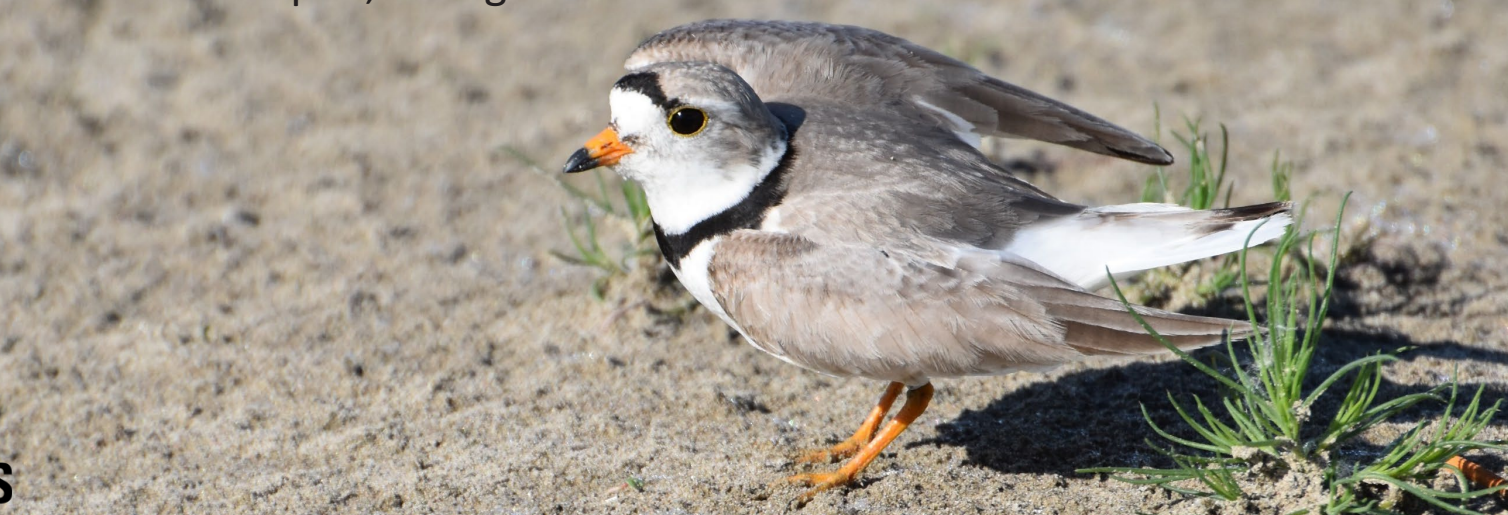

The piping plover breeds in three distinct breeding areas in North America (Atlantic coast, Great Lakes, and Great Plains). All three breeding populations are protected in Canada and the United States. This work focuses on the NGP population, which has been listed as federally threatened under the U.S. Endangered Species Act of 1973 (16 U.S.C. ch. 35 § 1531 et seq.) since 1985 (USFWS, 1985). Piping plovers are small-bodied, short-distance migratory shorebirds that are endemic to North America. They rely on early-successional habitat to breed that consists of mostly open, unvegetated areas of either sand or gravel substrates. 


\section{ఇUSGS}

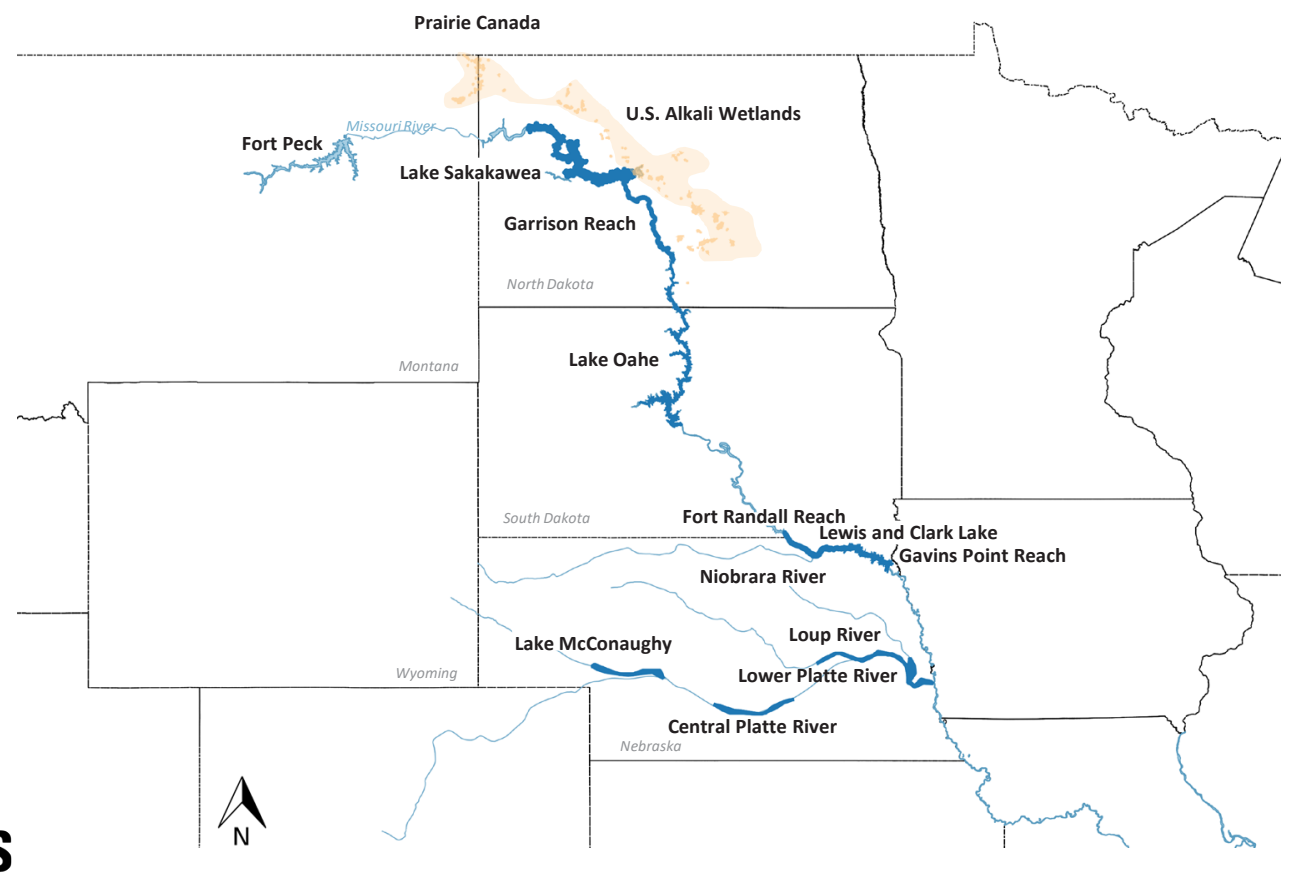

Piping plovers breed on three main habitat types in the NGP: wave- and ice-scoured shorelines of main-stem reservoirs of the Missouri River, sandbars created by variable flows along several prairie rivers (for example, the Missouri, Niobrara, and Platte Rivers), and naturally occurring wetlands in the Prairie Pothole Region, particularly alkali wetlands where salinity prohibits vegetation growth.

\section{₹USGS}

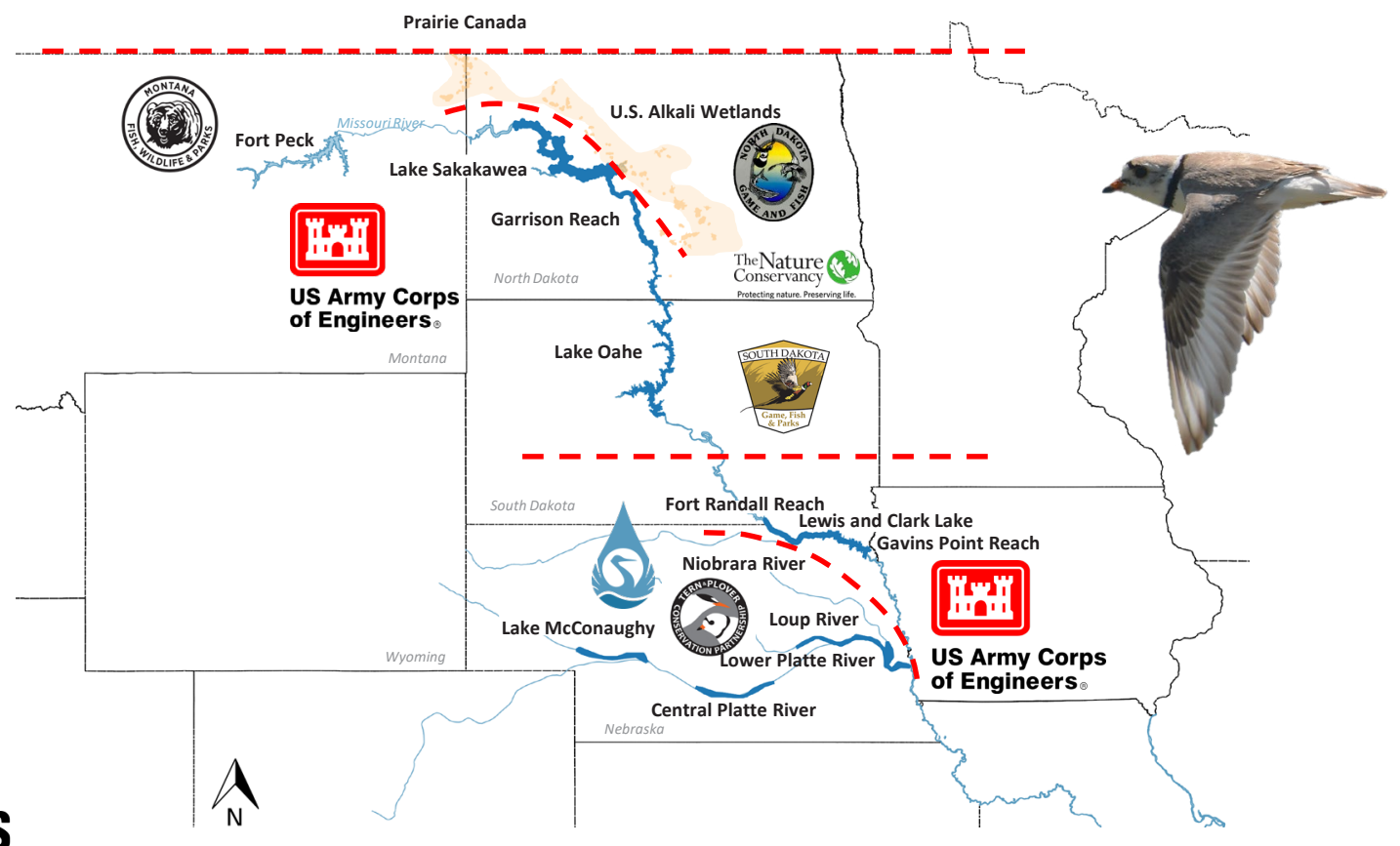

This map is labeled with each of the separate breeding areas that are managed by multiple Federal and State agencies and nongovernmental organizations who collaborated on this study. [Red dashed lines show some of the major divisions between management units.] 


\section{ॠUSGS}

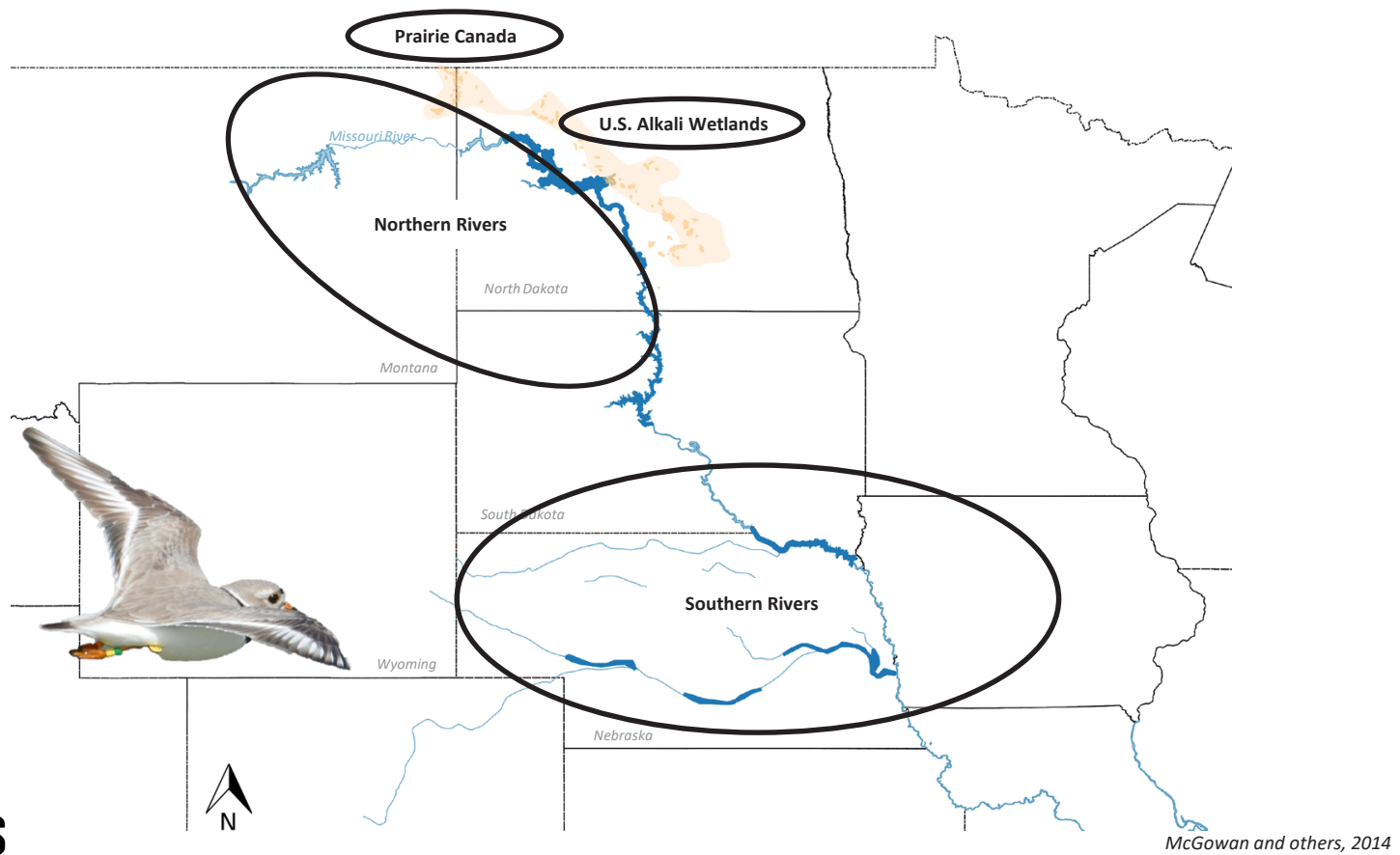

The population structure of the NGP piping plovers has been assumed based on long-term capture-mark-resight studies in the Prairie Provinces region of Canada (called "Prairie Canada" herein), on the southern units of the Missouri River, and the Platte River in the United States (Roche and others, 2010; Cohen and Gratto-Trevor, 2011; Catlin and others, 2015, 2016, 2019). Based on this information, McGowan and others (2014) conducted a simulation-based study to assess extinction risk for NGP piping plovers. They assumed a metapopulation structure that consisted of four breeding groups (Prairie Canada, U.S. Alkali Wetlands, Northern Rivers, and Southern Rivers; black circles) based on previous banding studies. 


\section{₹USGS}

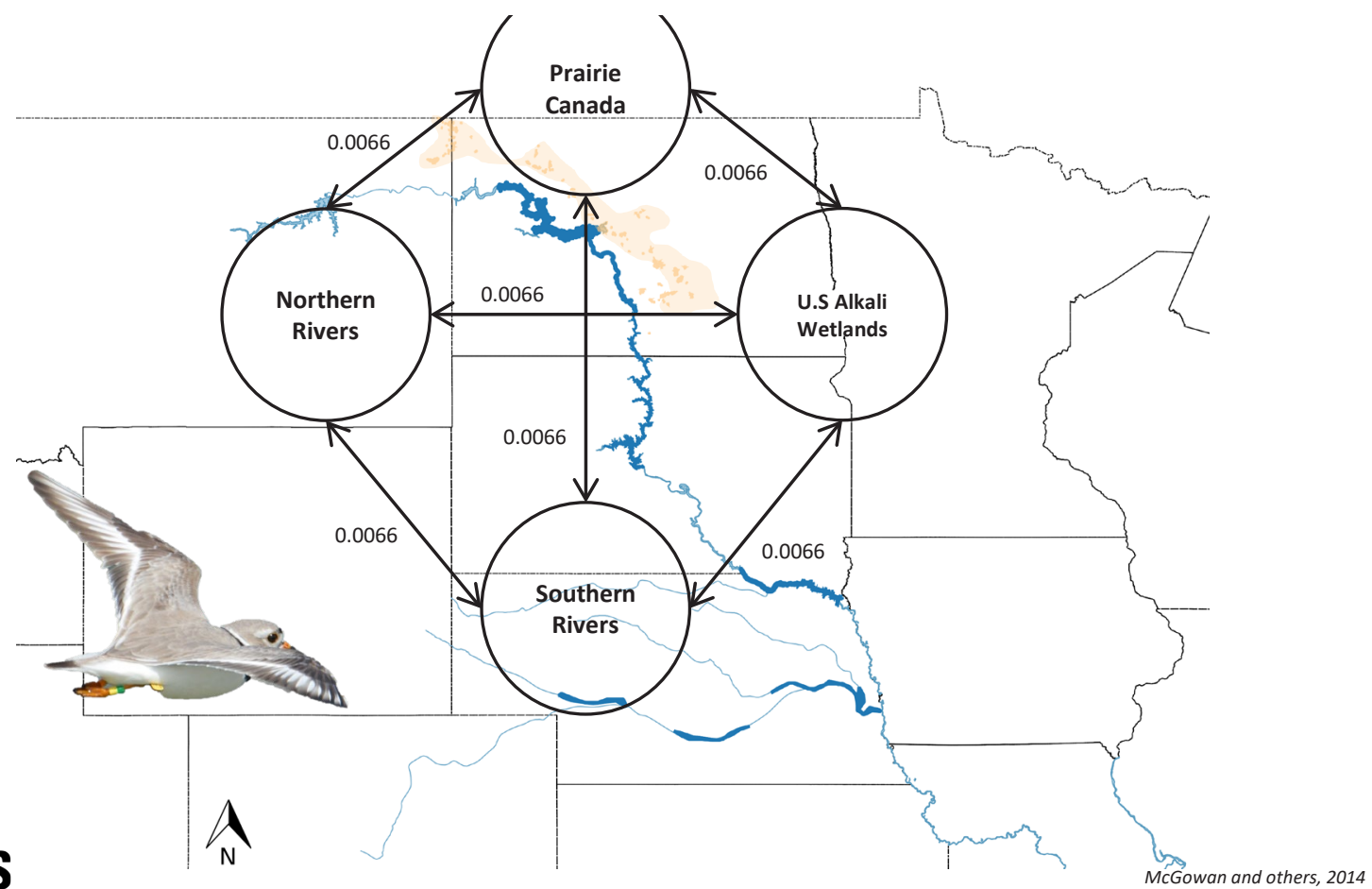

McGowan and others (2014) assumed low dispersal amongst these defined groups (black circles) based on observations of marked birds seen outside their previous breeding group. In their simulation, they assumed a 0.02 movement rate away from a breeding area with balanced movements within the region (that is, 0.0066 individual transition rates between breeding groups). With these assumptions (four breeding groups with low, balanced dispersal), extinction risk for the entire NGP population was very low. However, based on anecdotal observations, there were lingering questions about whether the Northern River units of the Missouri River and the U.S. Alkali Wetlands might have higher rates of dispersal based on their geographic proximity. When higher dispersal rates were simulated (0.13), extinction risk increased in the simulation study (0.083; McGowan and others, 2014). 


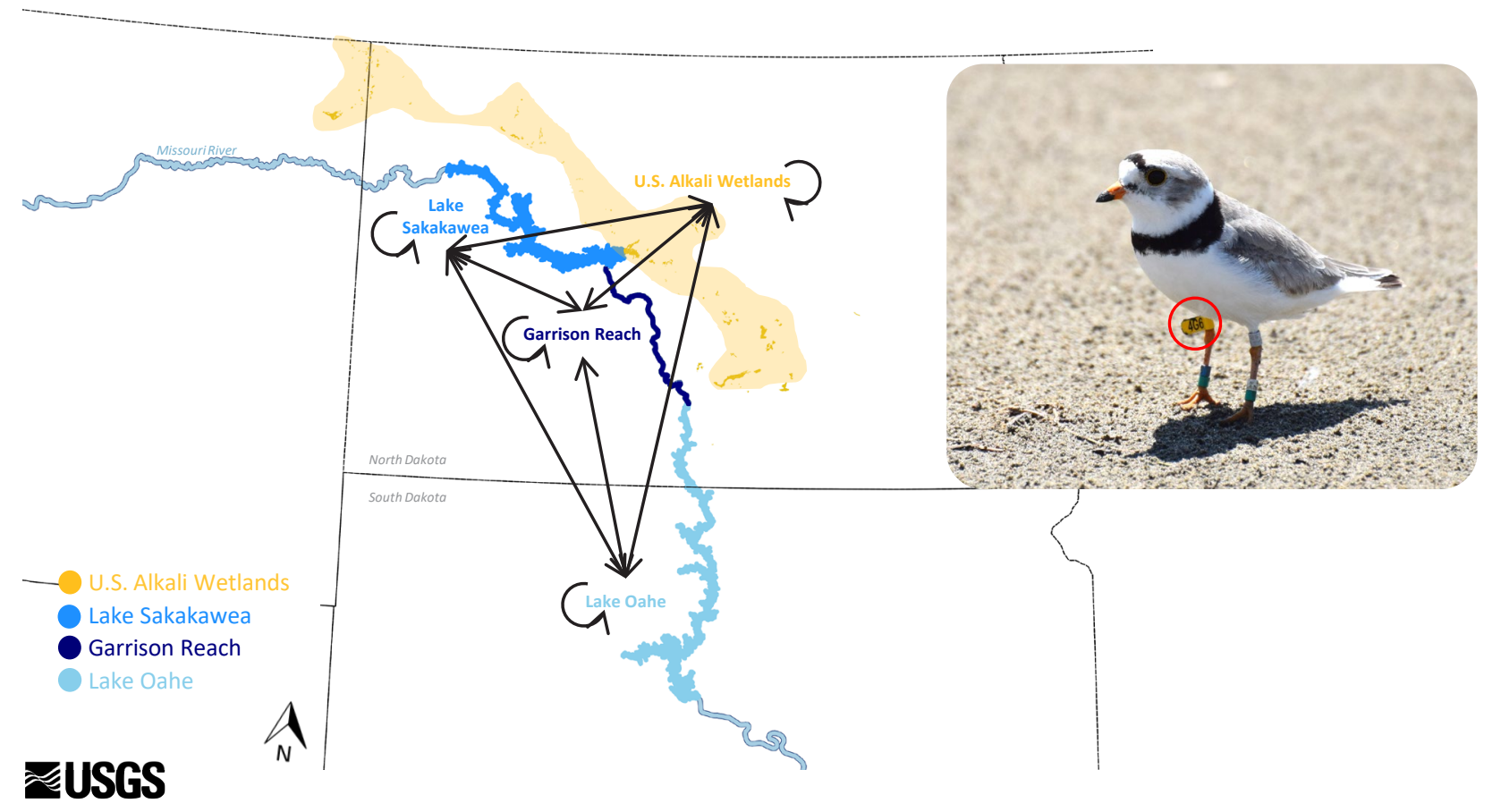

In 2014, in partnership with the USACE and the USFWS, the USGS started a large-scale capture-mark-resight/recapture study on the NGP piping plover population that focused on the Northern Rivers and the U.S. Alkali Wetlands breeding groups to estimate survival and dispersal (black arrows) in four distinct management units (U.S. Alkali Wetlands, gold; Lake Sakakawea, bright blue; the Garrison Reach of the Missouri River, navy; and Lake Oahe, light blue) for hatch-year and adult piping plovers. We used unique alpha-numeric, yellow leg flags shown here in the photograph to the right to identify individuals. [The colors used for each management unit on this map are used throughout this presentation, and the Missouri River units are always in a shade of blue.] 


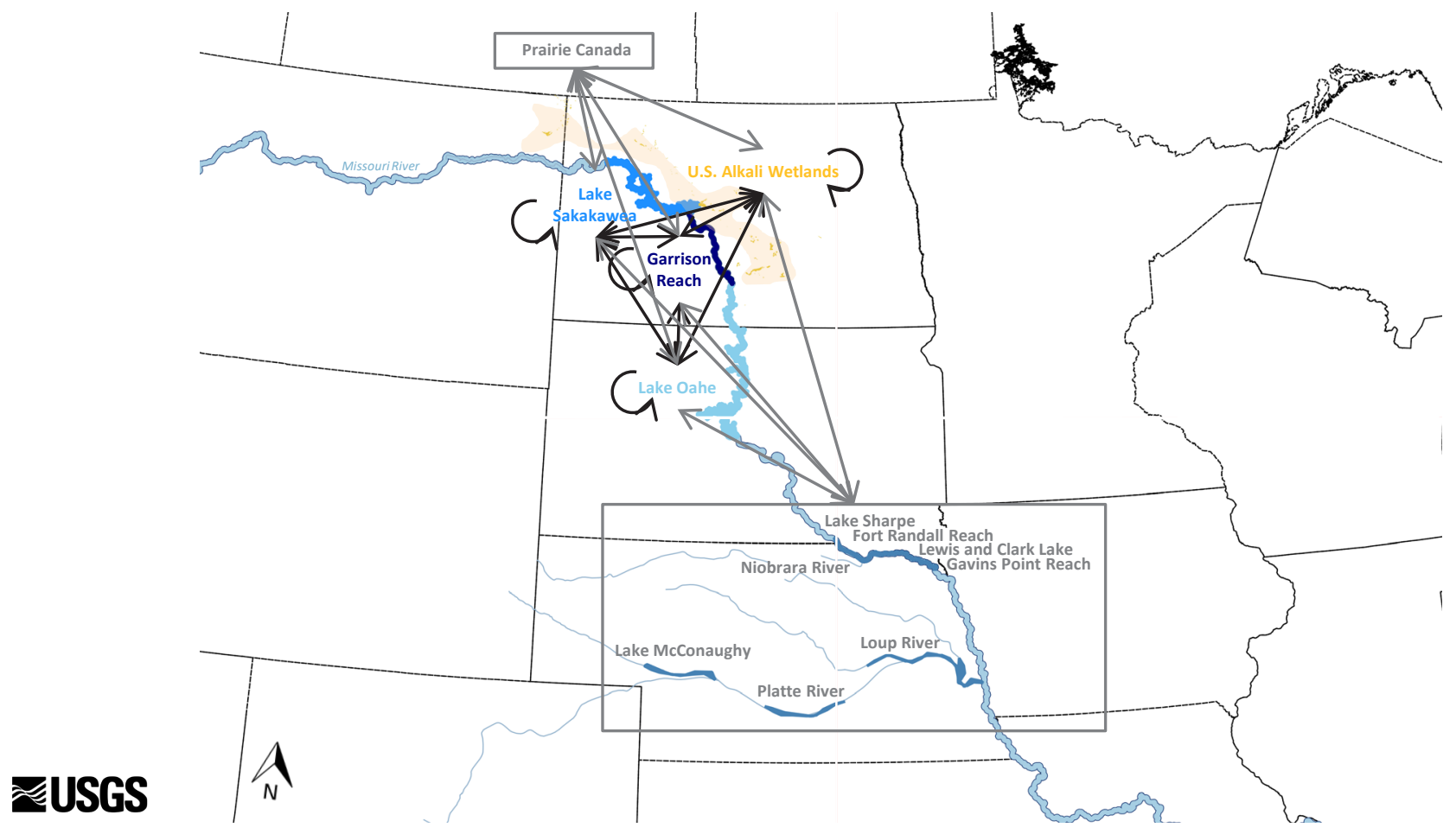

An additional goal of this work was to collaborate with other managers and researchers working in Prairie Canada and the Southern River units (gray boxes) to attempt to assess emigration and immigration outside of the focal study area (gray arrows). Resighting effort in other areas varied considerably from anecdotal observations by birdwatchers to low-effort surveys by other agencies. Because resighting effort differed substantially from the USGS resighting effort in the focal study area and because there were no coincident banding efforts in other breeding areas, data to estimate dispersal rates outside of the focal study area are insufficient. However, we do provide the number of piping plovers that emigrated and presumed immigrant linkages. [Black arrows indicate dispersal in the focal study area.] 


\section{Overview of field effort}

\begin{tabular}{lllllll}
\hline Management unit & 2014 & 2015 & 2016 & 2017 & 2018 & 2019 \\
\hline U.S. Alkali Wetlands & & & & & & \\
Lake Sakakawea & & & & & & \\
Garrison Reach & & & & & & \\
Lake Oahe & & & & & \\
\hline
\end{tabular}

Banding, resighting, and nest and chick survival monitoring
Banding and resighting
Resighting only

\section{₹USGS}

From 2014 to 2016, we banded and resighted piping plover adults and chicks in all four management units. In addition, we intensively monitored nest and chick survival. In 2017, efforts focused on banding adults and chicks and resighting adults; thus, we stopped intensively monitoring nest and chick survival. Our permit required that resighting continue to occur for 2 years after the last banding year. Therefore, in 2018 and 2019, field efforts were restricted to resighting adults, and no new adults or chicks were banded. 


\section{Additional observations}

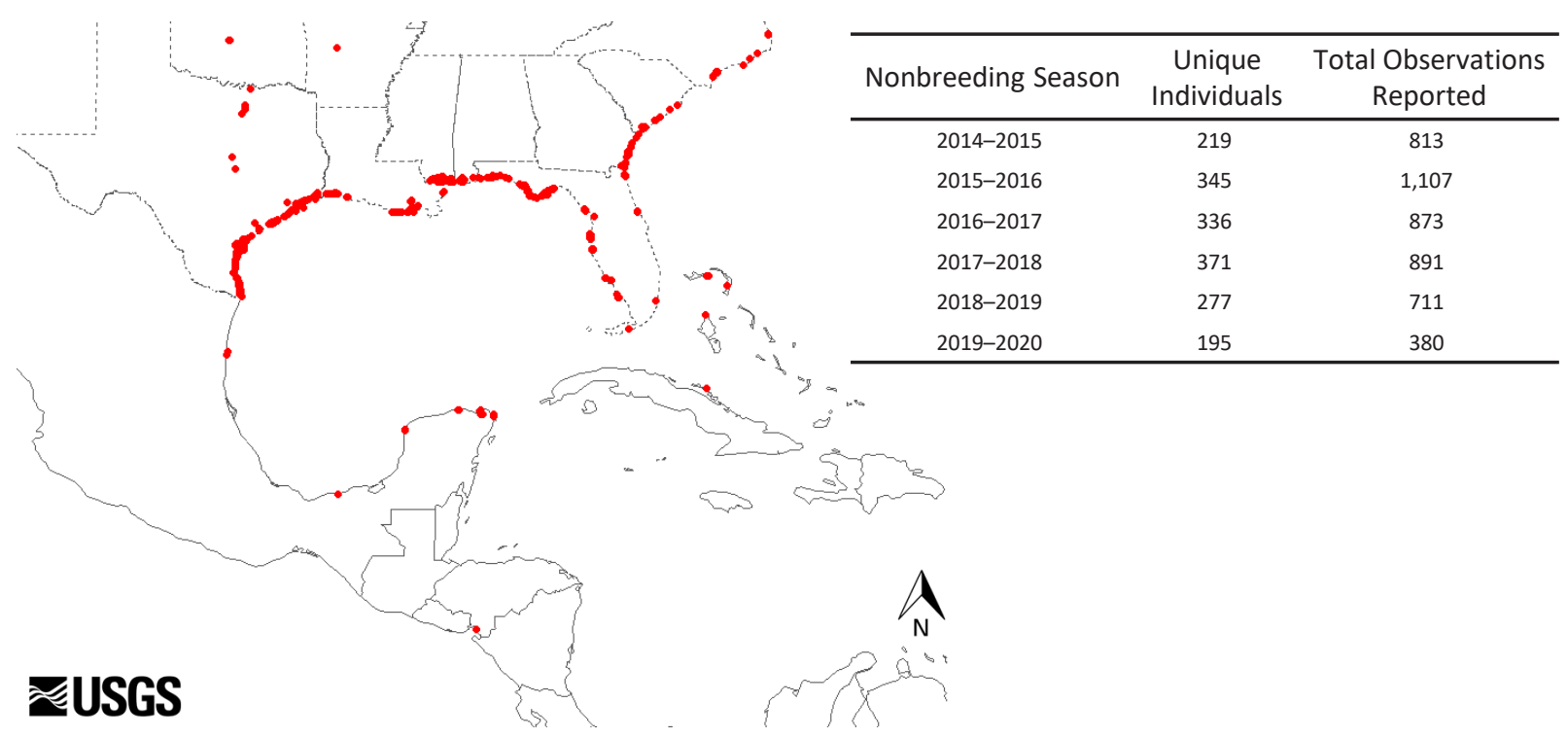

We also collected observations of individuals from outside the NGP breeding areas. These resights were collected through a variety of methods including monitoring programs, standardized resight surveys, and incidental observations. We compiled observations reported directly to us, to the USGS Bird Banding Laboratory, and from photographs of banded individuals posted on eBird (https://ebird.org/), iNaturalist (https://www.inaturalist.org/), and Facebook birding groups. We used the observations from the nonbreeding season (October-March) to supplement observations of individuals from this study. [Red dots indicate observations of piping plovers banded by the USGS that were reported outside the focal study area.] 


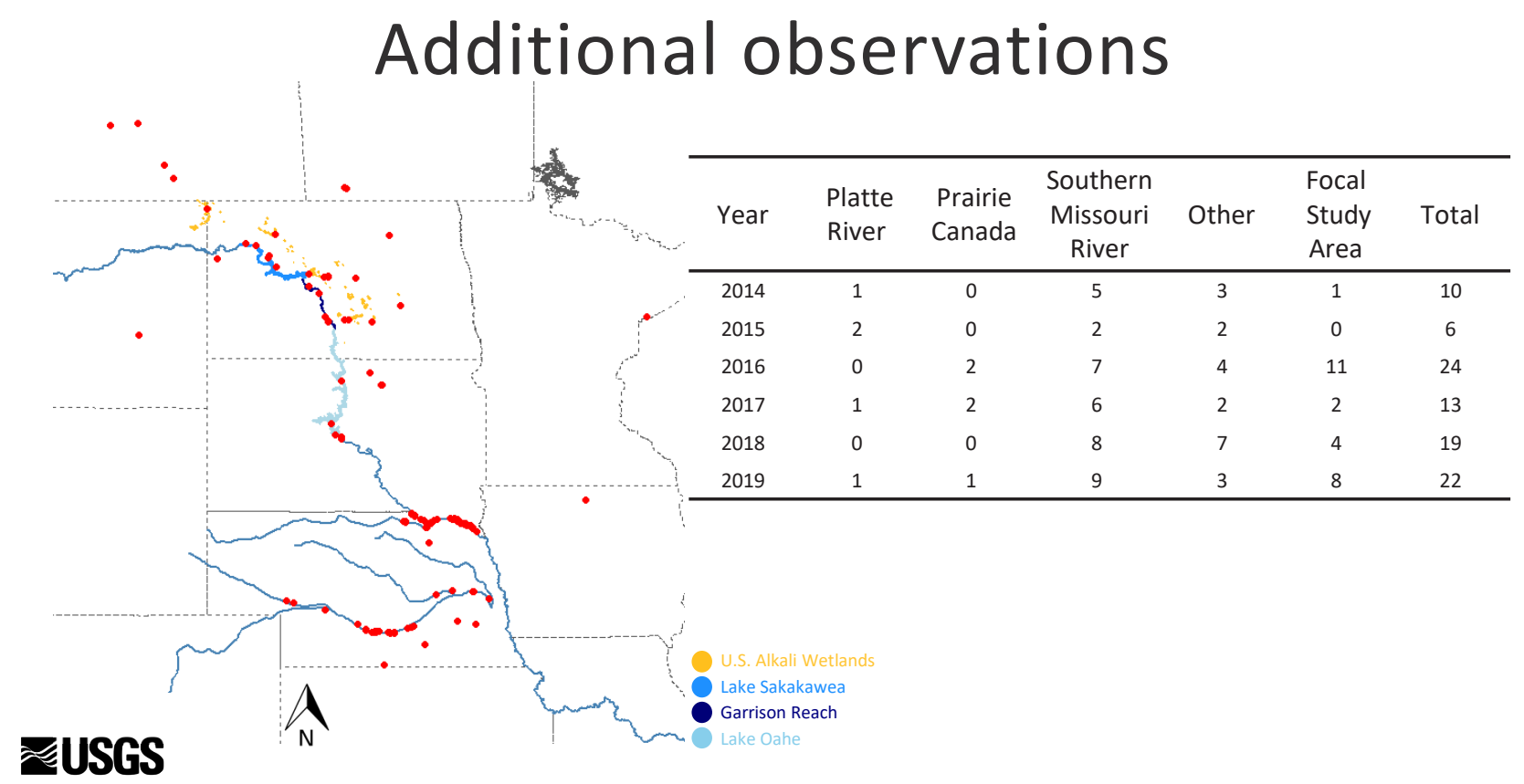

We also collected observations reported to the USGS from breeding areas and during migration. These observations (from within the focal study area but not collected by USGS or USFWS crews) were used to supplement the observations from this study and to provide the number of individuals that emigrated to the southern Missouri River units, the Platte River, or to Prairie Canada (shown in table). [Red dots indicate observations of piping plovers banded by the USGS and reported to the USGS by other observers.] 


\section{a priori hypotheses for each analysis}
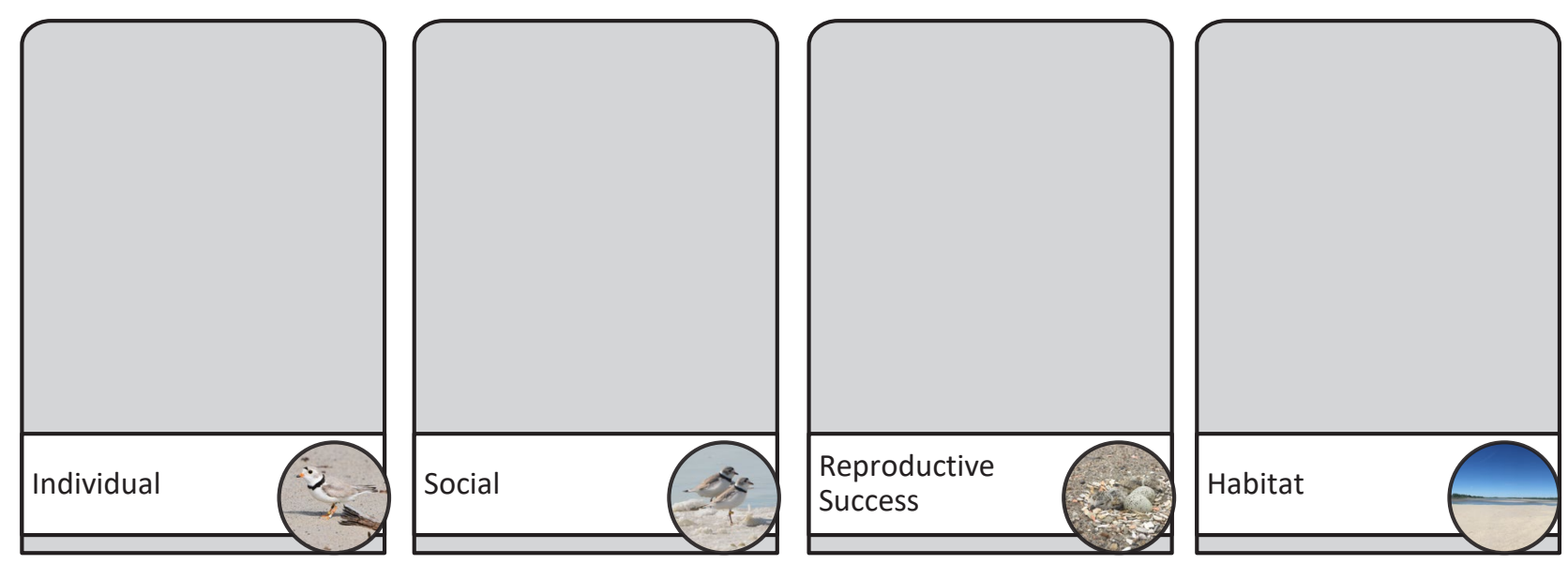

\section{ఇUSGS}

For each analysis, we created a priori hypotheses for each covariate included in the analysis; see the "Individual Covariates" section for these hypotheses and the next eight slides for covariates used in each analysis. We included four classes of variables: individual-level factors like age or previous breeding experience, social factors regarding conspecific density, information on their reproductive attempts, and data on habitat availability or quality.

\section{Renesting propensity covariates}
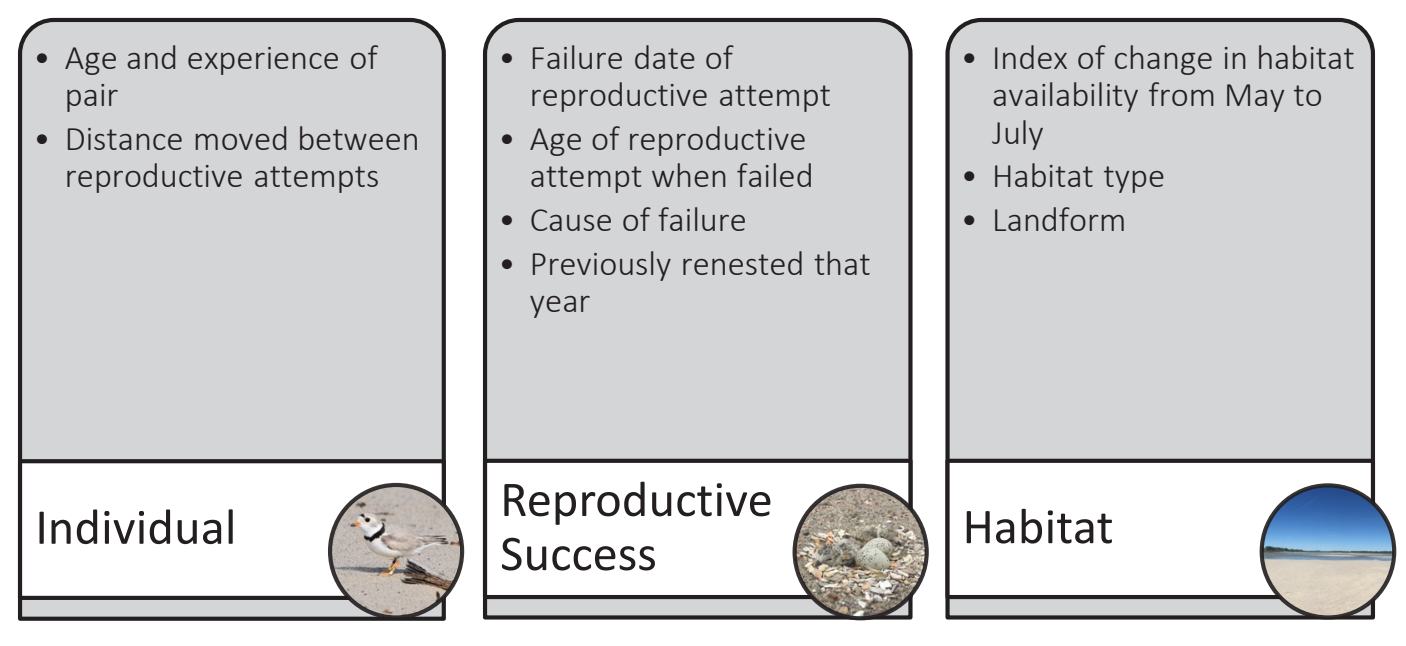

\section{₹USGS}

For each analysis, we included only covariates that had a priori hypotheses regarding how each covariate might explain variation in the specific parameter of interest. Those covariates included in the renesting propensity analysis are summarized here. 


\section{Renest reproductive success covariates}

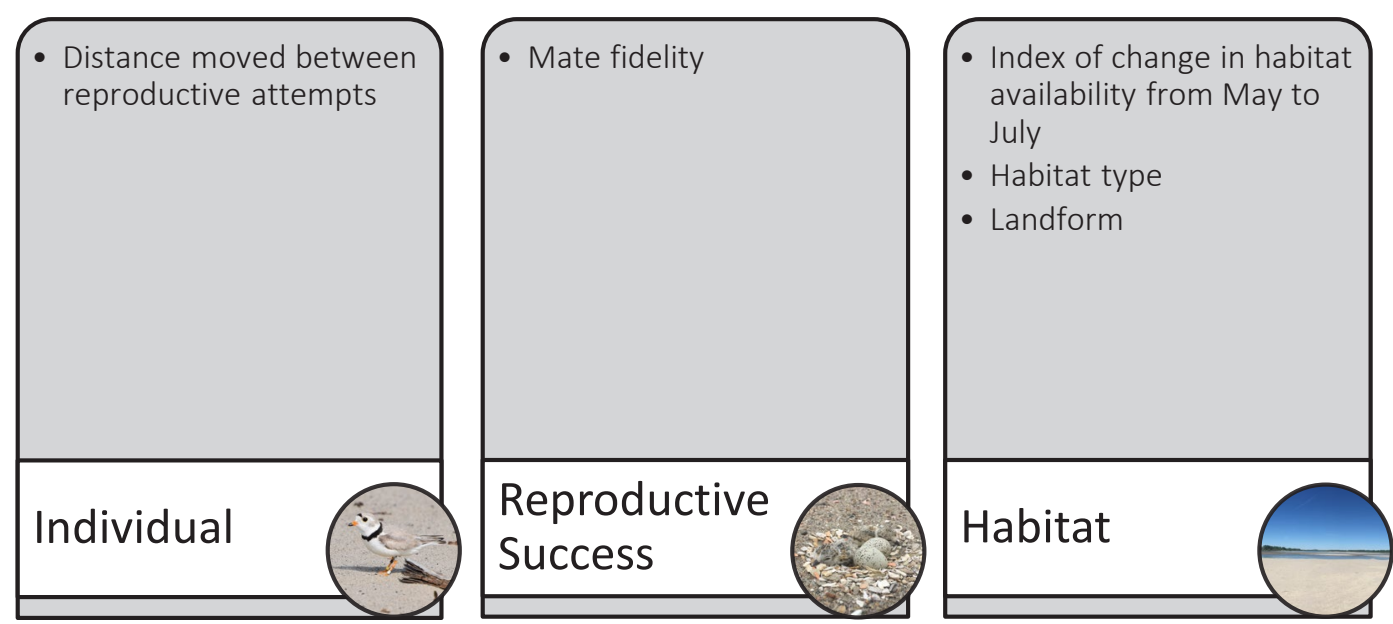

\section{₹USGS}

Those covariates that we had a priori hypotheses for in the renest reproductive success analysis are summarized here.

\section{Hatch-year survival covariates}
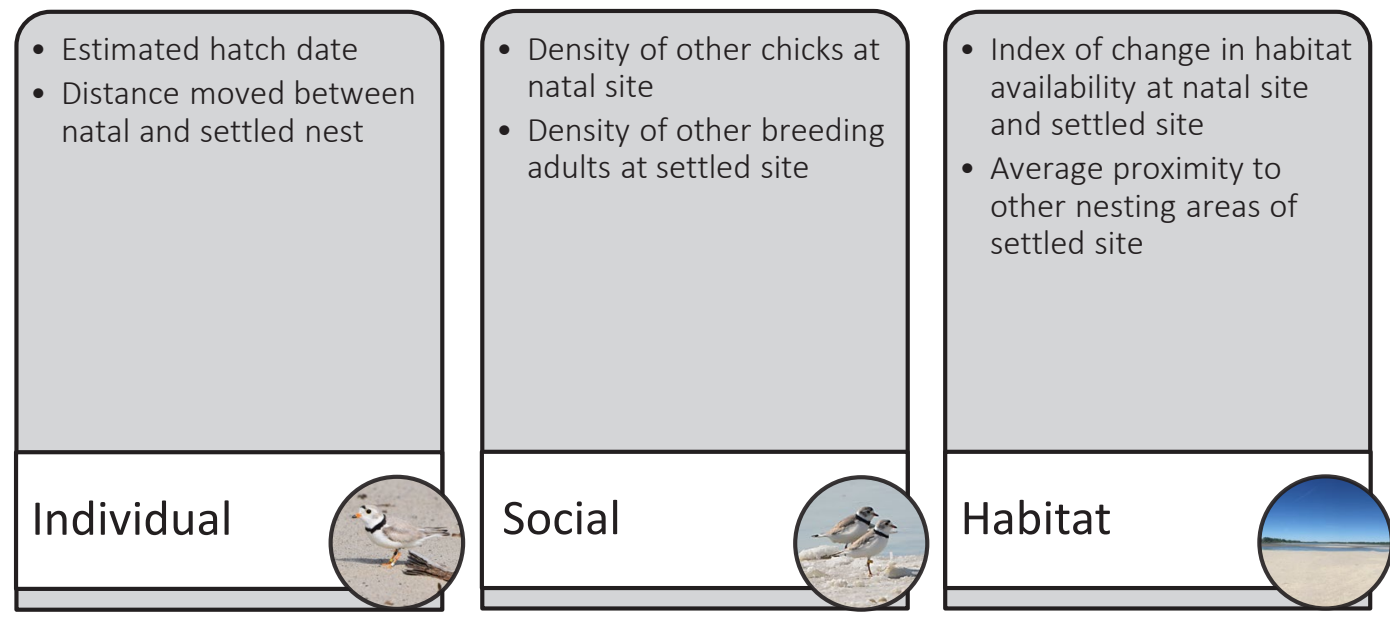

\section{₹USGS}

For each analysis, we included only covariates that had a priori hypotheses regarding how each covariate might explain variation in the hatch-year survival analysis. 


\section{Natal dispersal probabilities covariates}

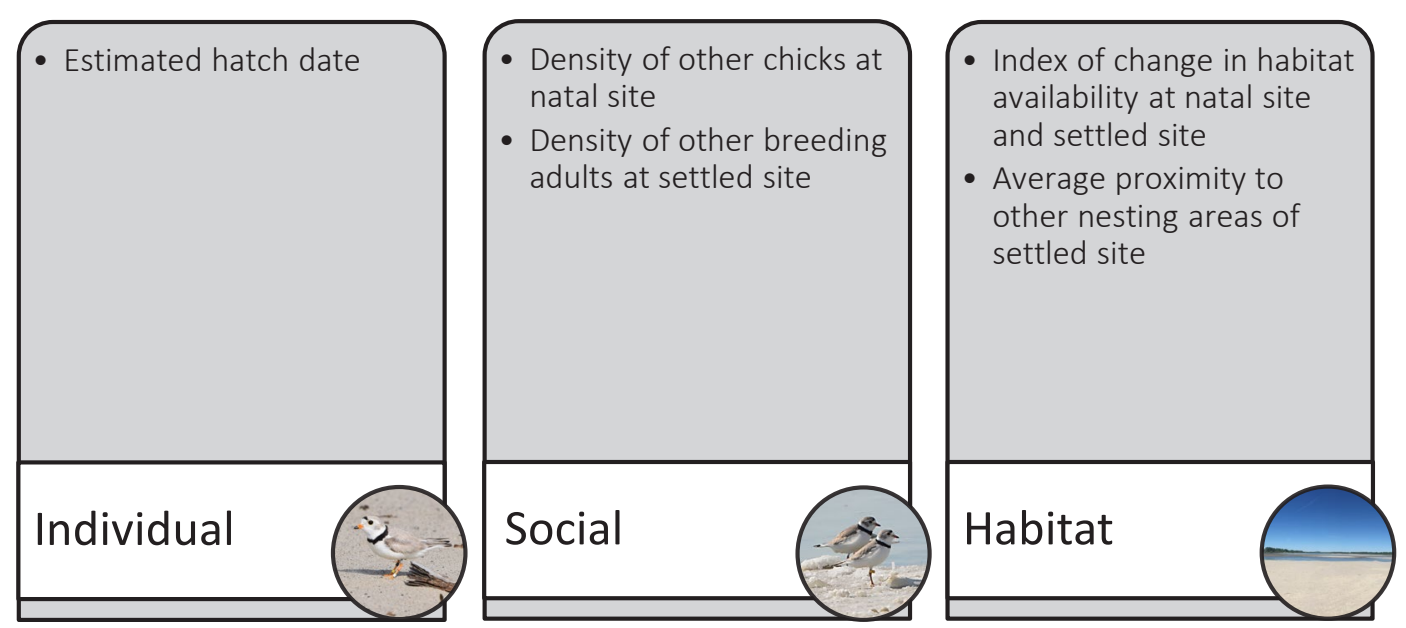

\section{‡USGS}

The covariates that had a priori hypotheses to explain variation in the natal dispersal probabilities analysis are summarized here.

\section{Natal dispersal distance covariates}

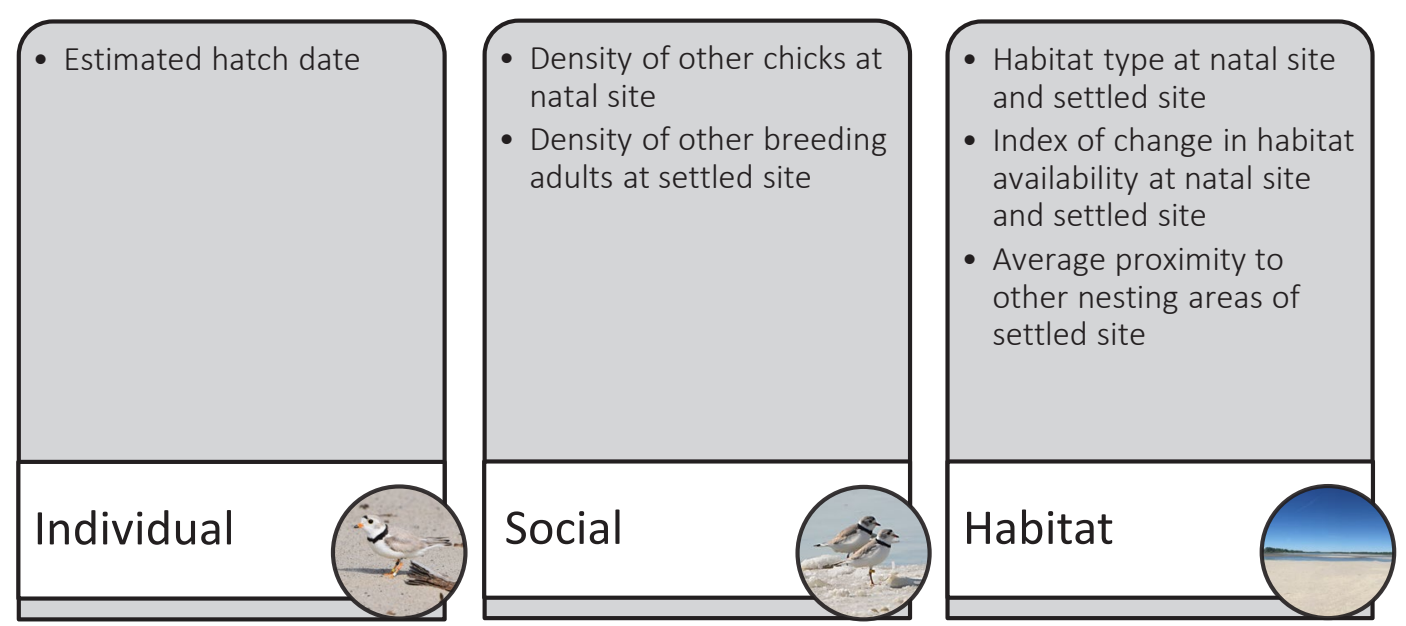

\section{ఇUSGS}

For each analysis, we included only covariates that had a priori hypotheses regarding how each covariate might explain variation in the specific parameter of interest. Those covariates included in the natal dispersal distance analysis are summarized here. 


\section{Adult annual survival covariates}
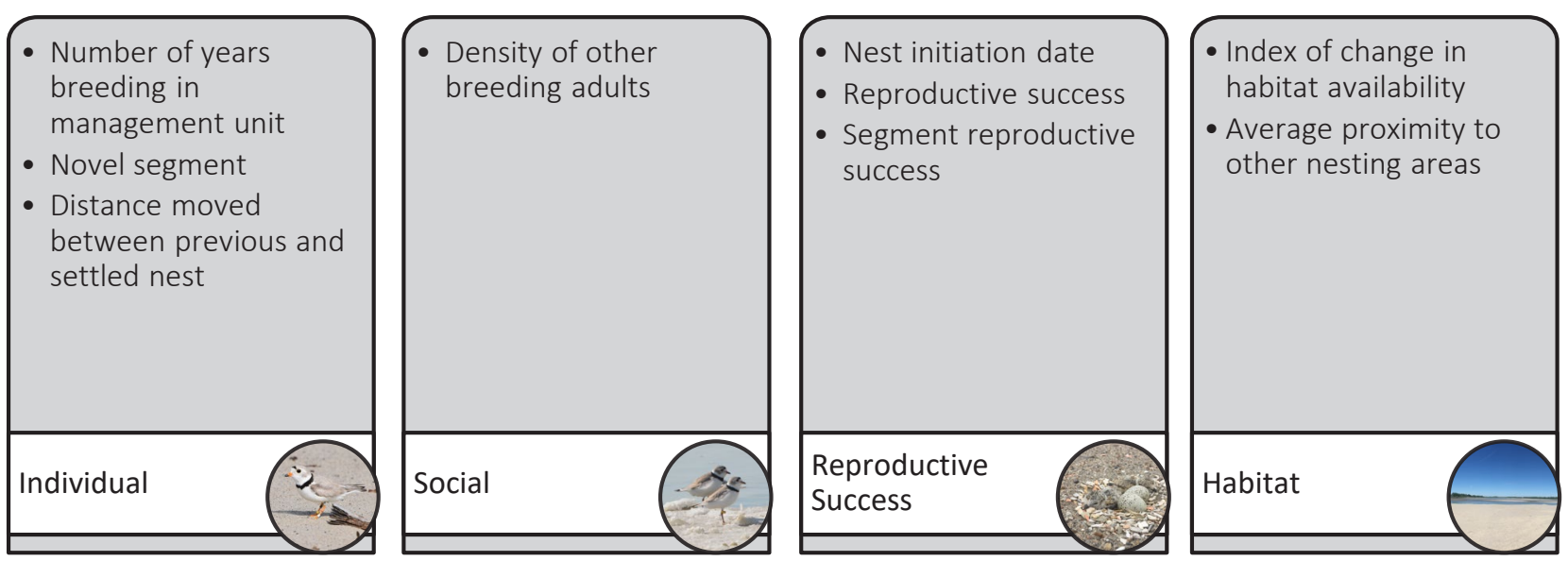

\section{‡USGS}

Those covariates that we had a priori hypotheses for the annual adult survival analysis are summarized here.

\section{Adult dispersal probabilities covariates}
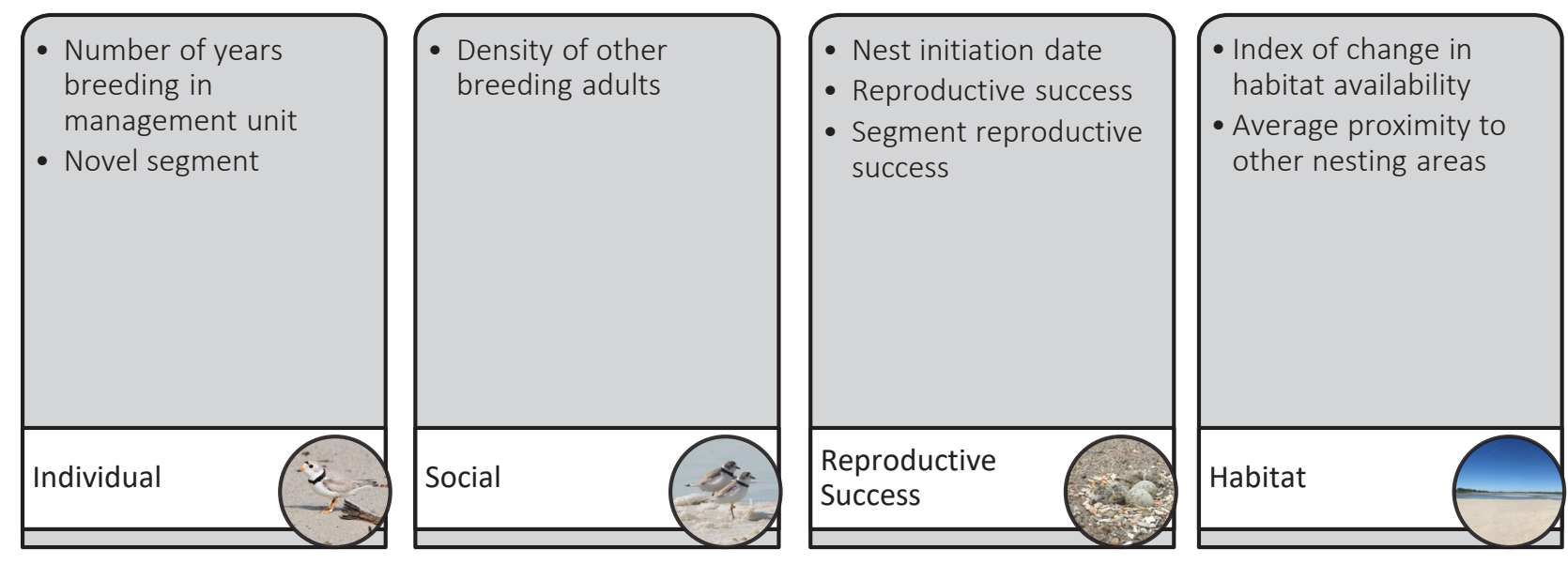

\section{ఇUSGS}

For each analysis, we included only covariates that had a priori hypotheses regarding how each covariate might explain variation in the adult dispersal probabilities analysis. 


\section{Adult dispersal distance covariates}

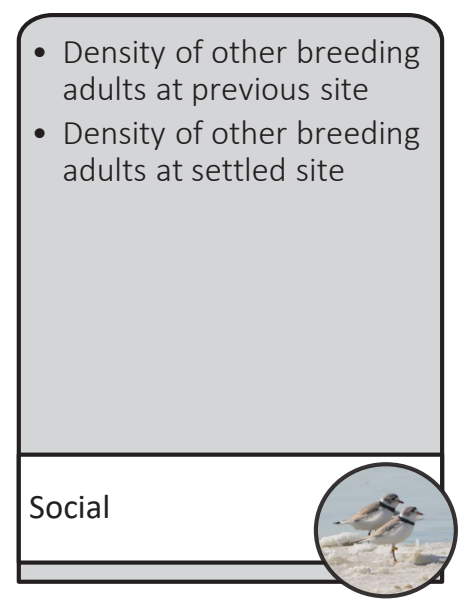

- Nest initiation date of settled nest

- Reproductive success at previous site

- Reproductive success at settled site

- Mate fidelity

\section{‡USGS}

The covariates that had a priori hypotheses to explain variation in the adult dispersal distance analysis are summarized here.

\section{Habitat type}
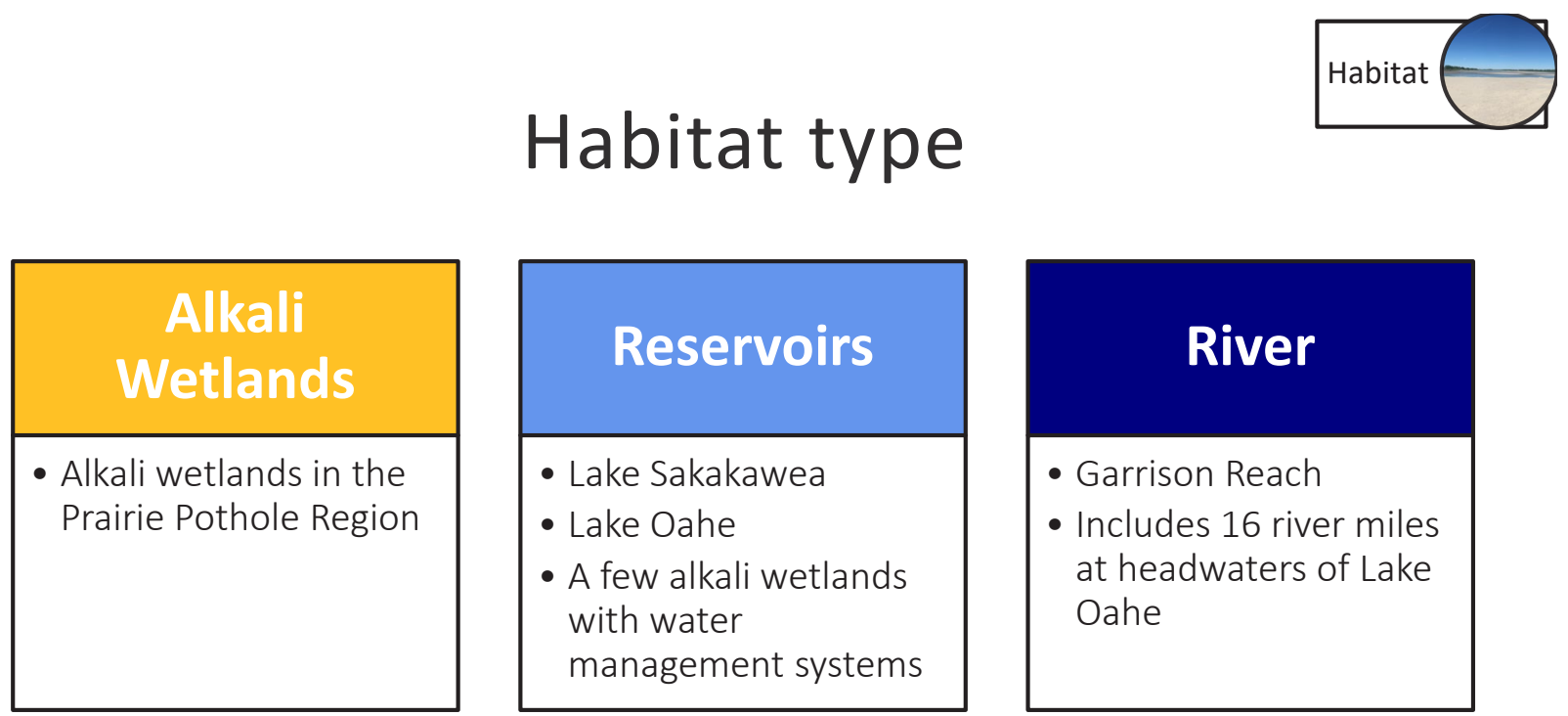

\section{₹USGS}

Habitat type was treated as a three-level factor (alkali wetland, reservoir, or river). The ALK management unit was treated as alkali wetland habitat types except for some wetlands with water management systems, which were treated as reservoirs. The two main-stem reservoirs of the Missouri River, SAK and OAH, were treated as reservoirs, and the GRR was the only river habitat. 


\section{Segment}

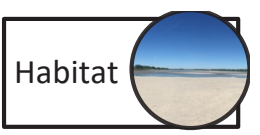

\begin{tabular}{|c|}
\hline \multicolumn{1}{|c|}{ Alkall } \\
Wetlands \\
\hline - Individual wetland \\
basin \\
- Perimeter
\end{tabular}
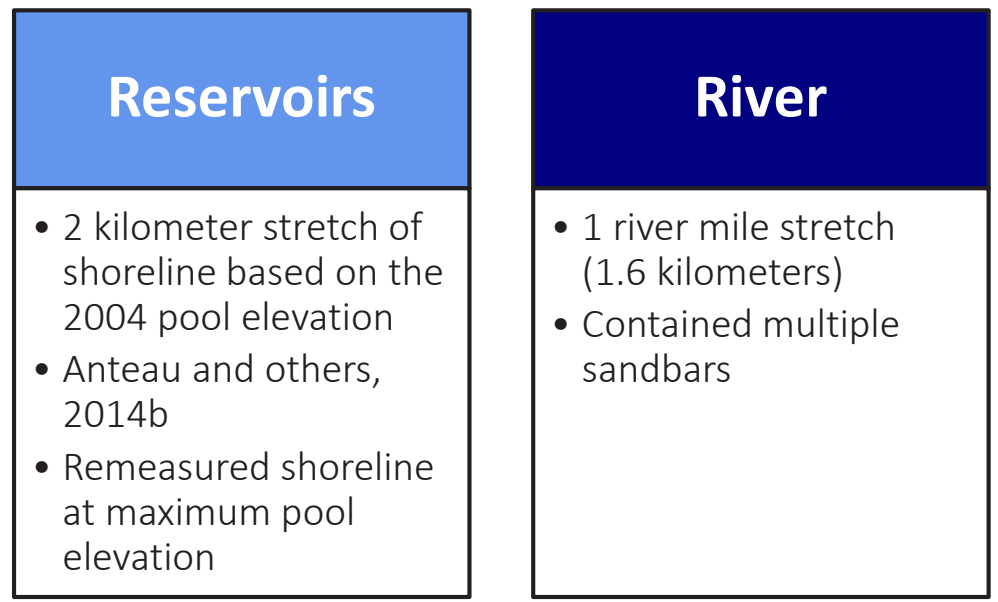

\section{‡USGS}

A segment was defined differently for each habitat type and was used to create local-scale variables. On alkali wetlands, a segment was the wetland basin itself, and its perimeter was used. On the reservoirs (SAK and OAH), we used previously described segments of about 2 kilometers $(\mathrm{km})$ of reservoir shoreline based on the 2004 pool elevation (Anteau and others, 2014b). If a length was required, we used the perimeter at the maximum pool elevation rather than the 2004 pool elevation. For the GRR, a segment was a predefined section of equal length $(1.6 \mathrm{~km})$ that included stretches of sandbar and shoreline habitat. 


\section{Dynamic water system \\ Within or Between years $\rightarrow$ change in amount of available habitat}

\section{₹USGS}

The Prairie Pothole Region in the NGP has a highly dynamic climate, which affects wetland water levels (Euliss and Mushet, 1996; Euliss and others, 2004; Anteau, 2012). Similarly, on the Missouri River system, reservoir water levels and river flow have fluctuated greatly (Hunt and others, 2018; Anteau and others, 2019). Piping plovers nest in early-successional habitat that is created when water scours shorelines of vegetation and retreats to make open, unvegetated habitat available (Catlin and others, 2010; Anteau and others, 2014b). The amount of habitat that is available and suitable for piping plovers to breed can change rapidly within a year or between years. 


\section{Dynamic water system \\ Within or Between years $\rightarrow$ change in amount of available habitat \\ Missouri River \\ Alkali wetlands} Habitat

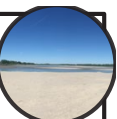

Local and regional precipitation
Local precipitation and evaporation

\section{‡USGS}

In this study, we compare two different water regimes. The Missouri River is hydrologically linked, and downstream flows can be partially controlled through dam releases. Water flowing into the Missouri River is affected by local and regional precipitation (including Rocky Mountain snowpack and melting rates). In contrast, the alkali wetlands are affected mostly by local precipitation and evaporation. Because of varying watershed size and connectivity to groundwater among Prairie Pothole wetlands, each wetland is independent from the next-even those near one another (McCauley and others, 2015).

\section{Dynamic water system \\ Within or Between years $\rightarrow$ change in amount of available habitat \\ Missouri River \\ Alkali wetlands} Habitat

Local and regional precipitation

Reservoir filling

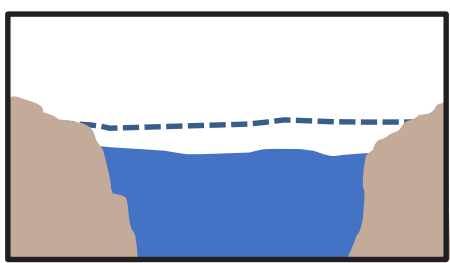

\section{₹USGS}

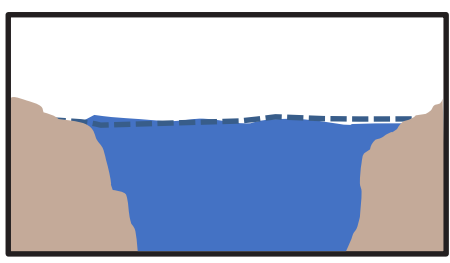

Local precipitation and evaporation

Wetland retreating
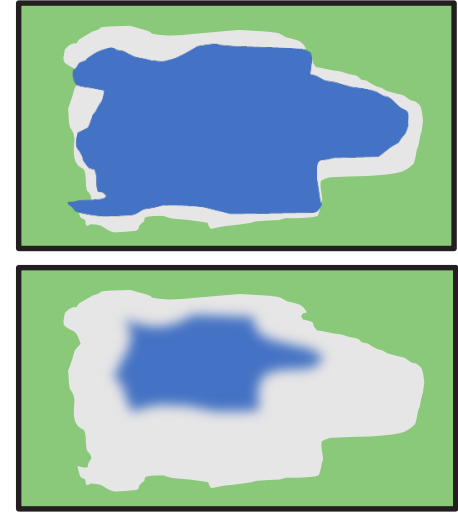

For example, within a breeding season or between years, a reservoir may fill, decreasing habitat because of midsummer water-level rise, whereas the area of ponded water at a nearby alkali wetland may retreat because of low precipitation and high evaporation, increasing habitat. The opposite situation could also occur. 


\section{Habitat availability}

Habitat

Within or Between years $\rightarrow$ change in amount of available habitat

\begin{tabular}{|l|}
\hline \multicolumn{1}{|c|}{ Alkali } \\
Wetlands \\
\hline - Standardized \\
Precipitation- \\
Evapotranspiration \\
Index \\
- Calculated for each \\
wetland basin \\
\hline
\end{tabular}
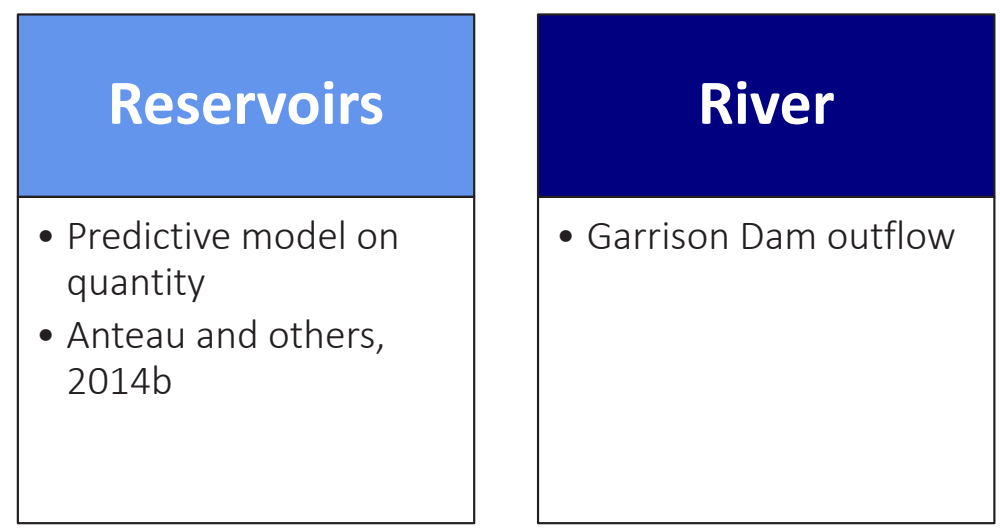

\section{※USGS}

To estimate habitat availability, we calculated a standardized index of habitat availability and derived the change in available nesting habitat from the year before to the year of interest or within a year for renesting analyses. See the "Individual Covariates" section for detailed methodology.

\section{Average proximity to other nesting areas relative to a settled site}
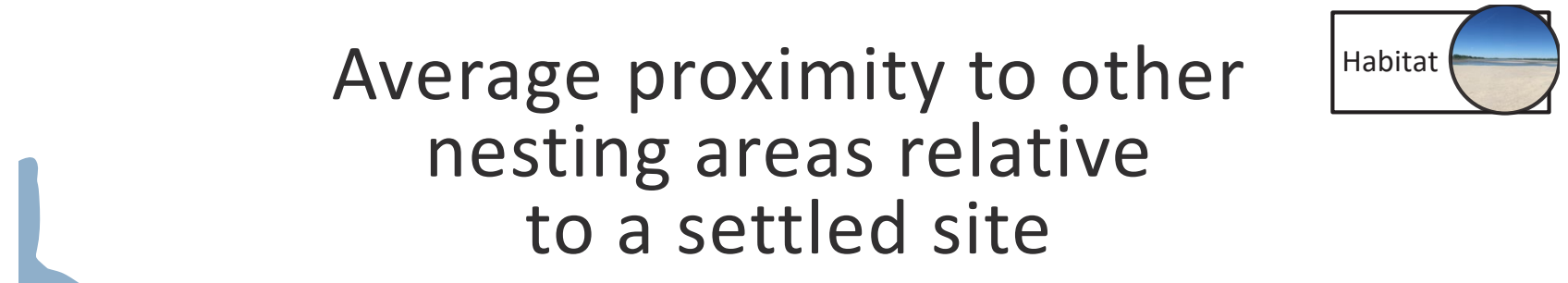

\section{‡USGS}

This and the next five slides demonstrate the technique used to derive the average proximity to other nesting areas relative to a settled site. Detailed methods are provided in the "Individual Covariates" section. [Vertical dashed lines indicate different segments.] 


\section{Average proximity to other nesting areas relative to a settled site}
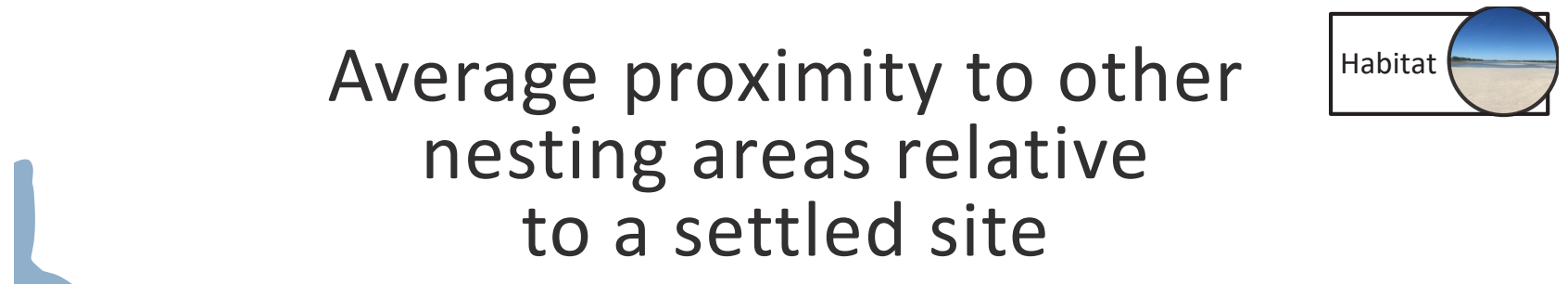

\section{‡USGS}

Each sandbar may host different densities of nesting piping plovers or no piping plovers at all. [Vertical dashed lines indicate different segments. Black dots indicate piping plover nests.]

\section{Average proximity to other nesting areas relative to a settled site}

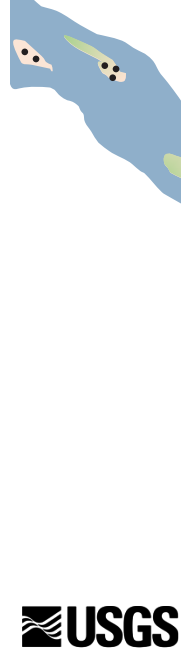

For each nest, we calculated the distance from the nest to the closest nest in another segment (red line). [Vertical dashed lines indicate different segments. Black dots indicate nests. Red dot indicated focal nest for example calculation.] 


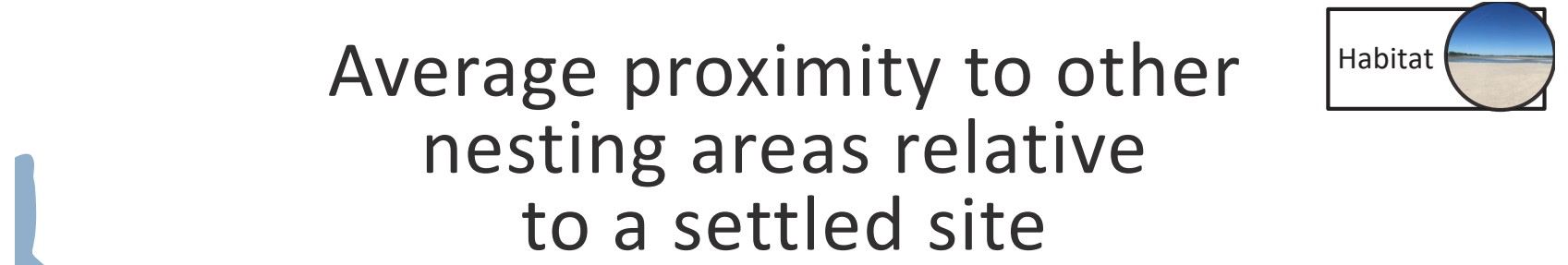

And we calculated the mean of the three distances

\section{‡USGS}

Then, we calculated the distances (red lines) to the second- and third-closest nests in another segment. And, lastly, we used the mean of the three distances as the measure of proximity. [Vertical dashed lines indicate different segments. Black dots indicate nests. Red dot indicates the focal nest.]

\section{Average proximity to other nesting areas relative to a settled site}

\section{₹USGS}

We also used this technique for reservoirs, as shown in this example. [Vertical dashed lines indicate different segments on the reservoir shoreline. Red lines indicate the three distances. Black dots indicate nests. Red dot indicates the focal nest.] 


\section{Average proximity to other nesting areas relative to a settled site}

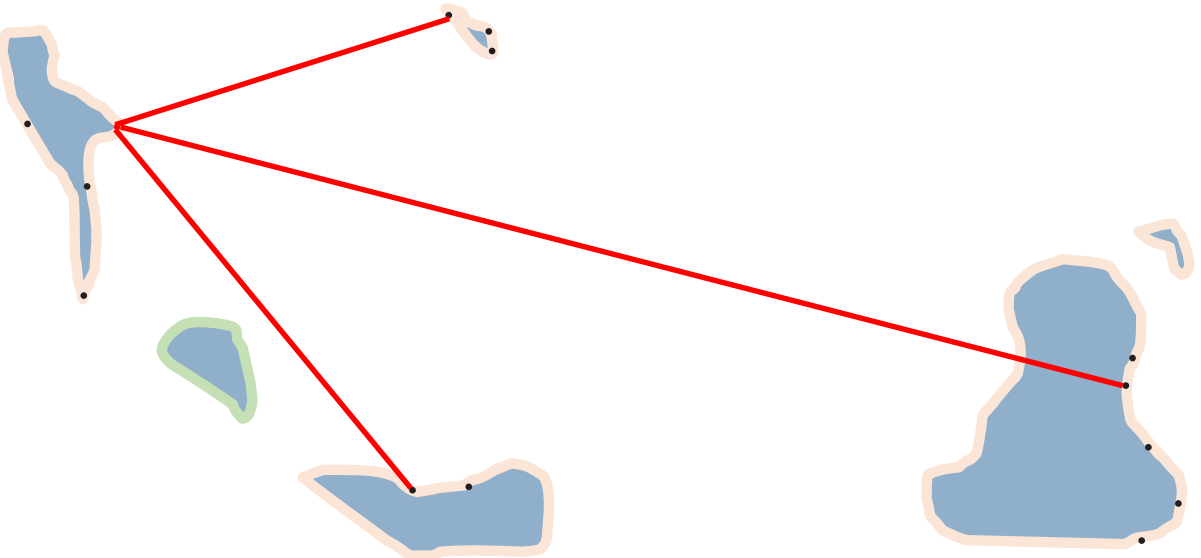

\section{‡USGS}

We also used this technique for alkali wetlands, as shown in this example. Because a segment was the wetland itself, the three distances (red lines) must be to three other wetlands. [Black dots indicate nests. Red dot indicates the focal nest.] 


\section{Reproductive success}

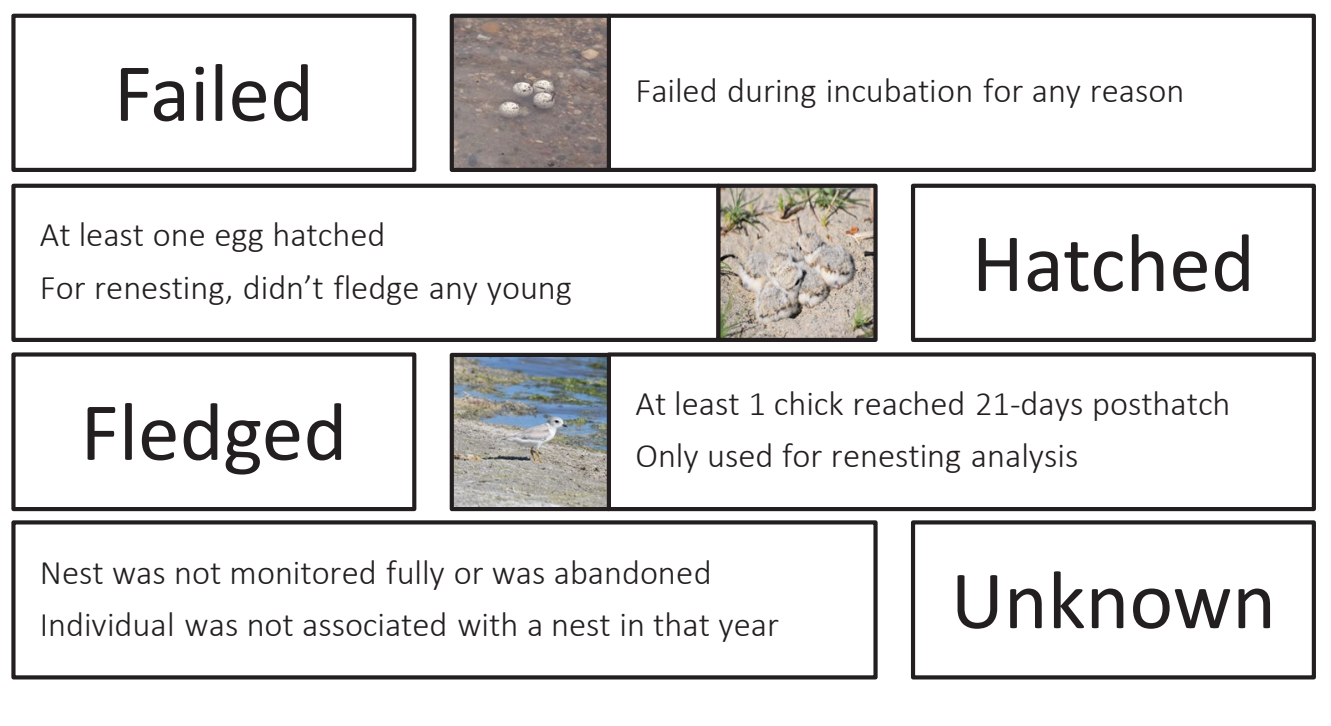

For dispersal probabilities, reproductive success was estimated based on nesting success. If the nest an individual was tied to contained evidence that chicks had hatched (chicks were found and banded) or were presumed to have hatched (multiple lines of evidence that chicks hatched, like pipping fragments and chicks nearby, and near estimated hatch date), we assumed the nest 'hatched'; otherwise, we assumed the nest failed and did not attempt to determine why the nest failed. Not all individuals were associated with a nesting attempt that year nor were all nests monitored to completion in all years. For dispersal probabilities, those individuals were classified into an unknown category. For renesting analyses, we included a fledged category when at least one chick was seen after 21 days posthatch and the causes of nest failures during incubation. 


\section{Cause of nest failure}

Reproductive

Success
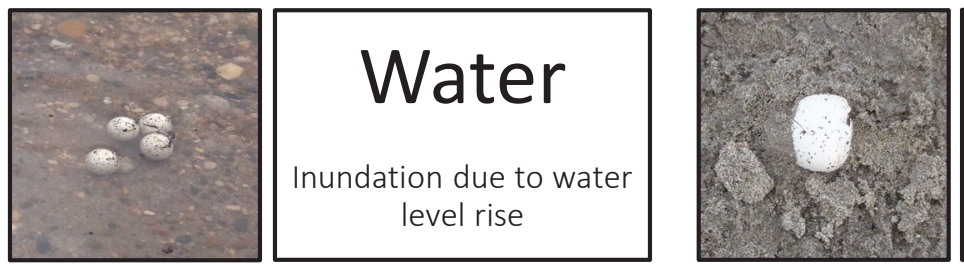

\section{Weather}

Severe storms

Hail

\section{Predators}

Various native species Human- or cattle-caused
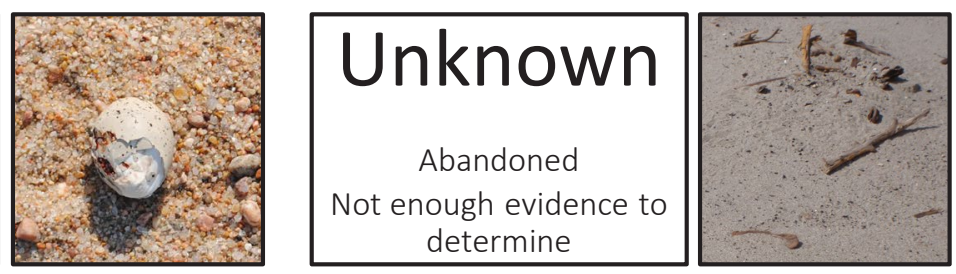

\section{‡USGS}

For renesting analyses, we treated cause of reproductive attempt failure as a categorical factor with five levels. We were unable to determine cause of brood failures (for example, predators and flooding), so all reproductive attempts that failed after hatching were treated as one category (hatched), distinct from the causes of nest failures: depredation, flooding, severe weather, or abandoned/unknown. Cause of nest failure was only included for renesting analyses that coincided with our intensive nest monitoring (only occurred from 2014 to 2016). See the “Individual Covariates" section or Swift and others (2020b) for more detailed information. 


\section{Known flooding failures 2014-2016}

\begin{tabular}{|c|c|c|c|c|}
\hline & ALK & SAK & GRR & OAH \\
\hline $\begin{array}{l}\text { Percentage of nests } \\
\text { that failed due to } \\
\text { flooding }\end{array}$ & $\begin{array}{c}0 \\
\text { (0 of } 232 \\
\text { failed nests) }\end{array}$ & $\begin{array}{c}57 \\
\text { (172 of } 302 \\
\text { failed nests) }\end{array}$ & $\begin{array}{c}3 \\
\text { (11 of } 362 \\
\text { failed nests) }\end{array}$ & $\begin{array}{c}33 \\
\text { (38 of } 114 \\
\text { failed nests) }\end{array}$ \\
\hline $\begin{array}{l}\text { Total nests } \\
\text { monitored }\end{array}$ & 564 & 564 & 753 & 179 \\
\hline
\end{tabular}

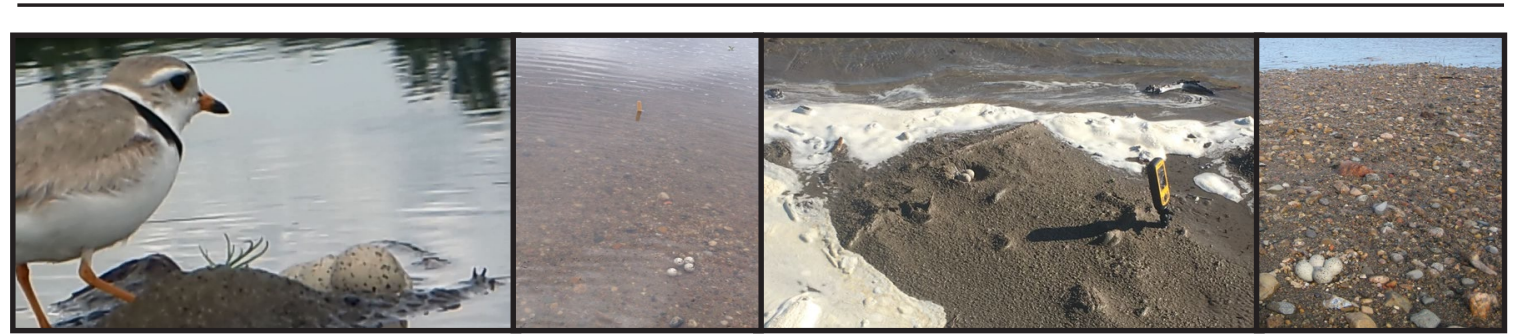

\section{ఇUSGS}

This table shows the percentage of failed nests for each management unit that failed because of inundation, as well as the total number of nests found in each management unit (not all fully monitored). On SAK, 57 percent of failed nests were attributed to inundation.

\section{Known predation failures 2014-2016}

\begin{tabular}{lcccc}
\hline & ALK & SAK & GRR & OAH \\
\hline $\begin{array}{l}\text { Percentage of nests } \\
\text { that failed due to }\end{array}$ & 18 & 5 & 17 & 7 \\
$\begin{array}{l}\text { (41 of } 232 \\
\text { failed nests) }\end{array}$ & $\begin{array}{c}\text { (16 of } 302 \\
\text { failed nests) }\end{array}$ & $\begin{array}{c}\text { (62 of } 362 \\
\text { failed nests) }\end{array}$ & $\begin{array}{c}\text { (8 of } 114 \\
\text { failed nests) }\end{array}$ \\
$\begin{array}{l}\text { Total nests } \\
\text { monitored }\end{array}$ & 564 & 564 & 753 & 179 \\
\hline
\end{tabular}

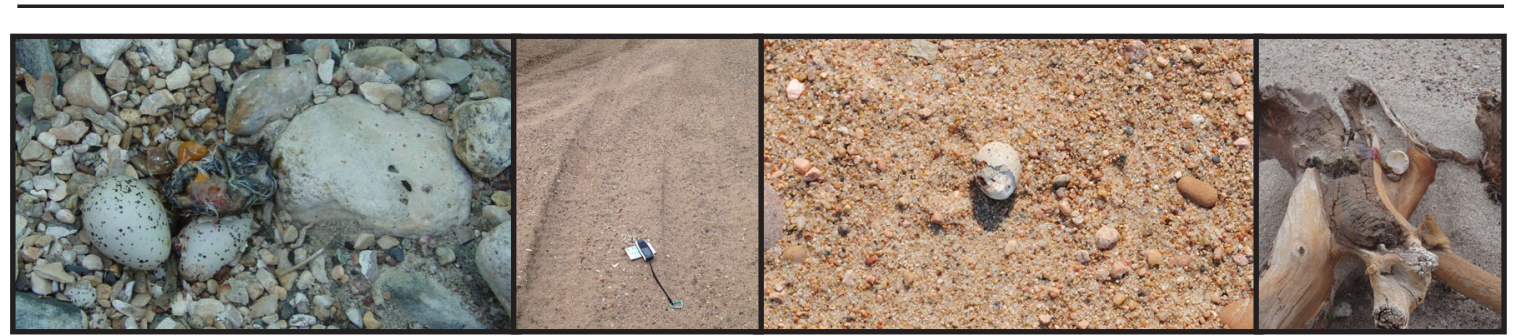

\section{₹USGS}

This table shows the percentage of failed nests attributed to predation (including human caused and livestock). Rates of predation were lower at SAK and OAH than the ALK or the GRR. 


\section{Annual segment reproductive success}

Reproductive Success
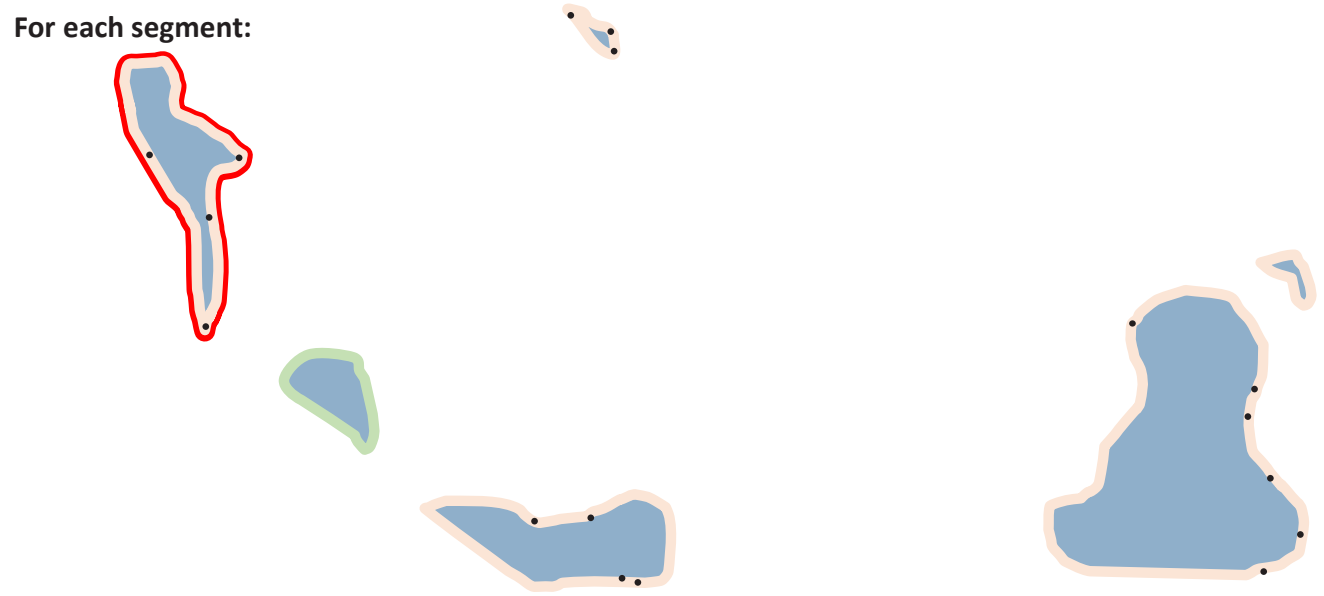

\section{‡USGS}

This and the next two slides demonstrate the technique used to rank annual reproductive success for each segment. Detailed methods for this procedure are provided in the "Individual Covariates" section. [Red outline indicates the focal segment. Black dots indicate nests.]

\section{Annual segment reproductive success}

Reproductive Success
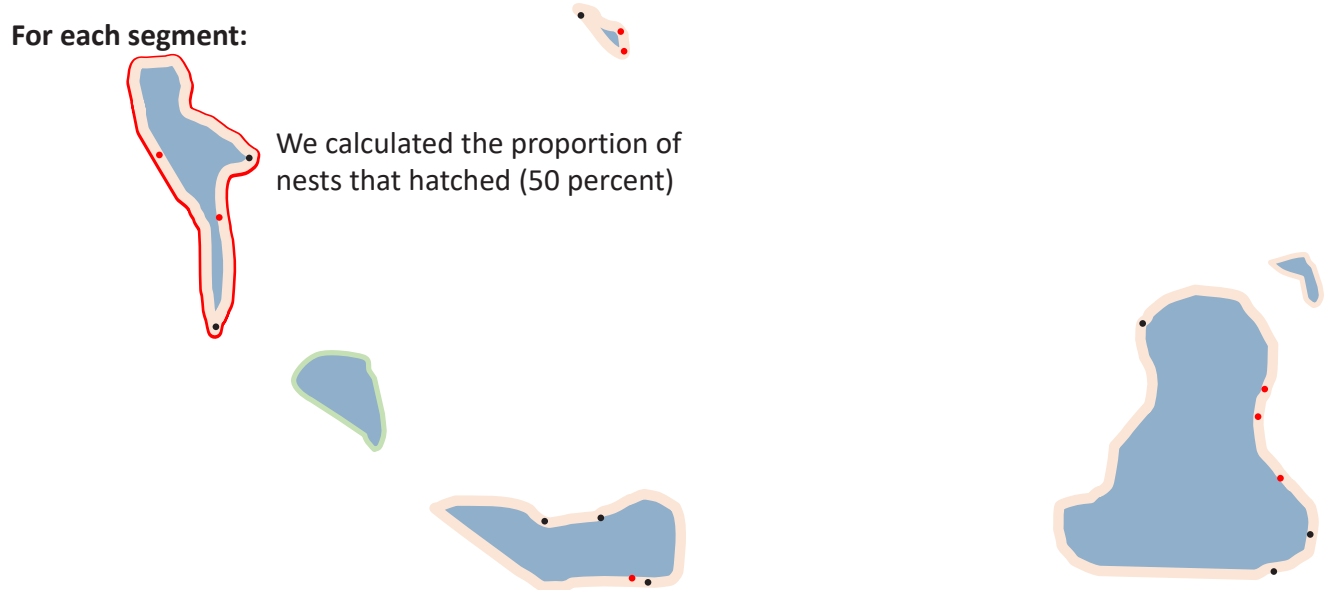

\section{‡USGS}

For each segment, we calculated the proportion of nests that hatched on that sandbar. The focal segment (red outline) has a 50-percent hatching success rate (two of four nests hatched). [Red dots indicate hatched nests. Black dots indicate unhatched nests.] 


\section{Annual segment reproductive success}

For each segment:

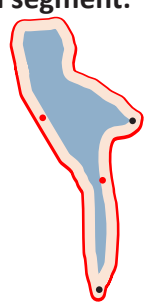

We calculated the proportion of nests that hatched (50 percent)

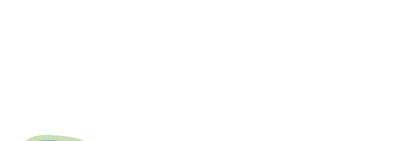

And compared that to the population mean (for example, 47 percent hatching success). Thus, the example segment circled in red is above average.
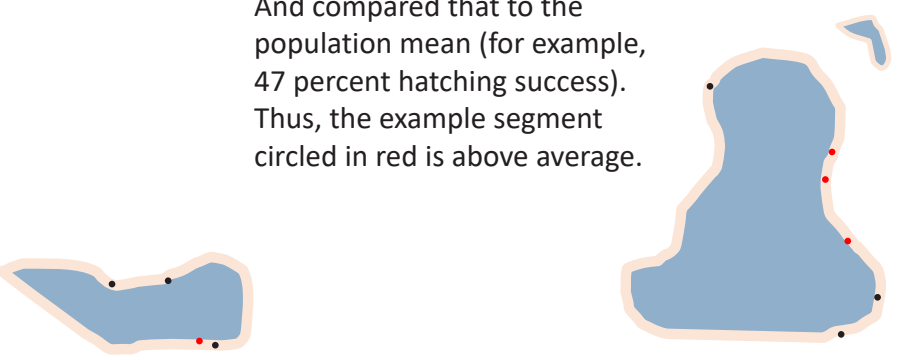

\section{₹USGS}

We compared whether or not a segment has higher hatching success than the population mean hatching success (47 percent in this example). The focal segment (red outline) is above average (hatching rate is greater than the population mean). [Red dots indicate hatched nests. Black dots indicate unhatched nests.]

\section{Individual}

\section{Mate fidelity}
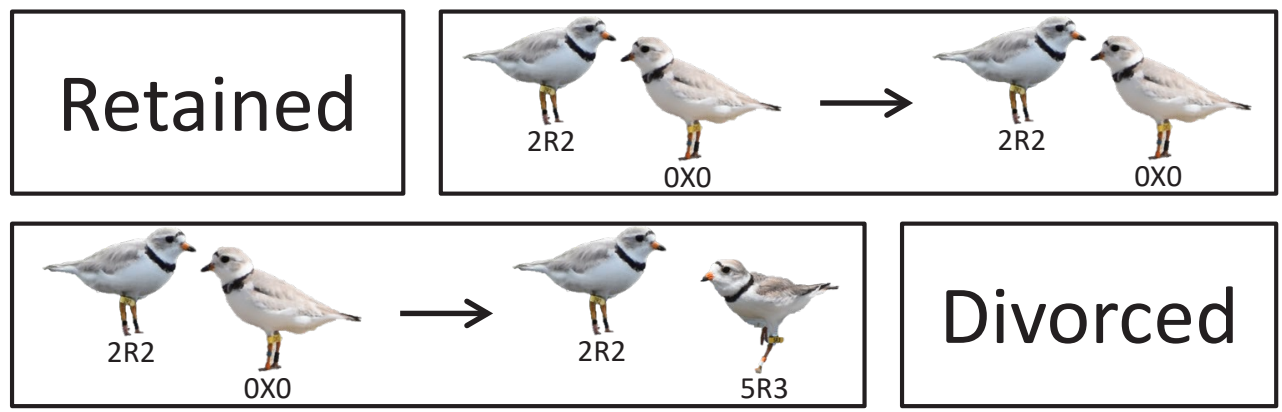

\section{Unknown}

\section{‡USGS}

For adults, we categorized mate fidelity as a three-level factor: retained mate from previous year (both mates known in both years), divorced mate from previous year (both mates known in both years), and unknown (in one or both years, mate was unknown or was unbanded). 


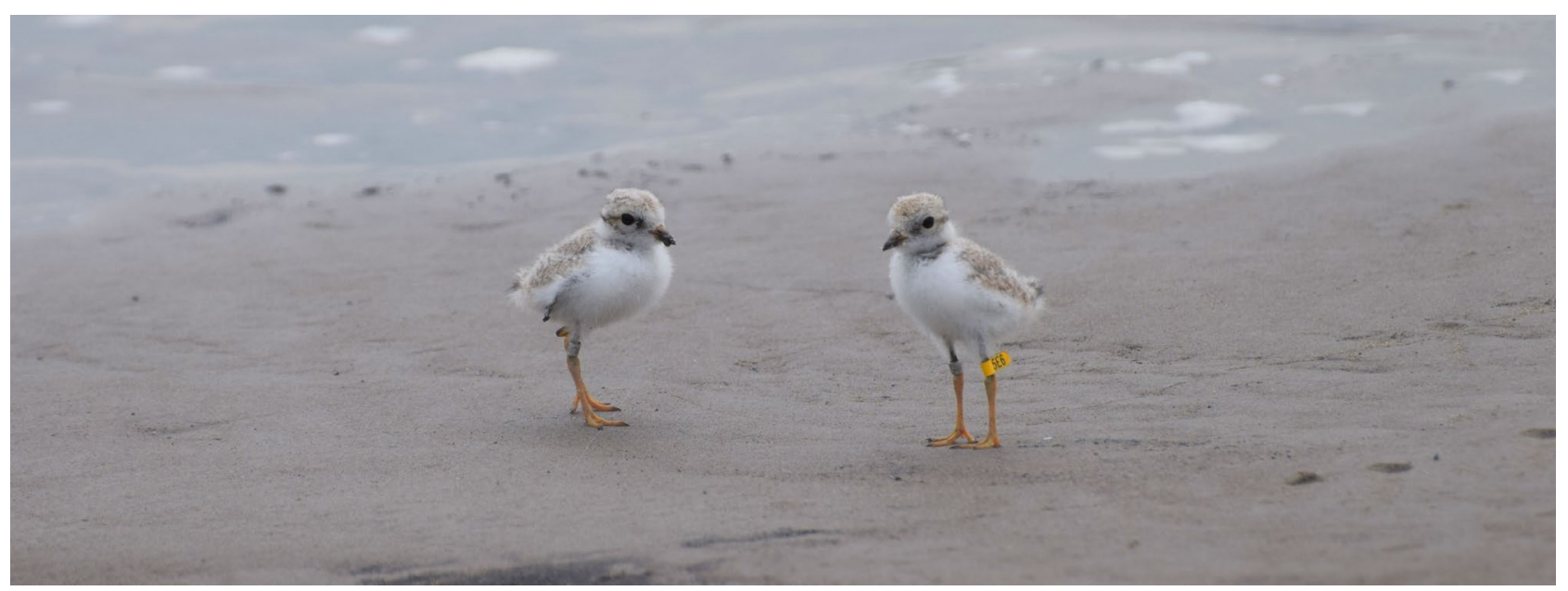

\section{HATCH-YEAR SURVIVAL AND NATAL DISPERSAL INFLUENCE RECRUITMENT \\ Objectives 1, 2, 3, \& 5}

\section{ॠUSGS}

We were interested in determining sources of variation in natal dispersal rates, hatch-year survival to adulthood, and natal dispersal distances. Natal dispersal was defined as the movement from an individual's hatching location to their first location where breeding occurred or was presumed to occur because of at least three resightings within a breeding season. 


\title{
Hatch-year survival
}

\author{
Local recruitment and survival of post-fledging \\ chicks are influential but challenging to estimate
}

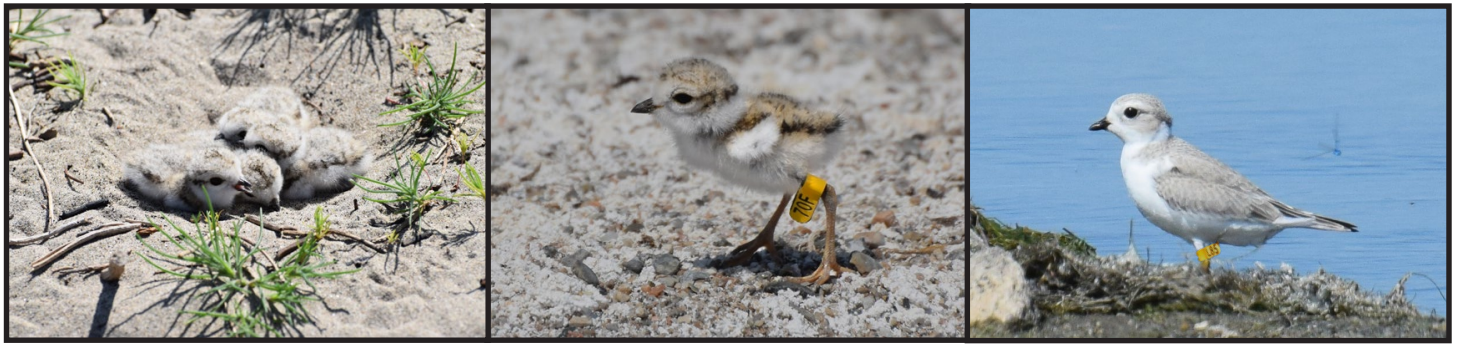

\section{ఇUSGS}

Unbiased and precise estimates of demographic parameters are essential for understanding the population dynamics of small or imperiled bird populations (Beissinger and Westphal, 1998). Demographic parameters are usually age structured, making accurate population models difficult without age-specific vital rates. Hatch-year survival is particularly difficult to estimate because natal dispersal co-occurs with postfledgling mortality, thus confounding estimates of both parameters (Greenwood and Harvey, 1982; Larson and others, 2000; Stenzel and others, 2007). However, hatch-year survival will affect local and population-level recruitment and population trends and is therefore important to conservation managers. 


\title{
Natal dispersal
}

\author{
Has important consequences for population dynamics through \\ the movement of individuals
}

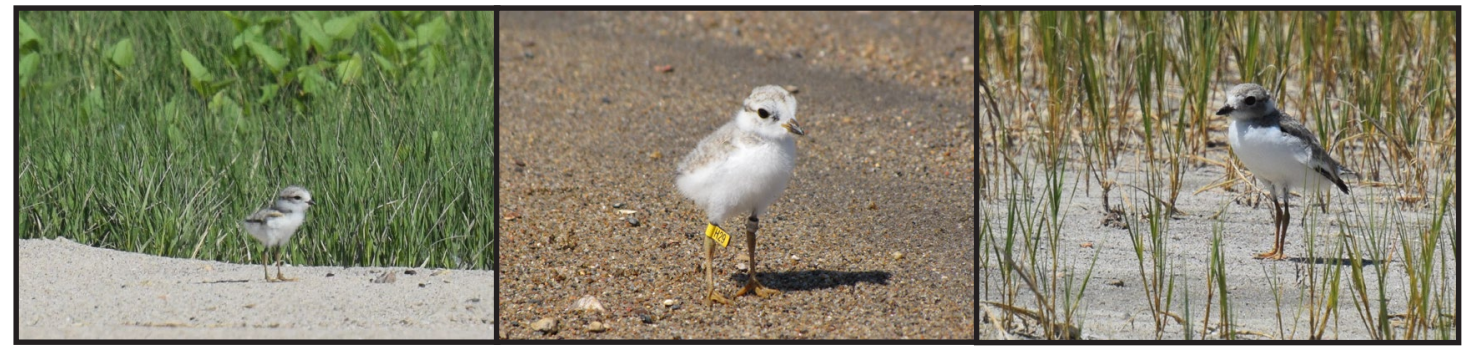

\section{‡USGS}

Dispersal is a fundamental life-history trait that affects individual fitness, gene flow, and population structure (Greenwood and Harvey, 1982). Dispersal in territorial animals is driven by numerous selection pressures including inbreeding avoidance, competition, and spatiotemporal variation in habitat quality (Bowler and Benton, 2005; Roze and Rousset, 2005). Natal dispersal is defined as the movement from natal areas to an individual's first breeding territory. Natal dispersal has evolved to reduce competition and inbreeding and is the primary mechanism for maintenance of genetic population structure (Paradis and others, 1998). 


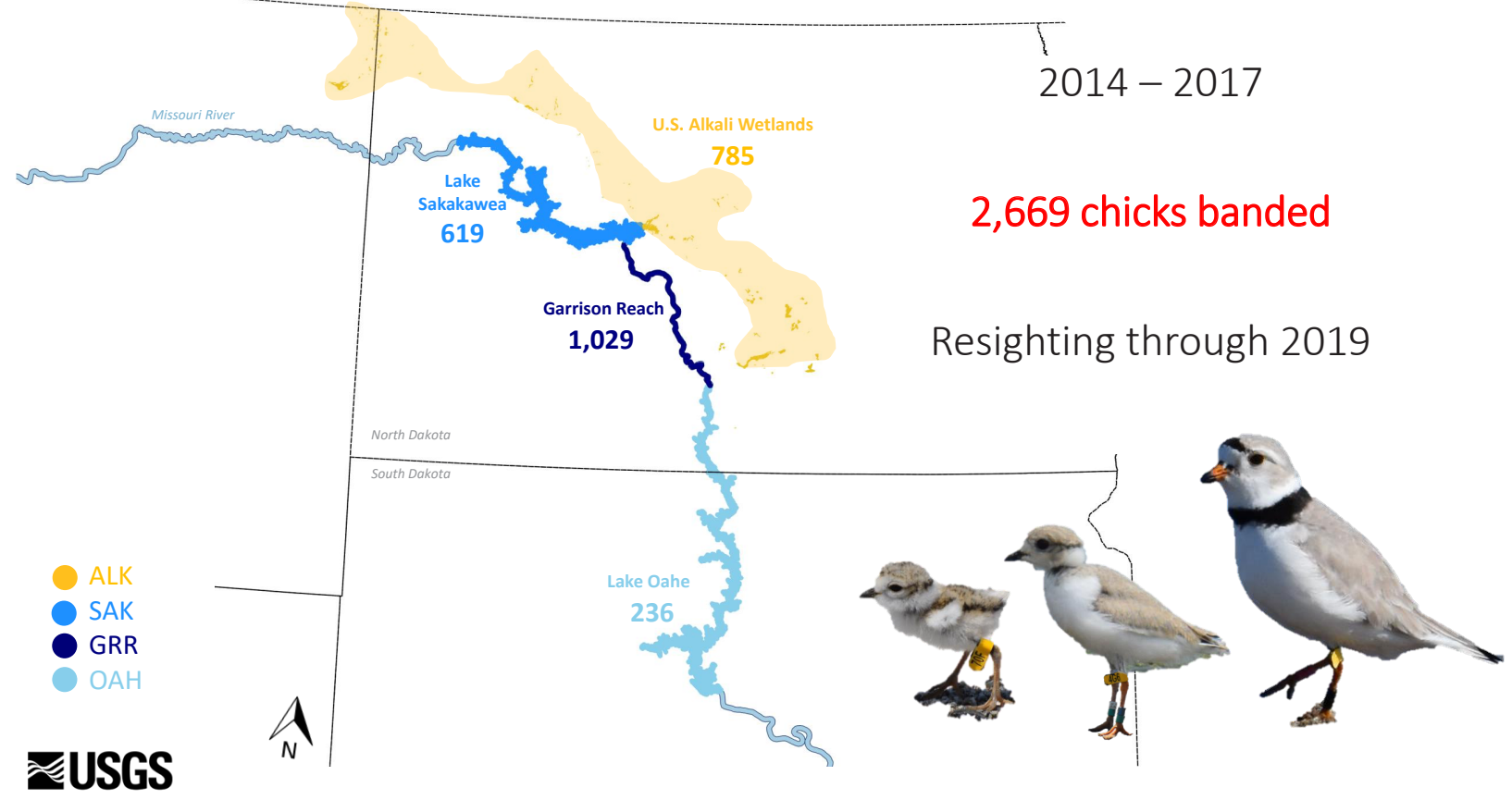

From 2014 to 2017, nests near the estimated hatch date were visited frequently to band chicks while in the nest bowl. We attempted to evenly distribute total chicks banded for each management unit within a given year while following permit restrictions for the total number of chicks we were allowed to band. However, distribution of total chicks banded varied among management units depending on availability of chicks. The total number of chicks banded in each management unit is shown on the map. See the "Chicks" section for more information. 


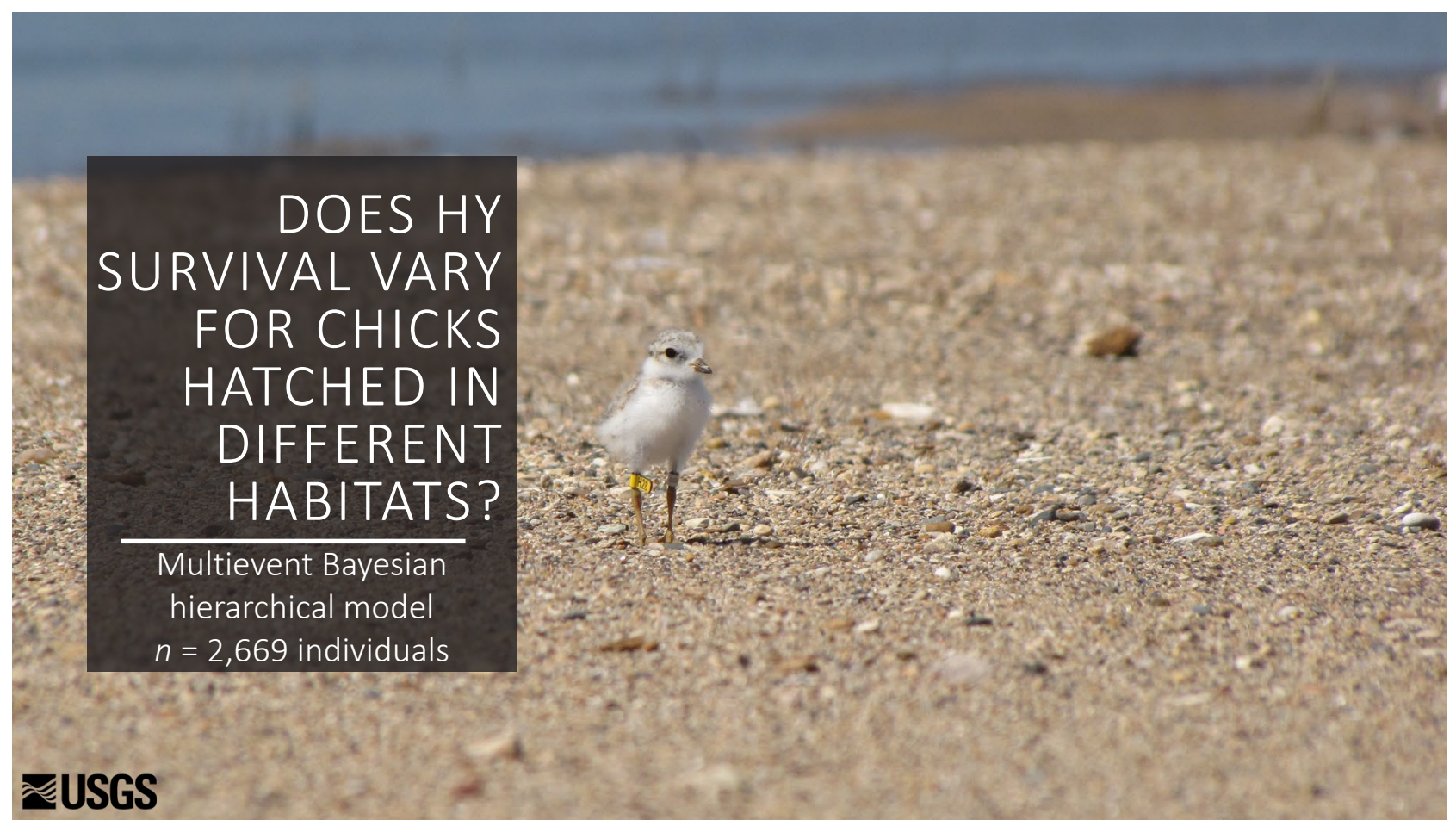

We developed a simplified multievent model to estimate apparent survival $(S)$ and transition $(\Psi)$ probabilities between location states, allowing for uncertainty in an adult's state assignment (Pradel, 2005). We separately provide estimates for either the Missouri River system (MRS) and the ALK or for the ALK, SAK, the GRR, and OAH. Because model assumptions vary when state assignments change (in other words, two versus four locations), similar estimates are not comparable between models with different state structures. All estimated annual vital rates were produced from either state-based or state- and year-based models representing the mean over all covariates. The tests of the effect of covariates were from the global covariate model with simplified states (the MRS and the ALK). See the "Natal Survival and Dispersal Probabilities" section for detailed methodologies. [HY, hatch year; $n$, number] 


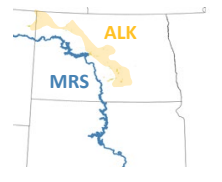

\section{State structure}

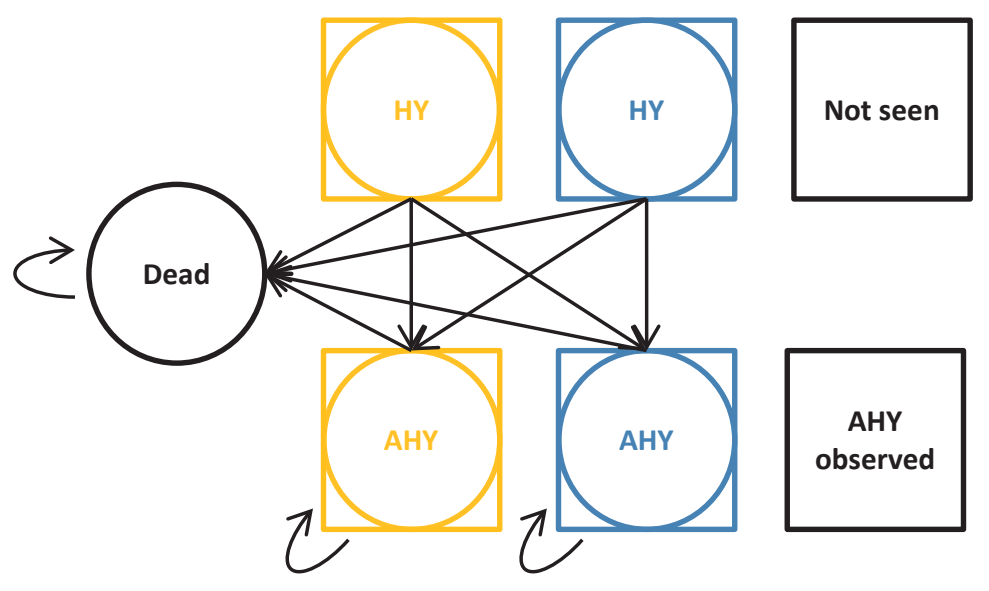

\section{‡USGS}

We used two separate model structures (this and the next slide) to produce the estimates that follow. Here, we show the simplified location-based states: the ALK and the MRS. We produced mean, annual, and covariate estimates from simplified models built on these five states (circles) that describe the age and location of individuals at time, $t$. Age was divided into two distinct stages: hatch year (HY) and adults (AHY; 2 years and older). The observation process is represented with squares. Because breeding status could not be determined for all individuals, adults could also be observed in an unknown state. Because we were primarily interested in natal dispersal decisions (black arrows), we restricted adult individuals to retain their first known breeding location state (in other words, once an individual bred in one location, we did not allow them to transition to other locations). We constrained our model to preclude biologically infeasible transitions (in other words, decreasing in age). Because individuals automatically aged into the adult age states after their initial capture, we fixed detection for the hatch-year states. We fixed all $\delta$ estimates for the known hatch-year states because only adult states could be misclassified. Additional details are in the "Natal Survival and Dispersal Probabilities" section. 


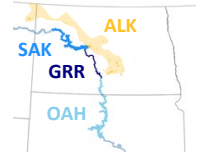

\section{State structure}

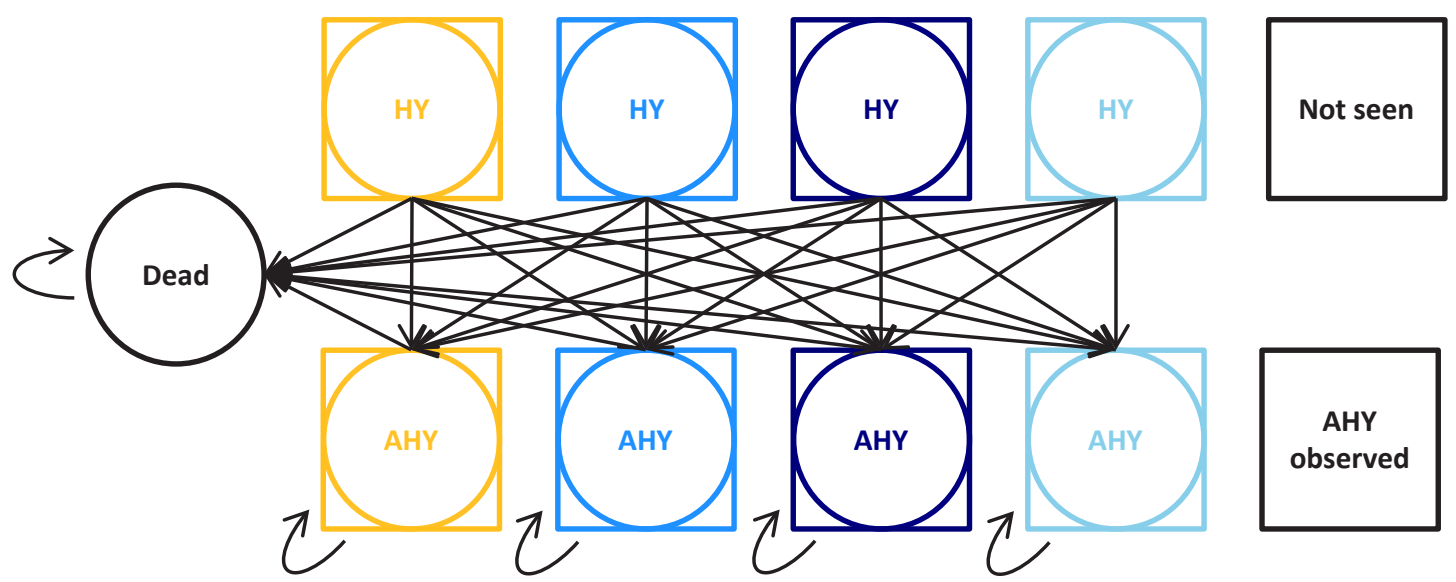

\section{₹USGS}

Here we show the second state structure, which was similar, but the MRS was divided into the three management units (SAK, the GRR, and $\mathrm{OAH}$ ). We included nine states (circles) in these models that describe the age and location of individuals at time, $t$. Age was divided into two distinct stages: hatch year (HY) and adults (AHY; 2 years and older). Individuals could occur in one of four location-based states (the ALK, SAK, the GRR, or OAH) based on the location of their natal nest (for hatch year) or the location of their first known breeding attempt. Although the eight location-based states could also be observed, there are two additional categories of observations (squares). Additional details are in the "Natal Survival and Dispersal Probabilities" section. 


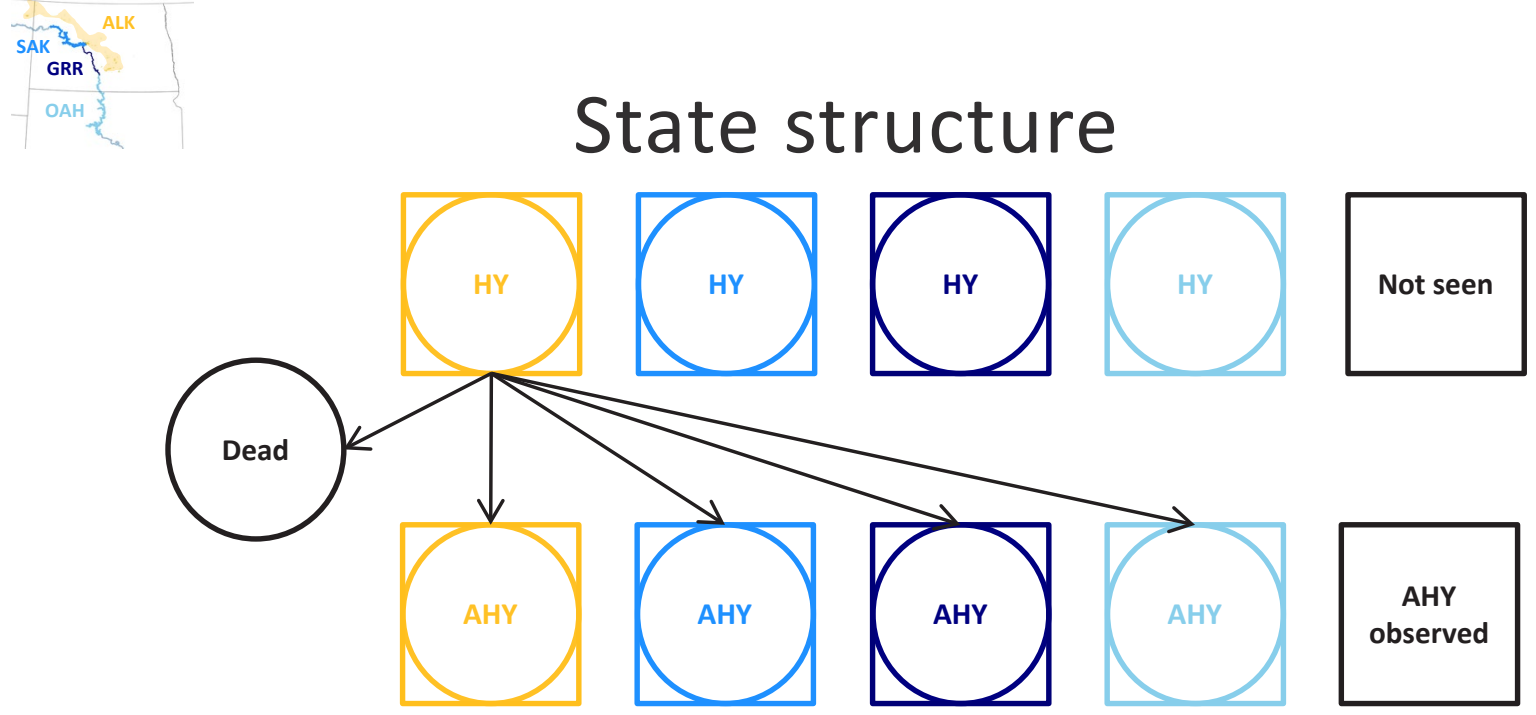

\section{₹USGS}

We constrained biologically infeasible transitions as described previously. For example, this diagram shows the potential state transitions (black arrows) that a chick hatched on an alkali wetland was allowed in the model with location-specific states. An individual could die or transition to one of the four location-specific breeding states (circles). Alternatively, an individual could not be seen, be seen in one of the four breeding locations, or be observed as an adult in an unknown state (squares). [HY, hatch year; AHY, adult, 2 years and older] 


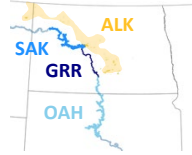

\section{State structure}

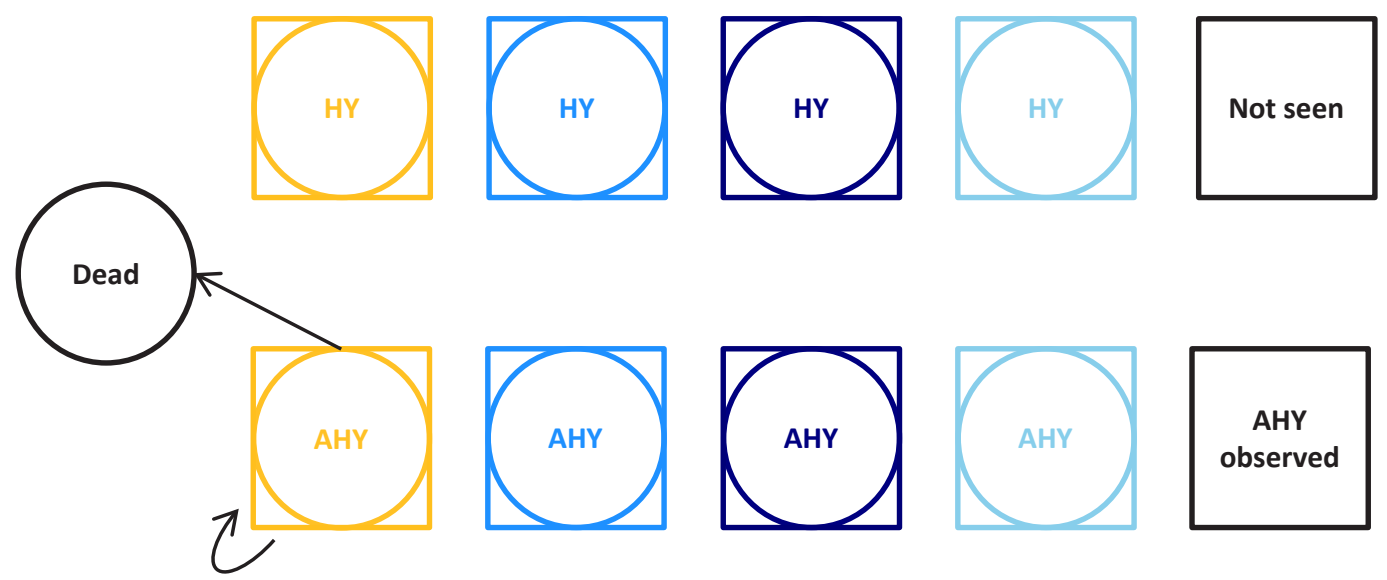

\section{‡USGS}

Alternatively, as shown in this alkali wetlands example, once an individual entered an adult breeding state, they could remain in that adult state or could die. [The observation process is represented with squares. Circles indicate states. HY, hatch year; AHY, adult, 2 years and older]

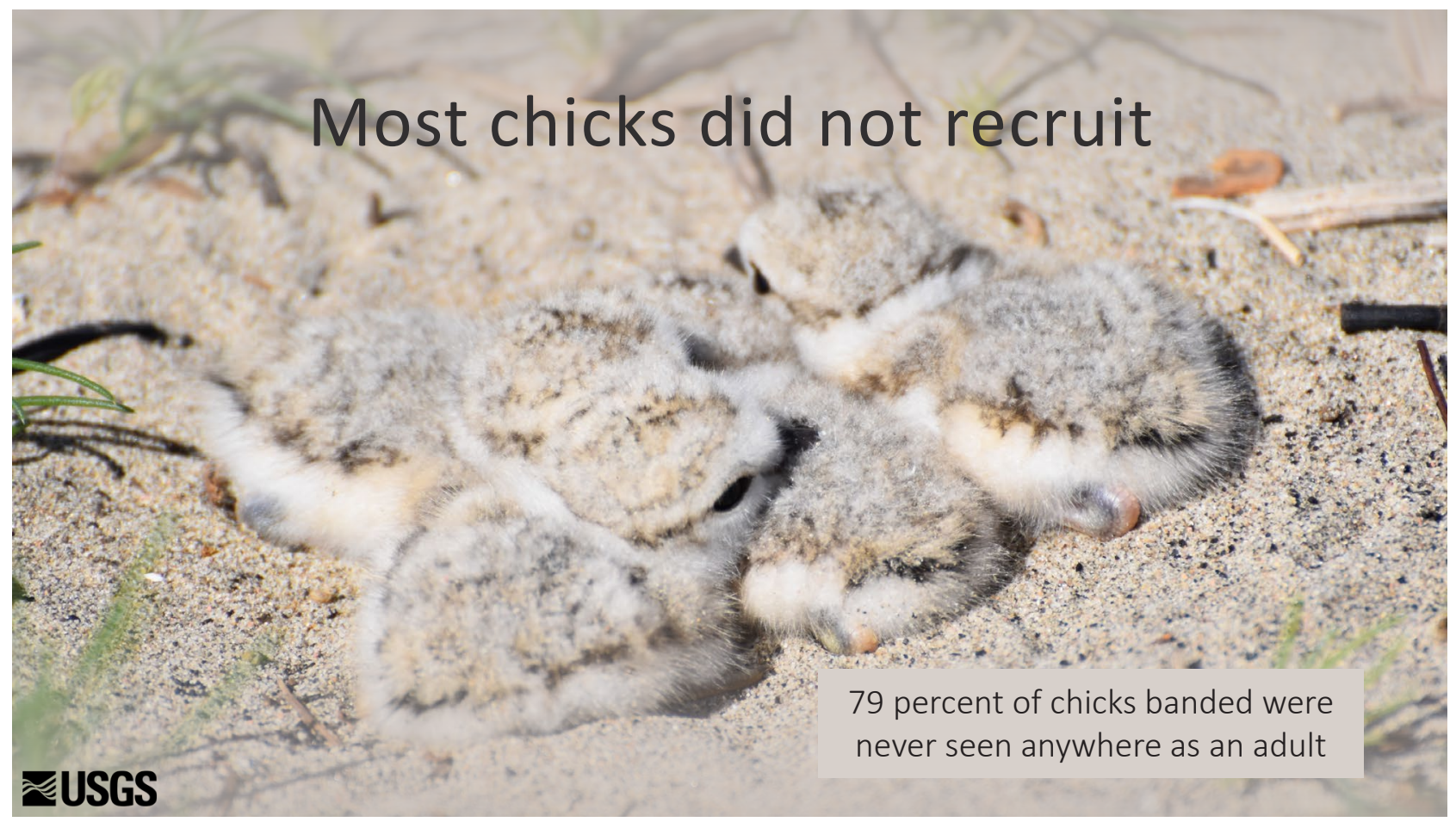

Of the 2,669 chicks banded between 2014 and 2017, 79 percent (2,109 individuals) were never seen as an adult by our crews or reported to us from other breeding populations or the nonbreeding areas. This percentage includes prefledging mortality. 


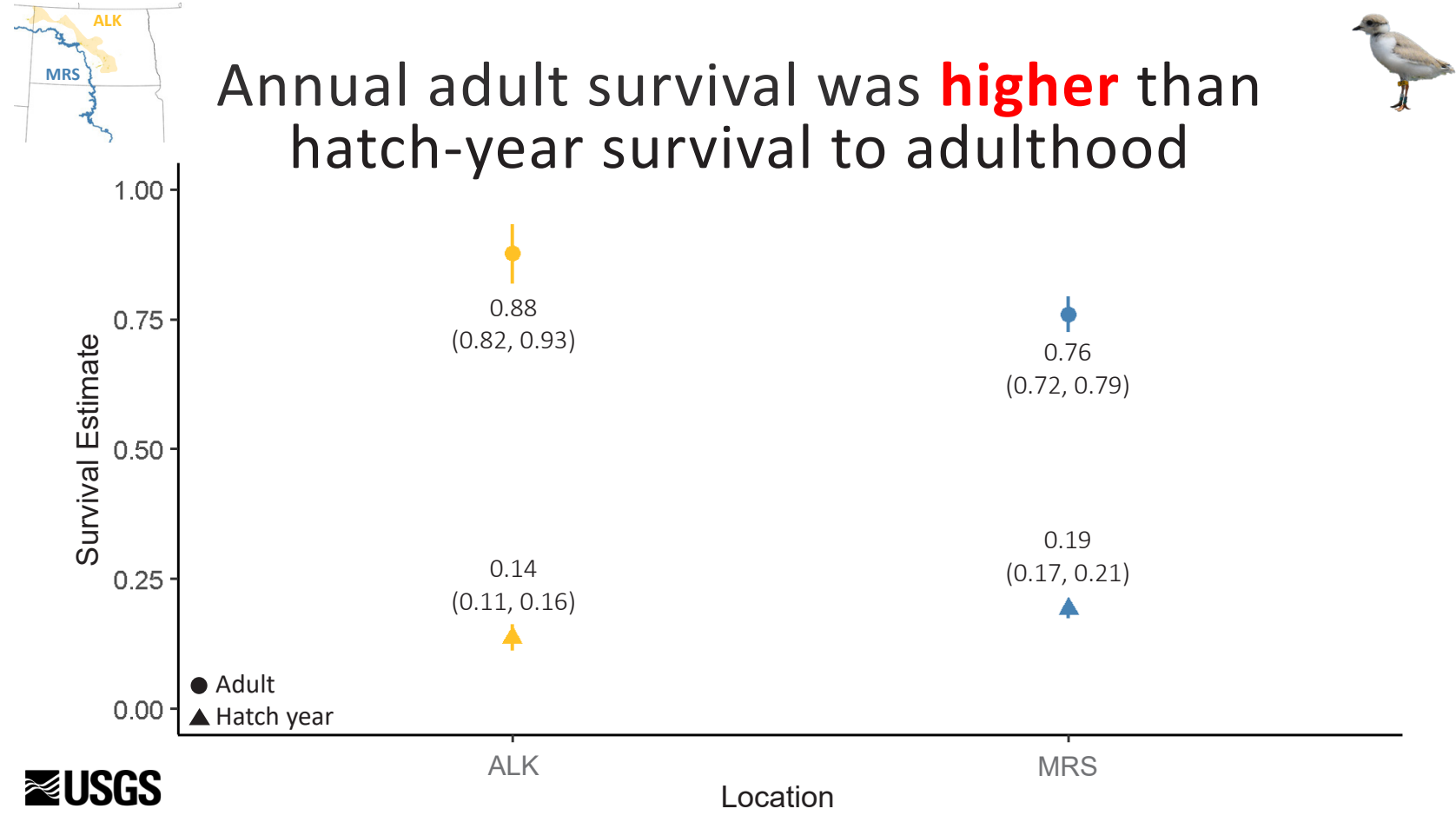

Our model structure estimated survival for locally banded individuals from hatch to adulthood and then annual adult survival. Annual adult survival (for individuals banded as chicks) was higher than hatch-year survival. Although our models included annual adult survival estimates, we did not interpret these for two reasons: first, because we can take advantage of a much larger dataset of marked adults (see results in 'Adult Survival Probabilities'), and second, because the artificial restraint we imposed on adult locations may create biased location-specific estimates. [Filled circles indicate mean annual adult survival estimates. Triangles indicate mean hatch-year survival estimates. Vertical lines indicate 95-percent credible intervals.] 


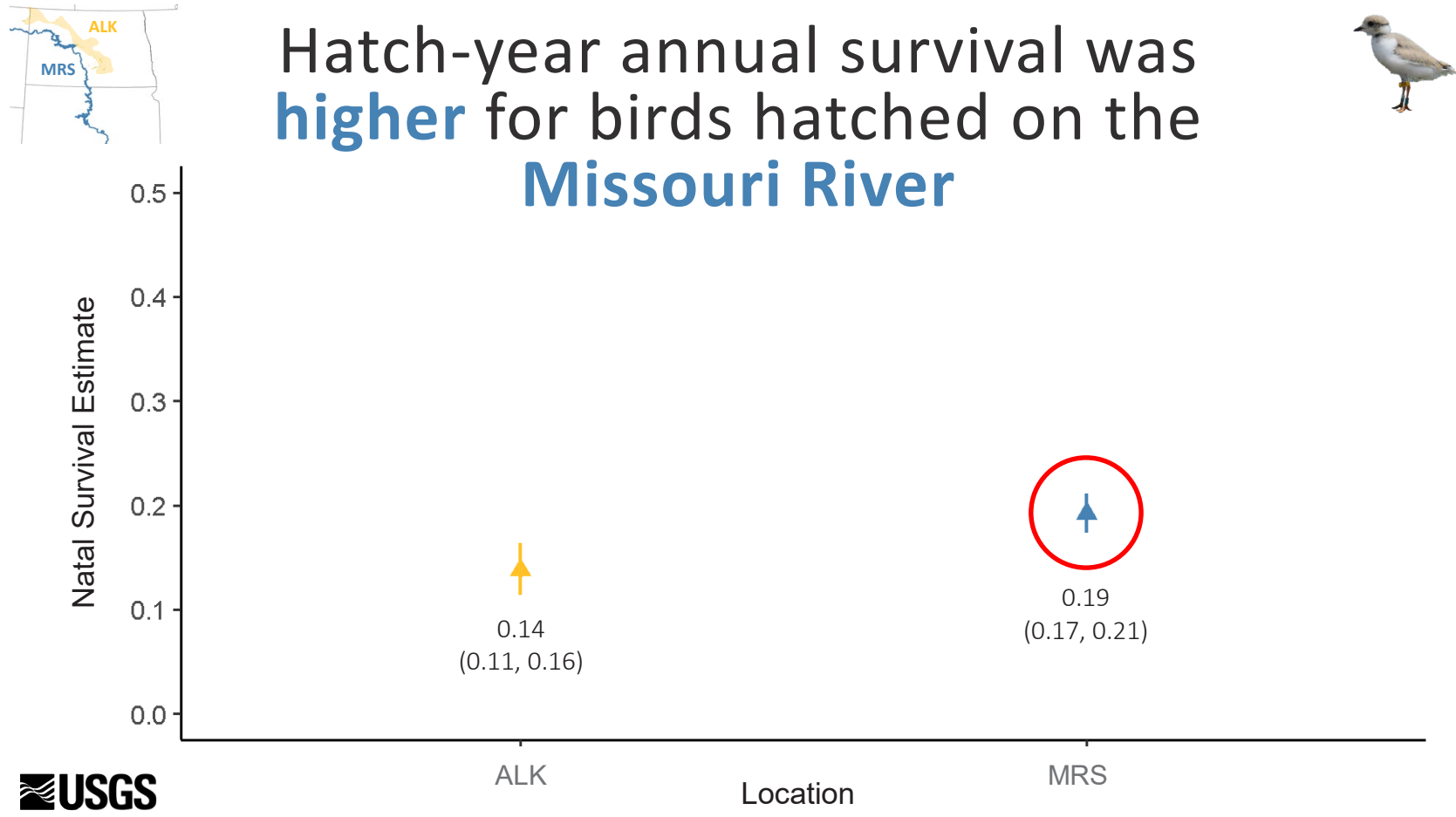

Individuals hatched on the MRS were more likely to survive to adulthood $(0.19, \mathrm{Cl}=0.17$ to 0.21 ; red circle) than those hatched on the $\operatorname{ALK}(0.14, \mathrm{Cl}=0.11$ to 0.16$)$. [Triangles indicate mean hatch-year survival estimates. Vertical lines indicate 95-percent credible intervals (Cls).]

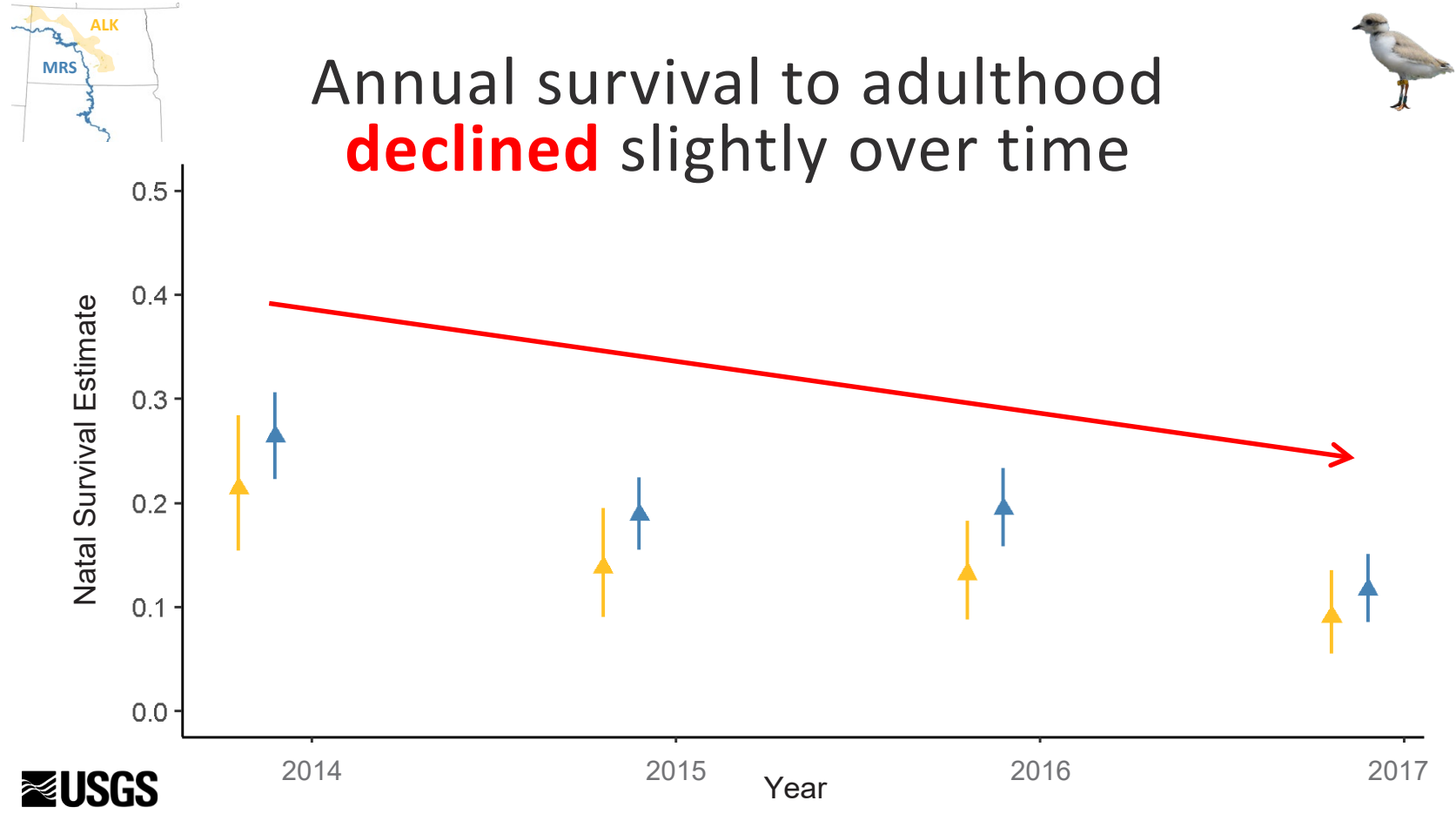

Hatch-year survival to adulthood was similar in most years between the MRS and the ALK birds, but survival seems to have declined (red arrow) during the study period. [The last year in a fully time-dependent model is not estimable. Triangles indicate mean hatch-year survival estimates. Vertical lines indicate 95-percent credible intervals.] 


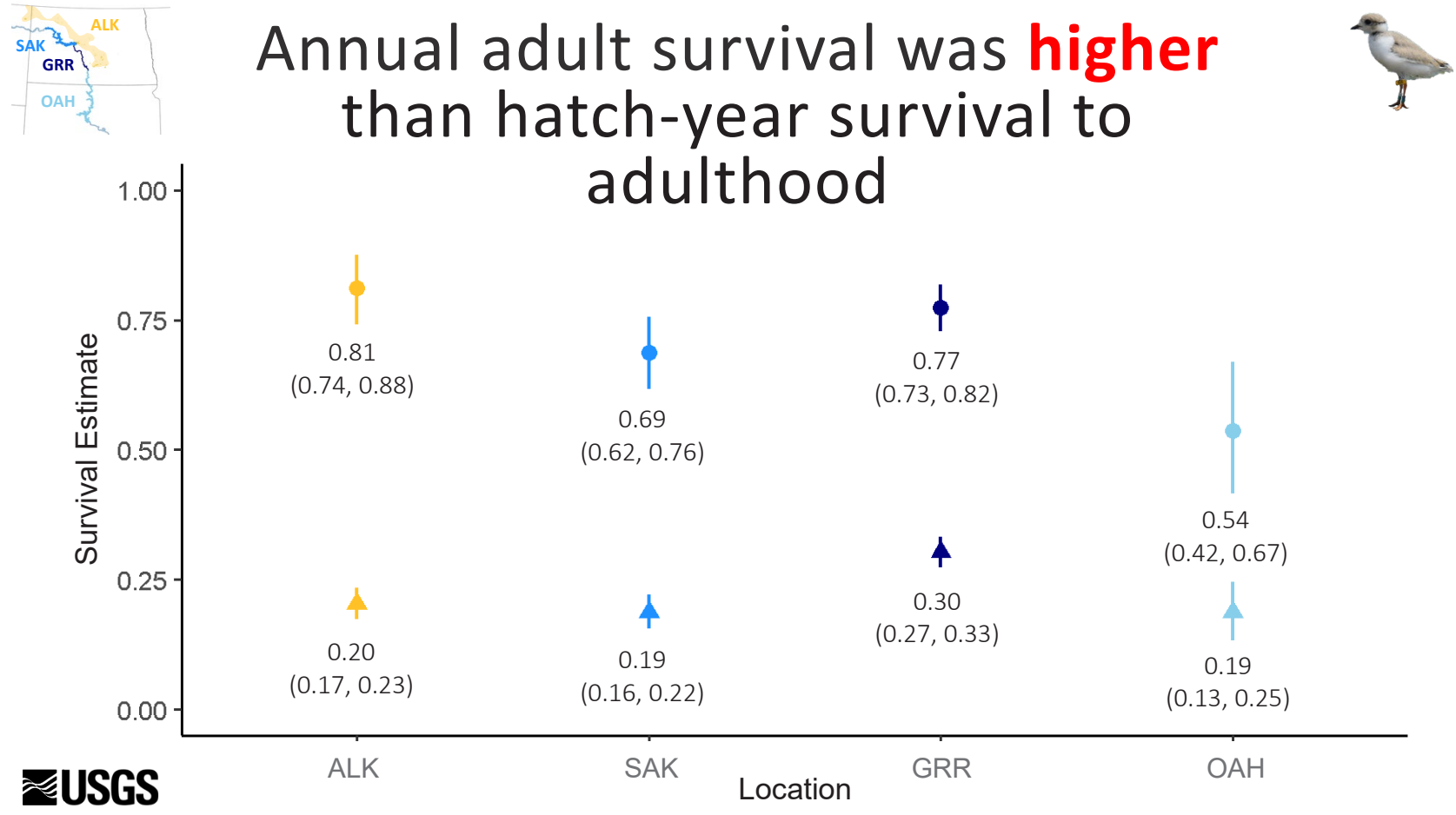

Our model structure estimated survival for locally banded individuals from hatch to adulthood and then annual adult survival for the four management units. Annual adult survival (for individuals banded as chicks) was higher than hatch-year survival for all four management units. Although our models included adult survival estimates, we did not interpret these for two reasons: first, because we can take advantage of a much larger dataset of marked adults (see the "Adult Survival Probabilities" section), and second, because the artificial restraint we imposed on adult locations may create biased location-specific estimates. [Filled circles indicate mean annual adult survival estimates. Triangles indicate mean hatch-year survival estimates. Vertical lines indicate 95-percent credible intervals.] 


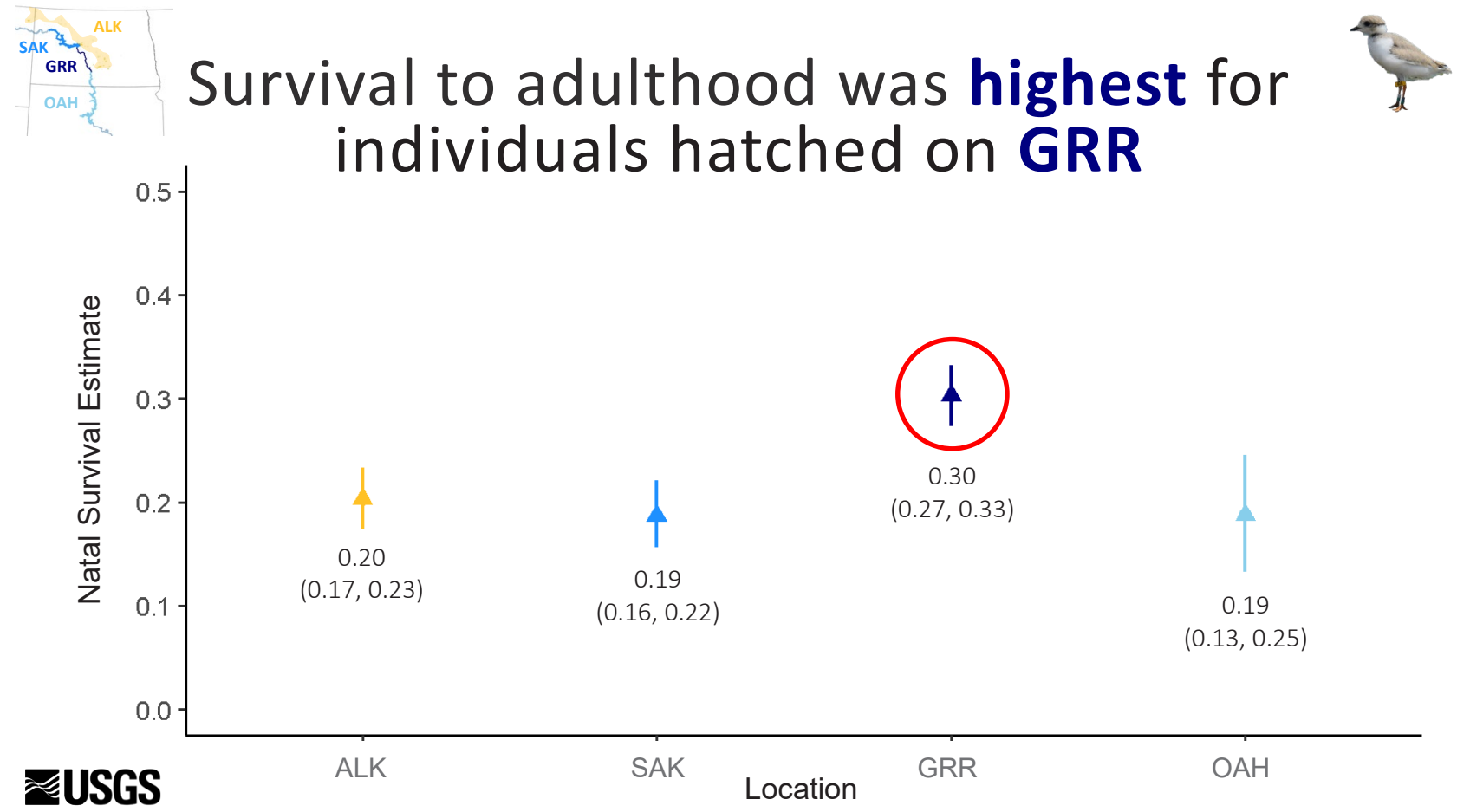

Hatch-year survival to adulthood was higher on the $\mathrm{GRR}(0.30, \mathrm{Cl}=0.27$ to 0.33 ; red circle) than the other three management units. [Triangles indicate mean hatch-year survival estimates. Vertical lines indicate 95-percent credible intervals (CIs).]

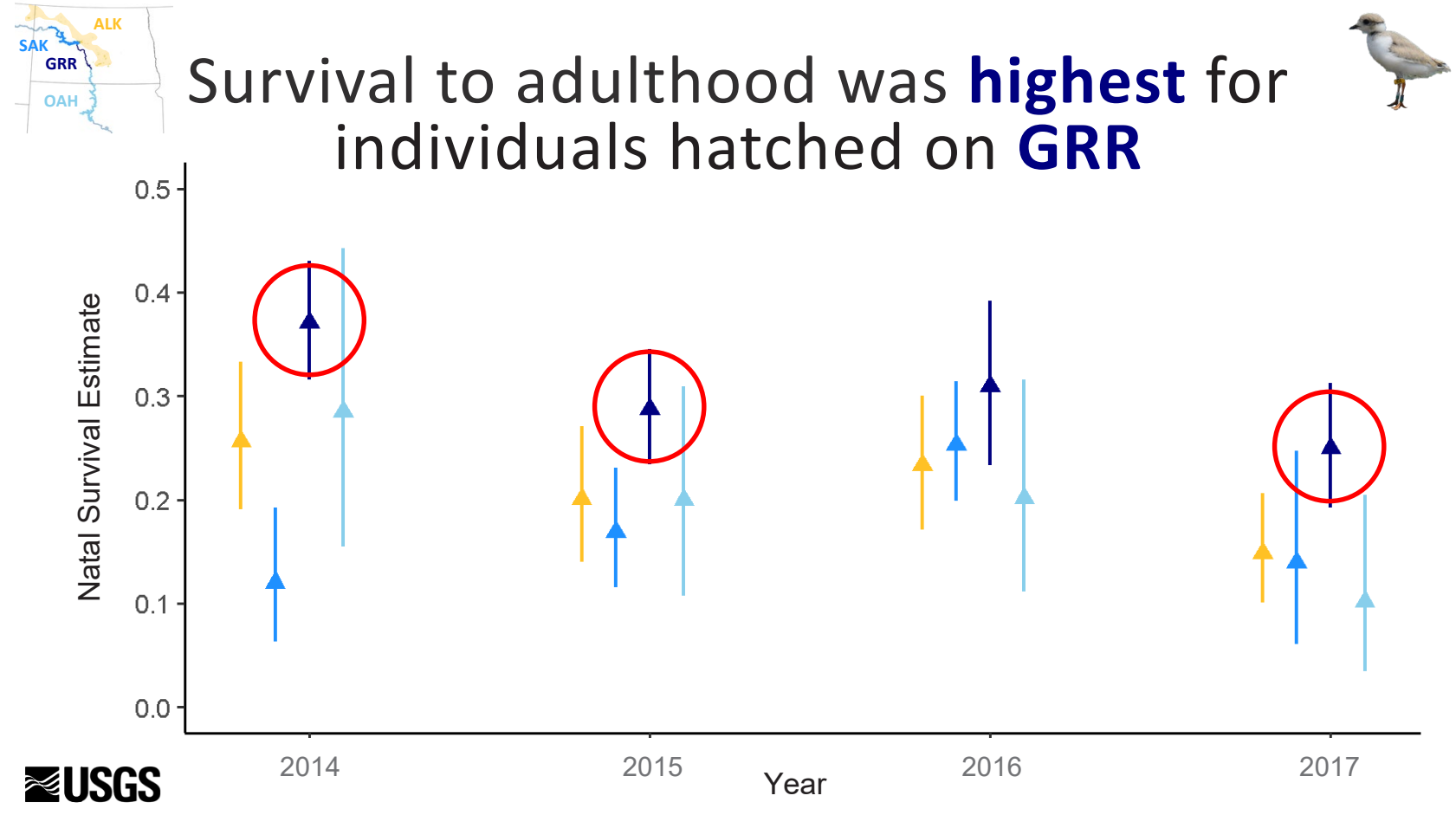

Hatch-year survival to adulthood was higher on the GRR than the other three management units for 3 of the 4 years (red circles). [The last year in a fully time-dependent model is not estimable. Triangles indicate mean hatch-year survival estimates. Vertical lines indicate 95-percent credible intervals.] 


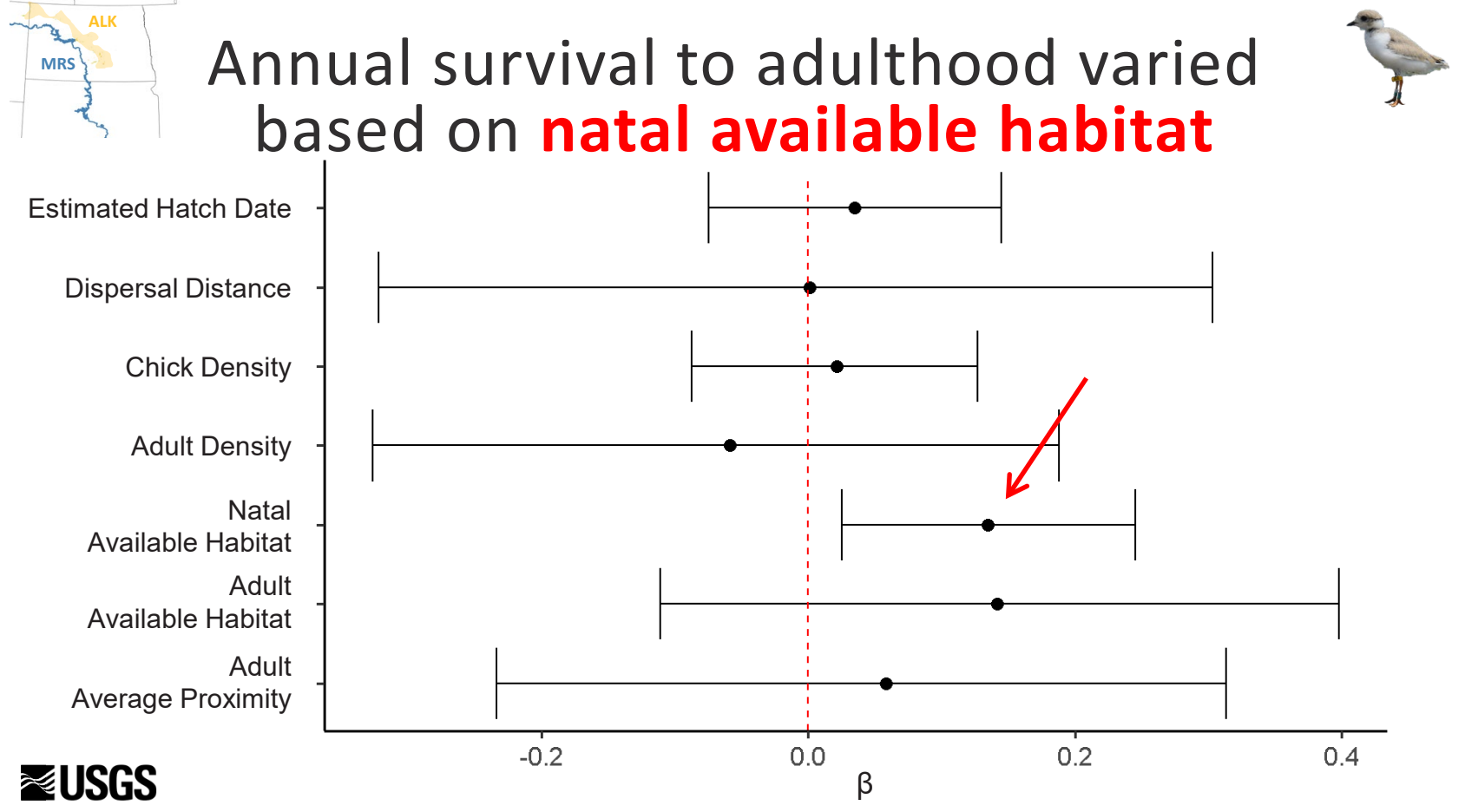

Only one a priori hypothesis (red arrow) explained annual survival to adulthood. (All but one of the 95-percent credible intervals for each $\beta$ covariate estimate cross zero.) [Filled circles indicate mean $\beta$ estimate. Whiskers indicate 95-percent credible intervals.]

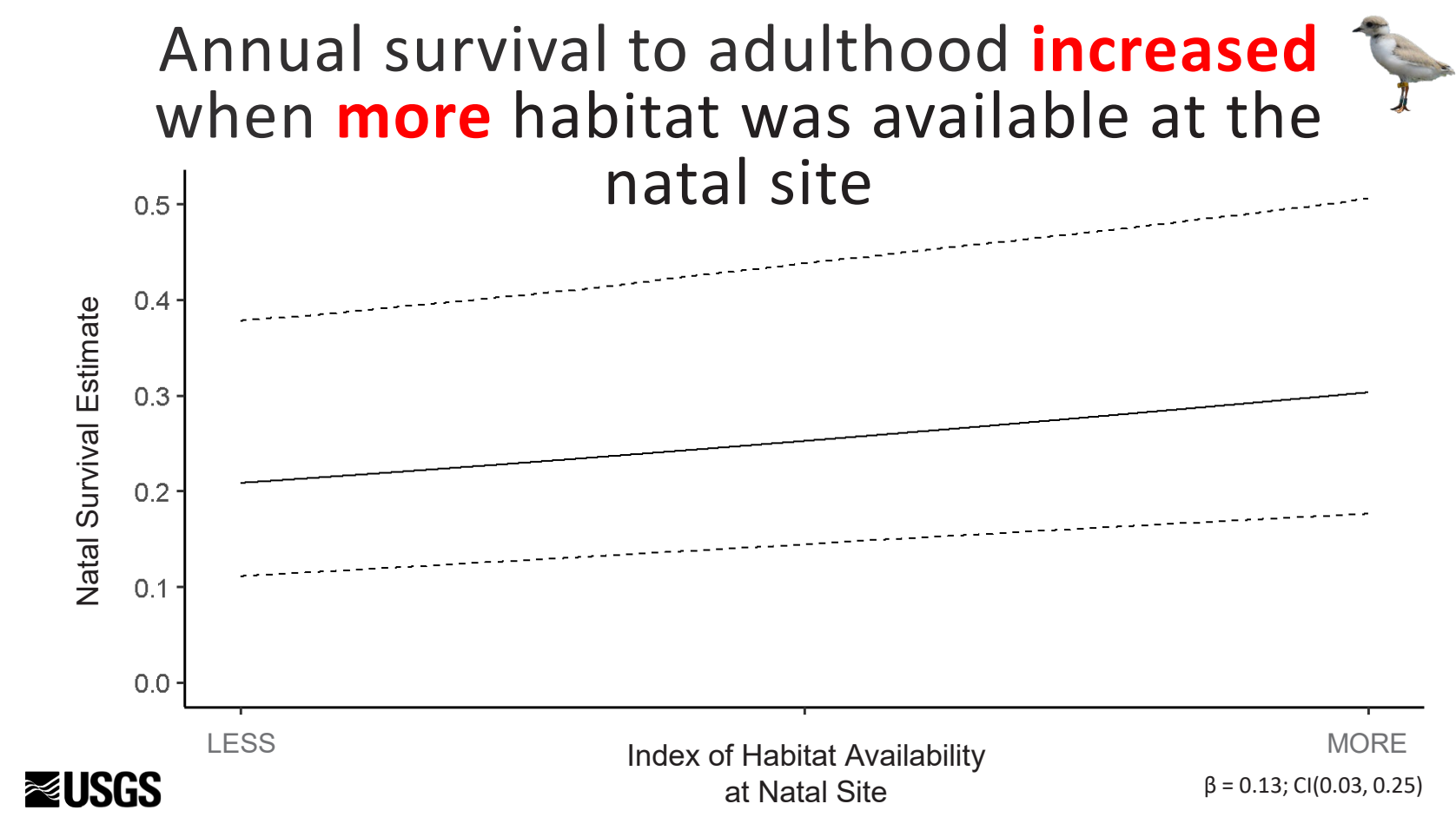

Annual survival to adulthood slightly increased (solid line) when more habitat was available than the year prior at the natal site $(\beta=0.13 ; C l=0.03$ to 0.25$)$. [Dashed lines indicate 95-percent credible interval (CI).] 


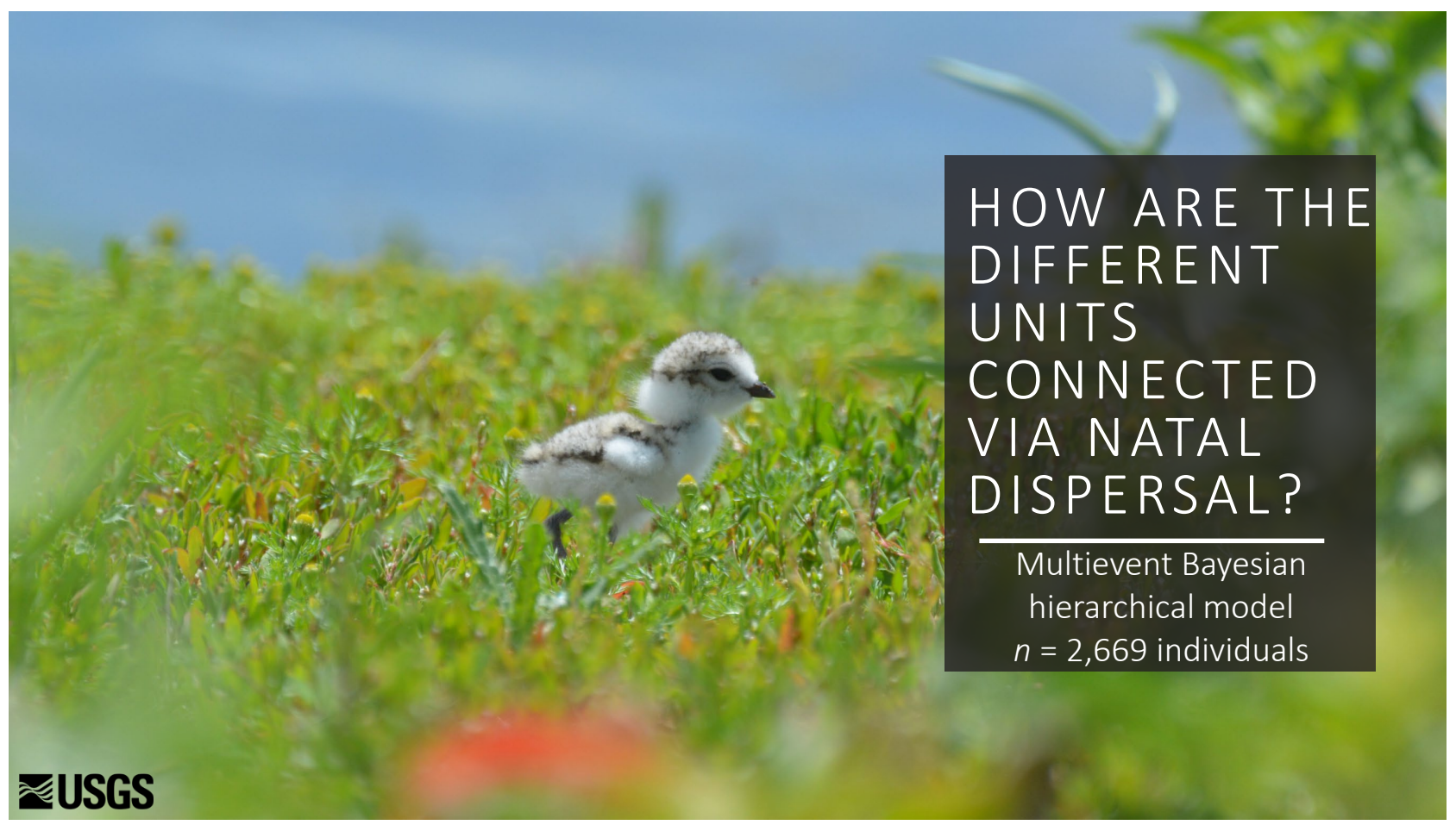

Natal dispersal was defined as the movement from an individual's hatching location to the first location where breeding occurred or was presumed to occur because of the number of resightings within a breeding season. See the "Natal Survival and Dispersal Probabilities" section for more detailed methodology. [n, number]

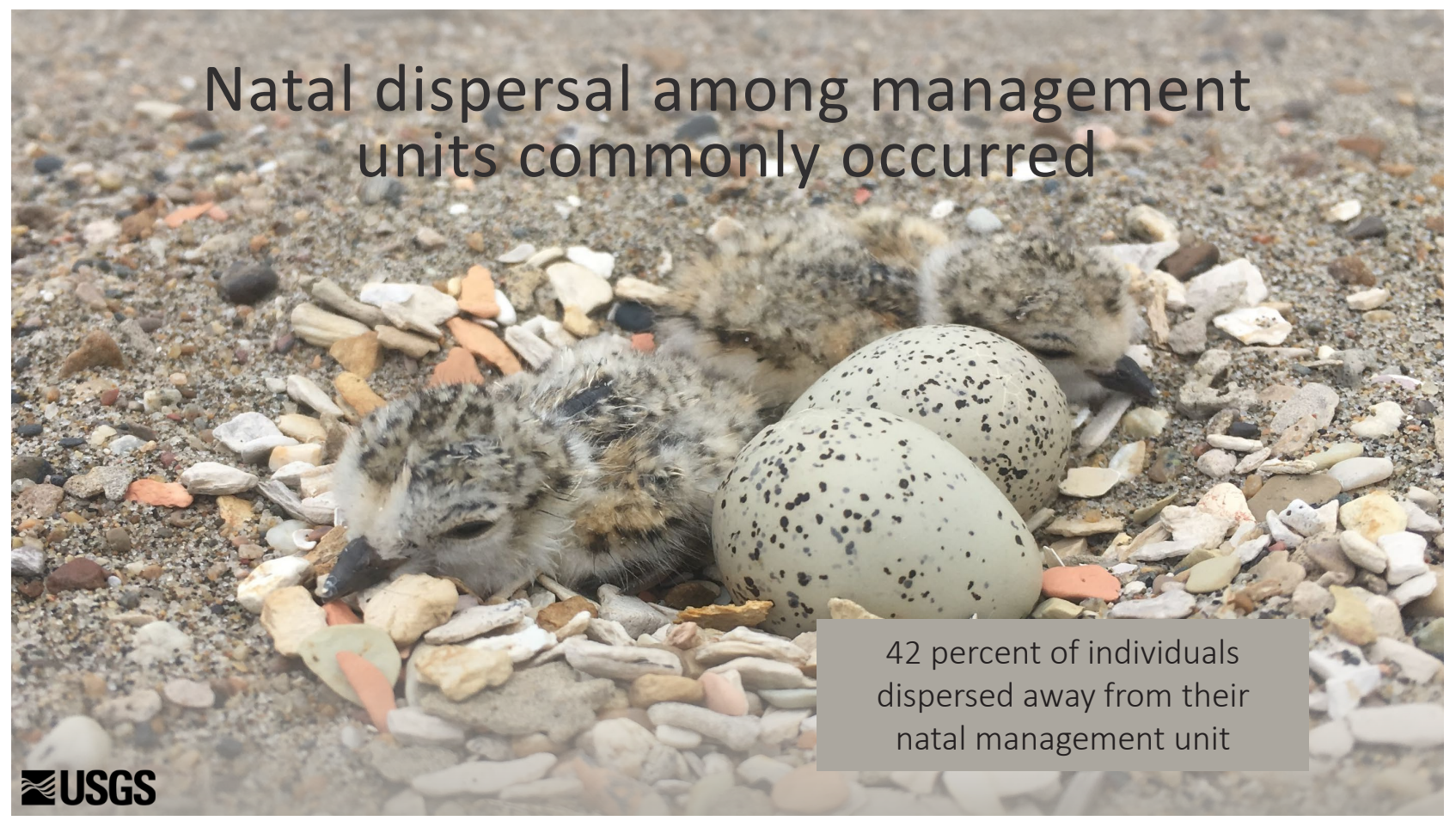

For the 440 individuals included in the multievent model that survived and recruited back into the population (3 individuals dispersed to breed outside the focal study area), 42 percent of individuals dispersed from their natal management unit (the ALK, SAK, the GRR, or OAH) for their first known breeding attempt. 


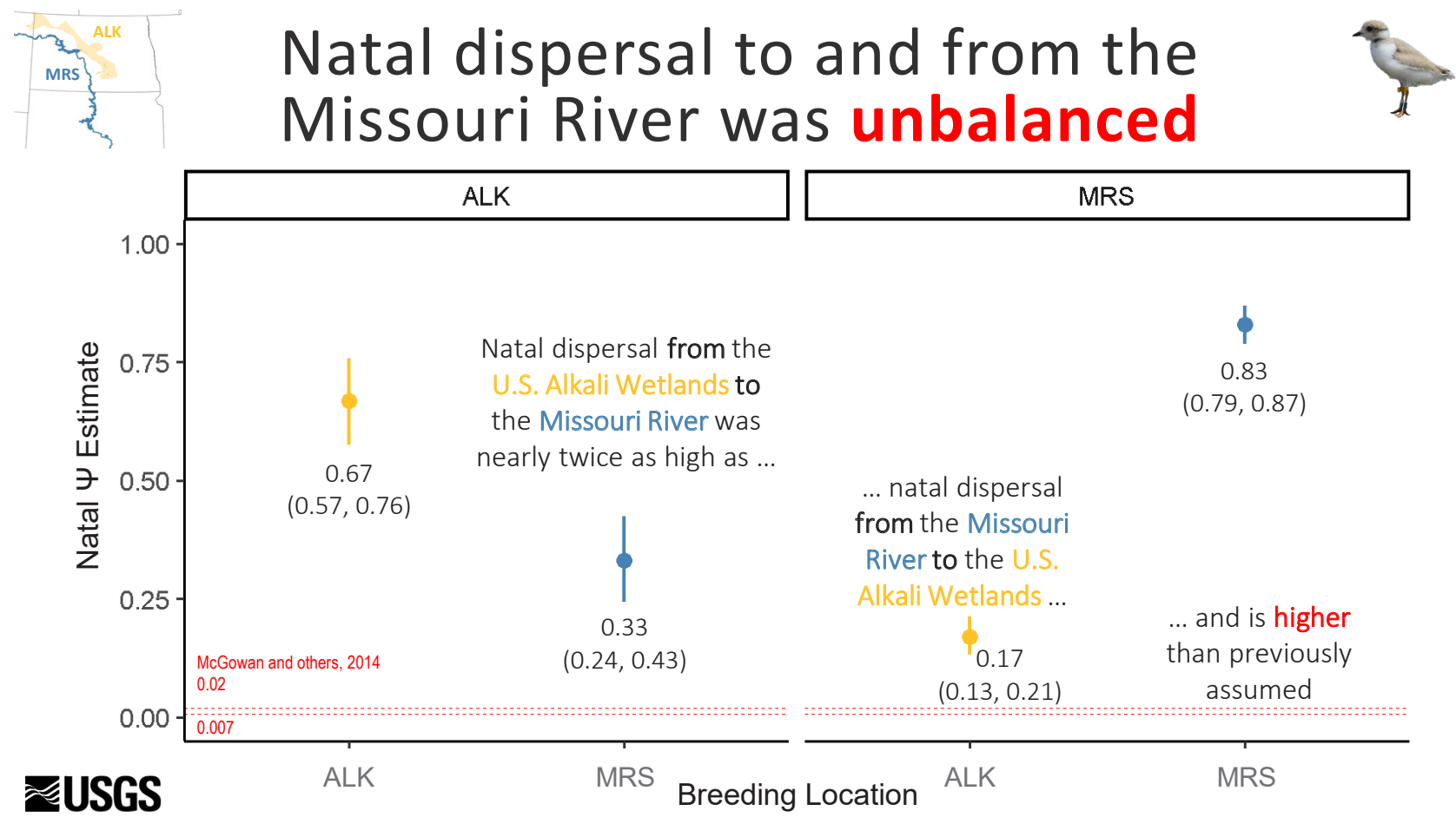

Natal dispersal between the MRS and the ALK is unbalanced and much higher than previously assumed. Individuals were more likely to disperse from the ALK to breed on the $\operatorname{MRS}(0.33, \mathrm{Cl}=0.24$ to 0.43$)$ than those hatched on the MRS were to disperse to breed on the $\operatorname{ALK}(0.17, \mathrm{Cl}=0.13$ to 0.21$)$. McGowan and others (2014) assumed balanced dispersal between these two breeding groups at 0.007 (with a total movement rate away from one group at 0.02; red dashed lines). Natal fidelity was therefore higher on the MRS $(0.83, \mathrm{Cl}=0.79$ to 0.87$)$ than on the $\operatorname{ALK}(0.67, \mathrm{Cl}=0.57$ to 0.76$)$. [Filled circles indicate mean $\Psi$ estimates. Vertical lines indicate 95-percent credible intervals (Cls).] 

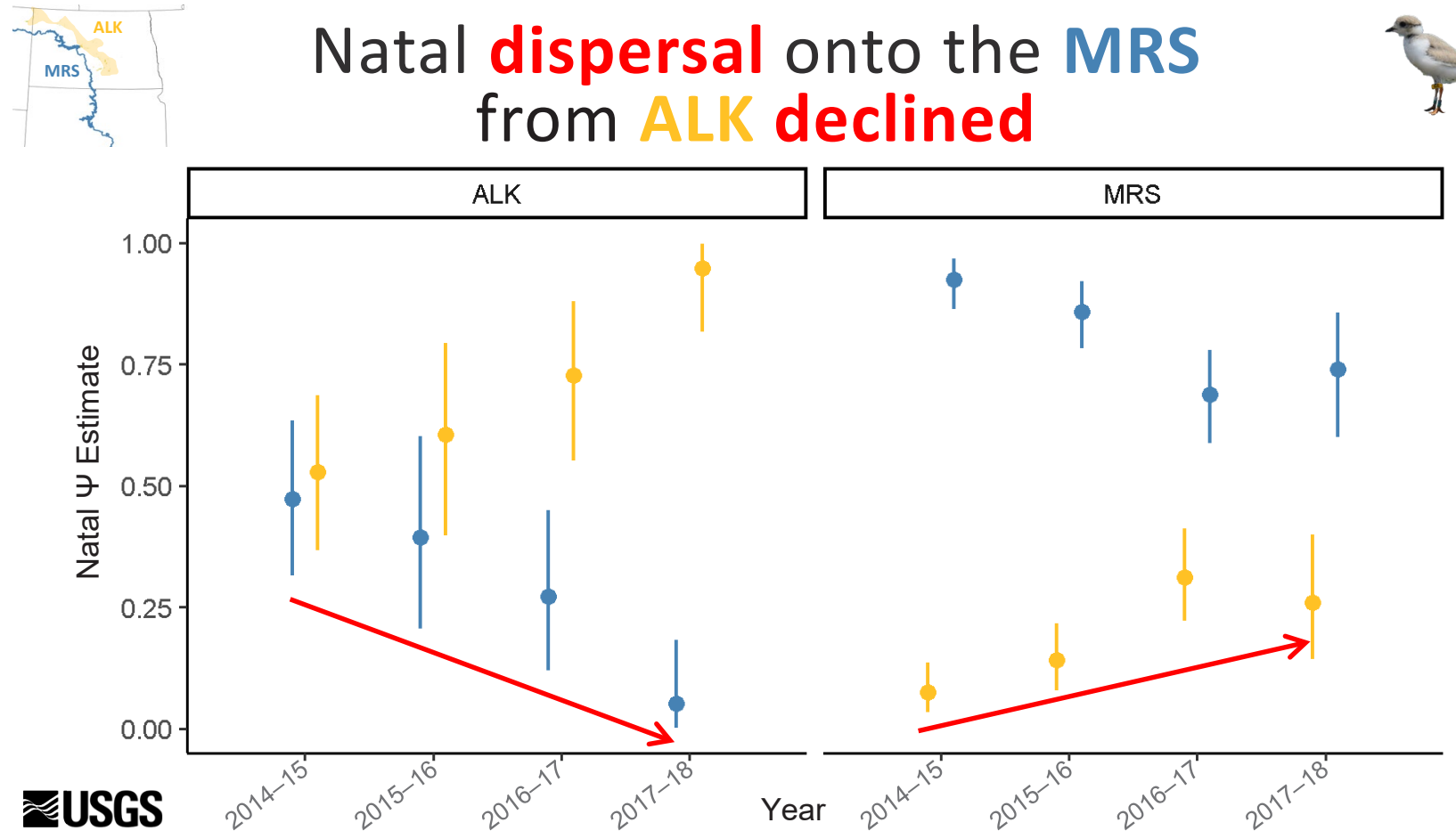

Natal dispersal from the ALK to breed on the MRS declined substantially during this study (left red arrow). Between 2017 and 2018 , individuals had only a 0.05 ( $C l=0.001$ to 0.18 ) probability of dispersing from the ALK to the MRS. In contrast, individuals were most likely to disperse from the MRS to breed on the ALK between 2016 and 2017 ( $0.31, \mathrm{Cl}=0.22$ to 0.41 ; right red arrow). [The last year in a fully time-dependent model is not estimable. Filled circles indicate mean $\Psi$ estimates. Vertical lines indicate 95-percent credible intervals (Cls).]
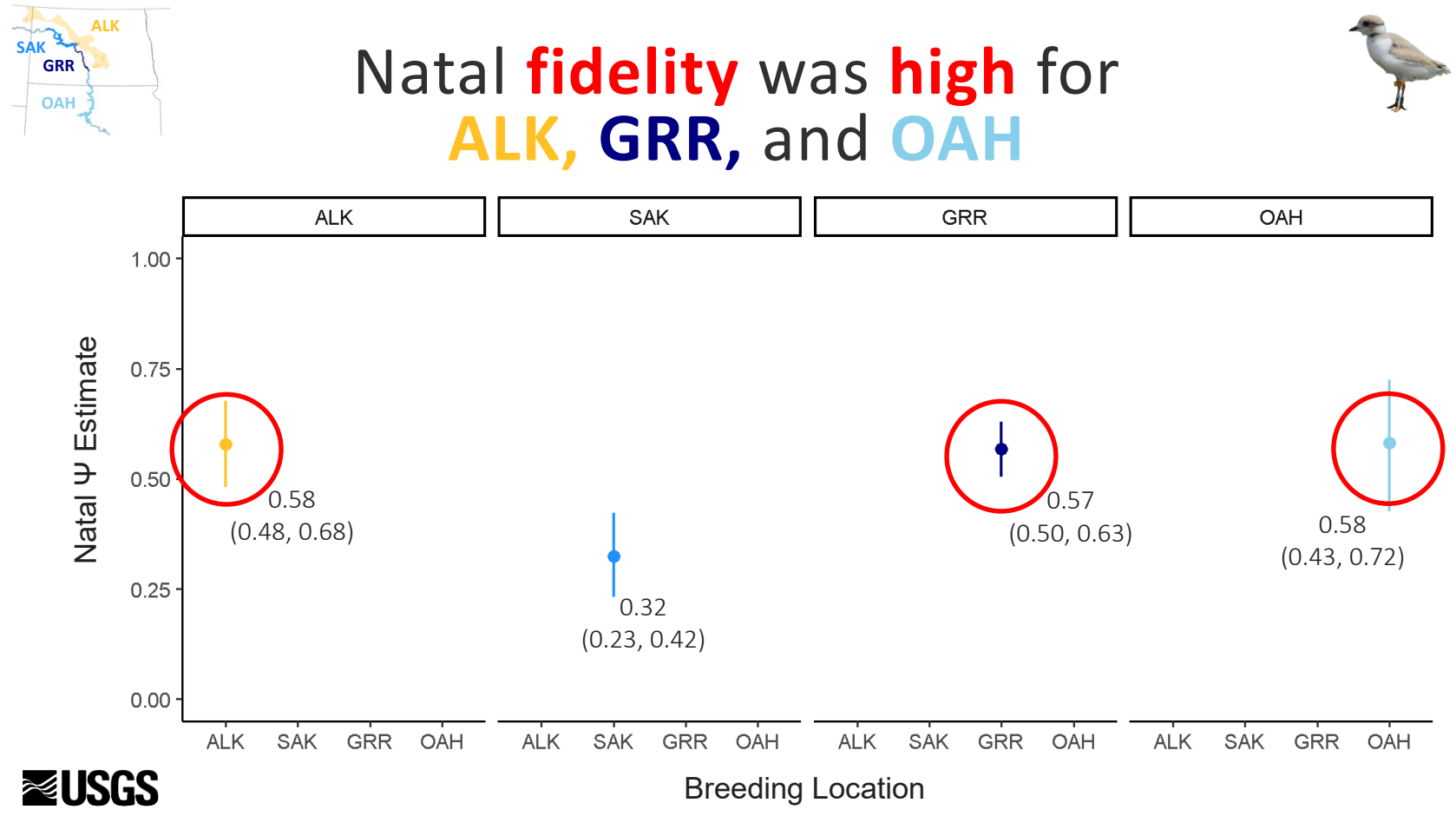

Natal fidelity (returning to breed to their natal location) was greater than 50 percent for the ALK, the GRR, and OAH (red circles). [Filled circles indicate mean $\Psi$ estimates. Vertical lines indicate 95-percent credible intervals.] 


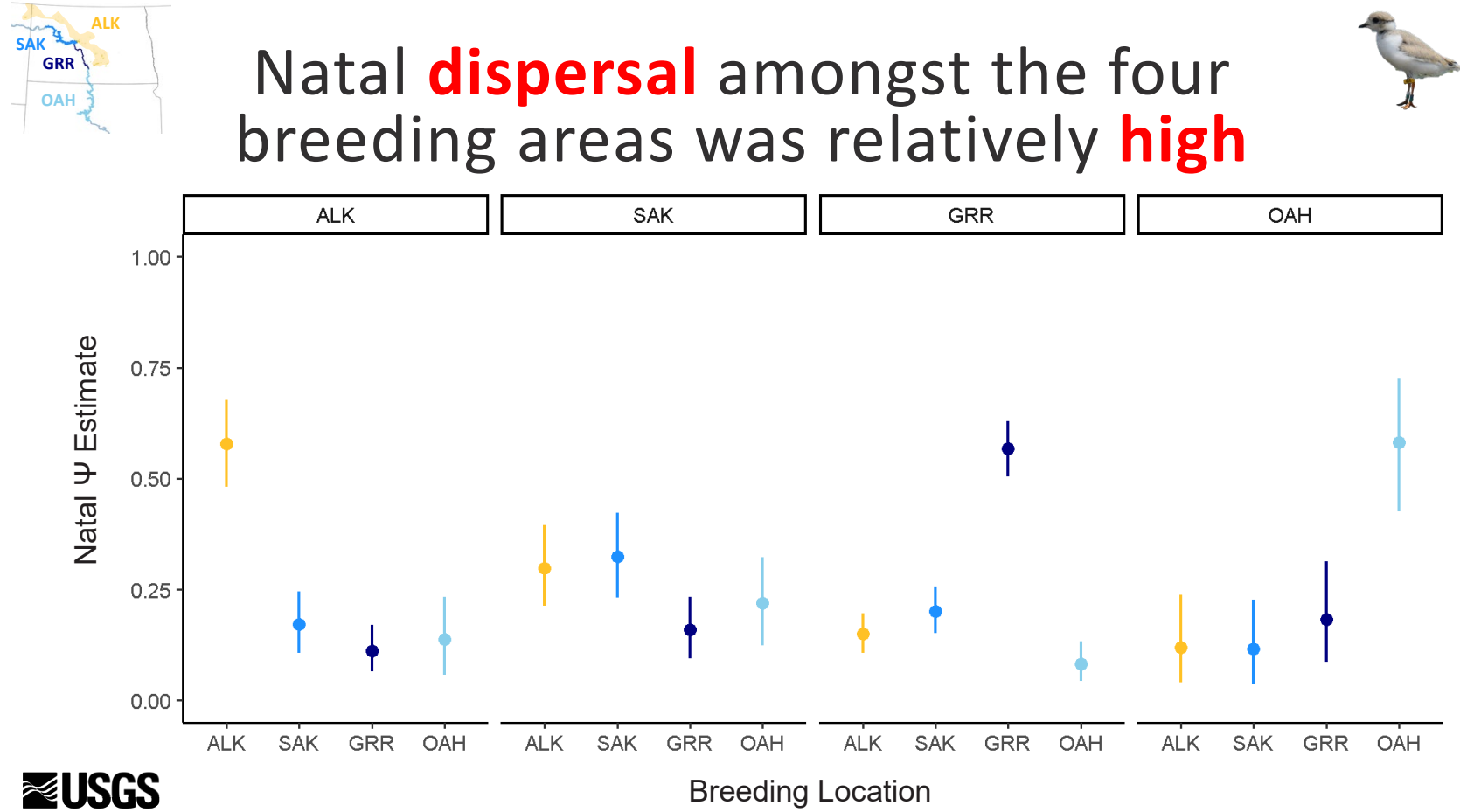

Natal dispersal amongst the four regions was high but relatively balanced (mean estimate range: 0.08 [the GRR to $0 \mathrm{AH}$ ] to 0.22 [SAK to OAH]). [Filled circles indicate mean $\Psi$ estimates. Vertical lines indicate 95-percent credible intervals.]
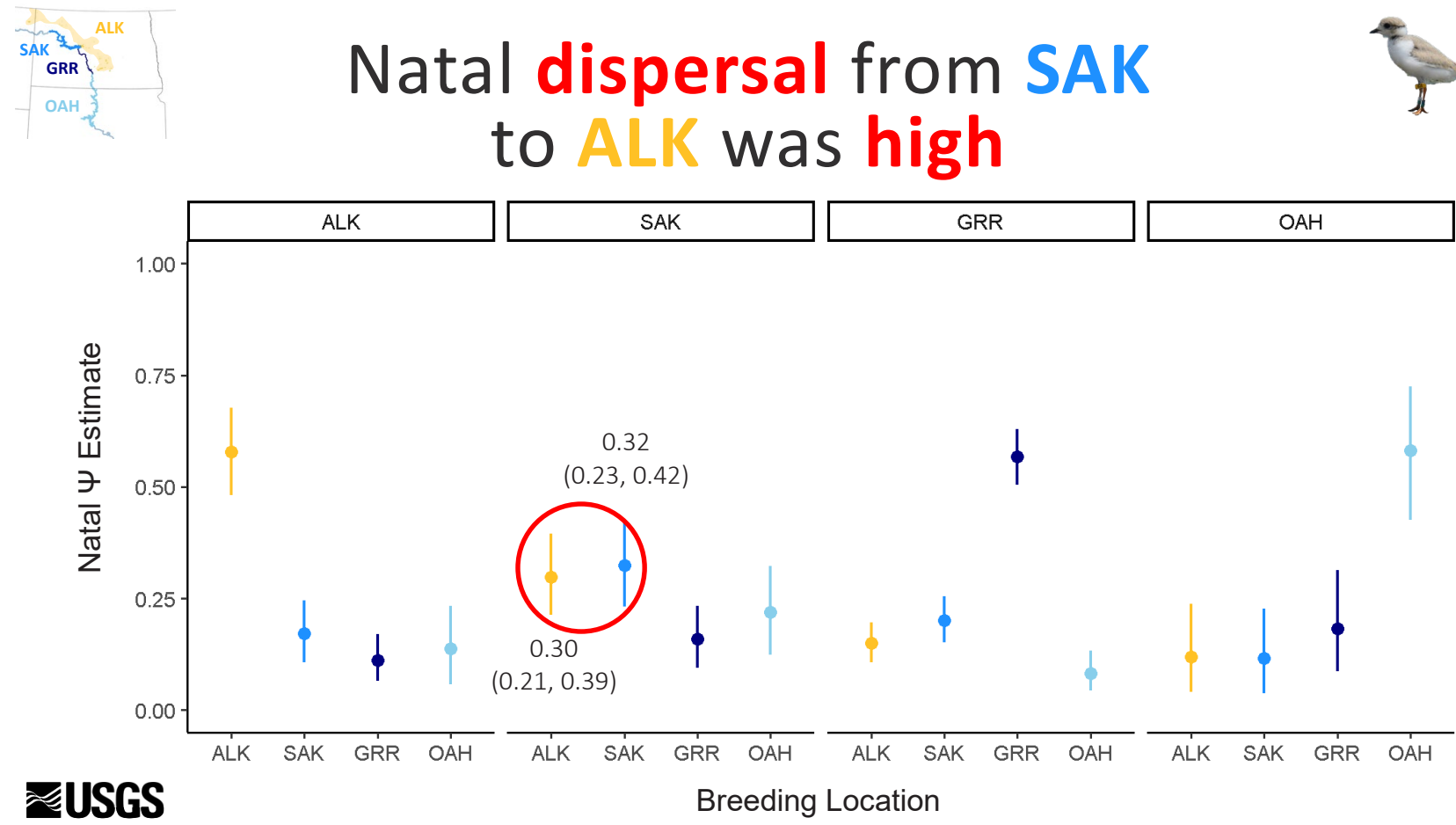

Natal dispersal amongst the four management units ranged from 0.08 to 0.22 , but there was one noticeable exception (red circle). Individuals hatched on SAK were equally likely to return to breed on SAK (fidelity; $0.32, \mathrm{CI}=0.23$ to 0.42 ) as they were to breed on the $\operatorname{ALK}(0.30, \mathrm{Cl}=0.21$ to 0.39$)$ for the first time. [Filled circles indicate mean $\Psi$ estimates. Vertical lines indicate 95-percent credible intervals (Cls).] 

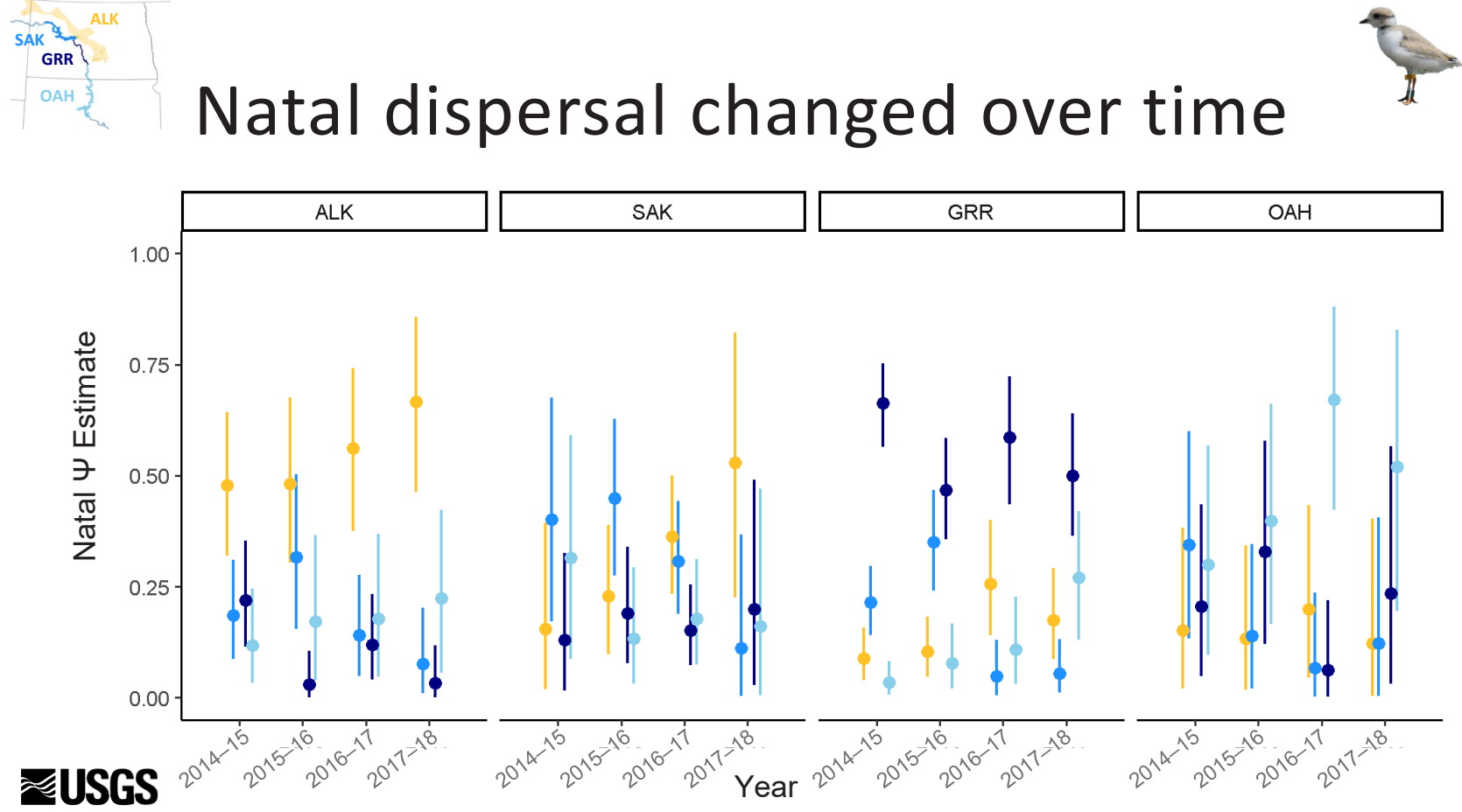

Over the course of the study, various patterns in natal dispersal occurred. See the next 10 slides for each natal location. [The last year in a fully time-dependent model is not estimable. Filled circles indicate mean $\Psi$ estimates. Vertical lines indicate 95-percent credible intervals.]
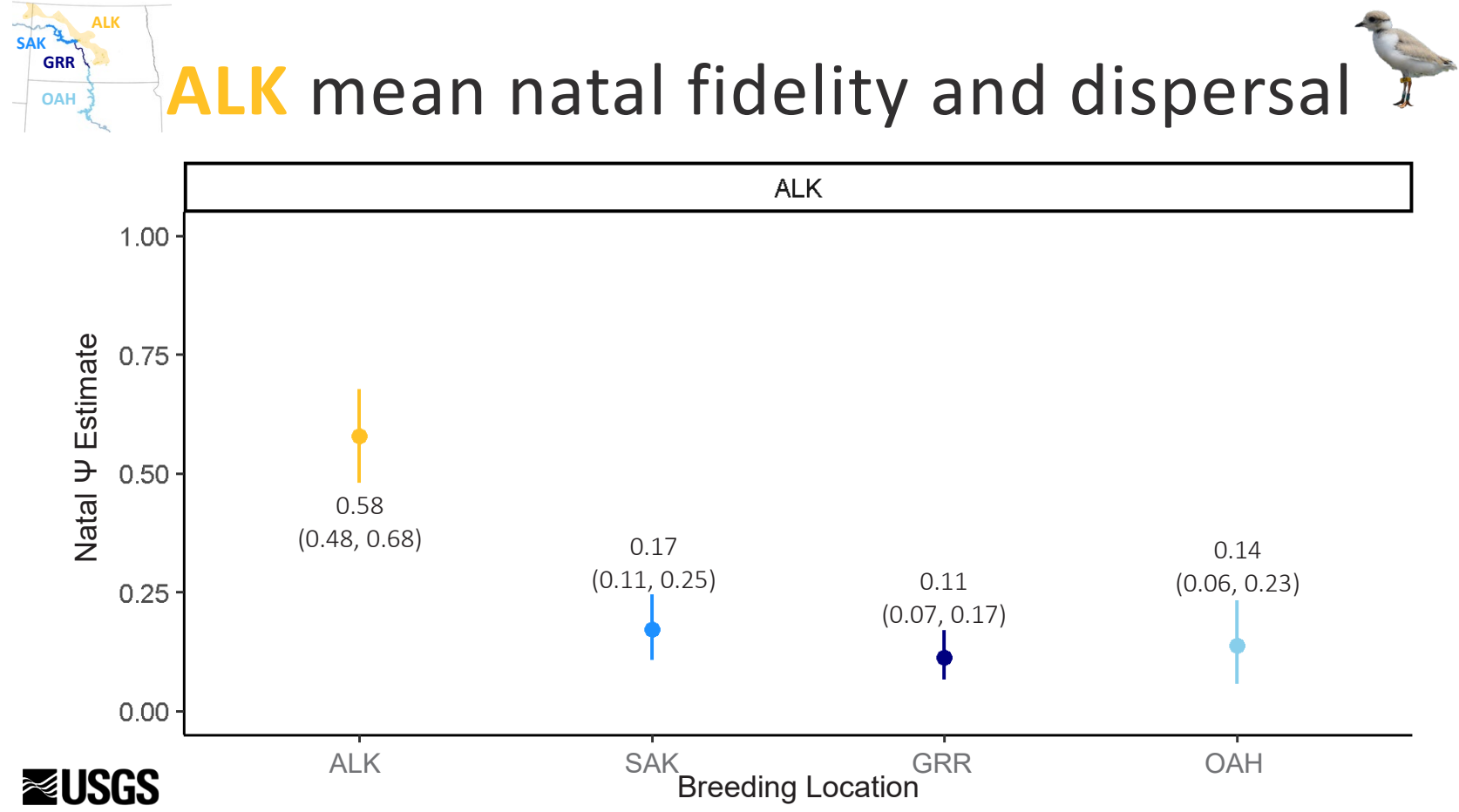

Individuals hatched on the ALK were most likely to return to the $\mathrm{ALK}(0.58, \mathrm{Cl}=0.48$ to 0.68$)$ for their first breeding attempt. If individuals dispersed, they were slightly more likely to breed on $\mathrm{SAK}(0.17, \mathrm{Cl}=0.11$ to 0.25$)$ than the $\mathrm{GRR}(0.11, \mathrm{Cl}=0.07$ to 0.17$)$ or $\mathrm{OAH}(0.14, \mathrm{Cl}=0.06$ to 0.23$)$. [Filled circles indicate mean $\Psi$ estimates. Vertical lines indicate 95 -percent credible intervals (Cls).] 

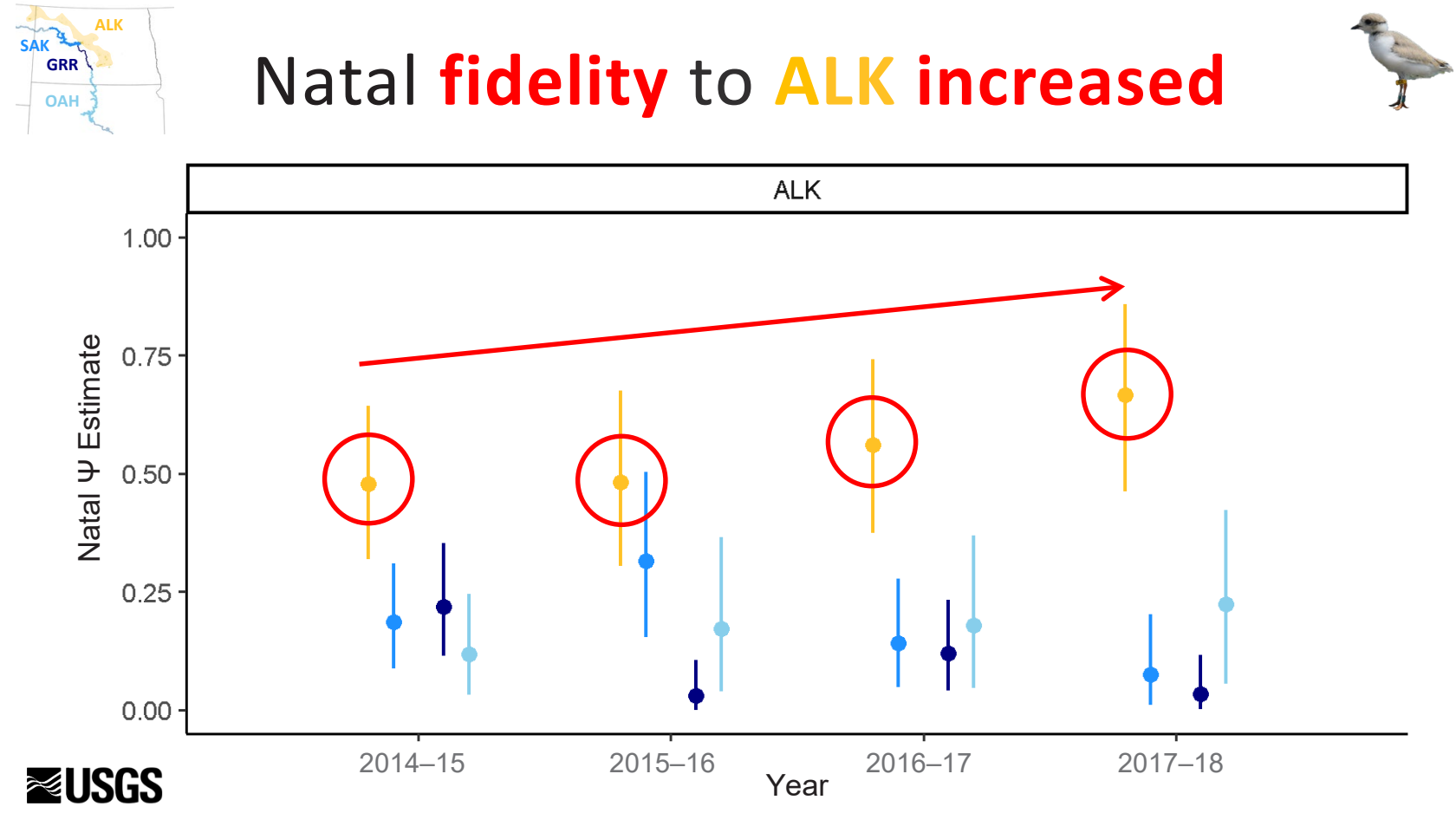

Natal fidelity for individuals hatched on the ALK increased (red line and circles), whereas individuals hatched on the ALK became less likely to breed for the first time on SAK. [The last year in a fully time-dependent model is not estimable. Filled circles indicate mean $\Psi$ estimates. Vertical lines indicate 95-percent credible intervals.]

SAK mean natal fidelity and dispersal

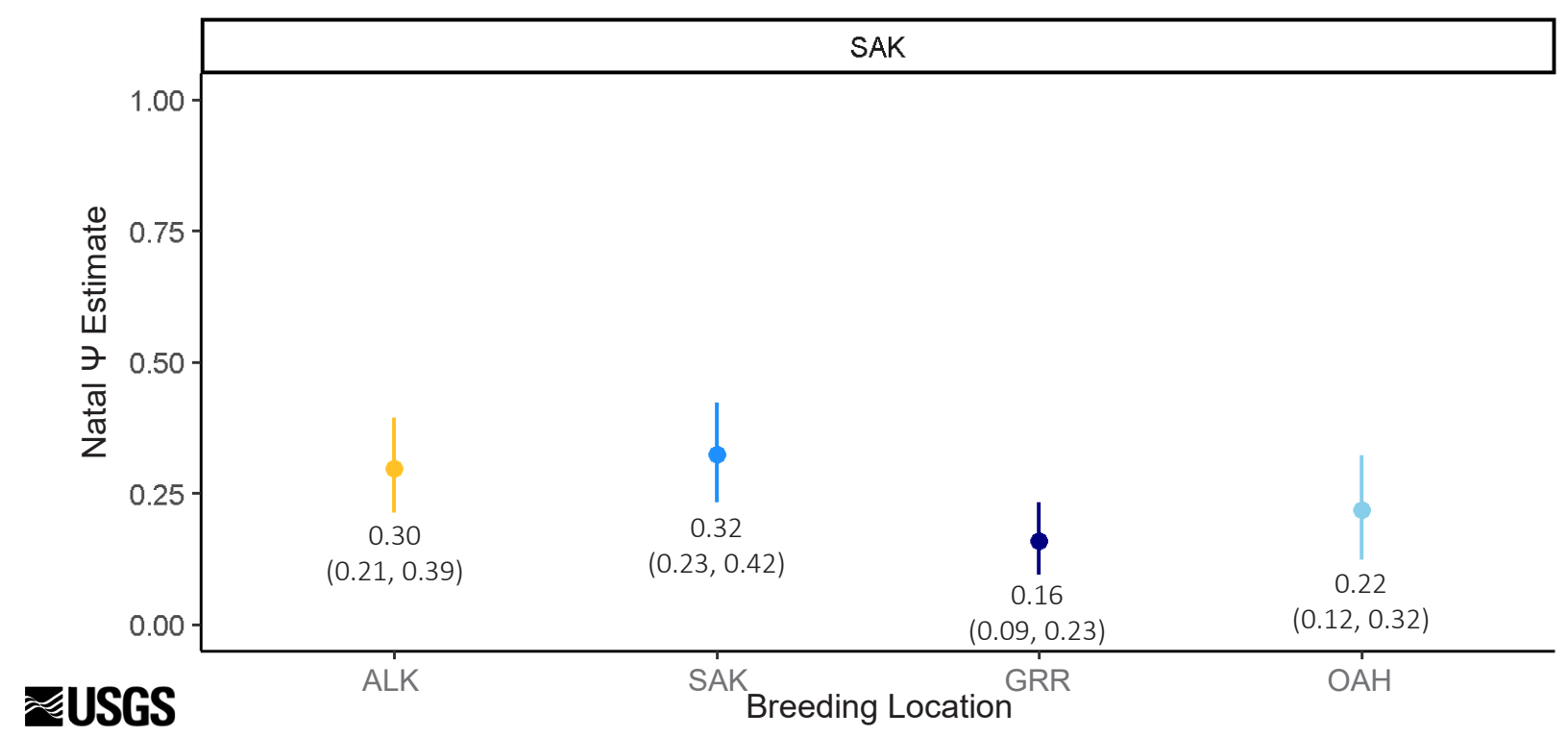

Individuals hatched on SAK were equally likely to return to SAK $(0.32, \mathrm{Cl}=0.23$ to 0.42$)$ for their first breeding attempt or to breed on the $\operatorname{ALK}(0.30, \mathrm{Cl}=0.21$ to 0.39$])$. Individuals were equally likely to breed on the $\mathrm{GRR}(0.16, \mathrm{Cl}=0.09$ to 0.23$])$ or $0 \mathrm{AH}(0.22$, $\mathrm{Cl}=0.12$ to 0.32 ) but less so than SAK or the ALK. [Filled circles indicate mean $\Psi$ estimates. Vertical lines indicate 95 -percent credible intervals (Cls).] 

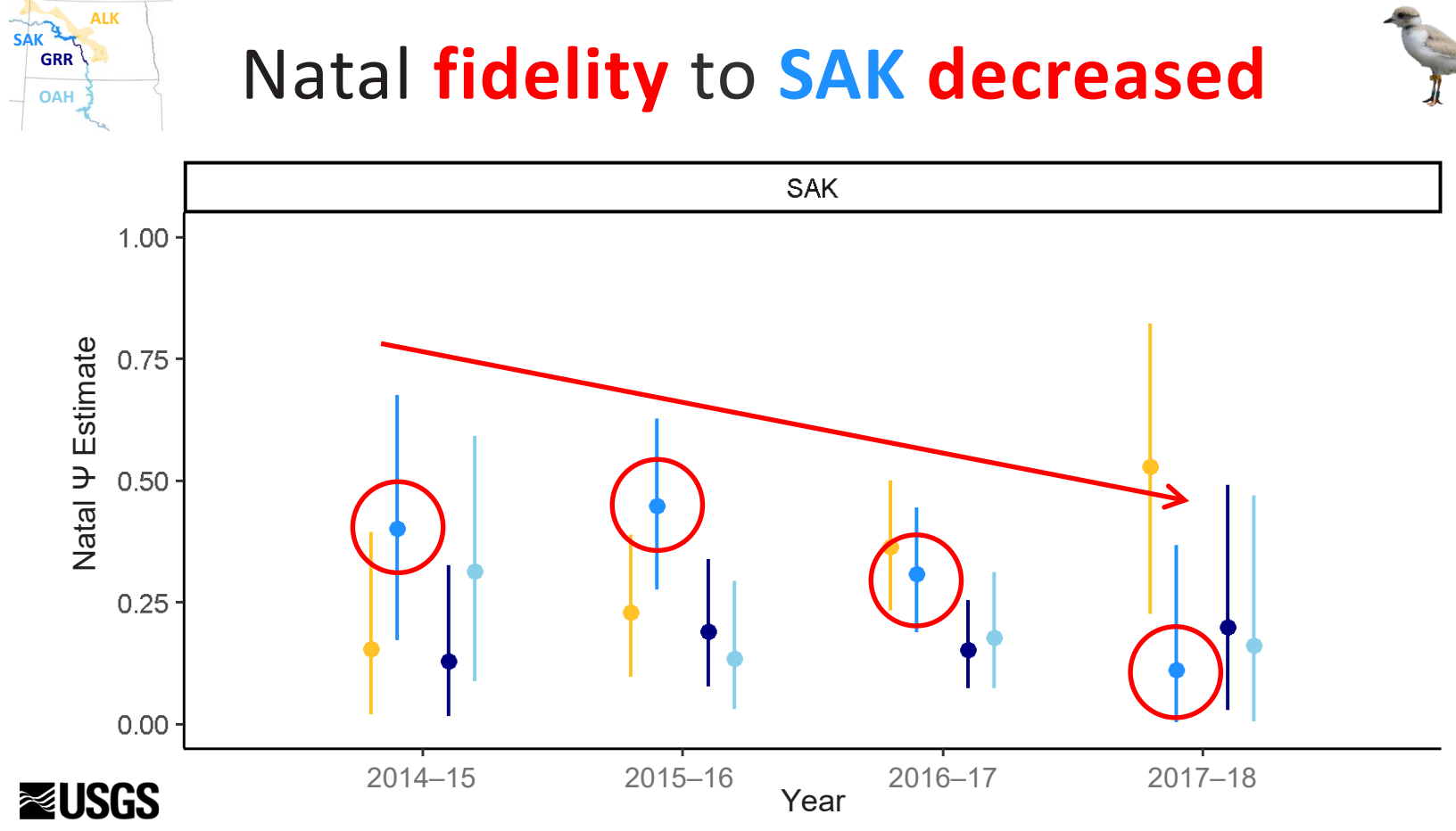

Natal fidelity to SAK decreased during the study (red line and circles). [The last year in a fully time-dependent model is not estimable. Filled circles indicate mean $\Psi$ estimates. Vertical lines indicate 95-percent credible intervals.]
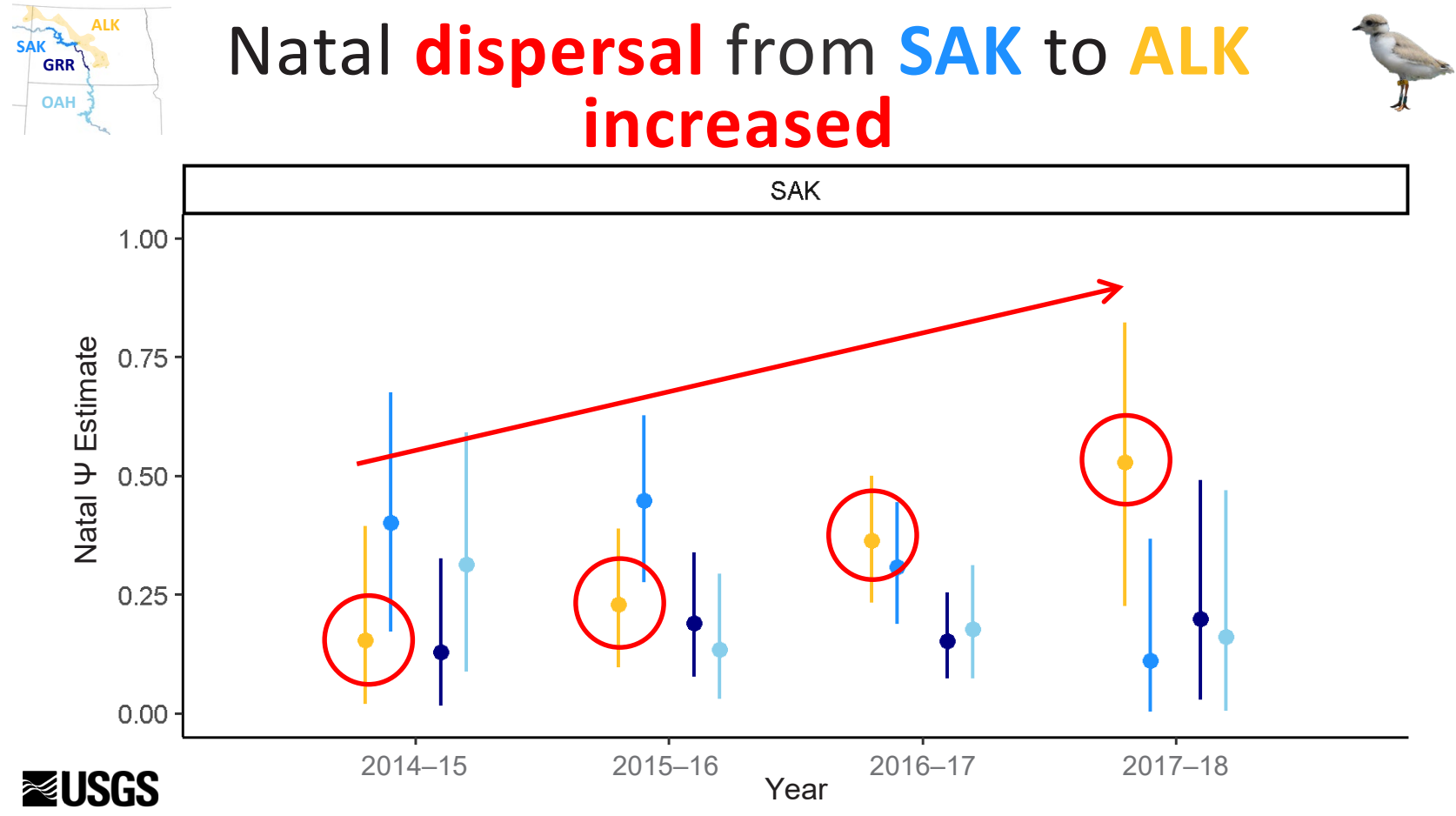

Concurrently, natal fidelity to SAK decreased, and natal dispersal from SAK to the ALK increased during the study (red line and circles). [The last year in a fully time-dependent model is not estimable. Filled circles indicate mean $\Psi$ estimates. Vertical lines indicate 95-percent credible intervals.] 
GRR mean natal fidelity and dispersal

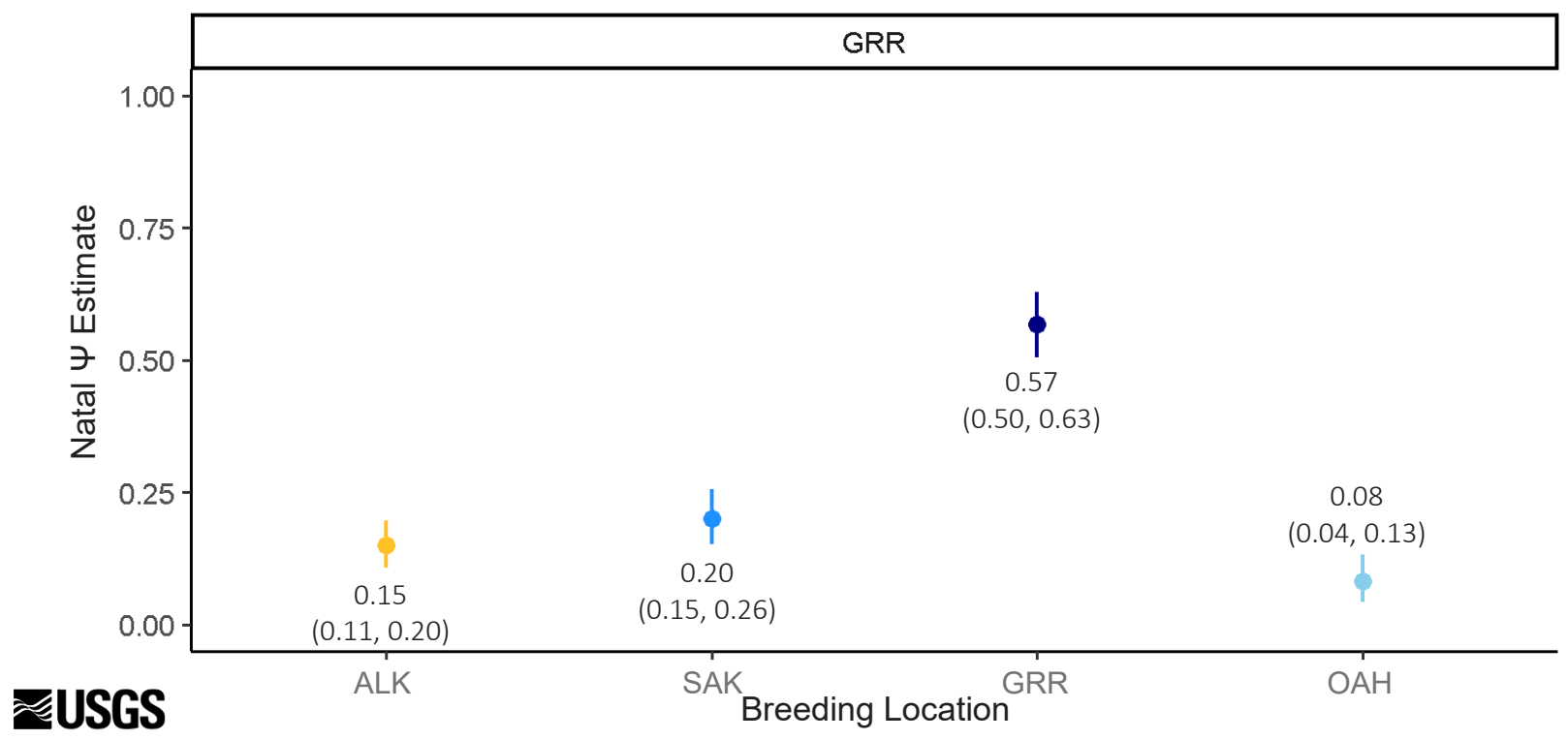

Individuals hatched on the GRR were most likely to return to the $\mathrm{GRR}(0.57, \mathrm{Cl}=0.50$ to 0.63$)$ for their first breeding attempt. If individuals dispersed, they were slightly more likely to breed on the $\operatorname{ALK}(0.15, \mathrm{Cl}=0.11$ to 0.20$)$ or $\operatorname{SAK}(0.20, \mathrm{Cl}=0.15$ to 0.26$)$ than $\mathrm{OAH}(0.08, \mathrm{Cl}=0.04$ to 0.13$)$. [Filled circles indicate mean $\Psi$ estimates. Vertical lines indicate 95 -percent credible intervals $(\mathrm{Cls})$.]
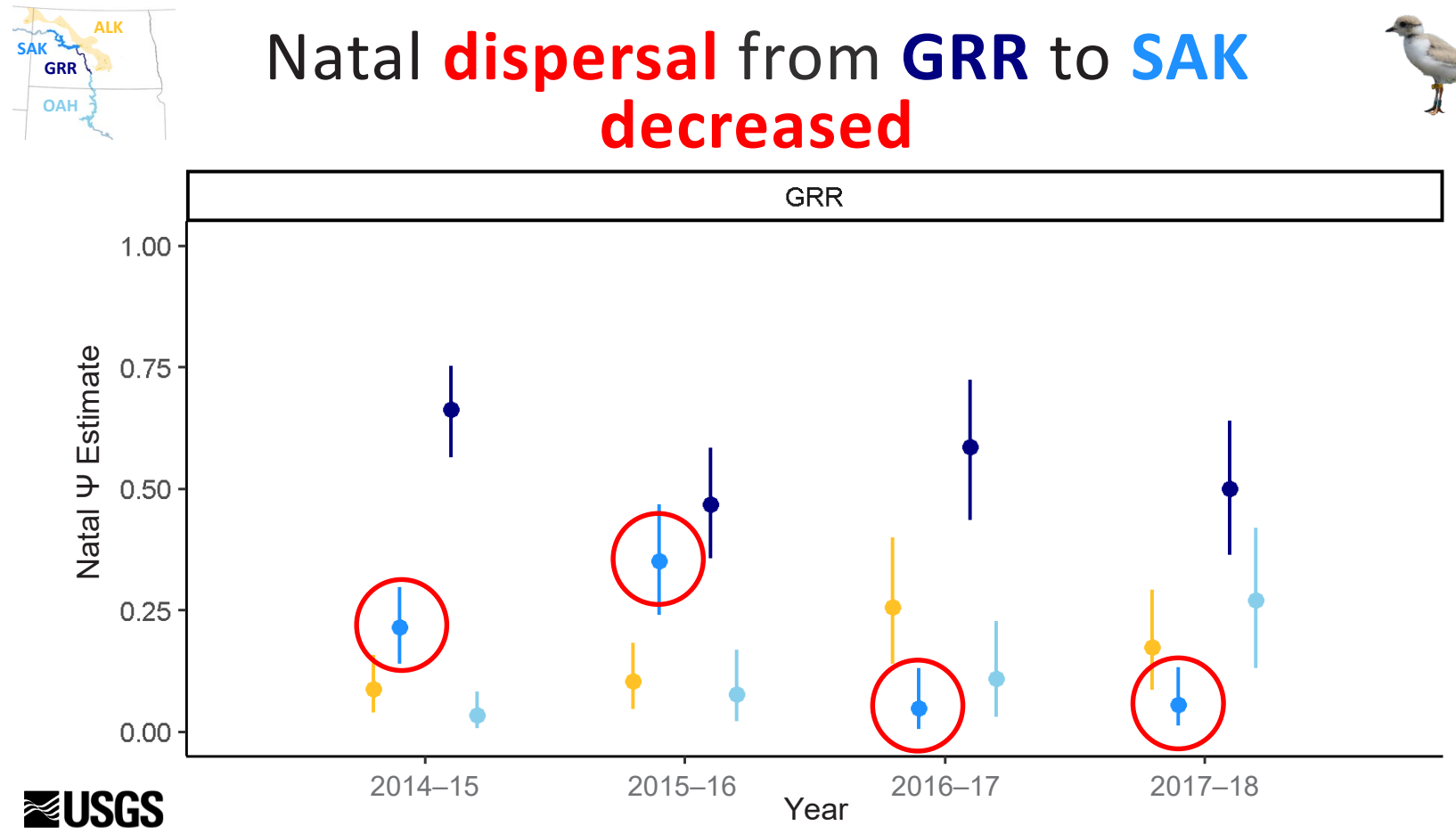

Although natal fidelity to the GRR remained constant during the study, individuals were less likely to disperse to SAK later in the study (red circles). [The last year in a fully time-dependent model is not estimable. Filled circles indicate mean $\Psi$ estimates. Vertical lines indicate 95-percent credible intervals.] 

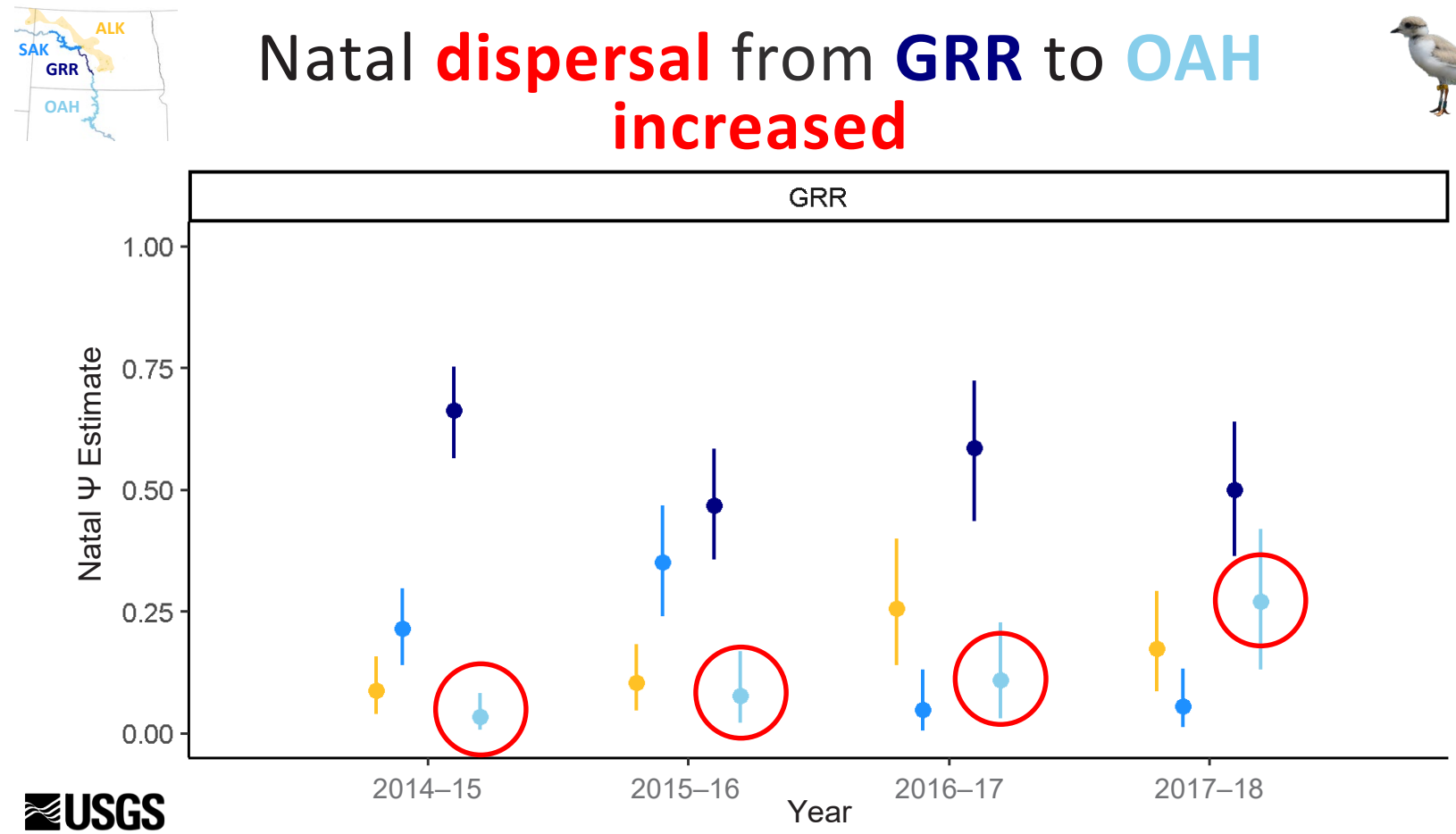

Concurrently, individuals were more likely to disperse to OAH from the GRR later in the study (red circles). [The last year in a fully time-dependent model is not estimable. Filled circles indicate mean $\Psi$ estimates. Vertical lines indicate 95 -percent credible intervals.]
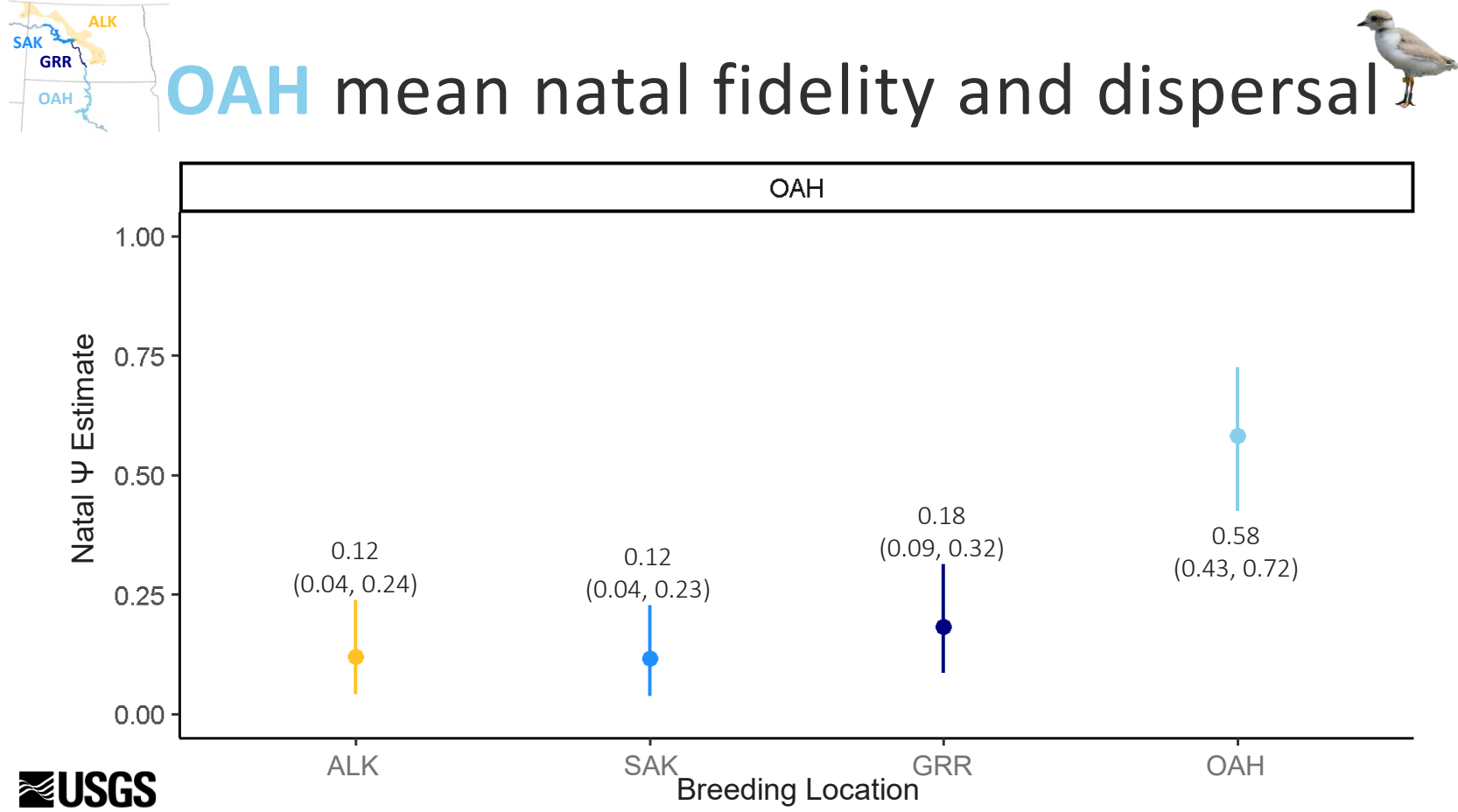

Individuals hatched on $\mathrm{OAH}$ were most likely to return to $\mathrm{OAH}(0.58, \mathrm{Cl}=0.43$ to 0.72$)$ for their first breeding attempt. If individuals dispersed, they were equally likely to breed on the $\operatorname{ALK}(0.12, \mathrm{Cl}=0.04$ to 0.24$)$, $\mathrm{SAK}(0.12, \mathrm{Cl}=0.04$ to 0.23$)$, or the GRR $(0.18, \mathrm{Cl}=0.09$ to 0.32 ). [Filled circles indicate mean $\Psi$ estimates. Vertical lines indicate 95 -percent credible intervals (Cls).] 

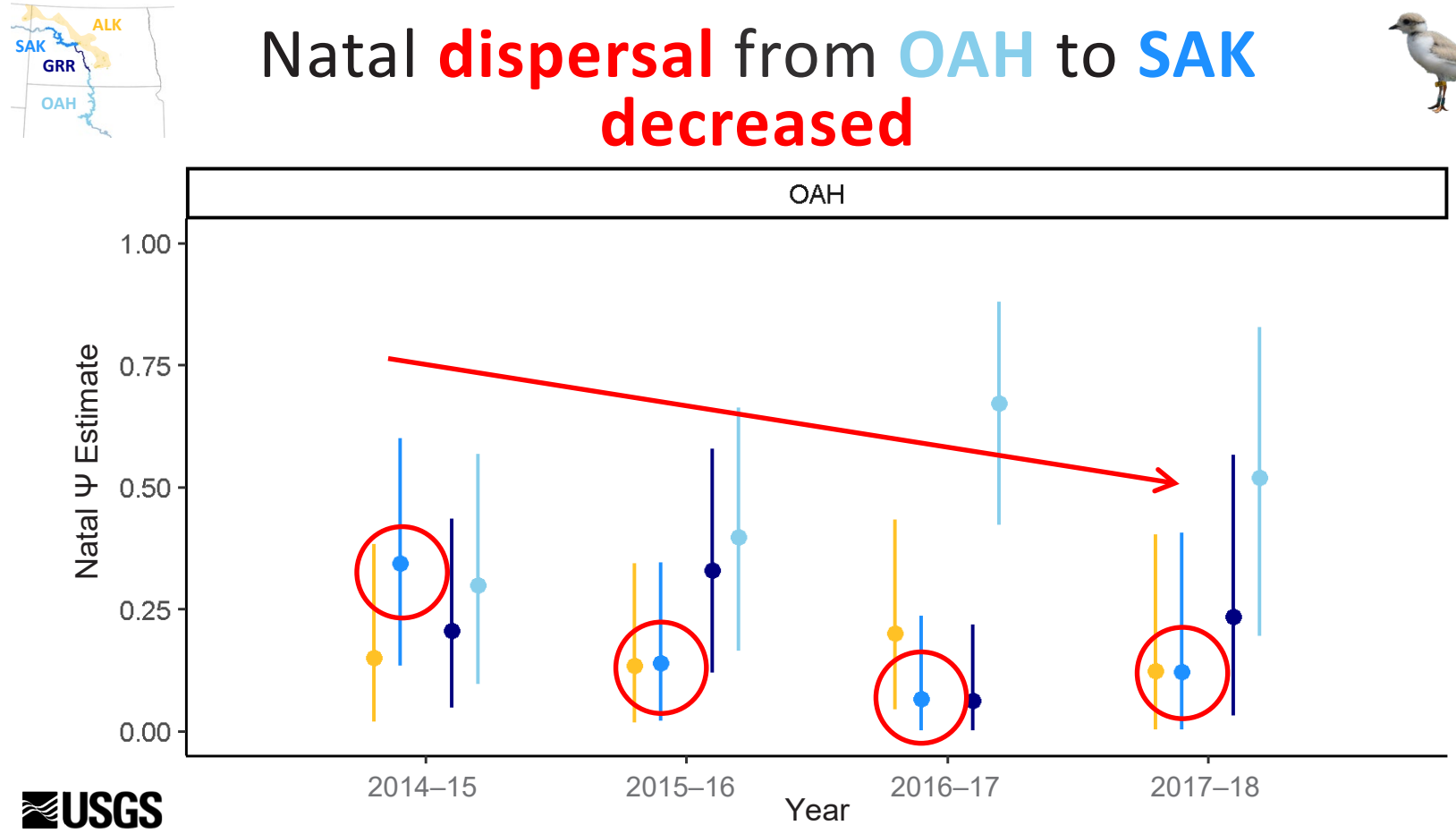

Although fidelity to $\mathrm{OAH}$ varied during the study, individuals were less likely to disperse to SAK later in the study (red line and circles). [The last year in a fully time-dependent model is not estimable. Filled circles indicate mean $\Psi$ estimates. Vertical lines indicate 95-percent credible intervals.]

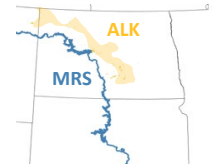

\section{Natal dispersal varied based on available habitat at the natal site}

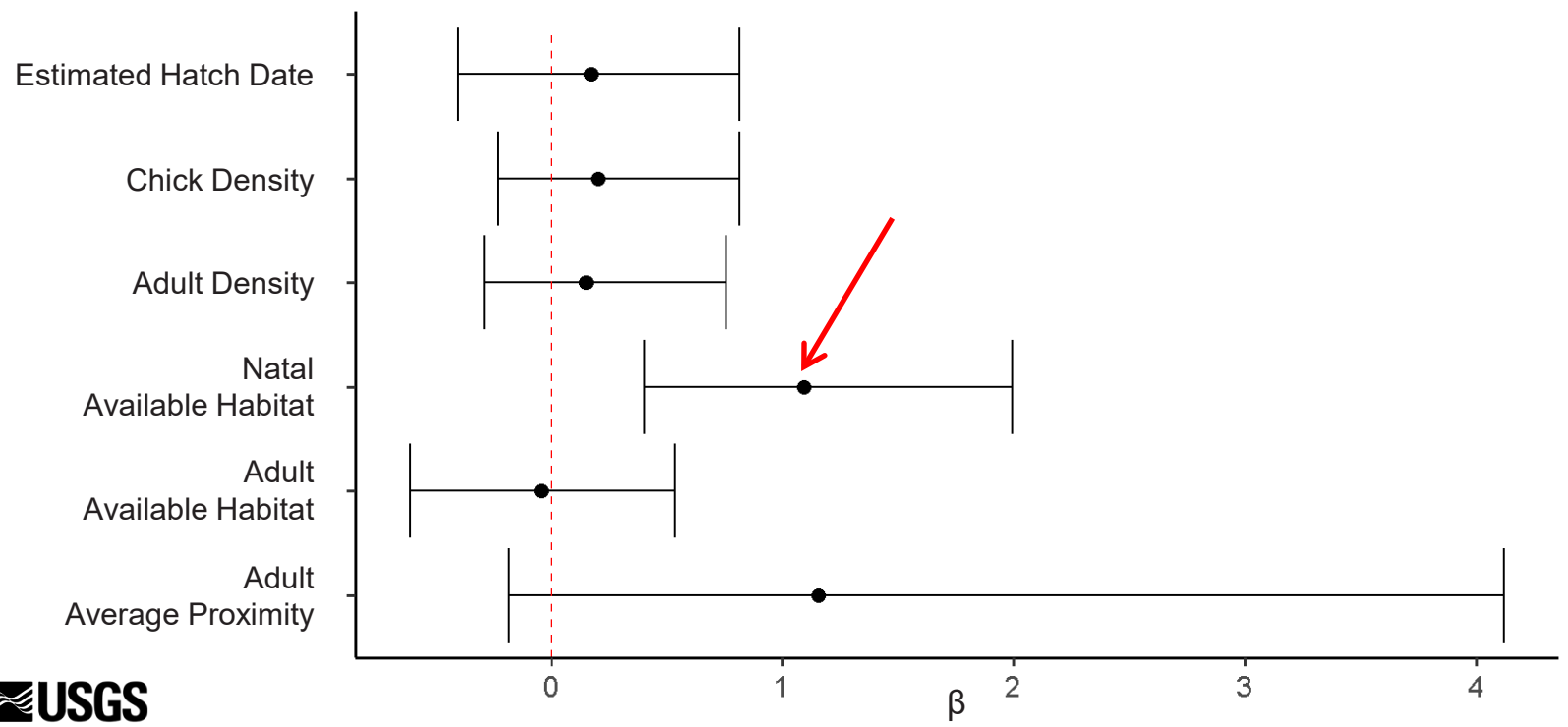

From the global fitted model with all seven a priori covariates included on natal dispersal probabilities, as well as a random effect of year, only one covariate (red arrow), the change in habitat available at the natal site, seems important based on nonoverlapping 95-percent credible intervals with zero. [Filled circles indicate mean $\beta$ estimate. Whiskers indicate 95-percent credible intervals.] 


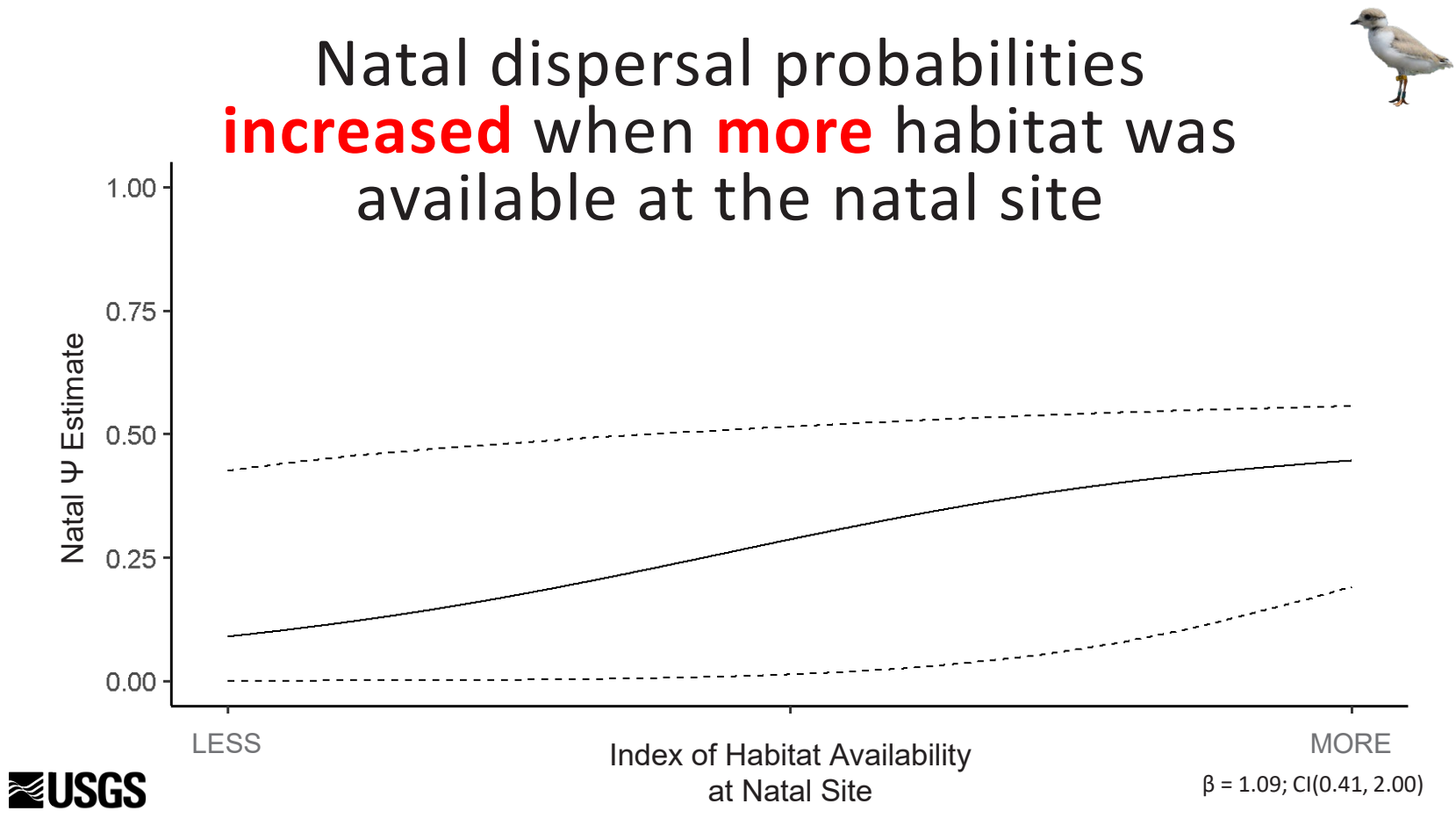

Contrary to our predictions, natal dispersal probabilities slightly increased (solid line) when more habitat was available at the natal site than in the year prior $(\beta=1.09 ; \mathrm{Cl}=0.41$ to 2.00). [Dashed lines indicate 95-percent credible interval (CI).]

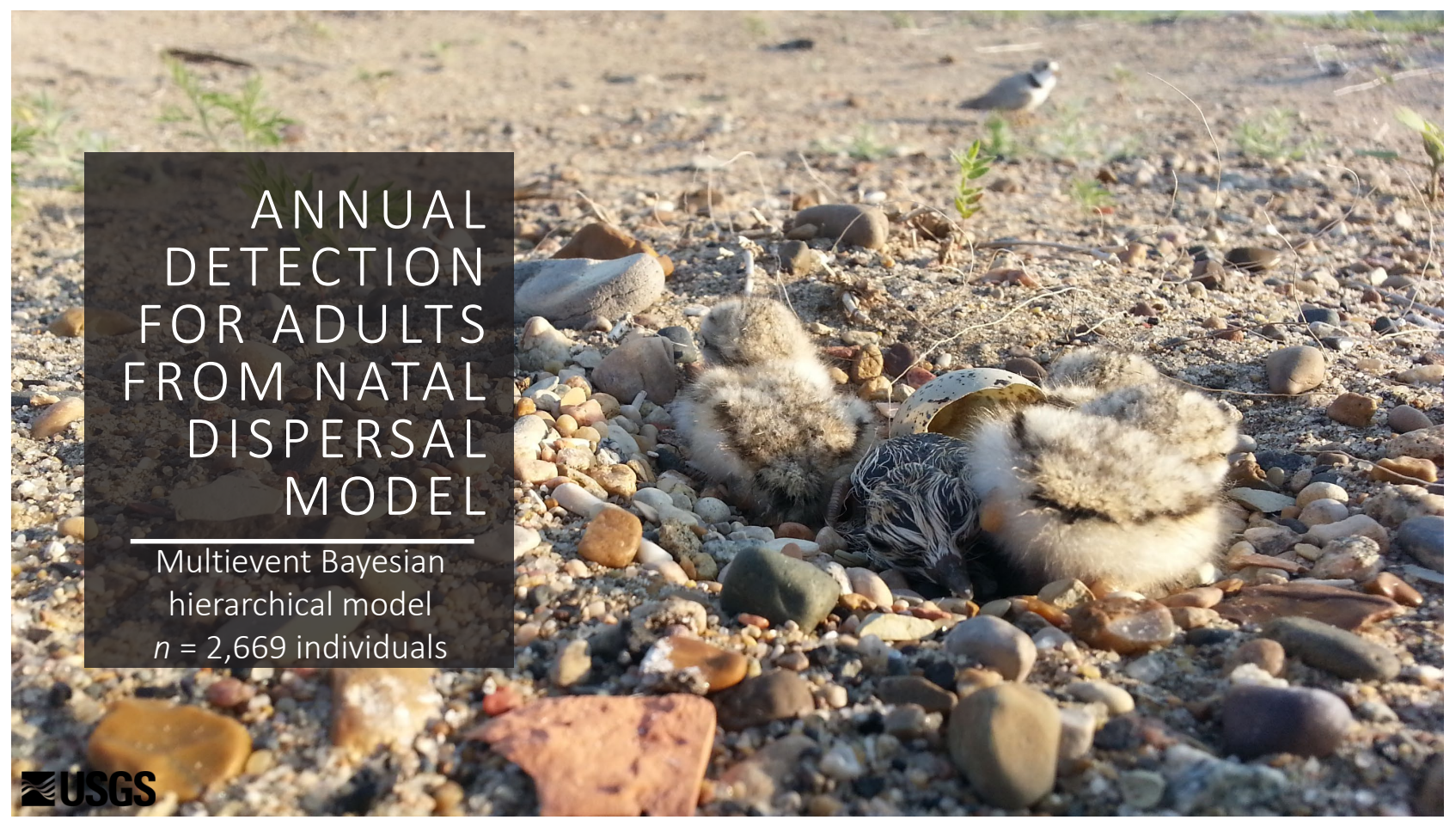

In this next section, we provide detection probability $(p)$ of breeding adult states estimated from the natal dispersal models. Detection of hatch-year individuals was fixed in the models. For more details, see the "Natal Survival and Dispersal Probabilities" section. [ $n$, number] 


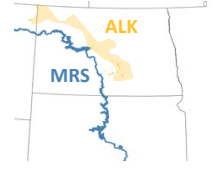

\section{Detection of MRS adults was higher than ALK adults}

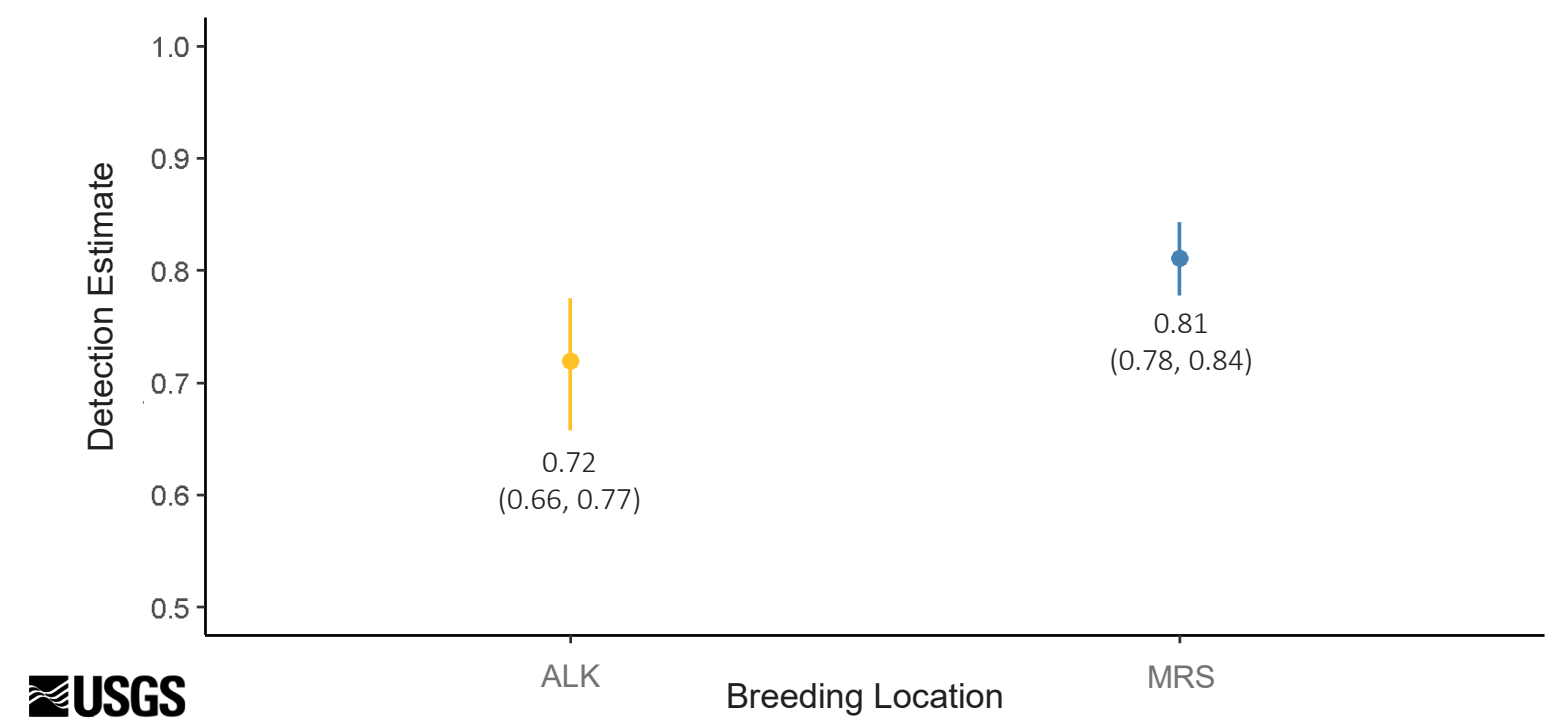

Detection probability $(p)$ of adults breeding on the MRS $(0.81, \mathrm{Cl}=0.78$ to 0.84$)$ was higher than on the $\mathrm{ALK}(0.72, \mathrm{Cl}=0.66$ to 0.77$)$. [Detection of hatch-year states was fixed. Filled circles indicate mean detection probability estimates. Vertical lines indicate 95-percent credible intervals (Cls).]
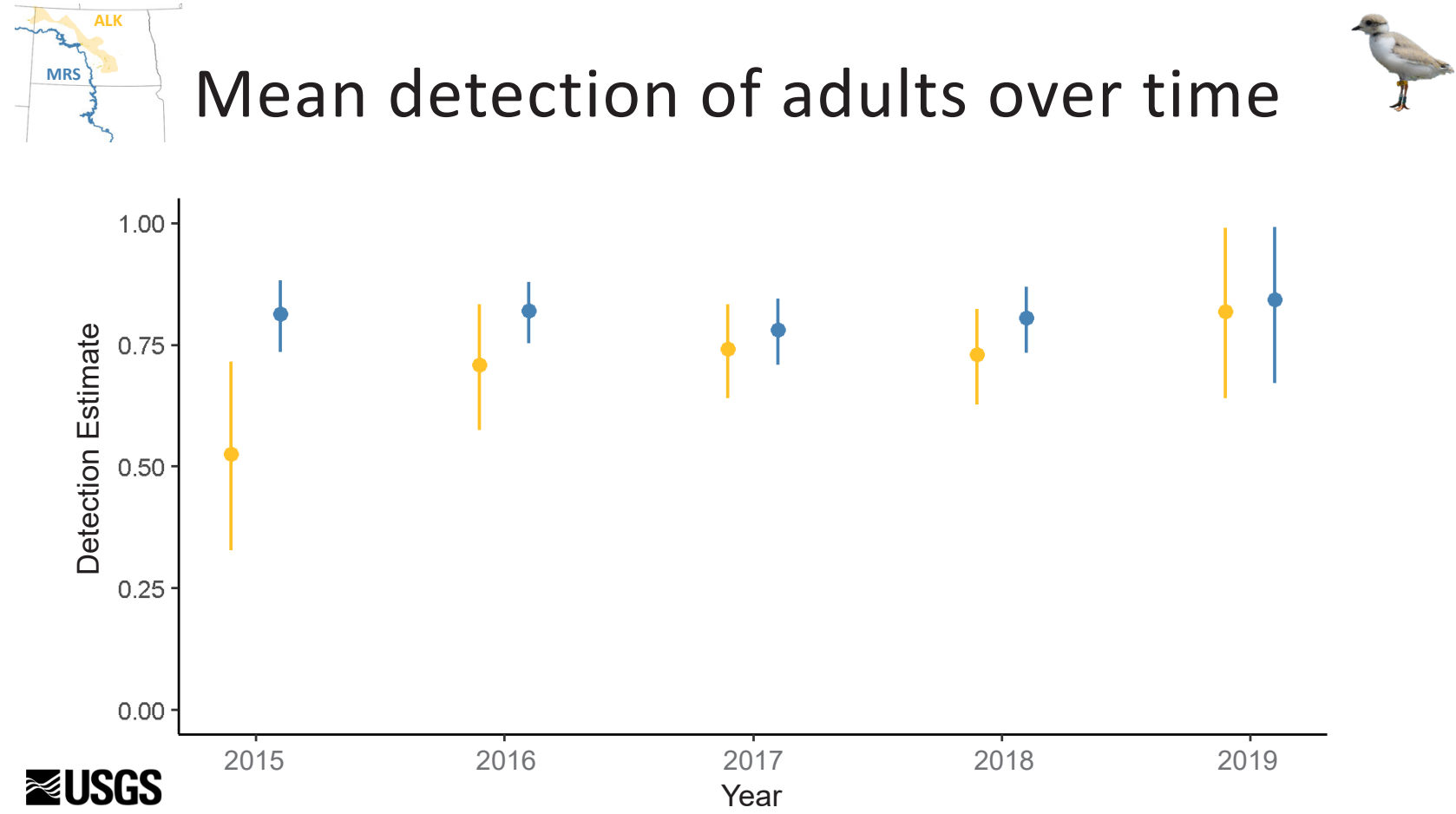

Mean detection probabilities of breeding adults on the MRS and the ALK varied over time but were generally similar. [The last year in a fully time-dependent model is not estimable. Detection of hatch-year states was fixed. Filled circles indicate mean detection probability estimates. Vertical lines indicate 95-percent credible intervals.] 

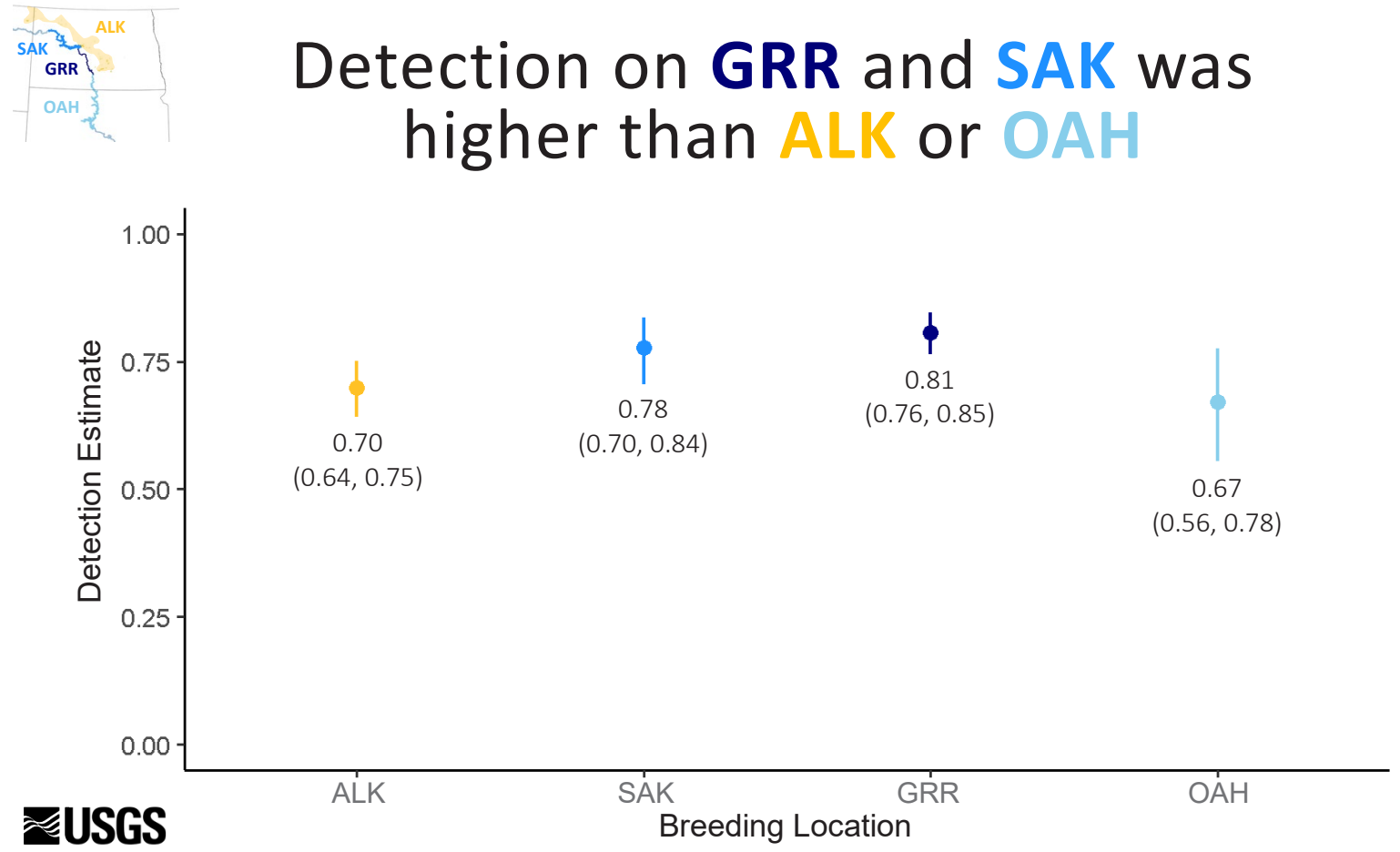

Mean detection probability of breeding adults from the four management units was similar for SAK $(0.78, \mathrm{Cl}=0.70$ to 0.84$)$ and the $\mathrm{GRR}(0.81, \mathrm{Cl}=0.76$ to 0.85$)$. Detection of adults on the $\mathrm{ALK}(0.70, \mathrm{Cl}=0.64$ to 0.75$])$ and $\mathrm{OAH}(0.67, \mathrm{Cl}=0.56$ to 0.78$)$ was slightly lower. [Detection of hatch-year states was fixed. Filled circles indicate mean detection probability estimates. Vertical lines indicate 95-percent credible intervals (Cls).]
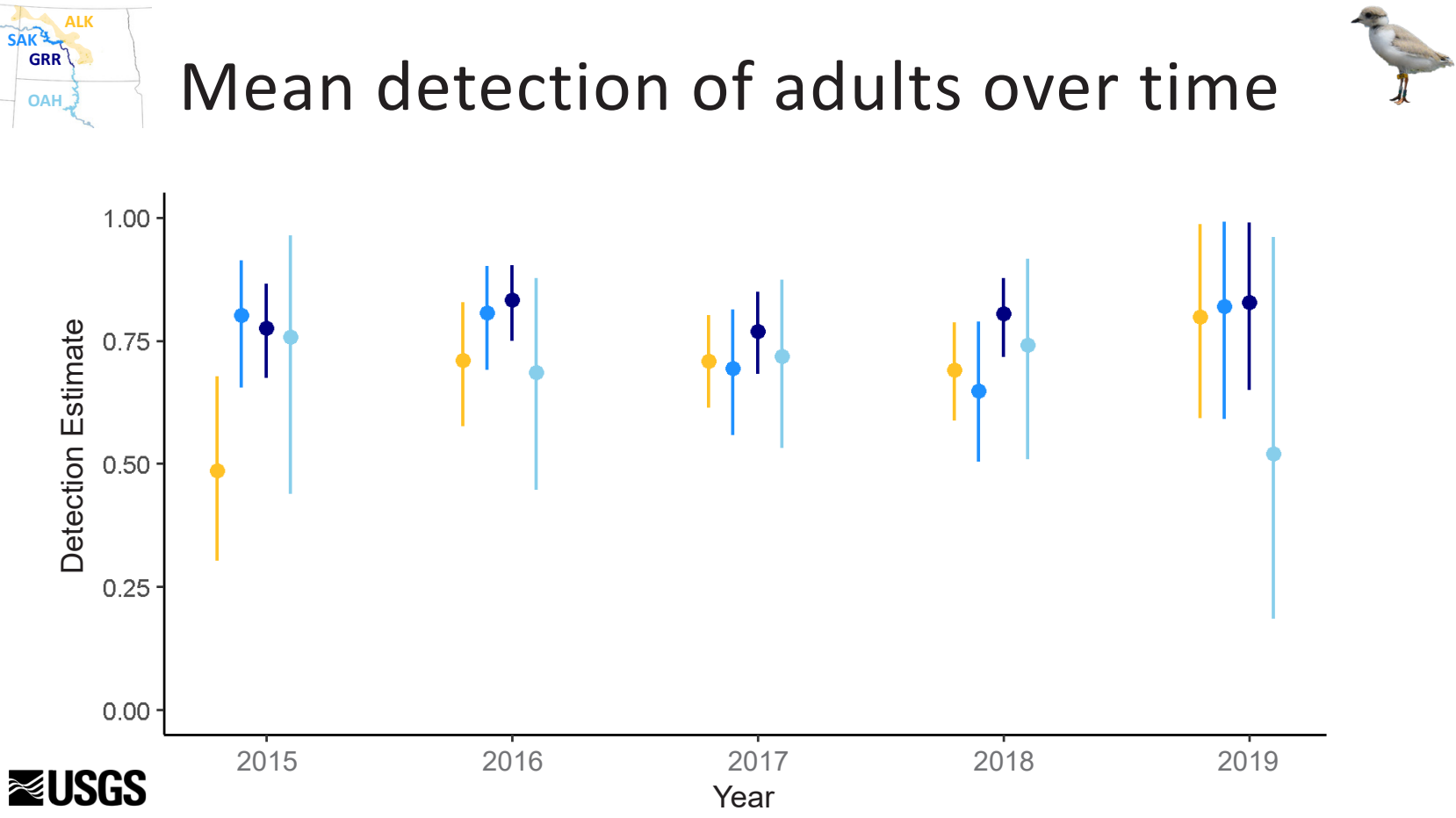

Mean detection rates of adults breeding in each of the four management units varied over time but were similar. [The last year in a fully time-dependent model is not estimable. Detection of hatch-year states was fixed. Filled circles indicate mean detection probability estimates. Vertical lines indicate 95-percent credible intervals.] 


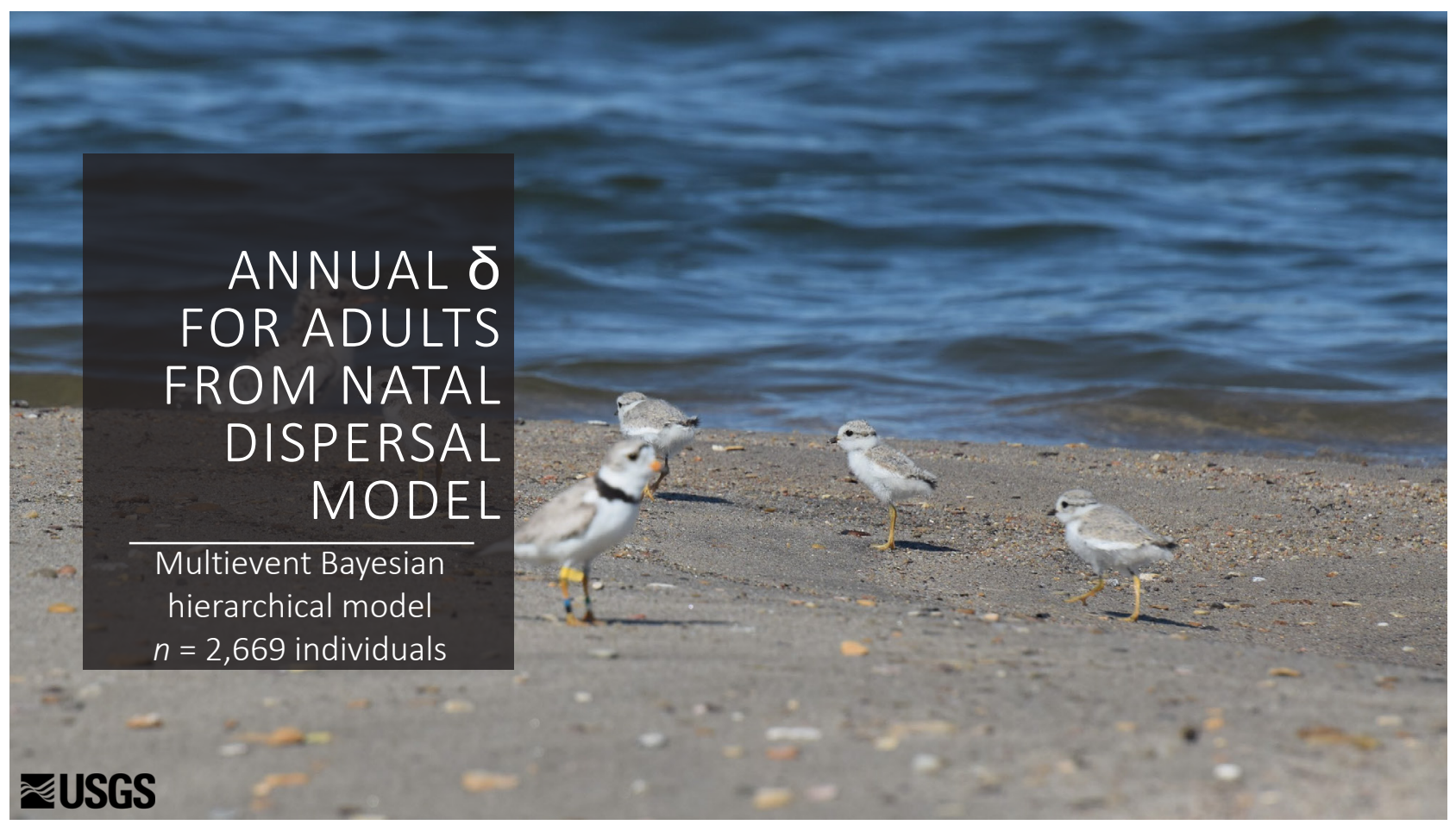

Misassignment error $(\delta)$ is the probability that the state of an individual that is in state, $s$, is correctly observed. Misassignment error for hatch-year individuals was fixed and therefore represents adult breeding locations. For more details, see the "Natal Survival and Dispersal Probabilities" section. [ $n$, number]
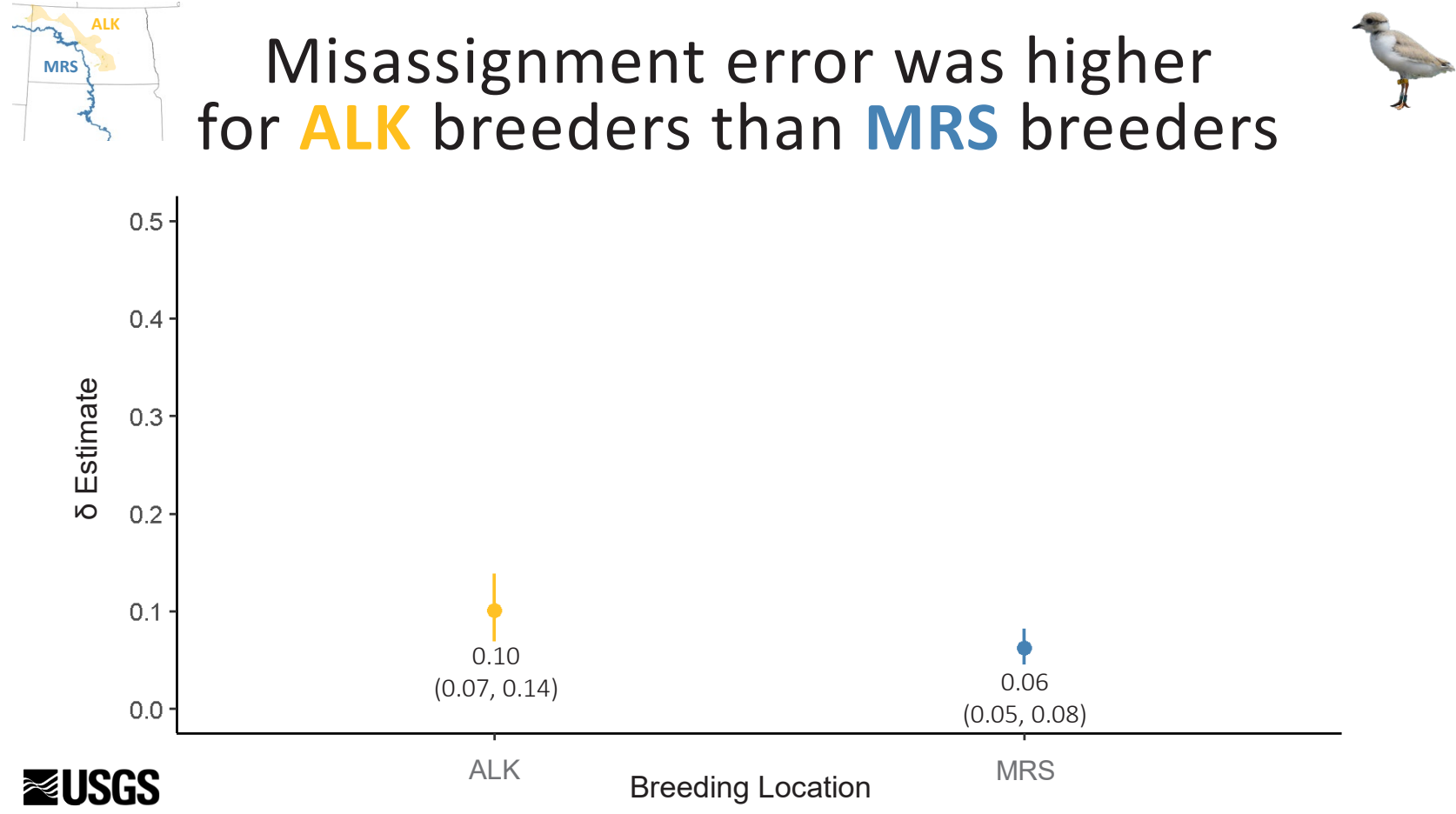

Misassignment error was higher on the $\operatorname{ALK}(0.10, \mathrm{Cl}=0.07$ to 0.14$)$ than the $\mathrm{MRS}(0.06, \mathrm{Cl}=0.05$ to 0.08$)$ for adults. [Misassignment error of hatch-year states was fixed. Filled circles indicate mean misassignment error probability $(\delta)$ estimates. Vertical lines indicate 95-percent credible intervals (Cls).] 


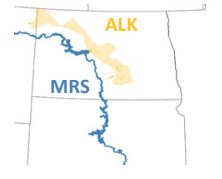

\section{Misassignment error declined over time}

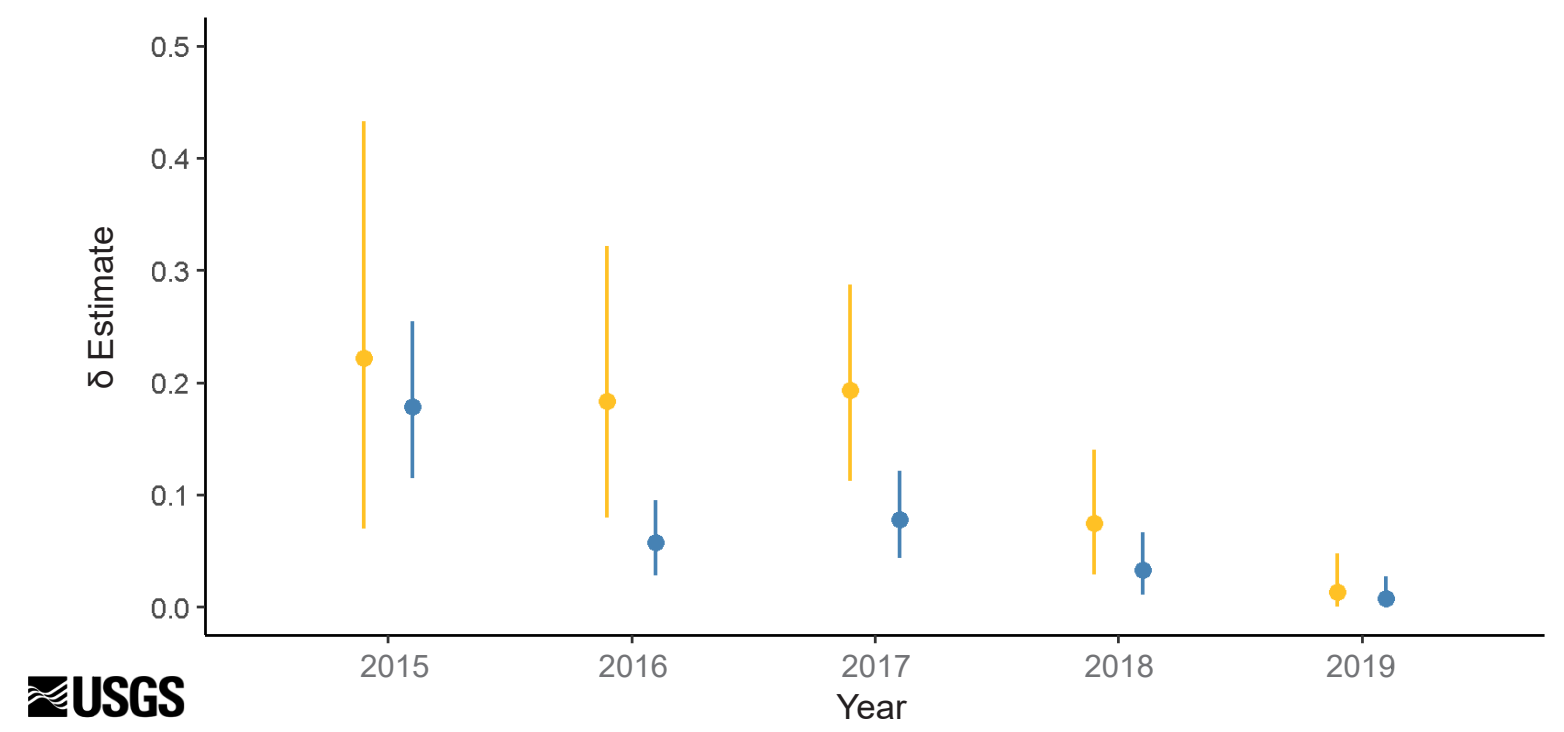

Misassignment error declined over the years. [The last year in a fully time-dependent model is not estimable. Misassignment error of hatch-year states was fixed. Filled circles indicate mean misassignment error probability ( $\delta)$ estimates. Vertical lines indicate 95-percent credible intervals.]
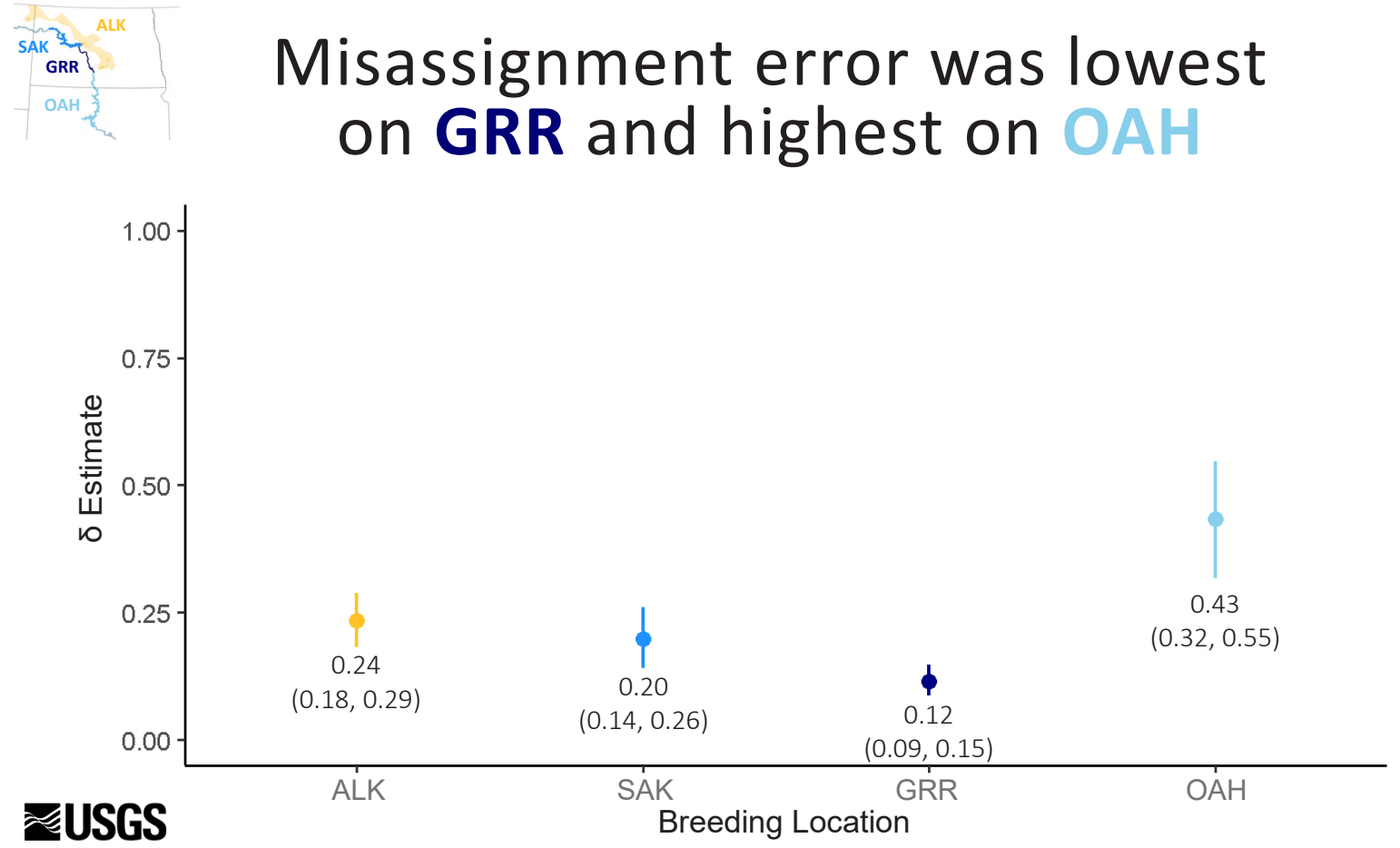

Misassignment error was higher on $\mathrm{OAH}(0.43, \mathrm{Cl}=0.32$ to 0.55$)$ than the $\mathrm{ALK}(0.24, \mathrm{Cl}=0.18$ to 0.29$)$ or $\mathrm{SAK}(0.20, \mathrm{Cl}=0.14$ to 0.26$)$, which were higher than the GRR $(0.12, \mathrm{Cl}=0.09$ to 0.15$)$ for adults. [Misassignment error of hatch-year states was fixed. Filled circles indicate mean misassignment error probability ( $\delta)$ estimates. Vertical lines indicate 95-percent credible intervals (Cls).] 


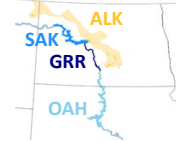

\section{Misassignment error over time}

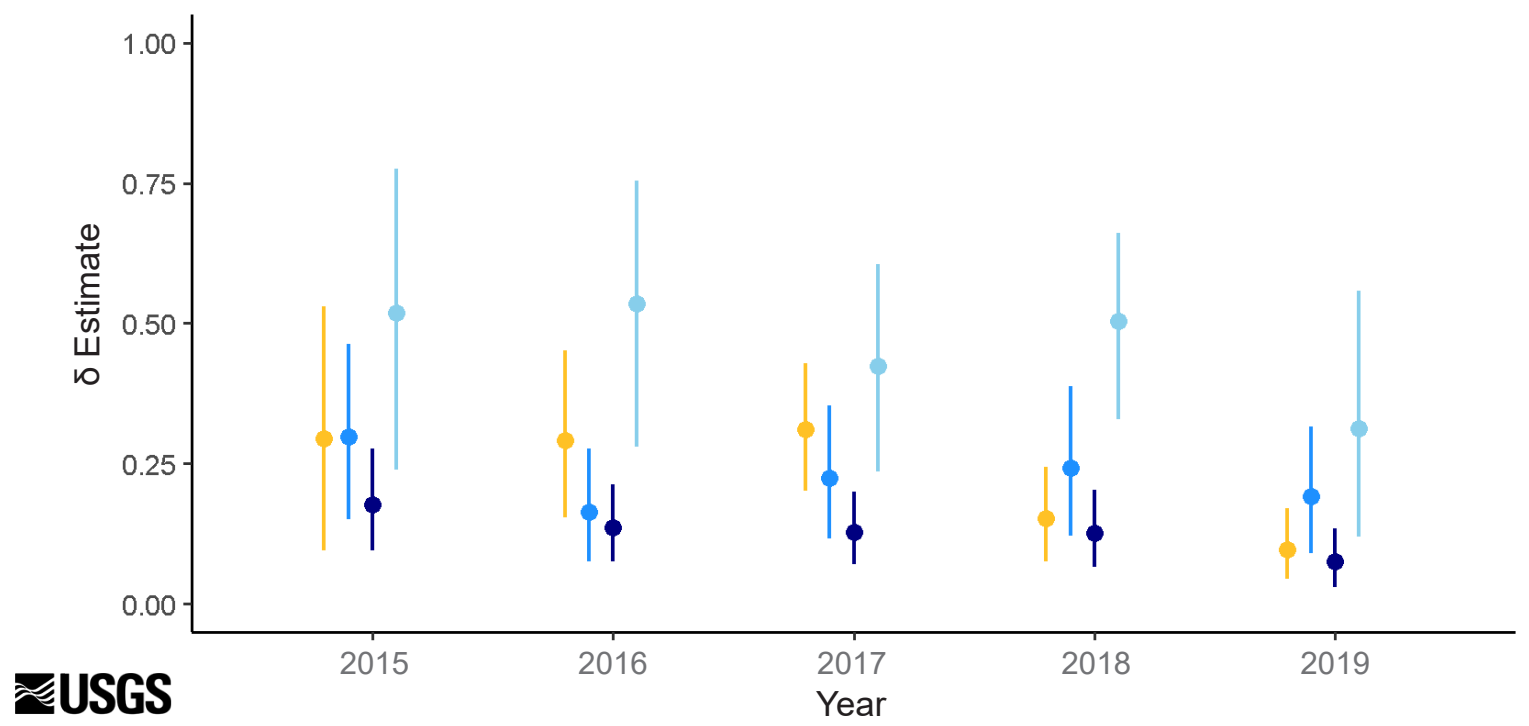

Misassignment error varied slightly over the years. [The last year in a fully time-dependent model is not estimable. Misassignment error of hatch-year states was fixed. Filled circles indicate mean misassignment error probability (ठ) estimates. Vertical indicate show 95-percent credible intervals.]

Natal dispersal from the U.S. Alkali Wetlands was higher than from the Missouri River, but this changed during the study as the Missouri River lost habitat in later years.

\section{尹USGS}

Overall, natal dispersal was highly unbalanced with transition probabilities from the ALK to the MRS twice as high as from the MRS to the ALK, but there was a declining trend in dispersal onto the MRS during the study. Using the specific location-based states, dispersal from SAK to the ALK was equally likely as fidelity to breed on SAK. Dispersal from SAK increased in later years when SAK's pool elevation increased. 


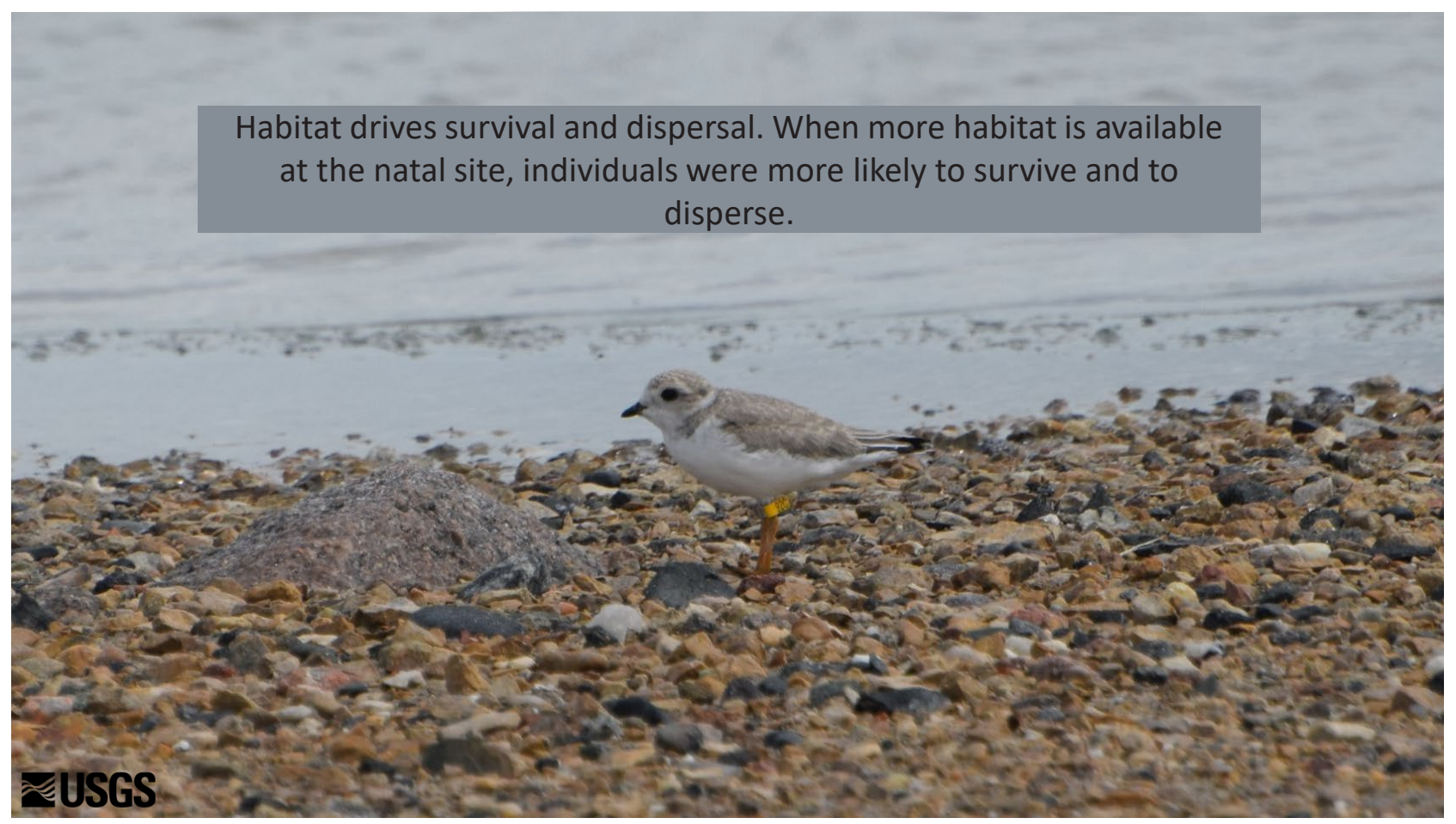

When more habitat was available at the natal site, annual hatch-year survival improved. Contrary to our predictions, when more habitat was available at the natal site transition probabilities also increased. Although we saw no effect of our estimate of chick density at the segment scale, density dependence could act at a larger scale, thereby forcing dispersal in years when habitat is plentiful because those years are correlated with improved reproductive success. Individuals could be prioritizing inbreeding avoidance in productive years with increased dispersal away from their natal management unit. Similarly, piping plovers may use natal habitat to infer habitat availability in alternative areas and assume in years of excess habitat that habitat may be similarly available in other areas. When natal habitat is in excess, it may be more difficult for individuals to distinguish between natal and novel areas because the potential neighborhood of habitat is larger. 


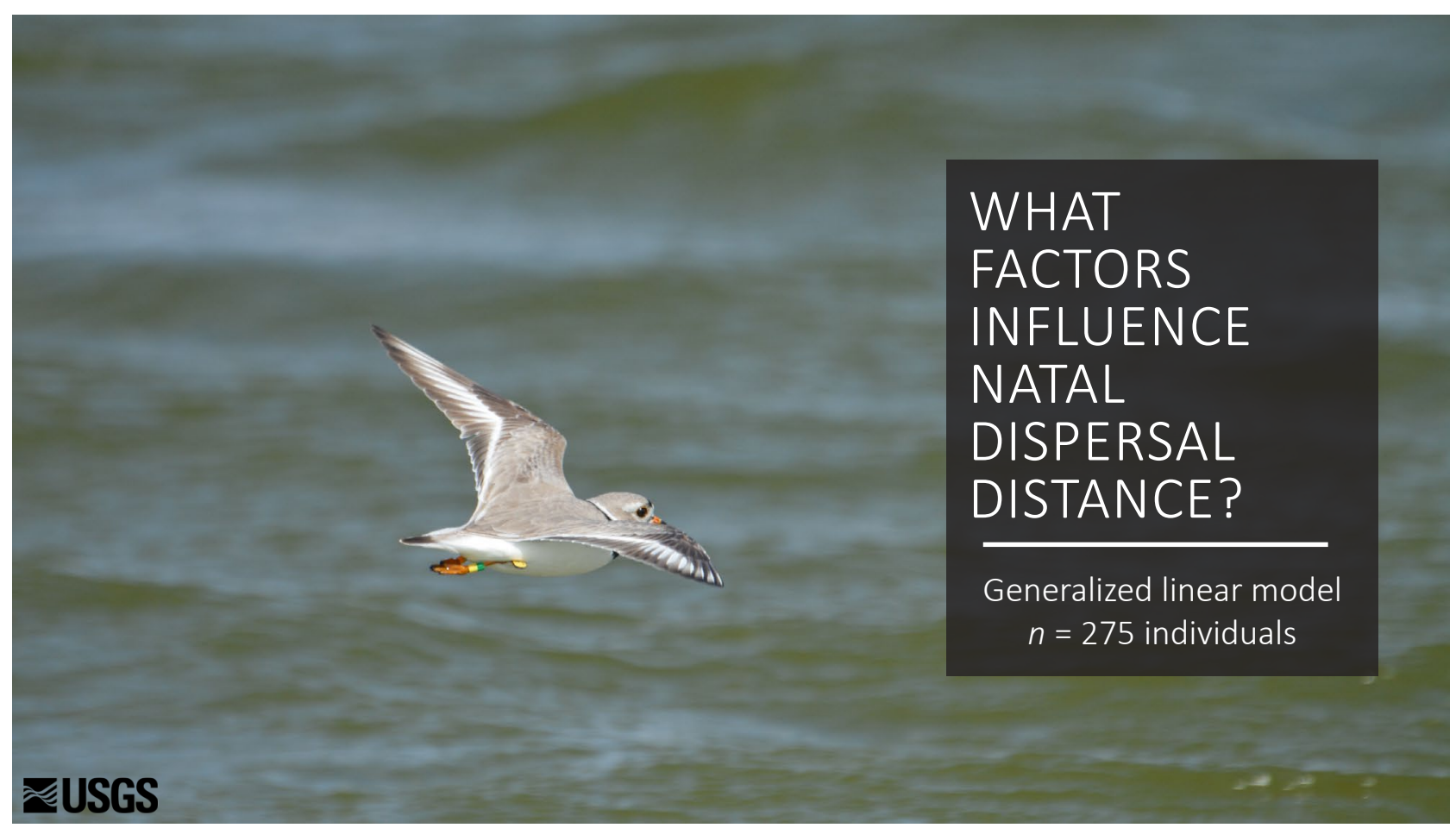

We calculated Euclidean dispersal distance as the distance between the nest a chick was hatched from to the location of the first known nest of that individual. We examined sources of variation in dispersal distance using a generalized linear model. See the "Dispersal Distances" section for detailed methodology. [ $n$, number] 


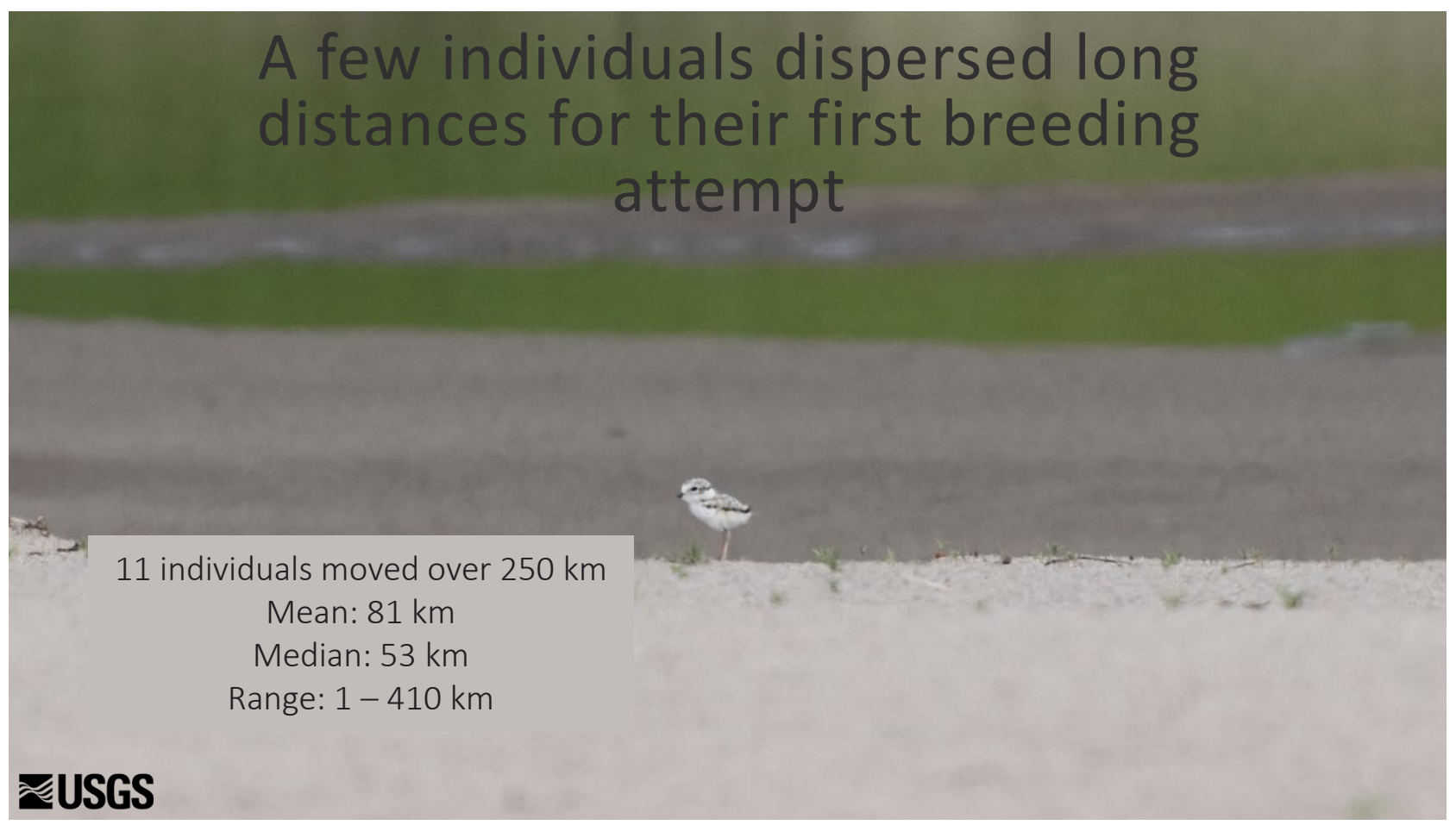

Dispersal distances of piping plovers between their natal nest and the location of their first known breeding attempt varied widely (mean: $81.0 \mathrm{~km}$, median: $53.0 \mathrm{~km}$, range: 1-410 km, coefficient of variation: $93.8 \mathrm{~km}$ ). We observed 278 natal dispersal events. Also, 53 percent of individuals bred at 2 years old for the first time. Three individuals left the focal study area to breed in the southern Missouri River units or on the central Platte River in Nebraska. Within the focal study area, two individuals dispersed more than $350 \mathrm{~km}$ : one from OAH to SAK and one from a northwestern alkali wetland to the GRR. An additional nine movements were longer than $250 \mathrm{~km}$. [km, kilometer] 


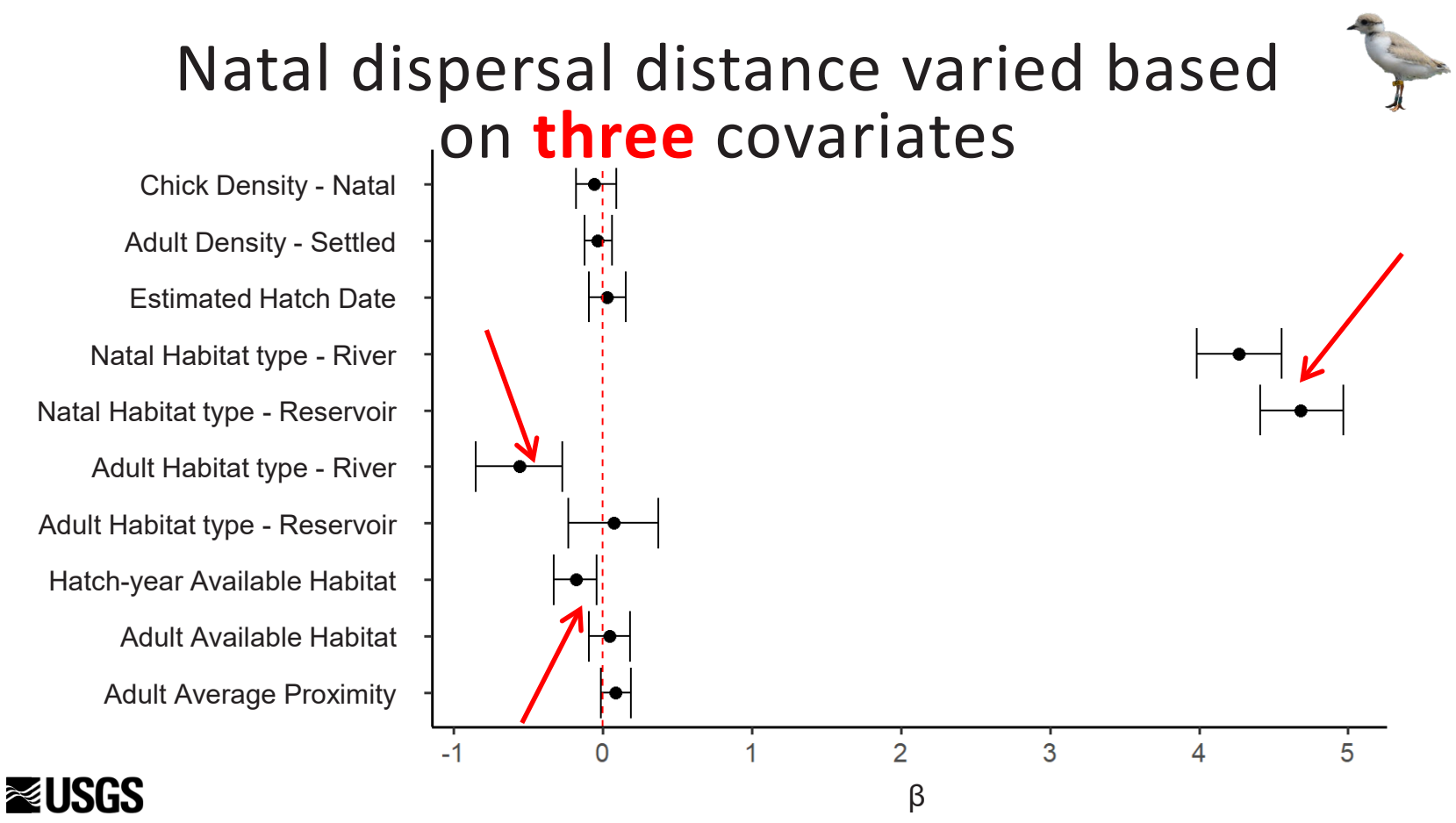

From the global fitted model with all a priori covariates included on natal dispersal distances, three covariates seem important based on nonoverlapping 95-percent confidence intervals with zero (red arrows). Natal habitat type, natal available habitat, and breeding location habitat type all substantially explained dispersal distance. [Filled circles indicate mean $\beta$ estimate. Whiskers indicate 95-percent confidence intervals.]

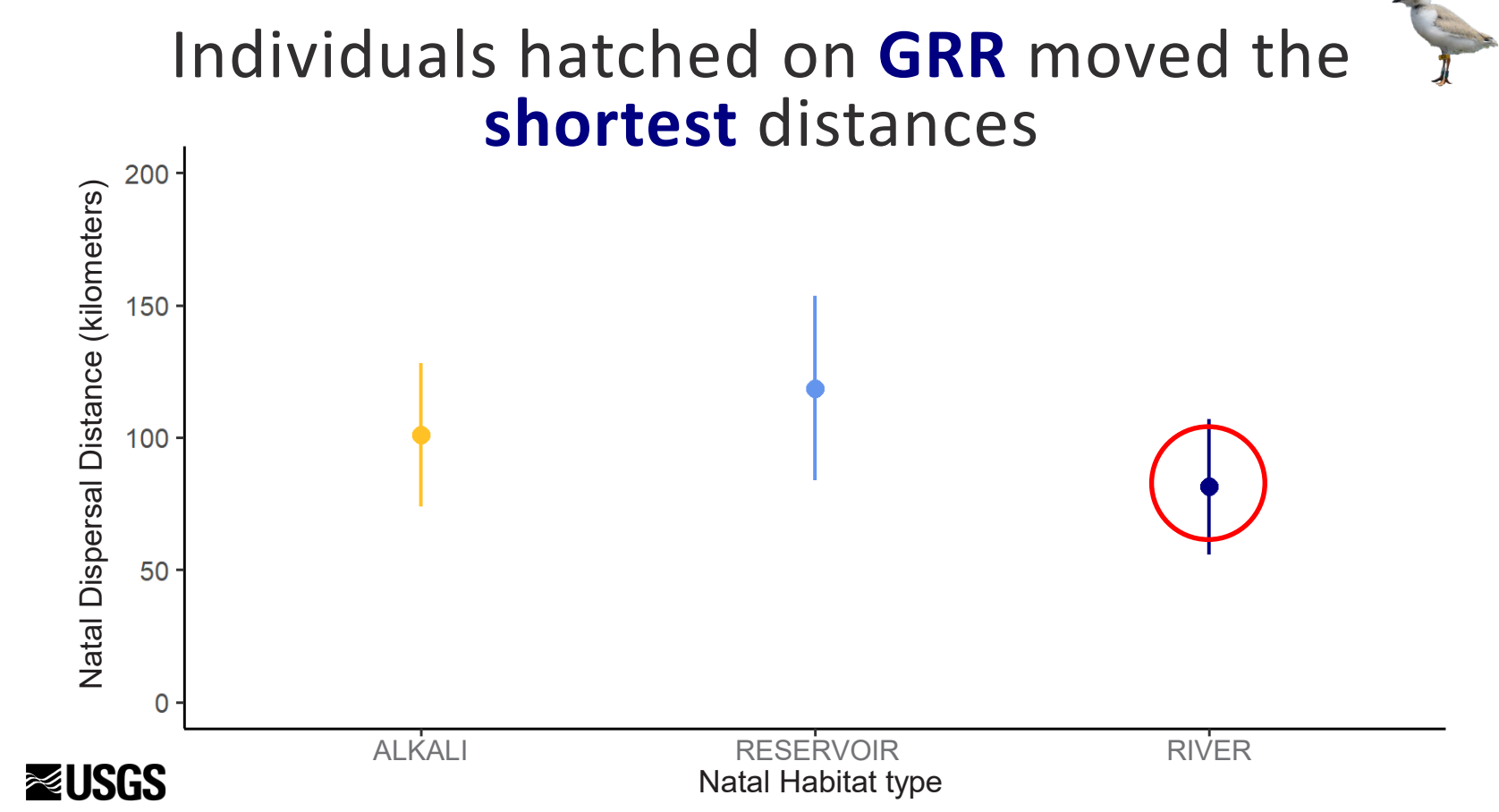

Individuals hatched on the river habitat (red circle) dispersed slightly shorter distances, whereas those hatched on reservoirs dispersed slightly farther. [Filled circles indicate mean distance estimates. Vertical lines indicate 95-percent confidence intervals.] 


\section{Hatch-year birds settling on the GRR dispersed the shortest distances}

क

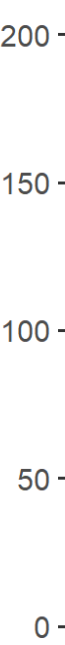

尹USGS
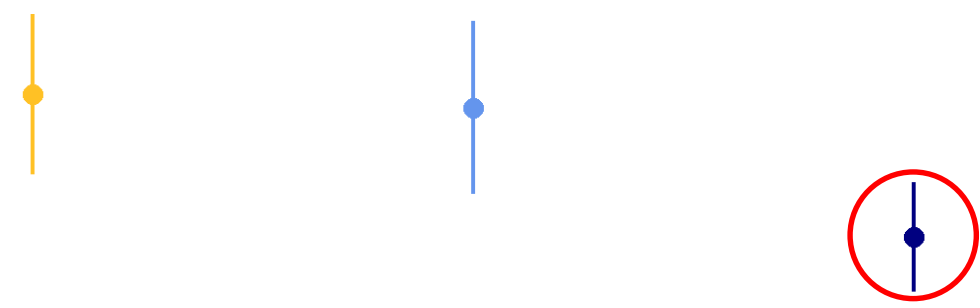

Individuals settling to breed on the river habitat (red circle) dispersed the shortest distances. [Filled circles indicate mean distance estimates. Vertical lines indicate 95-percent confidence intervals.]

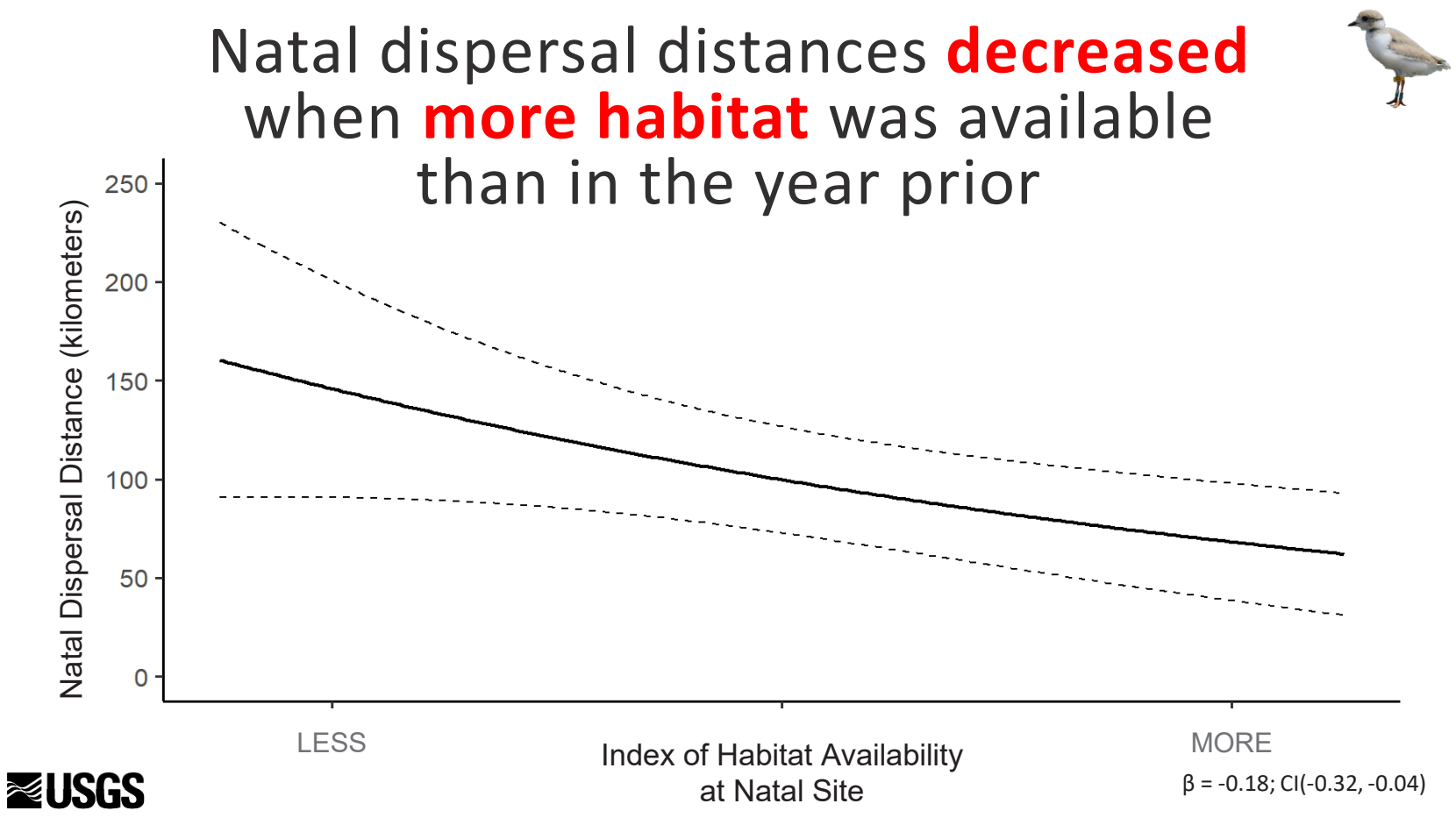

Natal dispersal distances (solid line) decreased when more habitat was available on their natal area than in the year prior $(\beta=-0.18 ; C l=-0.32$ to -0.04$)$. [Dashed lines indicate 95-percent confidence interval (CI).] 


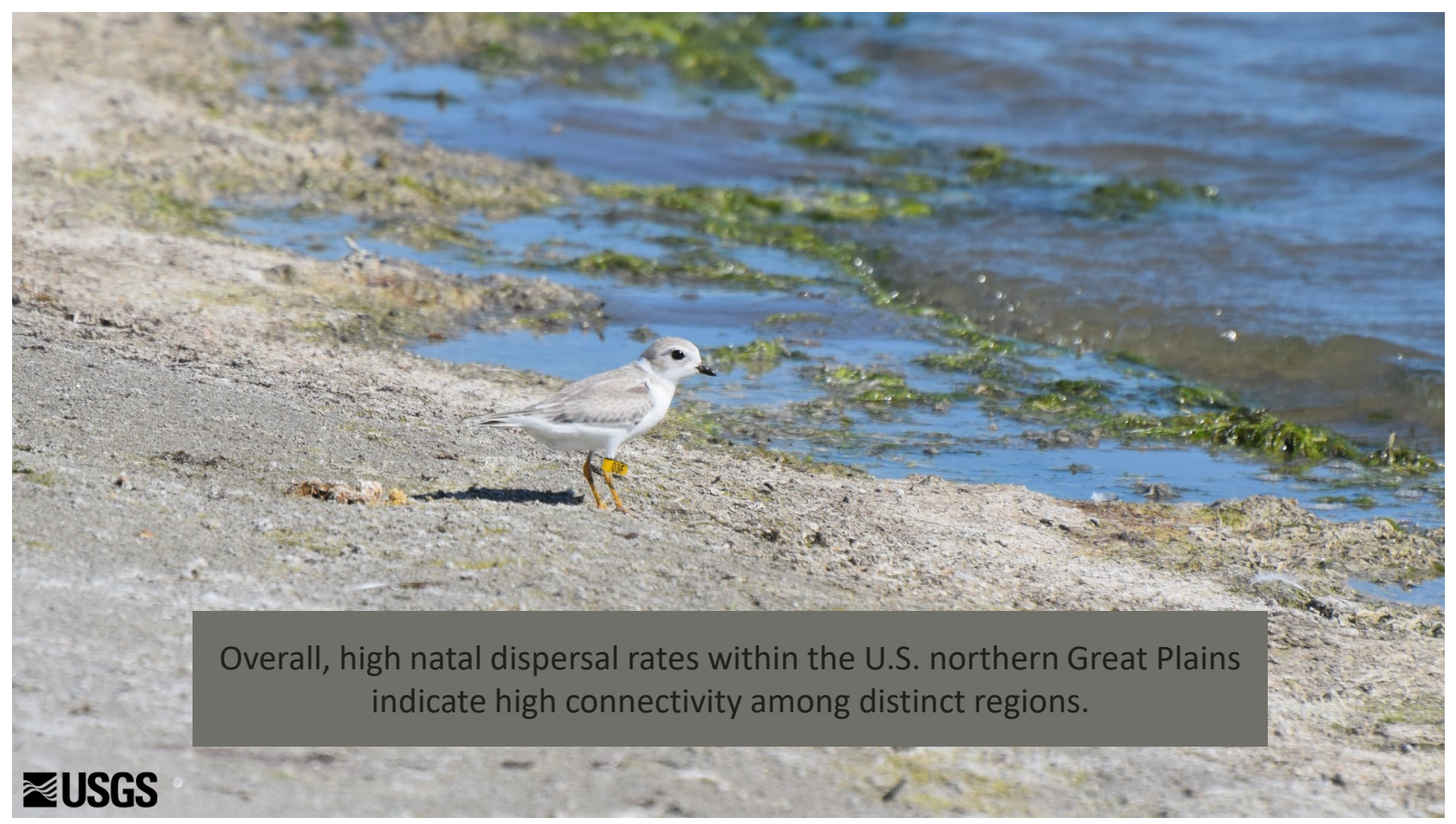

Natal dispersal was high within the focal study area. Individuals were equally likely to leave their natal management unit to breed for the first time versus returning to their natal management unit (natal fidelity rates roughly 0.5). Even within our focal study area, individual dispersal distances ranged widely with the shortest known distance between the natal nest and the first known nest about 1 km apart. Our study area covered about 84,000 square kilometers of semicontinuous (Missouri River) and discrete (wetland) habitat, yet individuals routinely dispersed amongst habitat types and over long distances suggesting that connectivity within this region is high. Although piping plovers are capable of infrequent large-scale dispersal between breeding populations, in this study, we did not document any movements between breeding populations, but we did show small numbers of individuals moving from the NGP to the southern units of the Missouri River and to the Platte River. However, we did find frequent long-distance dispersal within the northern units of the Missouri River and the U.S. Alkali Wetlands suggesting not only high connectivity within this region but also a dynamic landscape where individuals respond to the availability of habitat across space and time. 


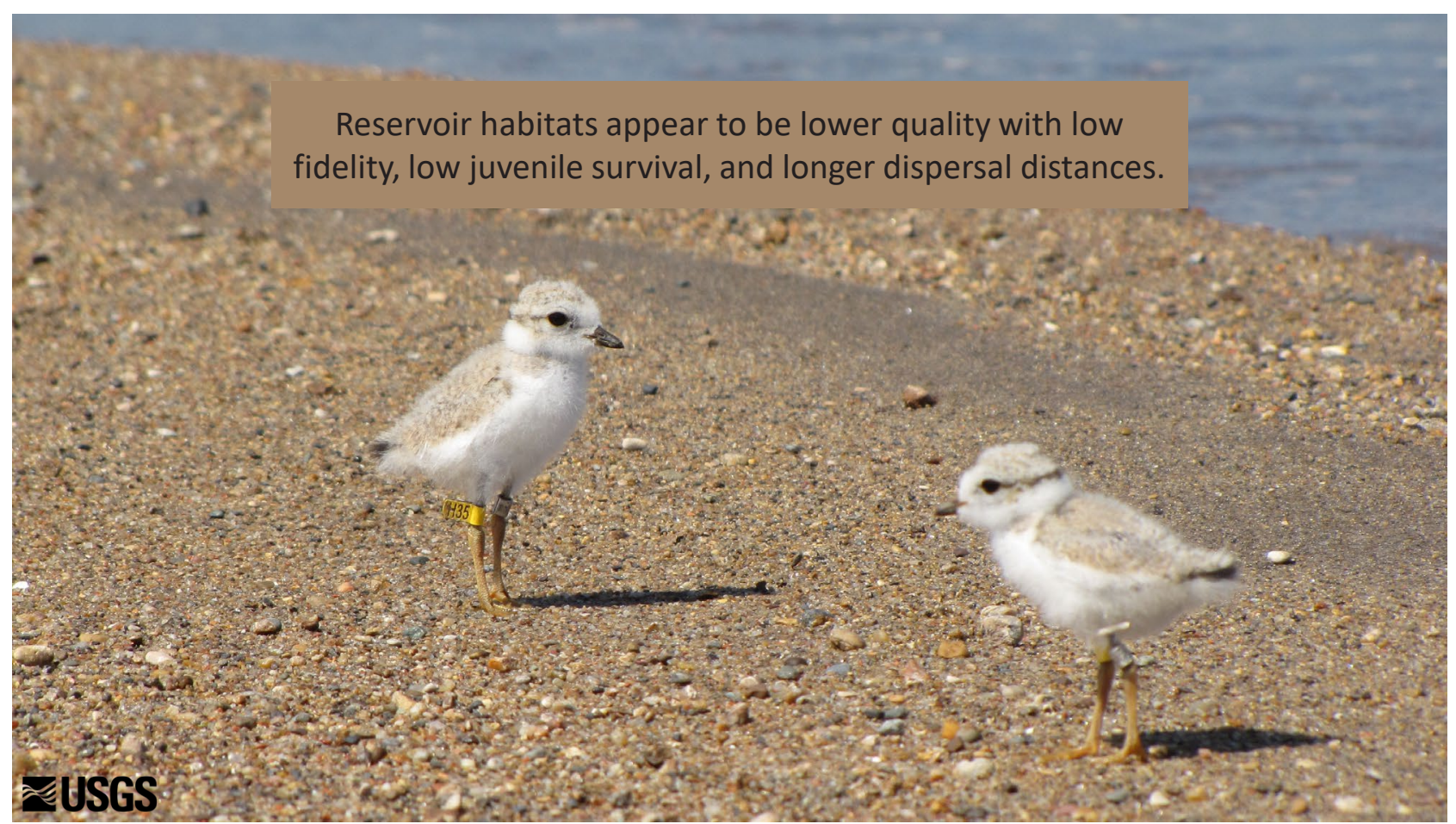

Reservoir habitats showed lower annual hatch-year survival, low fidelity (with high dispersal from this habitat), and longer dispersal distances compared to other habitat types. Most individuals that nested as an adult settled onto the GRR ( $n=184$ ), and $\mathrm{OAH}$ had the fewest adults settle $(n=41)$. One individual from $0 \mathrm{AH}$ dispersed about $410 \mathrm{~km}$, whereas no GRR individual moved more than $280 \mathrm{~km}$ to their first known nest location. 


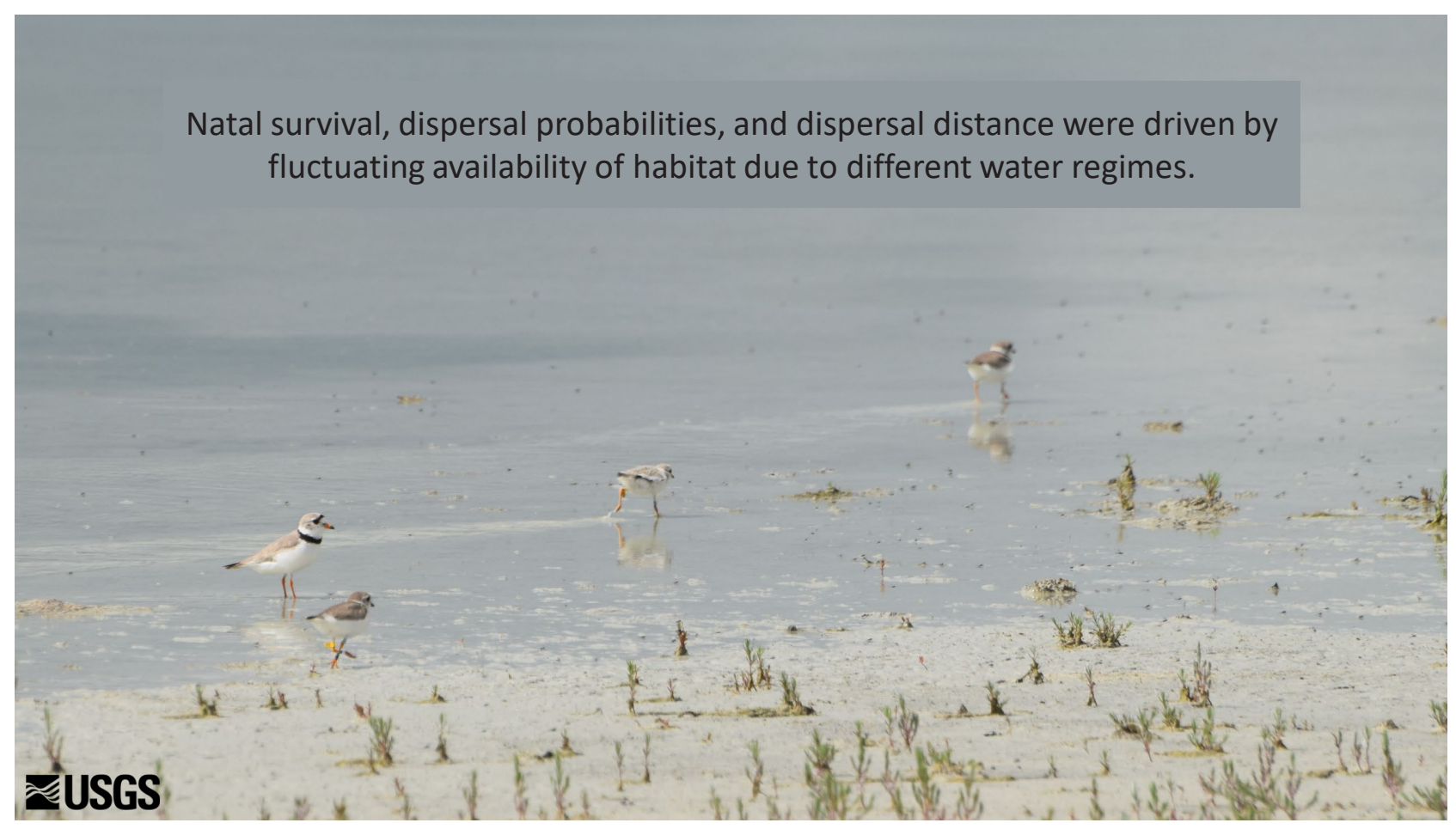

We determined that habitat type and habitat availability were the driving forces behind natal dispersal probabilities and dispersal distances for piping plovers. As predicted, individuals dispersed shorter distances when more habitat was available during their natal year, but dispersal probabilities increased when more habitat was available during their natal year than the year prior. Animals occupying habitats with unstable conditions typically show higher dispersal or longer movements between alternate breeding sites (Greenwood and Harvey, 1982). Piping plovers use early successional habitat for nesting, and on the Missouri River, depend on floods or wave and ice scour to remove or prohibit the growth of vegetation and create suitable nesting habitat. Historically, seasonal water-level fluctuations maintained early successional habitat conditions on prairie rivers, where peak flows in March and June submerged existing sandbars and redistributed sediments, creating unvegetated sandbars suitable for piping plover nesting as water levels receded (Catlin and others, 2010, 2016). In the absence of high natural flows, anthropogenic activities maintain vegetation-free sandbars through management (in other words, vegetation removal) or through the construction of sandbars (Sherfy and others, 2008; Catlin and others, 2016). Although the Missouri River is hydrologically linked and can have high spatiotemporal autocorrelation in habitat availability in some years, particularly when water levels are high and little habitat is available, precipitation in the Prairie Pothole Region frequently fluctuates and varies across the region; thus, different wetlands can have different water levels at the same time (McCauley and others, 2016; Post van der Burg and others, 2016). Therefore, along the Missouri River, and in particular the management units in northern river section, habitat is fairly continuous spatially, though it may be temporally variable based on releases from the upstream dams. Individuals hatched on, previously nested on, or settling on the GRR moved the shortest distances. Unlike reservoir or alkali wetland habitats, the sandbars on the GRR provide a semicontinuous corridor of appropriate nesting habitat. 


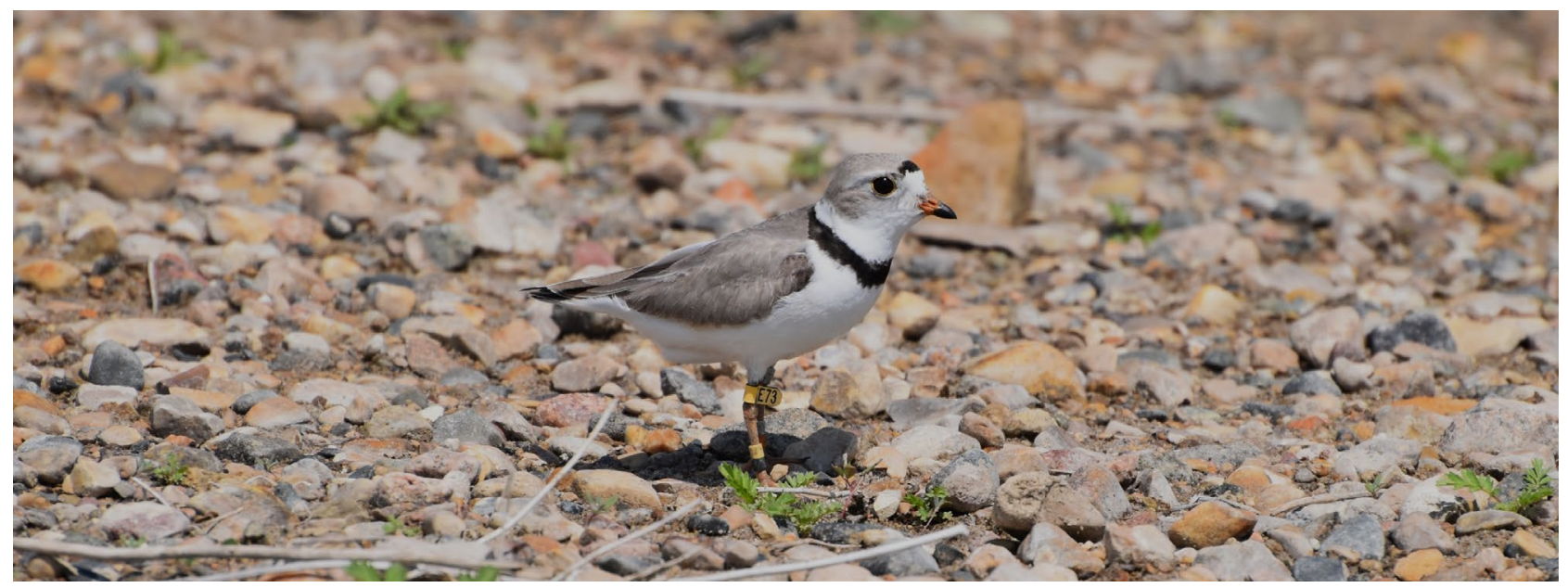

\section{ADULT SURVIVAL AND \begin{tabular}{r|r} 
BREEDING DISPERSAL INFLUENCE & objectives 1, 2, 4, \&5 \\
POPULATION STRUCTURE &
\end{tabular}}

\section{‡USGS}

We were interested in determining sources of variation in adult annual survival, breeding dispersal rates, and interannual breeding dispersal distances. 


\title{
Annual adult survival
}

\author{
Large influence on population growth rates and
}

the Missouri River adaptive management model

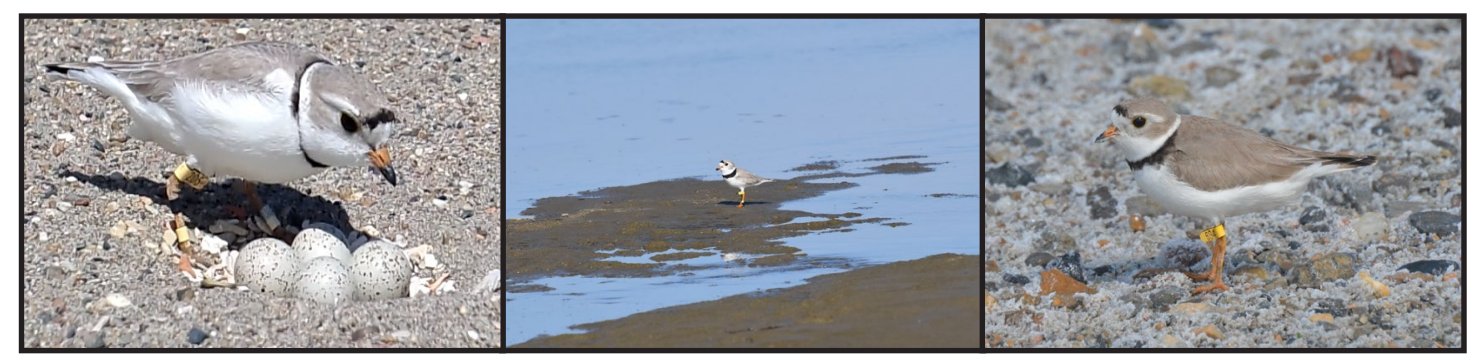

\section{₹USGS}

Survival of breeding adults has the greatest effect on population growth in most species of birds, including piping plovers, and so it is critically important for wild life managers to understand factors that affect variation in annual survival (Larson and others, 2000; Plissner and Haig, 2000; Sæther and Bakke, 2000; Calvert and others, 2006; Roche and others, 2010). Apparent survival is potentially confounded by permanent emigration, where a marked animal dispersing outside a regularly monitored study area and no longer available to be resighted is indistinguishable from a marked animal that dies and is no longer detected (Sandercock, 2006). Using observations during the nonbreeding season or from a large-scale study area provide less biased estimates that are closer to true survival. 


\title{
Breeding dispersal
}

\author{
Movements of individuals between reproductive attempts \\ determines spatial population structure
}

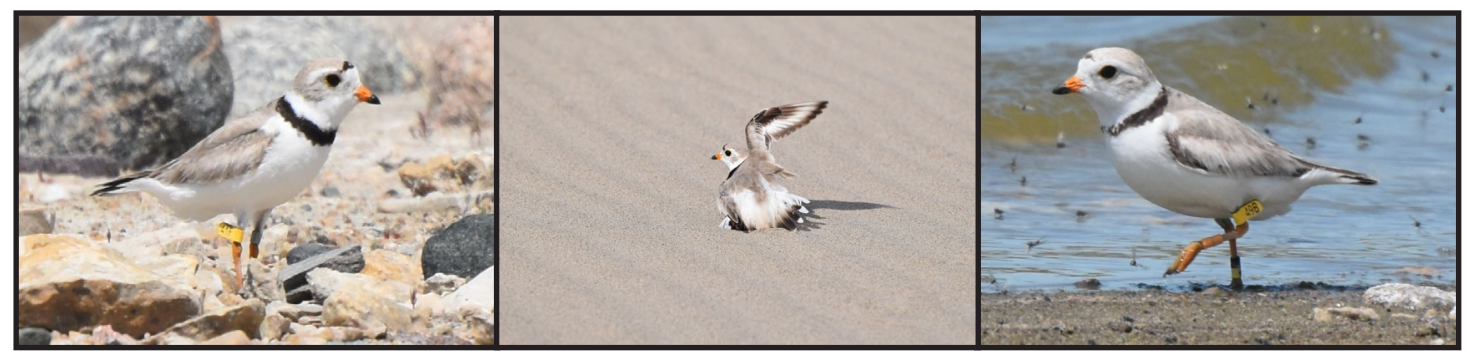

\section{₹USGS}

Dispersal is a nonrandom process that depends on an individual's social and physical environment and many factors that shape the cost-benefit balance of dispersal patterns (Matthysen, 2012). Breeding dispersal is likely adaptive because switching breeding territories may increase access to mates or to higher-quality habitats with fewer threats or competitors and, ultimately, can also enhance fitness (Boyce and Boyce, 1988; Forero and others, 1999). 


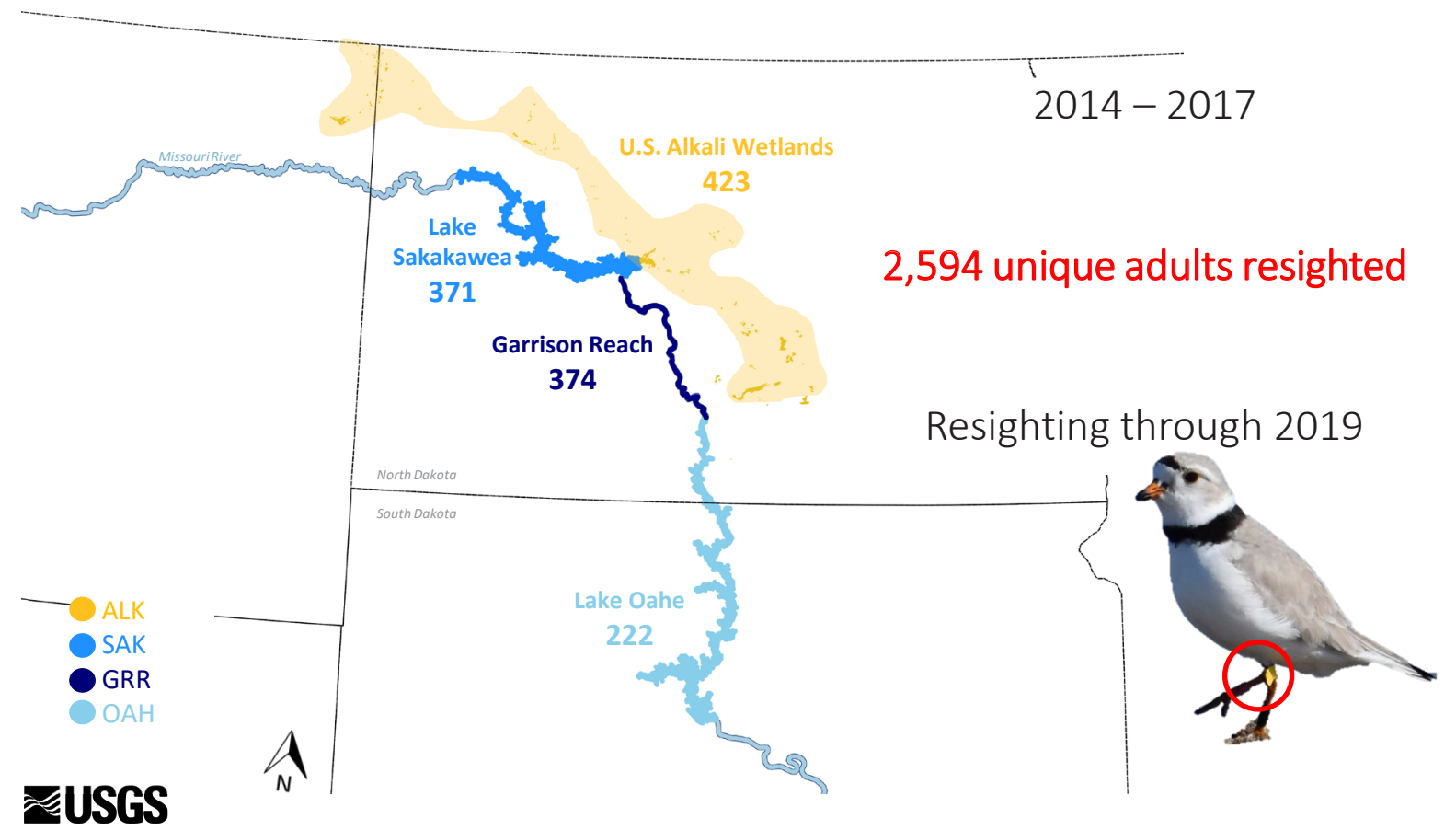

We banded piping plovers with a USGS metal band and unique alpha-numeric engraved flag (red circle). Before 2014, we banded piping plovers on SAK and the GRR. We included newly banded adults (sample sizes shown on map) as well as any uniquely identifiable adults resighted during the 6 years of the study (previously banded as an adult or chick). More individuals were included in the model that were banded previously as an adult, or those that were banded as chicks were included once they were observed as an adult. See the "Adults" section for more information.

\section{Emigration from our focal study area occurred to all other breeding areas}
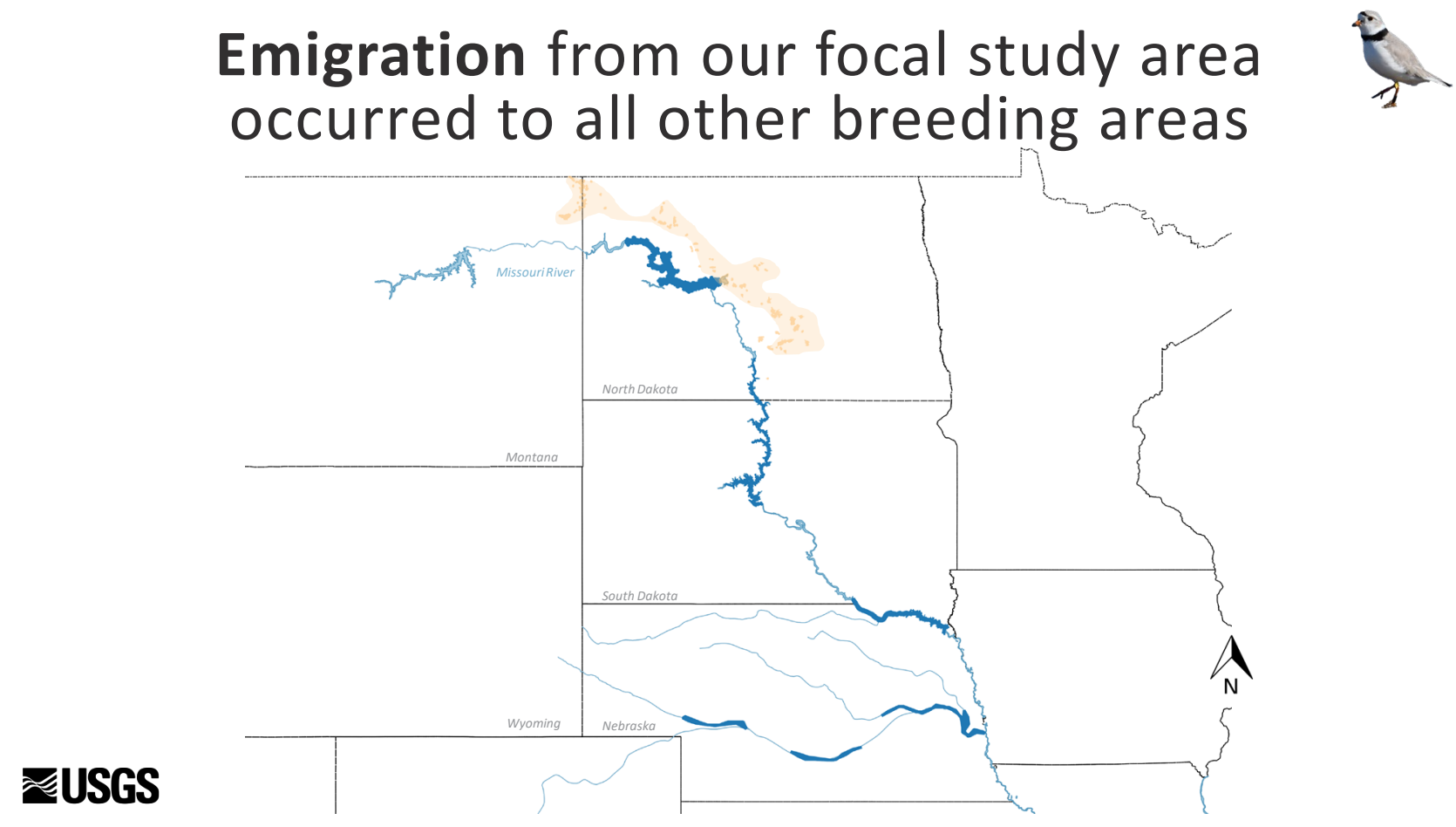

Emigration from the four management units occurred to the rest of the major breeding areas in the NGP. We provide Wetland Management District (WMD) specific locations for dispersal from the ALK. 


\section{7 individuals emigrated to the Platte River (Central, Lower, Lake McConaughy)}

\section{₹USGS}

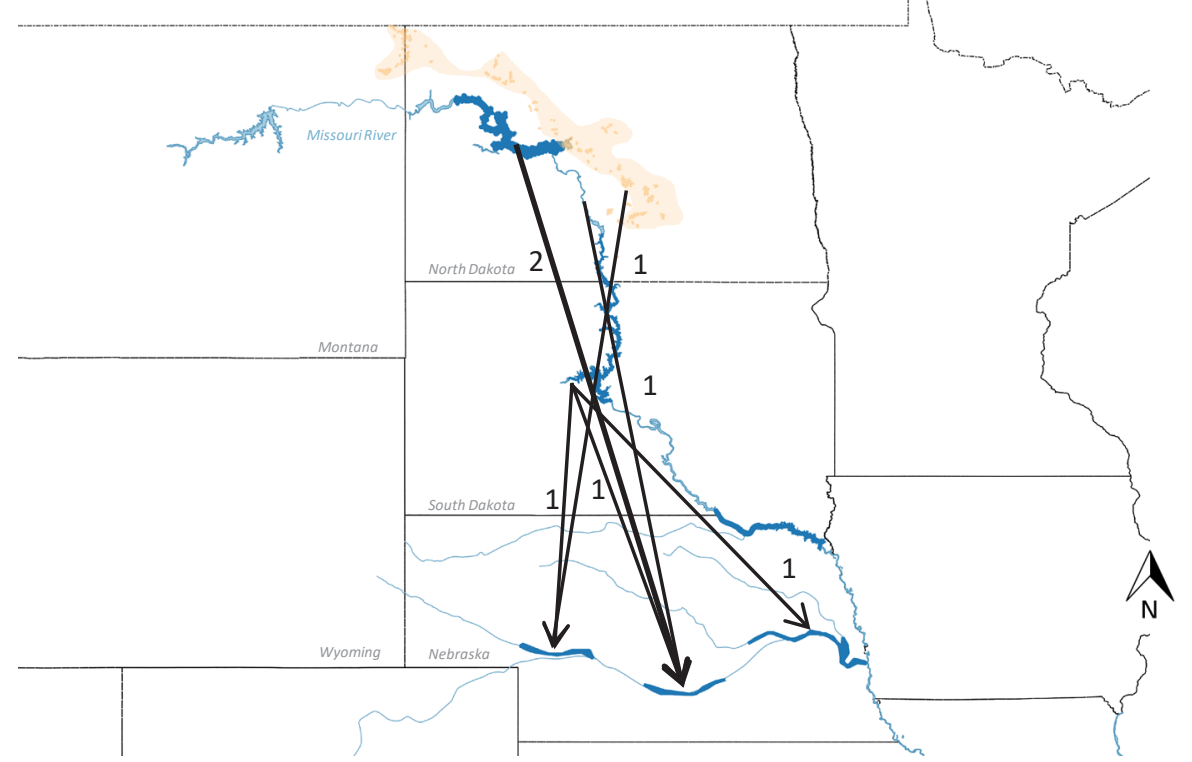

Seven individuals emigrated to the Central or Lower Platte River management units or Lake McConaughy (black arrows): 2 from SAK to the Central Platte River, 1 from the Long Lake WMD to Lake McConaughy, 1 from the GRR to the Central Platte River, 1 from $\mathrm{OAH}$ to Lake McConaughy, 1 from $\mathrm{OAH}$ to the Central Platte River, and 1 from $0 \mathrm{AH}$ to the Lower Platte and Loup Rivers.

\section{7 individuals emigrated to Prairie Canada}

\section{ఇUSGS}

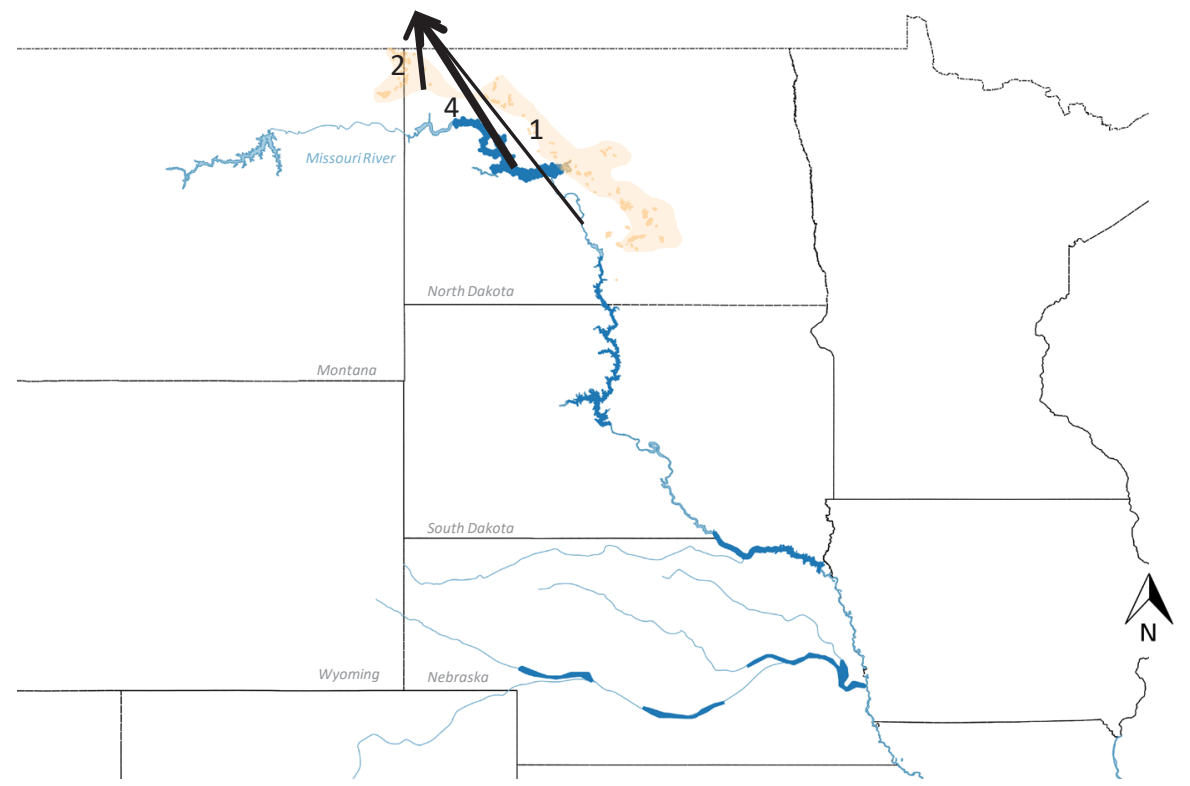

Seven individuals emigrated to Prairie Canada (black arrows): 2 from the Crosby WMD, 4 from SAK, and 1 from the GRR. 


\section{0 individuals emigrated to the southern Missouri River segments (Gavins Point, Fort Randall, Lewis and} Clark Lake, Lake Sharpe, Niobrara River)

\section{₹USGS}

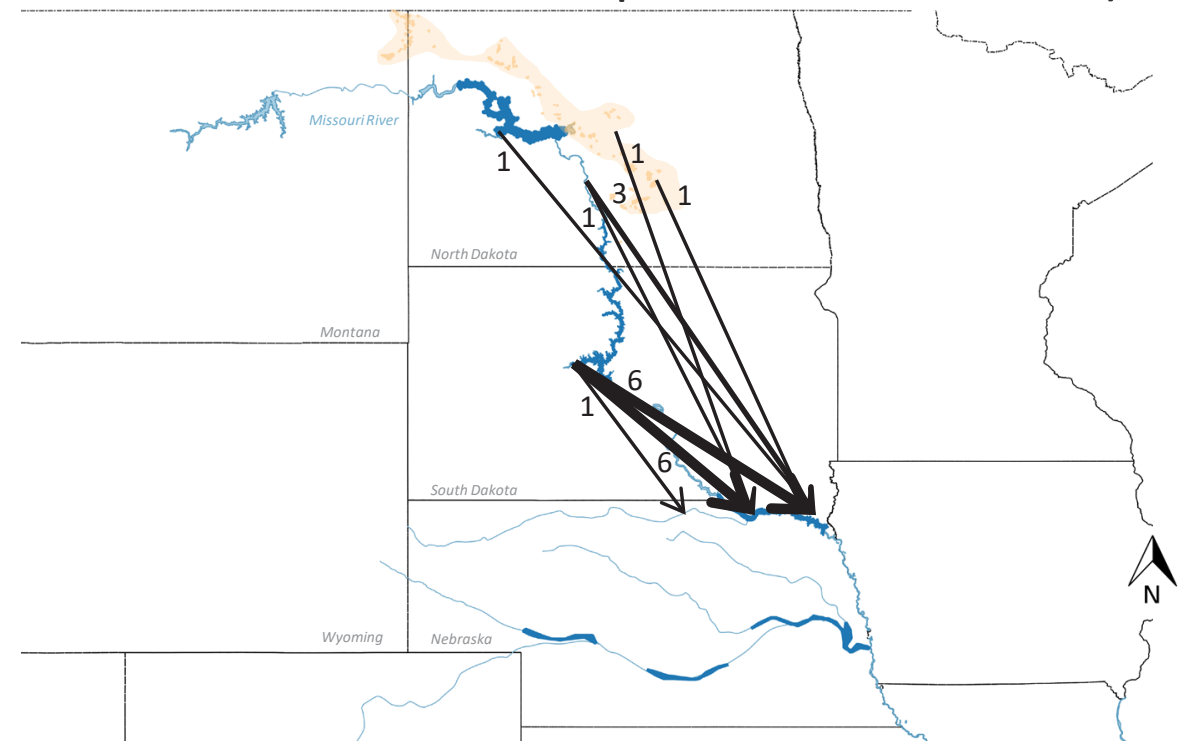

In total, 20 individuals were detected along the southern Missouri or Niobrara Rivers, and 11 of those went to Gavins Point Reach (black arrows): 1 from SAK to Gavins Point Reach, 1 from the Long Lake WMD to Gavins Point Reach, 3 from the GRR to Gavins Point Reach, 6 from OAH to Gavins Point Reach, 1 from the GRR to Lewis and Clark Lake, 1 from the Lake Audubon WMD to Lake Sharpe, 1 from OAH to the Niobrara River, 3 from OAH to Lake Sharpe, and 3 from OAH to the Fort Randall Reach. 


\section{ఇUSGS}

\section{Immigration to our focal study area} occurred from all other breeding areas

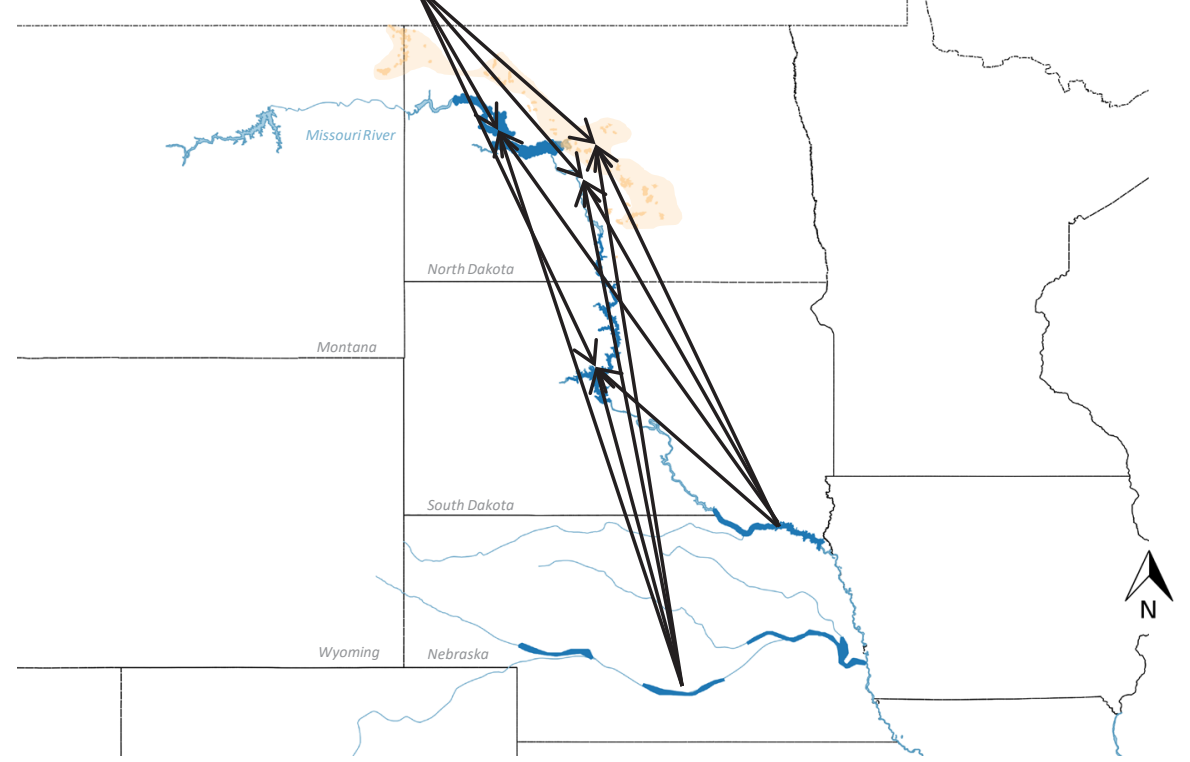

Individuals seemed to immigrate from Prairie Canada, the Platte River, and the southern Missouri River units into each of our four management units (black arrows). Many of these birds were not uniquely identifiable because of band loss or fading (in other words, flag colors identified study area origin but individual identity could not be distinguished), so we are not able to provide estimates of the number of individuals that immigrated into our focal study area. 


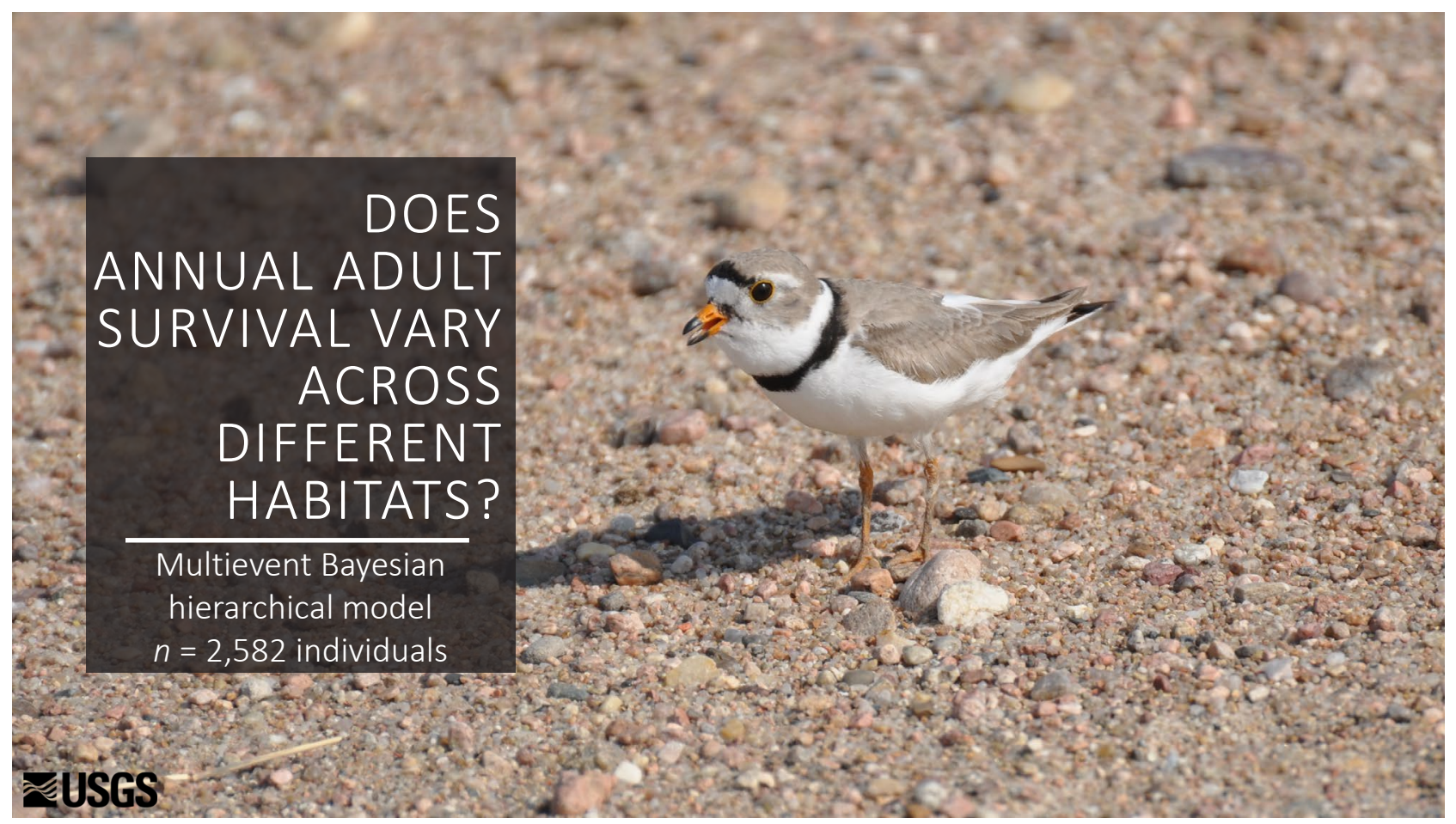

We developed a multievent model to estimate apparent survival $(S)$ and transition $(\psi)$ probabilities between breeding location states, allowing for uncertainty in an adult's state assignment (Pradel, 2005). We based parametrization of the multievent model after Pradel (2005) and a hierarchical Bayesian multievent model (Kéry and Schaub, 2012). We separately provide estimates either for just the MRS and the ALK or for the ALK, SAK, the GRR, and OAH; because model assumptions vary when state assignments change, these estimates are not comparable. All estimated annual vital rates were produced from either a state-based or state- and year-based model representing the mean over all covariates. The tests of the effect of covariates were from the global covariate model with simplified states (the MRS and the ALK). See the "Adult Survival and Breeding Dispersal Probabilities" section for detailed methodologies. [n, number] 


\section{Transient individuals}

Presumed nonbreeding or early failed breeders (NON)

Never associated with a nest during the breeding season but

\section{Seen in at least three management units during one breeding season}

\section{ఇUSGS}

Because a small portion of individuals, about 3 percent, were observed in three of the four management units during a single breeding season, we included an additional state in our location-specific models for transient individuals (NON), which we defined as individuals that are presumably nonbreeding or early failed breeders that were never associated with a nesting attempt and were seen in at least three management units during one breeding season.

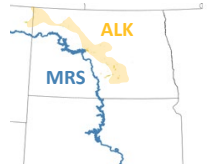

\section{State structure}
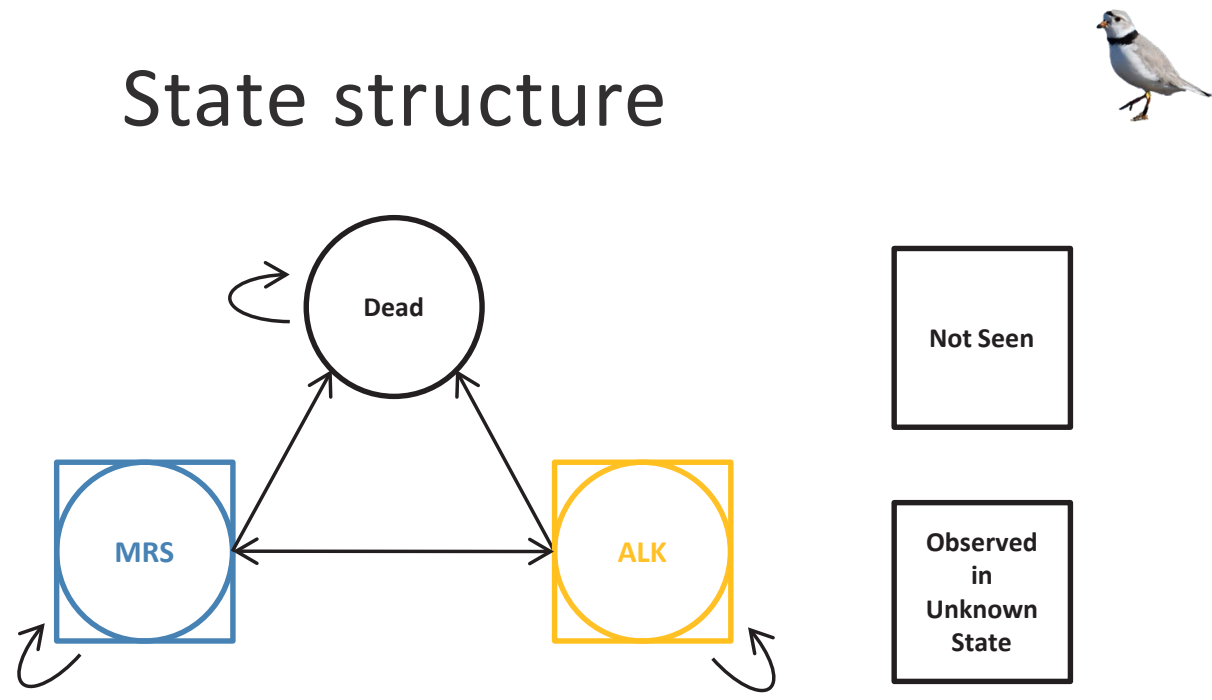

\section{$\approx$ USGS}

In our simplified state structure, we include two known breeding location states (the MRS and the ALK) and a newly dead state (circles). All possible state transitions (black arrows) were included. The observation process (squares) included observations of individuals in the known breeding states, observations of individuals in an unknown state, or individuals that were not seen. 


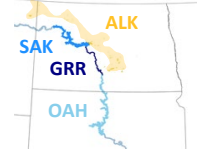

\section{State structure}

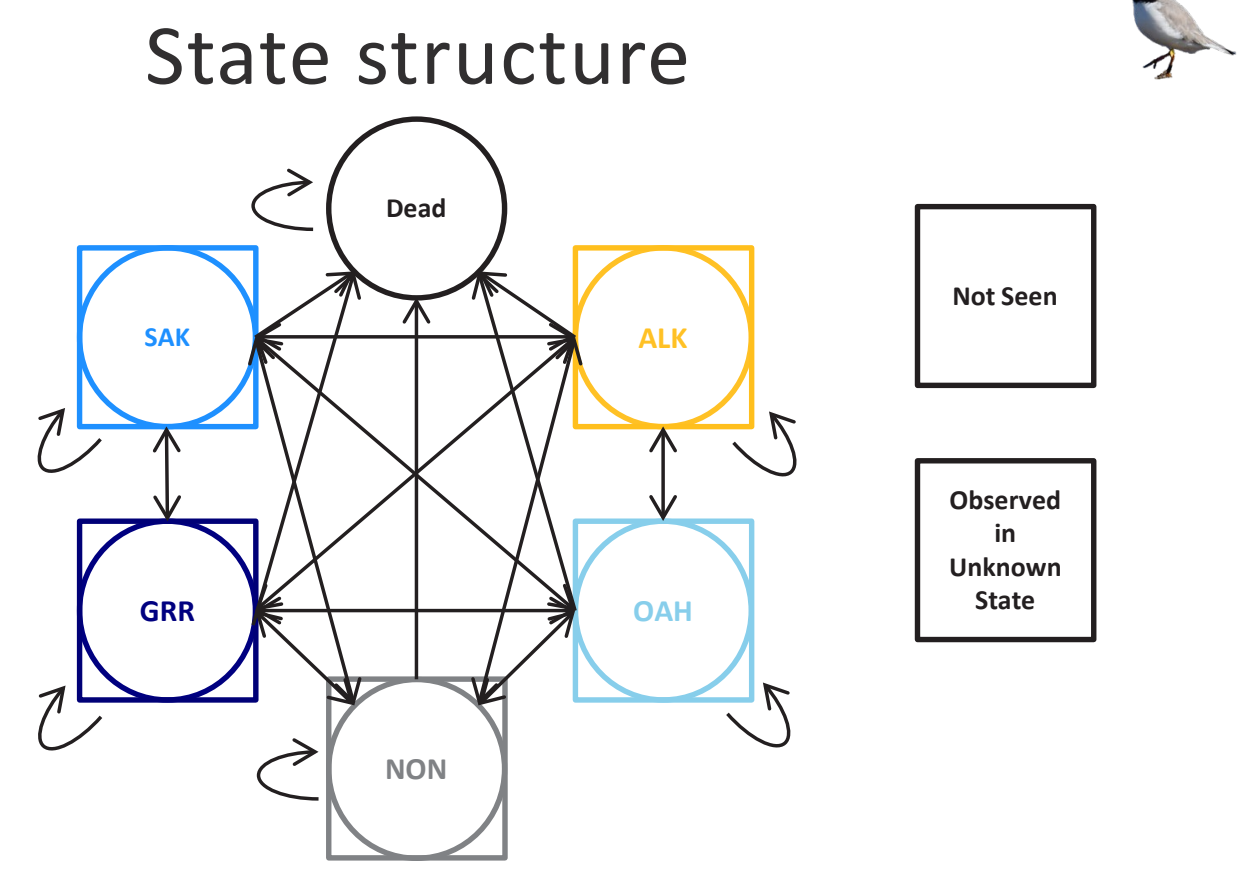

\section{‡USGS}

We defined six states (circles) among which individuals could transition (black arrows) in this model. Individuals could occur in one of four location-based breeding states (the ALK, SAK, the GRR, or OAH). In addition, a fifth state (NON) represented individuals seen in multiple locations during a single breeding season, which we assumed to be nonbreeders or failed breeders (transient). Lastly, we include a newly dead state. To account for uncertainty in state assignment, we divided the observation process (squares) into seven categories: seen in one of the four breeding locations (the ALK, SAK, the GRR, or $\mathrm{OAH}$ ), seen in the nonbreeding state (NON), seen but state unknown, and not seen. 


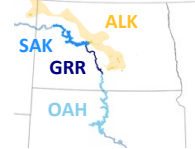

\section{State structure}

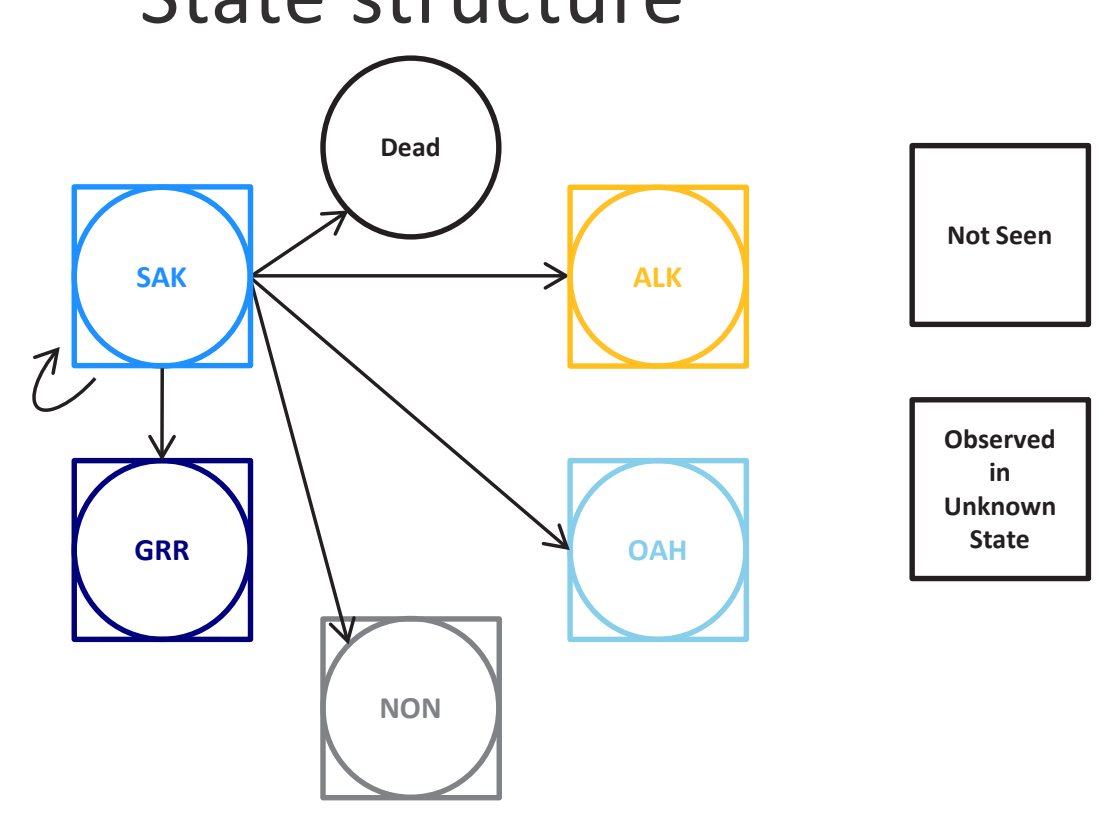

\section{‡USGS}

Here we show as an example the possible state (circles) transitions (black arrows) for an adult breeding on SAK. The individual could die, not be seen, be seen in an unknown state, be assigned to one of the four location-based states (the ALK, SAK, the GRR, or OAH), or be assigned as a transient individual. [Squares indicate the observation process.]

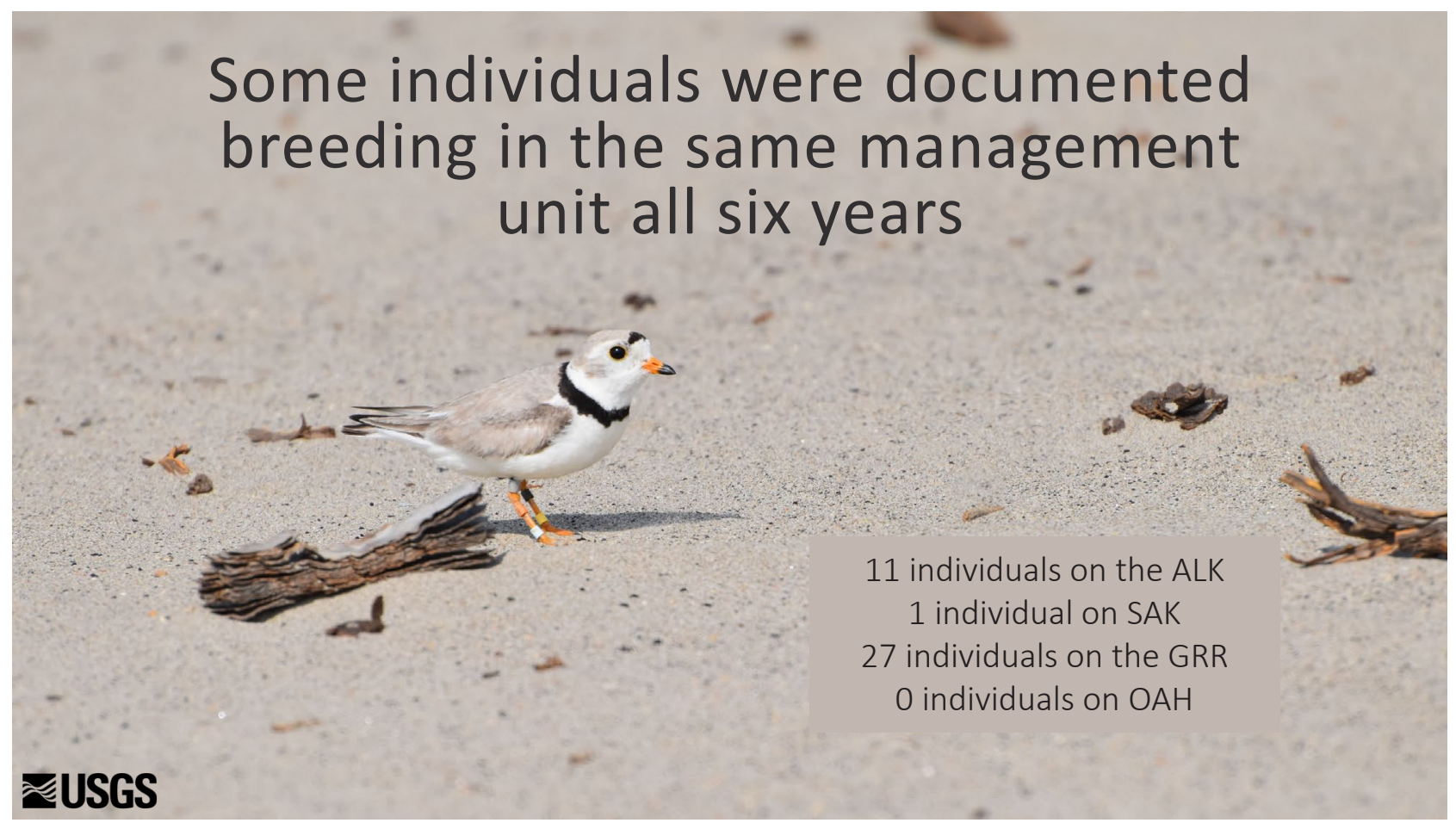

In some rare instances, we documented individuals breeding during all 6 years of the study in the same management unit. This was most common on the GRR ( $n=27$ individuals) and the ALK ( $n=11$ individuals) but never occurred on $0 \mathrm{AH}$, and only 1 individual was documented on SAK. 


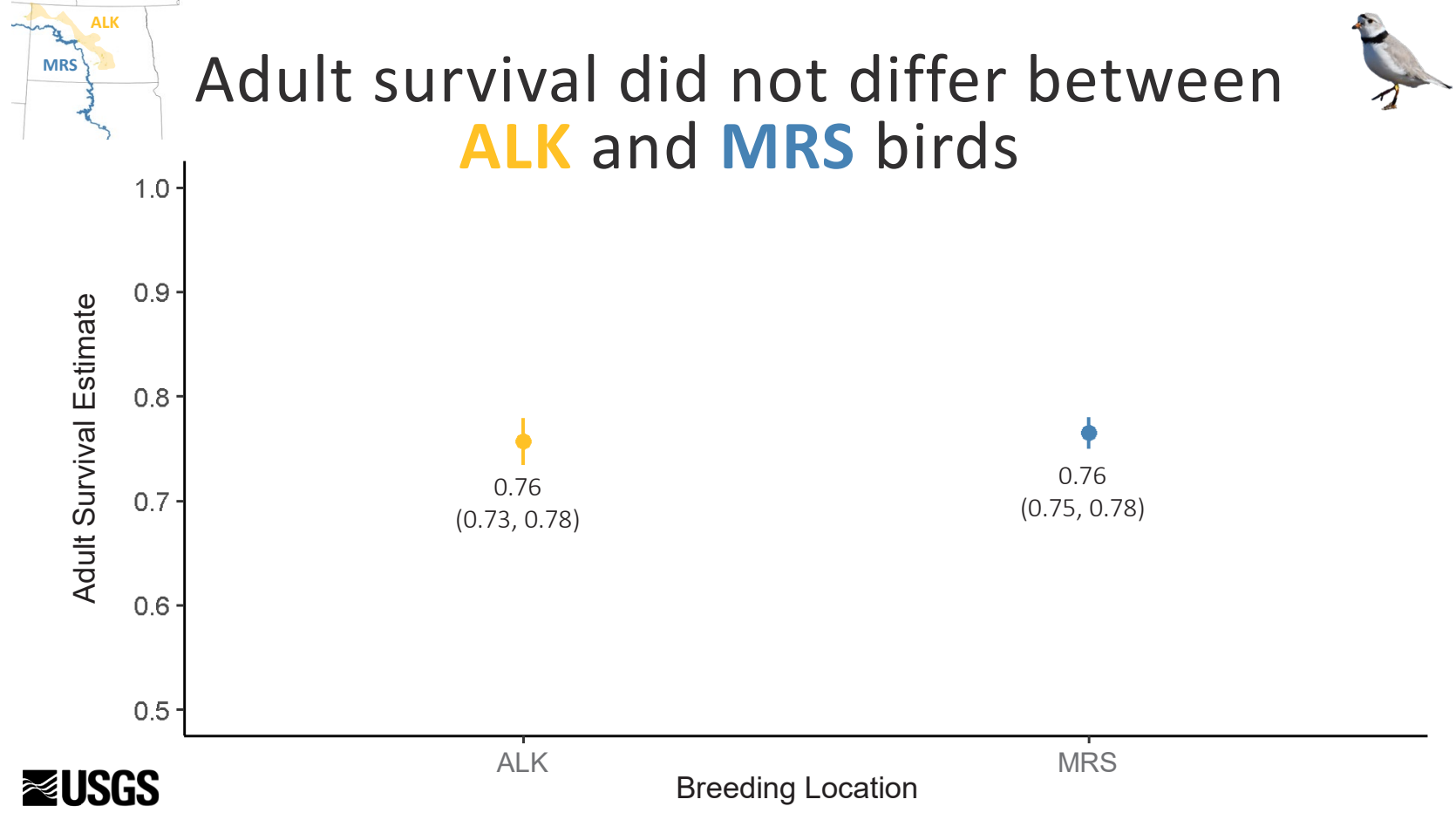

Annual adult survival did not differ between individuals breeding on the $\mathrm{ALK}(0.76, \mathrm{Cl}=0.73$ to 0.78$)$ and the $\mathrm{MRS}(0.76, \mathrm{Cl}=0.75$ to 0.78). [Filled circles indicate mean annual survival estimates. Vertical lines indicate 95-percent credible intervals (Cls).]

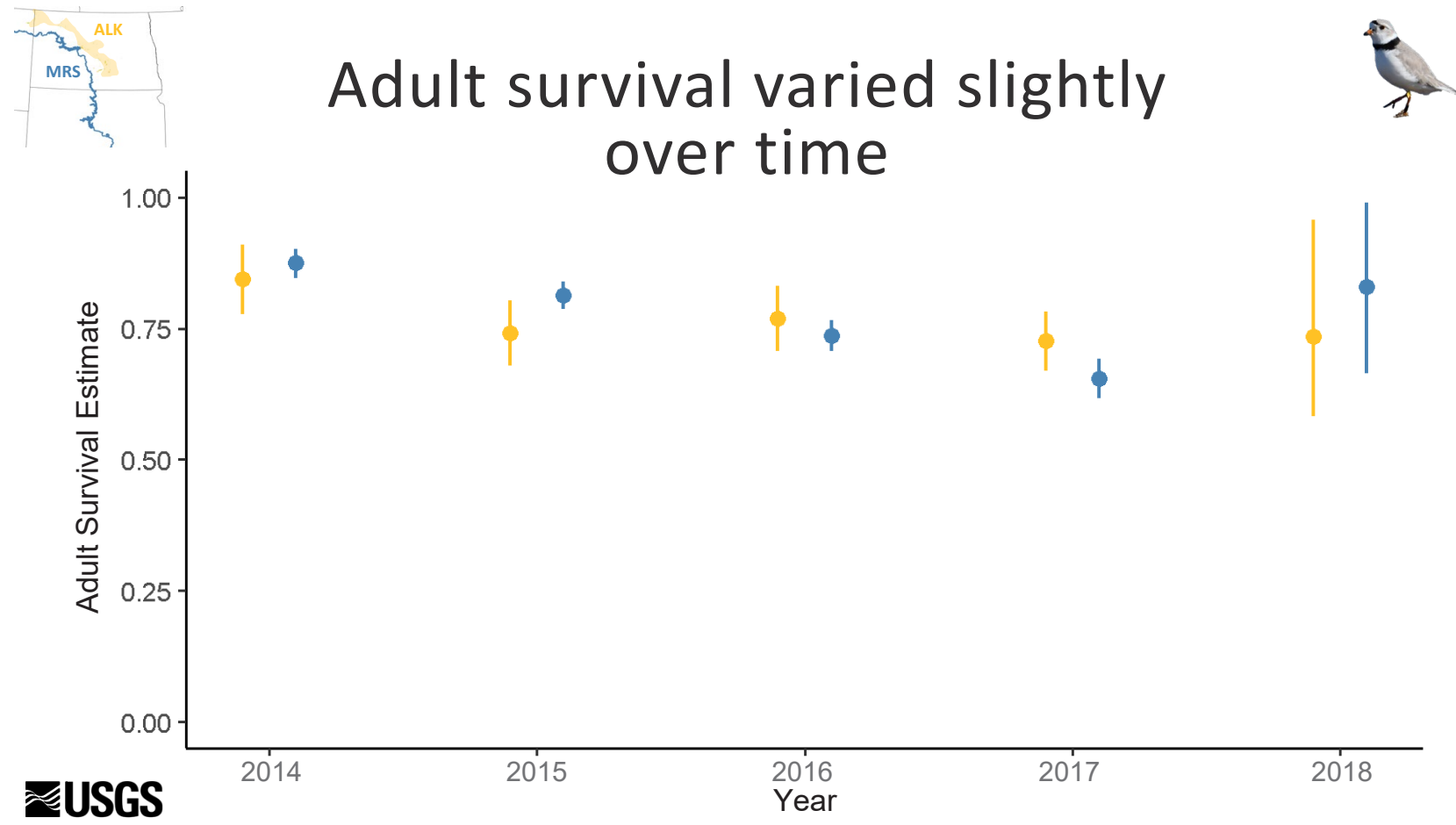

When comparing the ALK to the MRS individuals, we saw minimal differences in annual survival but a slight declining trend. [The last year in a fully time-dependent model is not estimable. Filled circles indicate mean annual survival estimates. Vertical lines indicate 95-percent credible intervals.] 


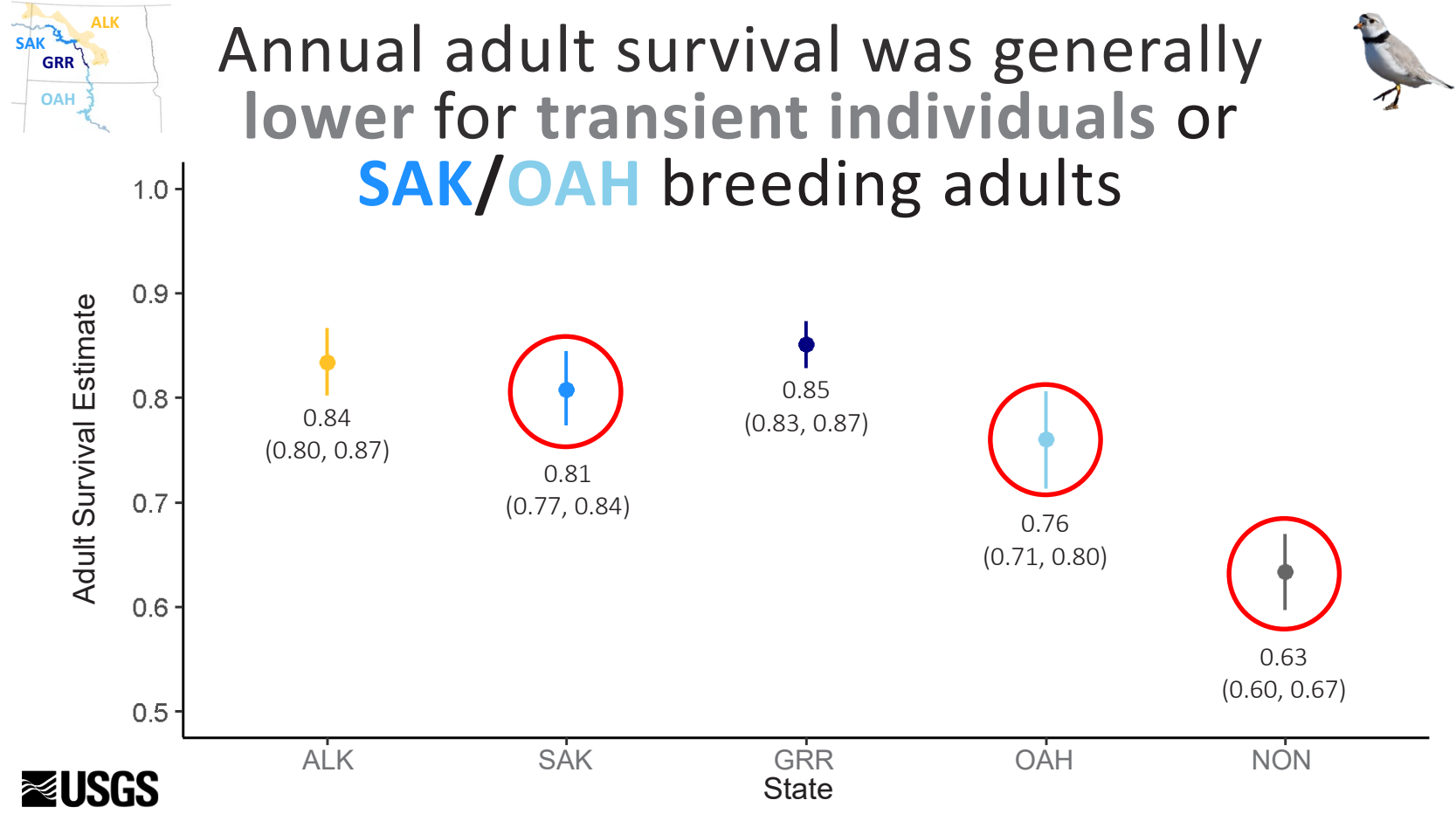

Annual adult survival was lowest for transient individuals (NON; $0.63, \mathrm{Cl}=0.60$ to 0.67 ). Individuals breeding on $\mathrm{SAK}$ and $0 \mathrm{AH}$ also had reduced annual survival compared to the ALK and the GRR breeding birds (red circles). [Filled circles indicate mean annual survival estimates. Vertical lines indicate 95-percent credible intervals (Cls).]

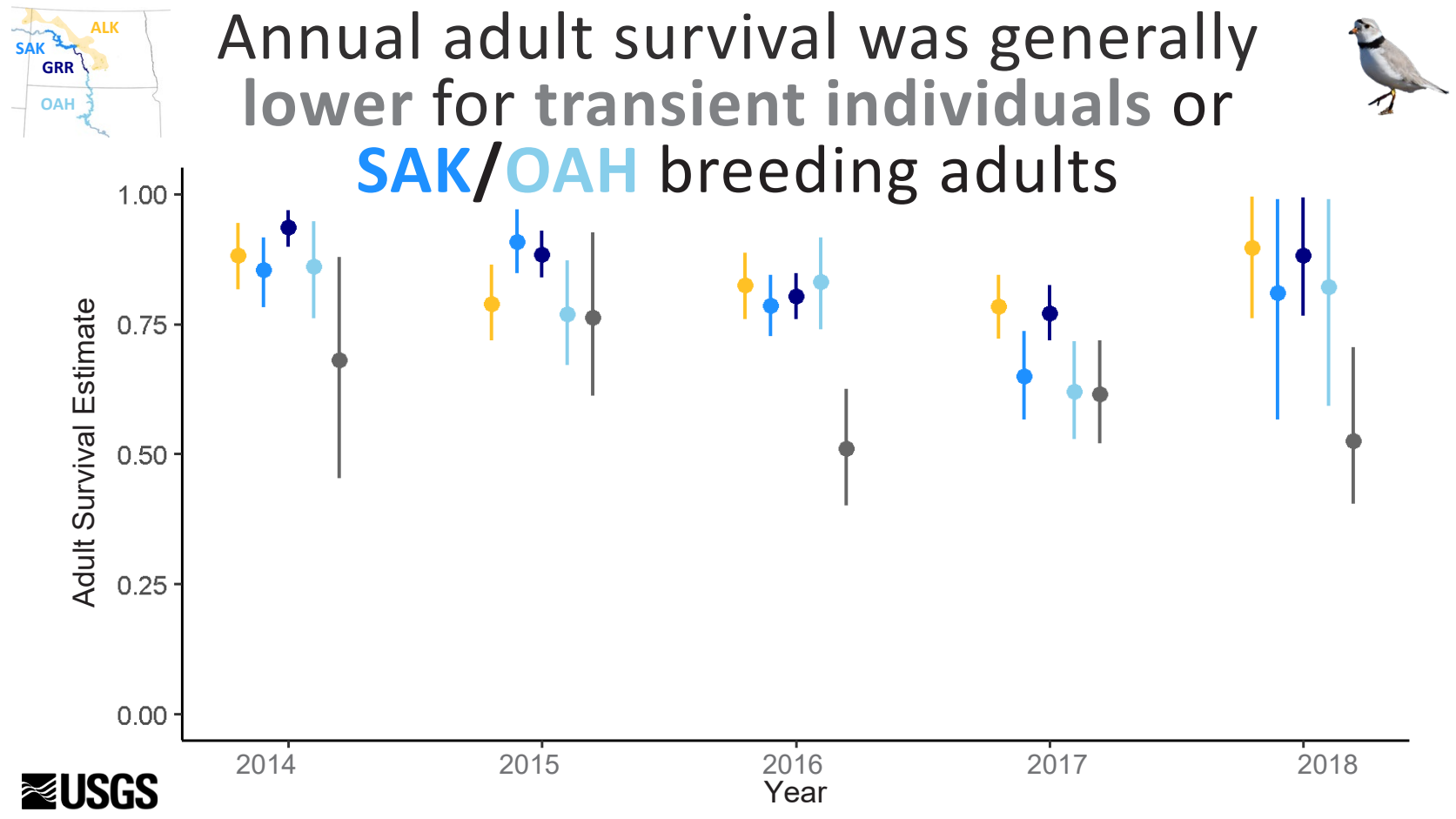

The pattern of low adult survival for transient individuals or those breeding on SAK or OAH varied over time. [The last year in a fully time-dependent model is not estimable. Filled circles indicate mean annual survival estimates. Vertical lines indicate 95-percent credible intervals.] 


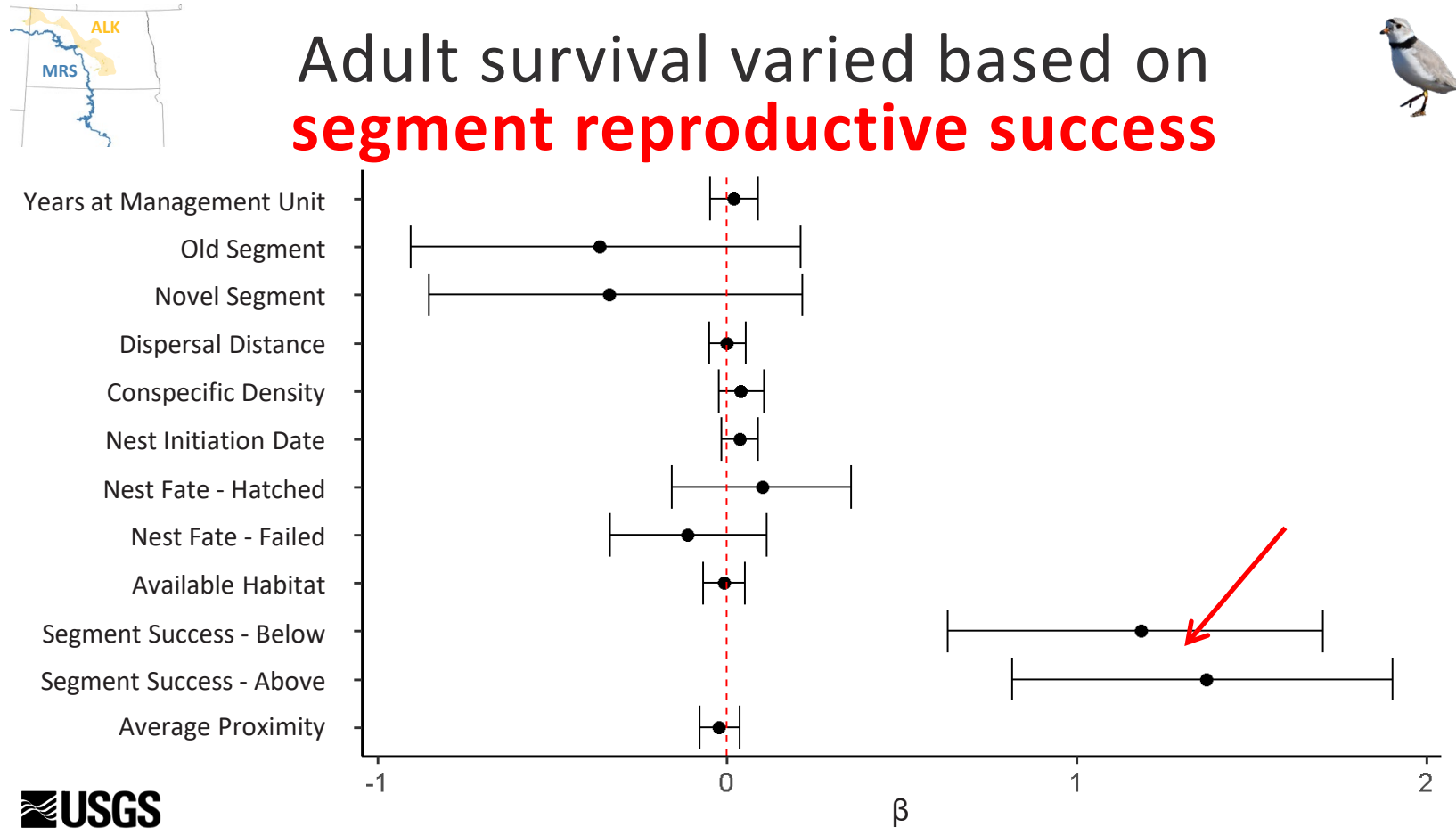

Only one of our a priori hypotheses (red arrow) explained annual adult survival (95-percent credible intervals for the $\beta$ covariate did not cross zero). [Filled circles indicate mean $\beta$ estimate. Whiskers indicate 95-percent credible intervals.]

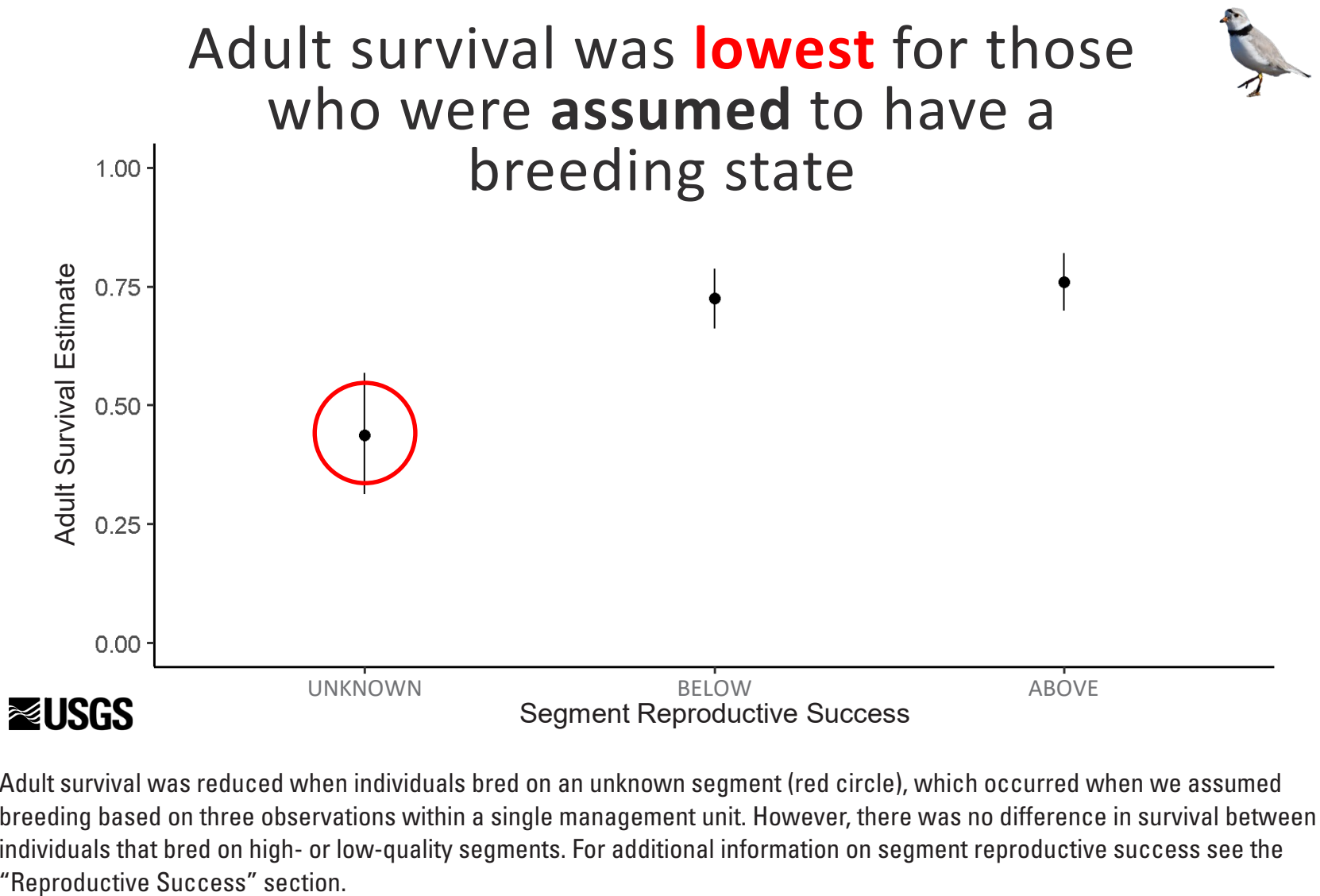




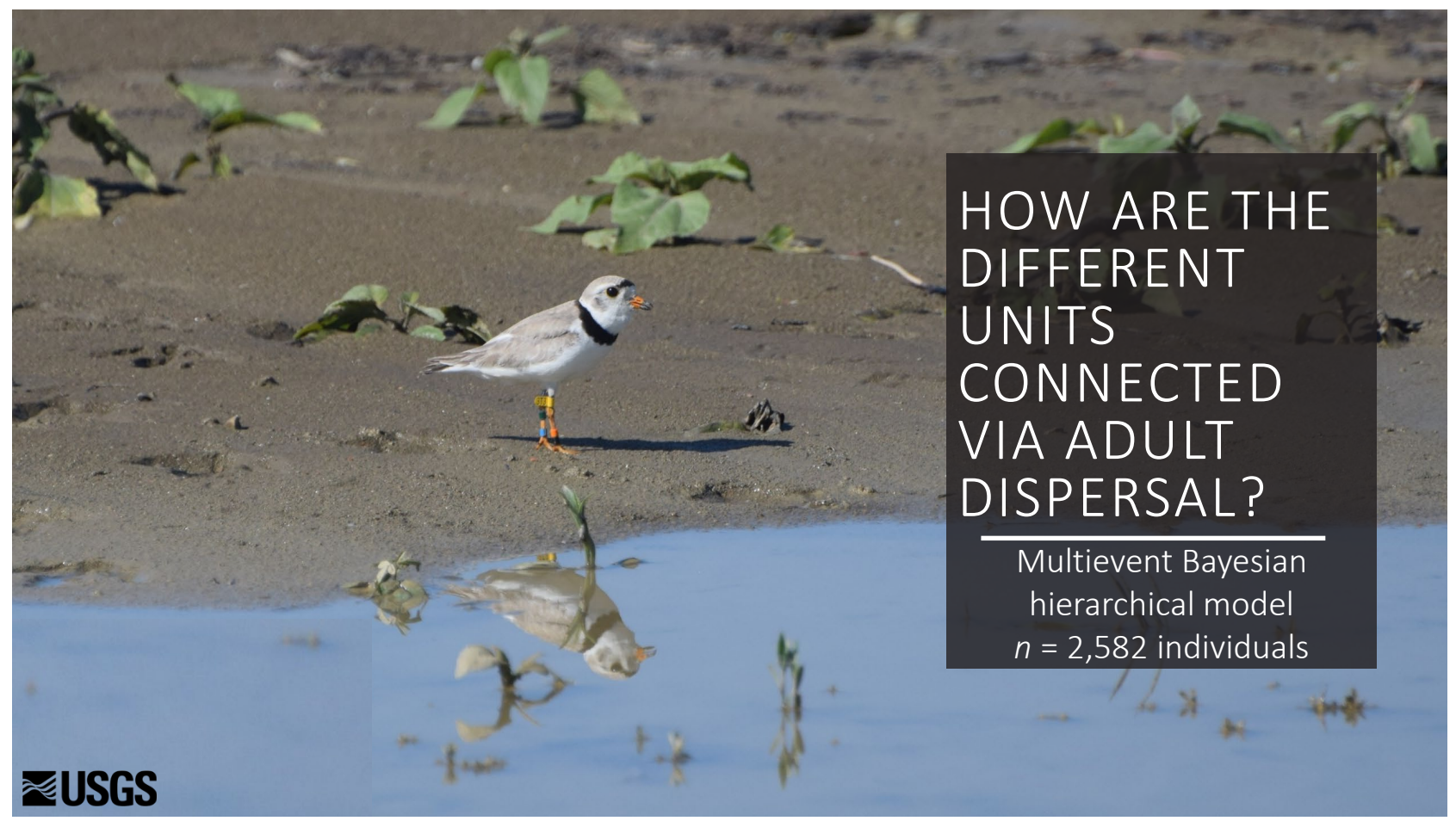

Estimates for dispersal were derived from the same models as survival described previously. See the "Adult Survival and Breeding Dispersal Probabilities" section for more detailed methodology. [ $n$, number]

\section{Some individuals dispersed often}

\section{7 individuals bred in 3 management units during the study \\ 13 percent of individuals changed management units at least once}

\section{ॠUSGS}

Although a rare behavior, some individuals seem to disperse between management units often. During the 6-year study, we documented 27 individuals breeding in at least 3 management units. In total, 13 percent of individuals changed management units at least one time during the study. 


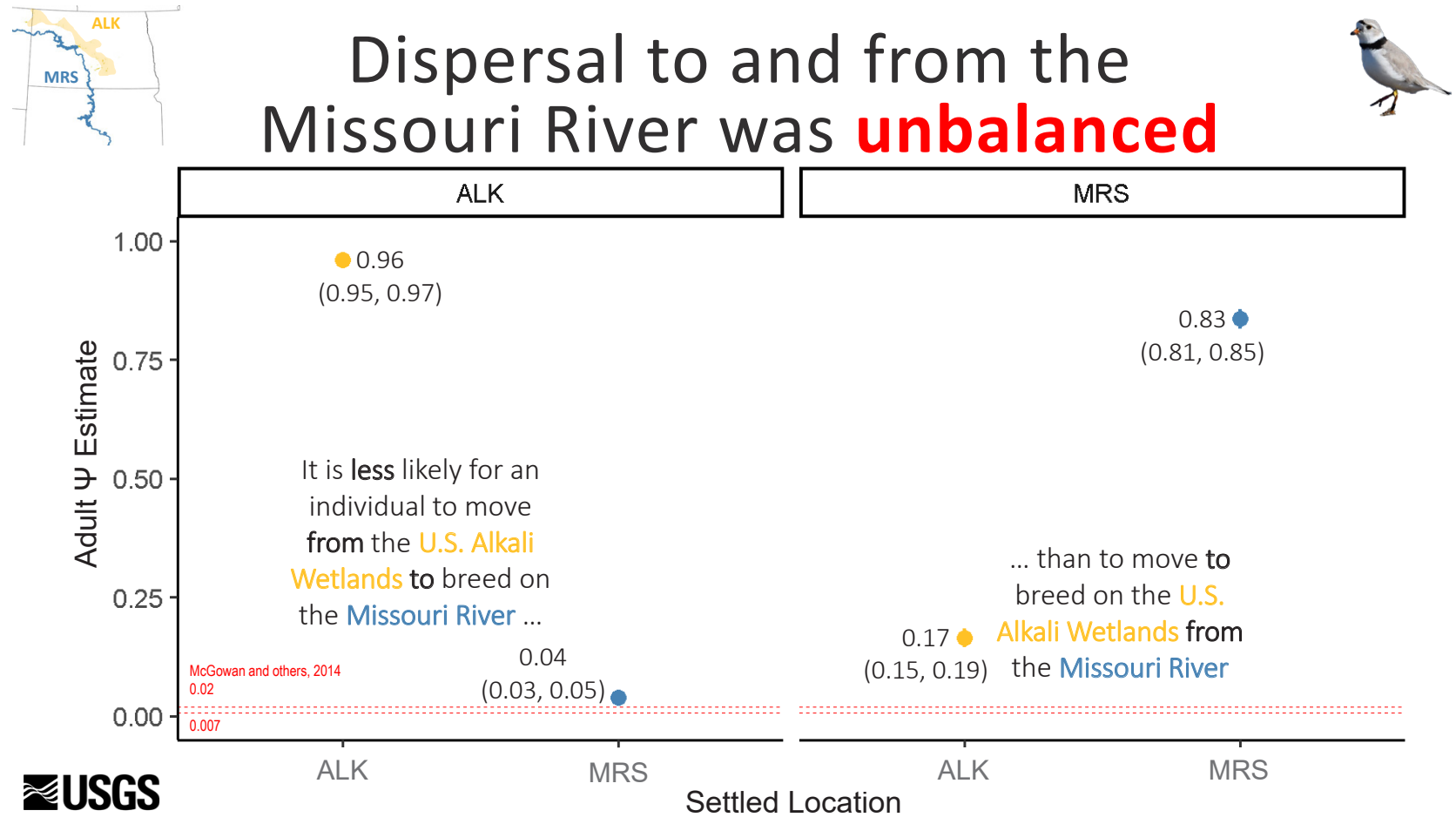

Adult breeding dispersal between the MRS and the ALK is unbalanced and much higher than previously assumed. Individuals were less likely to disperse from the $A L K$ to breed on the $\mathrm{MRS}(0.04, \mathrm{Cl}=0.03$ to 0.05$)$ than those breeding on the MRS were to disperse to breed on the $\operatorname{ALK}(0.17, \mathrm{Cl}=0.15$ to 0.19$)$. McGowan and others (2014) assumed balanced dispersal between these two breeding groups at 0.007 (with a total movement rate away from one group at 0.02; red dashed lines). Breeding fidelity was higher to the $\operatorname{ALK}(0.96, \mathrm{Cl}=0.95$ to 0.97$)$ than the $\mathrm{MRS}(0.83, \mathrm{Cl}=0.81$ to 0.85$)$. [Filled circles indicate mean $\Psi$ estimates. Vertical lines indicate 95 -percent credible intervals (Cls).] 


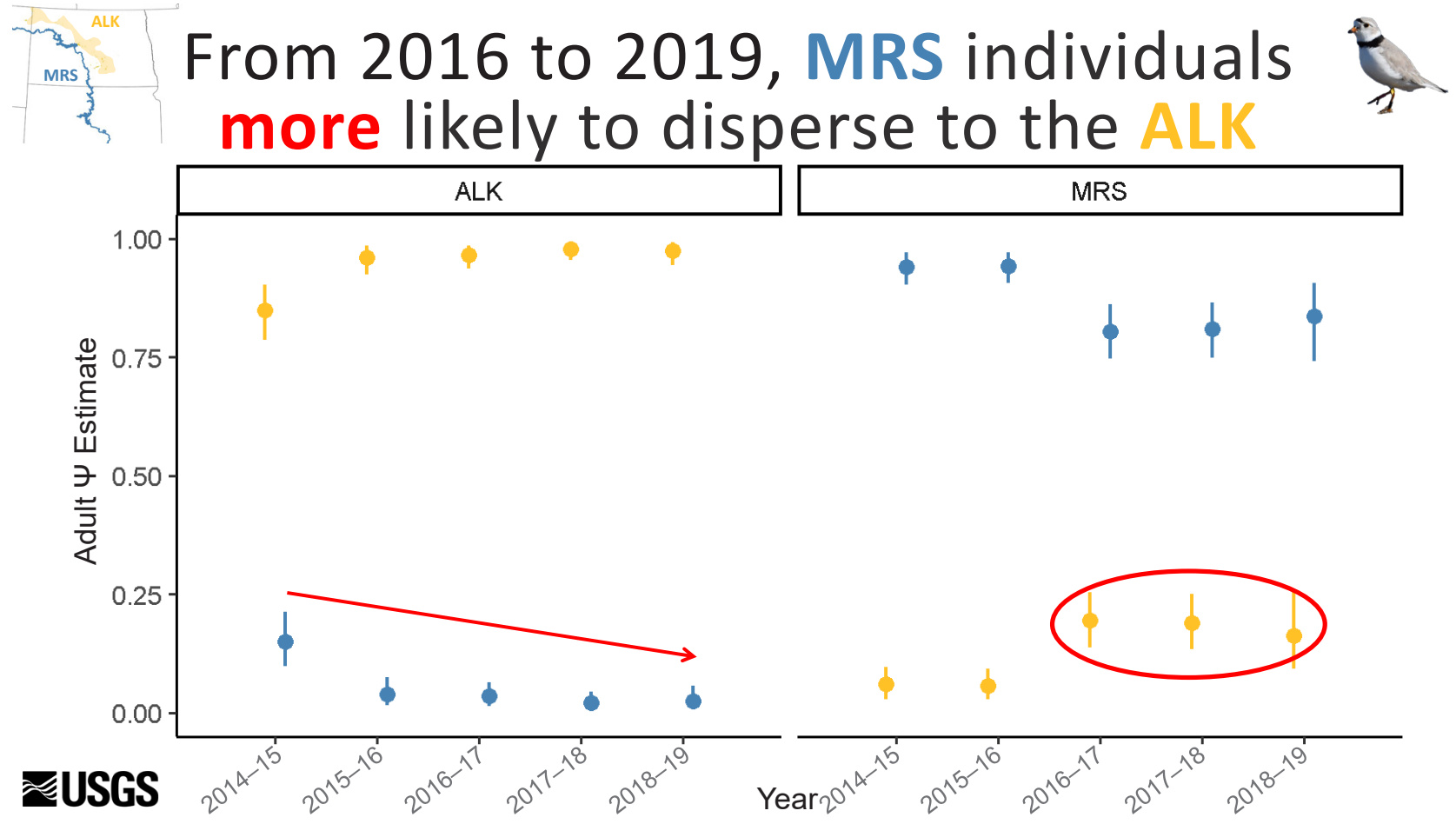

Adult dispersal and fidelity showed an interesting pattern between the MRS and the ALK over the years of this study. Individuals became less likely to disperse to the MRS from the ALK (red arrow; mean annual estimates from the ALK to the MRS: 2014-15: 0.15, 2015-16: 0.04, 2016-17: 0.04, 2017-18: 0.02, 2018-19: 0.02) and more likely to disperse to the ALK from the MRS (red circle; mean annual estimates from the MRS to the ALK: 2014-15: 0.06, 2015-16: 0.06, 2016-17: 0.20, 2017-18: 0.19, 2018-19: 0.16). [The last year in a fully time-dependent model is not estimable. Filled circles indicate mean $\Psi$ estimates. Vertical lines indicate 95-percent credible intervals.] 


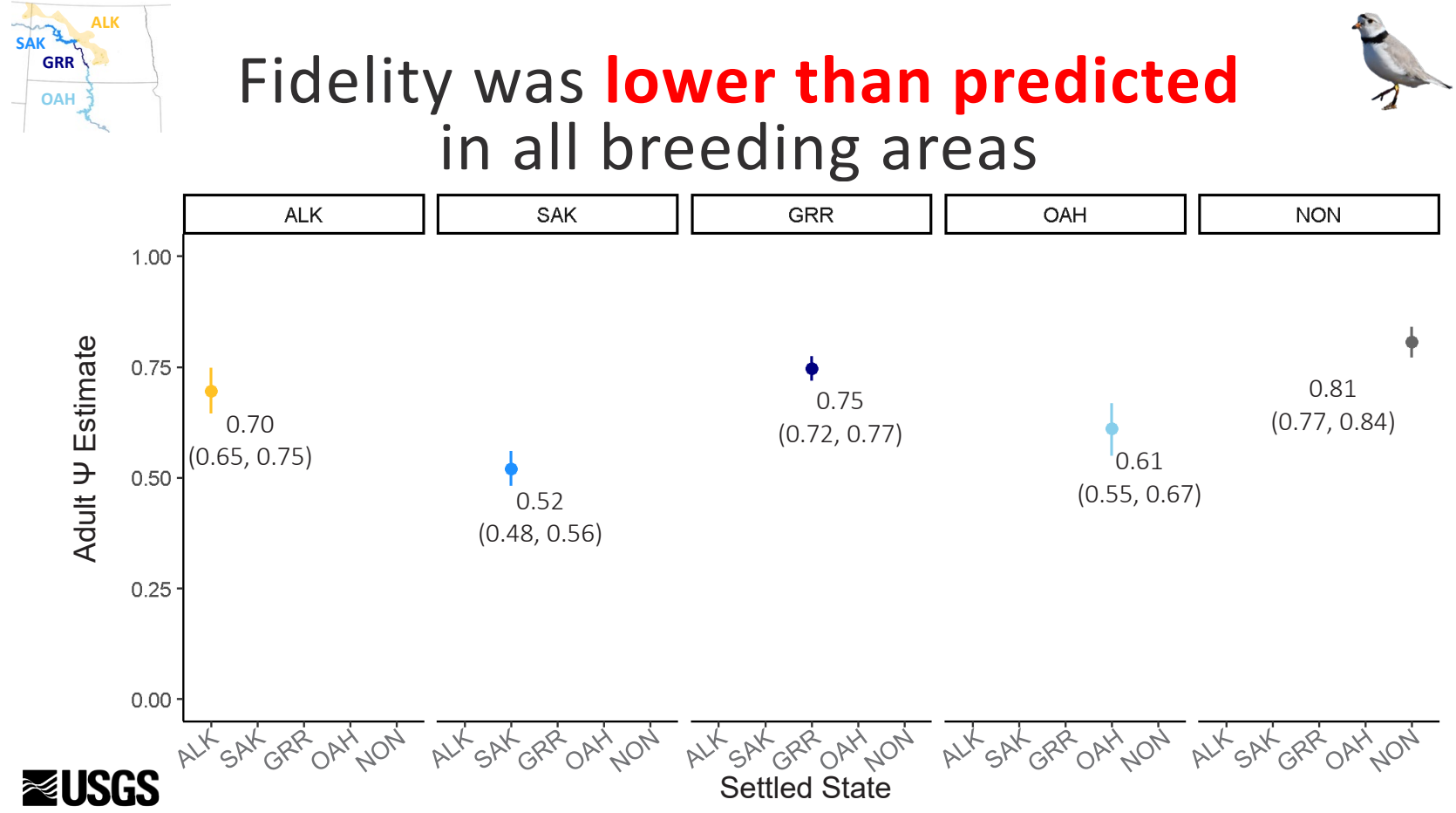

Adult breeding fidelity was much lower than assumed previously, though remained higher than natal fidelity. Individuals were least likely to remain to breed on $\operatorname{SAK}(0.52, \mathrm{Cl}=0.48$ to 0.56$)$ or $\mathrm{OAH}(0.61, \mathrm{Cl}=0.55$ to 0.67$)$. [Filled circles indicate mean $\Psi$ estimates. Vertical lines indicate 95-percent credible intervals (Cls).]

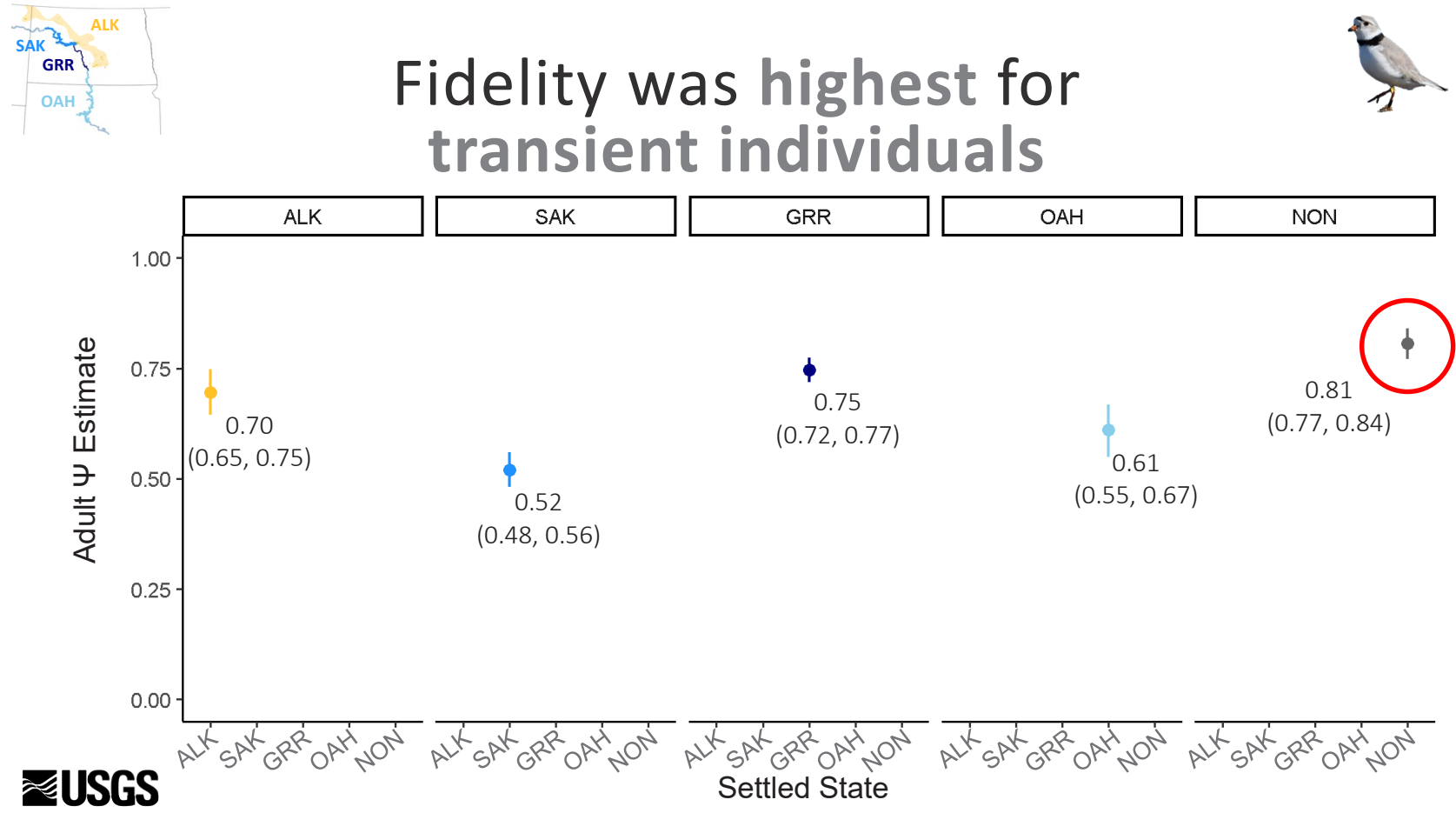

Interestingly, fidelity to the transient state $(0.81, \mathrm{Cl}=0.77$ to 0.84 ; red circle) was even higher than fidelity to any of the breeding locations. [Filled circles indicate mean $\Psi$ estimates. Vertical lines indicate 95-percent credible intervals (Cls).] 


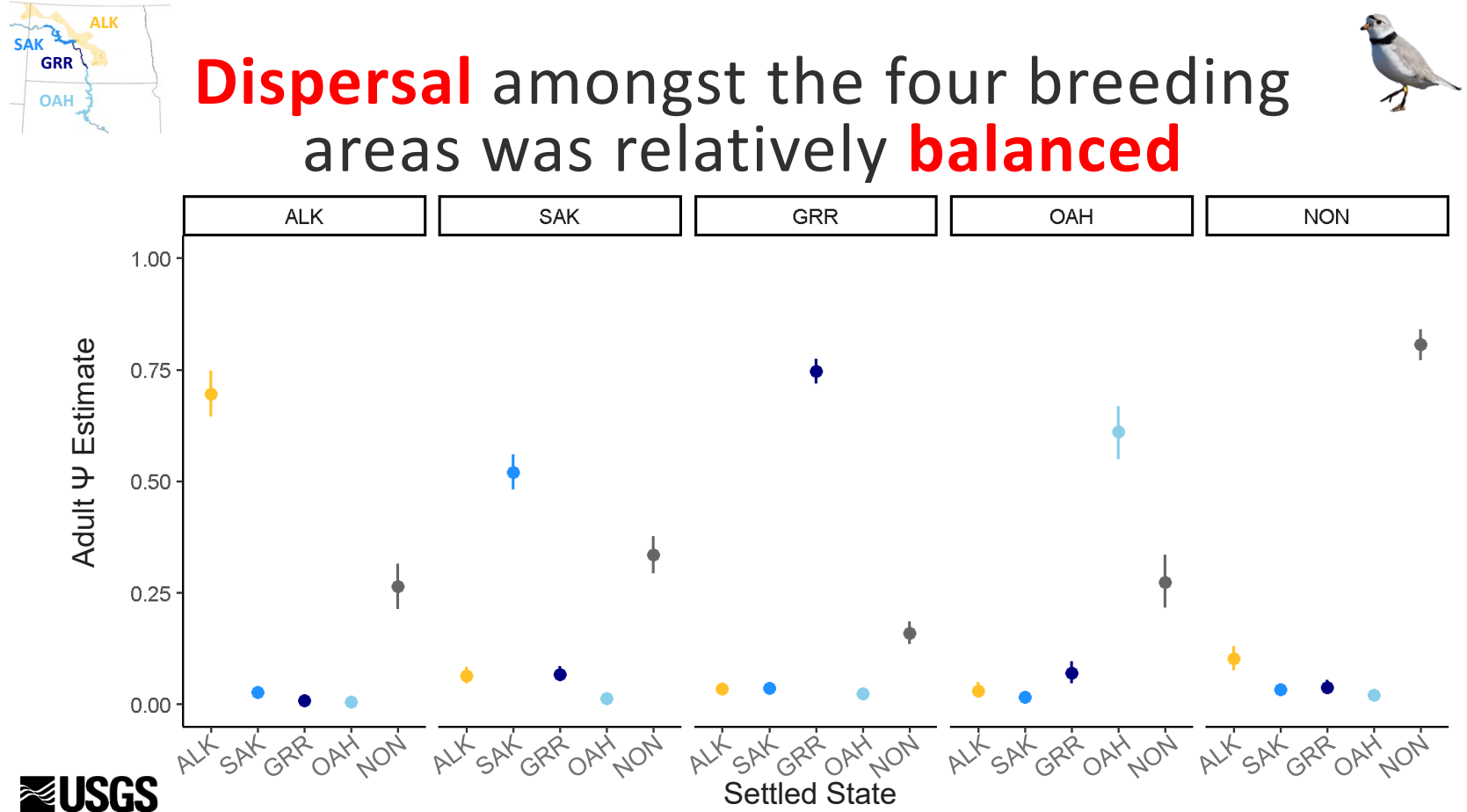

Dispersal amongst the four management units was higher than predicted but relatively balanced (mean estimate range: 0.006 [the ALK to $\mathrm{OAH}$ ] to 0.07 [OAH to the GRR]). Transient individuals were most likely to transition to breed on the ALK (0.10, $\mathrm{Cl}=0.08$ to 0.13$)$ and least likely to transition to breed on $\mathrm{OAH}(0.02, \mathrm{Cl}=0.01$ to 0.03$)$. [Filled circles indicate mean $\Psi$ estimates. Vertical lines indicate 95-percent credible intervals (Cls).]
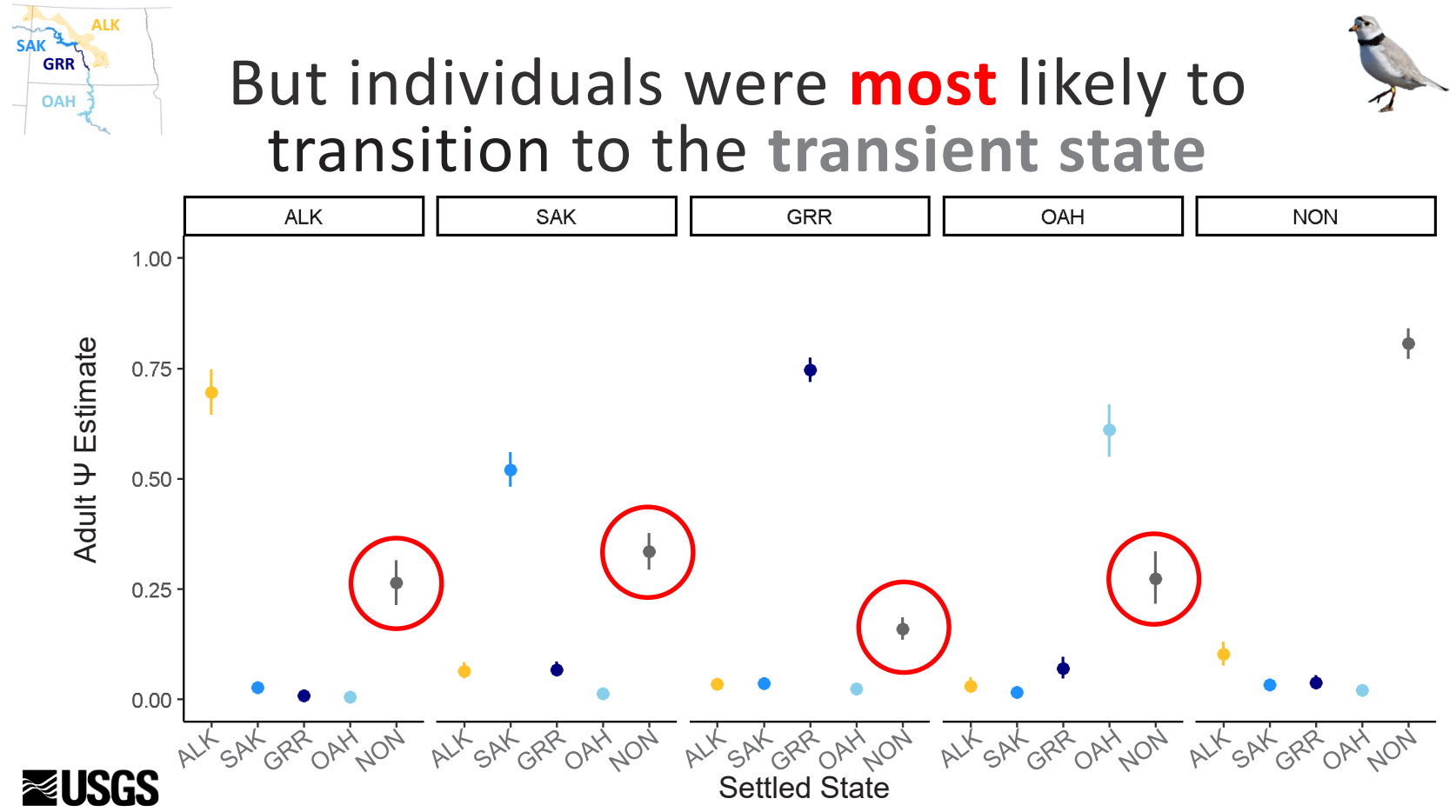

However, the transition probabilities (not including fidelity) were highest to the nonbreeding/transient state (mean estimate range: 0.16 [the GRR to NON] to 0.34 [SAK to NON]; red circles). This suggests that individuals are more likely to forgo breeding rather than to disperse and breed in another location. [Filled circles indicate mean $\Psi$ estimates. Vertical lines indicate 95-percent credible intervals.] 


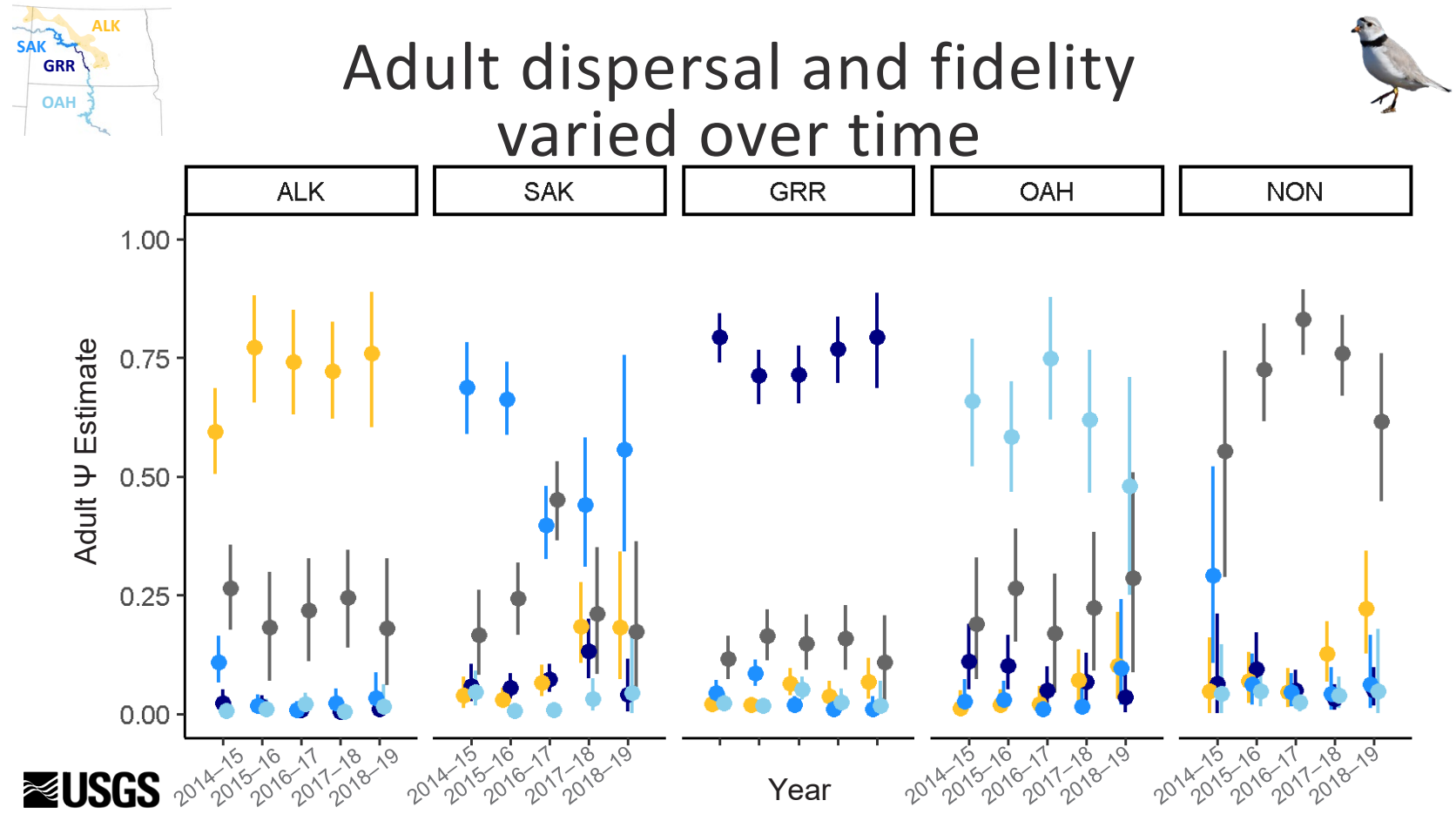

Over the course of the study, various patterns in adult dispersal occurred. See the following 11 slides. [The last year in a fully time-dependent model is not estimable. Filled circles indicate mean $\Psi$ estimates. Vertical lines indicate 95 -percent credible intervals.]
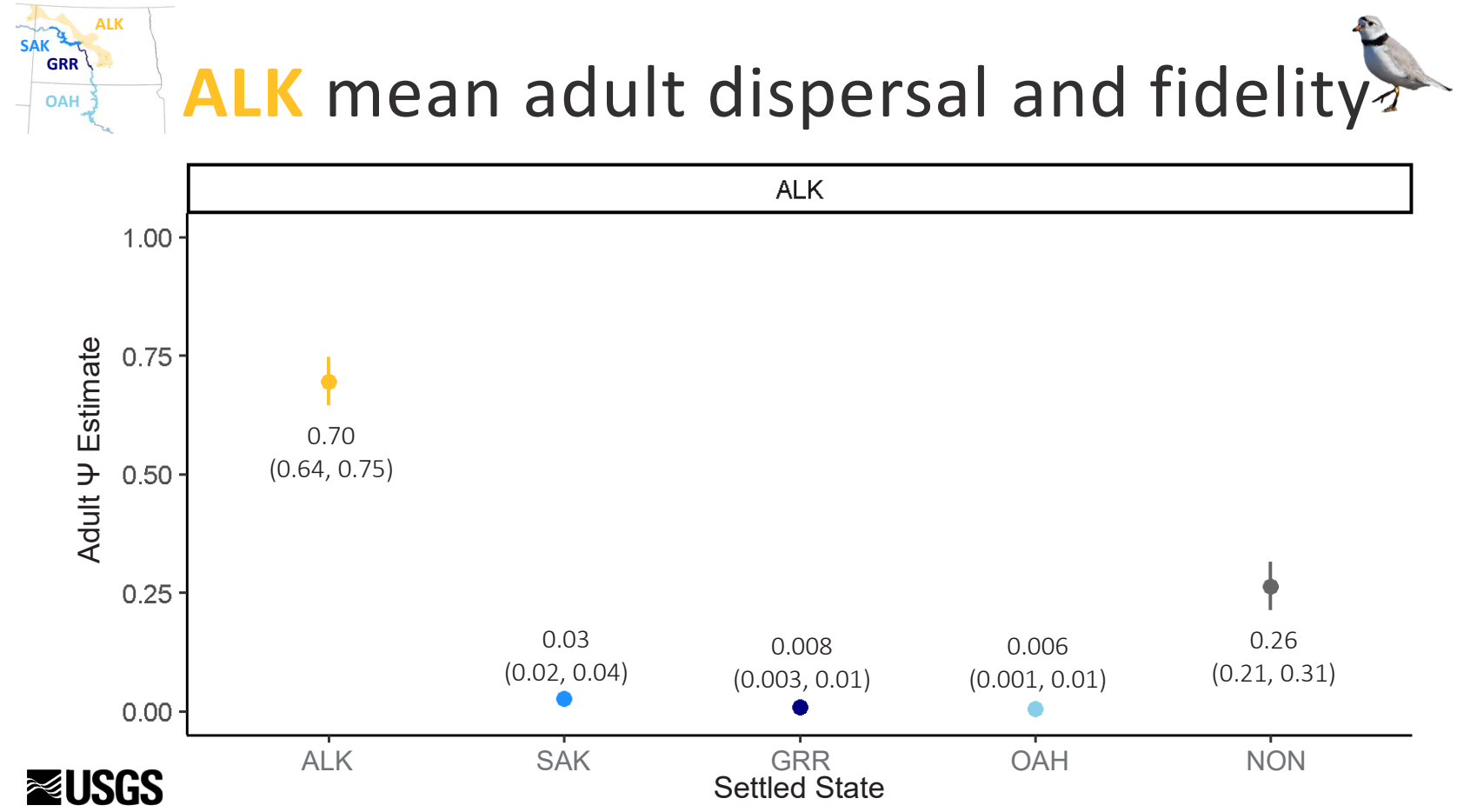

Adults breeding on the ALK were most likely to return to breed on the ALK $(0.70, \mathrm{Cl}=0.64$ to 0.75$)$. Transitioning to breed on $\mathrm{SAK}$ $(0.03, \mathrm{Cl}=0.02$ to 0.04$)$ was slightly more likely than the $\mathrm{GRR}(0.008, \mathrm{Cl}=0.003$ to 0.01$)$ or $0 \mathrm{AH}(0.006, \mathrm{Cl}=0.001$ to 0.01$)$, which were very unlikely. Most individuals that did not return to breed on the ALK transitioned to the transient state $(\mathrm{NON} ; 0.26, \mathrm{Cl}=0.21$ to 0.31). [Filled circles indicate mean $\Psi$ estimates. Vertical lines indicate 95-percent credible intervals (Cls).] 


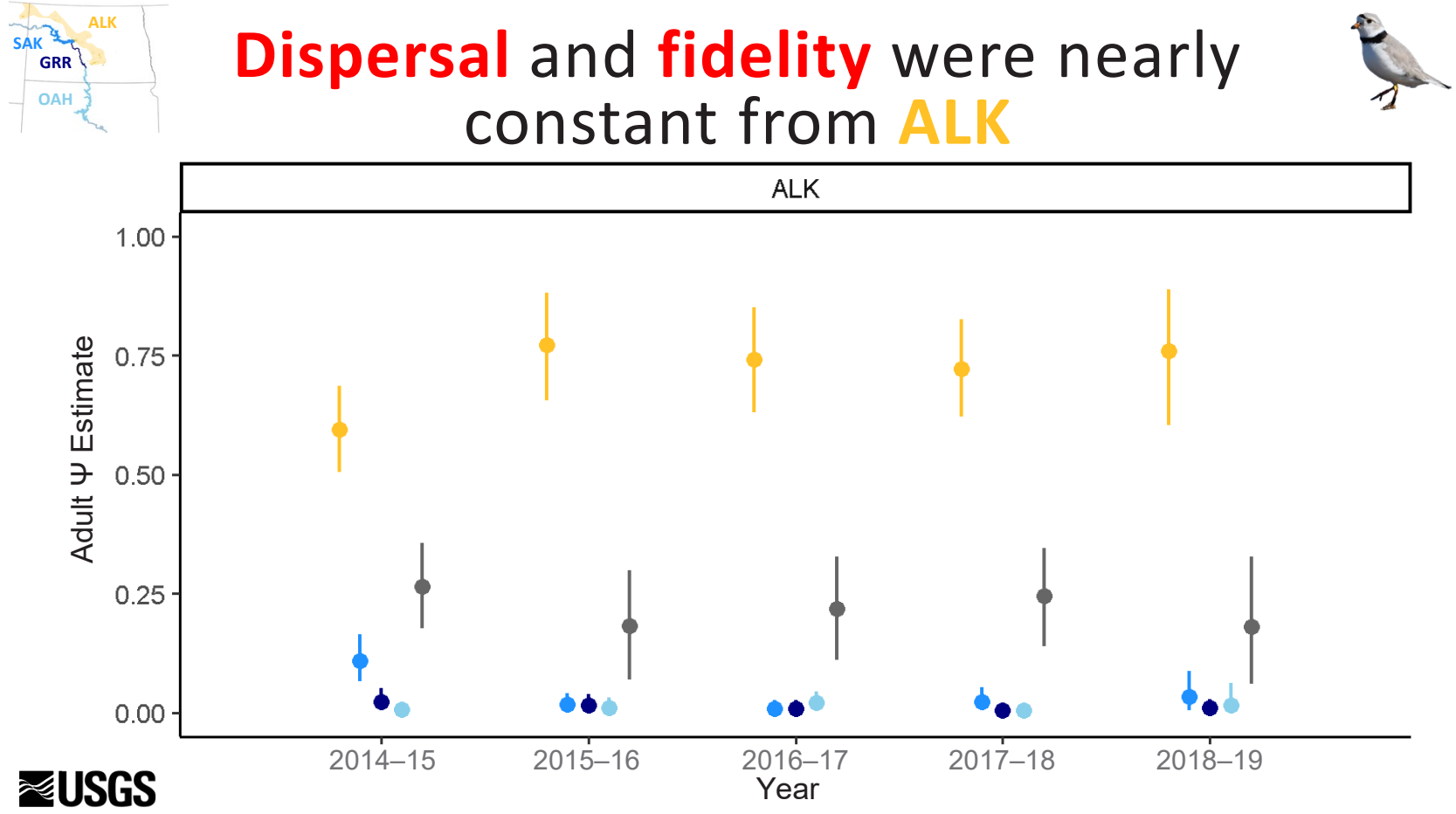

Adult dispersal and fidelity for individuals breeding on the ALK were nearly constant over the years. Individuals were most likely to stay to breed on the ALK, next likely to transition to the transient state, and lastly were slightly more likely to breed on SAK than the GRR or OAH. [The last year in a fully time-dependent model is not estimable. Filled circles indicate mean $\Psi$ estimates. Vertical lines indicate 95-percent credible intervals.]
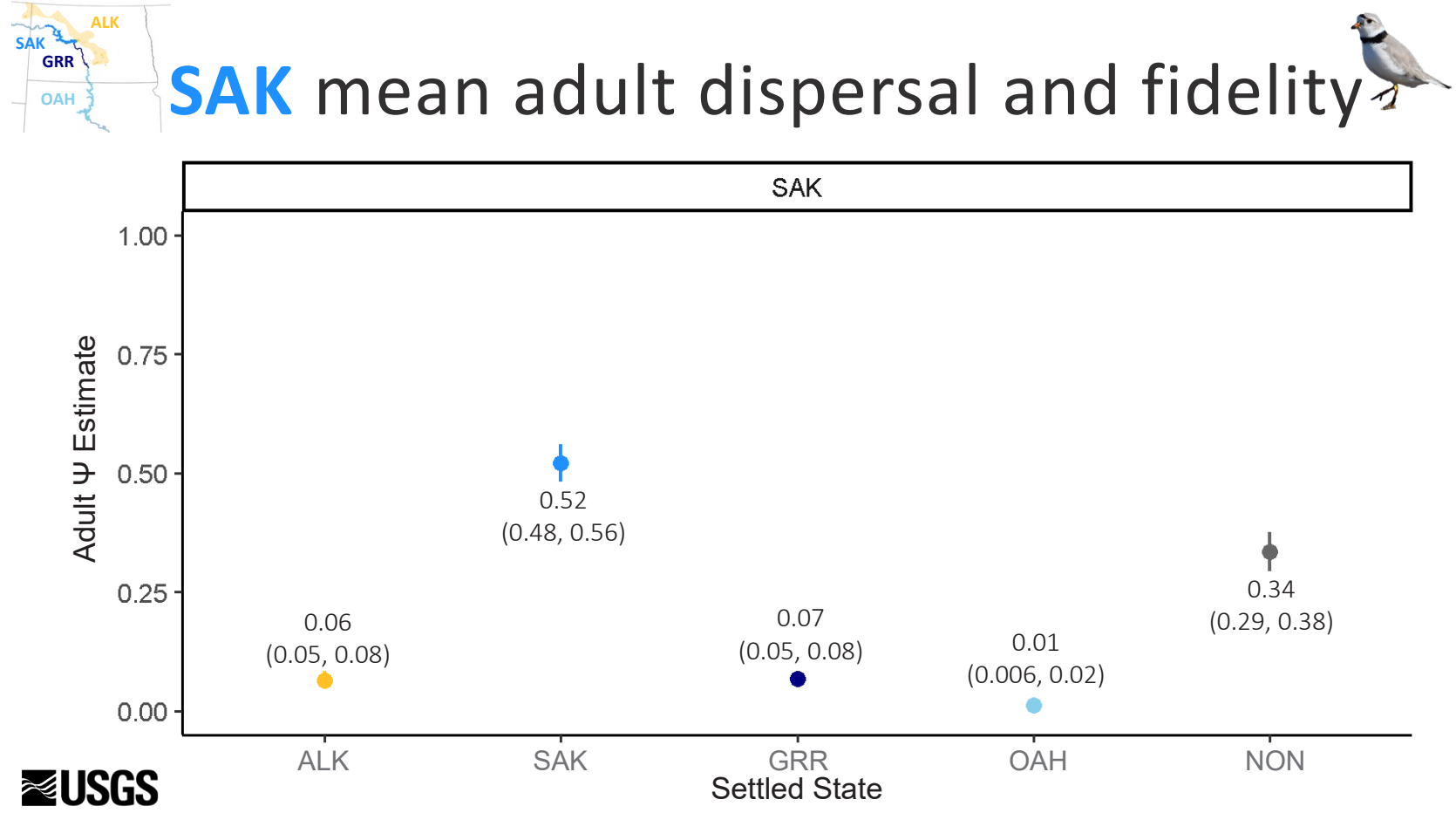

Adults breeding on SAK were most likely to return to breed on SAK $(0.52, \mathrm{Cl}=0.48$ to 0.56$])$. Transitioning to breed on the ALK $(0.06, \mathrm{Cl}=0.05$ to 0.08$)$ or the $\mathrm{GRR}(0.07, \mathrm{Cl}=0.05$ to 0.08$)$ was more likely than $\mathrm{OAH}(0.01, \mathrm{Cl}=0.006$ to 0.02$)$. Most individuals that did not return to breed on SAK transitioned to the transient state (NON; $0.34, \mathrm{Cl}=0.29$ to 0.38 ). [Filled circles indicate mean $\Psi$ estimates. Vertical lines indicate 95-percent credible intervals (Cls).] 


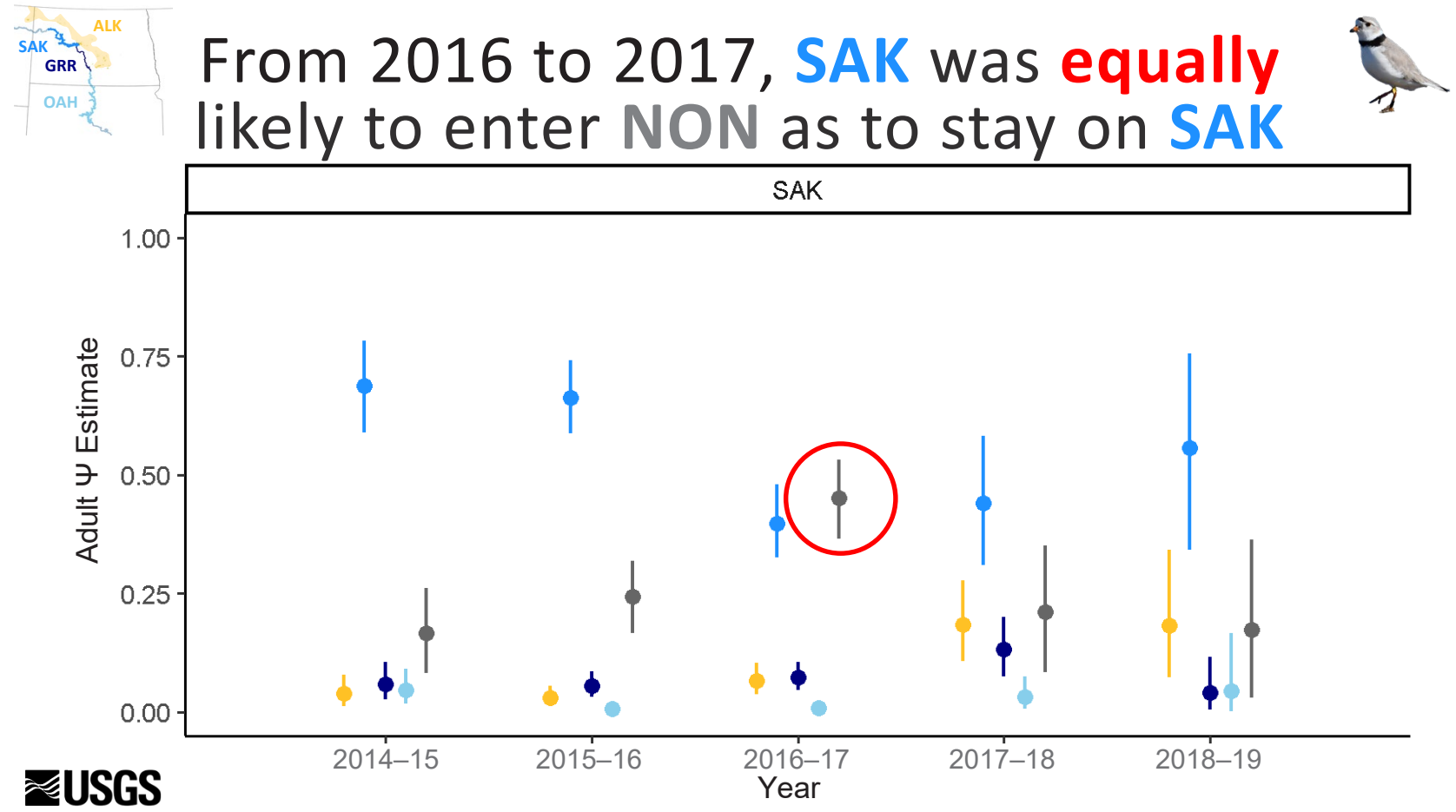

Adult dispersal and fidelity for individuals breeding on SAK varied over the years. Individuals were most likely to stay to breed on SAK, next likely to transition to the transient state, and lastly were slightly more likely to breed on the ALK or the GRR than OAH. Between 2016 to 2017, individuals were as likely to enter the transient state (red circle) as they were to remain to breed on SAK. [The last year in a fully time-dependent model is not estimable. Filled circles indicate mean $\Psi$ estimates. Vertical lines indicate 95-percent credible intervals.] 


\section{GRR mean adult dispersal and fidelitys}

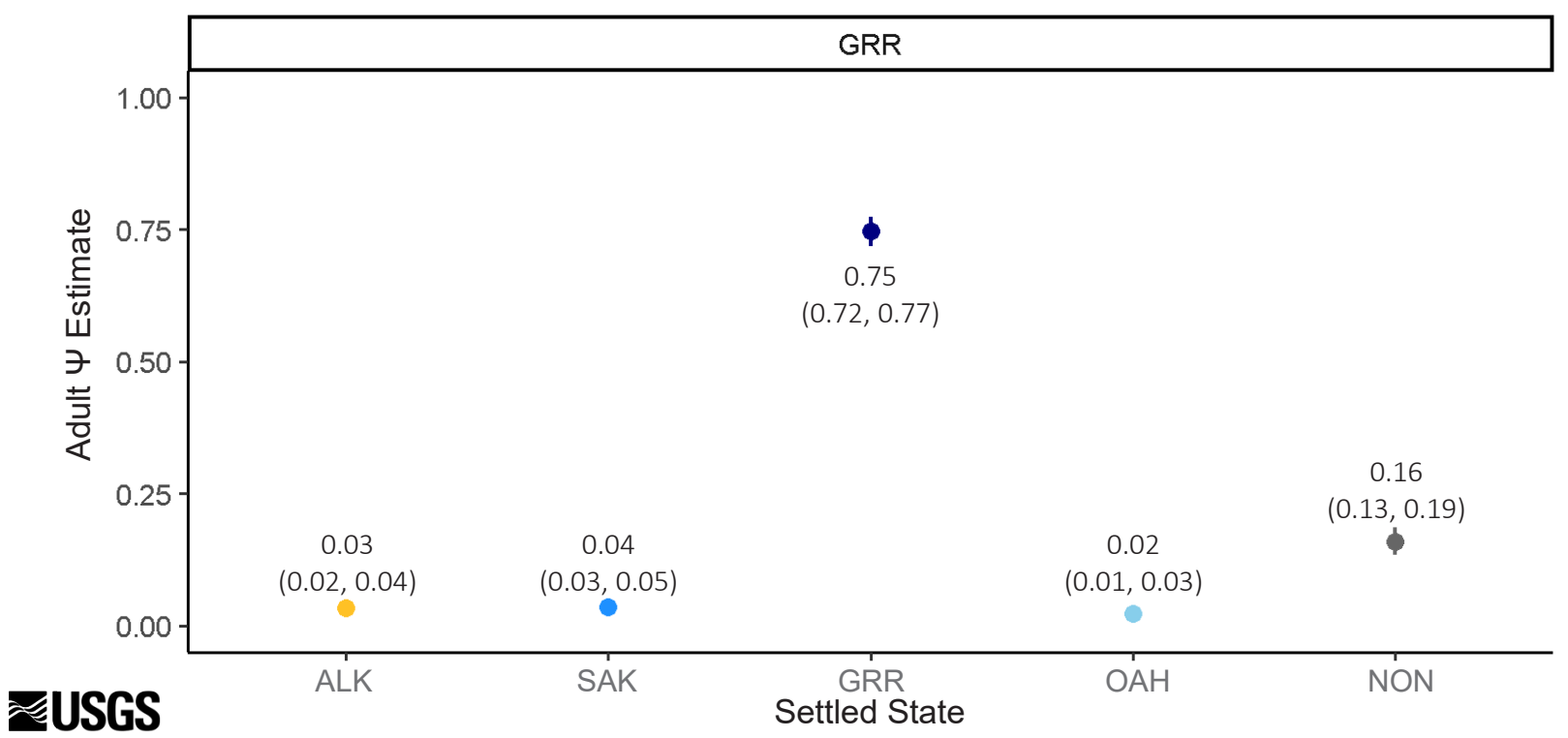

Adults breeding on the GRR were most likely to return to breed on the $\operatorname{GRR}(0.75, \mathrm{Cl}=0.72$ to 0.77$])$. Transitioning to breed on the $\operatorname{ALK}(0.03, \mathrm{Cl}=0.02$ to 0.04$])$, $\mathrm{SAK}(0.04, \mathrm{Cl}=0.03$ to 0.05$])$, or $\mathrm{OAH}(0.02, \mathrm{Cl}=0.01$ to 0.03$])$ was equally likely. Most individuals that did not return to breed on the GRR transitioned to the transient state (NON; $0.16, \mathrm{Cl}=0.13$ to 0.19 ]). [Filled circles indicate mean $\Psi$ estimates. Vertical lines indicate 95-percent credible intervals (Cls).] 


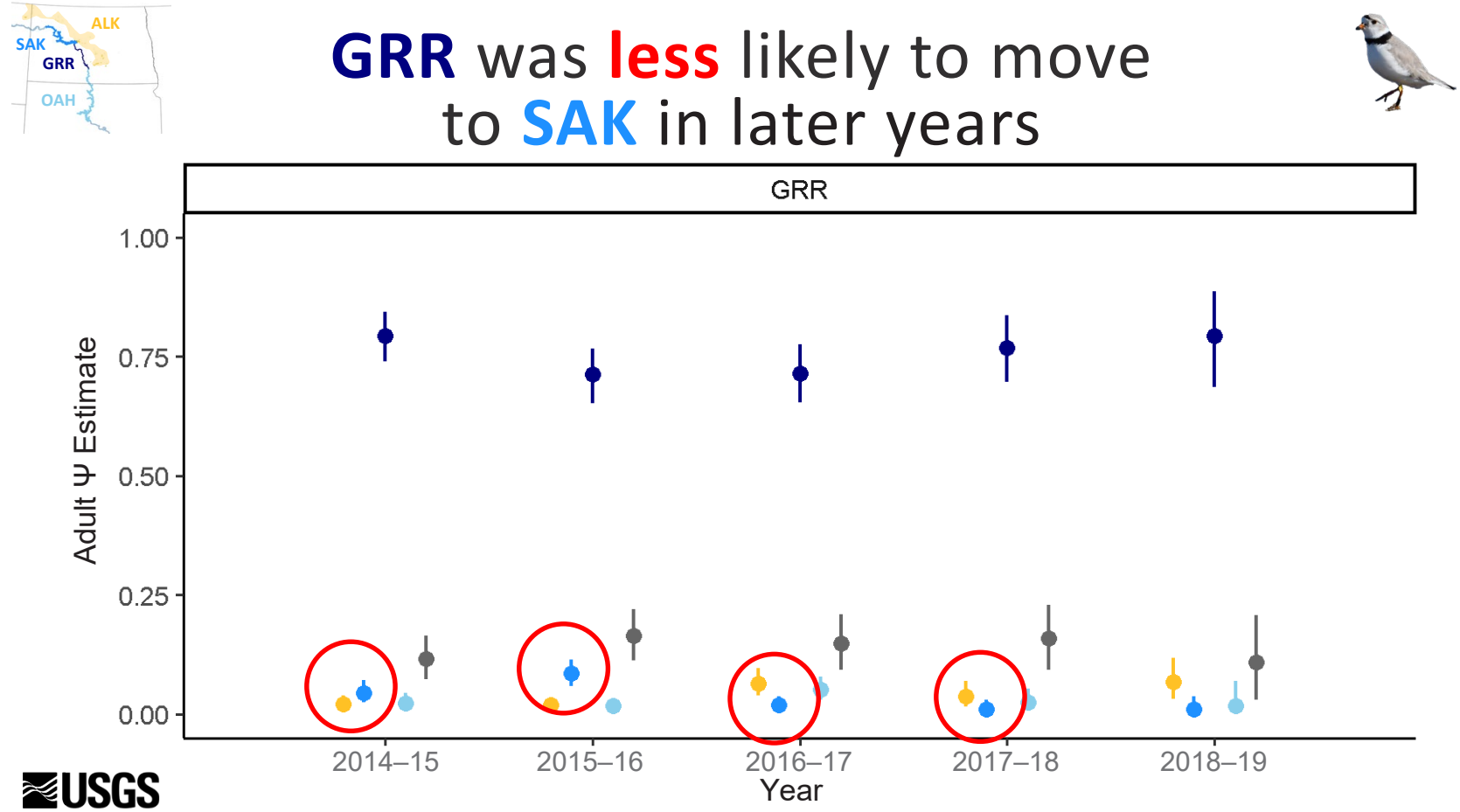

Adult dispersal and fidelity for individuals breeding on the GRR varied slightly over the years. Individuals were most likely to stay to breed on the GRR and next likely to transition to the transient state. Beginning in 2016 to 2017, individuals were least likely to disperse to breed on SAK (red circles; mean annual estimates the GRR to SAK: 2014-15: 0.04, 2015-16: 0.09, 2016-17: 0.02, 2017-18: 0.01, 2018-19: 0.009). [The last year in a fully time-dependent model is not estimable. Filled circles indicate mean $\Psi$ estimates. Vertical lines indicate 95 -percent credible intervals.] 

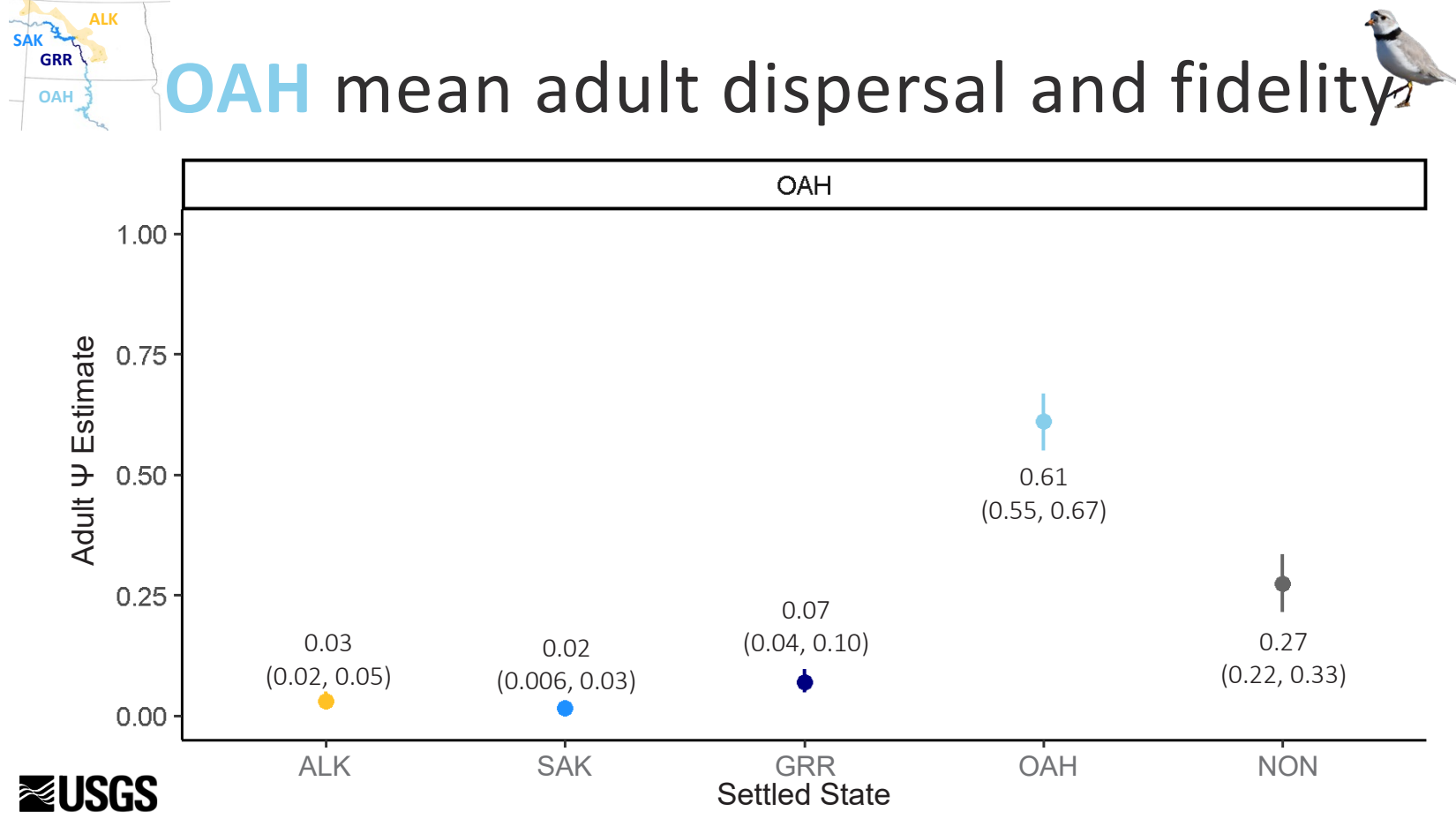

Adults breeding on $\mathrm{OAH}$ were most likely to return to breed on $\mathrm{OAH}(0.61, \mathrm{Cl}=0.55$ to 0.67$)$. Transitioning to breed on the $\mathrm{GRR}$ $(0.07, \mathrm{Cl}=0.04$ to 0.10$)$ was more likely than the $\operatorname{ALK}(0.03, \mathrm{Cl}=0.02$ to 0.05$)$ or $\mathrm{SAK}(0.02, \mathrm{Cl}=0.006$ to 0.03$)$. Most individuals that did not return to breed on $\mathrm{OAH}$ transitioned to the transient state (NON; $0.27, \mathrm{Cl}=0.22$ to 0.33 ). [Filled circles indicate mean $\Psi$ estimates. Vertical lines indicate 95-percent credible intervals (Cls).] 


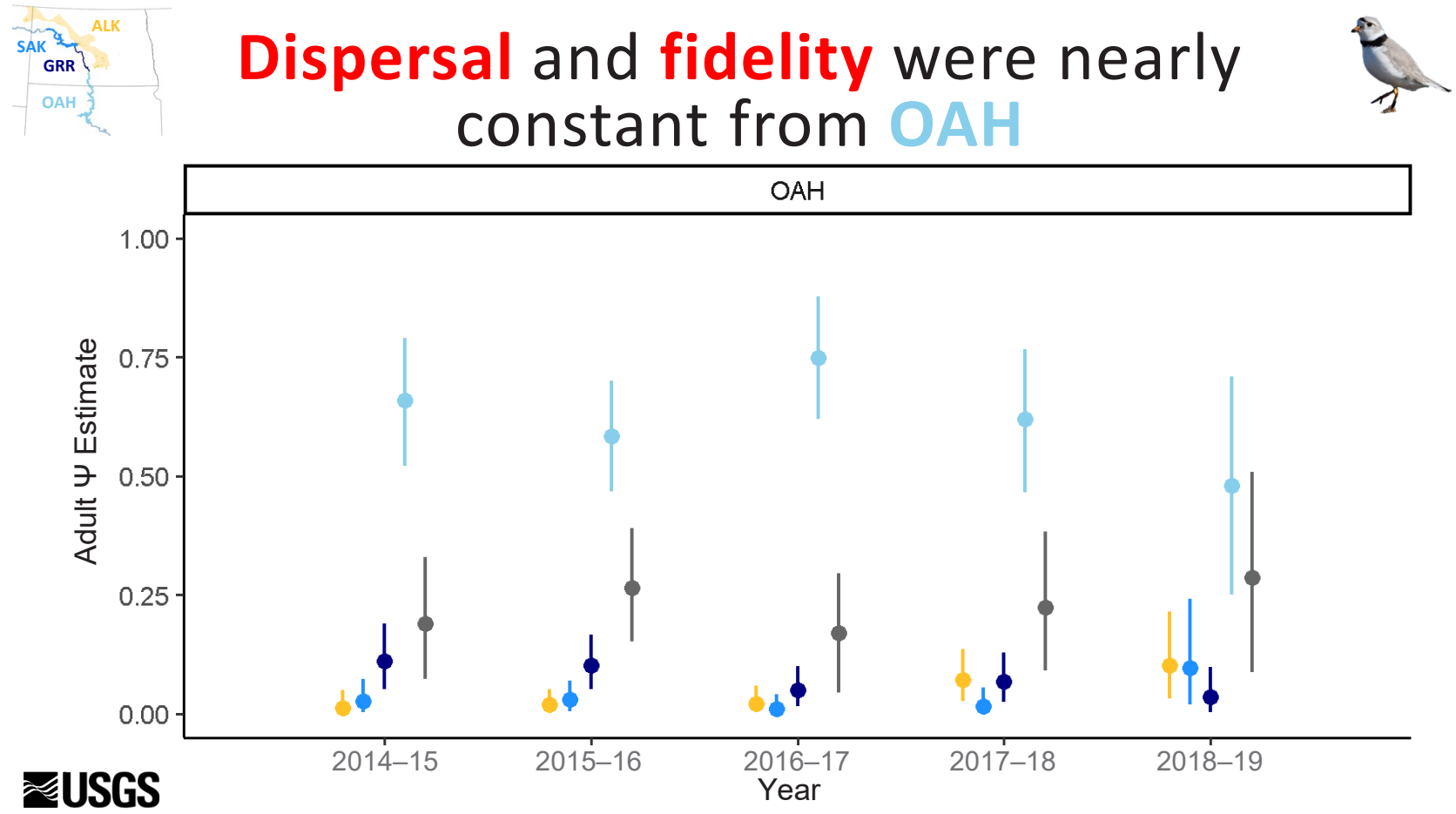

Adult dispersal and fidelity for individuals breeding on $\mathrm{OAH}$ varied slightly over the years. Individuals were most likely to stay to breed on $\mathrm{OAH}$ then to transition to the transient state. Individuals were more likely to disperse to the GRR than the ALK or SAK. In 2018-19, individuals were equally likely to enter the transient state as to stay to breed on OAH. [The last year in a fully time-dependent model is not estimable. Filled circles indicate mean $\Psi$ estimates. Vertical lines indicate 95-percent credible intervals.] 


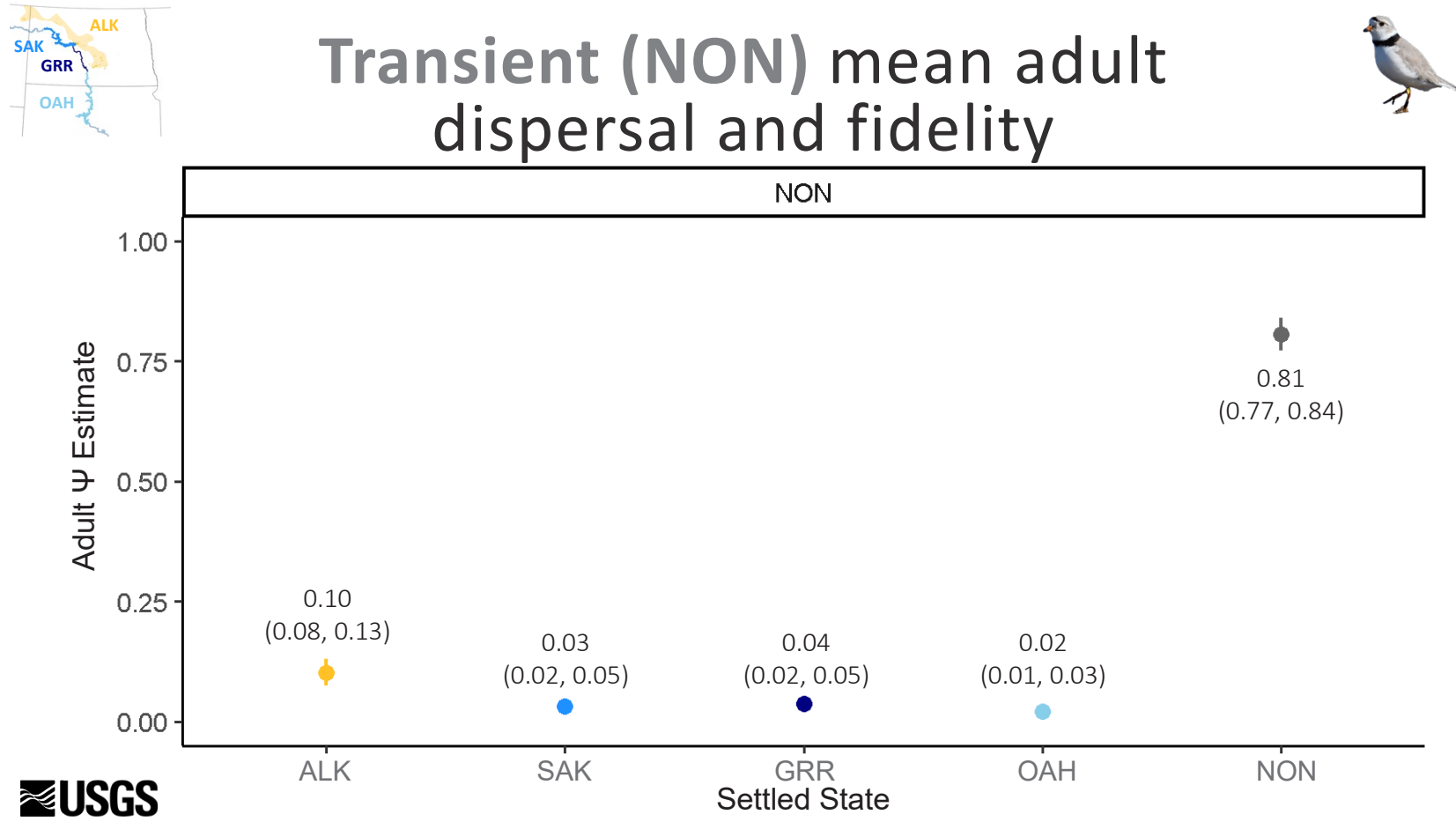

Transient individuals (NON) were most likely to remain transients $(0.81, \mathrm{Cl}=0.77$ to 0.84$)$. Transitioning to breed on the ALK (0.10, $\mathrm{Cl}=0.08$ to 0.13$)$ was more likely than $\operatorname{SAK}(0.03, \mathrm{Cl}=0.02$ to 0.05$)$, the $\mathrm{GRR}(0.04, \mathrm{Cl}=0.02$ to 0.05$)$, or $\mathrm{OAH}(0.02, \mathrm{Cl}=0.01$ to 0.03$)$. [Filled circles indicate mean $\Psi$ estimates. Vertical lines indicate 95-percent credible intervals (Cls).]

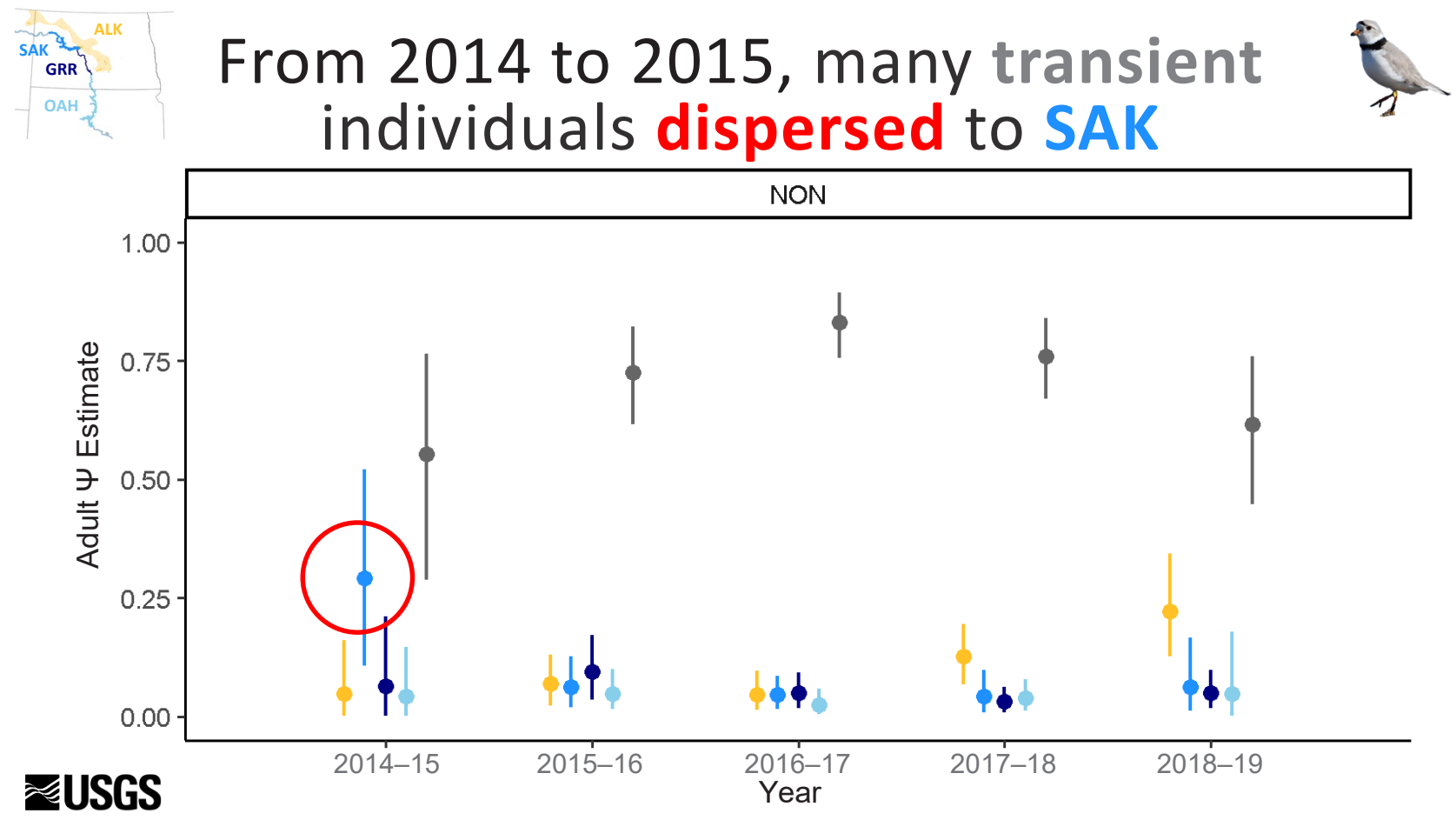

Adult dispersal and fidelity for individuals in the transient state varied over the years. Individuals were most likely to stay in the transient state in all years. From 2014 to 2015 , individuals were more likely to transition to breed on $\mathrm{SAK}(0.30, \mathrm{Cl}=0.11$ to 0.52; red circle) than to the ALK, the GRR, or OAH. In 2015-16 and 2016-17, the four breeding states were equally likely. [The last year in a fully time-dependent model is not estimable. Filled circles indicate mean $\Psi$ estimates. Vertical lines indicate 95-percent credible intervals (Cls).] 


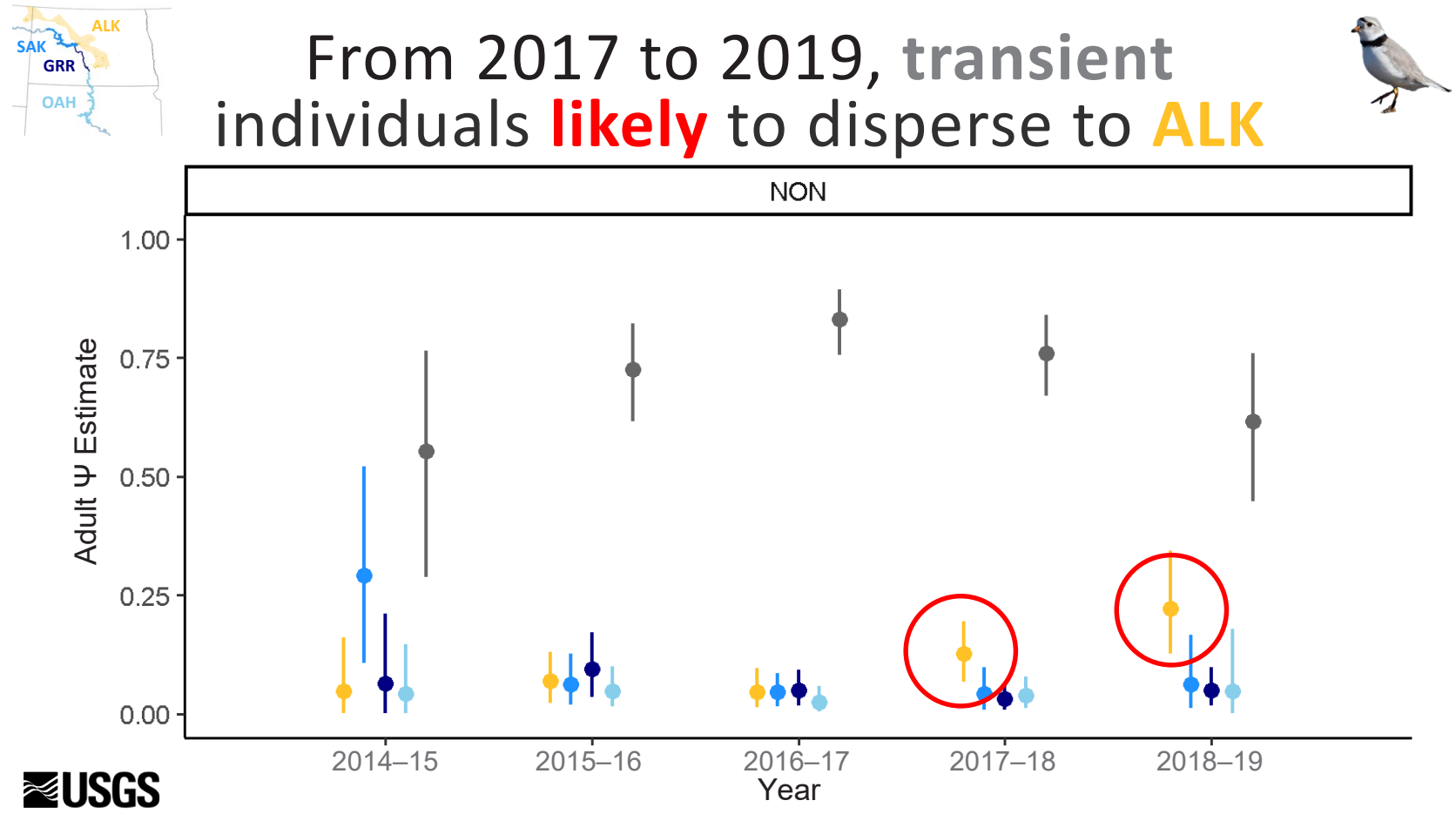

Adult dispersal and fidelity for individuals in the transient state varied over the years. Individuals were most likely to stay in the transient state in all years. In 2015-16 and 2016-17, the four breeding states were equally likely. In 2017-18 and 2018-19, individuals were more likely to breed on the ALK (red circles; mean annual estimates NON to the ALK: 2014-15: 0.05, 2015-16: 0.07, 2016-17: 0.05, 2017-18: 0.13, 2018-19: 0.22). [The last year in a fully time-dependent model is not estimable. Filled circles indicate mean $\Psi$ estimates. Vertical lines indicate 95-percent credible intervals.] 


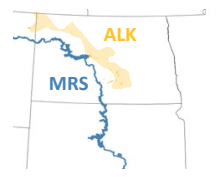

Years at Management Unit

Old Segment

Novel Segment

Conspecific Density

Nest Initiation Date

Nest Fate - Hatched

Nest Fate - Failed

Available Habitat

Segment Success - Below

Segment Success - Above

Average Proximity

\section{‡USGS}

Adult dispersal varied based on three covariates

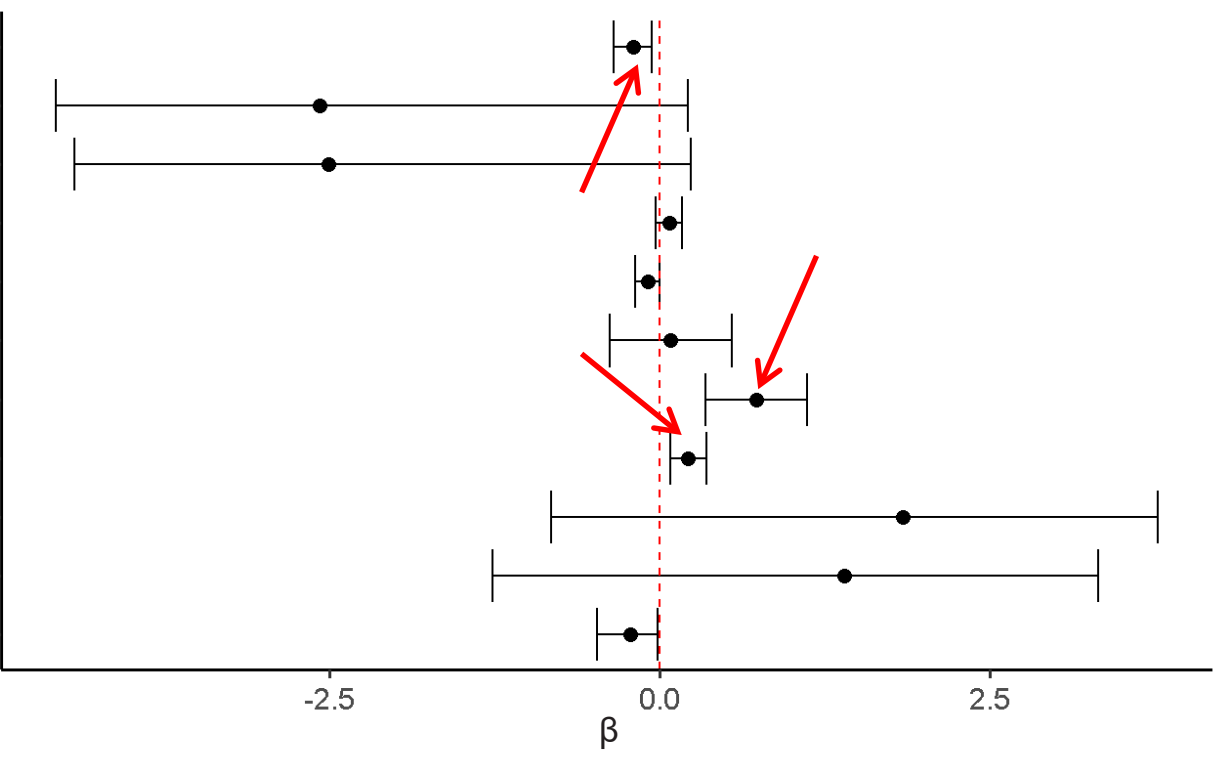

From the global fitted model with all eight a priori covariates included on adult dispersal probabilities as well as a random effect of year, three covariates (red arrows) seem important based on nonoverlapping 95-percent credible intervals with zero. [Filled circles indicate mean $\beta$ estimate. Whiskers indicate 95-percent credible intervals.]

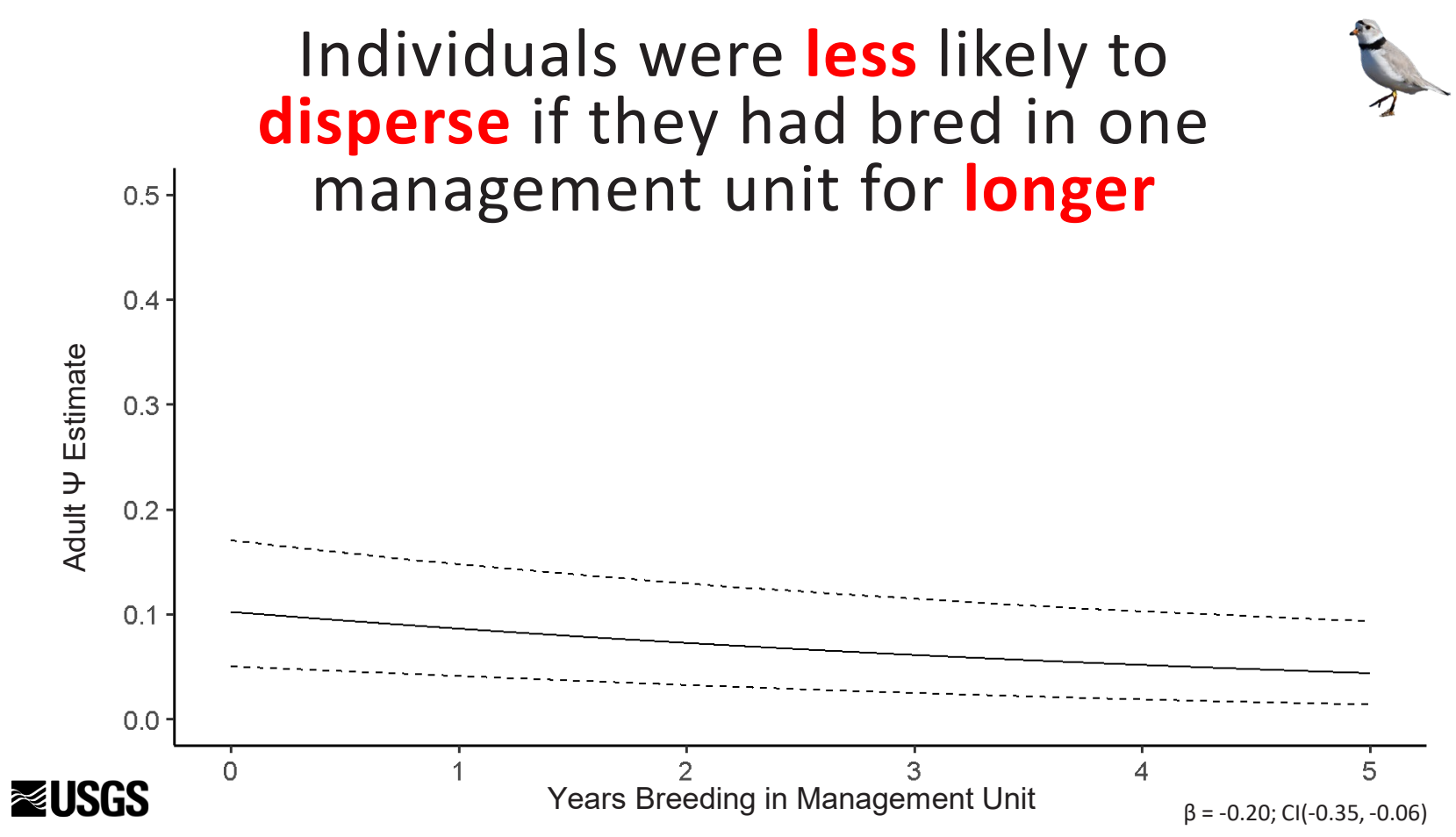

Adult dispersal probabilities decreased (solid line) when individuals had bred in the same management unit longer ( $\beta=-0.20$; $\mathrm{Cl}=-0.35$ to -0.06$)$. [Dashed lines indicate 95-percent credible interval (CI).] 


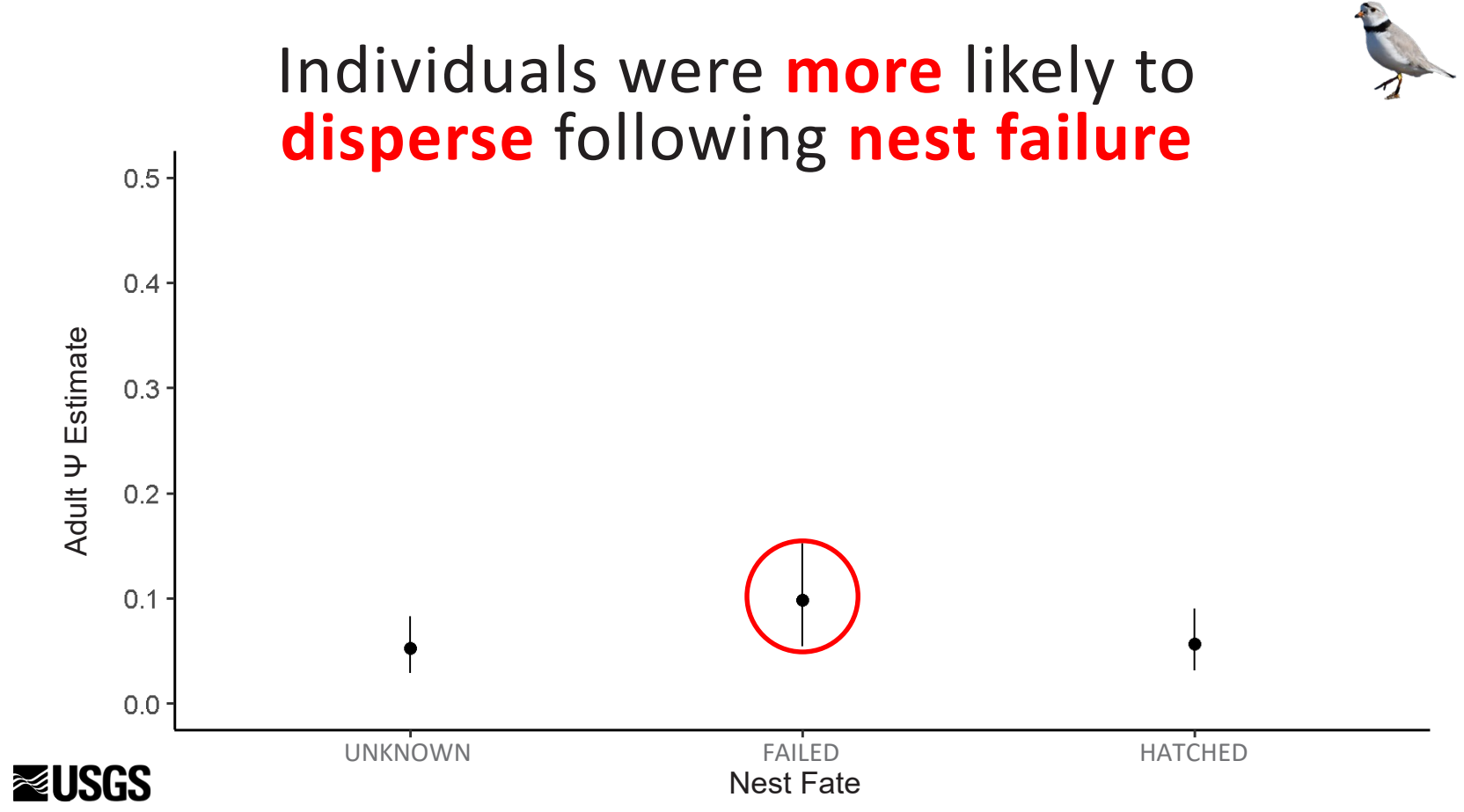

Adult dispersal probabilities increased when nests failed during incubation (red circle) compared to nests known to hatch or with unknown fates. [Filled circles indicate mean $\Psi$ estimates. Vertical lines indicate 95-percent credible intervals.]

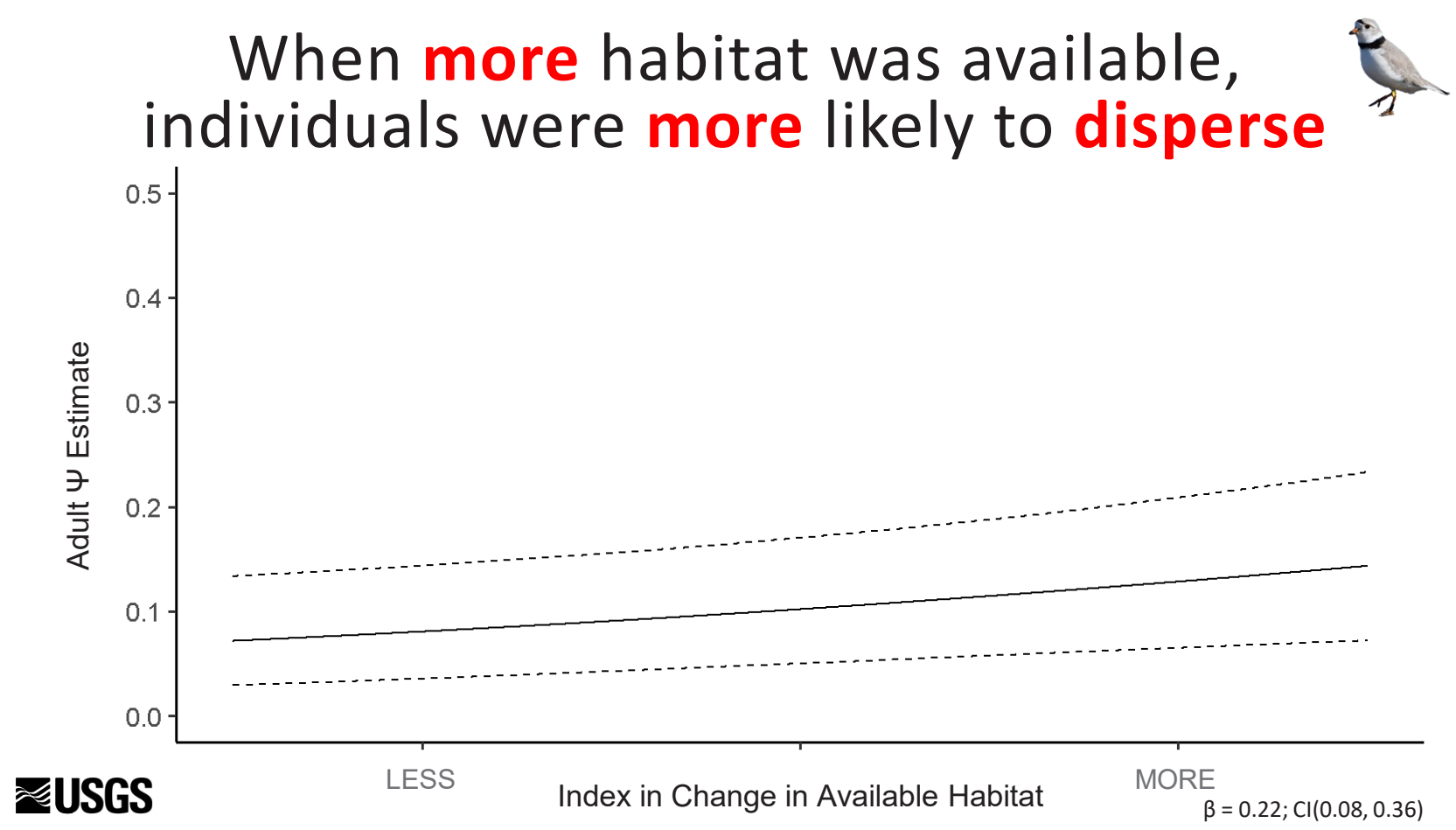

Contrary to our predictions, adult dispersal probabilities slightly increased (solid line) after a year when there was more habitat available than the prior year $(\beta=0.22 ; \mathrm{Cl}=0.08$ to 0.36$)$. [Dashed lines indicate 95 -percent credible interval (CI).] 


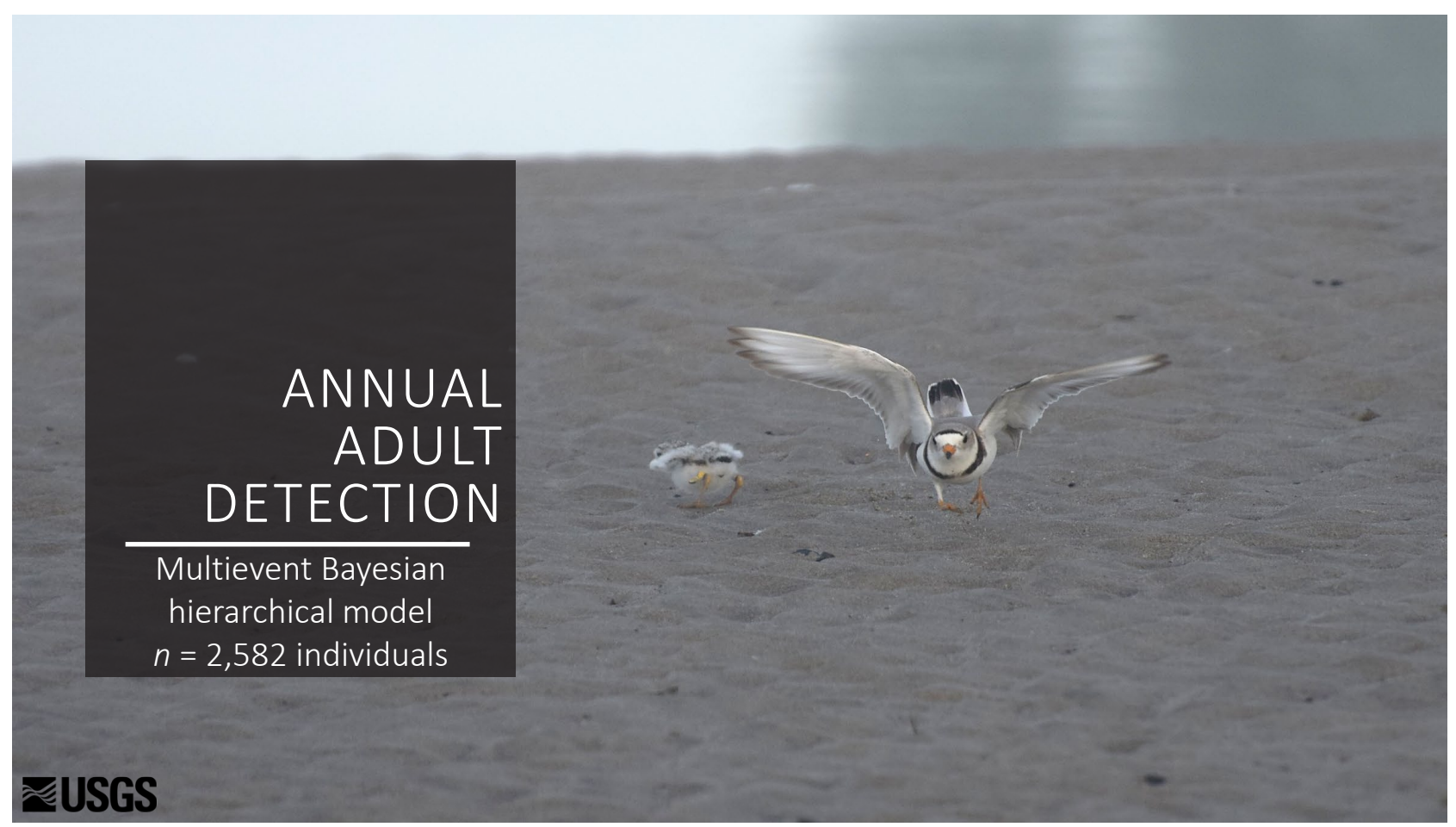

In this next section, we provide annual detection $(p)$ estimates from our multievent models for adults. For more details, see the “Adult Survival and Breeding Dispersal Probabilities" section. [n, number]

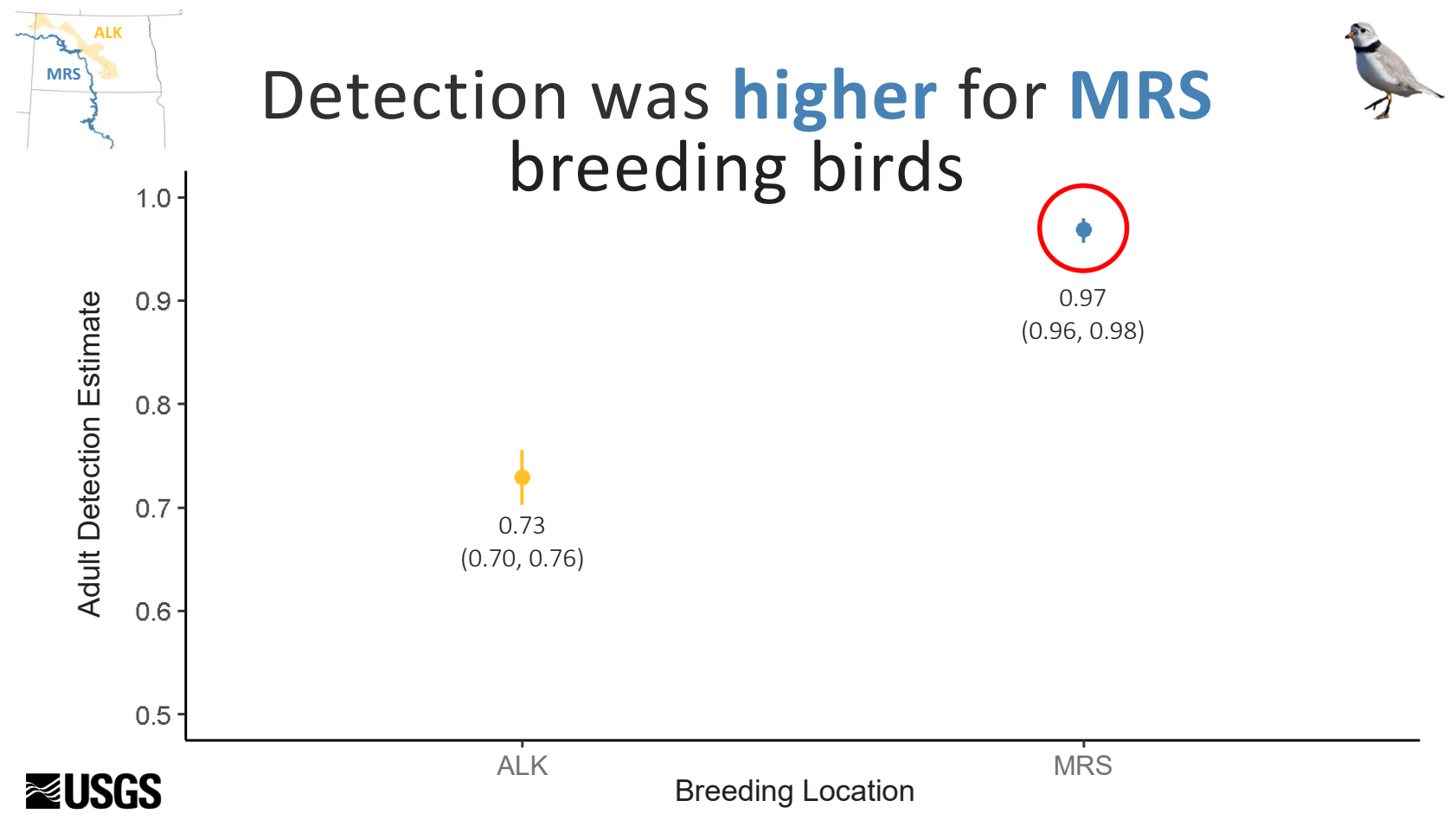

Annual detection of breeding adults on the ALK was lower $(0.73, \mathrm{Cl}=0.70$ to 0.76$)$ than for the $\mathrm{MRS}(0.97, \mathrm{Cl}=0.96$ to 0.98 ; red circle). [Filled circles indicate mean detection estimates. Vertical lines indicate 95-percent credible intervals (Cls).] 


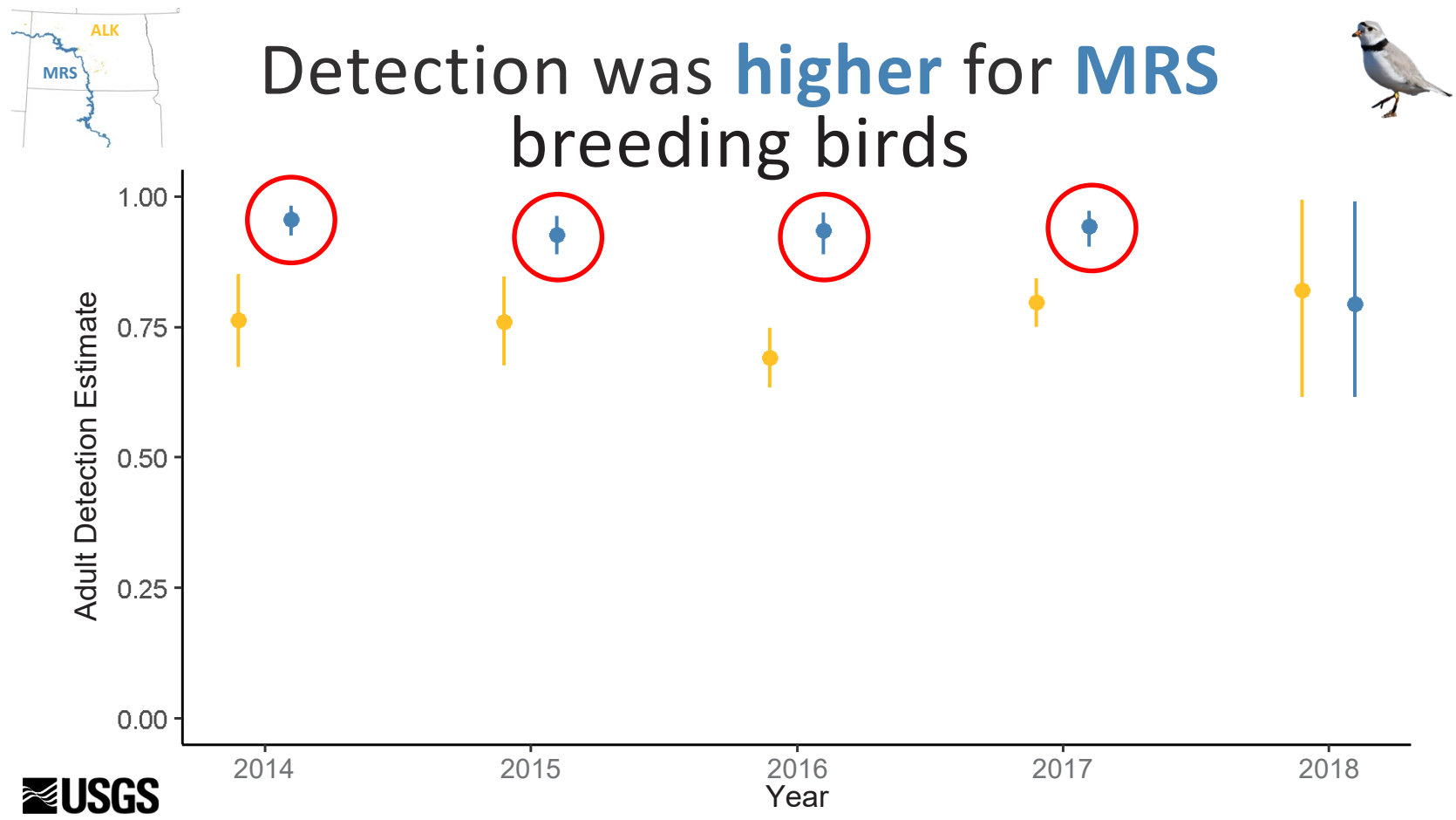

Annual detection of breeding adults on the ALK was lower than for the MRS in four years (red circles). [The last year of a fully time-dependent model is not fully estimable. Filled circles indicate mean detection estimates. Vertical lines indicate $95-$ percent credible intervals.]

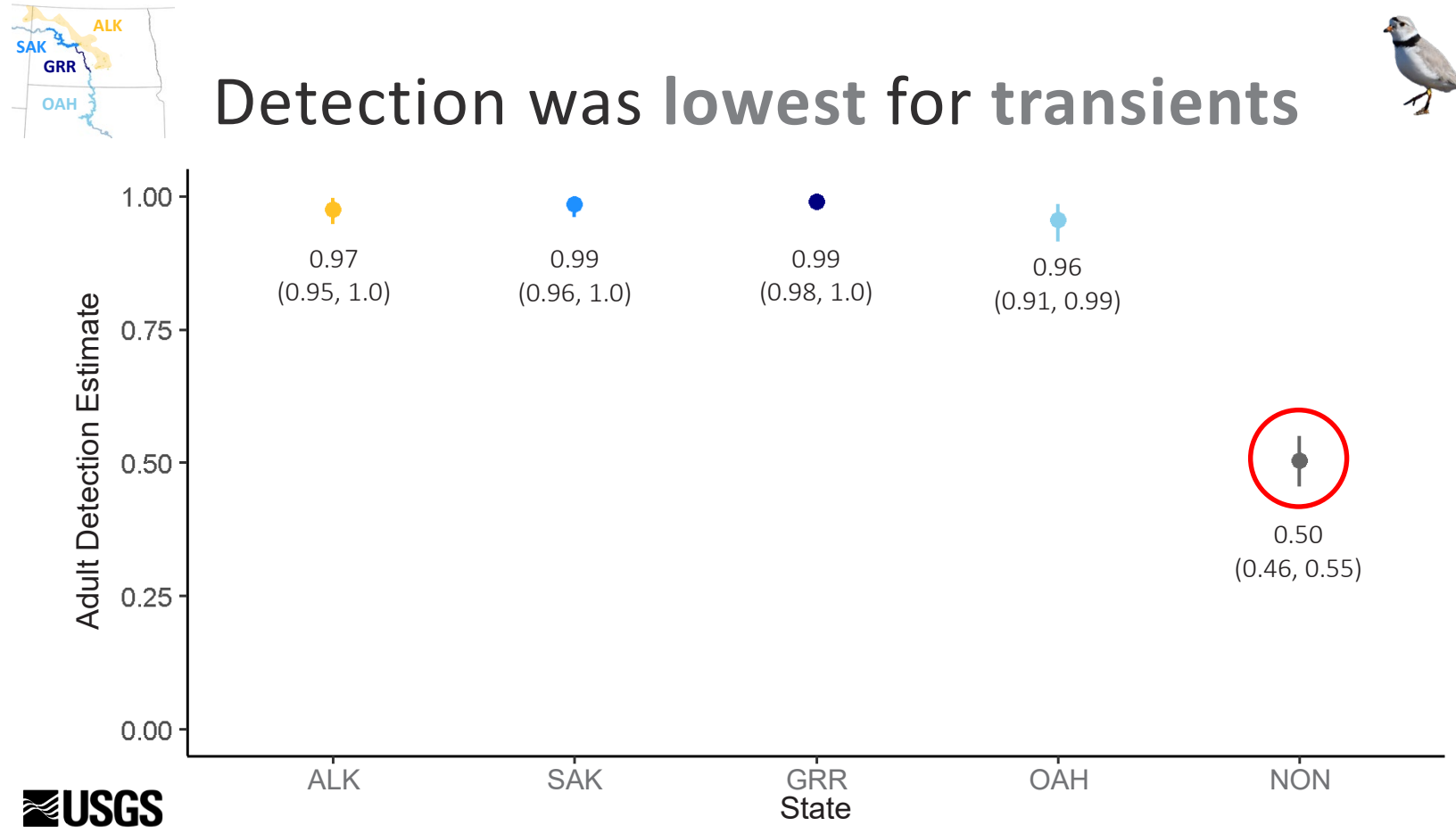

Annual detection was high for each of the breeding states (mean estimates range: $0.96-0.99$ ) but was significantly lower for transient individuals ( $N O N ; 0.50, \mathrm{Cl}=0.46$ to 0.55 ; red circle). [Filled circles indicate mean detection estimates. Vertical lines indicate 95 percent credible intervals (Cls).] 


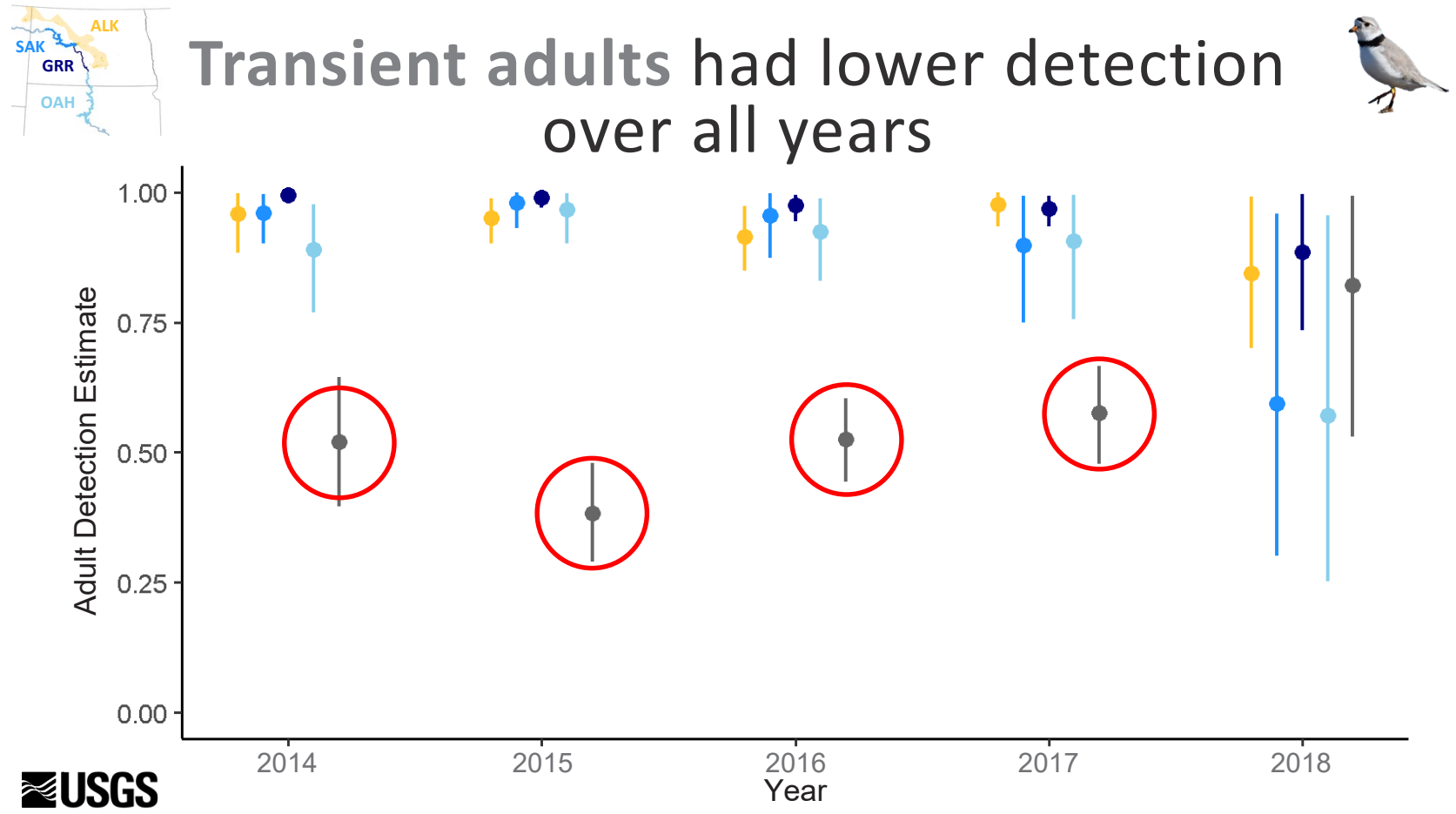

Transient individuals (red circles) had lower detection in all years except 2018. Detection for the four breeding states (the ALK, SAK, the GRR, and OAH) were similar to each other and high. [The last year of a fully time-dependent model is not fully estimable. Filled circles indicate mean detection estimates. Vertical lines indicate 95-percent credible intervals.]

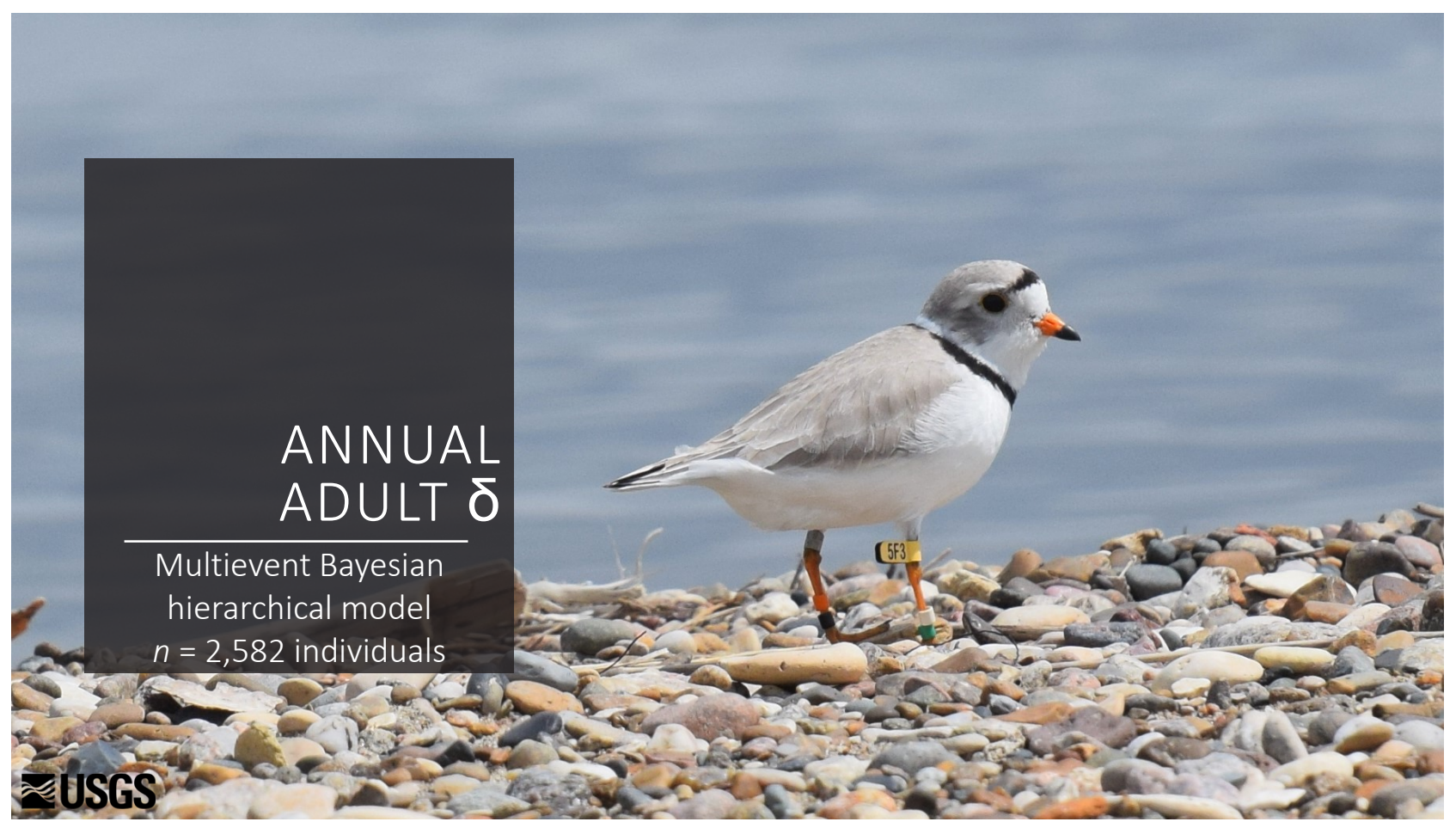

$\delta$ is the probability that the state of an individual that is in state, $s$, is correctly observed. For more details, see the "Adult Survival and Breeding Dispersal Probabilities" section. [n, number] 


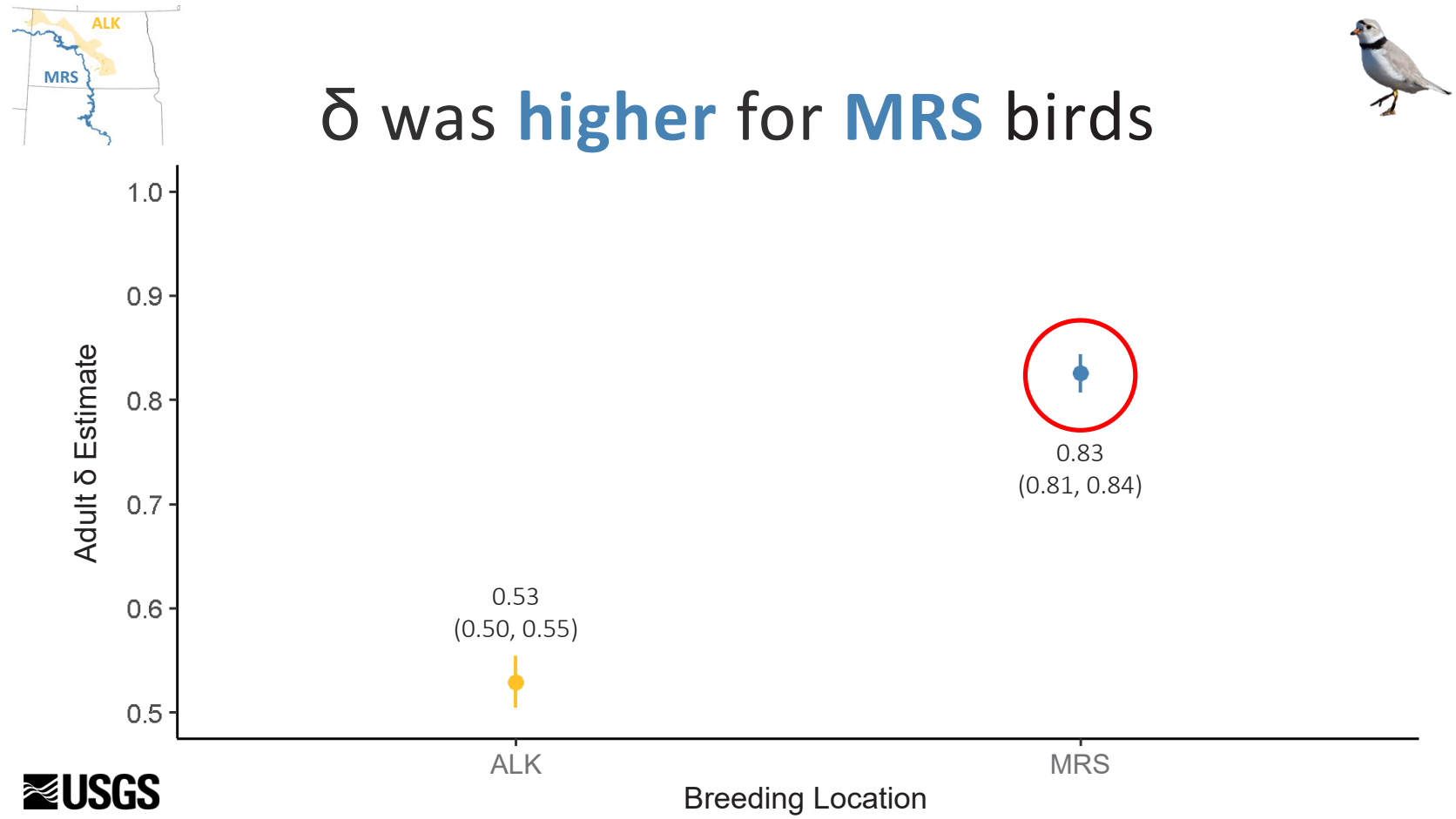

Individuals breeding on the MRS had a higher probability of being assigned the correct state $(0.83, \mathrm{Cl}=0.81$ to 0.84 ; red circle) than the ALK breeding birds $(0.53, \mathrm{Cl}=0.50$ to 0.55$)$. [Filled circles indicate mean $\delta$ estimates. Vertical lines indicate $95-$ percent credible intervals (Cls).]

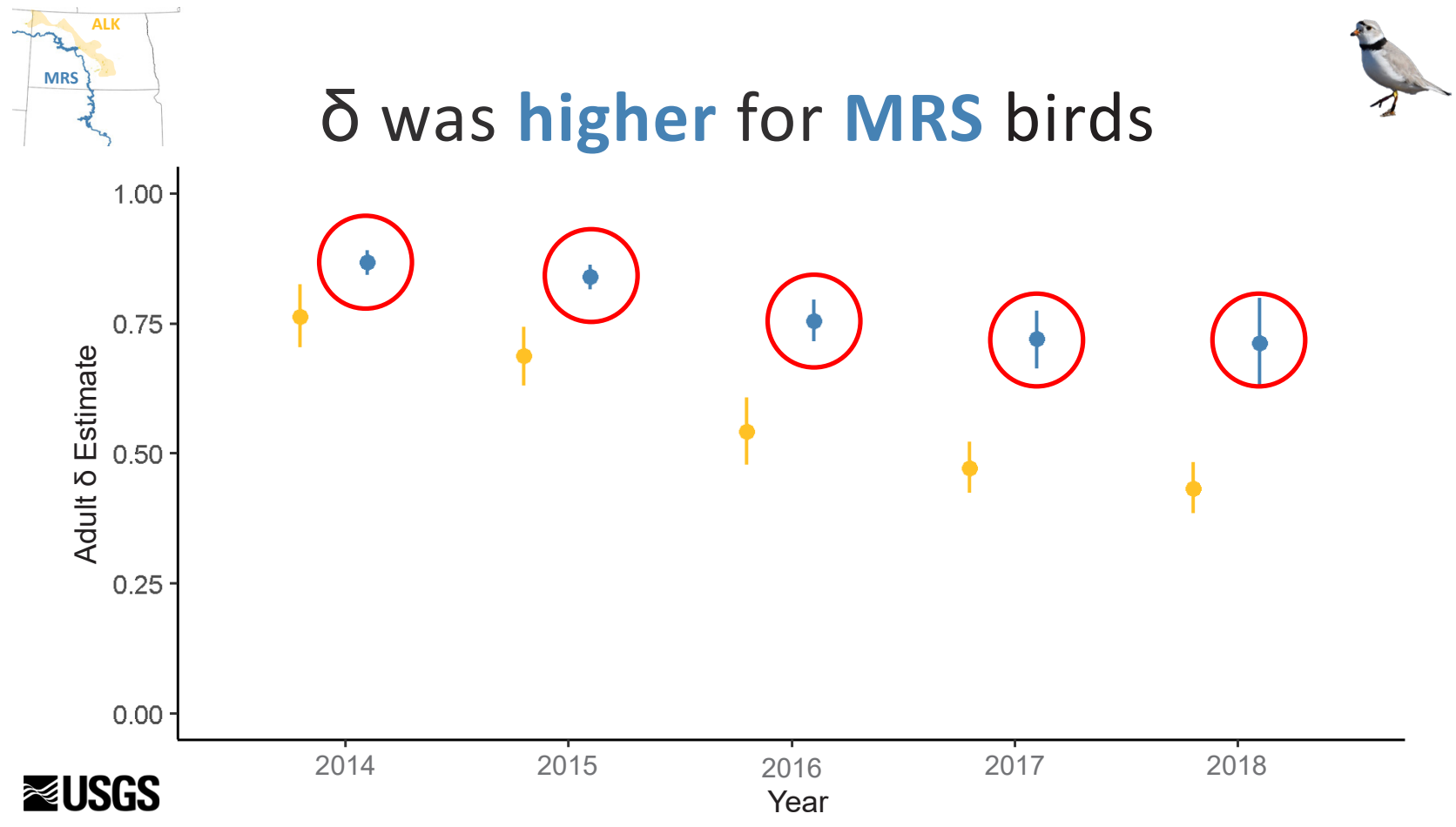

In all years, $\delta$ was higher for the MRS breeding birds (red circles) than the ALK breeding birds. [The last year of a fully time-dependent model is not fully estimable. Filled circles indicate mean $\delta$ estimates. Vertical lines indicate 95 -percent credible intervals.] 


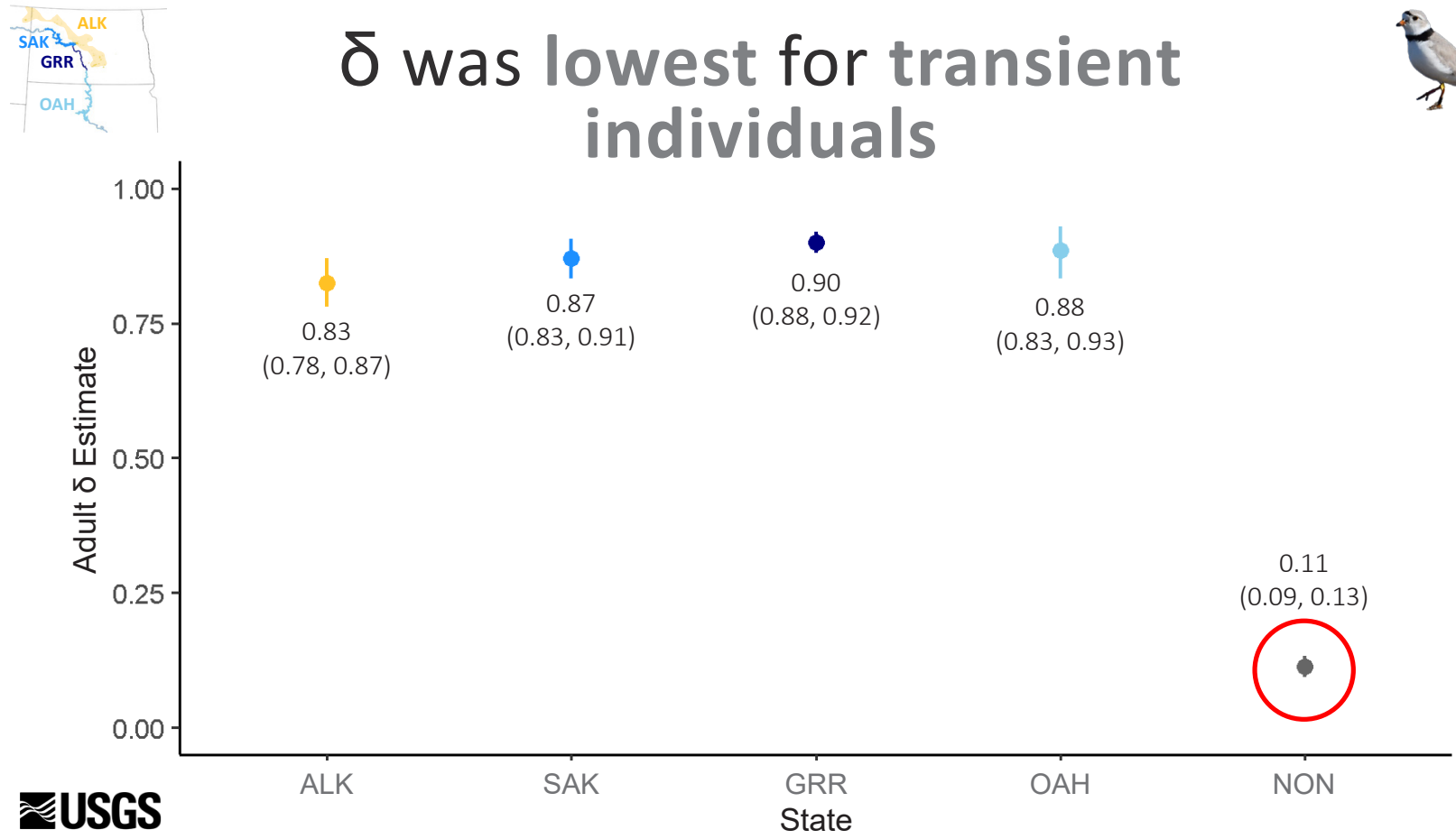

Individuals in the transient state (NON) were least likely to be assigned the correct state $(0.11, \mathrm{Cl}=0.09$ to 0.13 ; red circle). [Filled circles indicate mean $\delta$ estimates. Vertical lines indicate 95-percent credible intervals (Cls).]

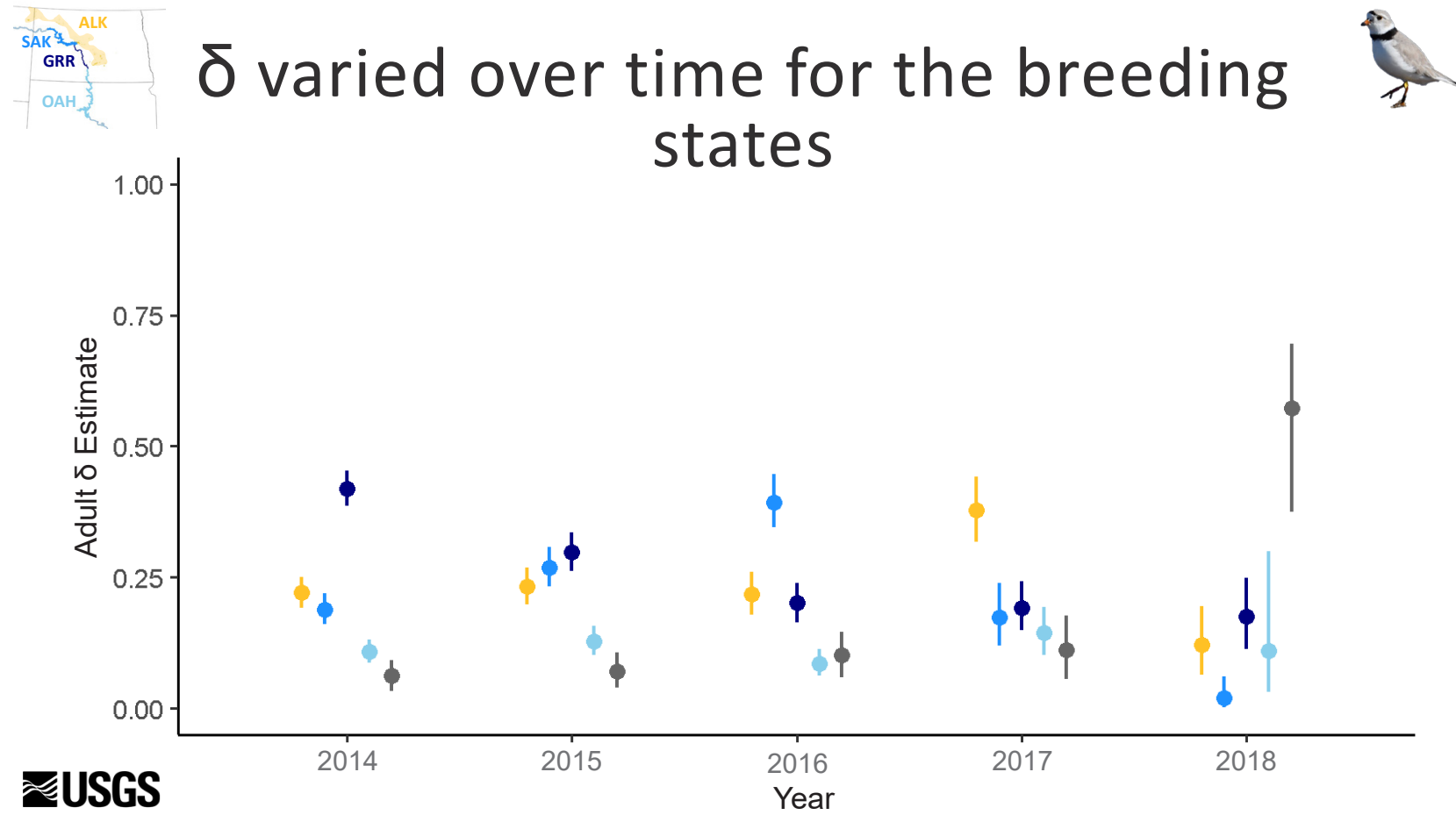

Misassignment error, $\delta$, varied over the years. [The last year of a fully time-dependent model is not fully estimable. Filled circles indicate mean $\delta$ estimates. Vertical lines indicate 95-percent credible intervals.] 


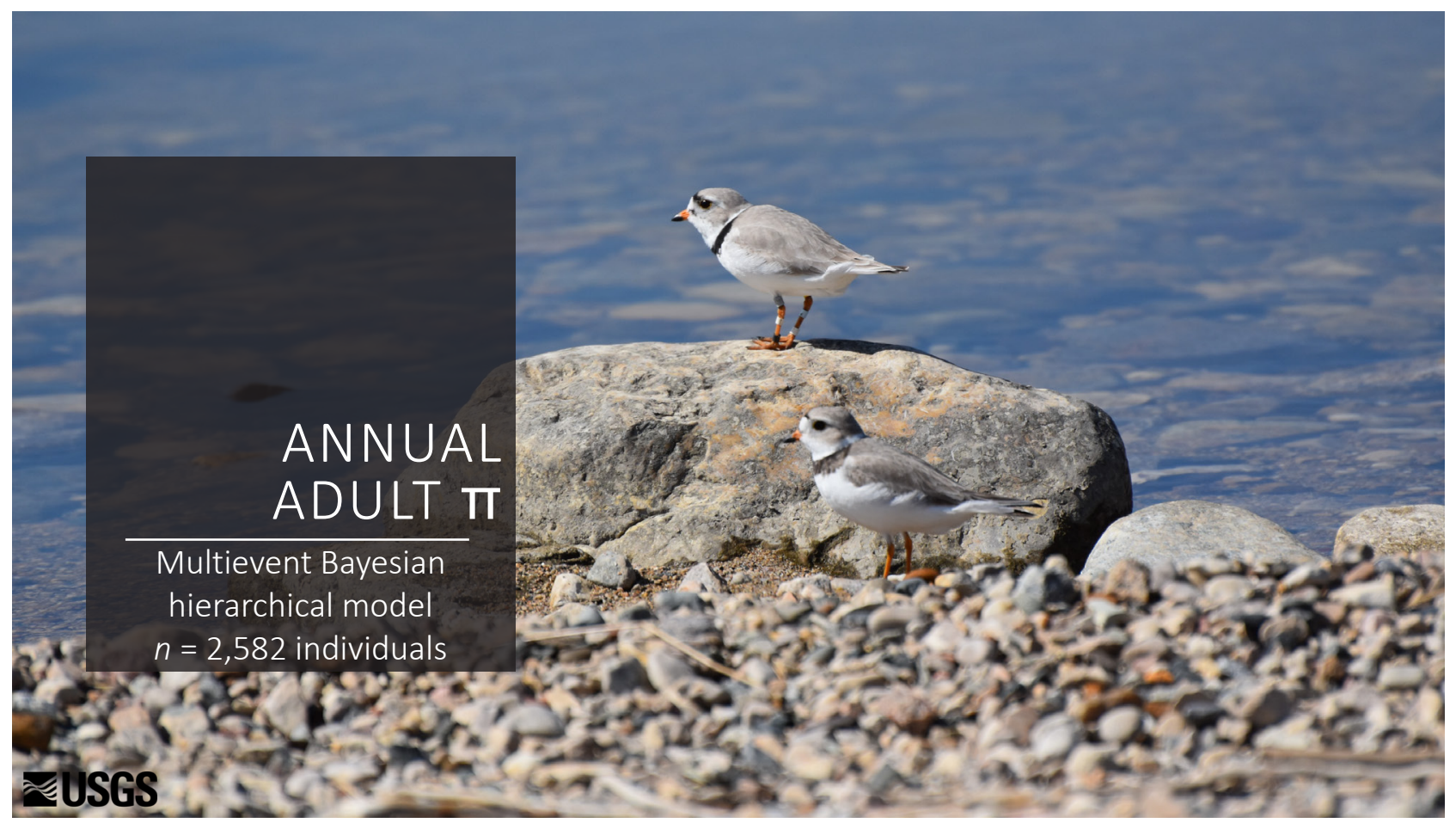

$\pi$ is the probability that an individual is in state, $s$, when first encountered. For more details, see the "Adult Survival and Breeding Dispersal Probabilities" section. [n, number]

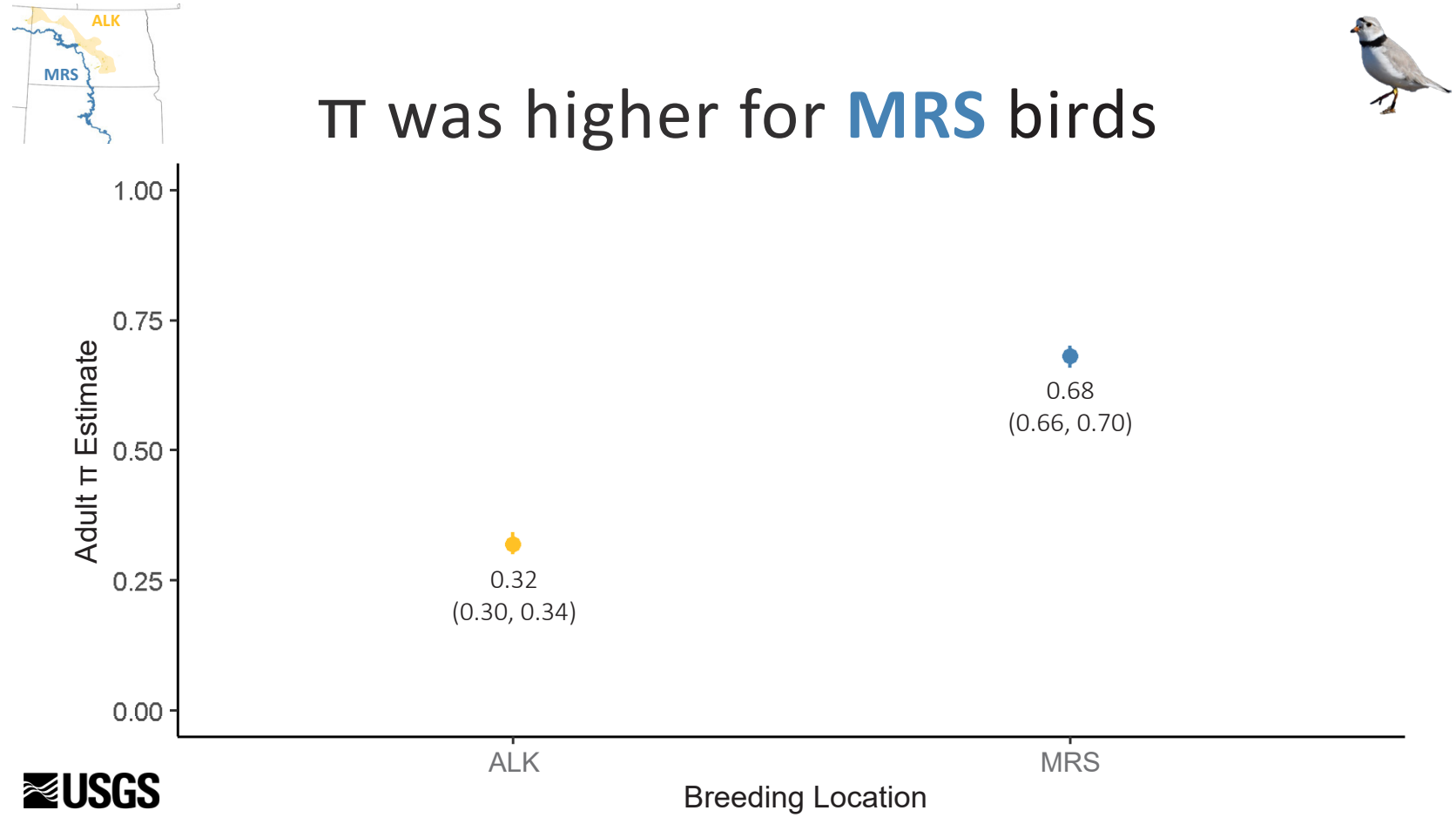

The probability of initial assignment ( $\pi)$ was higher for the MRS $(0.68, \mathrm{Cl}=0.66$ to 0.70$)$ than the ALK $(0.32, \mathrm{Cl}=0.30$ to 0.34$)$. [Filled circles indicate mean $\pi$ estimates. Vertical lines indicate 95-percent credible intervals (Cls).] 


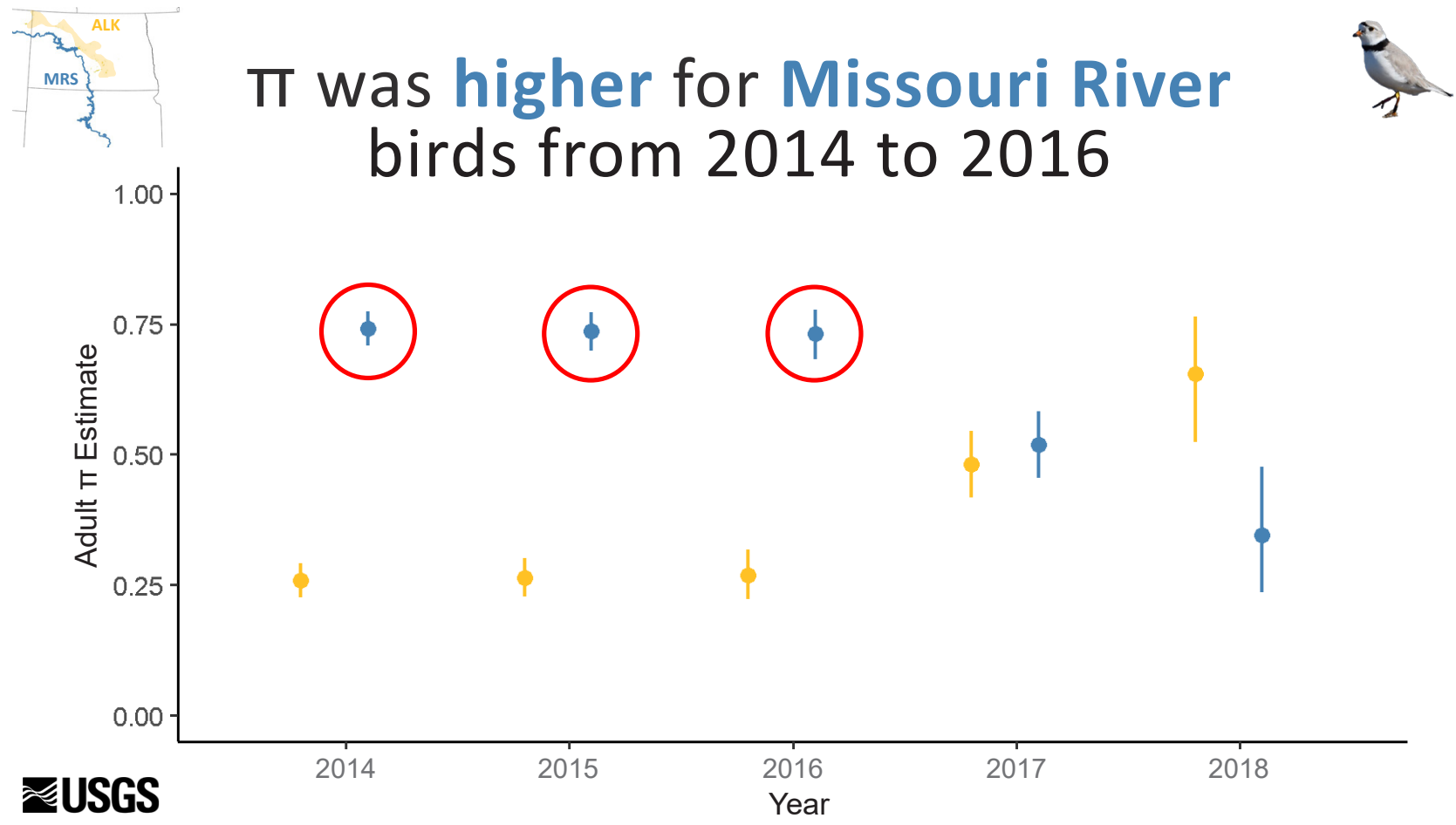

Before 2017, birds were more likely to be assigned to the MRS (red circles) than to the ALK upon first encounter. [The last year of a fully time-dependent model is not fully estimable. Filled circles indicate mean $\pi$ estimates. Vertical lines indicate 95-percent credible intervals.]

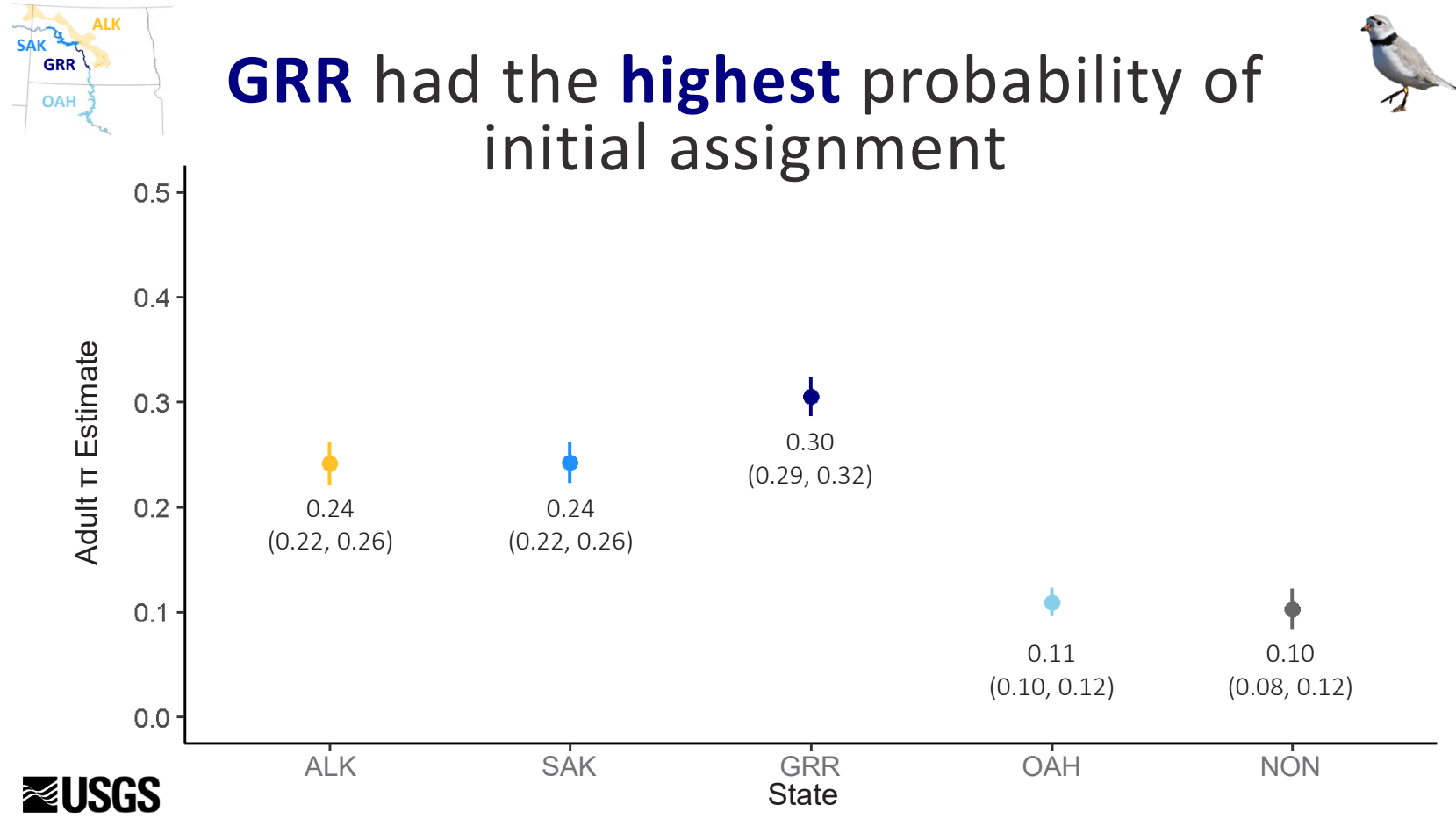

Of the four breeding locations, the GRR had the highest probability of initial assignment $(0.30, \mathrm{Cl}=0.29$ to 0.32$)$. The ALK and SAK had slightly lower probabilities $(0.24, \mathrm{Cl}=0.22$ to 0.26$)$ and $\mathrm{OAH}(0.11, \mathrm{Cl}=0.10$ to 0.12$)$ and transient individuals $(0.10, \mathrm{Cl}=0.08$ to 0.12) were least likely. [Filled circles indicate mean $\pi$ estimates. Vertical lines indicate 95-percent credible intervals (Cls).] 


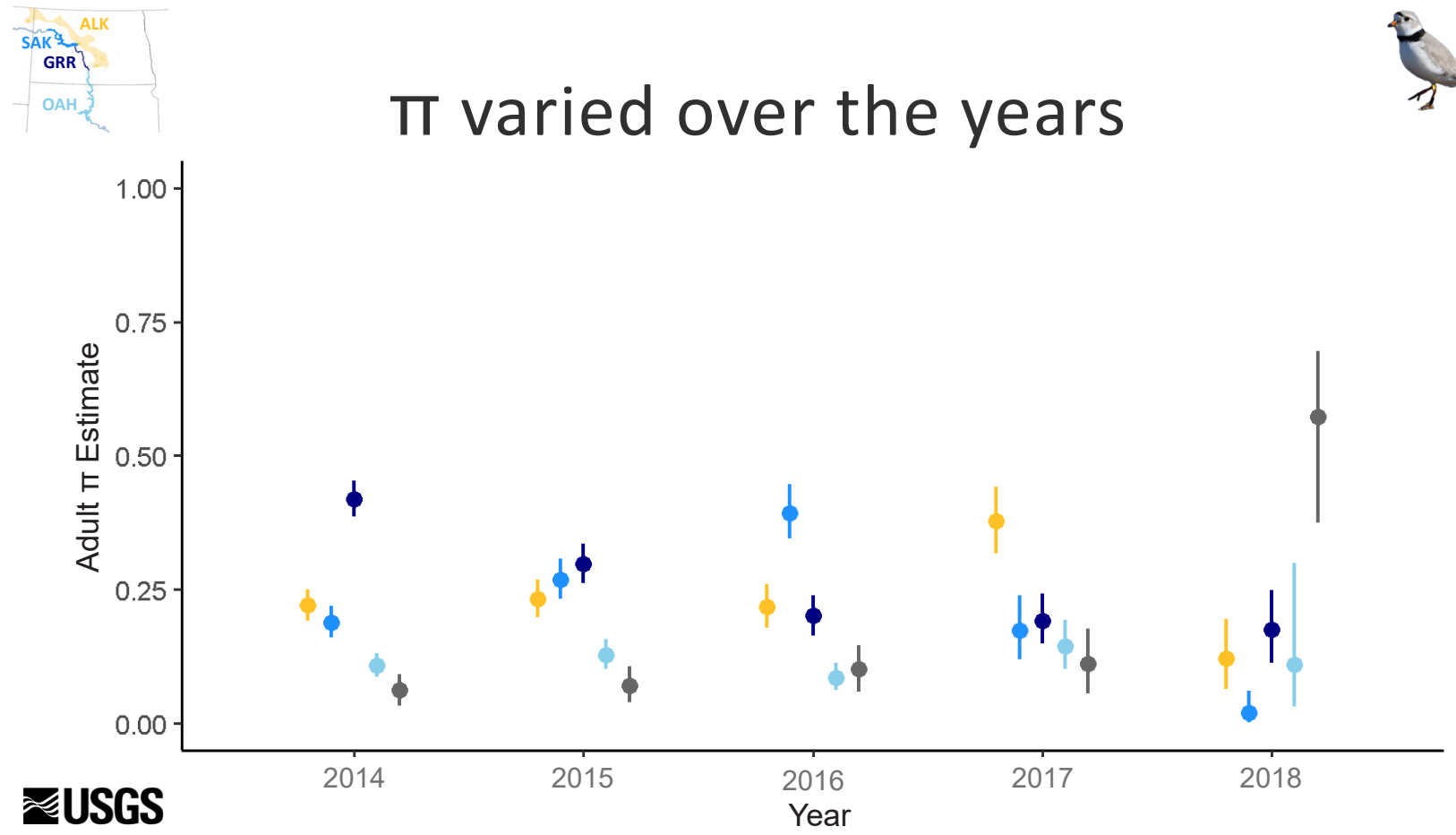

Probability of initial assignment $(\pi)$ varied over the years. [The last year of a fully time-dependent model is not fully estimable. Filled circles indicate mean $\pi$ estimates. Vertical lines indicate 95-percent credible intervals.]

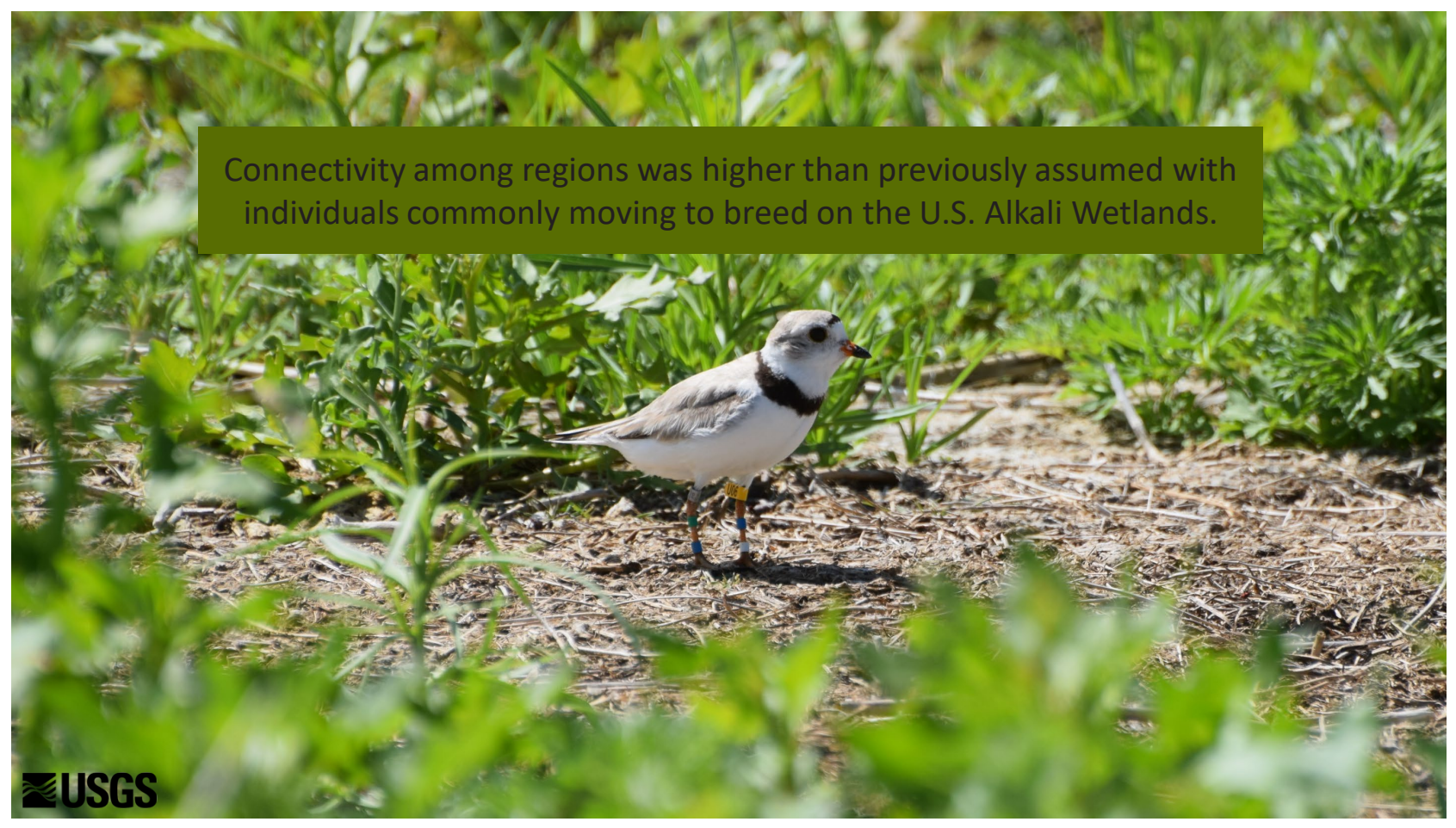

Based on prior work along the southern Missouri River units, the Platte River and tributaries, and Prairie Canada, connectivity amongst the four proposed breeding groups was assumed to be low (0.0066; McGowan and others, 2014). Although dispersal varied over the years, the mean dispersal rate between the ALK and the MRS (the ALK to the MRS: 0.04; the MRS to the ALK: 0.17) was much higher than the level used by McGowan and others (2014). The low dispersal (0.0066; McGowan and others, 2014) previously simulated assumed that isolation among breeding areas would have insulated the NGP piping plover population from heightened extinction risk. 


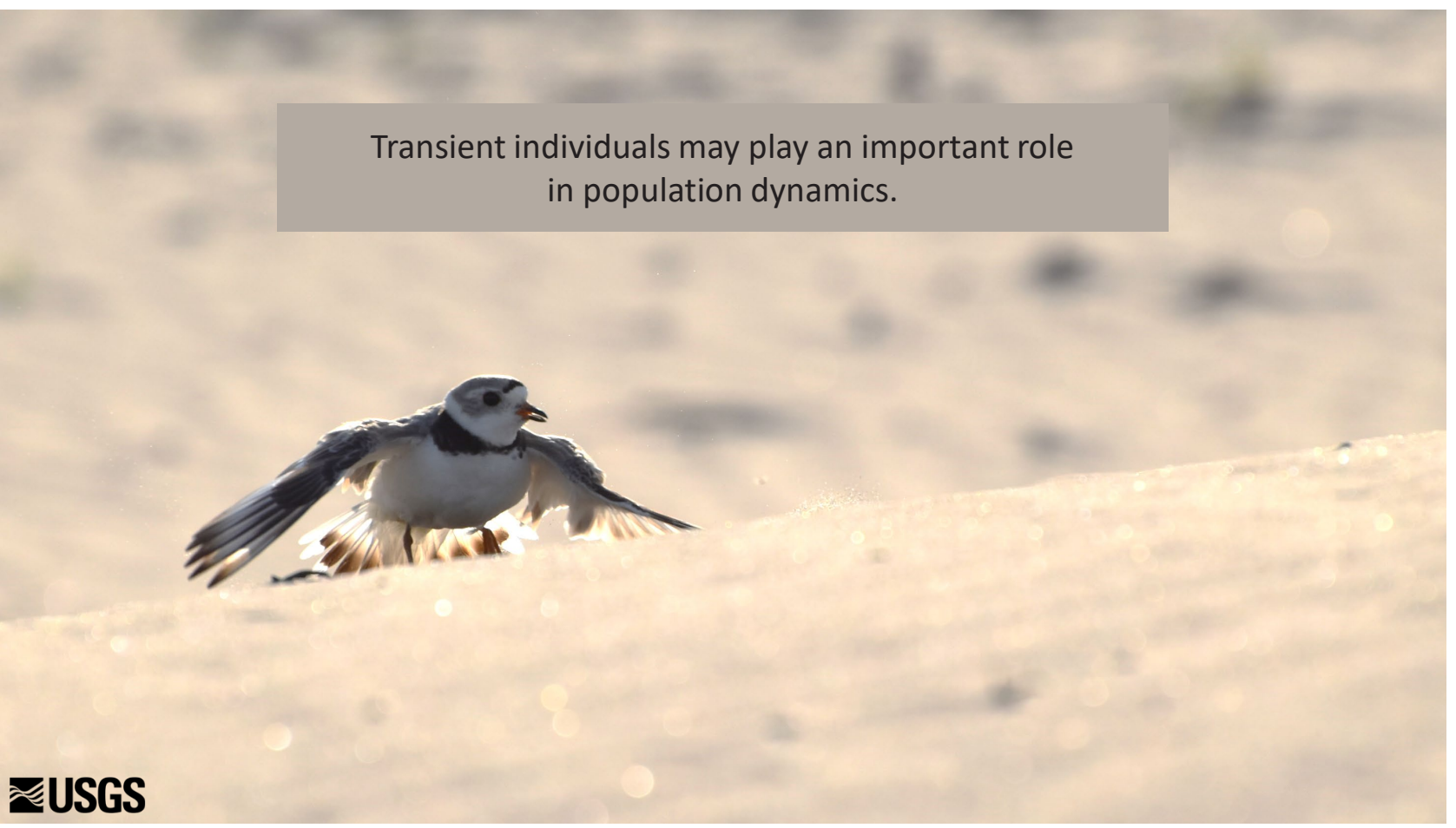

Transient individuals seem to play an important role in population dynamics for NGP piping plovers. Transient individuals, or early failed breeders seen in at least three management units, had substantially lower annual survival rates. When accounting for these individuals as a separate state, location-based survival estimates increased and improved (smaller credible intervals). Particularly interesting, though, was that fidelity to the transient state was high (0.81) suggesting that individuals that exhibit this transient behavior do so in multiple years. This fidelity has important ramifications for population dynamics because individuals were less likely to transition from the transient state into one of the breeding states and had reduced survival, essentially eliminating those individuals from future reproductive output. In years when habitat is not available on the Missouri River (for example in 2011), if individuals are unable to find mates or territories to breed on in the alkali wetlands, that may have a multiyear effect that reduces the adult population through reduced survival and reduced future reproductive output. 


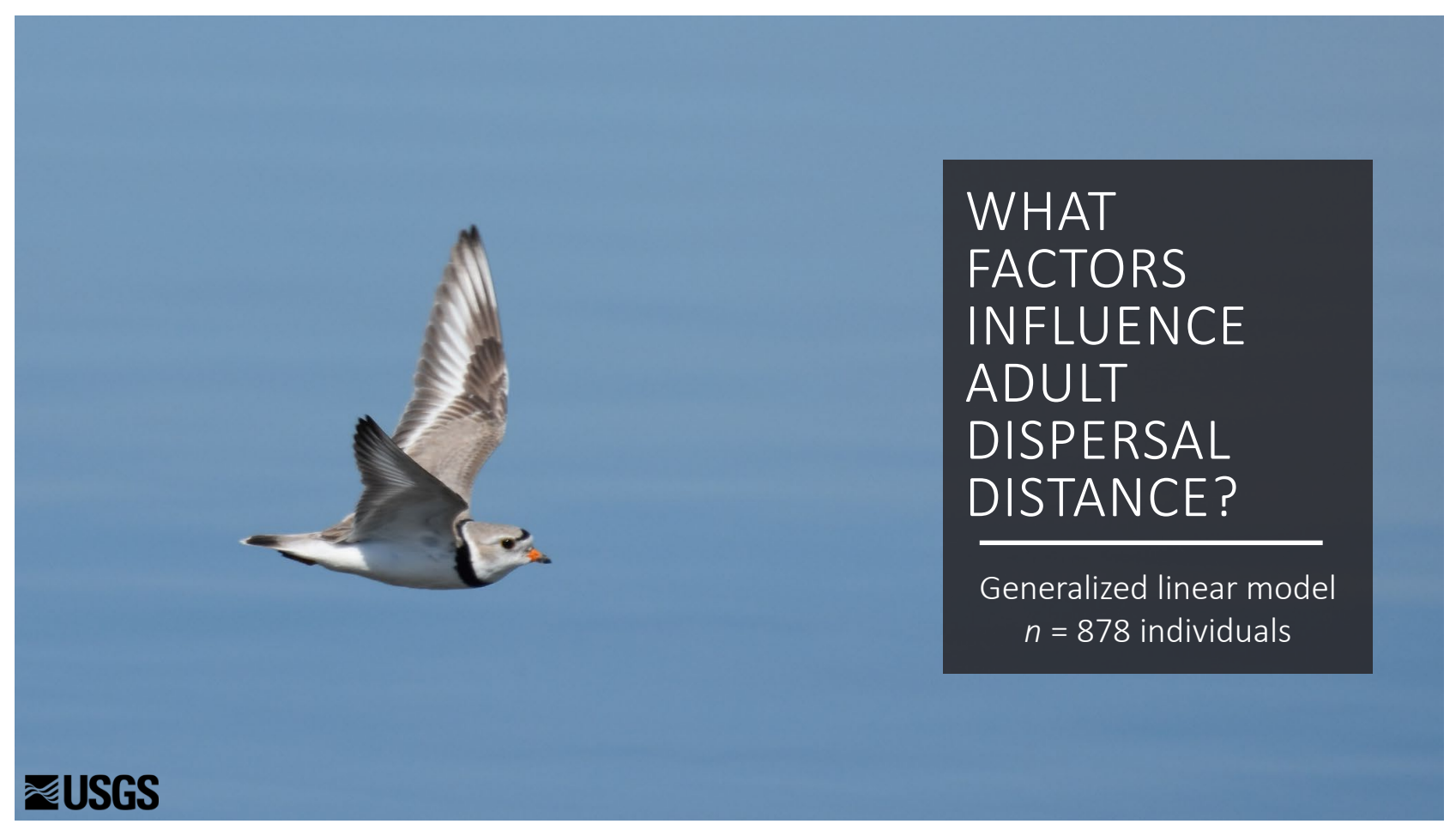

We calculated Euclidean dispersal distance as the distance between two successive breeding attempts for adults. Because piping plovers do not defend stable territories between years, we assumed that distances shorter than 50 meters (m) represented philopatric movements because the adults were likely using the same space in both years, and we removed them from our analysis. We investigated variation in dispersal distance in response to the a priori hypotheses on environmental, individual, and reproductive success factors. We examined sources of variation in dispersal distances using a generalized linear model. Additional details are provided in the "Dispersal Distances" section. [n, number] 


\section{Some individuals moved long distances between nests}

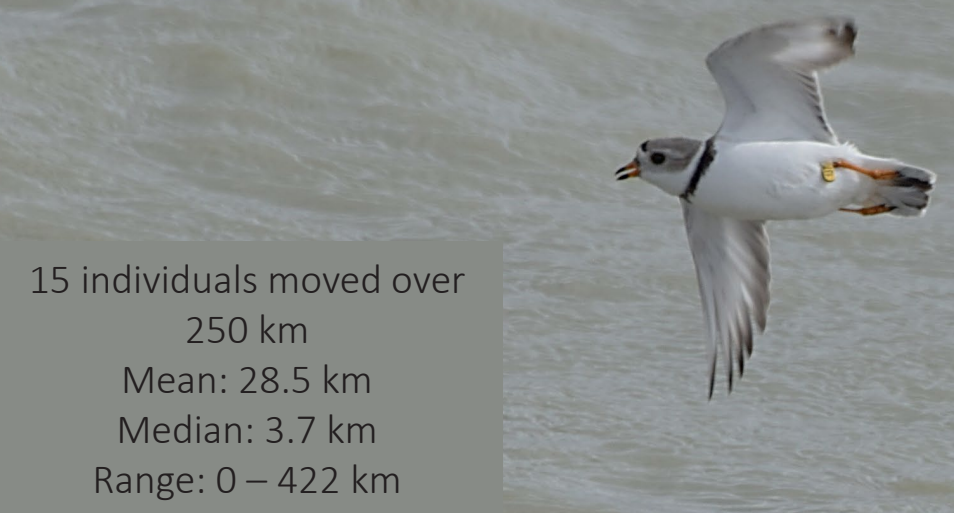

‡USGS

We observed 1,824 movements from 1,027 individuals. Adult movement distances varied widely (mean: $23.7 \mathrm{~km}$, median: $0.95 \mathrm{~km}$, range: $0-422 \mathrm{~km}$, coefficient of variation: $227.0 \mathrm{~km}$ ) and may include some philopatric individuals because we do not have data on piping plover territories. Adult movements showed low repeatability among years (Repeatability $=0.27$, confidence interval needed $=0.22$ to 0.32 ). After eliminating movements less than $50 \mathrm{~m}, 1,335$ adult movements remained for 878 individuals (mean: $28.5 \mathrm{~km}$, median: $3.7 \mathrm{~km}$ ). In total, 73 percent of the interannual breeding movements had no gap year between nest locations. The longest dispersal event within the focal study area was from Lake 0 ahe to a northwestern alkali wetland $(422 \mathrm{~km})$. In total, 15 individuals moved over $250 \mathrm{~km}$ within the focal study area. One individual dispersed between different management units four times during the study. 


\section{Adult dispersal distance varied based on seven covariates}

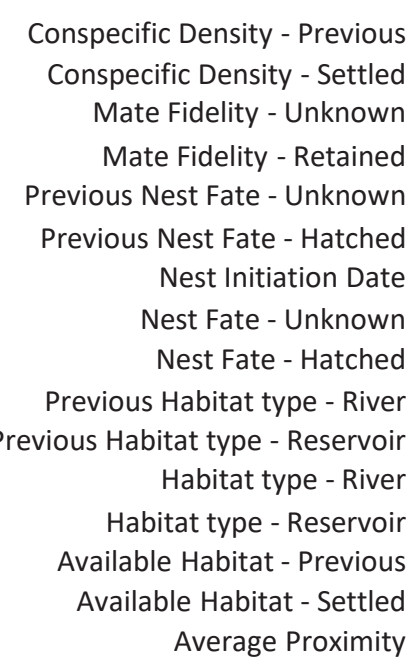

₹USGS

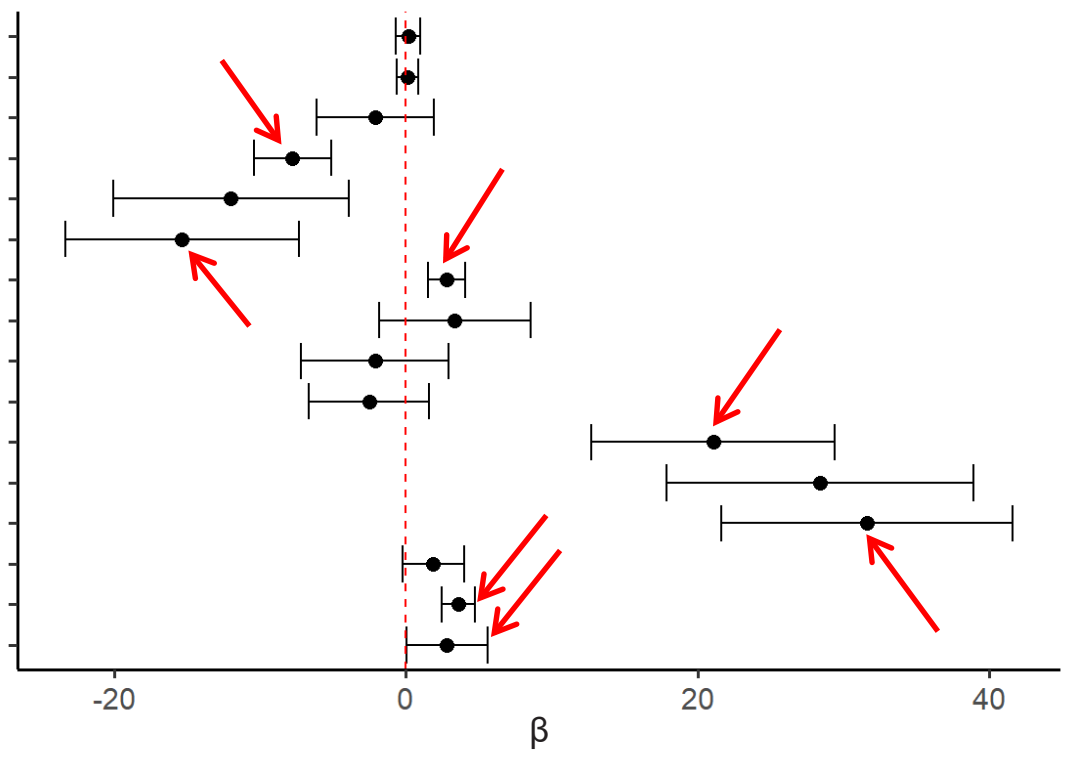

From the global fitted model with all a priori covariates included on adult dispersal distances, seven covariates (red arrows) seem important based on nonoverlapping 95-percent confidence intervals with zero. [Filled circles indicate mean $\beta$ estimate. Whiskers indicate 95-percent confidence intervals.]

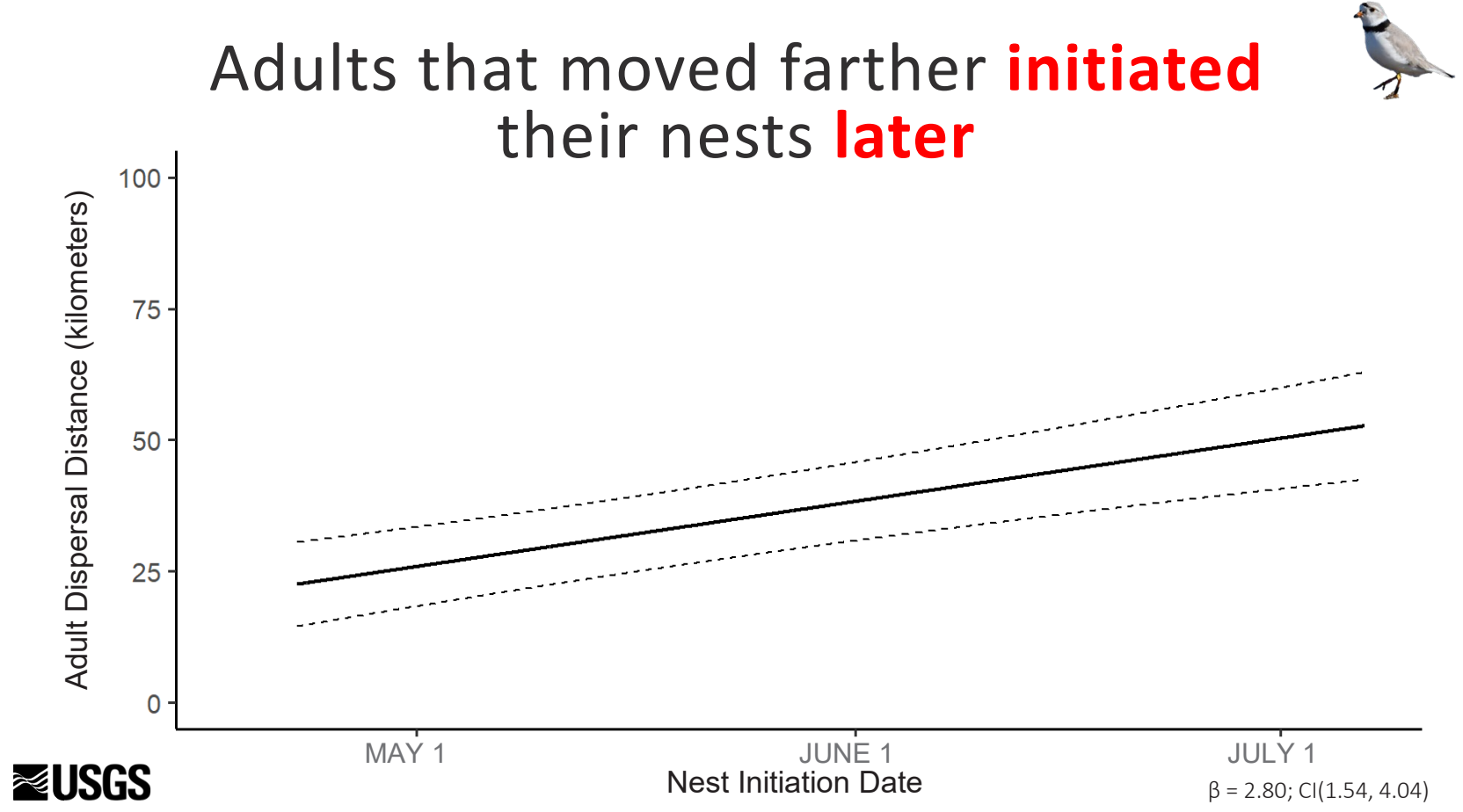

Longer distances were associated with later nest initiation dates on the settled site (solid line; $\beta=2.80 ; C l=1.54$ to 4.04). [Dashed lines indicate 95-percent confidence interval (CI).] 


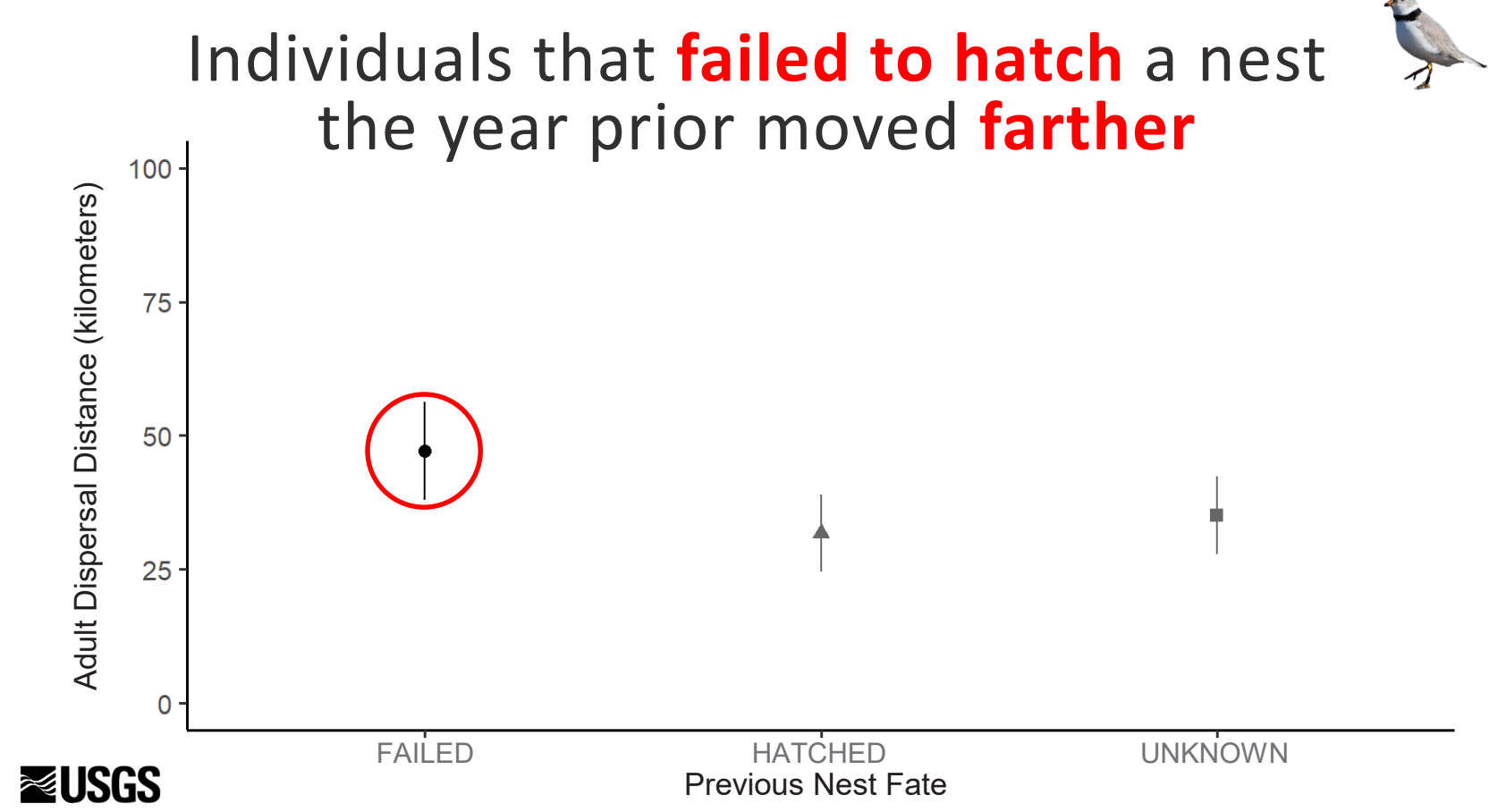

Individuals whose nests failed in the previous year's reproductive attempt moved longer distances (red circle), whereas a nest successfully hatching in the previous year's reproductive attempt shortened movement distances. [Filled points indicate mean distance estimates. Vertical lines indicate 95-percent confidence intervals.]

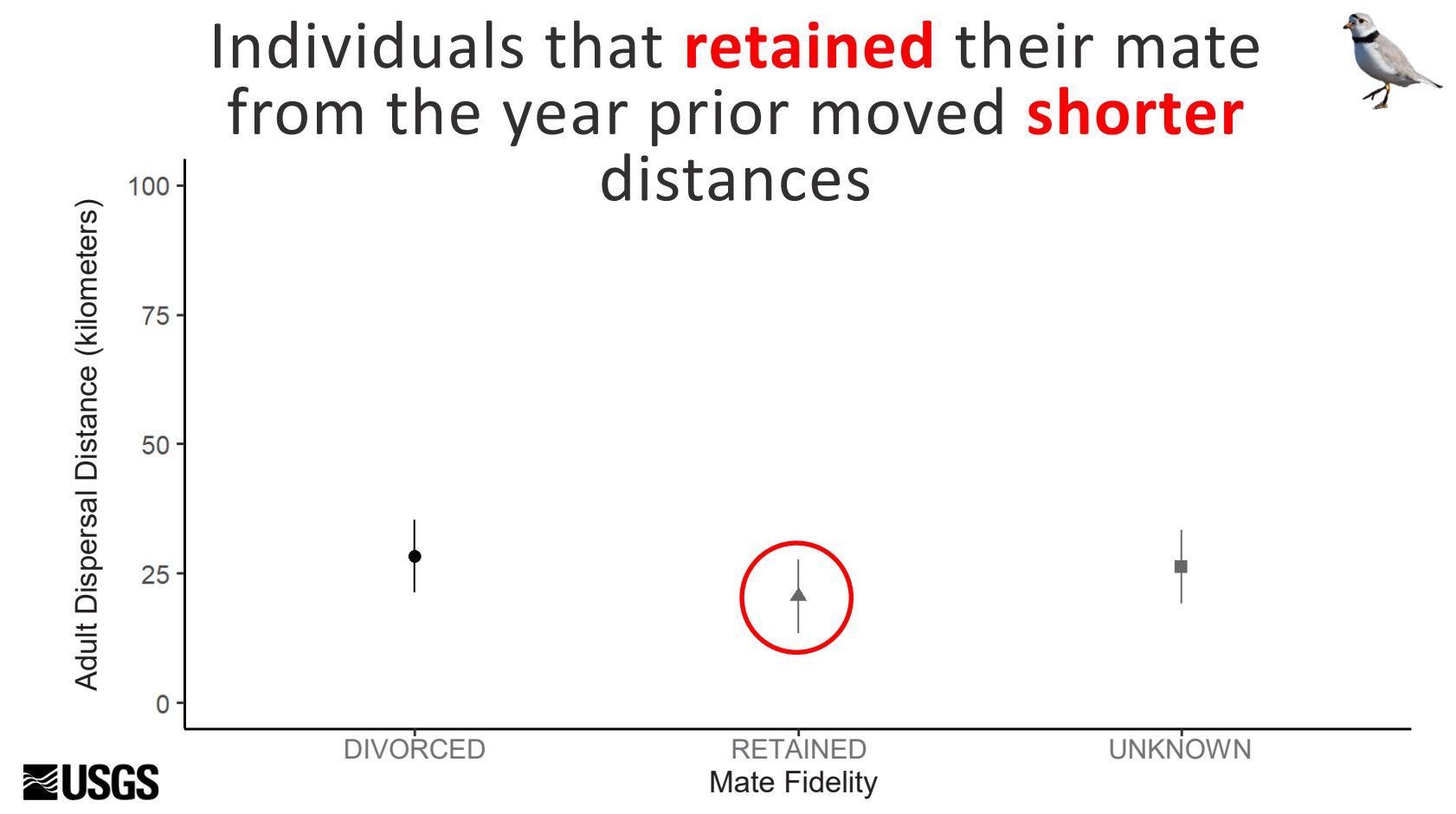

Individuals that divorced their mate from the previous year moved farther than those that retained their mate (red circle). [Filled points indicate mean distance estimates. Vertical lines indicate 95-percent confidence intervals.] 


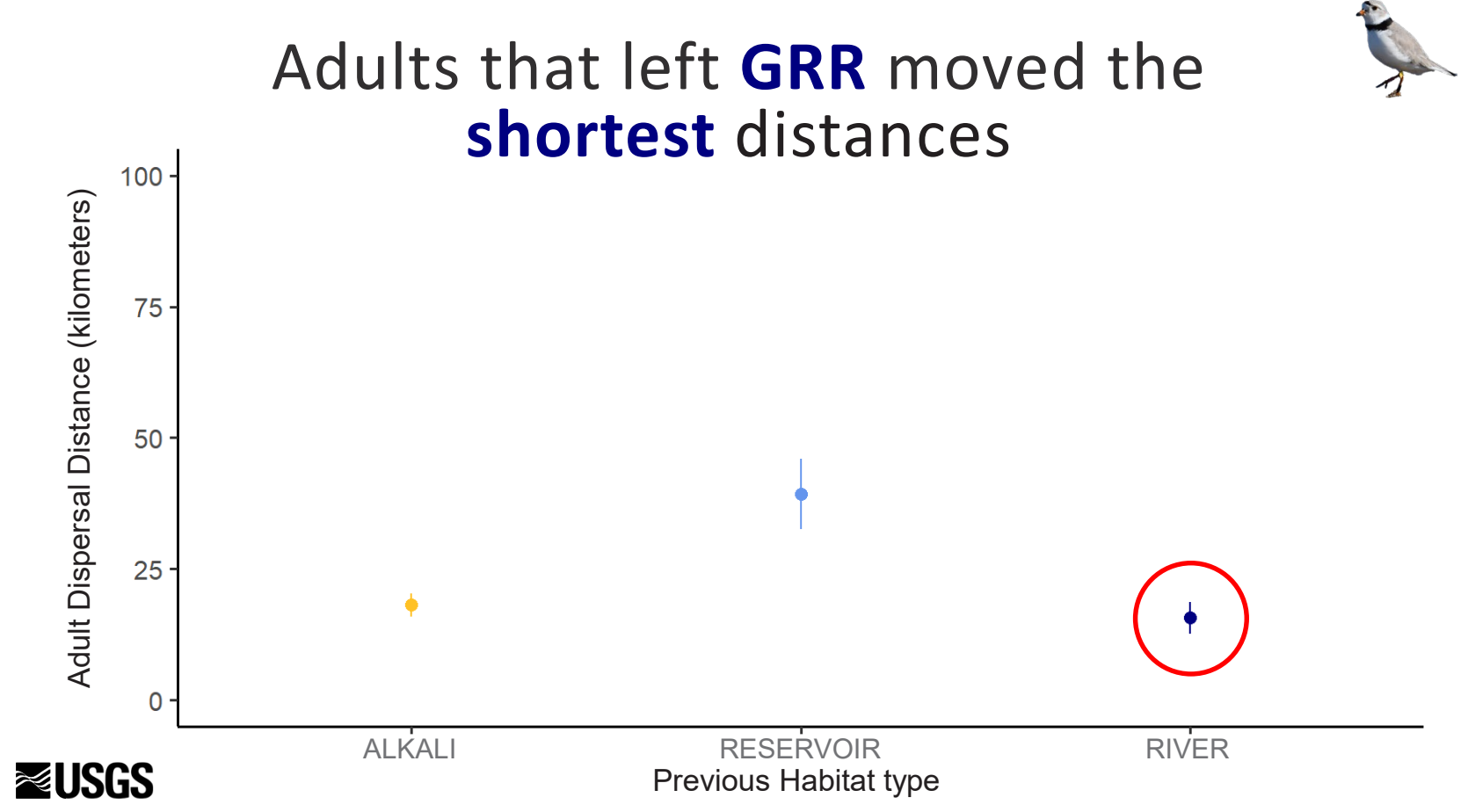

Individuals that previously bred on river habitats dispersed the shortest distances (red circle), whereas those that previously bred on reservoirs dispersed the farthest. [Filled points indicate mean distance estimates. Vertical lines indicate 95-percent confidence intervals.]

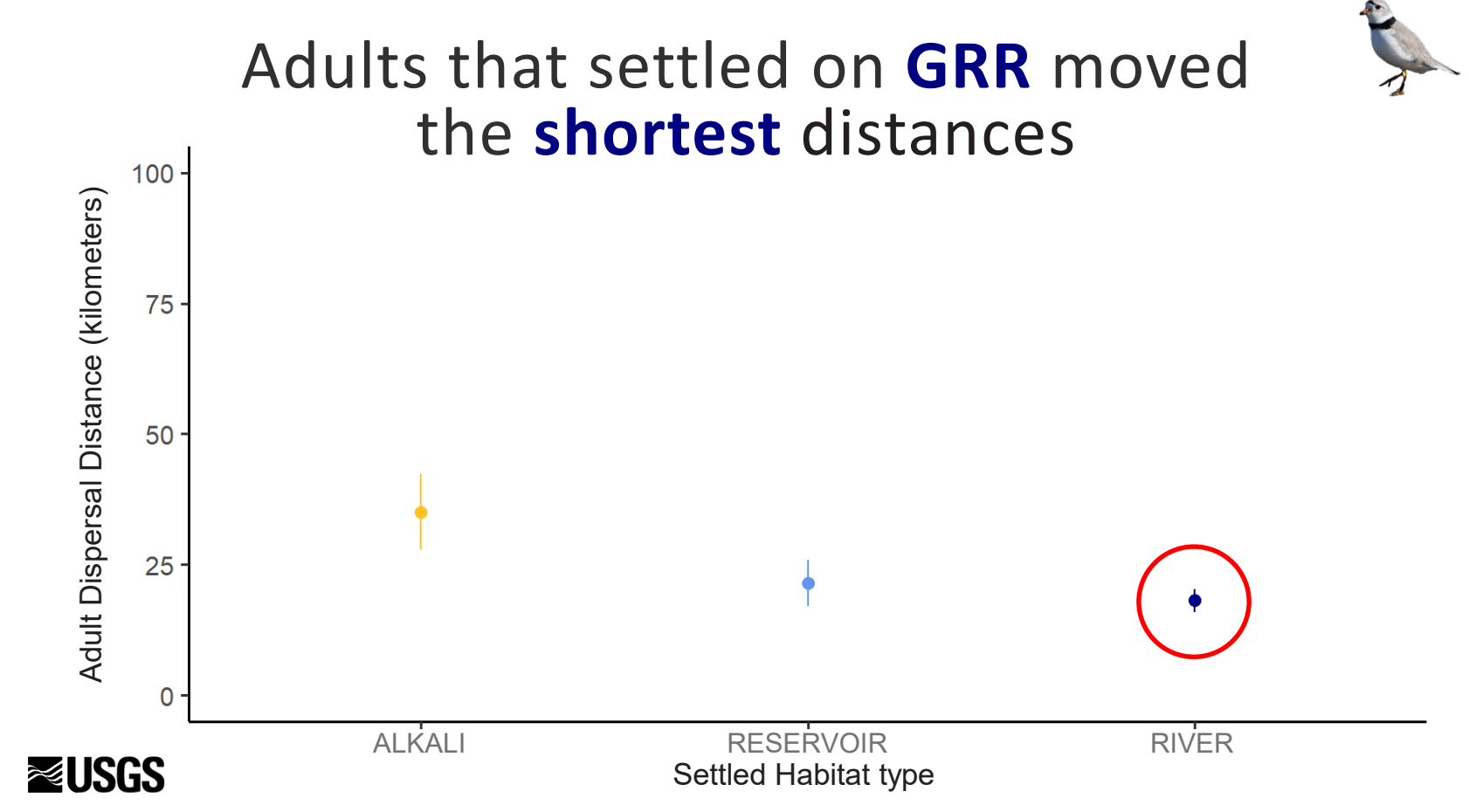

Individuals settling on river habitats dispersed the shortest distances (red circle), whereas those settling on alkali wetlands dispersed the farthest. [Filled points indicate mean distance estimates. Vertical lines indicate 95-percent confidence intervals.] 


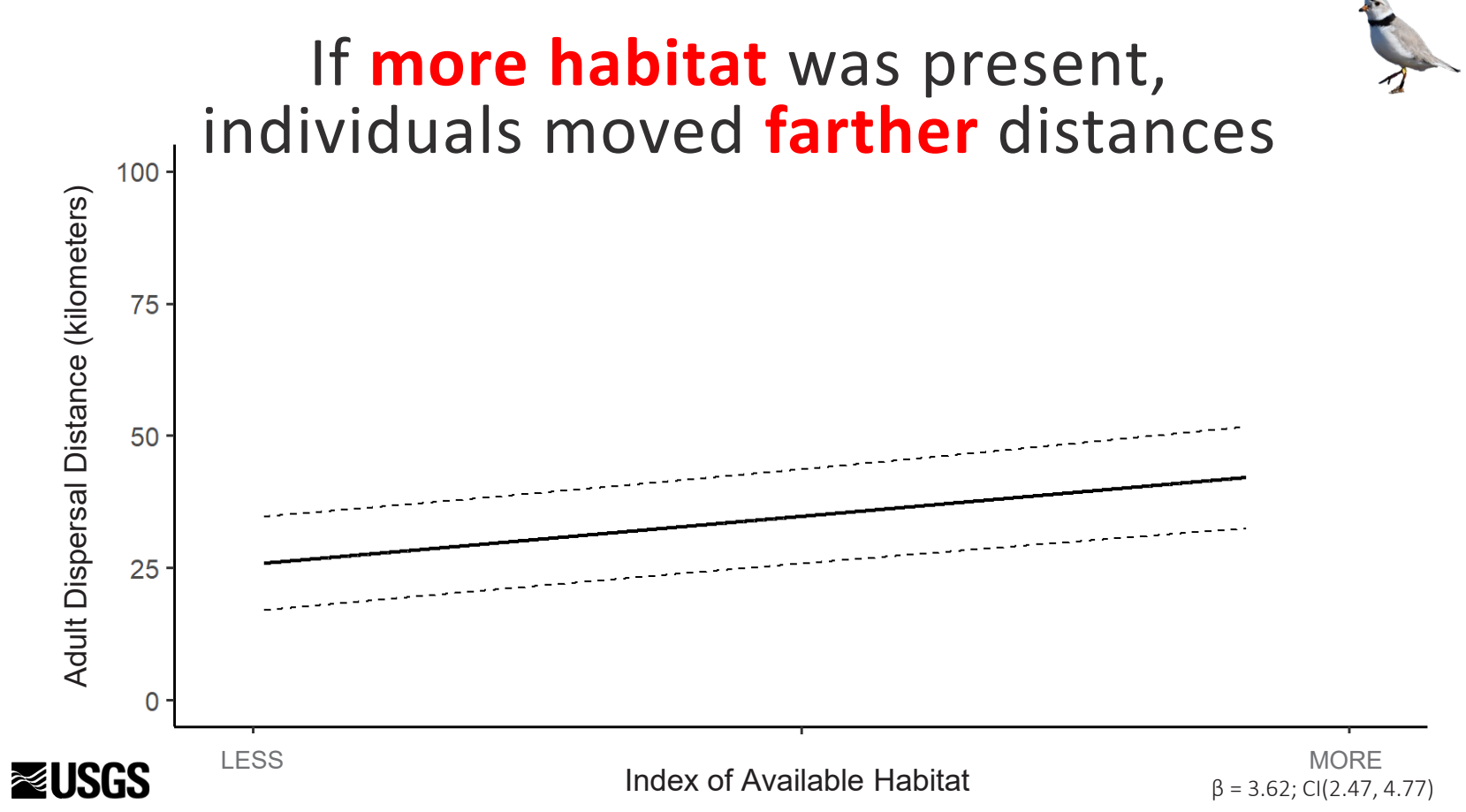

Individuals moved farther distances if there was more habitat available than the previous year (solid line; $\beta=3.62 ; \mathrm{Cl}=2.47$ to 4.77). [Dashed lines indicate 95-percent confidence interval (CI).]

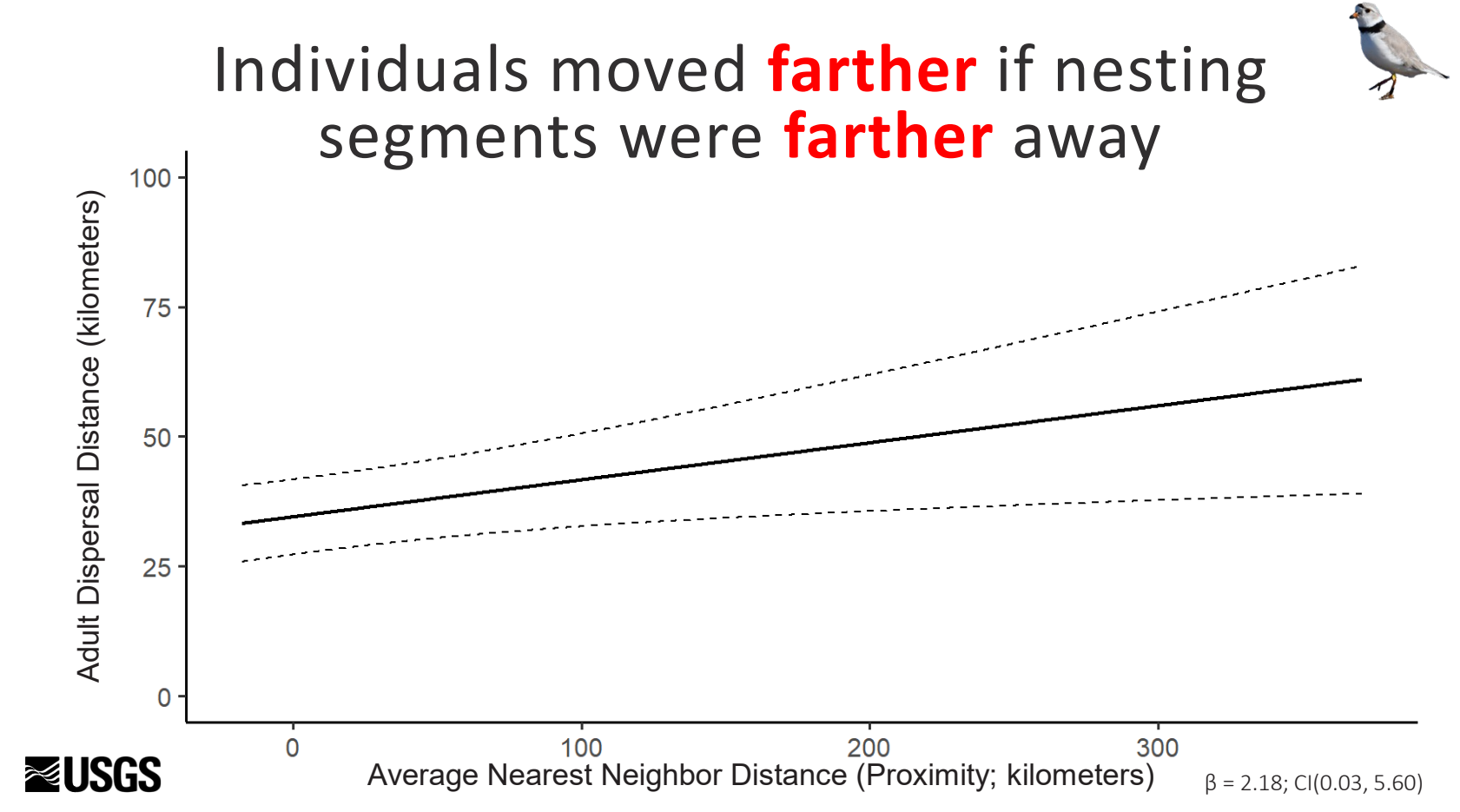

Breeding dispersal distances were shorter when settled sites were in closer proximity to other breeding segments (solid line; $\beta=2.18 ; \mathrm{Cl}=0.03$ to 5.60$)$. [Dashed lines indicate 95-percent confidence interval (CI).] 


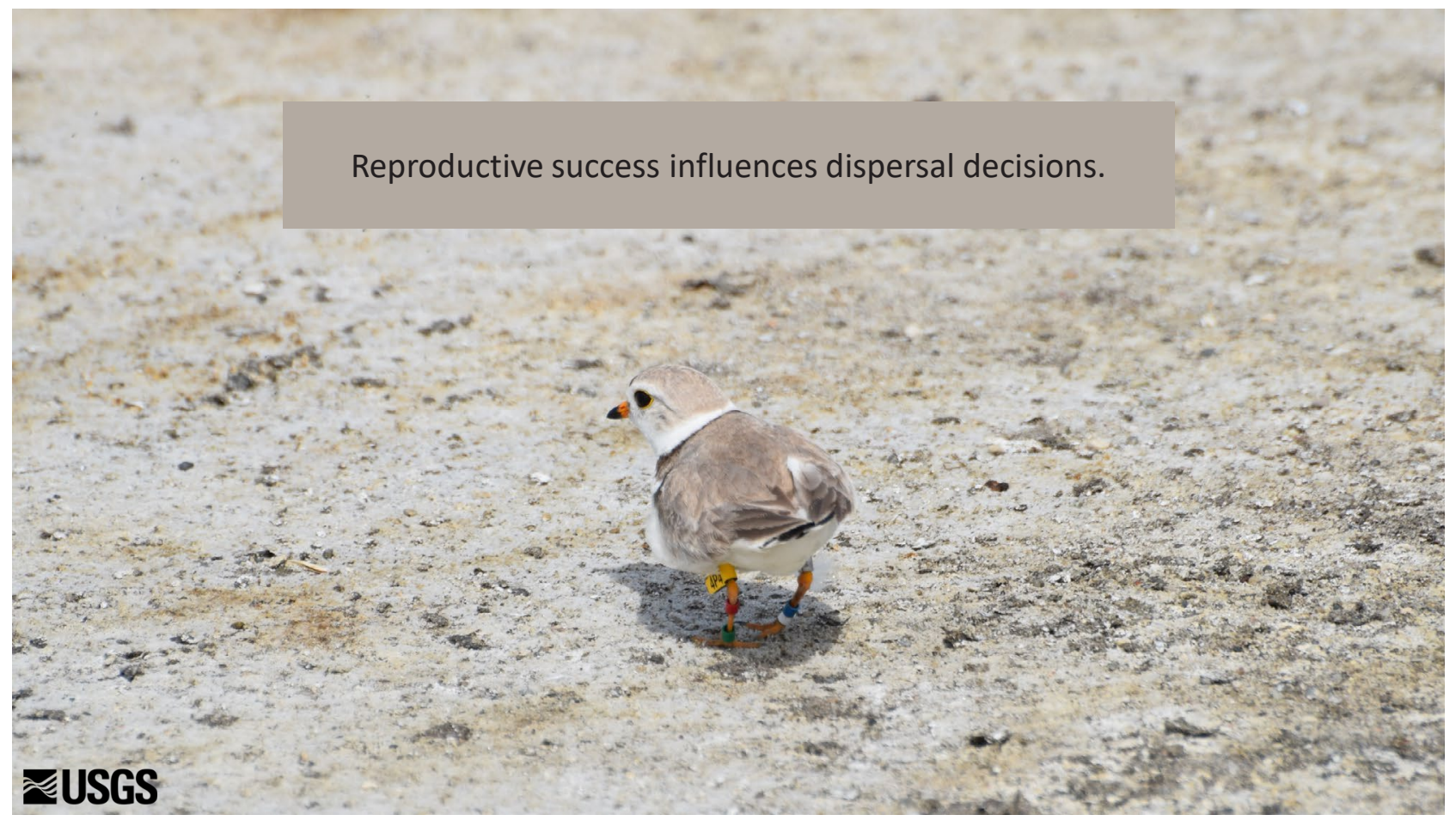

Previous and current reproductive success affected dispersal probabilities and interannual breeding distances for piping plovers. As we predicted, dispersal probabilities and distance increased for piping plovers that experienced hatching failure the previous year, and distance also increased for those that divorced their mate. Previous reproductive success can affect dispersal probabilities in piping plovers (Rioux and others, 2011; Roche and others, 2012), as would be expected because dispersal is only adaptive if fitness increases. Individuals that have low reproductive success presumably attempt to disperse to an area of higher quality the next year to increase reproductive output (Schaub and Von Hirschheydt, 2009; Lagrange and others, 2017), and individuals may divorce their mates to improve reproductive success (Halimubieke and others, 2020). Nests on alkali wetlands during this same period had higher survival rates compared to river or reservoir habitats (Swift and others, 2020b). Piping plovers dispersed the farthest when settling to breed on alkali wetlands. Although this could be due to the inherent dispersed nature of habitat within the alkali wetlands, individuals could also move to alkali wetlands to improve future reproductive success. However, longer dispersal distances may still retain some costs for piping plovers. Individuals that moved farther initiated their current nest later in the breeding season, likely a manifestation of some immediate travel cost to individuals or because of difficulties locating a new territory or mate. Delayed breeding suggests that long-distance dispersal may have fitness consequences because daily nest survival declines later in the breeding season for piping plovers in all three habitat types (Swift and others, 2020b). This study did not find other potential costs, such as reduced survival, which could also reduce potential fitness benefits of dispersing farther. 


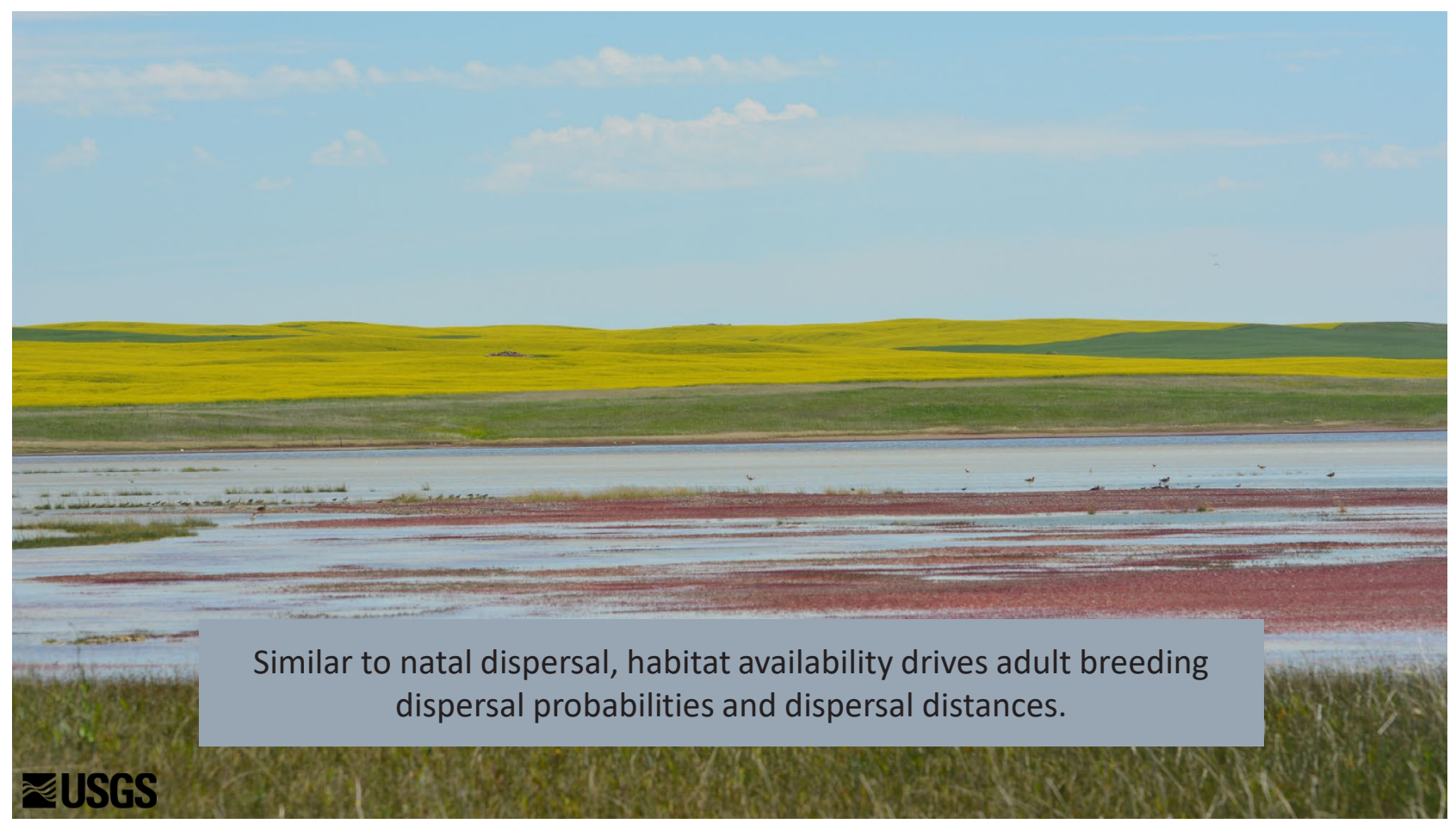

Adult dispersal probabilities increased the year after habitat availability increased, which was contrary to our prediction. This was similar to our finding of natal dispersal probability in relation to natal-year habitat and could be driven by density-dependent processes the year after a good reproductive event. Similarly, adult individuals moved farther distances in response to more habitat available than the previous year. 


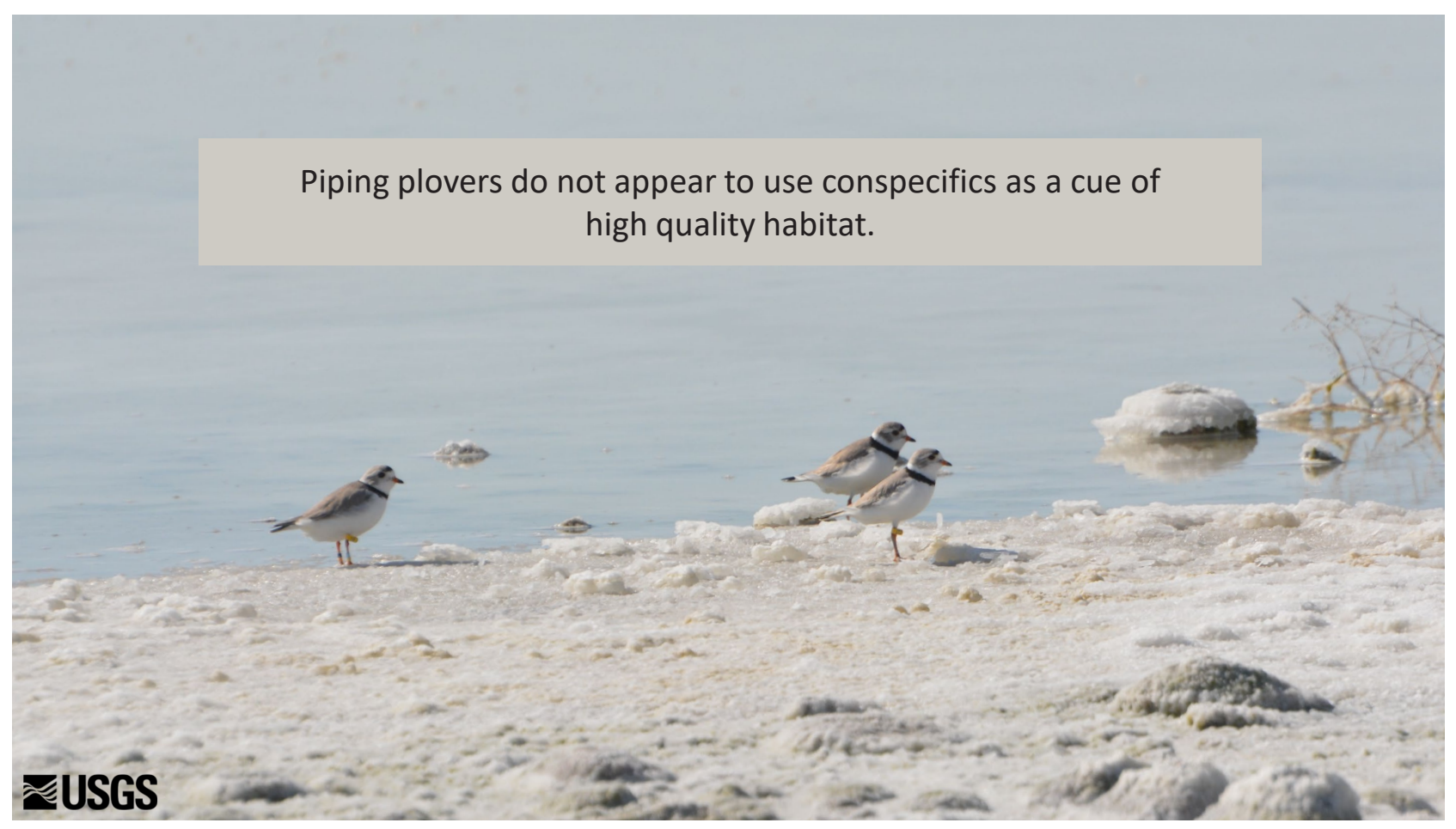

Conspecific densities during the breeding season can confer varied effects on piping plover reproduction, including rates of double brooding (Hunt and others, 2015) and nest survival (Swift and others, 2020c). Although density-dependent dispersal is thought to be due to limitations in available habitat, we failed to detect a relation between dispersal probabilities or movement distance with adult density at the settling site. Adult piping plovers have used public information (Danchin and others, 2004) to select nesting sites when there is interannual variation in habitat quality (Rioux and others, 2011). The lack of support for a relation between natal dispersal distance and chick or adult densities may indicate that first-time breeders are constrained to lower-quality nesting habitats because of intraspecific competition. Our results differ from previous findings from other study areas (Catlin and others, 2015; Rioux and others, 2011); therefore, piping plover dispersal may be mediated by density-dependent processes in some, but not all, habitats. True habitat-based density estimates might further enlighten this relation. Indeed, an international piping plover census indicated that piping plovers do not use all apparently suitable habitats within their geographic range (Plissner and Haig, 2000), suggesting that a better understanding of the factors contributing to habitat quality is still needed. 


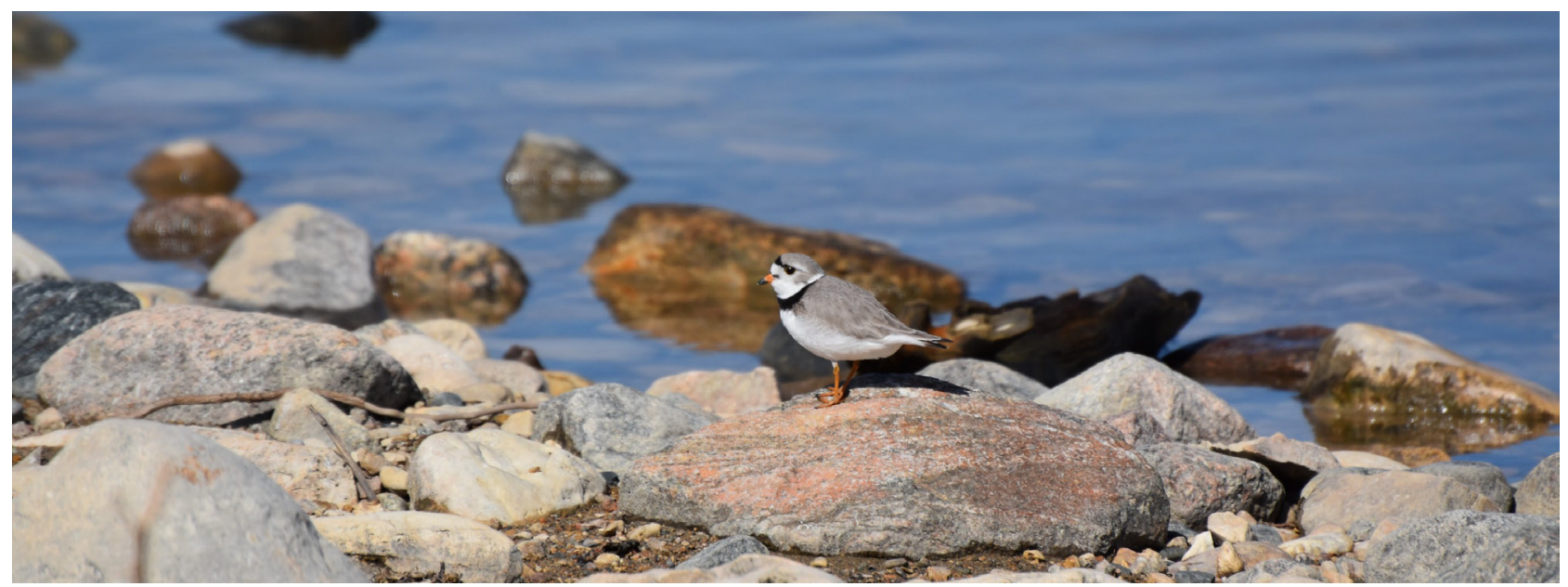

CAN RENESTING BE AN EFFECTIVE REPRODUCTIVE STRATEGY AND HOW DOES IT INFLUENCE CONSERVATION OF PIPING PLOVERS?

Objective 6

Swift and others 2020b, The Auk

\title{
※USGS
}

Swift and others (2020b) examined how renesting propensity, renesting intervals, and renest reproductive success may be an effective reproductive strategy of NGP piping plovers. Here, we will present a subset of this work.

\section{Renesting propensity}

\author{
Loss of nest or brood leads to decisions: \\ to have another nest attempt or not \\ to divorce or to move and how quickly
}

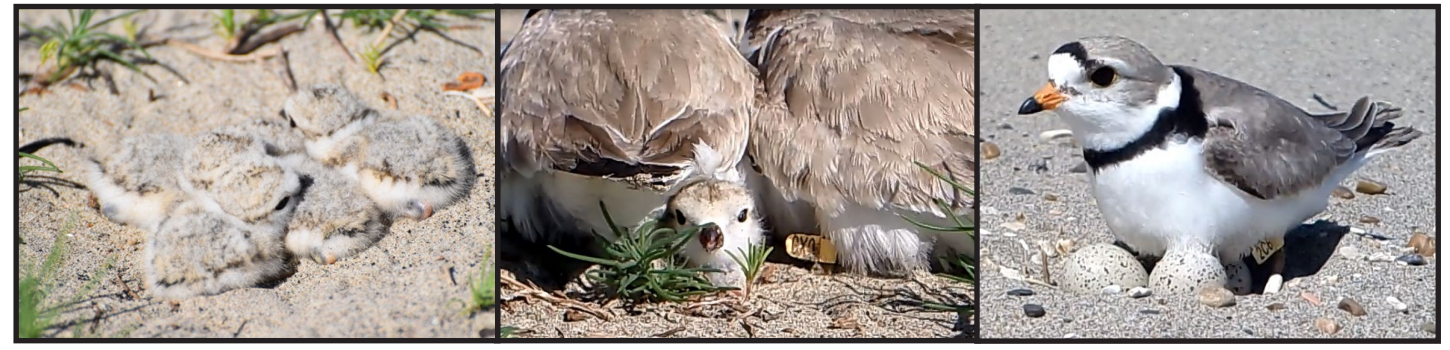

\section{ॠUSGS}

Upon reproductive failure, many bird species make a secondary attempt at nesting (hereafter called "renesting"). Renesting may be an effective strategy to maximize current and lifetime reproductive success, but individuals face uncertainty in the probability of success because reproductive attempts initiated later in the breeding season often have reduced nest, prefledging, and postfledging brood survival. 


\title{
Productivity of the system
}

\author{
Nest loss and renesting probabilities have \\ implications for productivity, recruitment, and, \\ ultimately, population demography
}

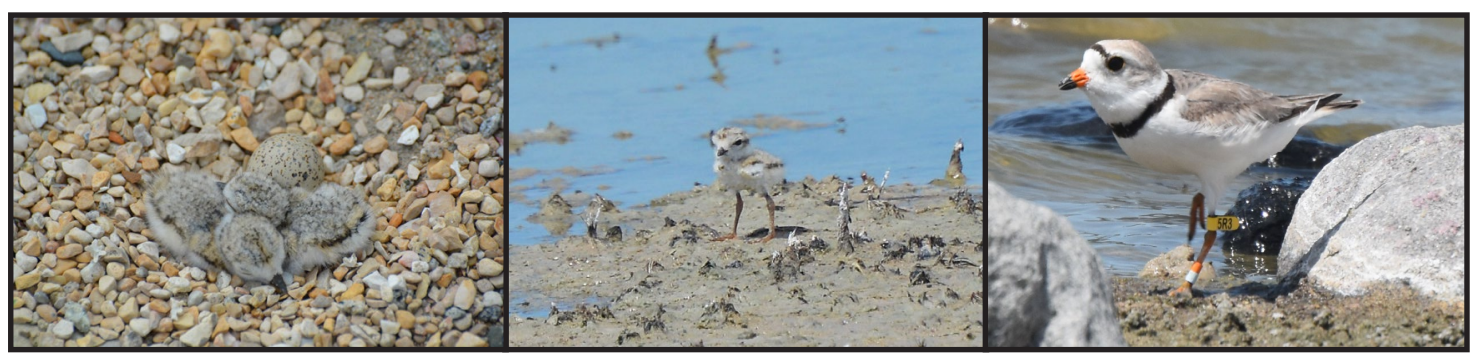

\section{‡USGS}

Although the benefit of successful renesting is obvious, the laying of replacement clutches may increase lifetime reproductive success only if this strategy does not inflict severe costs, such as a reduction in future fecundity or survival of breeders, as predicted by life-history theory. At best, renesting can only partially compensate for high rates of nest failure. Renesting can make important contributions to an individual's annual fecundity and lifetime reproductive success, and replacing lost clutches may be an important reproductive strategy especially for species with high rates of nest failure (Arnold, 1993; Sandercock and others, 1999; Arnold and others, 2010). Clearly, quantifying renesting behavior is important for modeling population dynamics and for obtaining estimates of fecundity (Hoekman and others, 2002; Pakanen and others, 2016). However, renesting propensity is poorly understood, and demographic models frequently lack accurate estimates of renesting rates, which can lead to underestimates of fecundity and overestimates of population size (Sandercock and others, 2008; Arnold and others, 2010). For species of conservation concern, accurate demographic parameters are essential for ensuring conservation and management efforts are focused on processes that are most critical, particularly in dynamic and stochastic environments (Pakanen and others, 2016). 


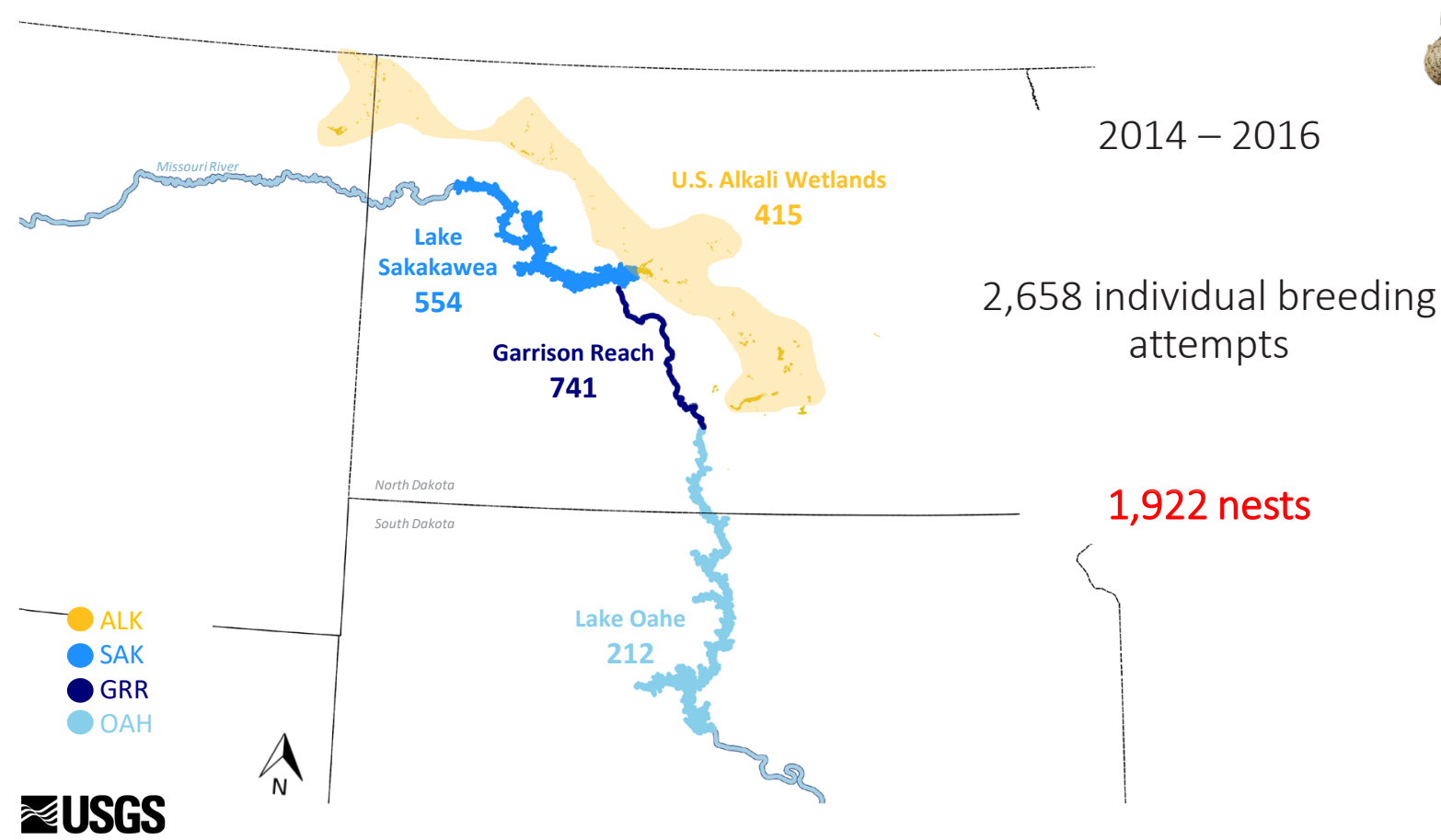

We obtained data from 2,658 individual breeding attempts representing 1,785 unique individuals. We monitored 1,922 nests over 3 years (2014-16); individual sample sizes are shown on map. Most nests were found on the GRR ( $n=741)$, and OAH had the fewest nests $(n=212)$ over the 3 years.

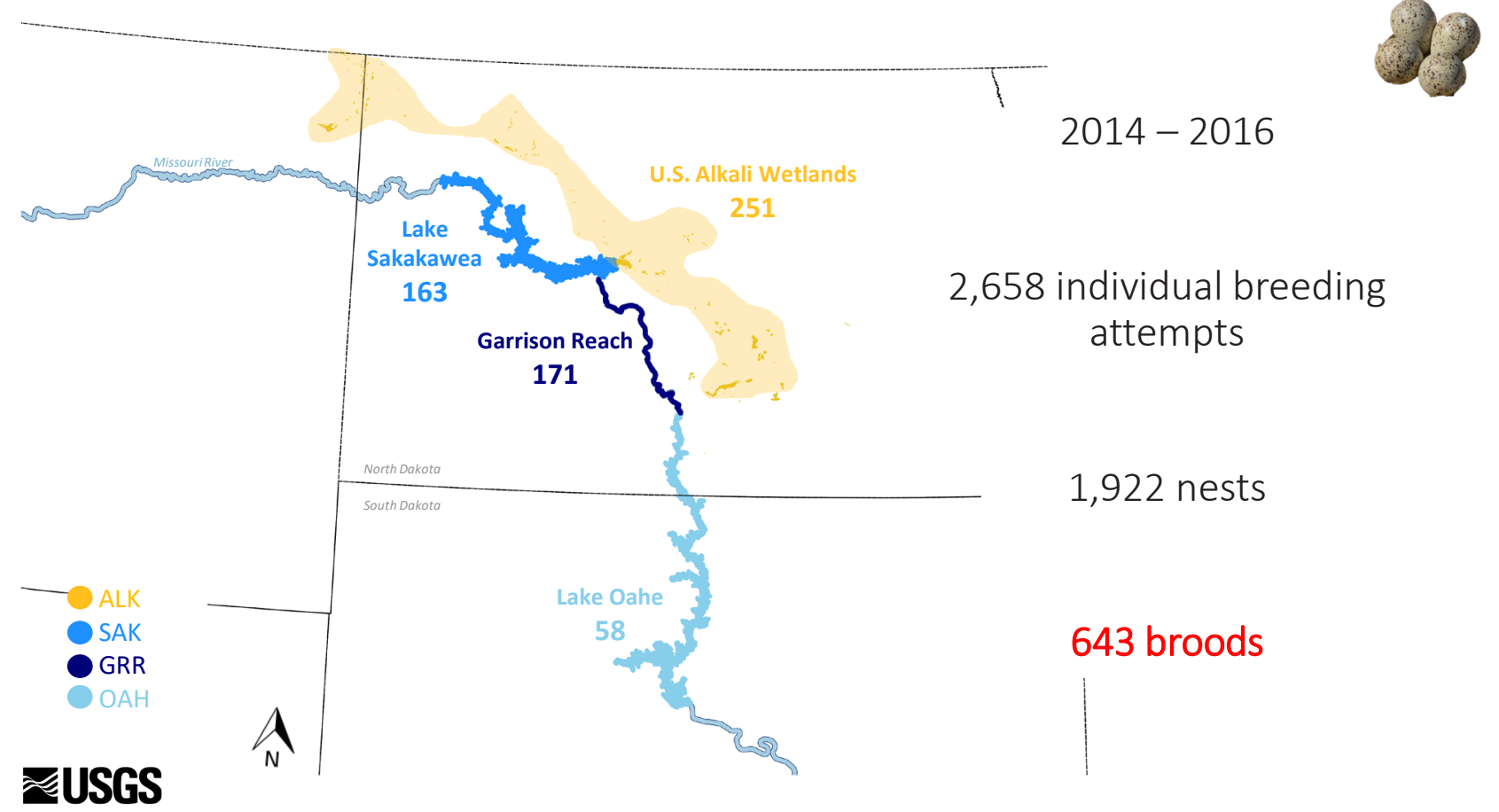

Of those 1,922 nests, we followed 643 broods from hatch to at least 21 days posthatch; individual sample sizes are shown on map. Most chicks were banded on the ALK ( $n=251)$ and OAH had the fewest chicks $(n=58)$ over the 3 years. 


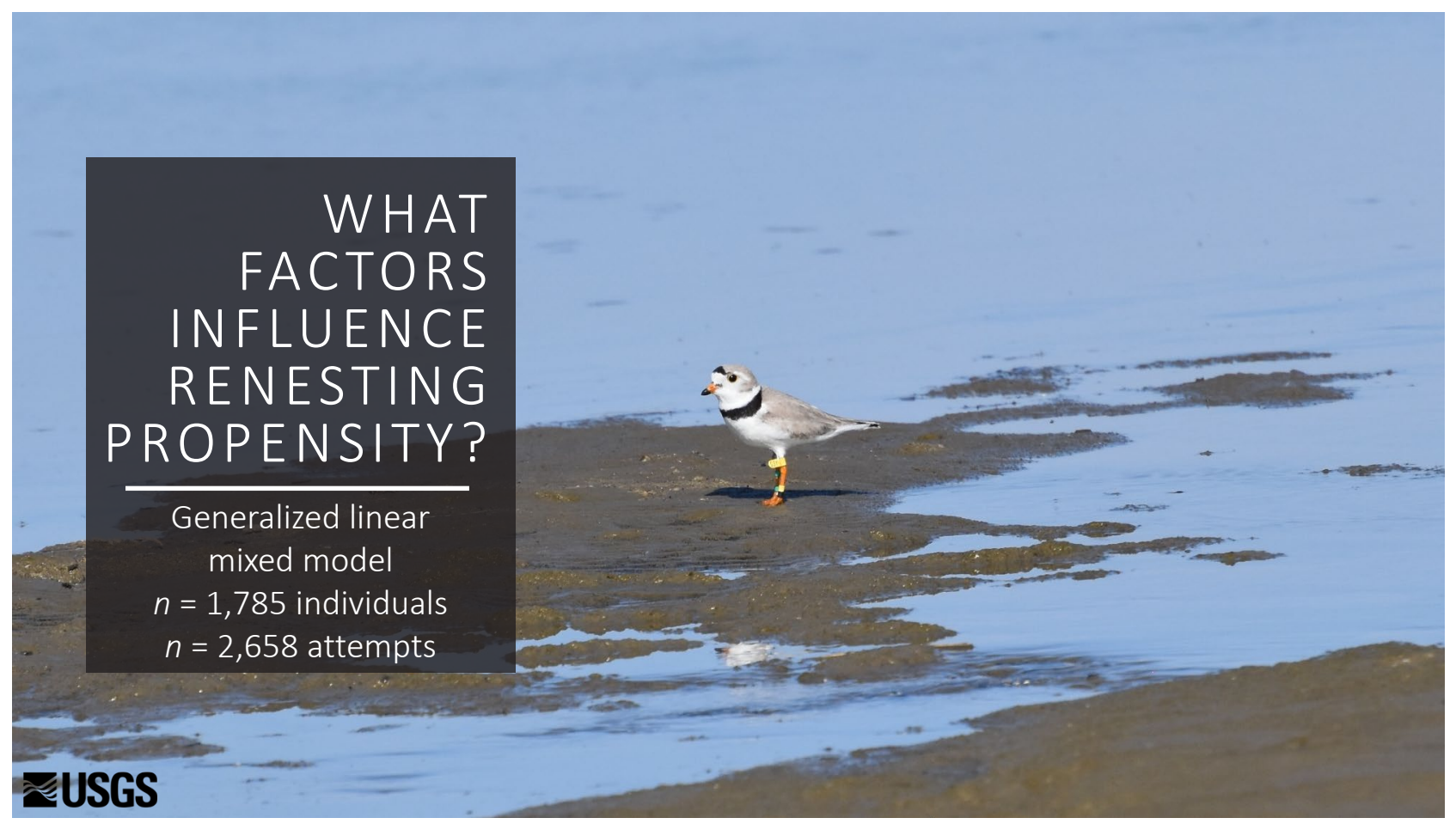

A renest was defined as an additional reproductive attempt after a failure. We examined the nesting period (egg laying and incubation until hatching) and the brood-rearing period (hatching to 21 days posthatch). We defined apparent renesting propensity as the proportion of individuals that renested after a failed previous reproductive attempt (Arnold, 1993; Claassen and others, 2014). Reproductive failure could occur during either nesting or brood-rearing stages. We investigated sources of variation in renesting propensity using a generalized linear mixed model. See the "Renesting" section for more detailed methodology. [n, number] 


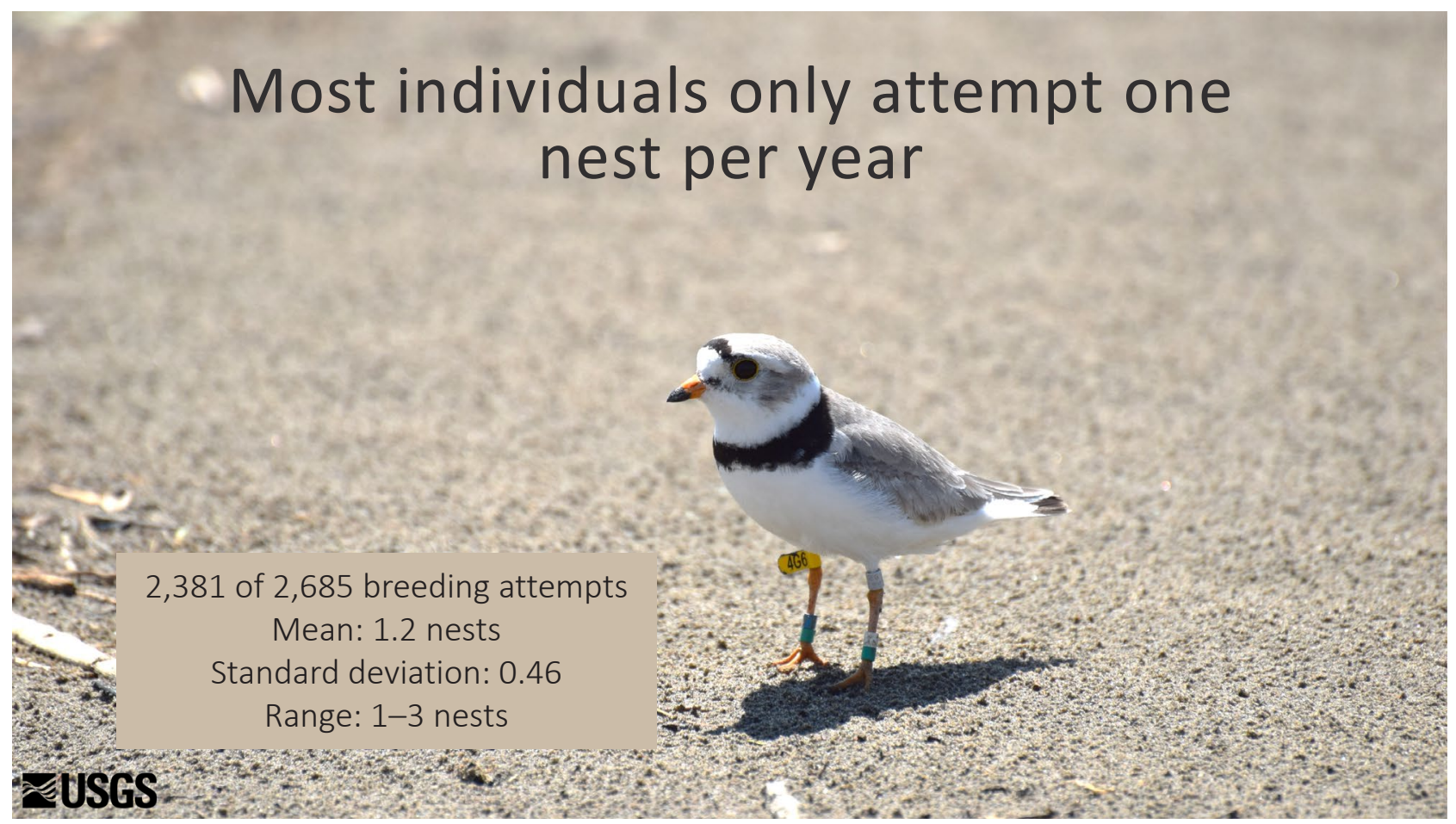

Overall, most individuals only attempted 1 nest per year (mean: 1.2 nests, standard deviation: $0.46, n=2,381$ of 2,685 individual breeding year attempts). In total, 10 individuals attempted 3 nests, and 256 individuals attempted 2 nests within 1 year. Estimates of renesting propensity represent minimum values because some nests likely failed prior to detection.

\section{About 10 percent of individuals moved habitat types between renesting attempts}

\section{ॠUSGS}

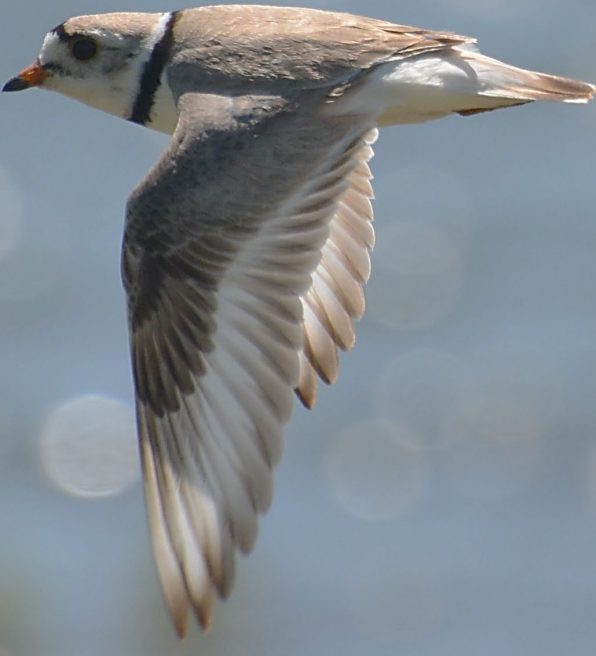

We found that 10 percent of individuals that renested changed habitat types between the first and renest attempts. Of those, 70 percent of individuals that moved left reservoir habitats; whereas only 19 percent left river habitats, and 11 percent left the alkali wetlands. 


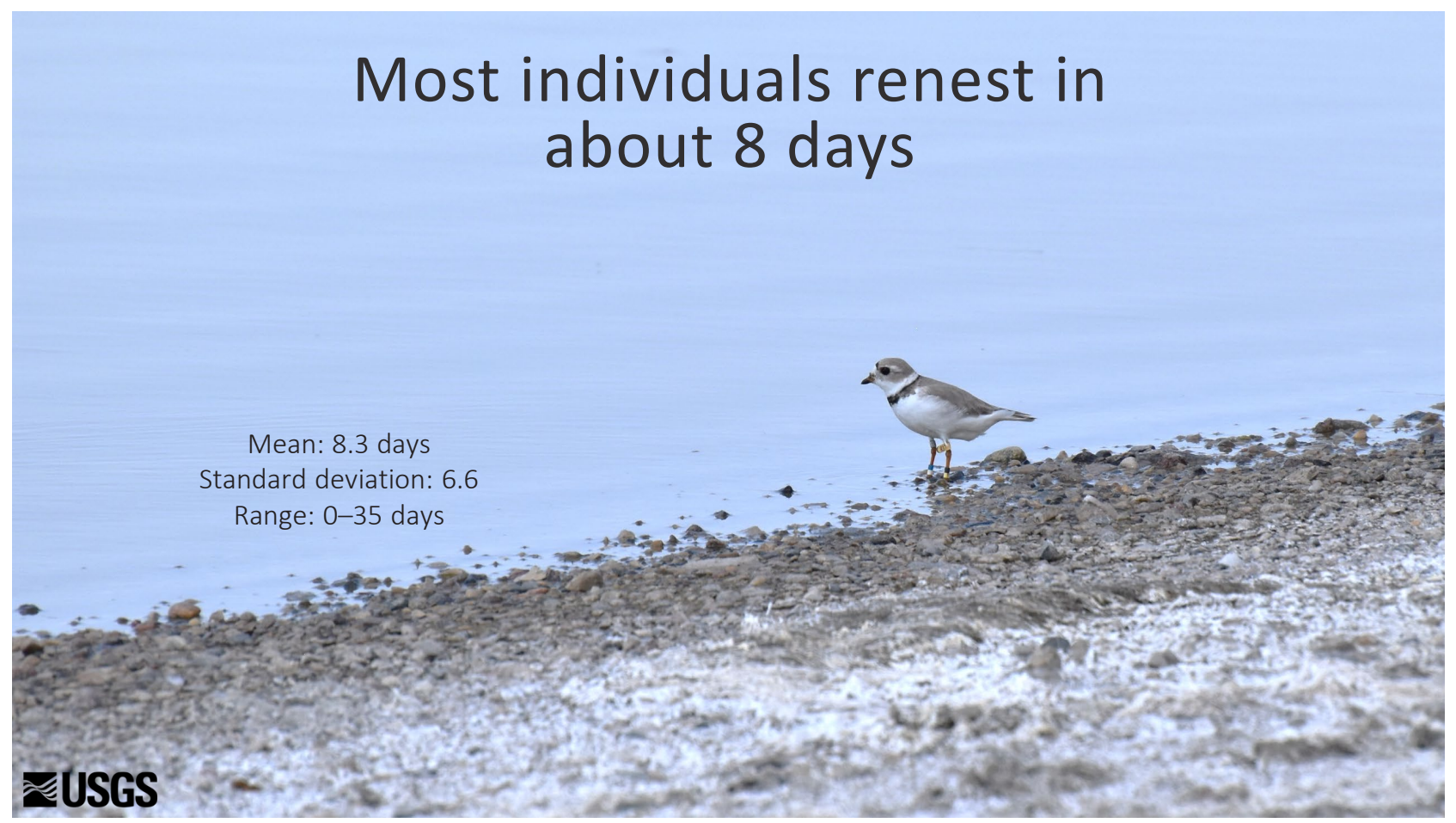

There was a wide range of estimated renest intervals (the periods between the date the first nest failed and the estimated first egg date of the renest). See Swift and others (2020b) for detailed analysis on the factors that affected renest intervals.

\section{6 percent of reproductive failures renest}

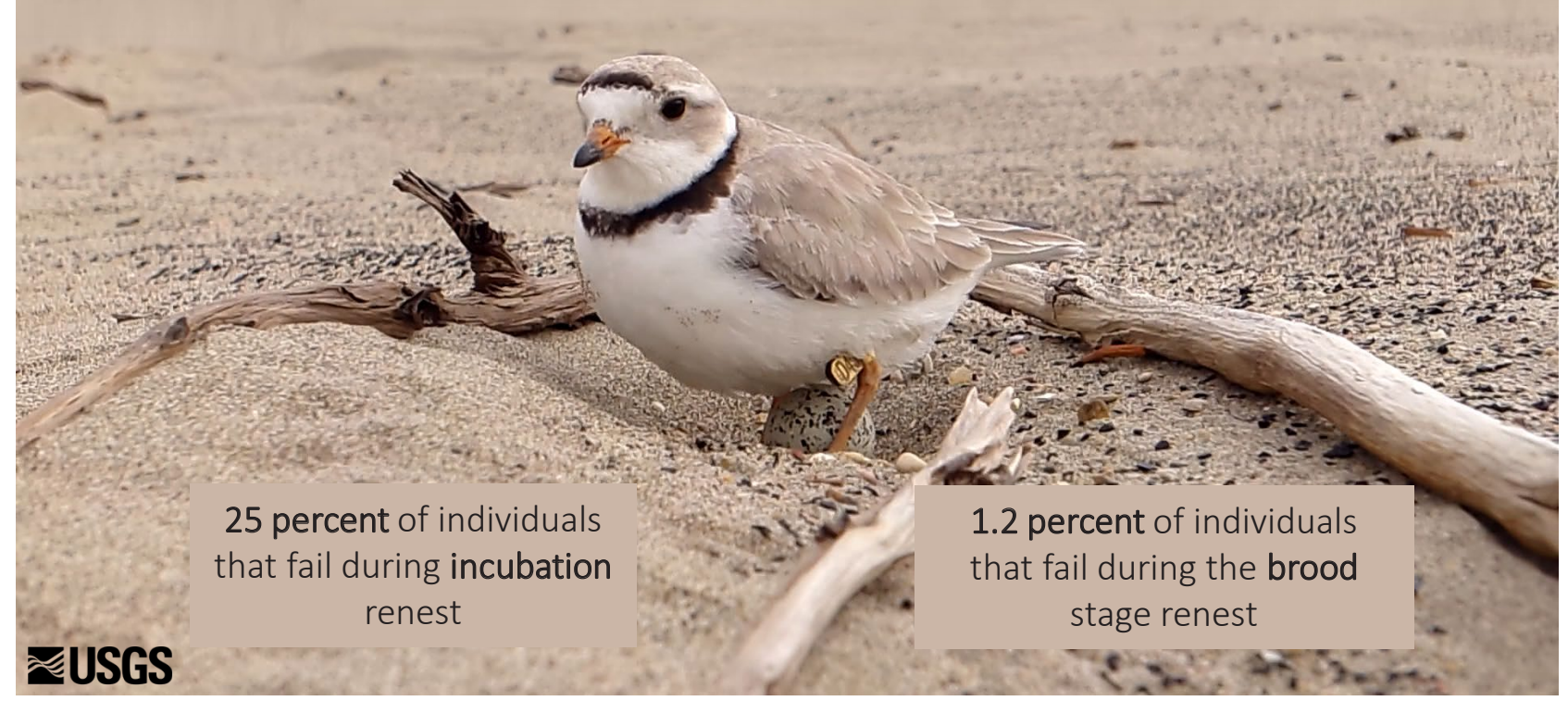

Piping plovers renested 247 times after 1,501 failed individual breeding attempts, a 16-percent apparent renesting propensity. This propensity differed based on the stage of reproductive failure; individuals renested after 240 of 960 (25 percent) attempts that failed in the nesting stage, but renested after only 7 of 541 (1.2 percent) broods failed. 


\section{Renesting propensity varied based} on four covariates

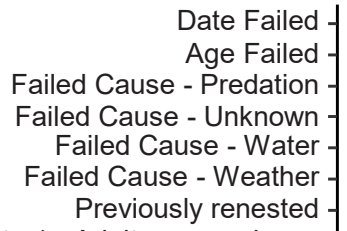

Mate 1 - Adult no experience Mate 1 - Adult prior experience Mate 1 - 2nd year no experience Mate 2 - Adult no experience Mate 2 - Adult prior experience Mate 2 - 2nd year no experience 2015 2016

Habitat type - River Habitat type - Reservoir Available Habitat Landform - Island

Habitat type - River : Available Habitat Habitat type - Reservoir : Available Habitat

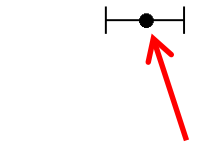

个

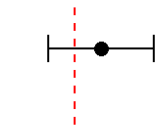

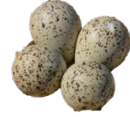

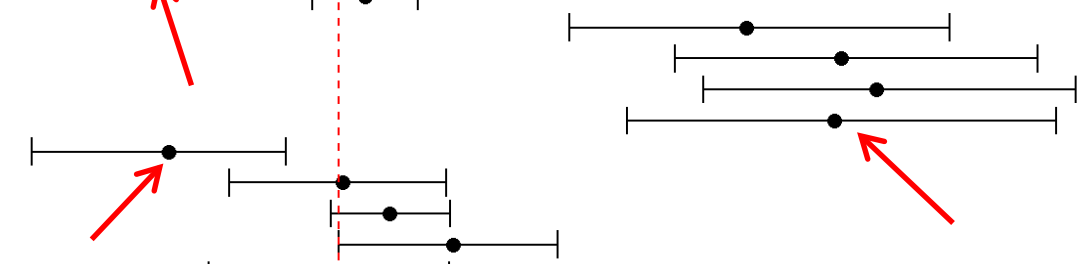

\section{‡USGS}

From the global fitted model with all a priori covariates included on renest reproductive success, four covariates (red arrows) seem important based on nonoverlapping 95-percent confidence intervals with zero. [Filled circles indicate mean $\beta$ estimate. Whiskers indicate 95-percent confidence intervals.]

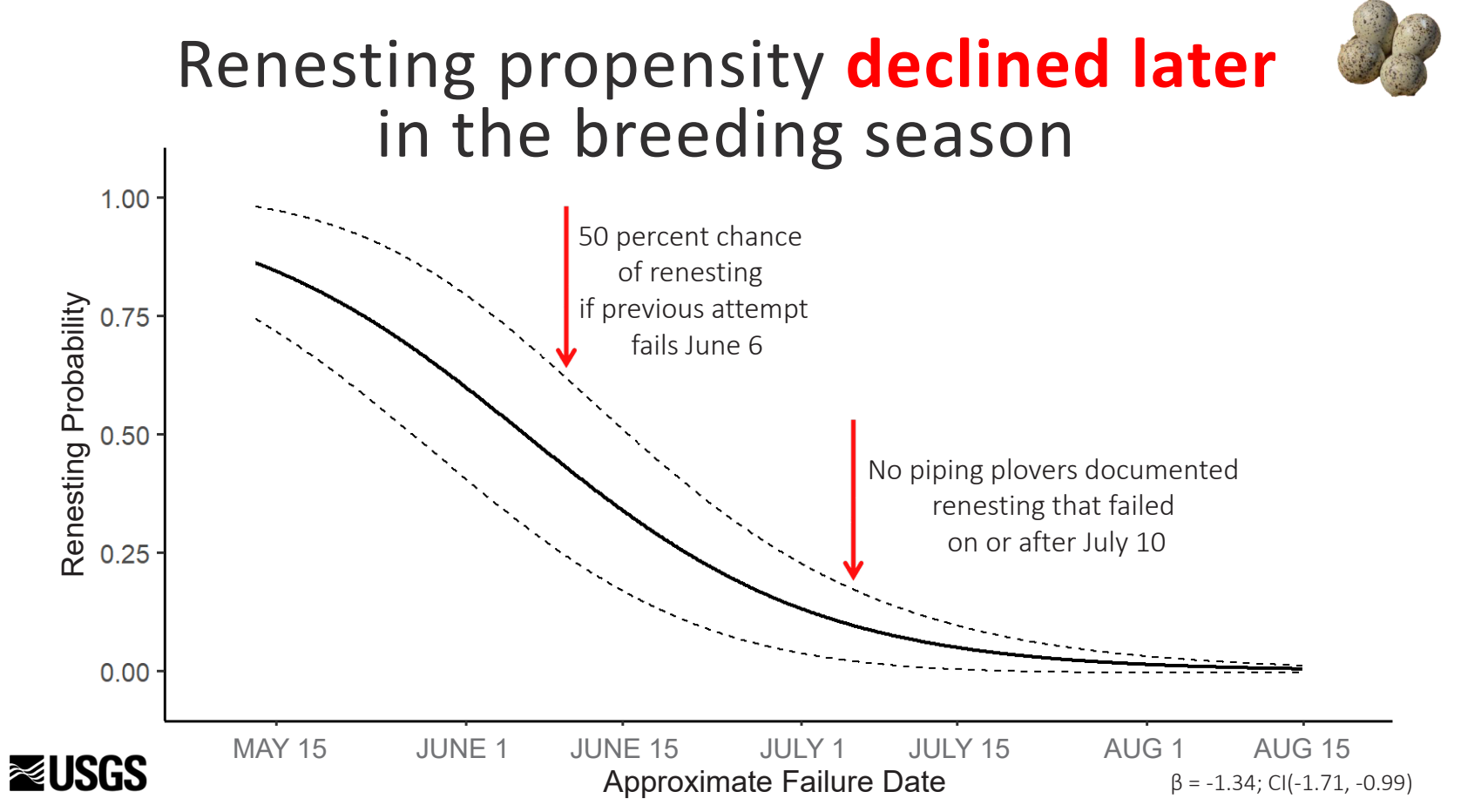

Renesting propensity decreased with later dates of reproductive failure (solid line; $\beta=-1.34 ; C l=-1.71$ to -0.99 ). No piping plover was documented renesting that failed after July 10 . Our predictive model states a roughly 50 -percent chance of renesting if the previous attempt failed on June 6. [Dashed lines indicate 95-percent confidence interval (CI).] 


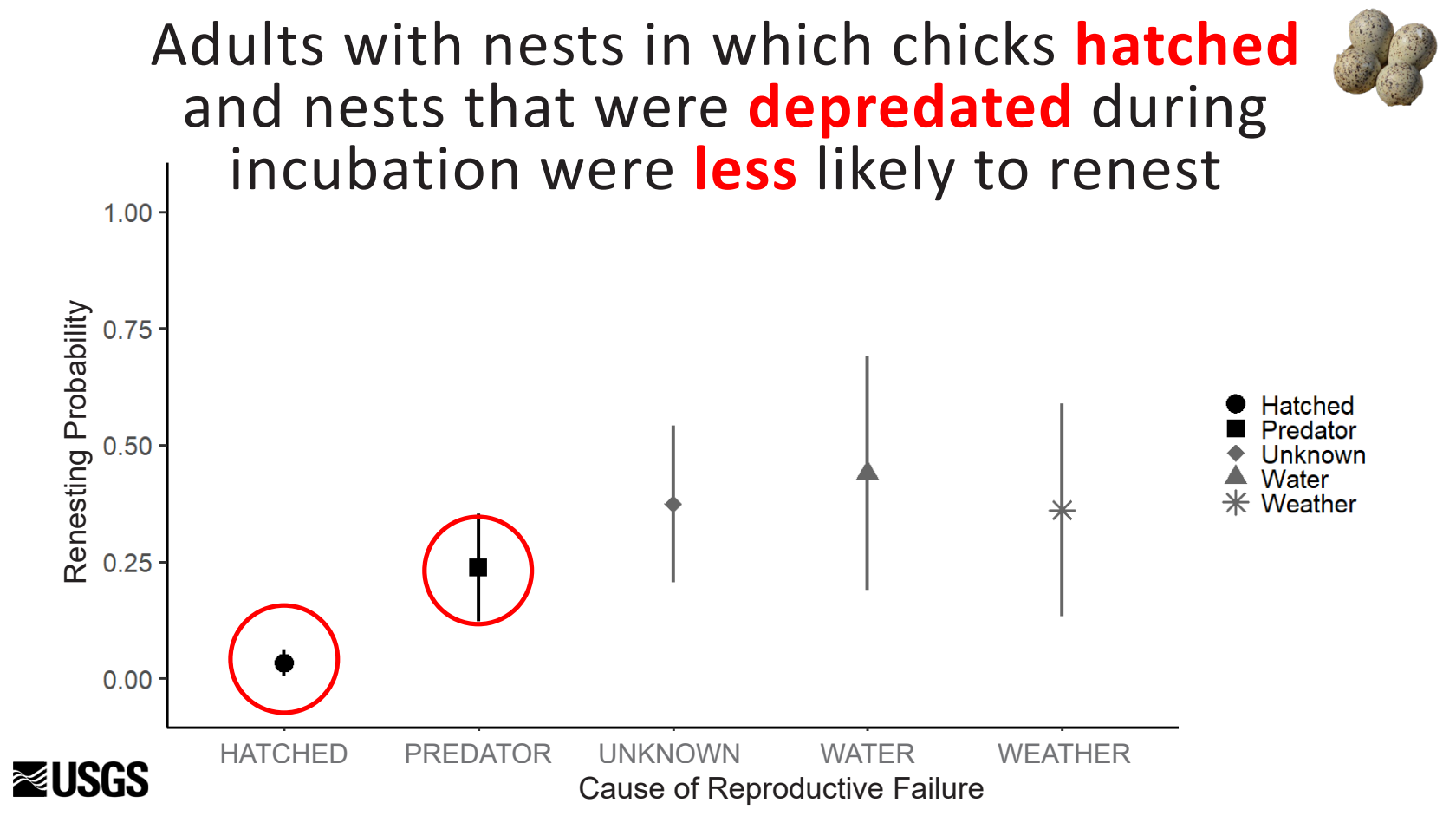

Nests in which chicks hatched (but failed during the brood-rearing stage) were less likely to be replaced, followed by nests that were depredated (red circles), compared to nests that failed because of unknown causes, inundation (water), or severe storms (weather). [Filled points indicate mean renesting probability estimates. Vertical lines indicate 95-percent confidence intervals.]

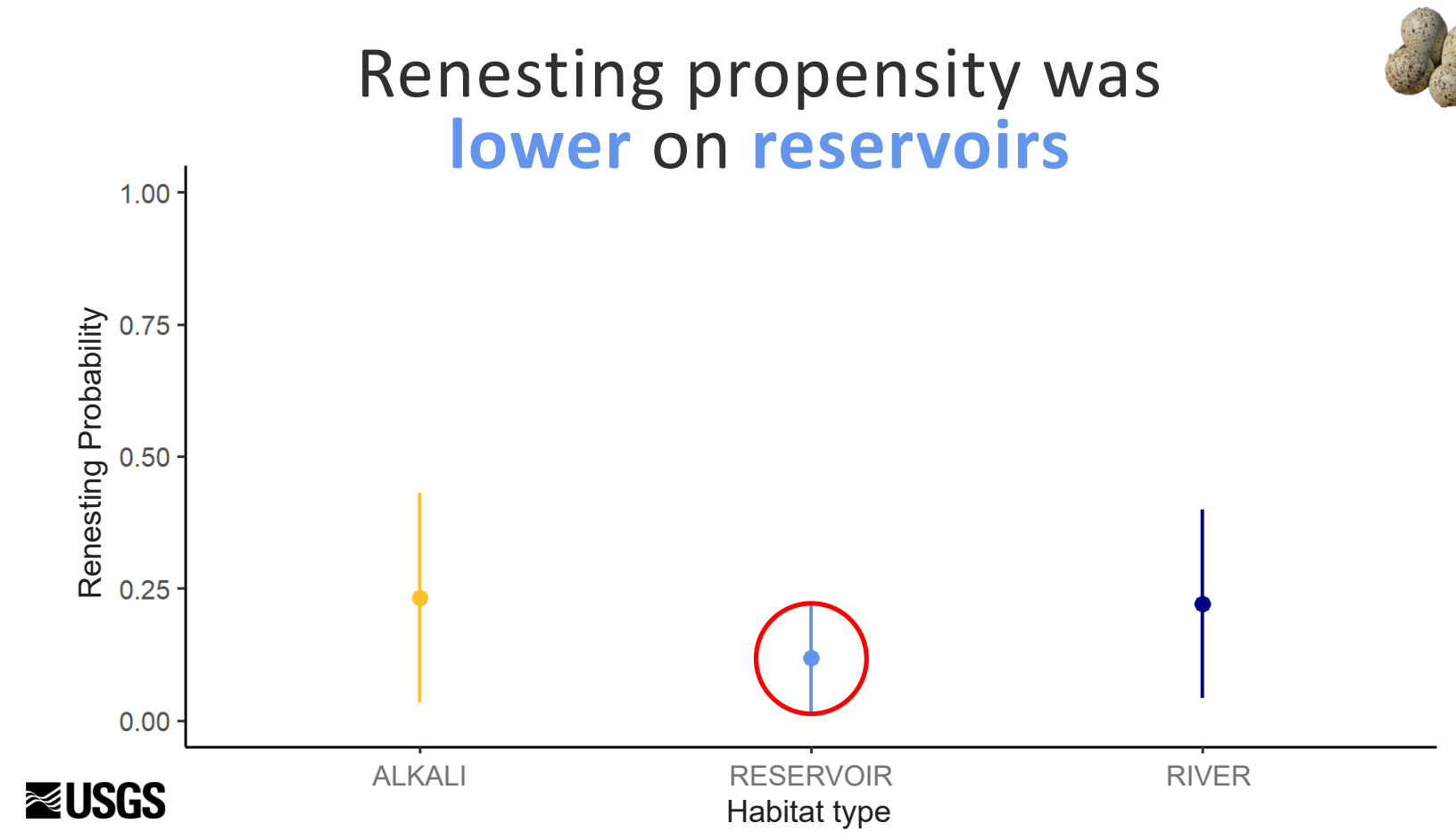

Renesting propensity was lower for birds that nested on reservoirs (red circle) compared to alkali wetlands or rivers. [Filled circles indicate mean renesting probability estimates. Vertical lines indicate 95-percent confidence intervals.] 


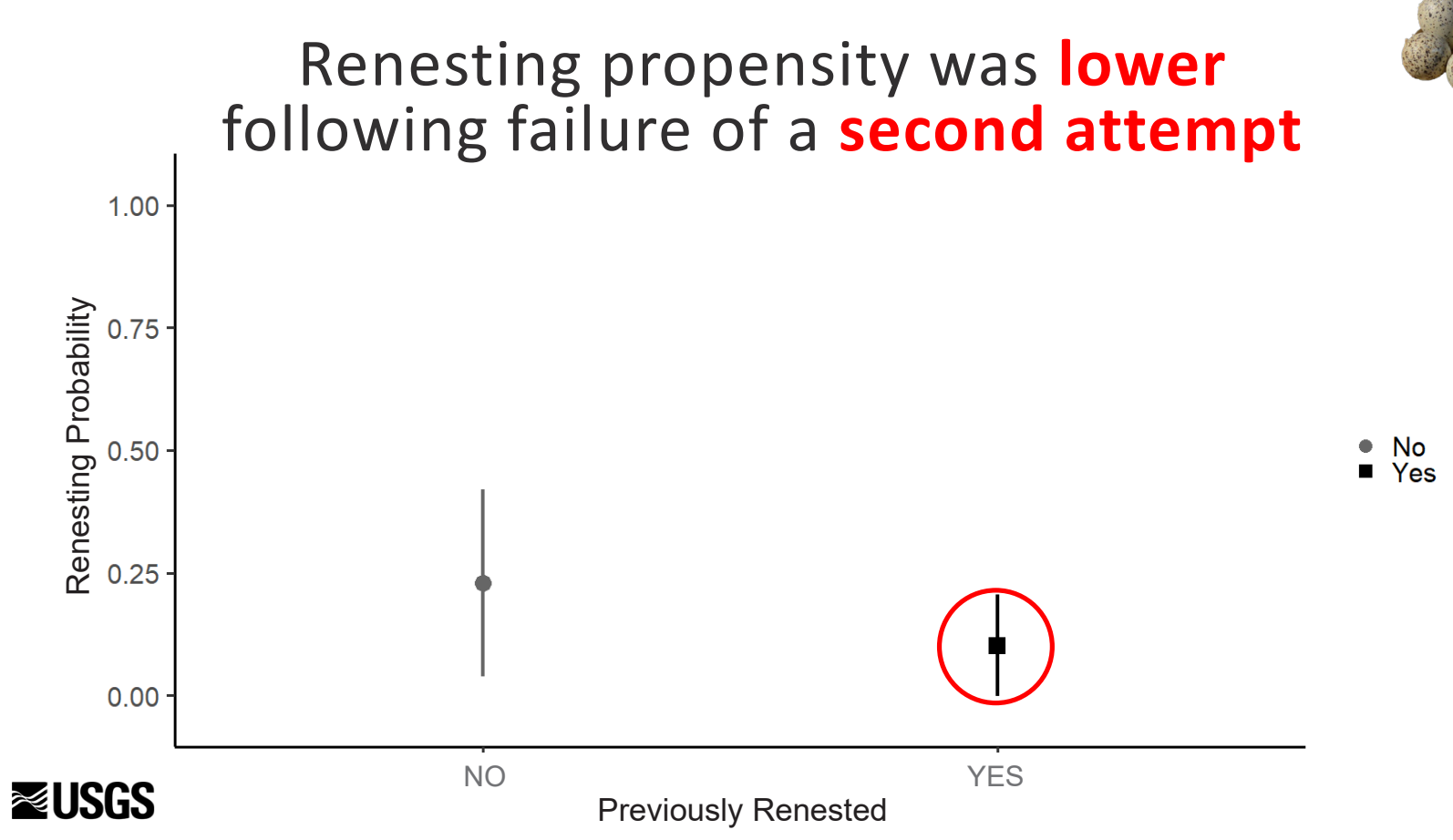

Individuals were less likely to renest after failure of their second nest attempt (red circle). [Filled points indicate mean renesting probability estimates. Vertical lines indicate 95-percent confidence intervals.]

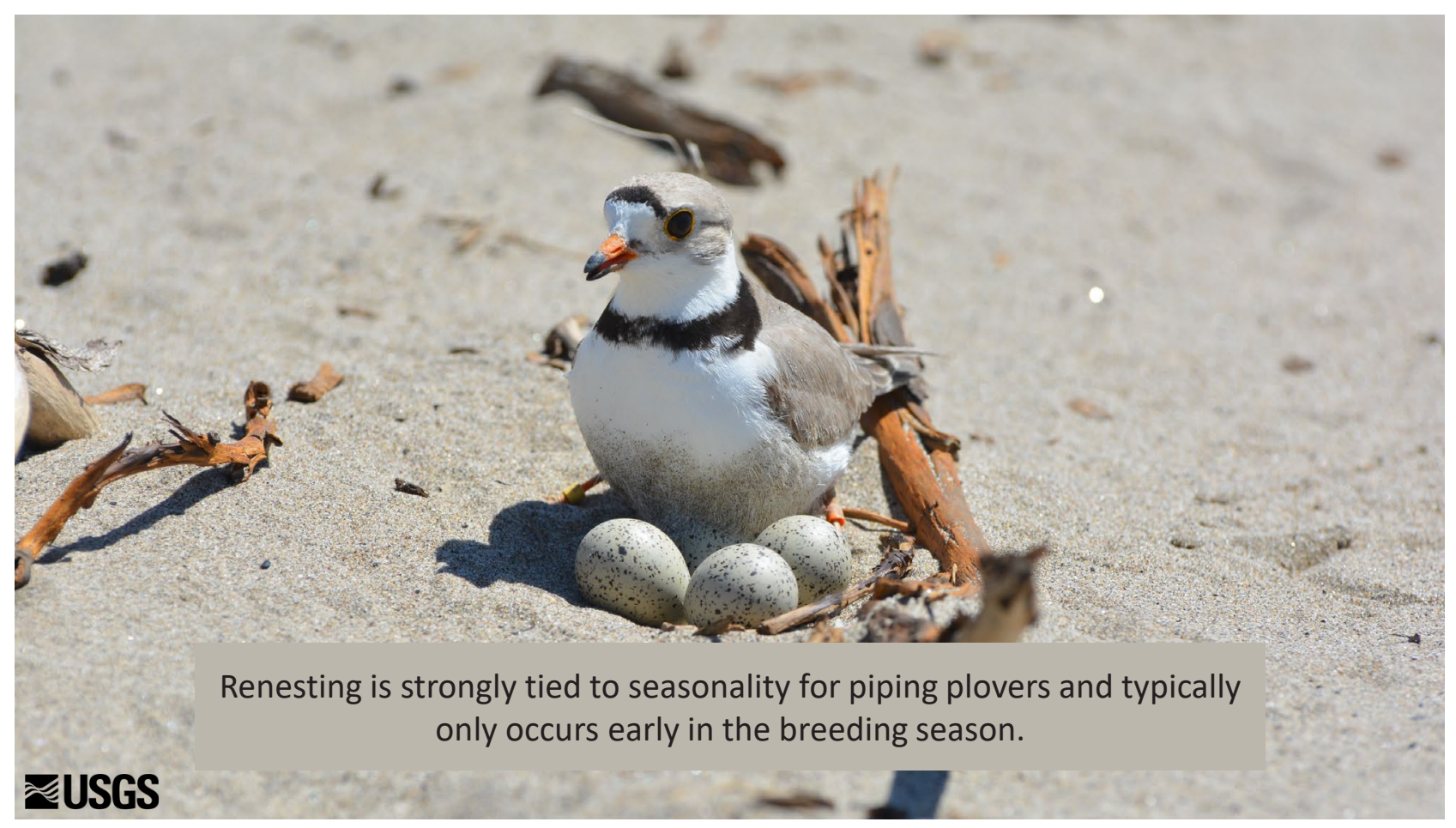

Renesting in piping plovers was affected by temporal, environmental, and individual factors. Until a detailed population model is completed, we cannot quantitatively explore the benefits (increased productivity) of investing in current reproductive success against any potential costs (survival). However, it seems that the benefits of renesting are low for piping plovers nesting in the NGP. In general, renesting propensity declined during the breeding season with individuals less likely to renest when nests or broods failed at later dates. 


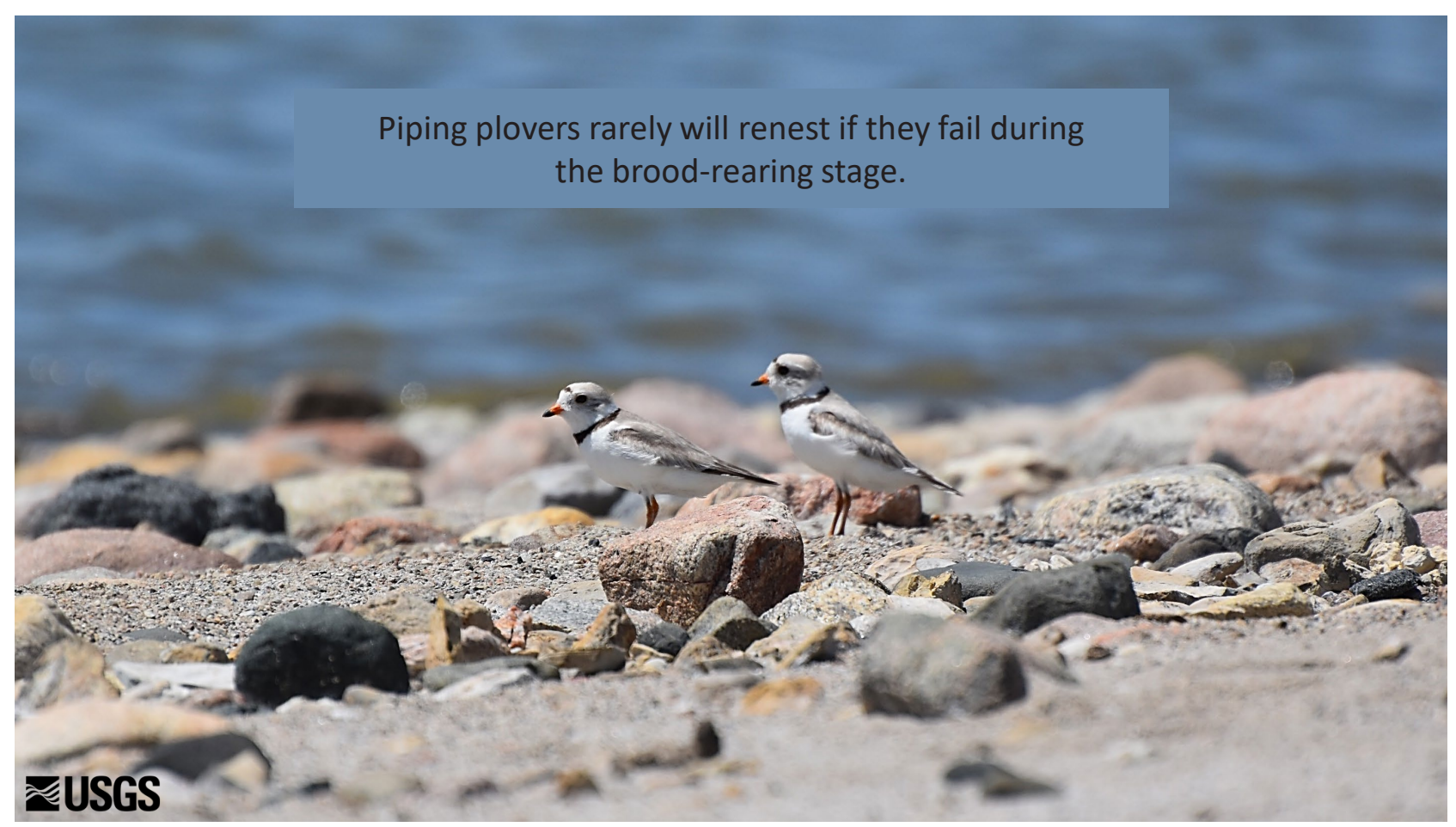

The cause of reproductive failure affected renesting propensity. Reproductive attempts that failed during the brood-rearing stage were far less likely to be followed by a renest, regardless of age of brood at the time of failure, than those that failed during egg laying or incubation, which may be a result of temporal or physiological constraints. The cost of egg laying after completing incubation (about 32-36 days from nest initiation to hatch) may be too high for most individuals or may occur too late in the breeding season. Renesting may be an evolutionary adaptation to compensate for high rates of egg loss to predators and weather-related events (Sandercock and others, 1999; Lishman and others, 2010; Claassen and others, 2014). Interestingly, depredated nests were less likely to be followed by a renest than those that failed because of severe storms or flooding. Instead, piping plovers may be associating nest loss because of predators as a threat to their own survival or as a cue of higher probability that future attempts may also be at risk of nest predation because predators are likely to return to previous sites of predation (Martin and others, 2000; Pakanen and others, 2014). Water-level rise that resulted in flooded nests did not lower the rate of renesting, nor did nest failure because of severe storms, but these threats to nests probably pose less of a threat to adult survival than predators and are less predictable. Piping plovers seem to adjust renesting decisions in relation to cues of predation risk based on their direct experience. 


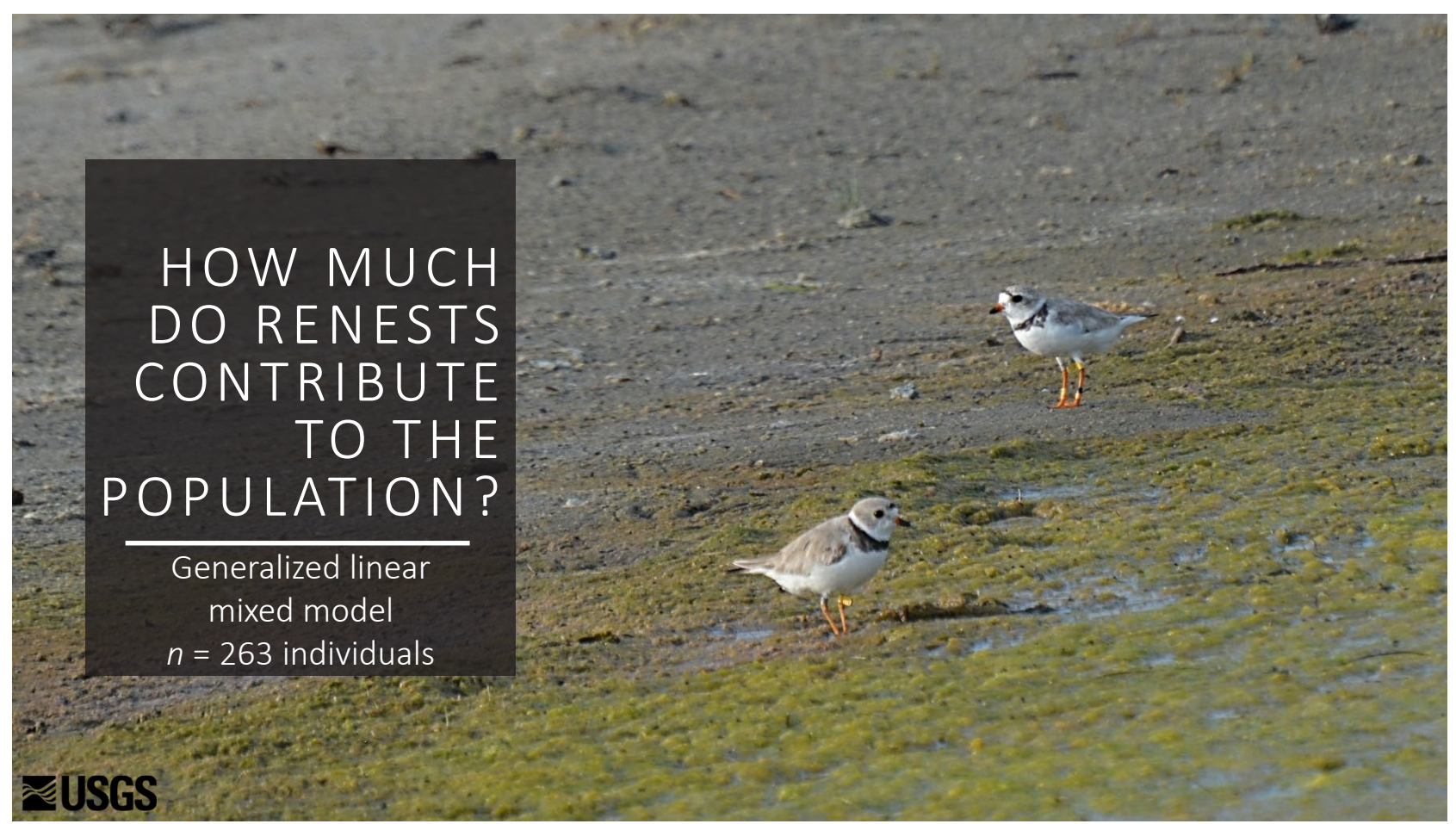

We defined renest reproductive success as a categorical response with reproductive attempts failing during nesting (failed), failing during the brood-rearing period (hatched), or successfully fledging one chick to at least 21 days posthatch (fledged). Our categorization of fledged nests likely represents a minimum estimate because of imperfect detection of older chicks. We investigated sources of variation in renest reproductive success using a generalized linear mixed model. See the "Renesting" section for more detailed methods. [n, number] 


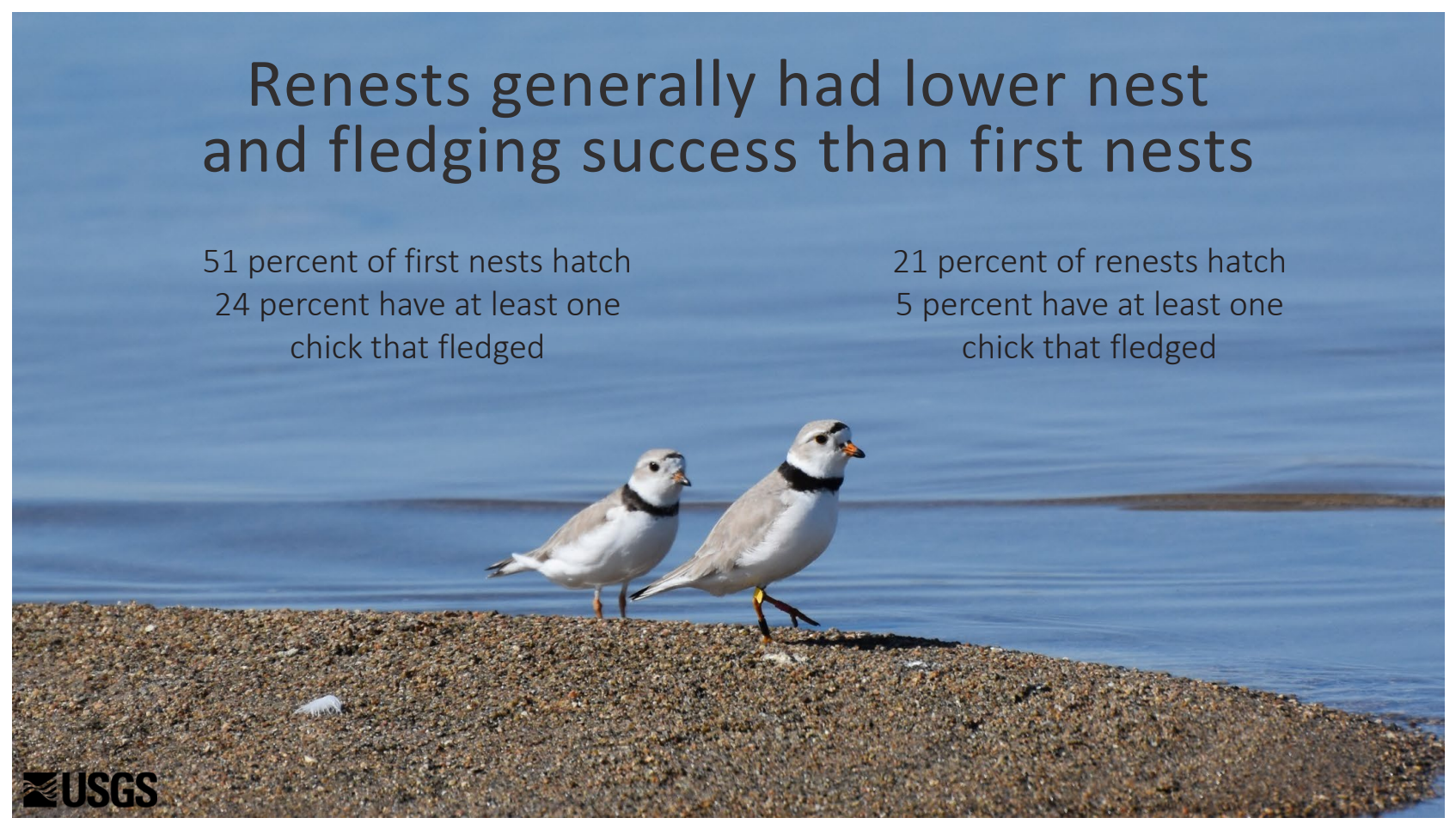

Renests generally were not as productive as first nests because only 21 percent of renests hatched (compared to 51 percent of first nests) and 5 percent fledged at least one chick (compared to 24 percent of first attempts). Individuals that moved farther than $150 \mathrm{~m}$ from their first nest had slightly lower hatching success (29.5 percent compared to 33.7 percent) and fledging success (23.8 percent compared to 24.1 percent). Renest reproductive success varied among years (2014: 57.5 percent nests failed, 8.0 percent fledged; 2015: 63.6 percent nests failed, 1.9 percent fledged; 2016 : 42.9 percent nests failed, 7.1 percent fledged). Renest reproductive success on reservoirs was lowest (apparent hatching success: 21 percent, apparent fledging success: 0 percent) compared to alkali wetlands (apparent hatching success: 27 percent, apparent fledging success: 20 percent) and rivers (apparent hatching success: 28 percent, apparent fledging success: 9 percent). 


\title{
Renest reproductive success varied based on three covariates
}

\author{
Mate Fidelity - Unknown \\ Mate Fidelity - Retained \\ Dispersal Distance \\ 2015 \\ 2016 \\ Habitat type - River \\ Habitat type - Reservoir \\ Available Habitat \\ Landform - Island \\ Habitat type - River \\ : Available Habitat \\ Habitat type - Reservoir \\ $\approx$ USGS
}

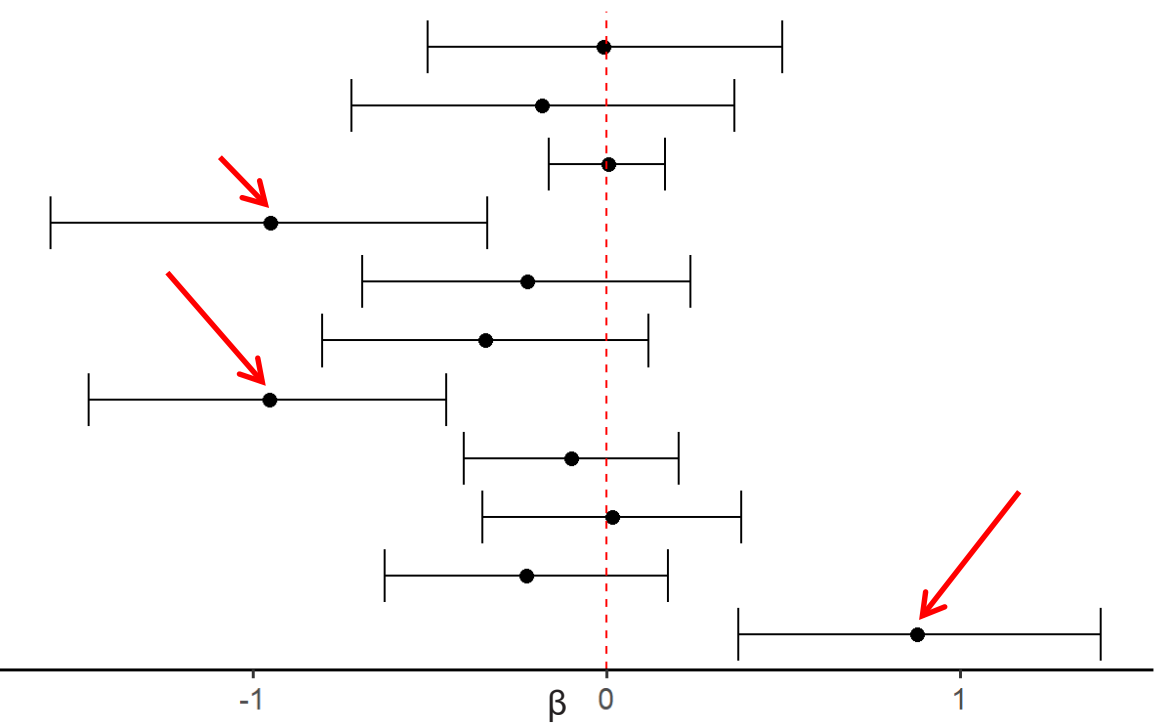

From the global fitted model with all a priori covariates included on renest reproductive success, two covariates and 2015 (red arrows) seem important based on nonoverlapping 95-percent confidence intervals with zero. [Filled circles indicate mean $\beta$ estimate. Whiskers indicate 95-percent confidence intervals.] 


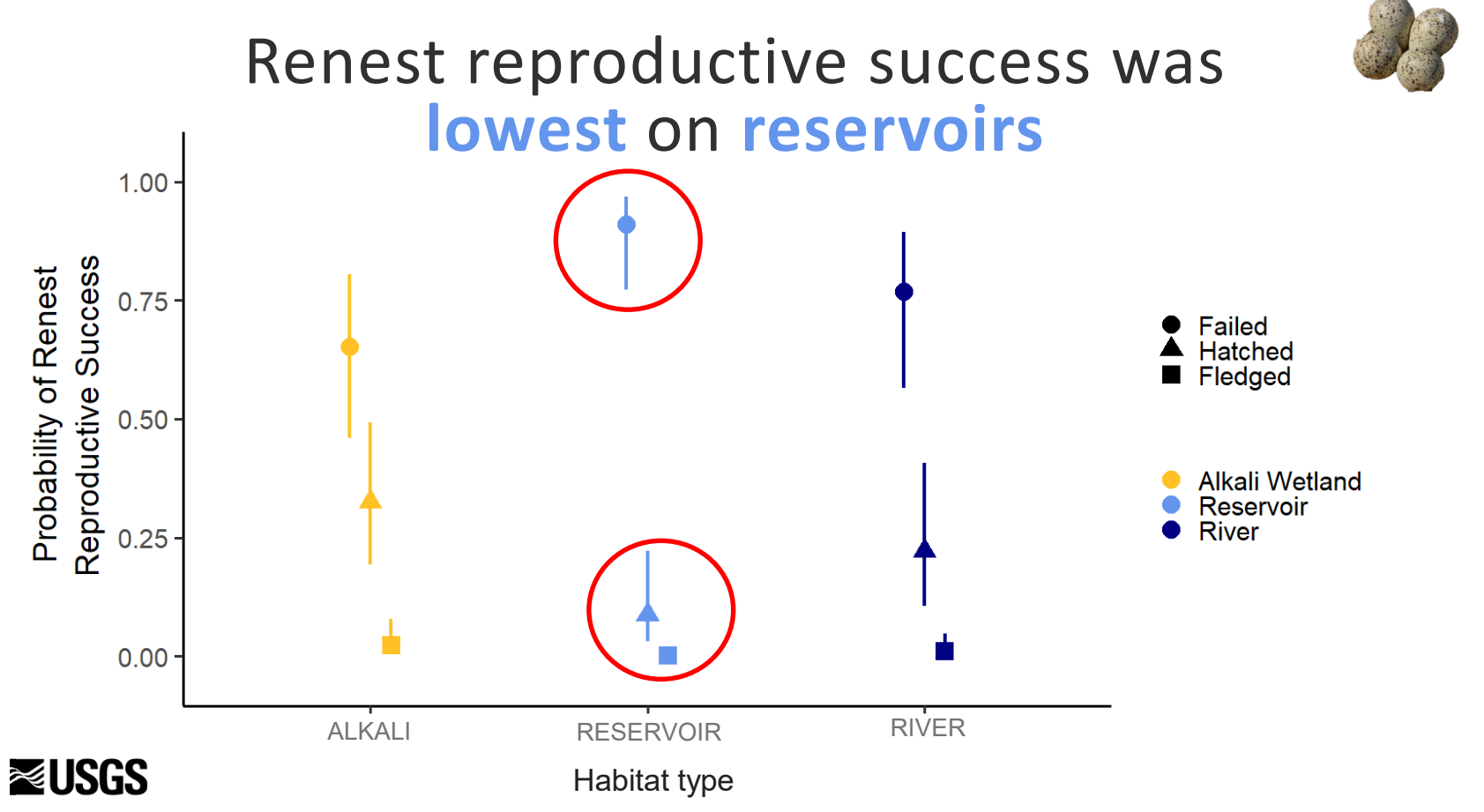

Renest reproductive success was lower on reservoirs than on alkali wetlands or rivers. Reservoirs had a high probability that renest reproductive attempts would fail during the nesting stage (red circles), whereas rivers and alkali wetlands had higher probabilities of fledging young. Renest reproductive success on reservoirs was lowest (probability of failing: 0.91, hatching: 0.09 , fledging: 0.001 ) compared to alkali wetlands (probability of failing: 0.65 , hatching: 0.33 , fledging: 0.02 ) and rivers (probability of failing: 0.77 , hatching: 0.22 , fledging: 0.01 ). [Filled points indicate mean renesting probability estimates. Vertical lines indicate 95-percent confidence intervals.] 


\section{Habitat availability affects renest fate differently between habitat types}
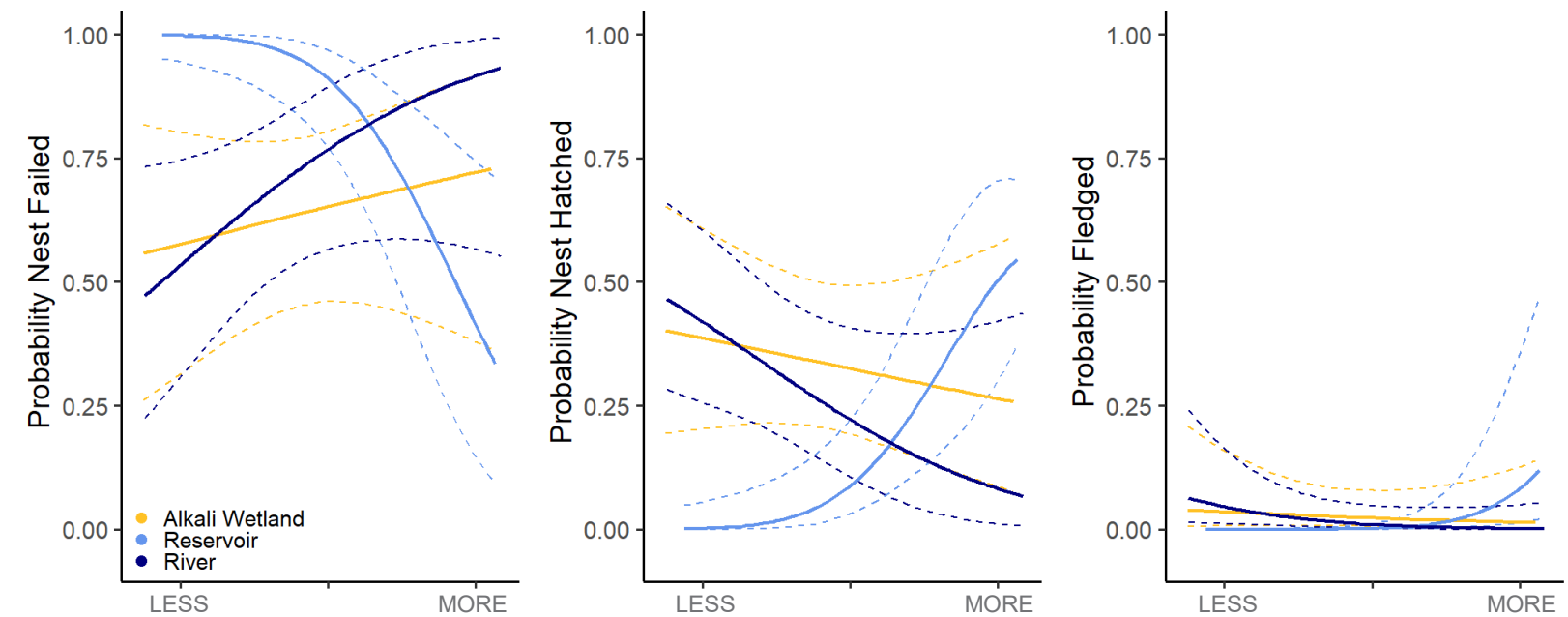

※USGS

Within Season Change in Available Habitat (May to July)

Renest fate on reservoirs interacted with the amount of available nesting habitat (solid lines). [Dashed lines indicate 95-percent confidence intervals.]

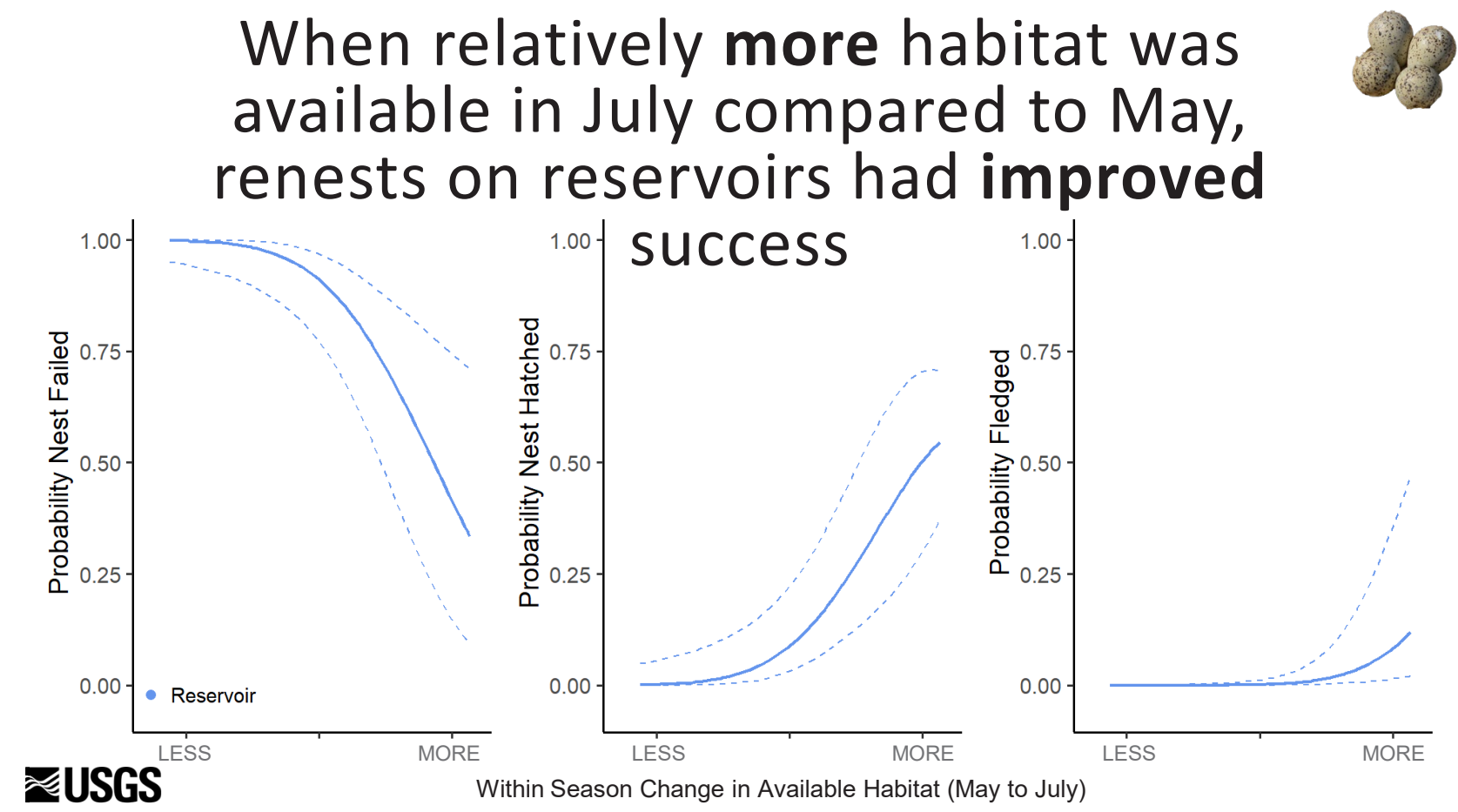

When relatively more habitat was available in July compared to May, renests on reservoirs had improved reproductive success with lower probabilities of nests failing and higher probabilities of nests hatching but failing during brood-rearing; however, if less habitat was available in July compared to May, renests on reservoirs had low hatching success and high probabilities of nests failing. [Dashed lines indicate 95-percent confidence intervals.] 


\section{Nest survival varied by habitat type, nest attempt, and during the breeding season}

\begin{tabular}{lccc}
\hline Model & DAICc & Model weight & Deviance \\
\hline Renest + Habitat type + Time & 0.00 & 0.94 & 4808.95 \\
Renest + Habitat type & 5.62 & 0.06 & 4816.57 \\
Habitat type + Time & 19.53 & $<0.001$ & 4830.47 \\
Habitat type & 40.57 & $<0.001$ & 4853.52 \\
Renest + Time & 76.58 & $<0.001$ & 4889.53 \\
Renest & 80.65 & $<0.001$ & 4895.60 \\
Time & 94.68 & $<0.001$ & 4909.63 \\
Null & 112.52 & $<0.001$ & 4929.47 \\
\hline
\end{tabular}

\section{ఇUSGS}

The final model selection table is shown for nest survival. We restricted our sample for daily nest survival to nests with known nest fates and short monitoring intervals (2-4 days). Nest survival varied within a breeding season (declining trend in daily survival), habitat type, and nest attempt. [ $\triangle \mathrm{AICC}$, the change in Akaike's information criteria corrected for small sample sizes (AICc) relative to the top-ranked model; <, less than]

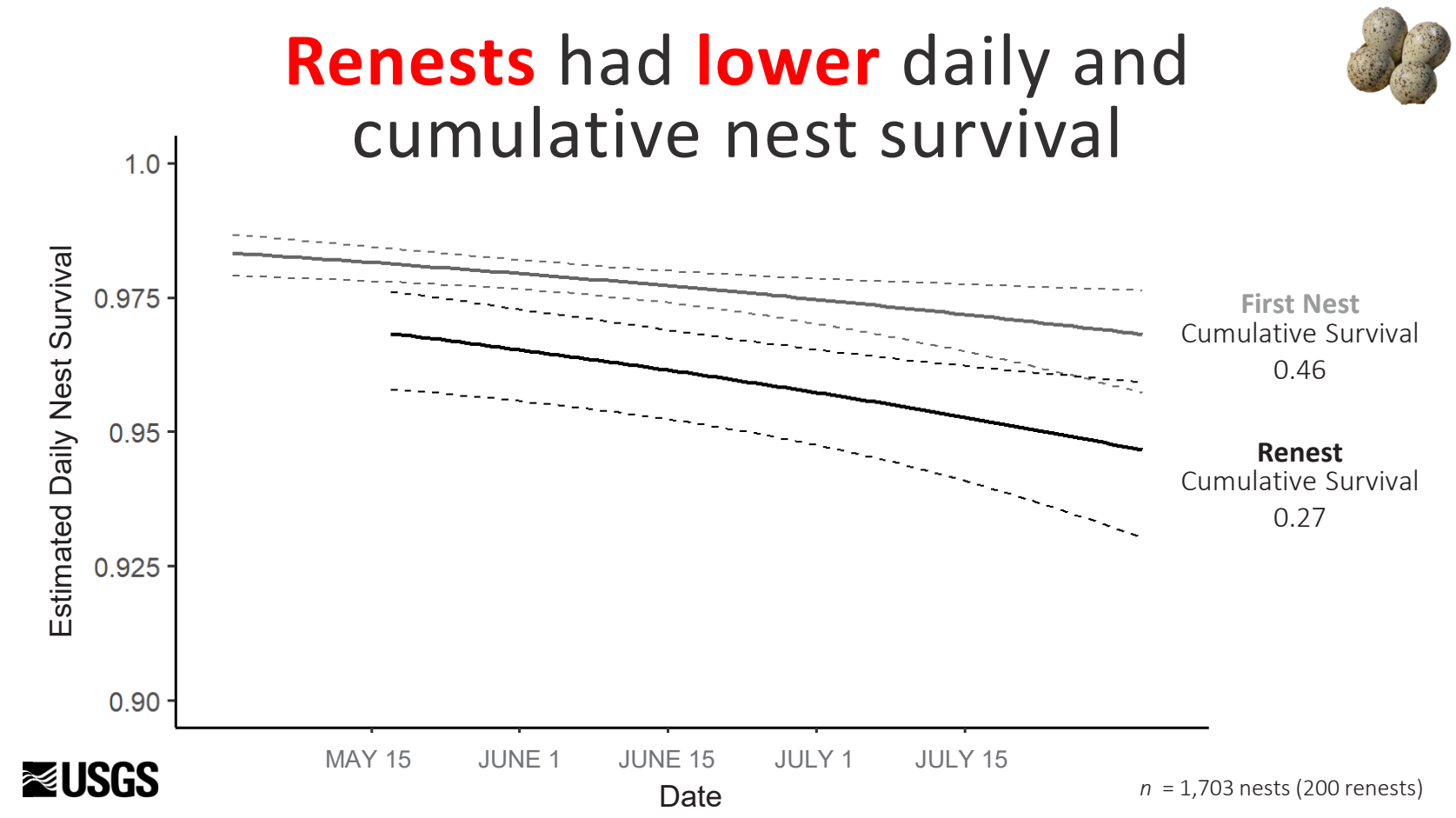

Our analysis included 1,703 nests (1,503 first nesting attempts [gray lines] and 200 renests [black lines]). Renests showed significantly lower daily nest survival, even with a linear temporal trend included (across habitat types). Cumulative nest survival averaged 0.46 for first nests but only 0.27 for renests. [Dashed lines indicate 95 -percent confidence intervals. $n$, number] 


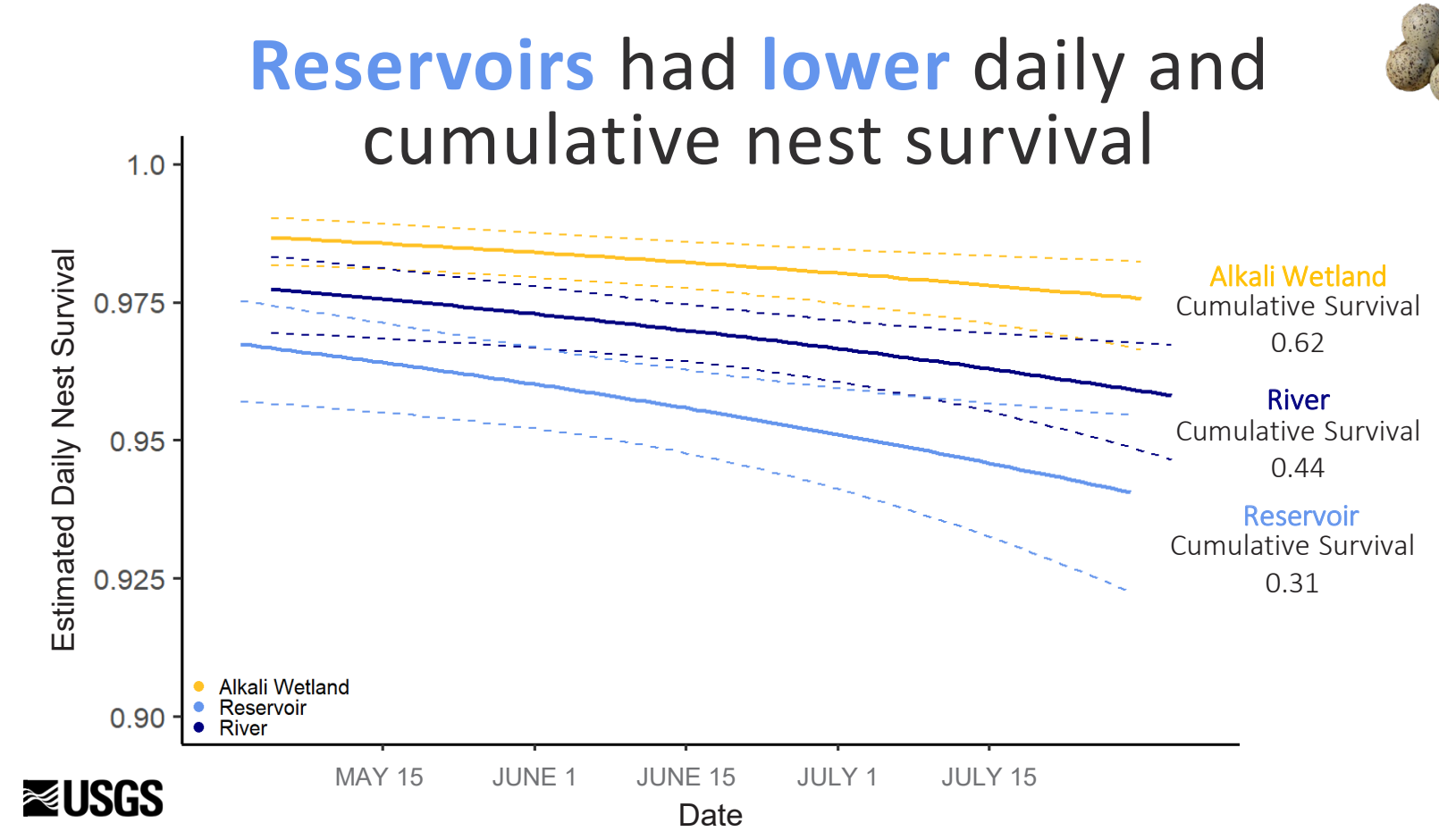

Reservoirs had lower daily nest survival than other habitat types (regardless of nest attempt). [Dashed lines indicate 95-percent confidence intervals.]

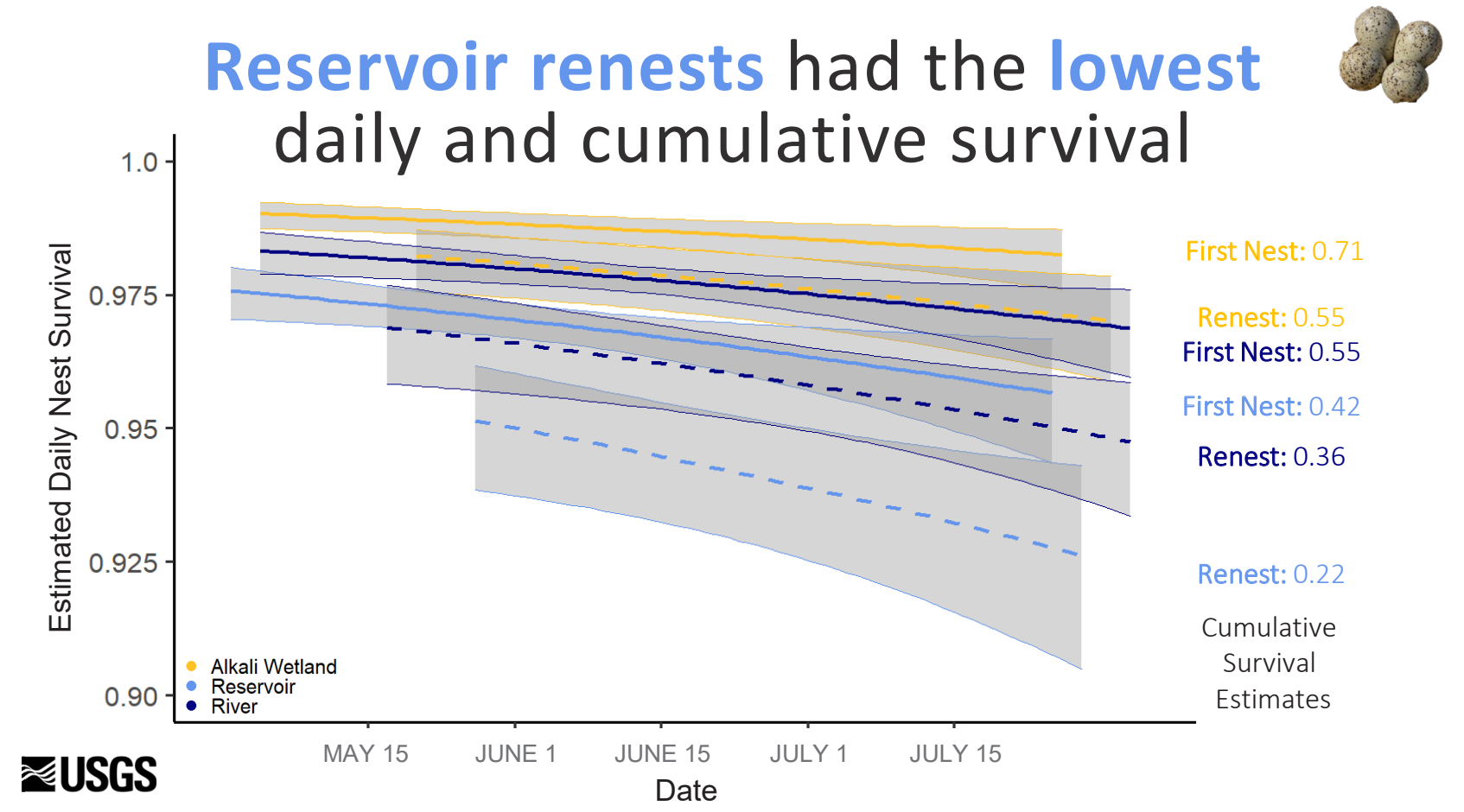

The effects of habitat type and nest type were additive. Therefore, reservoir renests had the lowest daily and cumulative (0.22) survival whereas first nests on the alkali wetlands had the highest daily and cumulative (0.71) survival. [Gray shading indicates 95-percent confidence intervals. First nests are shown with solid lines, and renests are shown with dashed lines.] 


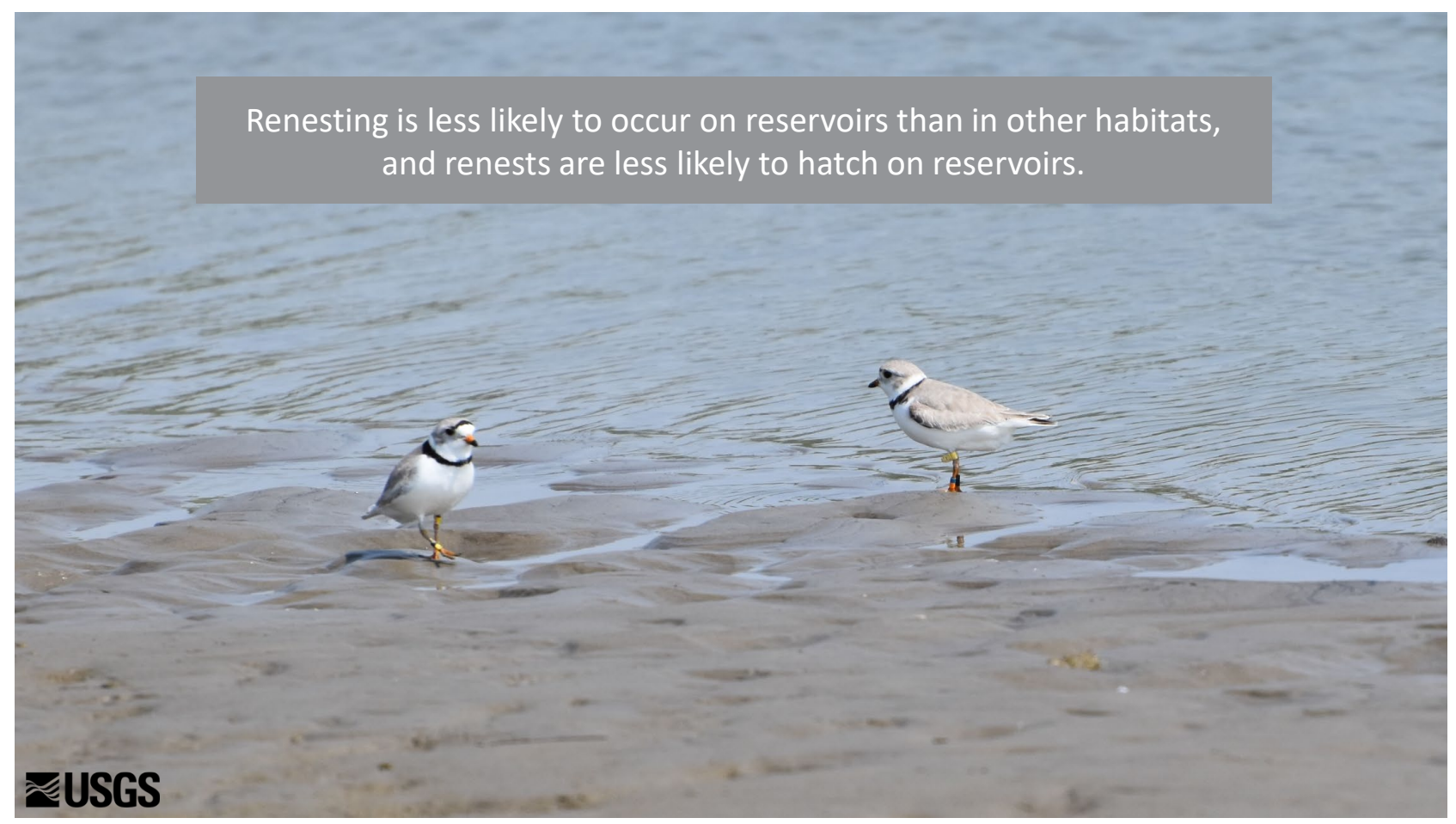

Individuals breeding on reservoirs had lower renesting propensity and renest reproductive success than those on the river or alkali wetland habitats. In fact, change in nesting habitat abundance was a significant predictor of renest reproductive success. Since the construction of dams on the Missouri River, piping plovers began nesting on shorelines and islands of reservoirs. As much as 60 percent of Missouri River piping plovers use main-stem reservoir habitats (Anteau and others, 2014b), and, in 2014-16, 43 percent of nests were on main-stem reservoirs (Anteau and others, 2014a; USFWS, 2003). However, reservoir use can vary among years, which is most likely correlated with water-surface elevation and thus available nesting habitat. In this study (2014-16), main-stem reservoir elevations were similar across years with 1-2 $m$ elevation water rise from May to July for Lakes Sakakawea and Oahe. Compared to average water elevations (from 1955 for Lake Sakakawea and 1967 for Lake Oahe to 2019), water levels were high for each year of this study. However, our index of available habitat did vary considerably among the 3 years. Compared to other habitat types, reservoir nesting individuals had much lower apparent renest reproductive success, unless available habitat increased during the breeding season from May to July. Reservoirs on the Upper Missouri River (upstream from Pierre, South Dakota) experience large interannual water-level fluctuations in response to management and wet-dry climate periods (Anteau and others, 2014a, b). Such interannual flooding and drawdown affects habitat abundance and availability among years, but within-year fluctuations in water elevations can dramatically affect individual nest success and renesting propensity. Because of snowmelt in the Rocky Mountains and local precipitation, reservoirs on the Upper Missouri River often show midseason water-level rise (Anteau and others, 2012b). Upward elevation shifts of only $1 \mathrm{~m}$ in height can completely inundate nesting islands and shoreline habitats, flooding nests and drowning unfledged chicks. Main-stem reservoir nesting individuals thus face a more dynamic system within and between years than individuals nesting on river or alkali wetland habitats, which may cause the reduced renesting propensity, apparent renest reproductive success, and daily nest survival seen here. Although individuals are capable of successfully hatching renests on reservoirs, we never documented a fledged renest attempt on reservoir habitats. Thus, midseason water-level rise on main-stem reservoirs may be contributing to reduced renesting and therefore lower reproductive success in piping plovers. Further, 70 percent of individuals that moved habitats between first and renest attempts left reservoir habitats. Some individuals may respond to this dynamic system through breeding dispersal to riverine or alkali wetland habitats. 


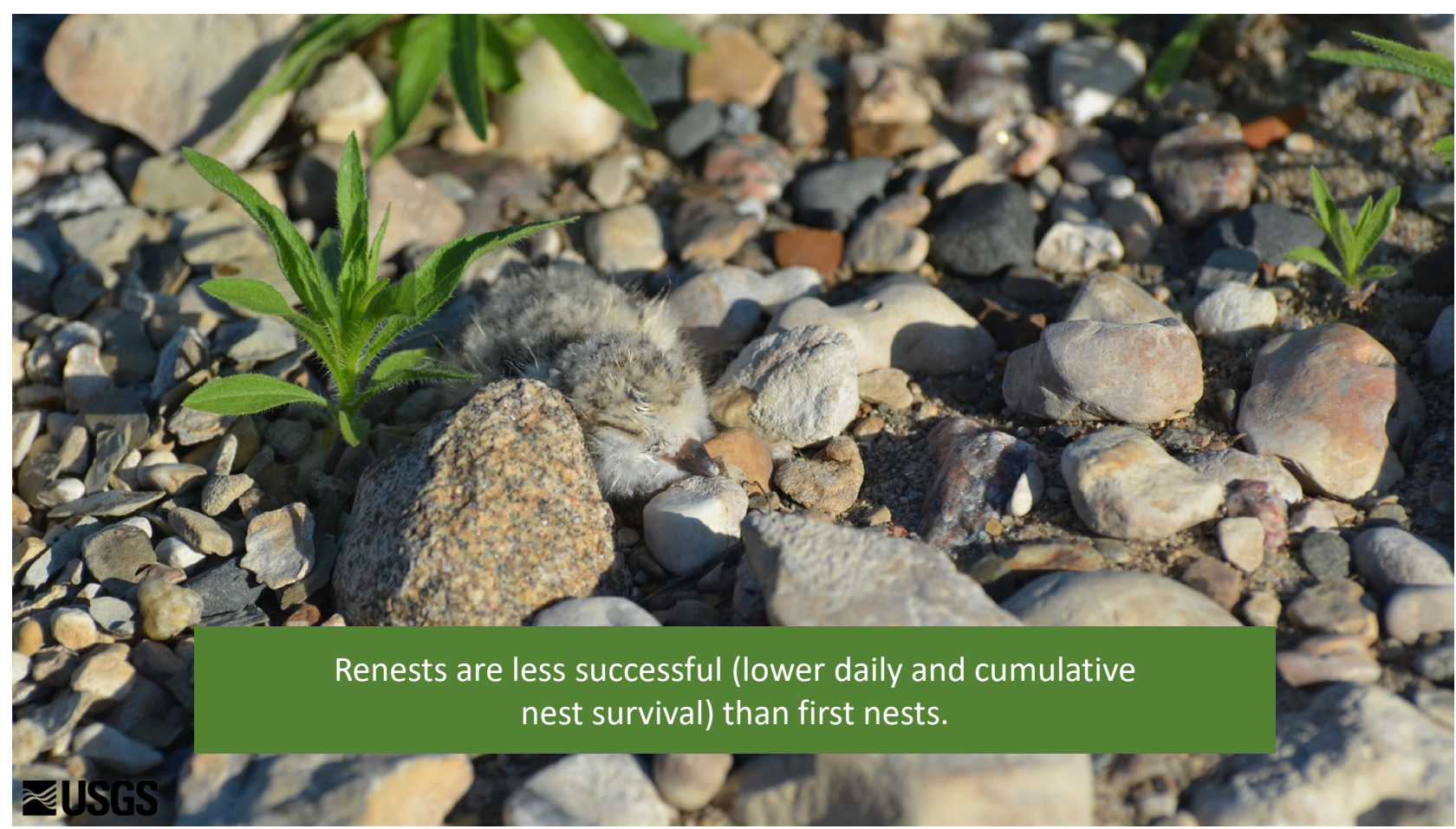

Other studies of piping plovers have also found strong seasonal effects on reproductive success (Anteau and others, 2012a; Brudney and others, 2013; Claassen and others, 2014), and any factors that cause piping plovers to nest later are likely to lead to lower annual breeding productivity. The mean chance of renesting in early June (around June 6) was 50 percent but declined to near 0 percent after a reproductive failure after July 10 . Furthermore, the date of reproductive failure had a stronger affect for renesting probability than the age of the reproductive attempt at the time of failure. Temporal constraints may be less severe compared to Holarctic breeders (Swift and others, 2018; Weiser and others, 2018); however, the observed cutoff of reproduction in mid-July and shorter renesting intervals suggest some threshold for breeding even in northern temperate latitudes. Although individuals continued to initiate nests between June 6 and July 10, only 38 percent were successful at hatching, and only 13 percent of those fledged at least one chick. Further, first and renest attempts had a substantial linear decline with date in daily nest survival. Thus, reproductive attempts initiated later in the breeding season have less productivity. 


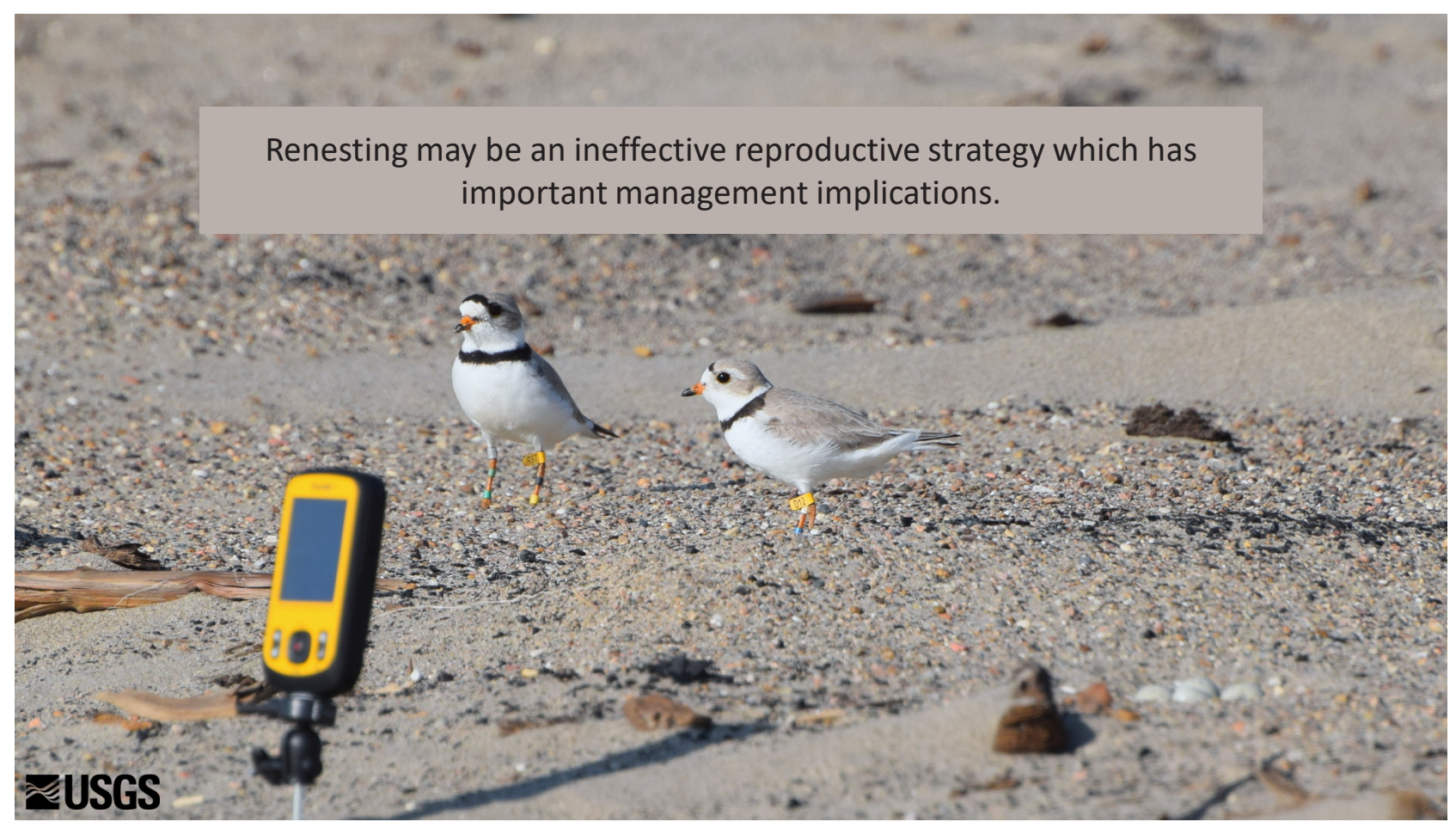

Replacing lost nests or broods through renesting may be an unproductive strategy for piping plovers in the NGP. Renests had lower daily nest survival throughout the breeding season, and cumulative survival was lower for renests than for first nests. Additionally, apparent renest reproductive success, which included posthatch to fledge survival of broods, was low, particularly for individuals nesting on reservoirs. Renests may have lower daily nest survival because of some inherent quality of the individuals attempting those nests, because of suboptimal timing, or because individuals rush to nest in unsafe or unknown areas. Further, with seasonal declines in reproductive success, renesting may not increase current reproductive success, or at least may come at some long-term cost to annual survival (Becker and Zhang, 2011). Lastly, renesting was uncommon with only 25 percent of individuals that failed during the nesting stage replacing lost attempts. This differs considerably from the Great Lakes population of piping plovers, where 49 percent of failed pairs renested, and one pair made five attempts in 1 year (Claassen and others, 2014). The dynamic and unstable environmental conditions, which characterize habitat for the NGP population, likely contrast with those conditions in the Great Lakes. If so, then these two populations may have settled on different bet-hedging strategies to cope with uncertainty and spatiotemporal variability in selective pressures to maximize lifetime fecundity (Olofsson and others, 2009; Chalfoun and Schmidt, 2012). Piping plovers in the NGP may therefore be under different selective pressures than those in the Great Lakes, and thus, NGP piping plovers may rely on relatively high annual survival (Roche and others, 2010; Anteau and others, 2019) to maximize lifetime reproductive success. Further, the difference between the apparent renesting rate for the two populations and the overall lack of renest success of NGP piping plovers provide evidence that patterns from one population may not accurately inform the other. If managers use data from one population to inform intensive conservation and management strategies, the outcomes may not be similar across the two populations. Thus, unlike the Great Lakes population, the costs for NGP piping plovers to renest likely do not outweigh the potential reproductive gains, which are modest at best. 


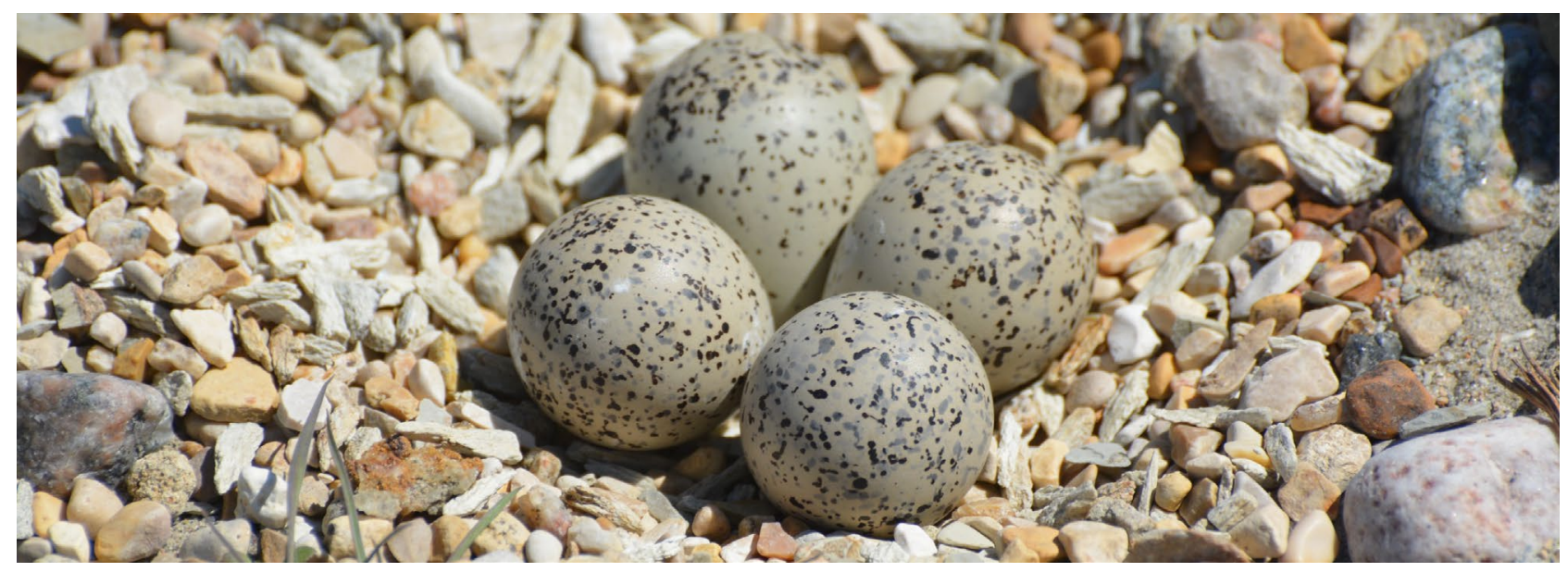

\section{IS REPRODUCTIVE SUCCESS HIGH ENOUGH TO ACCOUNT FOR UNBALANCED DISPERSAL?} Objective 7

‡USGS

We estimated an index of reproductive output and addressed how this could affect population growth rates.

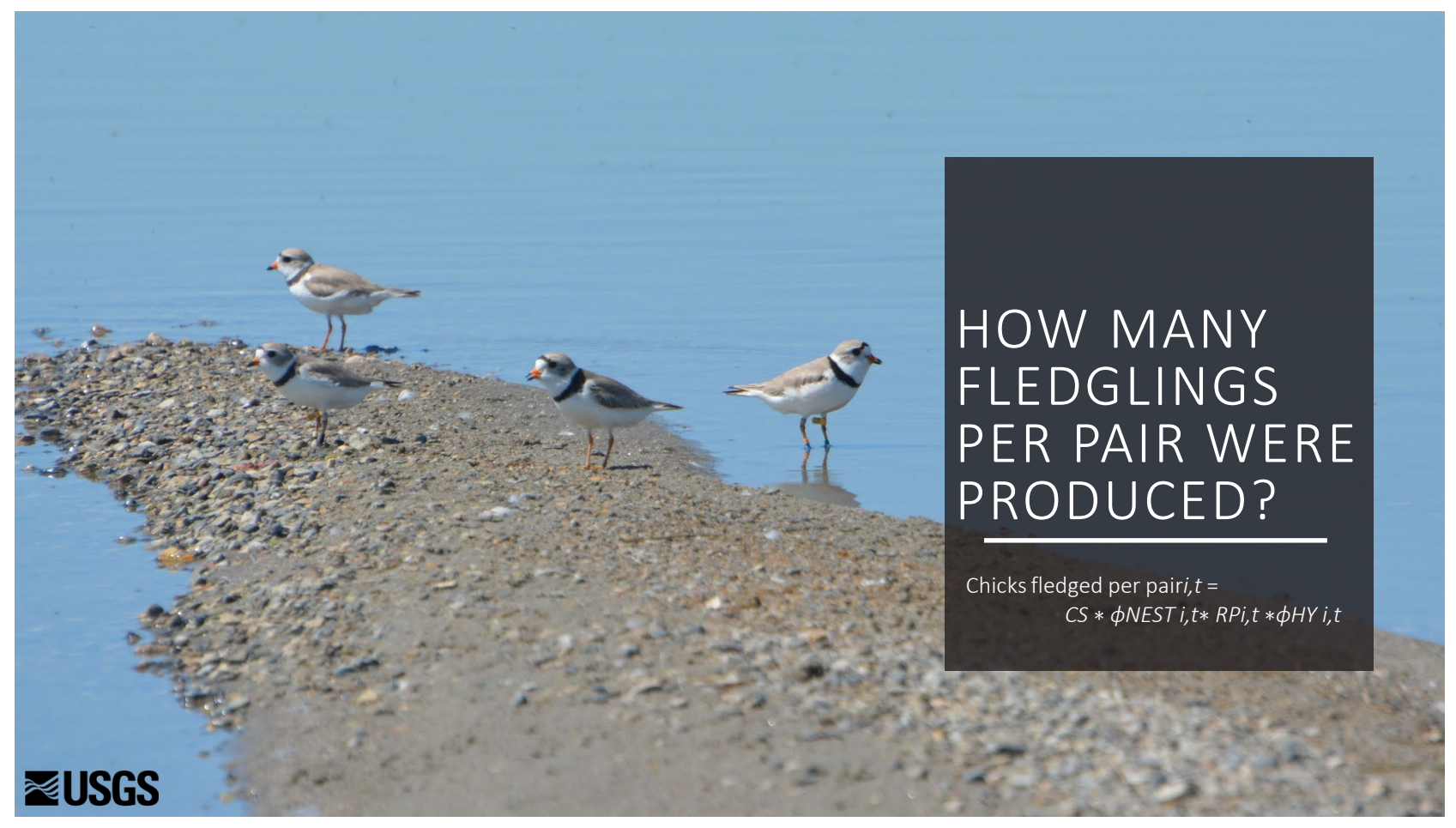

We estimated observed reproductive output as the number of fledged chicks per pair to estimate an index of reproductive success using our year and management unit specific estimates of nest and chick survival using this equation. [i, management unit; $t$, year; $C S$, clutch size; $\phi_{N E S T}$, the probability that an individual has a successful nest in a given year; $R P$, the probability an individual replaces a lost reproductive attempt; $\phi_{H Y}$, cumulative survival from hatch to fledge (21 days posthatch)] 


\title{
Observed reproductive output
}

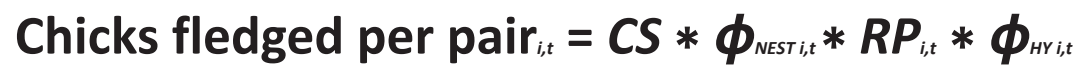

\section{ఇUSGS}

To assess population stability, we estimated observed reproductive output as the number of fledged chicks per pair for each management unit from 2014 to 2016. In the equation, $i$ represents each management unit, $t$ represents year, CS is the mean clutch size of piping plovers in this system (mean $=3.49$ ), $\phi_{N E S T}$ represents the probability that an individual has a successful nest in a given year (represented here by cumulative nest survival), $R P$ is the probability an individual replaces a lost reproductive attempt, and $\phi_{H Y}$ is cumulative survival from hatch to fledge (21 days posthatch). We calculated year and management unit specific estimates of fledged chicks per pair by calculating the mean, 5th, and 95th percentiles of 100,000 estimates. See the "Reproductive Output" section for more information. 


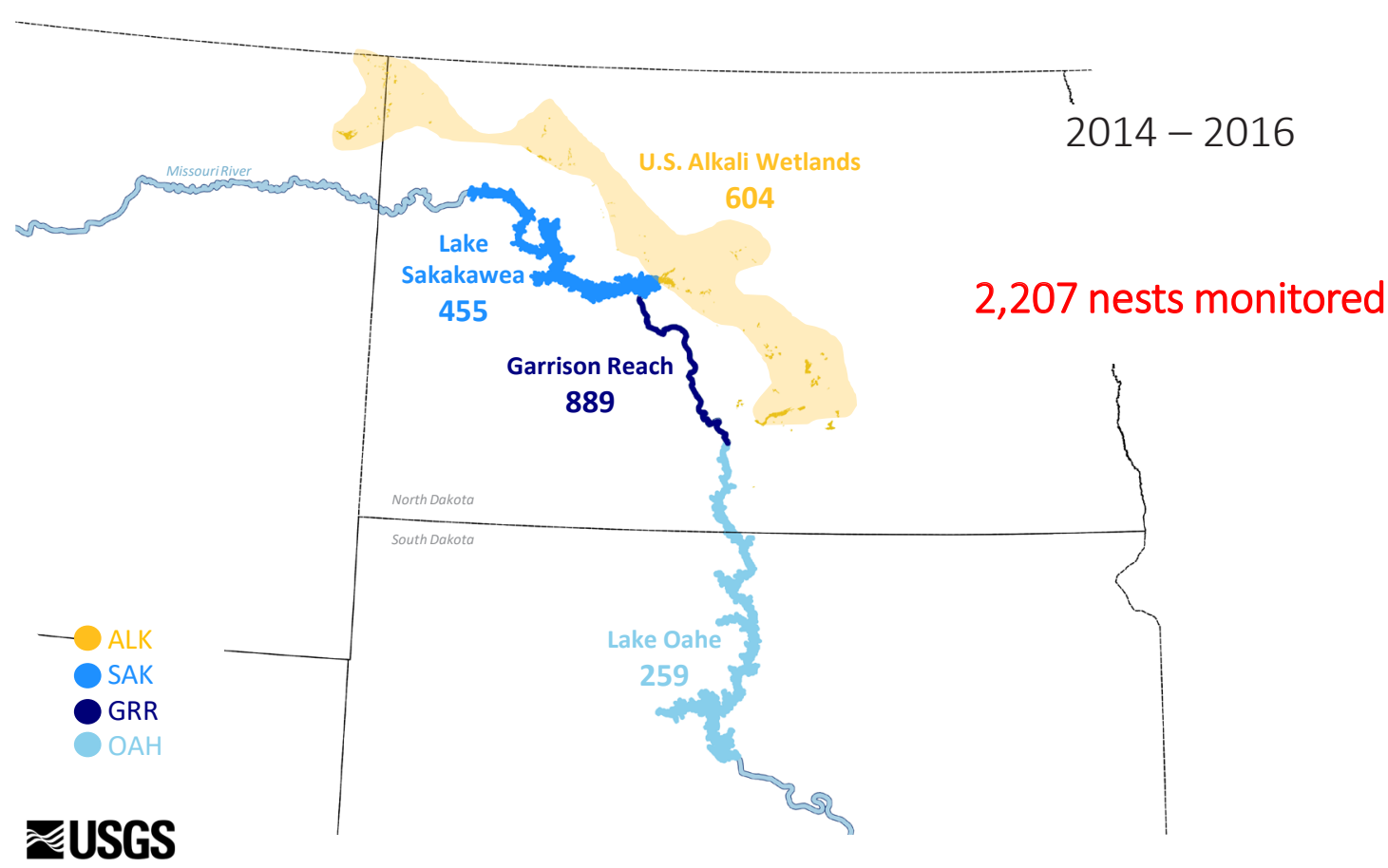

We estimated cumulative nest survival during the nesting period (egg-laying and incubation). We monitored 2,207 nests over 3 years (2014-16); individual sample sizes are shown on map. Most nests were found on the GRR ( $n=889)$, and OAH had the fewest nests ( $n=259$ ) over the 3 years. See the "Reproductive Output" section for detailed methods.

\section{Nest survival varied by year, management unit, and during the breeding season}

\begin{tabular}{lcccc}
\hline Model & $\begin{array}{c}\text { Number of } \\
\text { parameters }\end{array}$ & $\Delta$ AICc & Model weight & Deviance \\
\hline Unit : Year + Time & 17 & 0.00 & 1 & 5550.80 \\
Unit + Year + Time & 8 & 129.02 & $<0.001$ & 5697.84 \\
Unit + Time & 5 & 155.69 & $<0.001$ & 5730.51 \\
Year + Time & 5 & 305.79 & $<0.001$ & 5880.61 \\
Time & 2 & 329.67 & $<0.001$ & 5910.49 \\
Null & 1 & 337.21 & $<0.001$ & 5920.04 \\
\hline
\end{tabular}

\section{‡USGS}

The final model selection table is shown for daily nest survival estimates. Nest survival varied within a breeding season (declining trend in daily survival) and was year and management unit specific. [ $\triangle \mathrm{AICC}$, the change in Akaike's information criteria corrected for small sample sizes (AICC) relative to the top-ranked model; $<$, less than] 


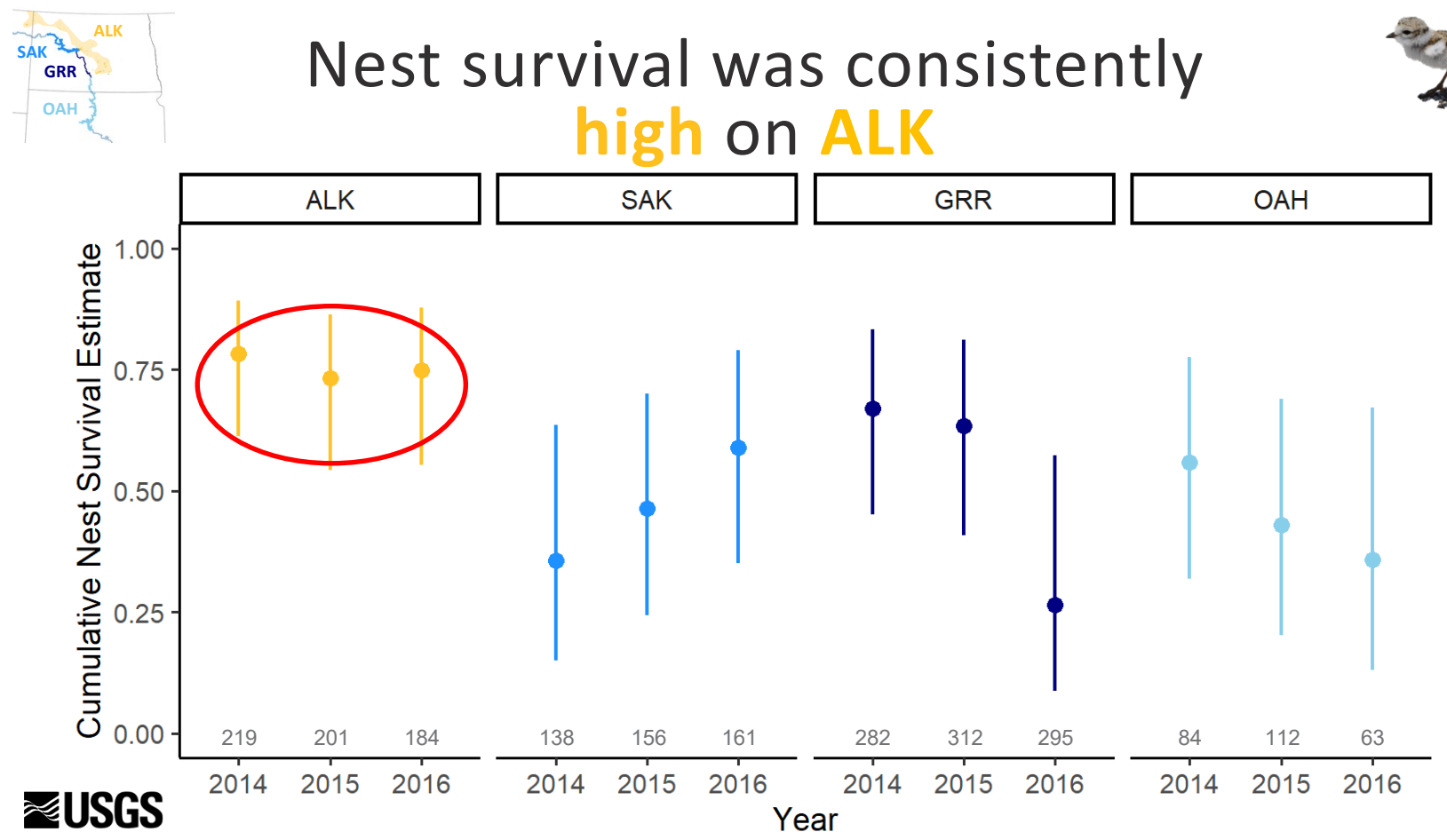

The ALK consistently had high cumulative nest survival (red circle). Cumulative nest survival rates (circles) and their associated 95-percent confidence interval (vertical lines) are shown. [The annual sample size of nests per year and management unit is listed above the $\mathrm{x}$-axis.]

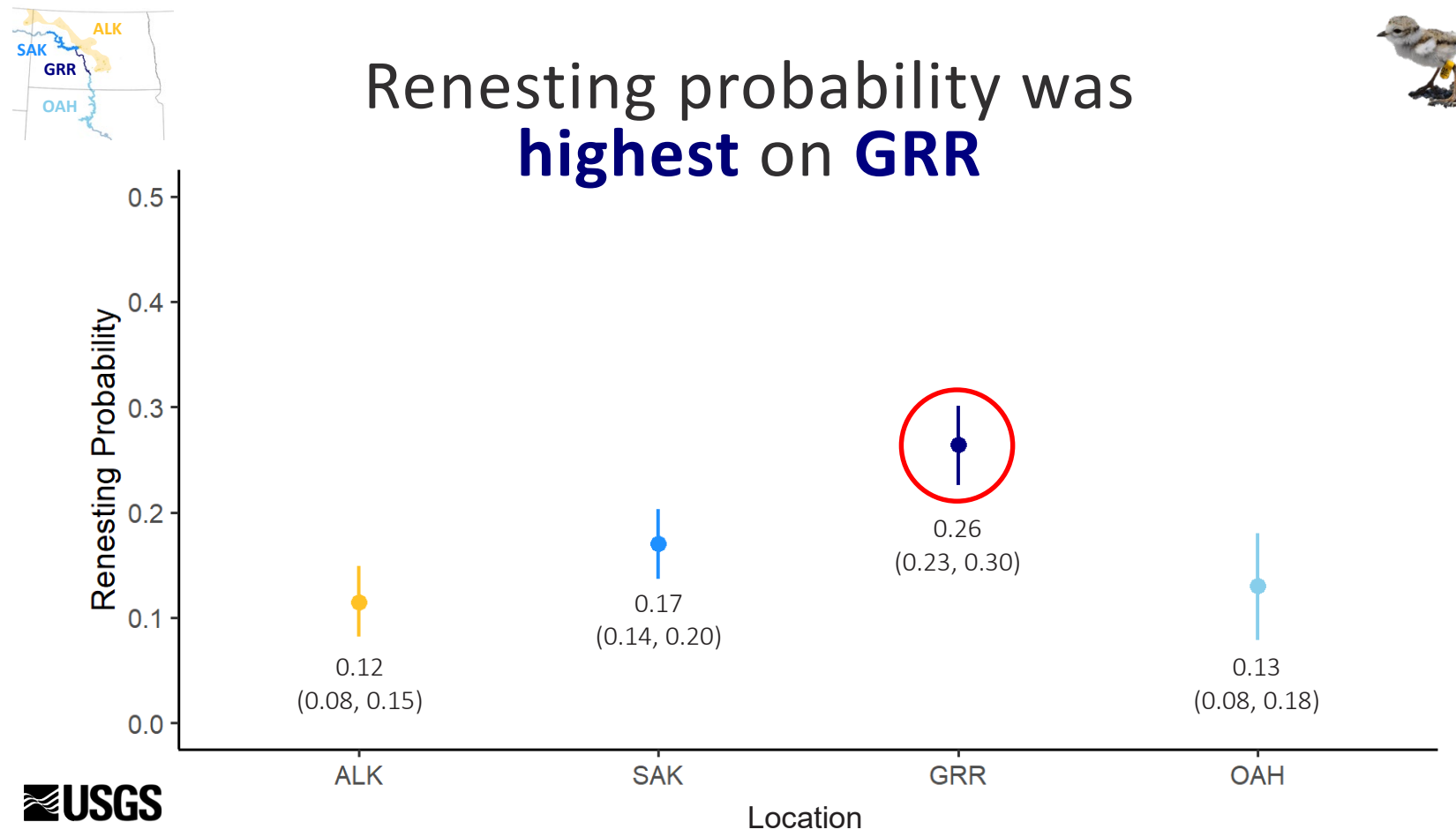

Renesting probability after a failed nesting attempt (failed during egg-laying or incubation) varied from 0.12 (the ALK) to 0.26 (the GRR; red circle). Estimates of renesting probability were lower than the 49 percent renesting probability estimated for piping plovers in the Great Lakes (Claassen and others, 2014). [Filled circles indicate mean renesting probability estimates. Vertical lines indicate 95-percent confidence intervals.] 


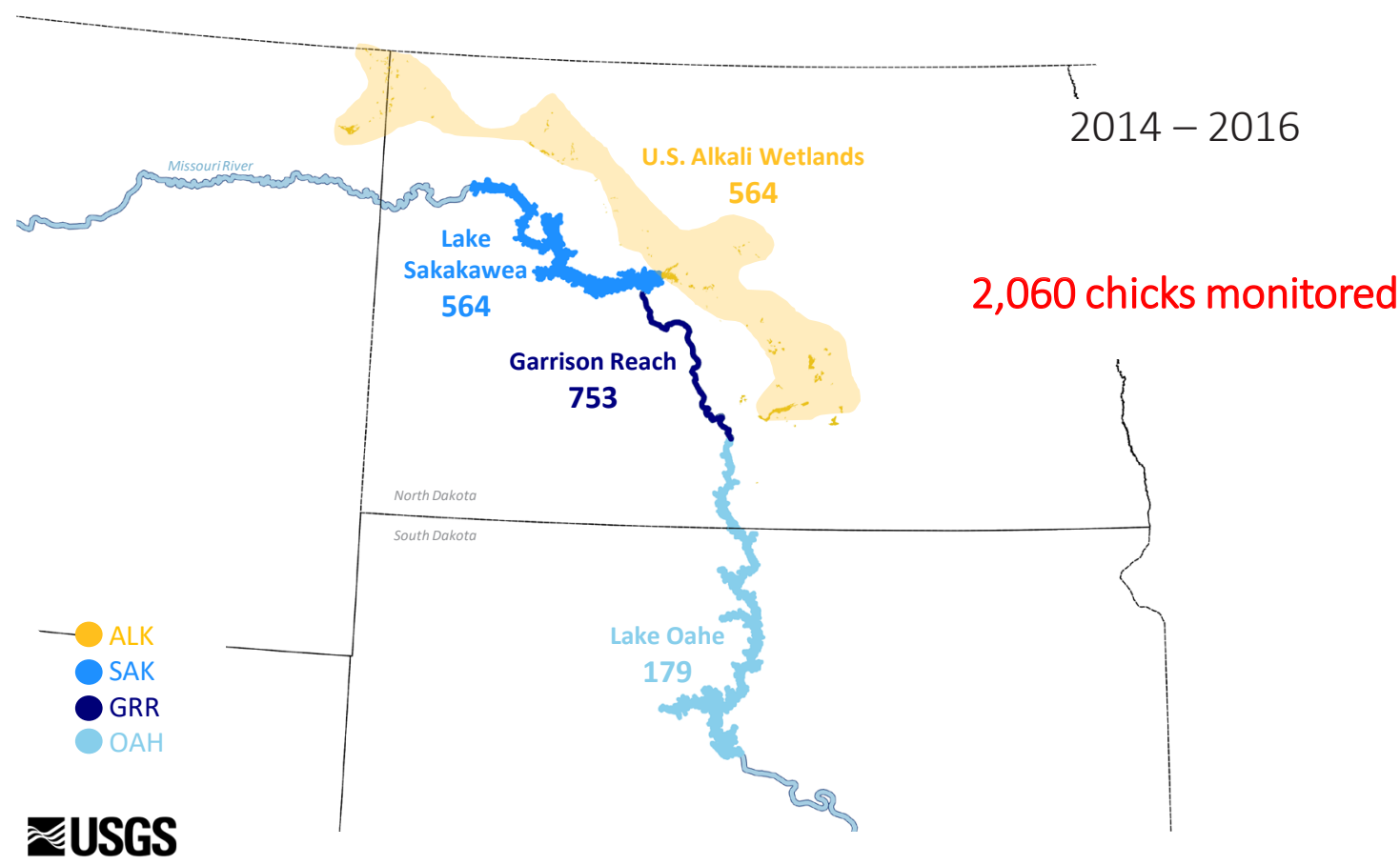

We built Cormack-Jolly-Seber models to estimate the daily probability of apparent survival $(\phi)$ and detection $(p)$ for piping plover chicks and calculated cumulative survival to fledging. We monitored 2,060 chicks over 3 years (2014-16); individual sample sizes are shown on map. Most chicks were banded on the GRR $(n=753)$, and OAH had the fewest $(n=179)$ over the 3 years. For more details on methods, see the "Reproductive Output" section. 


\section{Chick survival varied by year, management unit, and during the breeding season}

\begin{tabular}{|c|c|c|c|c|}
\hline Model & $\begin{array}{l}\text { Number of } \\
\text { parameters }\end{array}$ & $\triangle Q A I C c$ & $\begin{array}{l}\text { Model } \\
\text { weight }\end{array}$ & Deviance \\
\hline $\begin{array}{l}\text { Ф(Prefledge : Unit : Year + Time + Postfledge) } \\
\text { p(Prefledge : Unit : Year + Time + Postfledge) }\end{array}$ & 70 & 0.00 & 1 & 89.57 \\
\hline $\begin{array}{l}\text { Ф(Prefledge : Unit + Time + Postfledge) } \\
\text { p(Prefledge : Unit : Year + Time + Postfledge) }\end{array}$ & 44 & 22.16 & $<0.001$ & 165.05 \\
\hline $\begin{array}{l}\Phi(\text { Prefledge : Year + Time + Postfledge) } \\
\text { p(Prefledge : Unit : Year + Time + Postfledge) }\end{array}$ & 48 & 26.54 & $<0.001$ & 161.26 \\
\hline $\begin{array}{l}\Phi(\text { Prefledge + Time + Postfledge }) \\
\text { p(Prefledge : Unit : Year + Time + Postfledge) }\end{array}$ & 38 & 133.59 & $<0.001$ & 288.69 \\
\hline $\begin{array}{l}\Phi(\text { Prefledge + Postfledge) } \\
\text { p(Prefledge : Unit : Year + Time + Postfledge) }\end{array}$ & 37 & 145.55 & $<0.001$ & 302.68 \\
\hline
\end{tabular}

\section{‡USGS}

The final model selection table is shown for the chick survival analysis. Chick survival varied within a breeding season (declining trend in daily survival) and was year and management unit specific. [ $\triangle O A I C c$, the change in Akaike's information criteria corrected for small sample sizes and overdispersion (OAICc) relative to the top-ranked model; $\phi$, apparent survival; $p$, detection; <, less than]

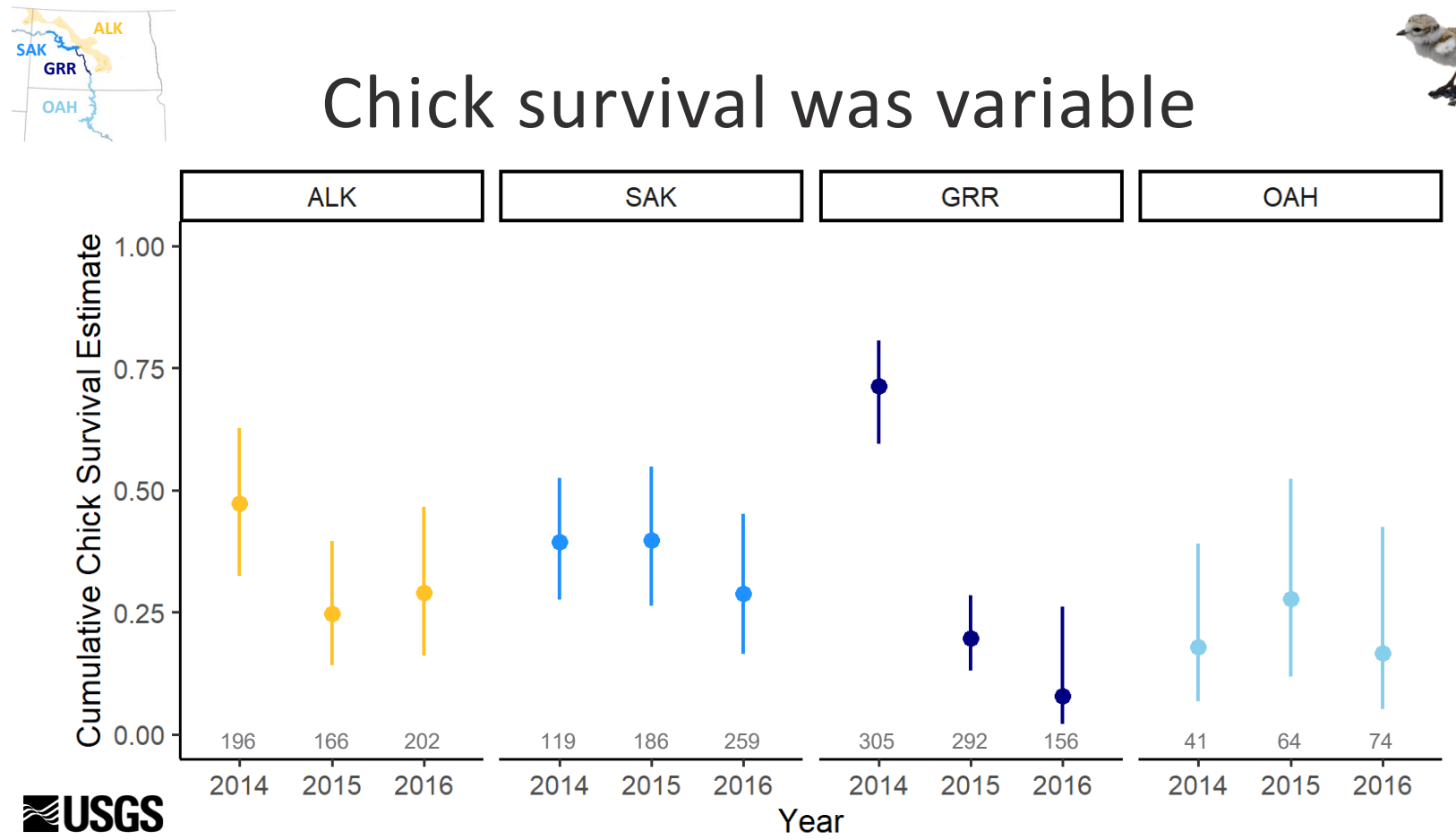

Cumulative chick survival to fledging was highly variable over the years. In 2014, the GRR had very high cumulative survival to fledge. [The annual sample size of chicks per year and management unit is listed above the x-axis. Filled circles indicate mean cumulative chick survival to fledging estimates. Vertical lines indicate 95-percent confidence intervals.] 


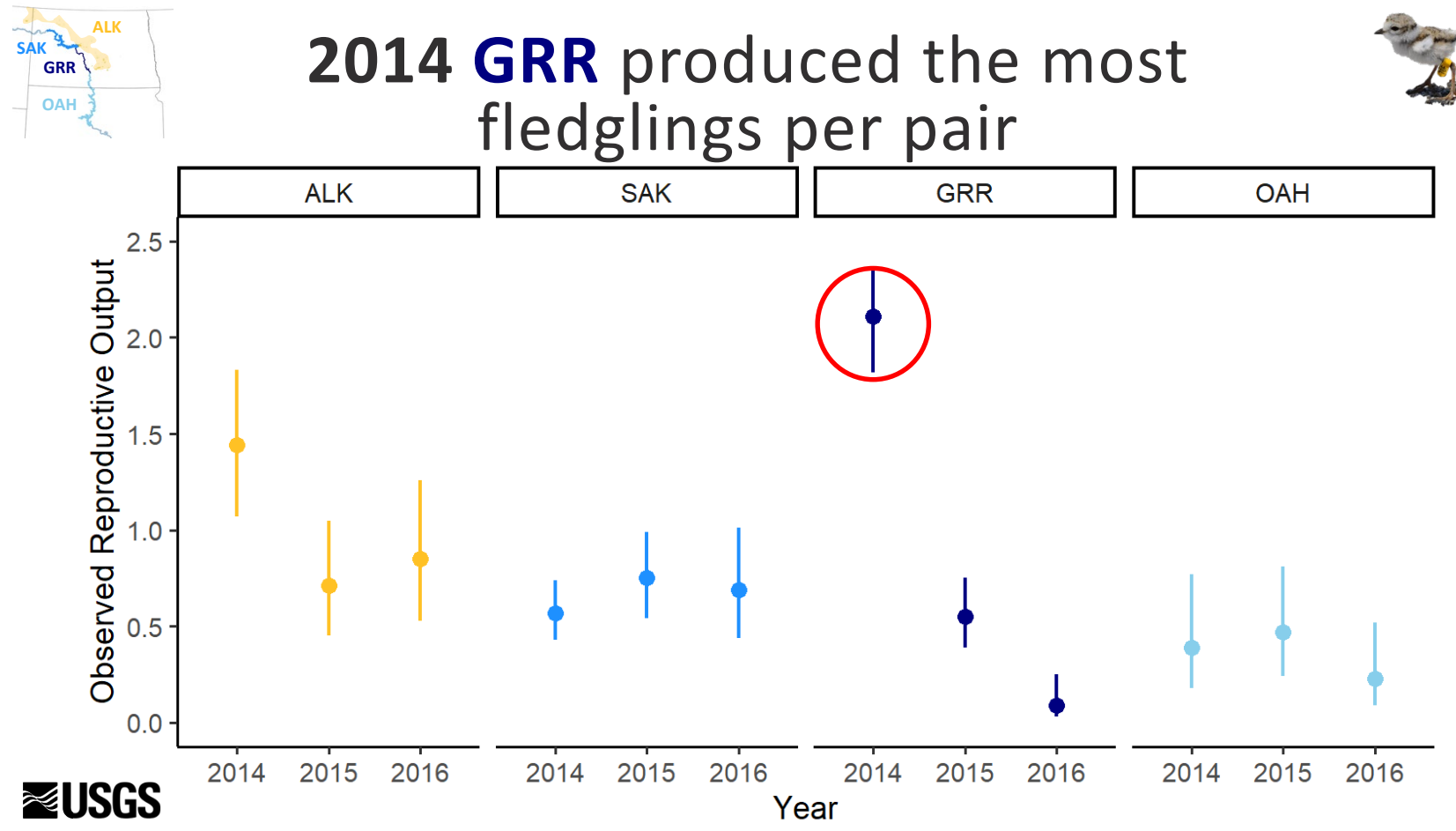

In 2014, the GRR produced an estimated 2.11 ( $\mathrm{Cl}=1.82$ to 2.35 ) fledglings per pair (red circle). SAK and OAH never produced more than one fledgling per pair. [Filled circles indicate mean observed reproductive output estimates. Vertical lines indicate 95-percent confidence intervals (Cl).] 


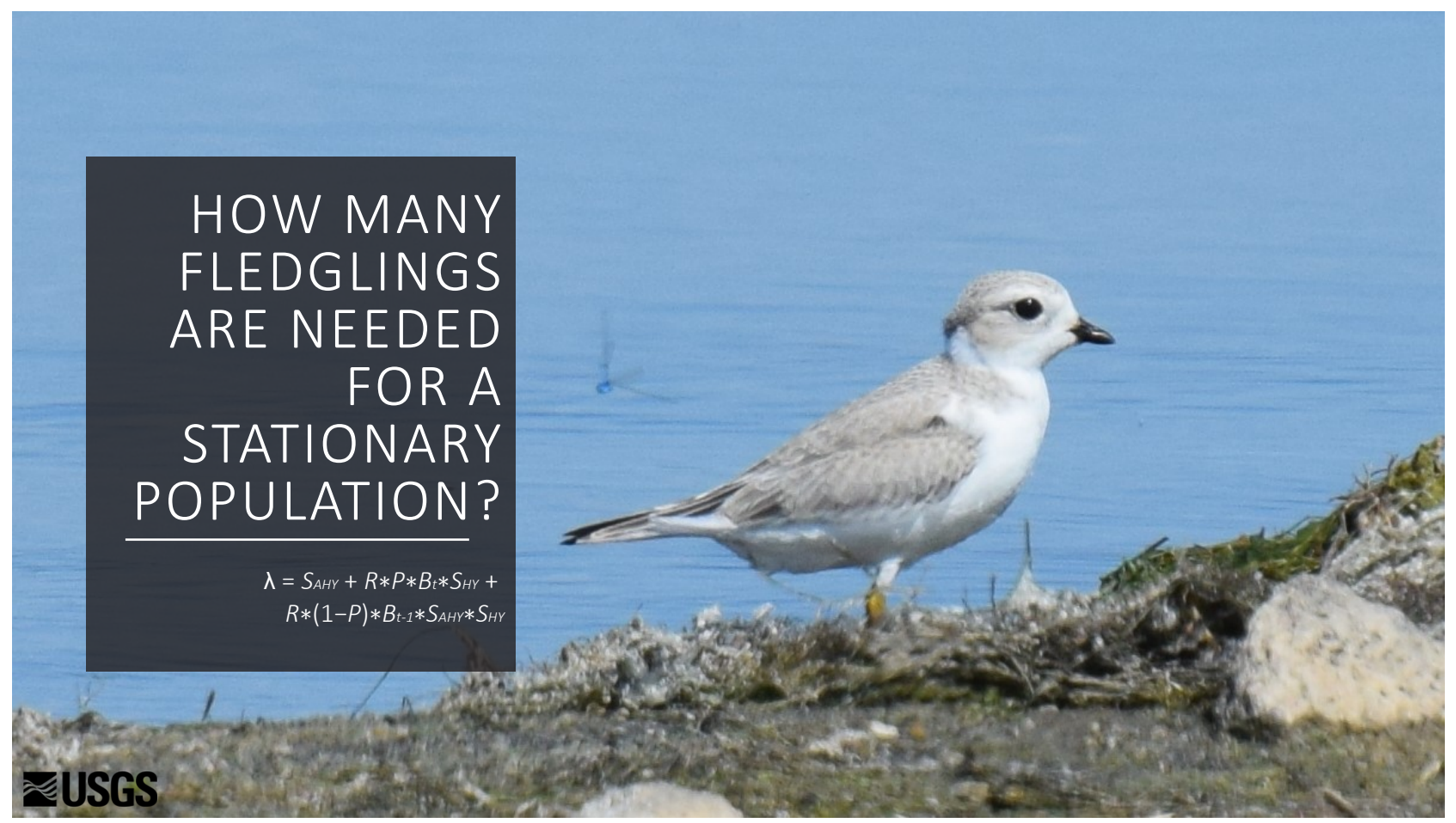

We used our estimates of adult and hatch-year survival to calculate the reproductive output needed to maintain a stable population (stationarity) as an index of reproductive success for each management unit. We followed the methods used by Cohen and Gratto-Trevor (2011) and Catlin and others (2015) to make comparable estimates across studies. We used this equation. [ $\lambda$, population growth rate from year $t$ to $t+1 ; S_{A H Y}$, true survival for adult individuals; $R$, sex ratio at hatch; $P$, the probability that a returning hatch-year bird will breed in its first year; $B$, birth rate; $S_{H Y}$ true survival for hatch-year individuals] 


\title{
Reproductive output needed for stationarity
}

\author{
$\lambda=S_{A H Y}+R * P * B_{t} * S_{H Y}+R *(1-P) * B_{t-1} * S_{A H Y} * S_{H Y}$
}

\section{※USGS}

We used this equation to calculate reproductive output needed for stationarity (Cohen and Gratto-Trevor, 2011). In this equation, $\lambda$ is the population growth rate from year $t$ to $t+1, S_{A H Y}$ is true survival for adult individuals estimated in this study, $S_{H Y}$ is true survival for hatch-year individuals estimated in this study, $R$ is the sex ratio at hatch (assumed to be 0.5 ; Cohen and Gratto-Trevor, 2011), $P$ is the probability that a returning hatch-year bird will breed in its first year (assumed to be 0.68; Gratto-Trevor and others, 2010; Cohen and Gratto-Trevor, 2011), and $B$ is the birth rate defined as fledged chicks produced per pair. This equation accounts for breeding adults surviving from year $t$ to year $t+1$ and recruiting into the population in year $t+1$. Following Cohen and Gratto-Trevor (2011), we set $\lambda=1$ and solved for $B$, assuming that $B_{t}=B_{t-1}$, to determine the number of fledged chicks per pair to maintain stationarity. To incorporate variance into our estimate of $B$, we followed the same procedure as Cohen and Gratto-Trevor (2011) simulating 100,000 values of $S_{A H Y}$ and $S_{H Y}$ using a multivariate normal distribution. We then calculated $B$ using the above equation for each of the 100,000 runs and calculated a mean value and the 5 th and 95th percentiles of those values. See the "Reproductive Output" section for more detailed methodology. 

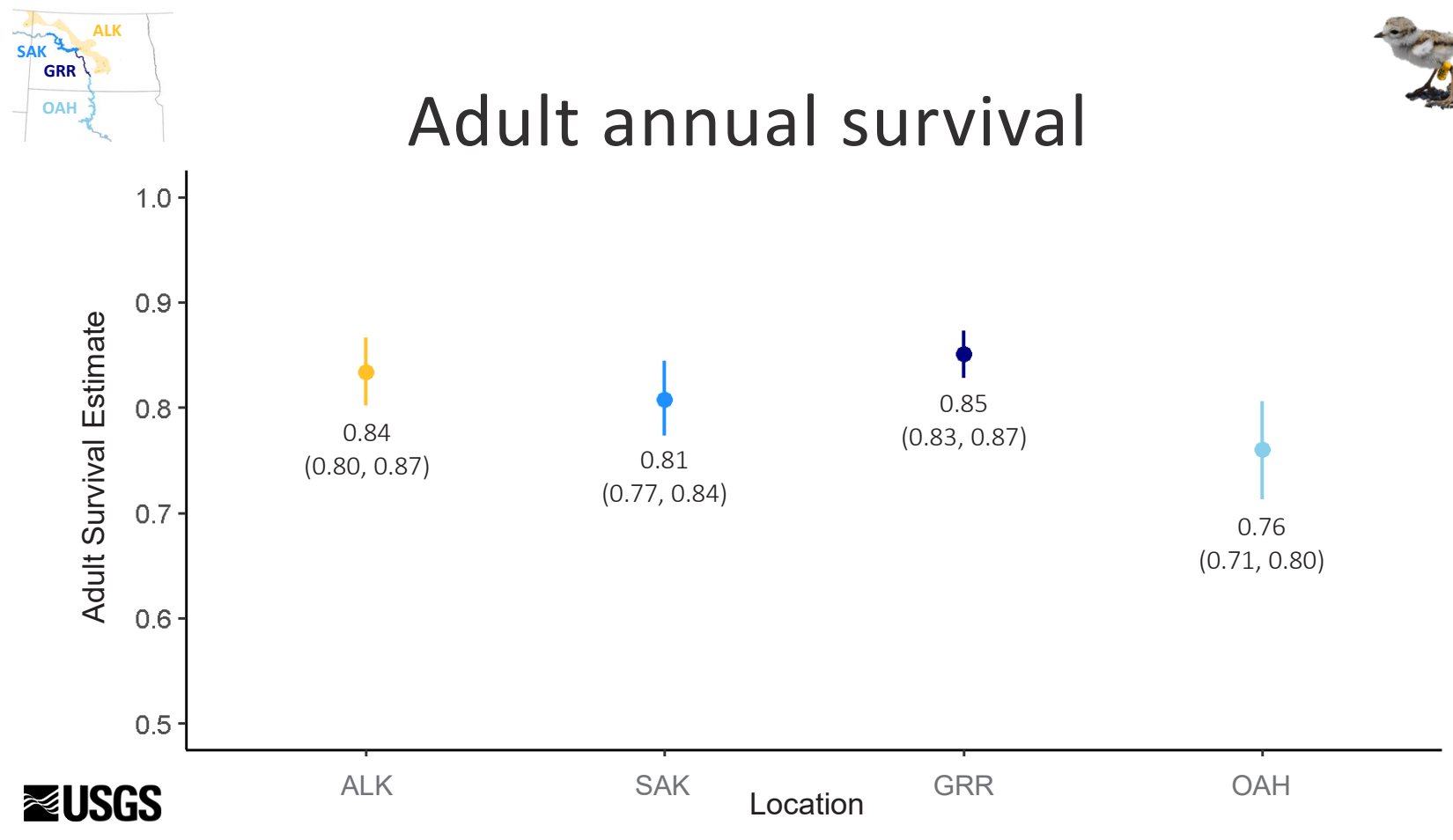

We used these estimated values of adult annual survival for each management unit in the equation to calculate reproductive output needed for stationarity. [Filled circles indicate mean annual adult survival estimates. Vertical lines indicate 95-percent credible intervals.]
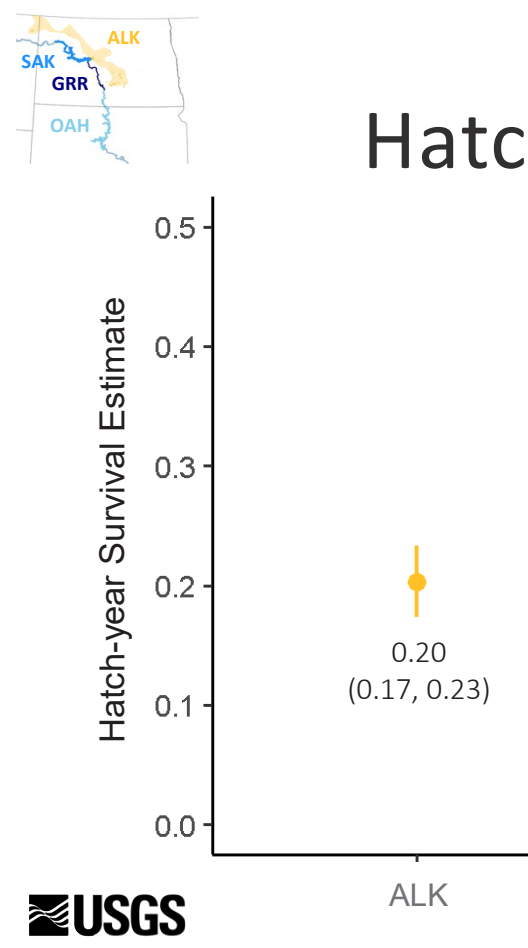

\section{Hatch-year annual survival}

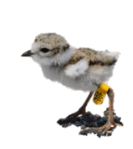

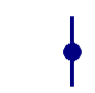

0.30

$(0.27,0.33)$

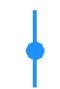

0.19

$(0.16,0.22)$

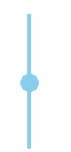

0.19

$(0.13,0.25)$

We used these estimates of hatch-year annual survival in the equation to calculate reproductive output needed for stationarity. [Filled circles indicate mean hatch-year survival estimates. Vertical lines indicate 95-percent credible intervals.] 


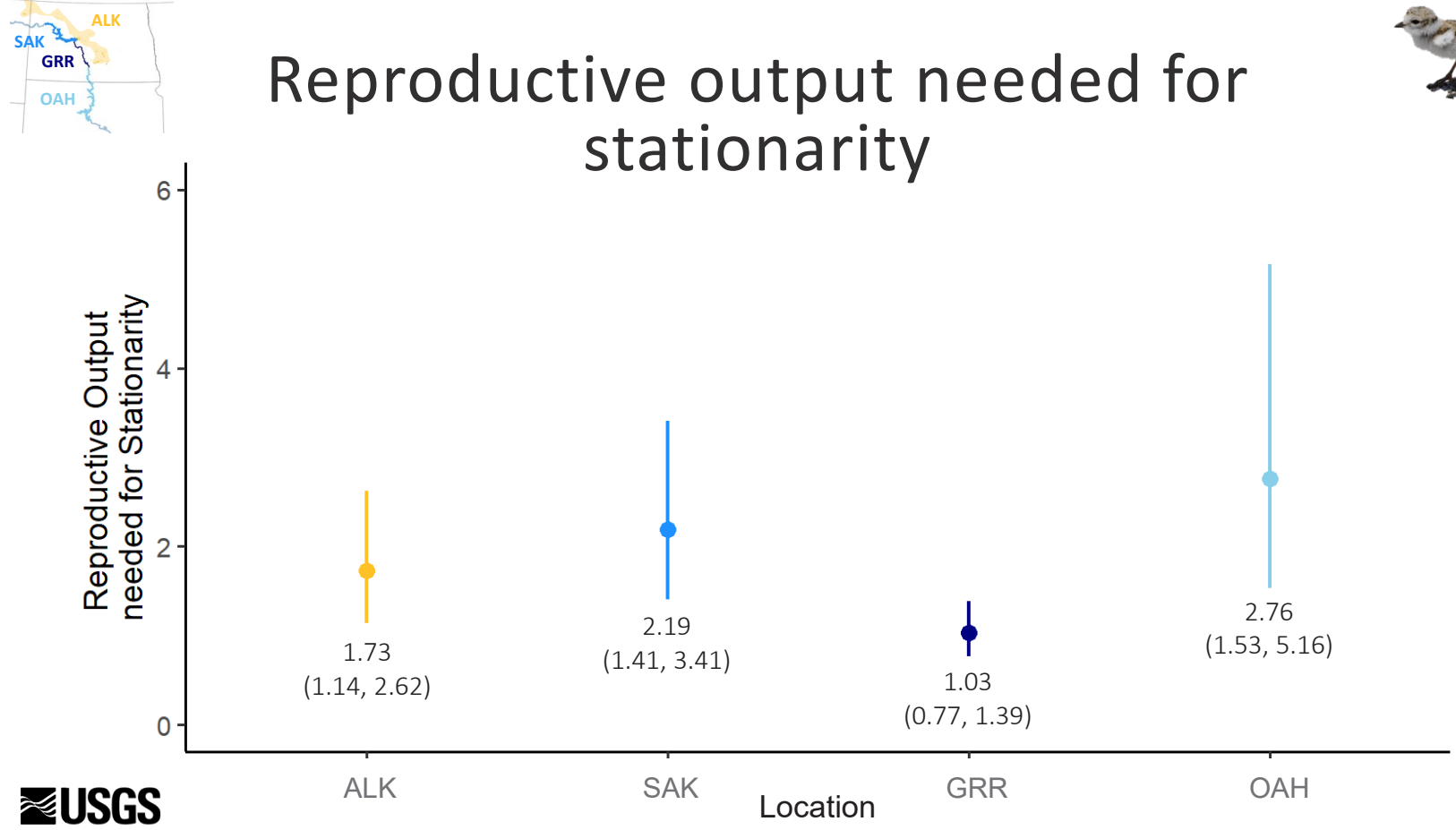

Between 1.03 (the GRR) and 2.76 (OAH) fledged chicks per pair were needed for the population to achieve stationarity from 2014 to 2016. [Filled circles indicate mean estimates. Vertical lines indicate 95-percent confidence intervals.]

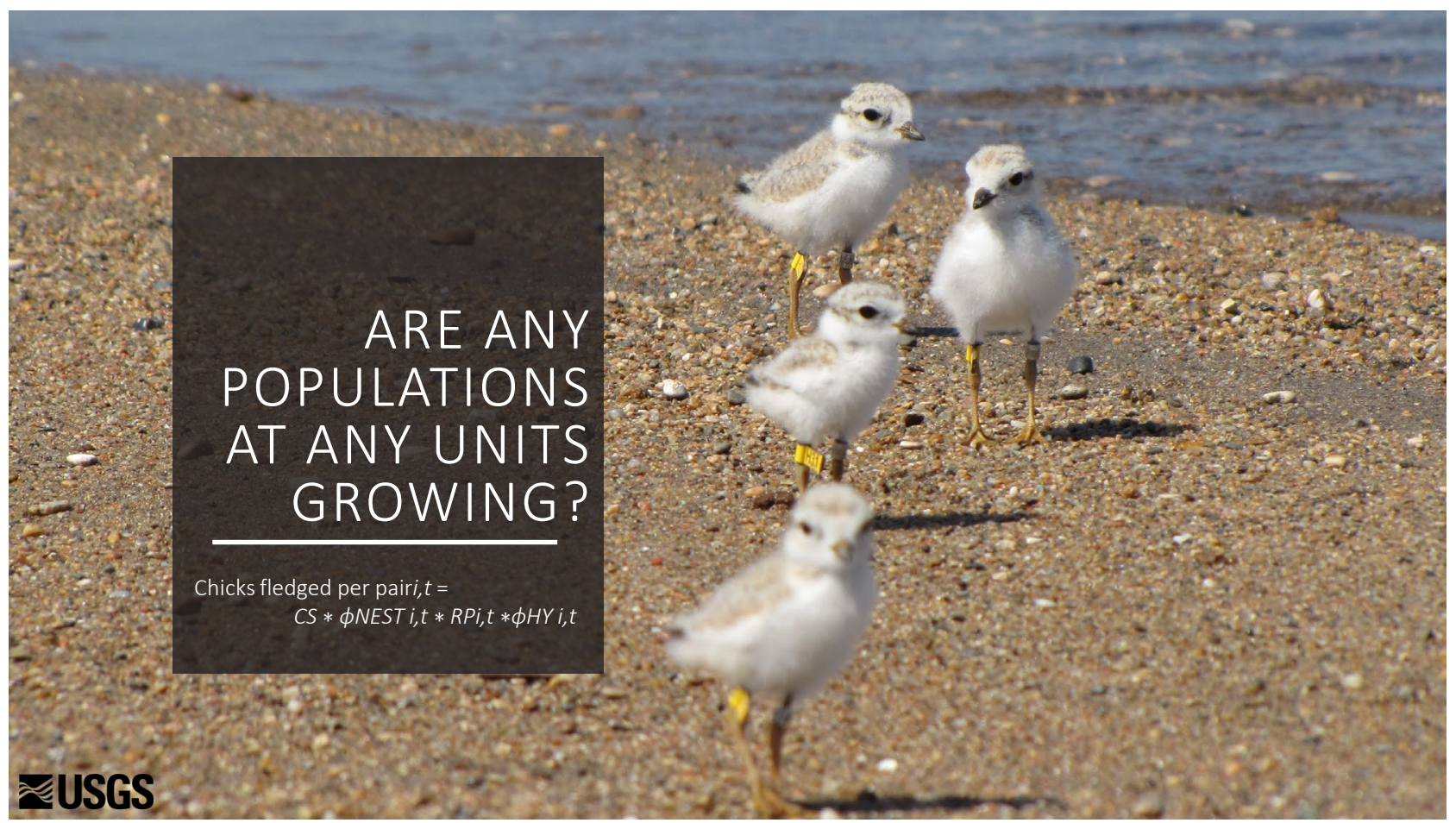

We estimated observed reproductive output as the number of fledged chicks per pair to compare against the value needed for stationarity using our year and management unit specific estimates of nest and chick survival using this equation. [i, management unit; $t$, year; $C S$, clutch size; $\phi_{N E S T}$, the probability that an individual has a successful nest in a given year; $R P$, the probability an individual replaces a lost reproductive attempt; $\phi_{H Y_{1}}$ cumulative survival from hatch to fledge (21 days posthatch)] 


\title{
Observed reproductive output
}

\author{
Chicks fledged per pair ${ }_{i t}=C S * F S_{i t} * \phi_{H r i t}$ \\ Compare to value needed for \\ stationarity
}

\section{ఇUSGS}

To determine if any management unit from 2014 to 2016 showed population growth or stability, we compared our estimates of observed reproductive output with those needed for stationarity calculated previously. [i, management unit; $t$, year; $C S$, clutch size; FS, the probability an individual succeeds at reproducing; $\phi_{H Y}$, cumulative survival from hatch to fledge (21 days posthatch)] 


\section{Observed reproductive output}

Chicks fledged per pair ${ }_{i, t}=C S * F S_{i, t} * \phi_{H r i, t}$

$$
\begin{gathered}
F S_{i, t}=\phi_{N E S T i, t} * e^{\left(1-\phi \phi_{N E S T} i, t\right)^{2}} \\
F S_{i, t}=\phi_{N E S T i, t} * R P_{i, t}
\end{gathered}
$$

\section{ॠUSGS}

We estimated female success (FS) two separate ways. First, we used Cowardin and Johnson's (1979) equation for female success (top) to account for continued nesting attempts after nest failure in our estimate of reproductive output. This is the same method as Catlin and others (2015). Second, we used our known estimates of renesting probability (RP; bottom equation) to compare estimates of reproductive output with management unit specific rates. [i, management unit; $t$, year; $\phi_{H Y}$, cumulative survival from hatch to fledge (21 days posthatch); $\phi_{N E S T}$, the probability that an individual has a successful nest in a given year; e, Euler's number] 


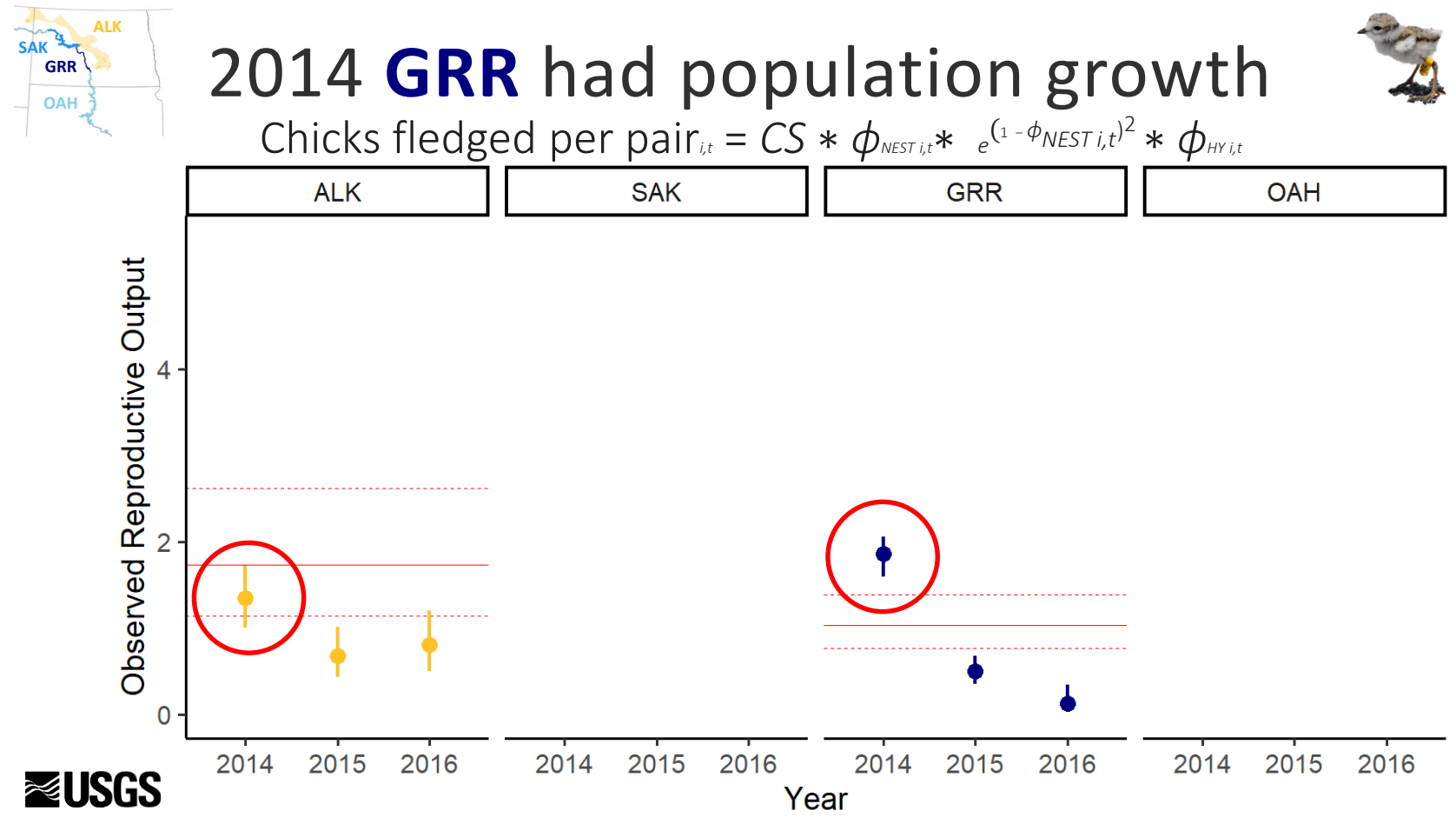

Using Cowardin and Johnson's (1979) equation, only the GRR in 2014 showed population growth and the ALK in 2014 may have remained stable (falls within confidence intervals; red circles). [Filled circles indicate mean estimates. Vertical lines indicate 95-percent confidence intervals (Cls). The red solid lines show the mean estimate of output needed for stationarity for each management unit. The red dashed lines show the 95-percent Cls of the mean estimates. $i$, management unit; $t$, year; $C S$, clutch size; $\phi_{N E S T}$, the probability that an individual has a successful nest in a given year; e, Euler's number; $\phi_{H Y}$, cumulative survival from hatch to fledge (21 days posthatch)] 


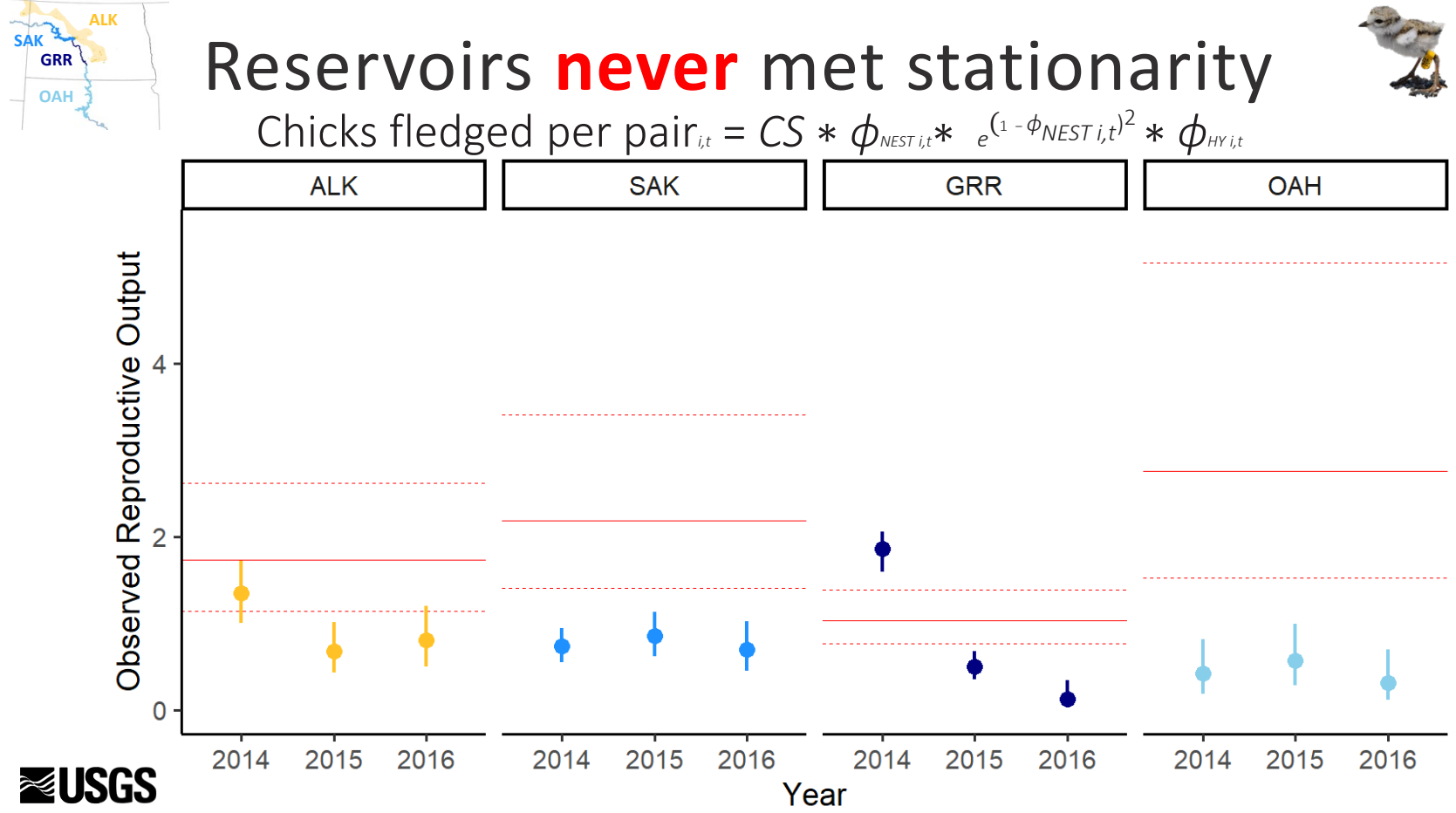

Using Cowardin and Johnson's (1979) equation, neither main-stem reservoir of the Missouri River (SAK or OAH) reached the number of fledged chicks per pair needed for stationarity. [Filled circles indicate mean estimates. Vertical lines indicate 95-percent confidence intervals (Cls). The red solid lines show the mean estimate of output needed for stationarity for each management unit. The red dashed lines show the 95-percent Cls of the mean estimates. $i$, management unit; $t$, year; $C S$, clutch size; $\phi_{N E S T}$, the probability that an individual has a successful nest in a given year; e, Euler's number; $\phi_{H Y}$, cumulative survival from hatch to fledge (21 days posthatch)] 


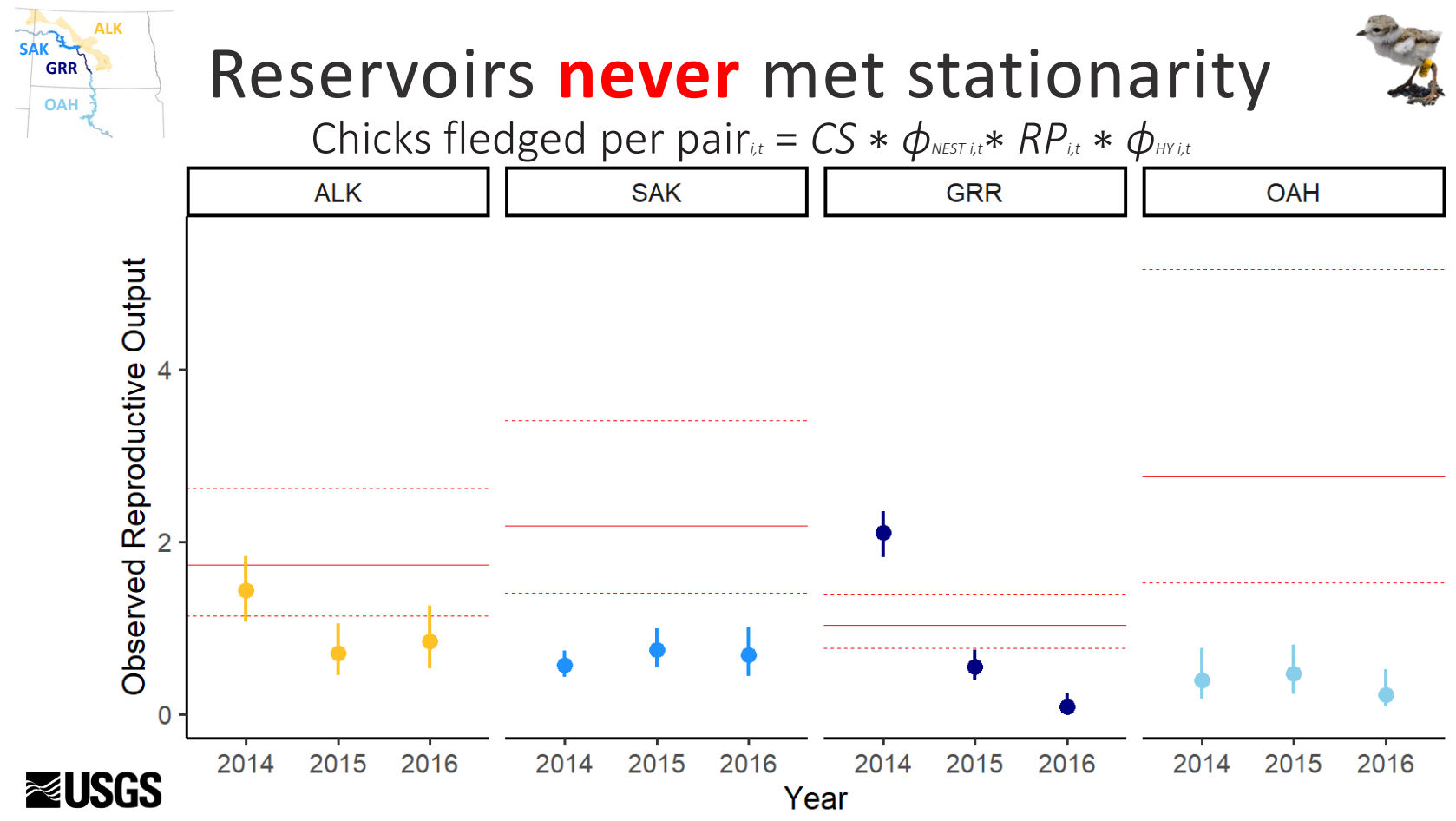

Estimates using renesting probabilities specific to each management unit (shown here) were similar to those derived from Cowardin and Johnson's (1979) equation. Neither main-stem reservoir of the Missouri River (SAK or OAH) reached the number of fledged chicks per pair needed for stationarity. [Filled circles indicate mean estimates. Vertical lines indicate 95-percent confidence intervals (Cls). The red solid lines show the mean estimate of output needed for stationarity for each management unit. The red dashed lines show the 95-percent Cls of the mean estimates. $i$, management unit; $t$, year; $C S$, clutch size; $\phi_{N E S T}$, the probability that an individual has a successful nest in a given year; $R P$, the probability an individual replaces a lost reproductive attempt; $\phi_{H Y}$ c cumulative survival from hatch to fledge (21 days posthatch)] 


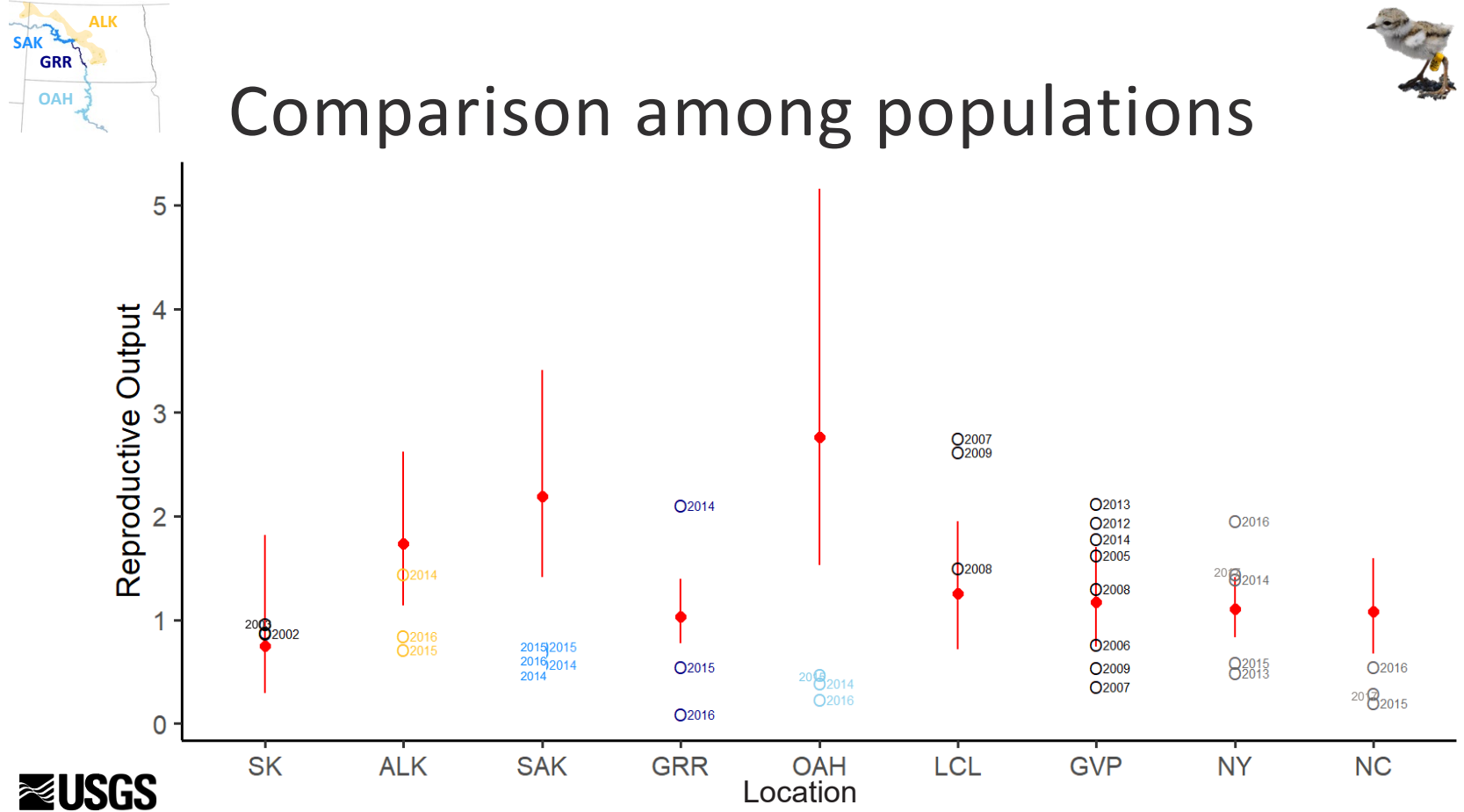

Here, we present the estimates of observed reproductive output (open circles) calculated as part of this study (the ALK, SAK, the GRR, and OAH) relative to the number of fledglings per pair needed for population stationarity (red filled circles with 95-percent confidence intervals shown as vertical red lines) to those calculated for other populations of piping plovers. The two estimates for population stationarity on the reservoirs (SAK, OAH) are higher than most others, suggesting that the main-stem reservoirs are unique and may affect piping plover demography differently than other habitat types. Estimates of observed reproductive output are similar to other location estimates. The estimate from 2014 on the GRR is similar to estimates on Gavins Point Reach (GVP) after the 2011 flood of the Missouri River. See appendix 1 for more detailed vital rates from other studies. [SK, Saskatchewan: 2002-05, Cohen and Gratto-Trevor (2011); LCL, Lewis and Clark Lake: 2005-12, Catlin and others (2015); GVP, Gavins Point Reach: 2005-12, Catlin and others (2015), 2005-09 and 2012-14, Hunt and others (2018); NY, New York: 2013-17, Weithman and others (2019); NC, North Carolina: 2015-17, Weithman and others (2019)] 


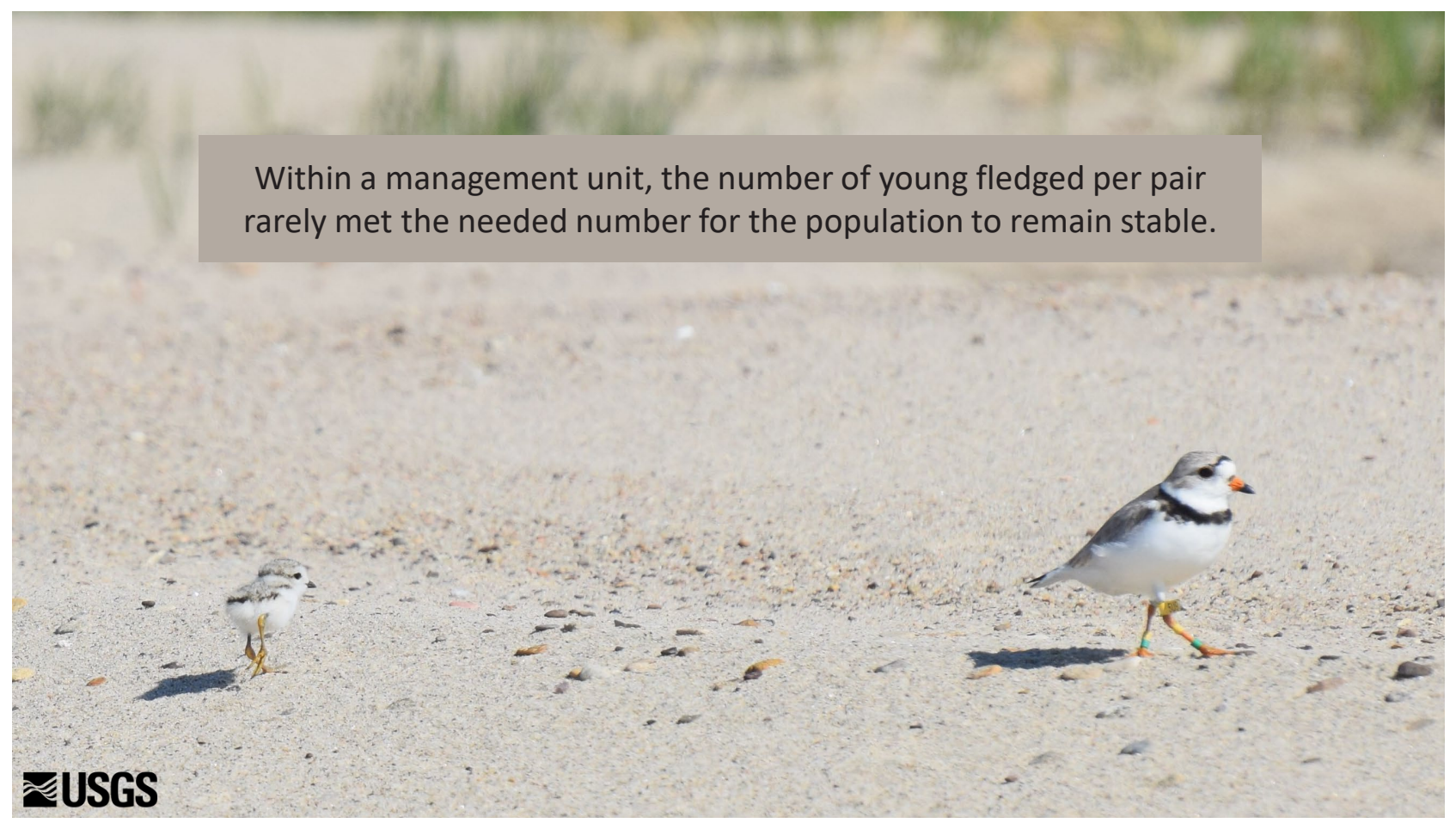

Based on the values assumed or estimated from this study, no management unit produced enough extra fledglings per pair to compensate for lower reproductive output in other areas through immigration. The reservoirs never produced enough fledglings per pair to reach population stationarity. Years when chick survival was higher had a strong effect on improving reproductive output. 


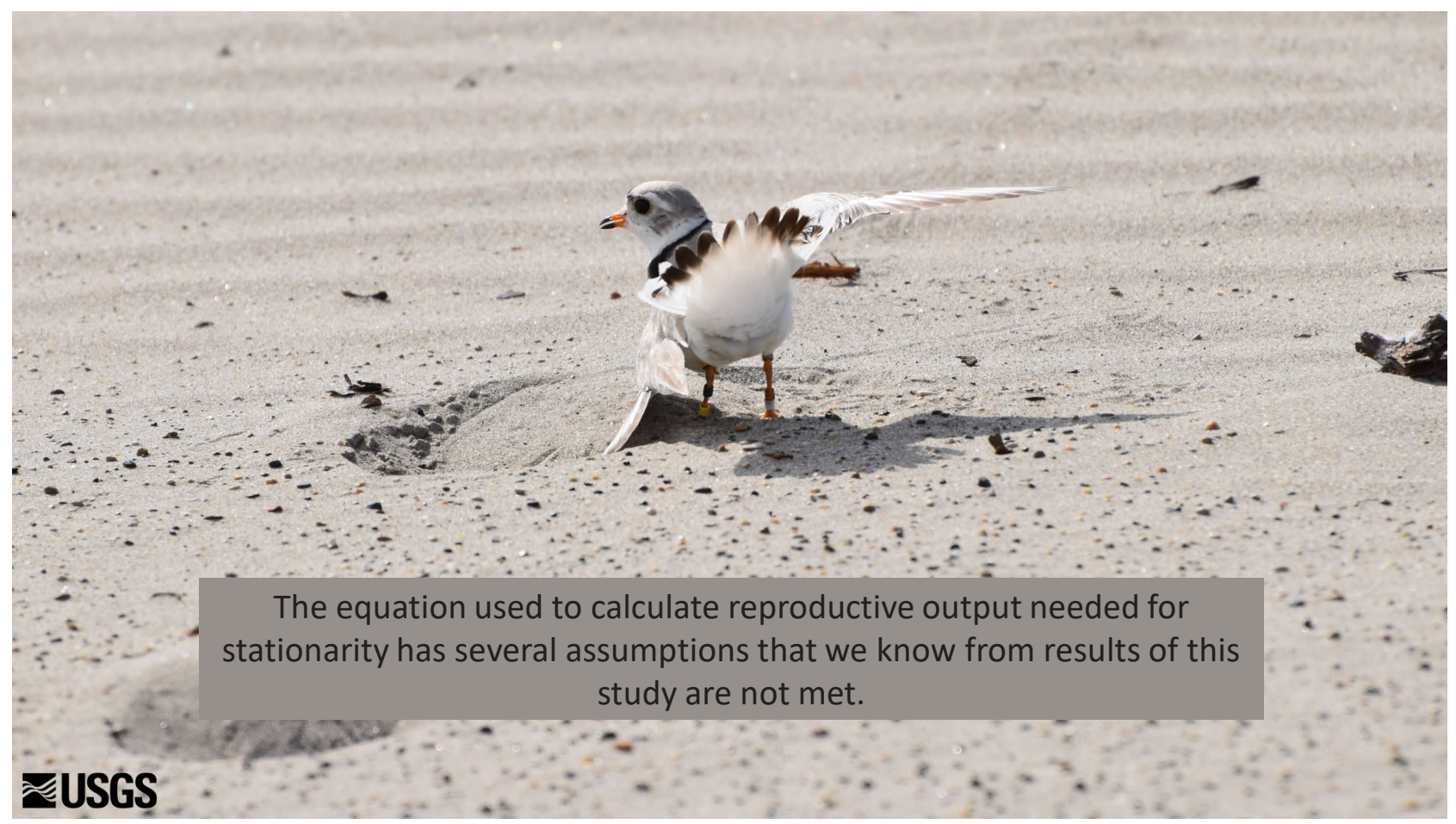

Although using the same equation to calculate reproductive output needed for stationarity has the benefit of providing comparable estimates to other piping plover studies, this simple equation has several assumptions. Based on the results of this study, we now know that the equation used to calculate the number of fledglings per pair needed to achieve population stationarity has some flaws (in other words, assumptions that are not met). 


\title{
Reproductive output needed for stationarity
}

\author{
$\lambda=S_{A H Y}+R * P * B_{t} * S_{H Y}+R *(1-P) * B_{t-1} * S_{A H Y} * S_{H Y}$ \\ Variation in productivity estimates \\ Different processes influence hatch-year and adult survival \\ Rates of second-year breeding unknown for northern Great Plains piping plovers \\ Not all adults breed each year \\ Uneven age class structure \\ Population is not closed (high dispersal within focal study area)
}

\section{ఇUSGS}

Here we mention a few of the problems in using this equation to calculate reproductive output needed for stationarity based on the results of this study. [ $\lambda$, population growth rate from year $t$ to $t+1 ; S_{A H Y}$, true survival for adult individuals; $R$, sex ratio at hatch; $P$, the probability that a returning hatch-year bird will breed in its first year; $B$, birth rate; $S_{H Y}$, true survival for hatch-year individuals] 


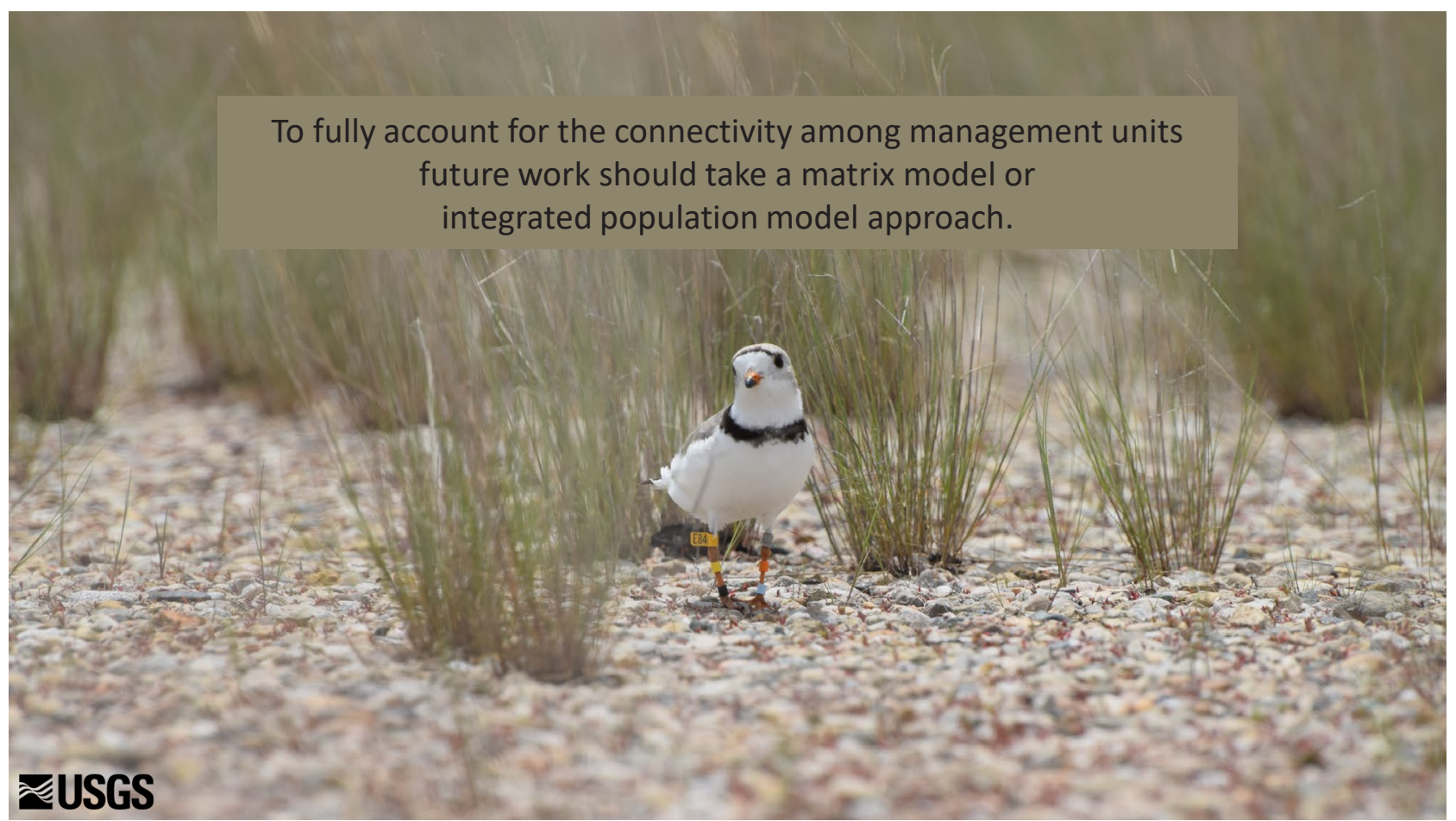

A matrix model or integrated population model approach could use existing data on nest-, chick- and adult-survival rates, age-specific dispersal probabilities, renesting probabilities, renest nest- and chick-survival rates, and counts of individuals to estimate population trends or solve for an unknown value (such as birth rate or immigration) to achieve stationarity. Barring complications from confounded parameters, these approaches could also account for unequal age structure, nonbreeding individuals, and variation in productivity to improve understanding of population dynamics for piping plovers in the NGP.

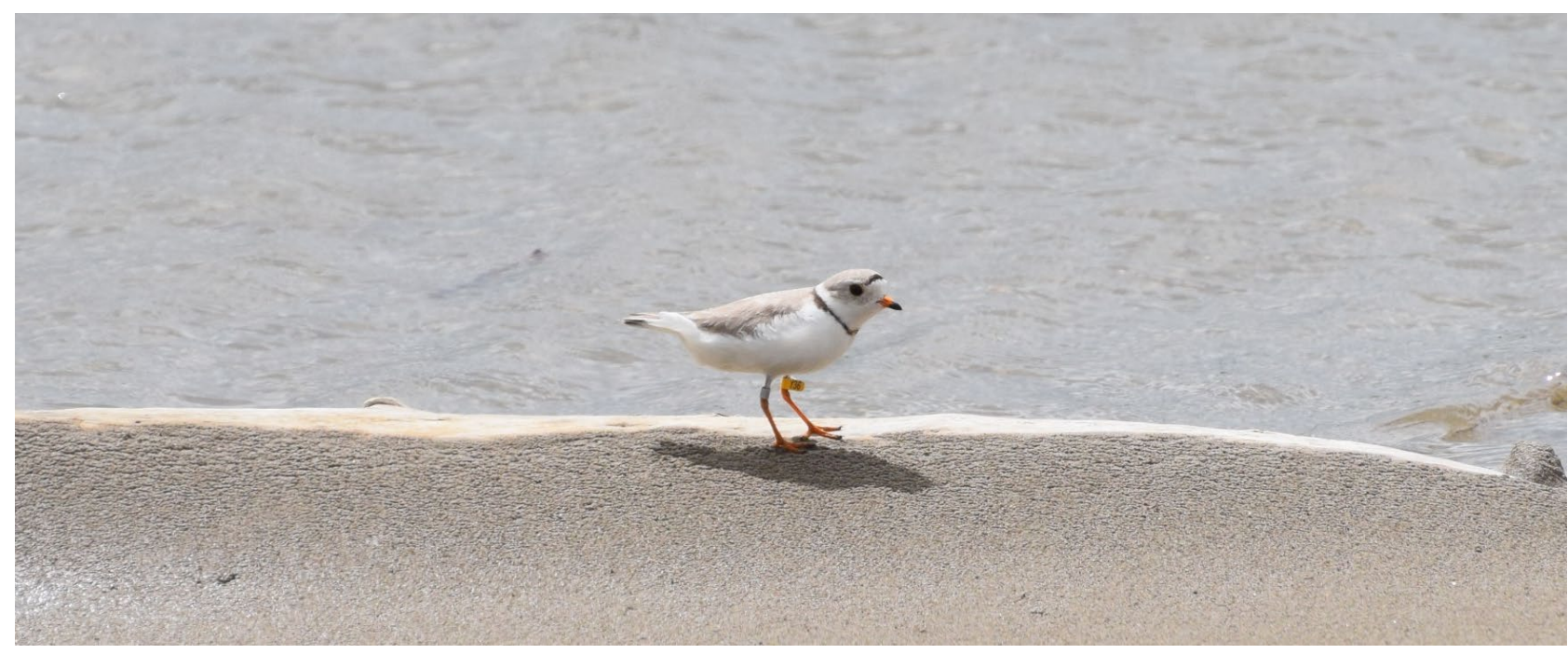

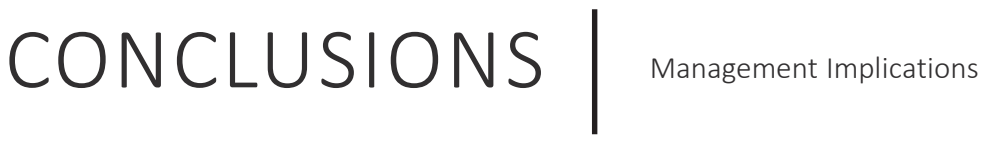

\section{ఇUSGS}

In the remaining slides, we summarize results from the previously shown analyses. 


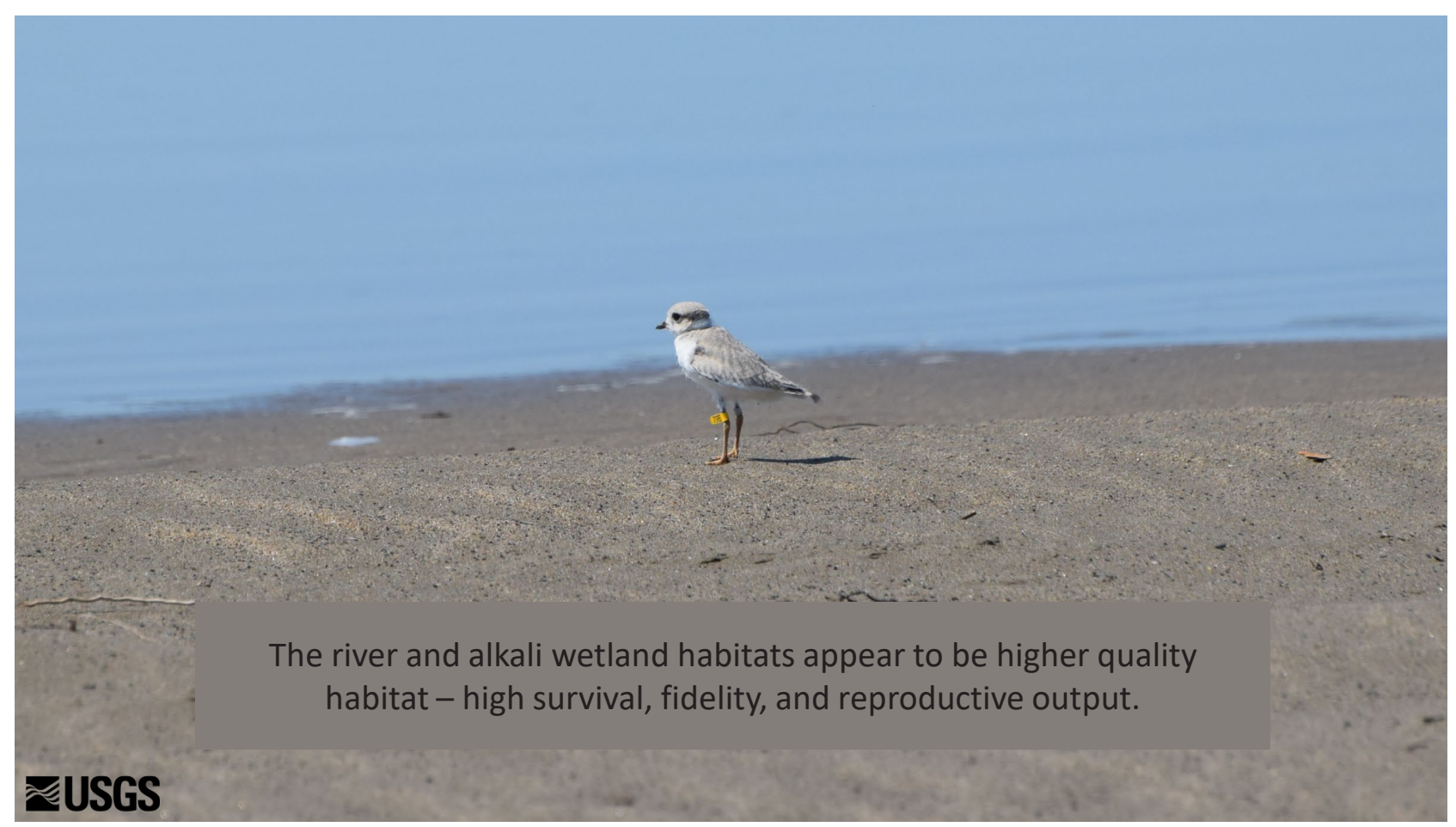

Annual survival to adulthood was higher for individuals hatched on the MRS than the ALK. When using the four specific management locations, individuals hatched on the GRR were more likely to survive to adulthood than individuals hatched anywhere else. Adult survival was also high on the GRR, and piping plovers on the GRR exhibited the lowest probability of transitioning into the nonbreeding state. Combined with high fidelity to the GRR and short dispersal distances from the GRR for hatch-year and adult piping plovers, the GRR may be favored as high-quality habitat for breeding. Unlike reservoir or alkali wetland habitats, the sandbars on the GRR provide a semicontinuous corridor of appropriate nesting habitat. Individuals on the GRR had higher daily nest survival, daily chick survival, renesting probabilities, renest reproductive success, and apparent annual survival compared to individuals on the reservoirs (Anteau and others, 2019; Swift and others, 2020b). Our analyses suggest that river habitats may be considered high quality because individuals rarely left the river study site and generally dispersed short distances within this habitat type. The alkali wetlands habitat showed similarly high fidelity and reproductive output suggesting such sites may also be a preferred habitat. 


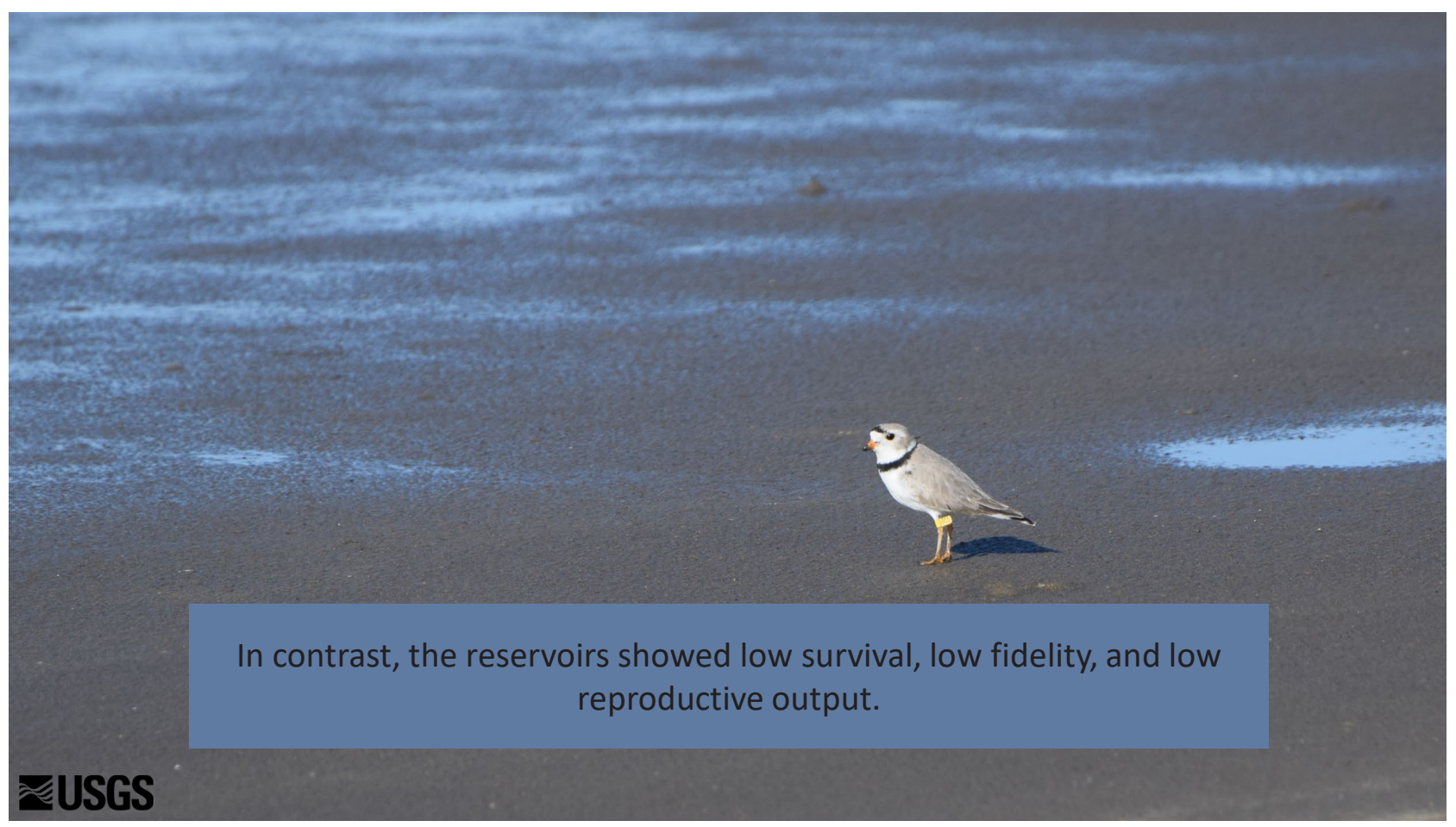

Annual survival to adulthood was lowest for individuals hatched on SAK or OAH. Adult survival was also lower on SAK and $\mathrm{OAH}$. Combined with high dispersal probabilities away from reservoirs and longer dispersal distances for both age classes, the reservoirs (SAK and $\mathrm{OAH}$ ) seem to be unfavored by breeding piping plovers. Additionally, piping plovers that nested on reservoirs were less likely to renest compared to other habitats and exhibited reduced nest and chick survival. Furthermore, renests on reservoirs had reduced apparent reproductive success and daily nest survival unless the predicted amount of habitat on reservoirs increased within the breeding season. Piping plovers nesting on reservoirs often face a novel threat of midseason water-level rise, which can flood nests and unfledged chicks and engulf nesting island habitats (Anteau and others, 2012a) and exacerbate the reproductive loss of first nest attempts. However, it is important to note that during the latter half of this study (especially 2018 and 2019), habitat was scant on both reservoirs because of high pool elevation levels. Thus, the high dispersal away from reservoirs may have been a result of lack of available nesting habitat, territories, or mates. Reservoirs may not have exhibited such low reproductive output in other years when more habitat was available for several consecutive years because breeding site fidelity is still prevalent in piping plovers. Alternatively, altering current management to improve the quality or increase the quantity and intra- and interannual stability of habitat on reservoirs may improve reproductive output and vital rates for piping plovers on SAK and OAH. 


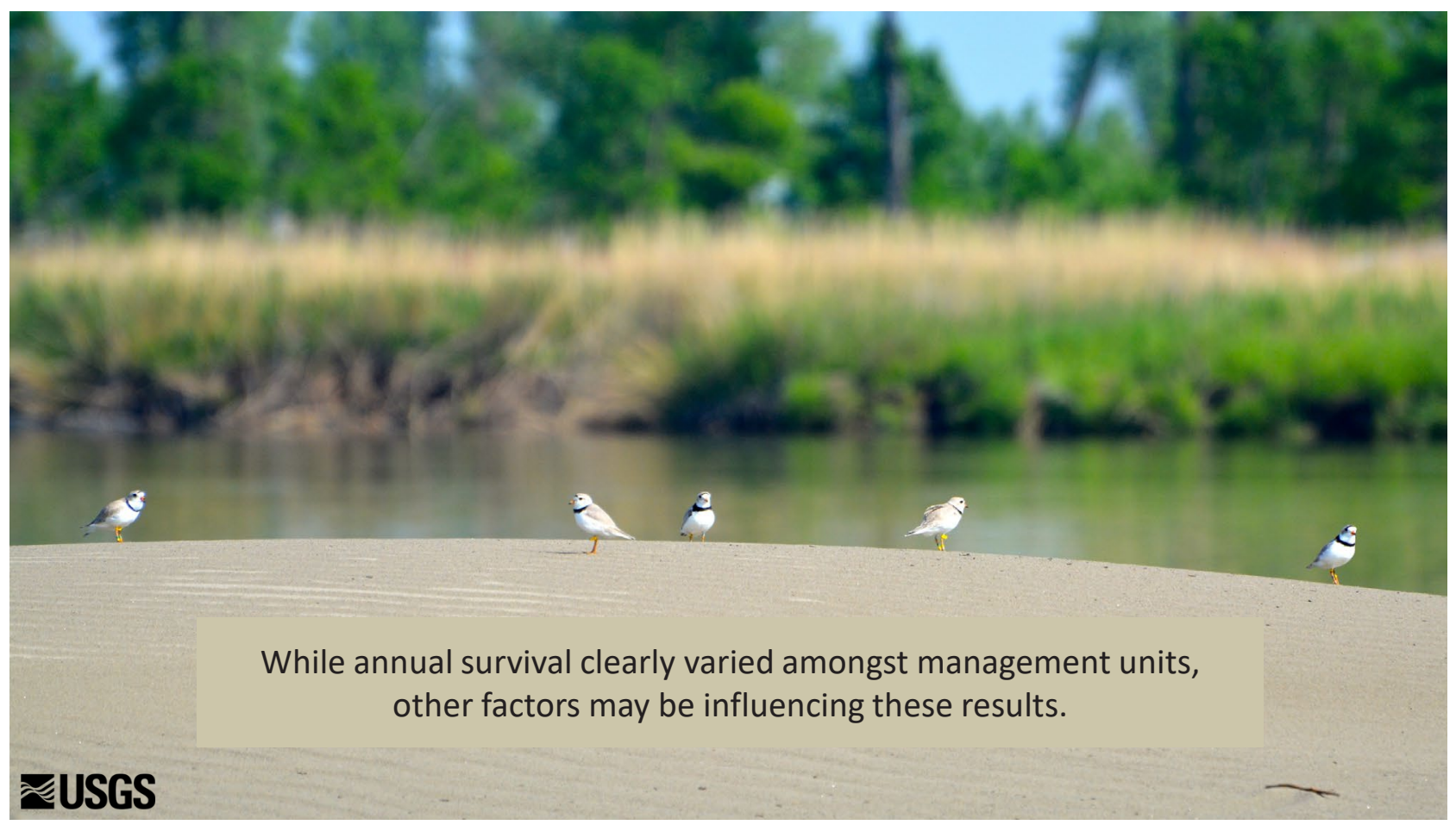

If individuals perceive some habitat to be of higher quality, competition may exclude low quality or younger individuals from establishing nesting territories on high-quality sites. Thus, the lower annual survival seen on the reservoirs may be due to lower-quality individuals. Alternatively, because we are estimating annual survival, factors from migration or the nonbreeding season may affect this survival estimate. This effect could lead to estimates that differ between breeding populations if there is high migratory connectivity between breeding and nonbreeding sites. 


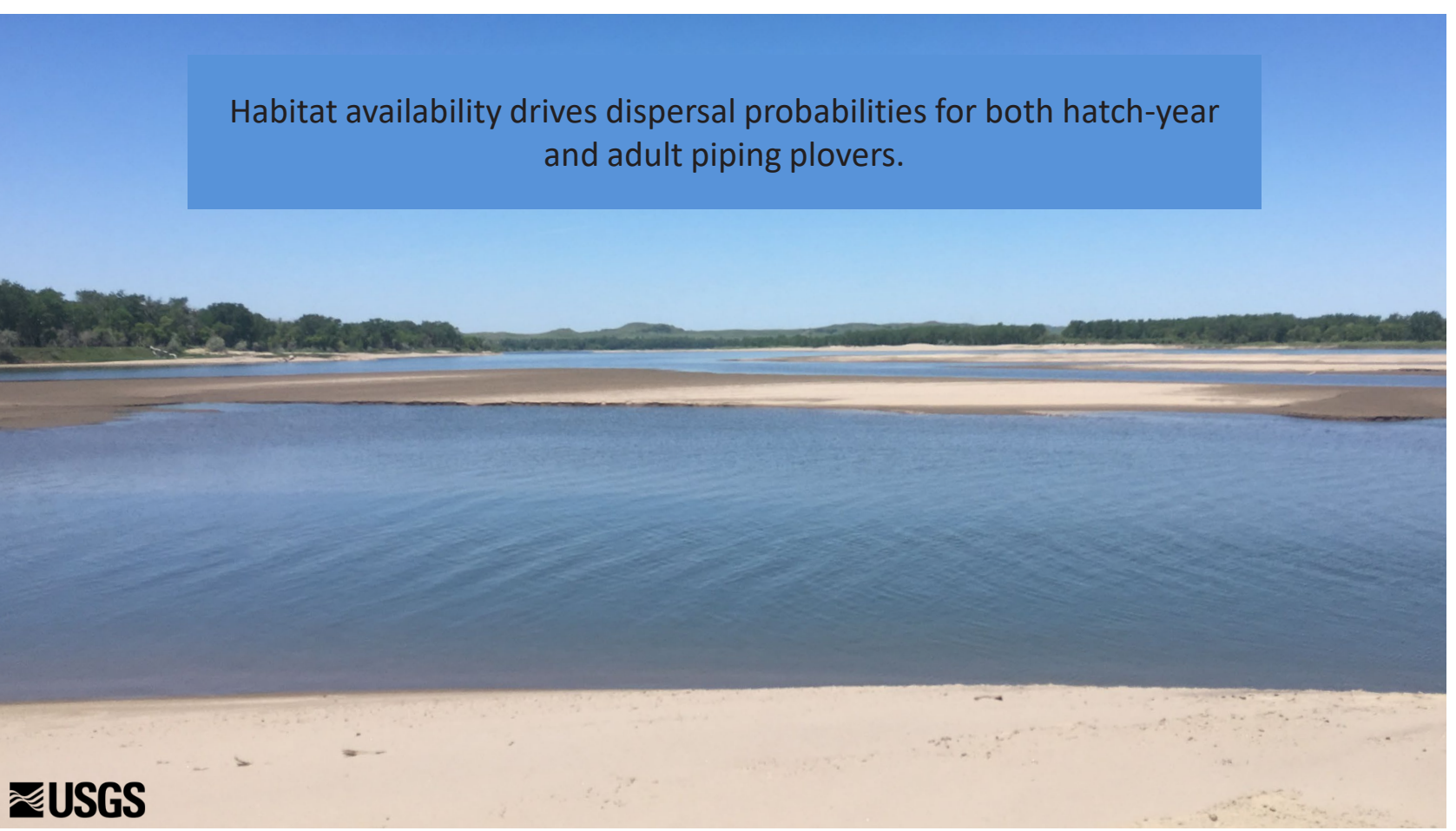

Habitat availability affected nearly every parameter we examined in this study. In general, when more habitat was available, we saw improved vital rates. As expected, dispersal from the MRS increased during the latter years of the study when little habitat was available. Adult and natal dispersal probabilities increased the year after there was an increase in habitat availability, which could be driven by density-dependent processes the year after a good reproductive event. Lastly, dispersal distances also responded to increased habitat availability (shorter distances for natal dispersal and longer for adult dispersal). Altogether, this suggests that piping plovers respond to dynamic habitat availability across the NGP regardless of habitat type. These findings support the current focus of managing the Missouri River for abundant breeding habitat for piping plovers. 


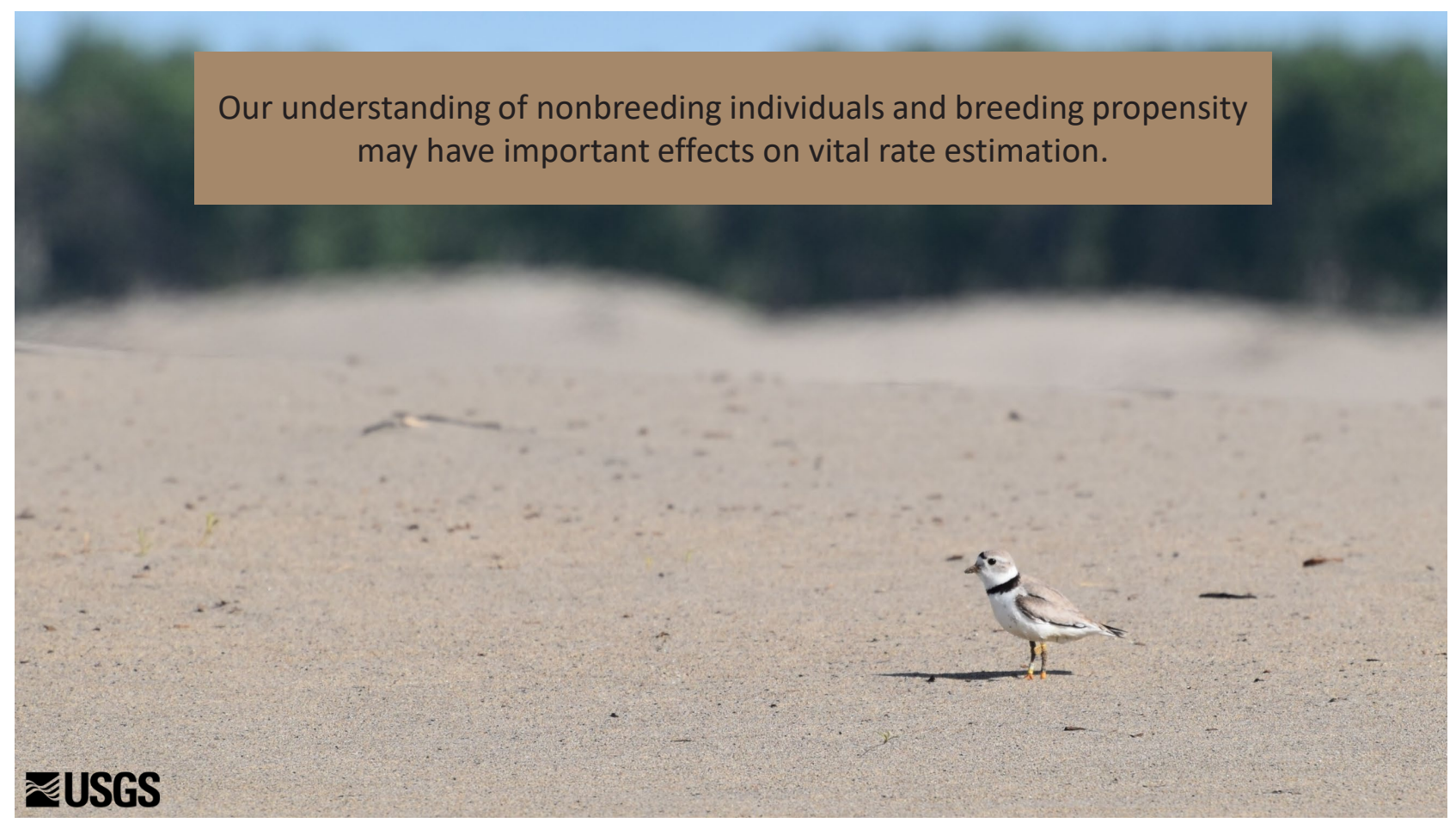

Individuals may be classified as nonbreeders or transient individuals because of variability in individual quality, delayed breeding, senescence, or density-dependent effects (saturation of available mates or territories). A study of breeding propensity from piping plovers breeding on Gavins Point Reach of the Missouri River (Catlin and others, 2019) also found reduced survival for nonbreeding adults $(0.58)$ compared to breeding adults $(0.80)$. However, our study shows higher rates of retaining the nonbreeding state $(0.81)$ compared to piping plovers on the Gavins Point Reach (0.53). Importantly, breeding survival and breeding propensity decreased with increasing nesting density on Gavins Point Reach, starting a feedback loop of indirect effects by increasing the proportion of nonbreeding birds with relatively low survival (Catlin and others, 2019). As the size of breeding populations increases, individuals can compress territories (Severinghaus, 1996), move to subpar habitat where survival and reproduction are relatively low (Gill and others, 2001), or skip breeding (Sedinger and others, 2001; Blomberg and others, 2017). However, if individuals skip breeding, based on our results and those found on Gavins Point Reach, it suggests that survival and reproductive output may be dramatically reduced for NGP piping plovers. The feedback loop we found between high fidelity to the nonbreeding state, low survival of transient individuals, and high transition probabilities into the transient state suggests that individuals that enter the nonbreeding state are not likely to leave or contribute further to the population. A better understanding of the factors that affect why individuals enter the nonbreeding state will shed light on this issue. 


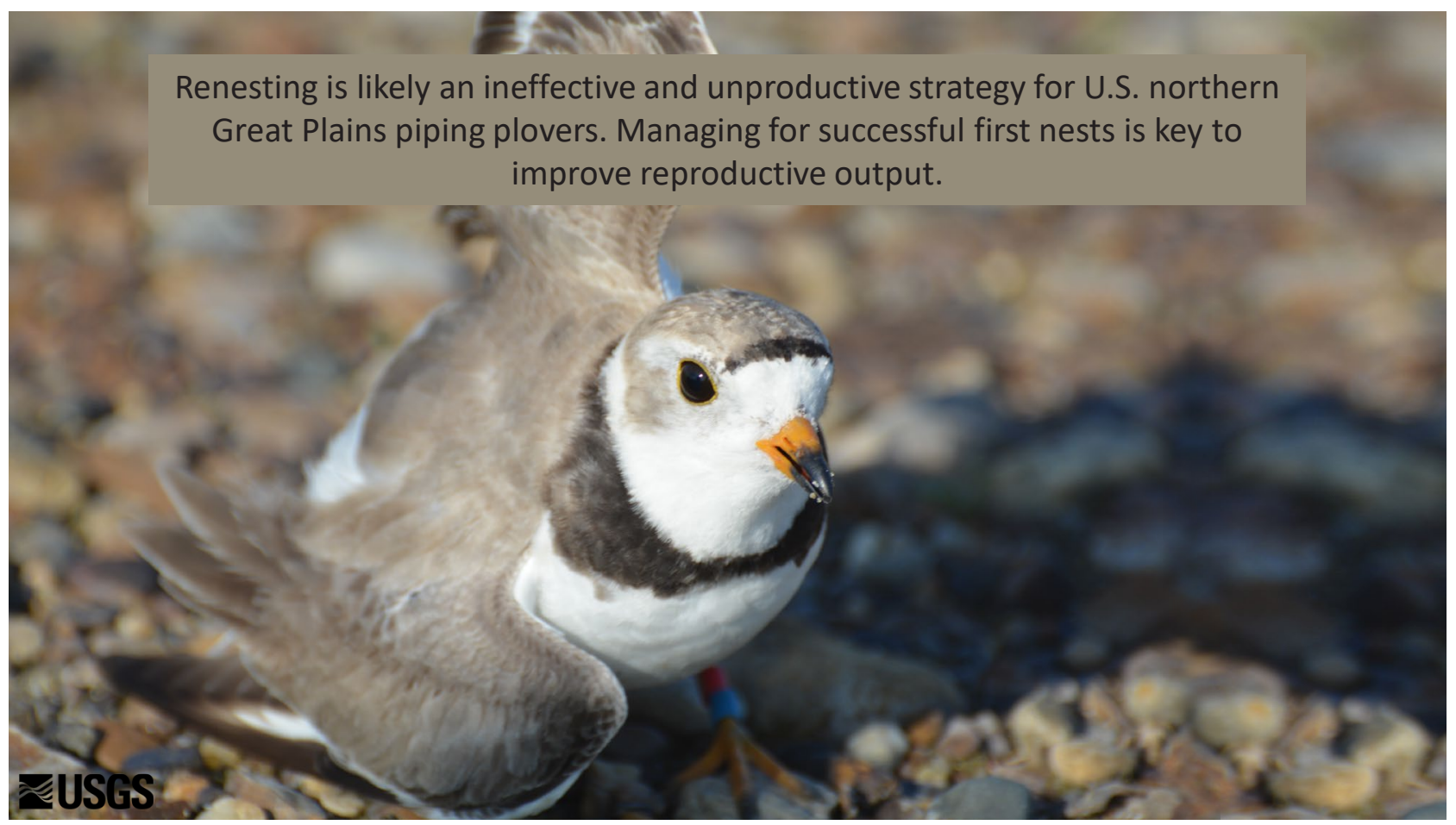

A federally listed species, piping plovers are intensively managed throughout their range, and in the NGP, management of water and predation (for example, predator exclosures and predator removal) are common conservation strategies (USFWS, 2016, 2018). Our results demonstrate that in the NGP first nests are more valuable to individuals than renests, which occur less frequently and are less likely to be successful. Therefore, intensive management focused on the protection of early nests or first nest attempts, or both, would likely be more effective than strategies that assume equivalent productivity from renests. Predator management would be most beneficial early in the breeding season, protecting first nests, and potentially remove the need to renest by improving first nest reproductive success. Predator exclosures may be a useful strategy if nests are found and protected early in the breeding season (May through early June). Alternatively, predator removal efforts that are successful at decreasing predator numbers early may reduce the number of first nests lost to predators. Predator management has the twofold benefit of protecting first nests and reducing the proportion of the population that may lose nests to predators, which had a low renesting propensity compared to other causes of nest failure. Currently, the USACE uses some discretion with water management of the Missouri River to minimize the flooding of riverine nests and chicks because of spring and midsummer rises (USFWS, 2003). However, water-management decisions are part of a complex balance of managing the Missouri River to mitigate downstream flooding, providing sufficient water supplies and flows for navigation, and supporting fisheries and endangered species (USFWS, 2018). When making water-management decisions, the USACE is often faced with tradeoffs such as sacrificing nests or nesting habitat on upstream reservoirs to protect downstream riverine habitat. Generally, midsummer rises are absorbed by the reservoirs of the Missouri River, particularly Lake Sakakawea, where increasing water levels are responsible for the greatest nest losses in most years (Anteau and others, 2012a; Shaffer and others, 2013). Previously published renesting rates from the Great Lakes (Claassen and others, 2014) gave managers some hope that nest loss on the reservoirs because of midsummer rise would be mitigated by renesting efforts in less vulnerable habitats. However, our results show that nest losses on reservoirs likely result in total reproductive failure for the year because individuals nesting on reservoirs were less likely to renest, and when they did renest, the secondary effort was likely not to fledge chicks (in fact none were observed). Reservoirs could still contribute to population growth, particularly if managers can withhold midsummer water-level rise until nests hatch. In years with lower midsummer water level rise, when habitat availability remains nearly constant or increases, nest survival was relatively high (Anteau and others, 2012a), and renest reproductive success was higher. Incorporating nest initiation date, or ideally nest attempt number, into adaptive-management plans could have important consequences when deciding the relative reproductive costs of nest loss because of water-management decisions. Areas with high numbers of renests would be worth less to productivity estimates than areas with high numbers of first nests. 


\section{₹USGS}

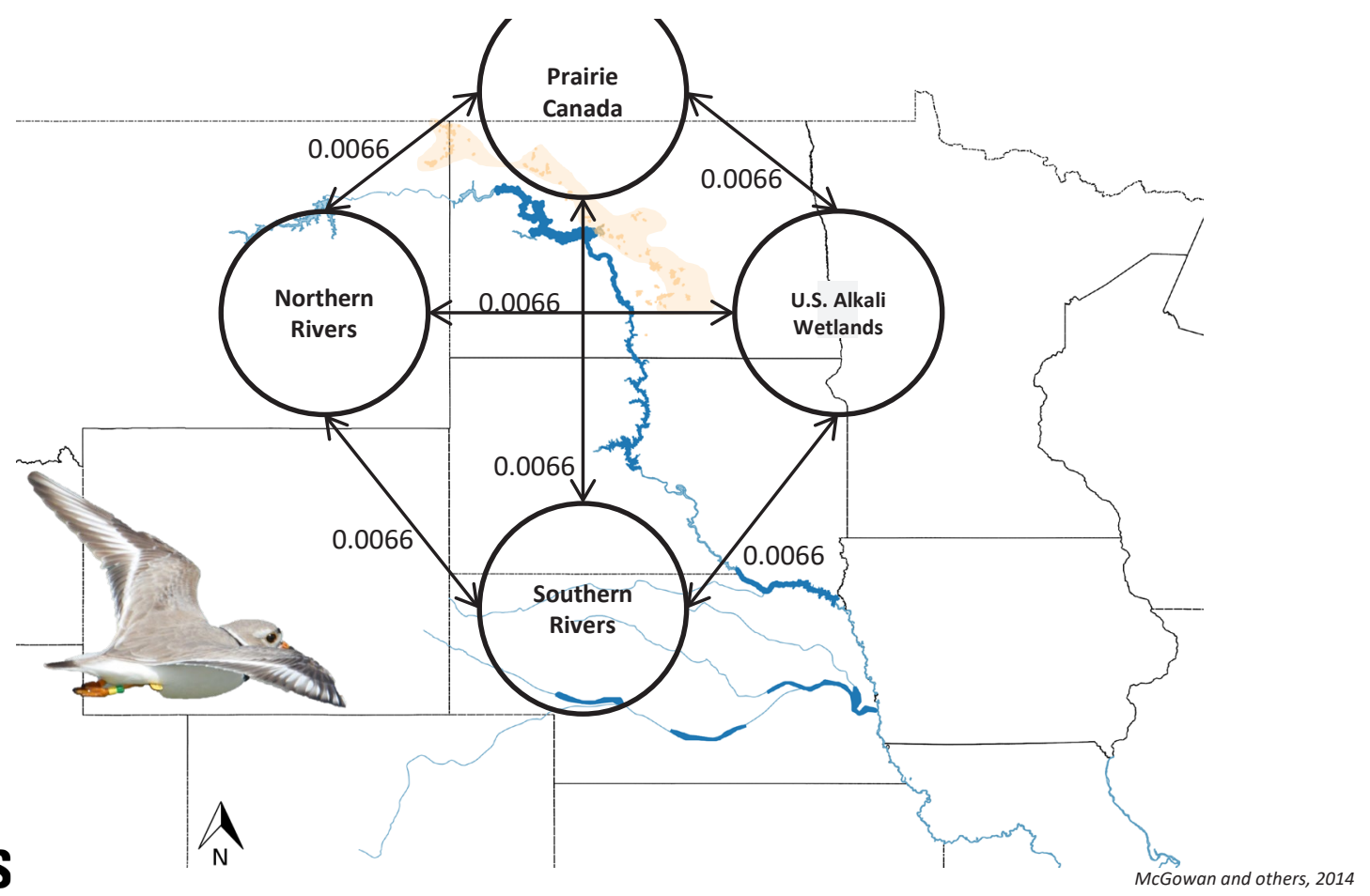

As a reminder, the latest population viability assessment by McGowan and others (2014) assumed low dispersal rates (black arrows) amongst these four defined breeding groups (black circles). In their simulation, they assumed a 0.02 movement rate away from a breeding area with balanced movements amongst the region, meaning 0.0066 individual transition rates between breeding groups. With these assumptions (four breeding groups with low, balanced dispersal), extinction risk for the entire NGP population was very low (0.031 probability). When simulated dispersal rates were increased (0.13), extinction risk also increased (0.08 probability; McGowan and others, 2014). 


\section{‡USGS}

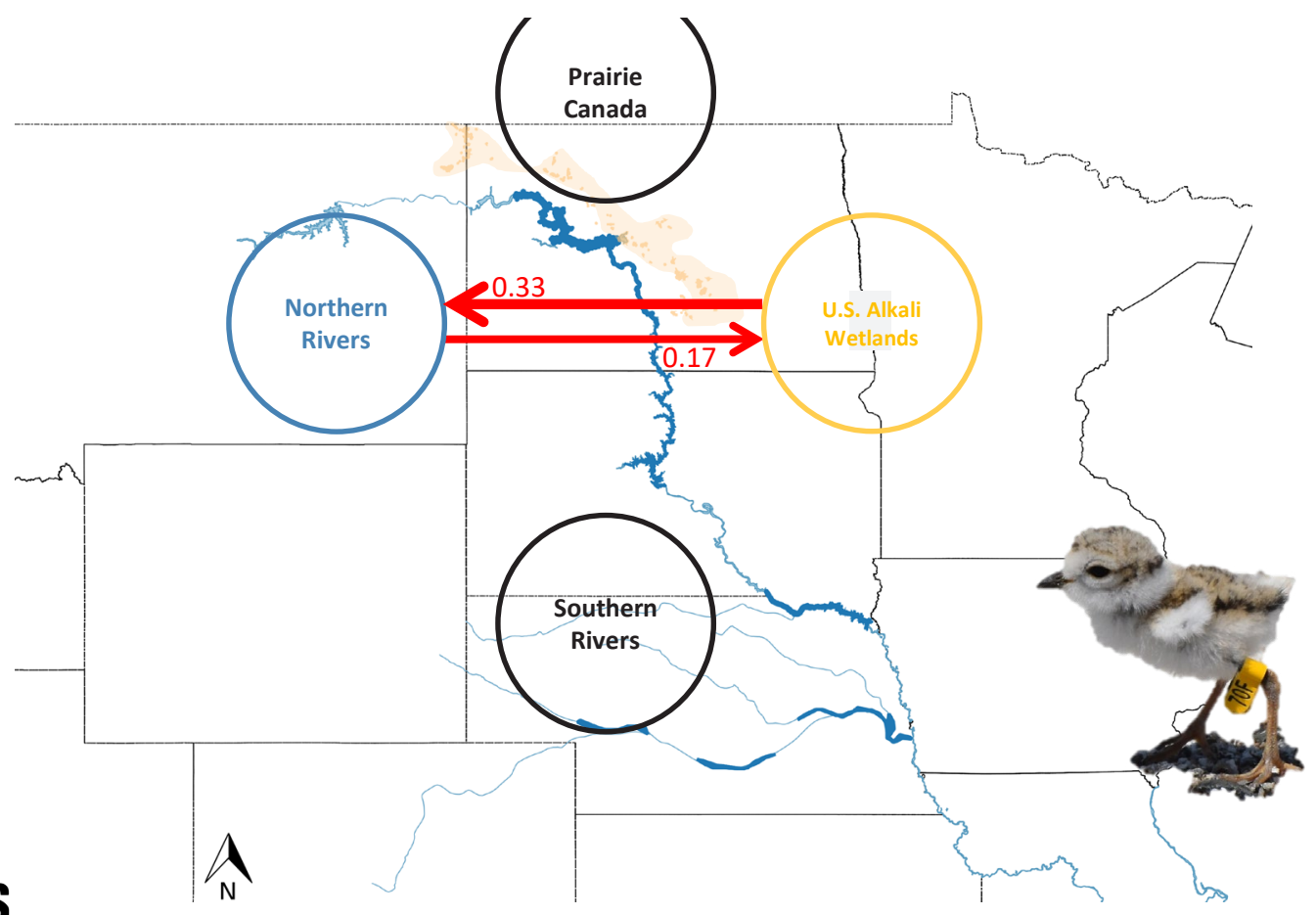

What we have found is highly unbalanced dispersal (red arrows) between the Northern Rivers units of the Missouri River and the U.S. Alkali Wetlands. Natal dispersal from the ALK to the MRS was nearly twice that of dispersal from the MRS to the ALK, and both rates were much higher than the movement rate assumed by McGowan and others (2014). [Assumed breeding groups are indicated by the circles.]

\section{₹USGS}

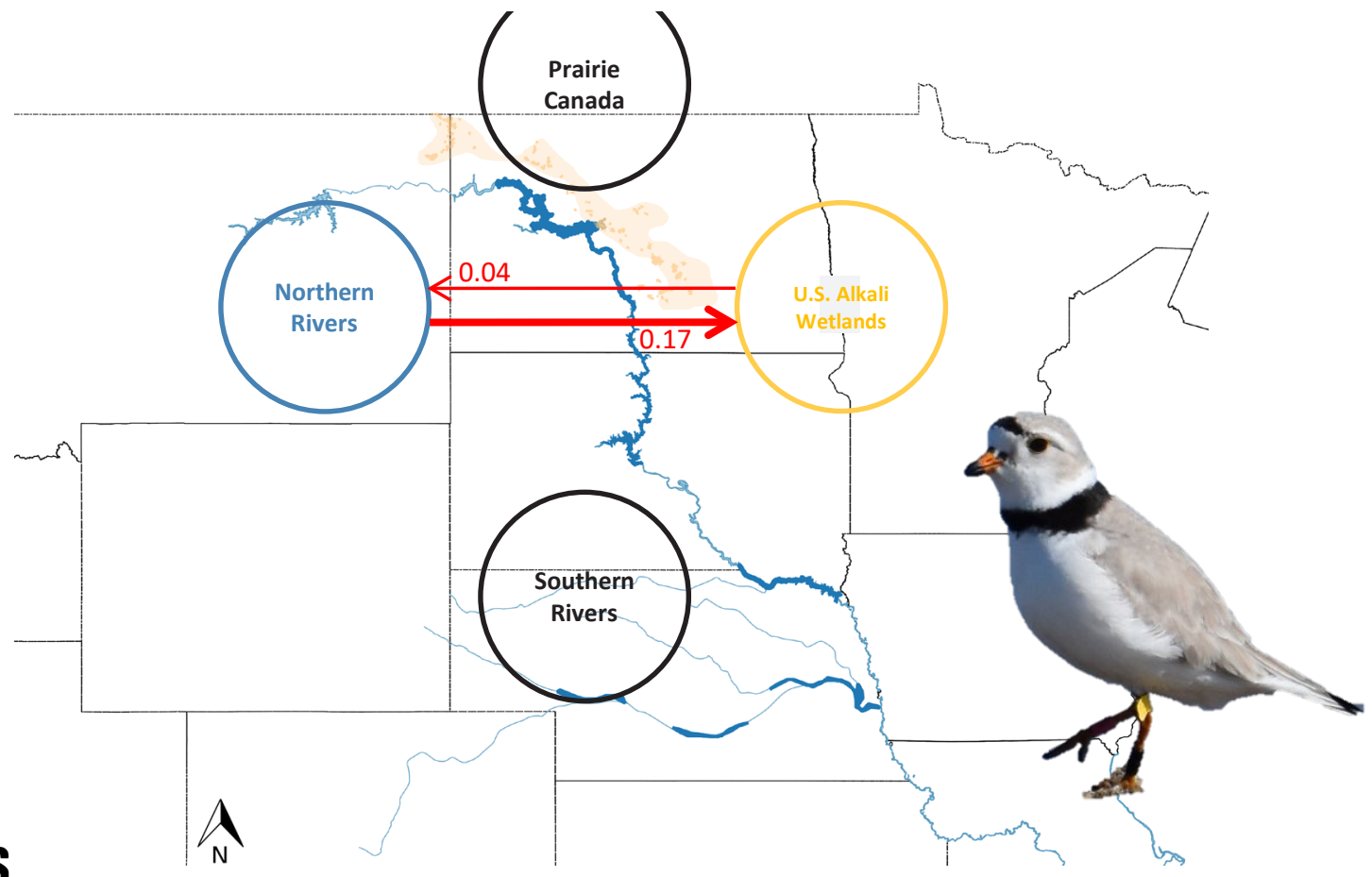

We also found unbalanced, high connectivity between the ALK and the MRS for adult breeding dispersal, though the direction was reversed (red arrows). Adult dispersal was four times higher from the MRS to the ALK than the ALK to the MRS. [Assumed breeding groups are indicated by the circles.] 


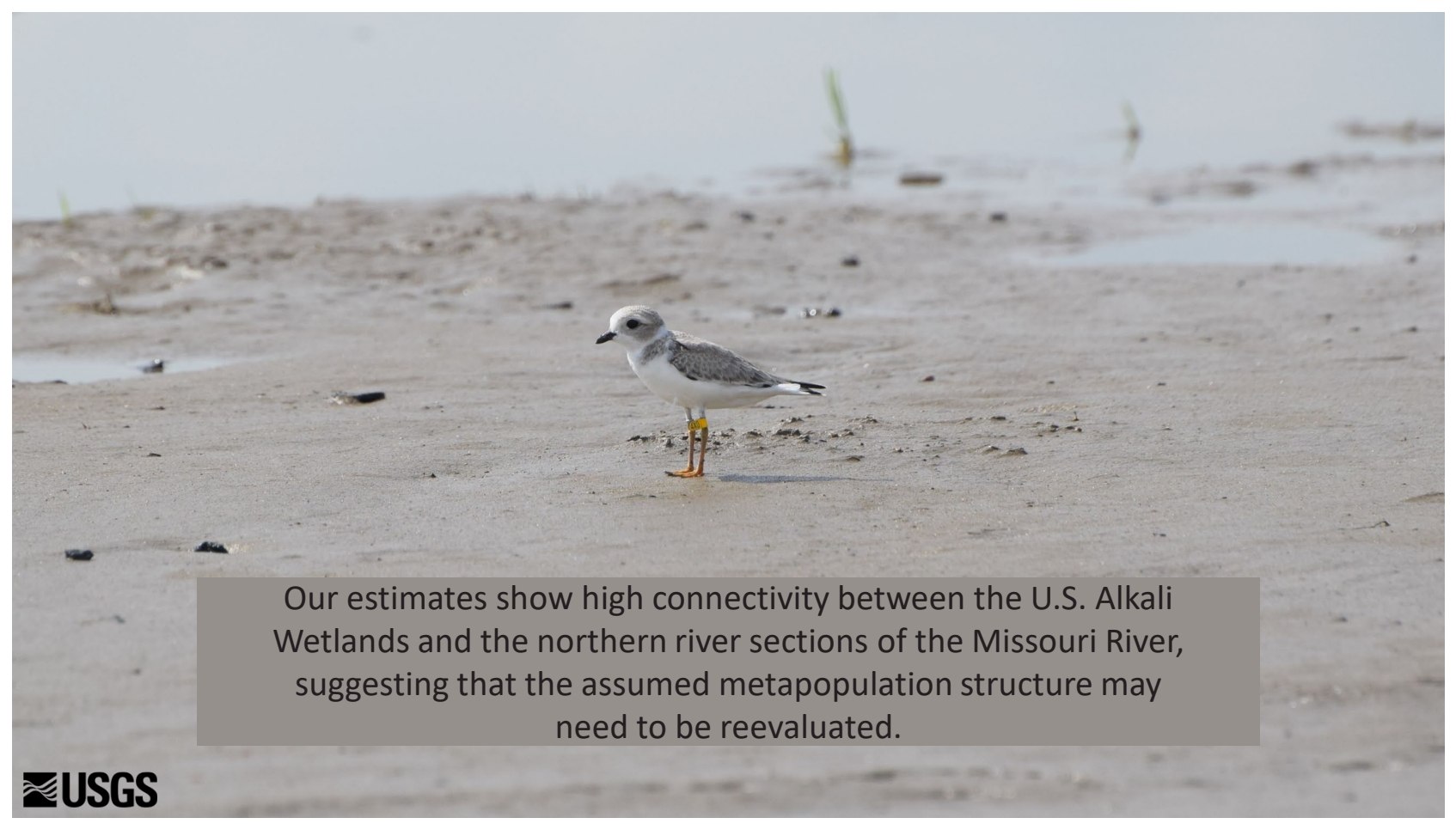

In the last population assessment of NGP piping plovers, McGowan and others (2014) made two important assumptions: four breeding groups and low, balanced dispersal amongst them representing a metapopulation. Our results are in contrast with these assumptions. Rates of movements between the northern Missouri River units and the U.S. Alkali Wetlands are substantially higher than those proposed in McGowan and others (2014) implying that either the rates of dispersal or the partitioning of defined breeding groups needs to be reevaluated. 


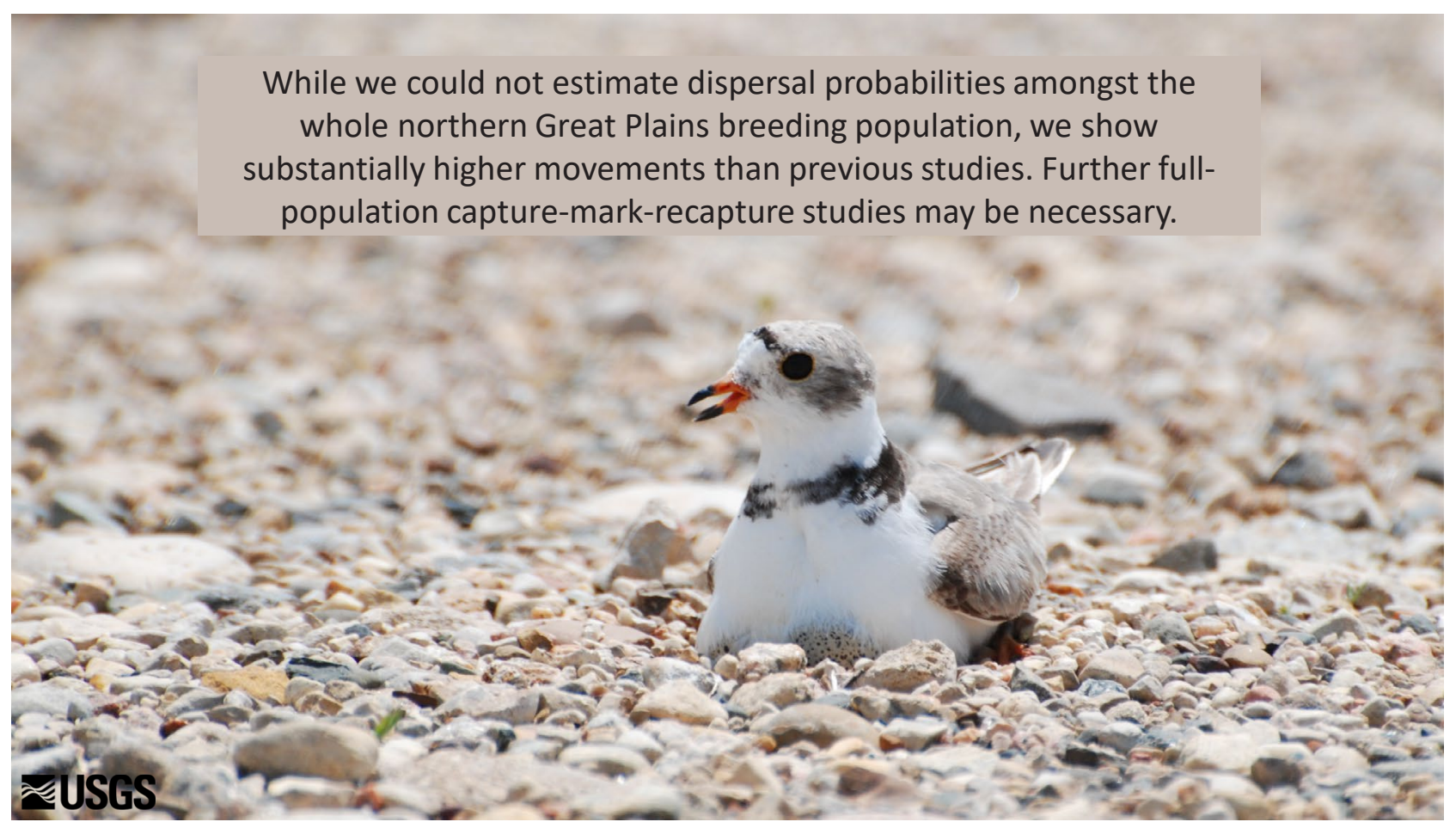

Even with our inability to estimate dispersal probabilities to other NGP breeding areas (Platte River, Prairie Canada, and the southern Missouri River units), we documented more individuals moving between these regions than previous studies (McGowan and others, 2014; Catlin and others, 2016). In fact, individuals from the Platte River and tributaries, Prairie Canada, and the southern Missouri River units immigrated to all four of our focal management units. In addition, we documented 34 individuals leaving our focal study area to breed in these other breeding areas based on observations reported to us by collaborators, representing a roughly 3.3 percent dispersal rate of known breeding dispersal outside our focal area. Previous studies had shown only a handful of individuals moving between the southern Missouri River units and our focal study area (McGowan and others, 2014; Catlin and others, 2016). To derive dispersal rates amongst the full population would require concurrent banding and resighting efforts throughout the NGP range. 


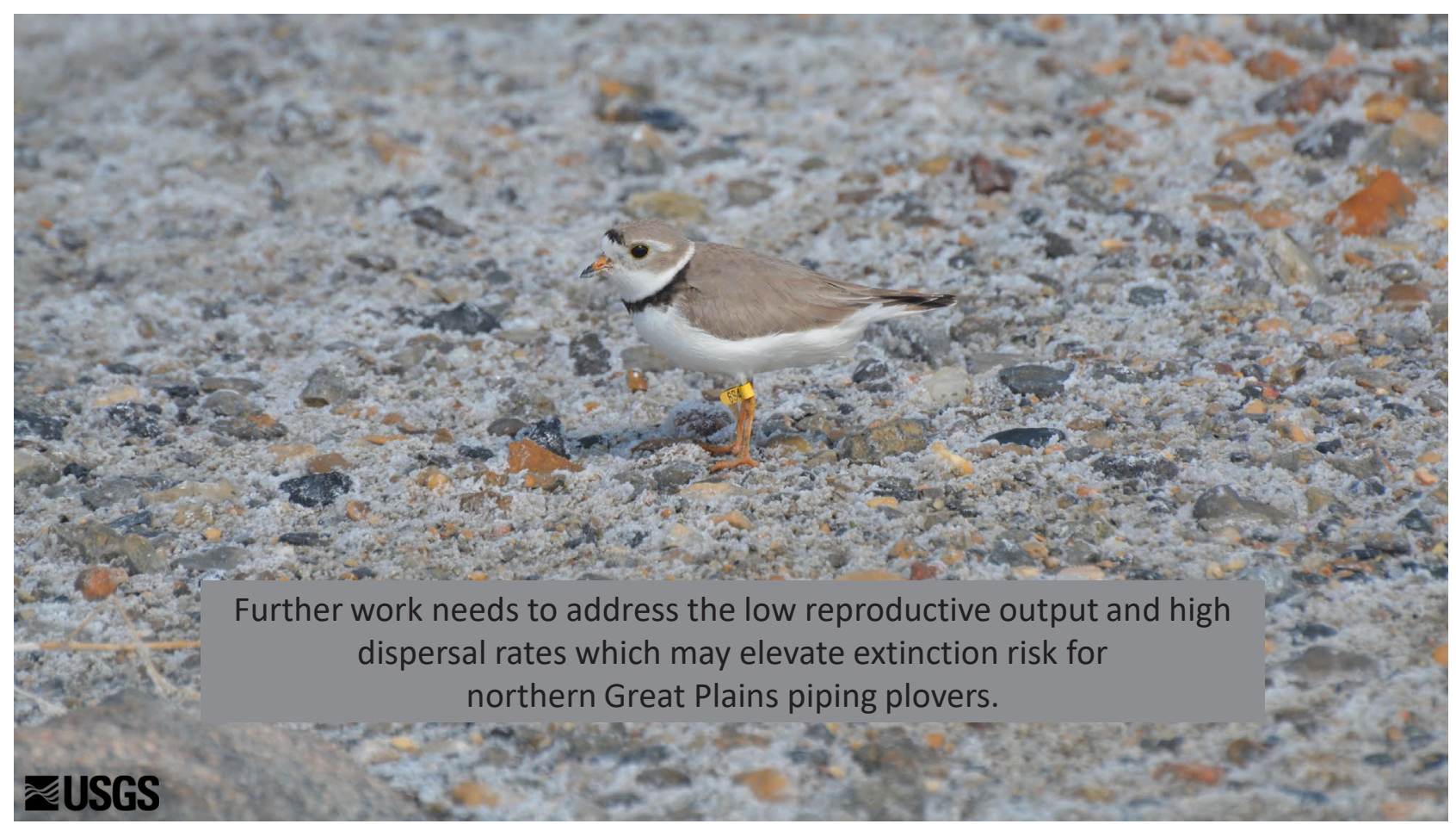

The low reproductive output documented and high connectivity among management units suggest that an updated population viability assessment is needed. Such an update should take into account the new information about movements not only within our focal study area but also the full NGP population, which is needed to reassess population extinction risk. Between the increased dispersal rates and low reproductive output shown in this study, piping plovers in the NGP may show higher extinction risk than currently presumed.

We greatly appreciate the support of our funders, partners, and collaborators. The hard work and dedication of hundreds of technicians and dozens of scientists greatly contributed to this study.

‡USGS

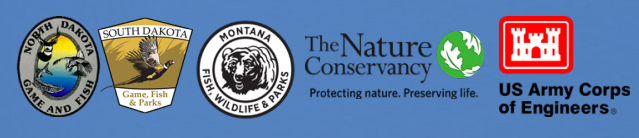

We greatly appreciate the support of our funders, partners, and collaborators. The hard work and dedication of hundreds of technicians and dozens of scientists greatly contributed to this study. 


\section{Study Species}

The Charadrius melodus (Ord, 1824) (piping plover) is a migratory species that breeds along sandbar and shoreline habitat of rivers and reservoirs in the northern Great Plains (NGP). The NGP breeding population is federally listed under the U.S. Endangered Species Act of 1973 (16 U.S.C. ch. $35 \S$ 1531 et seq.; U.S. Fish and Wildlife Service [USFWS], 1985, 2003, 2009), and habitat is managed extensively for plovers along the Missouri River. Plovers build nests on bare sand or gravel substrate and typically begin nesting in May. The male and female share incubation duties until hatching occurs (including egg -laying; incubation takes about 35 days), and they typically lay clutches of four eggs. Plover chicks are precocial, mobile, and capable of feeding themselves on the day they hatch but depend on their parents for thermoregulation during the first week after hatch and remain with their parents until fledging (about 21 days posthatch). By early August, plovers leave breeding areas for the coastal habitats of the southern United States, Caribbean, and eastern Mexico. Plovers spend the nonbreeding season (October-March) along shorelines and tidal habitats.

\section{Study Areas}

From 2014 to 2019, breeding piping plovers on alkali wetland, reservoir, and riverine nesting habitats were monitored from central South Dakota through North Dakota and into northeastern Montana, United States (fig. 2). In general, the entire extent of the U.S. Alkali Wetlands and the Northern Rivers groups of the NGP plover metapopulation as defined by McGowan and others (2014) was studied. For this study, the four breeding study areas are based on four management units: the U.S. Alkali Wetlands (ALK), Lake Sakakawea (SAK), the Garrison Reach of the Missouri River (GRR), and Lake Oahe $(\mathrm{OAH})$.

\section{U.S. Alkali Wetlands}

Although piping plovers periodically breed throughout the U.S. Prairie Pothole Region (McCauley and others, 2016), most nesting effort occurs in a more formally defined set of wetlands referred to as the U.S. Alkali Wetlands (Knetter and others, 2002; Ivan and Murphy, 2005; figs. 2, 3). The ALK study area is composed of about 150 depressions (in other words, lakes, ponds, or sloughs) distributed throughout the Prairie Pothole Region of North Dakota and Montana where salinity prohibits vegetation growth on shorelines (Knetter and others, 2002). These alkali wetlands are mostly affected by changes in local climate, and as water regimes change, wetlands can have wetting and drying periods. Although most of the wetlands retained suitable nesting habitat throughout the study, some wetlands did have wetting or drying to an extent that suitable habitat (represented by the Standardized Precipitation-Evapotranspiration Index; see the "Habitat" section for more information) was not present in all years (table 1). Therefore, some wetlands were only visited a few times some years (table 2). Plovers nesting in this study area are currently cooperatively monitored by partners including the USFWS and The Nature Conservancy who work together to secure site access from various private landowners. The ALK study area is effectively managed as seven regions based on managers and (or) wetland management districts (WMDs; fig. 3; table 1):

- Arrowwood National Wildlife Refuge, Arrowwood WMD

- Audubon National Wildlife Refuge, Audubon WMD

- Crosby WMD

- Long Lake National Wildlife Refuge, Long Lake WMD

- Lostwood National Wildlife Refuge, Lostwood WMD

- Medicine Lake National Wildlife Refuge, Montana WMD

- John E. Williams Preserve, The Nature Conservancy

\section{Lake Sakakawea}

The SAK study area was defined as the main-stem reservoir of the Missouri River (from Garrison Dam to White Tail Bay, North Dakota; Anteau and others, 2014a, b; fig. 2). Maximum pool elevation is 565.1 meters above sea level (MASL; elevation of spillway). The reservoir shoreline habitat was irregular and dissected and consisted of diverse substrate types (Anteau and others, 2012a, b). SAK's shoreline was divided into 2-kilometer $(\mathrm{km})$ segments totaling 545; only 254 of the segments contained suitable breeding habitat (Anteau and others, 2014b). Some segments were not visited every year because of availability of habitat caused by changing pool elevations (tables 3, 4).

\section{Garrison Reach of the Missouri River}

The river habitat consisted of the GRR, which extends from the Garrison Dam (river mile 1,389) to the headwaters of Lake Oahe, about $30 \mathrm{~km}$ south of Bismarck, N. Dak. (river mile 1,277). Habitat on the GRR occurred primarily on midchannel, low- to mid-elevation sandbars in some established woody vegetation. Included in the GRR study area were 16 river miles at the headwaters of Lake Oahe (river miles 1,277-1,303). This section of Lake Oahe was similar to riverine habitat present on the GRR and was therefore included as such. Changing outflows from Garrison Dam releases altered the amount of habitat on the river each year and therefore the number of segments visited (tables 4, 5). 


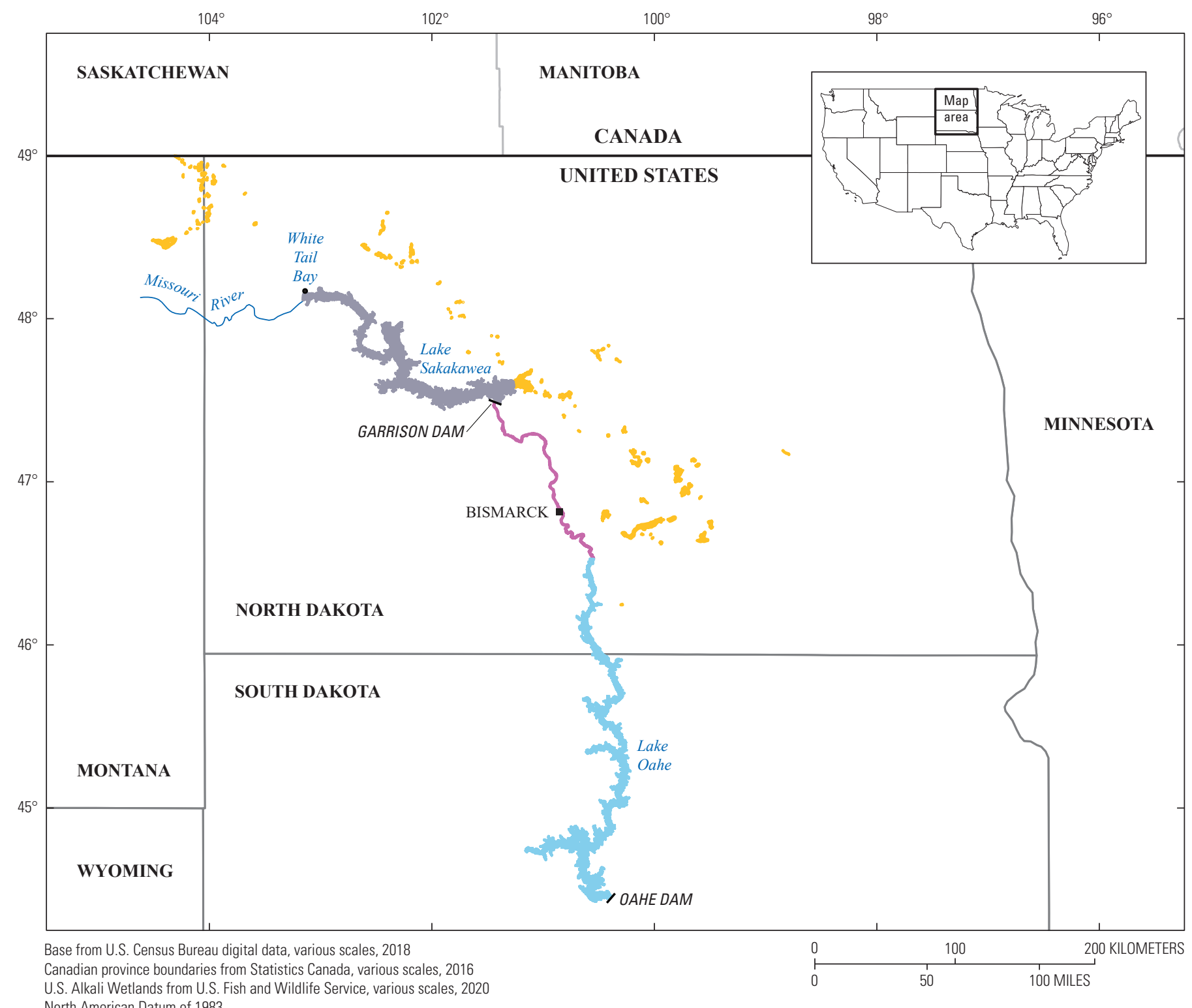

EXPLANATION

U.S. Alkali Wetlands (ALK)

Lake Sakakawea (SAK)

Garrison Reach of the Missouri River (GRR)

Lake Oahe (OAH)

Figure 2. Piping plover breeding study areas based on four management units in North Dakota, South Dakota, and Montana monitored from 2014 to 2019. 
Table 1. Mean and standard deviation of the Standardized Precipitation-Evapotranspiration Index from May through July for each region in the U.S. Alkali Wetlands study area, North Dakota and Montana.

[WMD, wetland management district; \pm , plus or minus; --, no data]

\begin{tabular}{|c|c|c|c|c|c|c|}
\hline \multirow{2}{*}{ Region manager and (or) WMD } & \multicolumn{6}{|c|}{$\begin{array}{l}\text { Mean and standard deviation of the Standardized } \\
\text { Precipitation-Evapotranspiration Index by year }\end{array}$} \\
\hline & 2014 & 2015 & 2016 & 2017 & 2018 & 2019 \\
\hline Crosby WMD & $0.90 \pm 0.06$ & $-0.21 \pm 0.02$ & $-0.31 \pm 0.05$ & $-1.54 \pm 0.18$ & $1.10 \pm 0.17$ & $1.46 \pm 0.17$ \\
\hline $\begin{array}{l}\text { Lostwood National Wildlife Refuge, } \\
\text { Lostwood WMD }\end{array}$ & $0.77 \pm 0.11$ & $0.14 \pm 0.07$ & $-0.14 \pm 0.10$ & $-0.56 \pm 0.20$ & $0.59 \pm 0.16$ & $0.64 \pm 0.13$ \\
\hline $\begin{array}{l}\text { Audubon National Wildlife Refuge, } \\
\text { Audubon WMD }\end{array}$ & $0.68 \pm 0.17$ & $-0.10 \pm 0.12$ & $-0.31 \pm 0.08$ & $-0.73 \pm 0.14$ & $0.64 \pm 0.23$ & $0.66 \pm 0.25$ \\
\hline $\begin{array}{l}\text { John E. Williams Preserve, The Nature } \\
\text { Conservancy }\end{array}$ & $0.82 \pm 0.02$ & $-0.22 \pm 0.04$ & $-0.43 \pm 0.02$ & $-1.01 \pm 0.02$ & $1.03 \pm 0.05$ & $1.15 \pm 0.04$ \\
\hline $\begin{array}{l}\text { Long Lake National Wildlife Refuge, } \\
\text { Long Lake WMD }\end{array}$ & $0.35 \pm 0.10$ & $-0.07 \pm 0.11$ & $-0.42 \pm 0.08$ & $-0.56 \pm 0.18$ & $0.61 \pm 0.16$ & $0.58 \pm 0.56$ \\
\hline
\end{tabular}

Table 2. Total wetlands visited by joint U.S. Geological Survey and U.S. Fish and Wildlife Service crews for each region in the U.S. Alkali Wetlands study area, North Dakota and Montana.

[WMD, water management district]

\begin{tabular}{|c|c|c|c|c|c|c|}
\hline \multirow{2}{*}{ Region manager and (or) WMD } & \multicolumn{6}{|c|}{ Total wetlands visited per year ${ }^{1}$} \\
\hline & 2014 & 2015 & 2016 & 2017 & 2018 & 2019 \\
\hline Medicine Lake National Wildlife Refuge, Montana WMD & 27 & 32 & 33 & 17 & 18 & 15 \\
\hline Lostwood National Wildlife Refuge, Lostwood WMD & 11 & 11 & 9 & 7 & 7 & 7 \\
\hline Audubon National Wildlife Refuge, Audubon WMD & 11 & 14 & 11 & 18 & 19 & 18 \\
\hline Long Lake National Wildlife Refuge, Long Lake WMD & 8 & 9 & 12 & 11 & 9 & 8 \\
\hline Arrowwood National Wildlife Refuge, Arrowwood WMD & 0 & 0 & 1 & 1 & 1 & 1 \\
\hline Total & 80 & 94 & 88 & 73 & 71 & 66 \\
\hline
\end{tabular}

${ }^{1}$ Totals only include wetlands visited for at least 5 minutes and at least three times per year. 


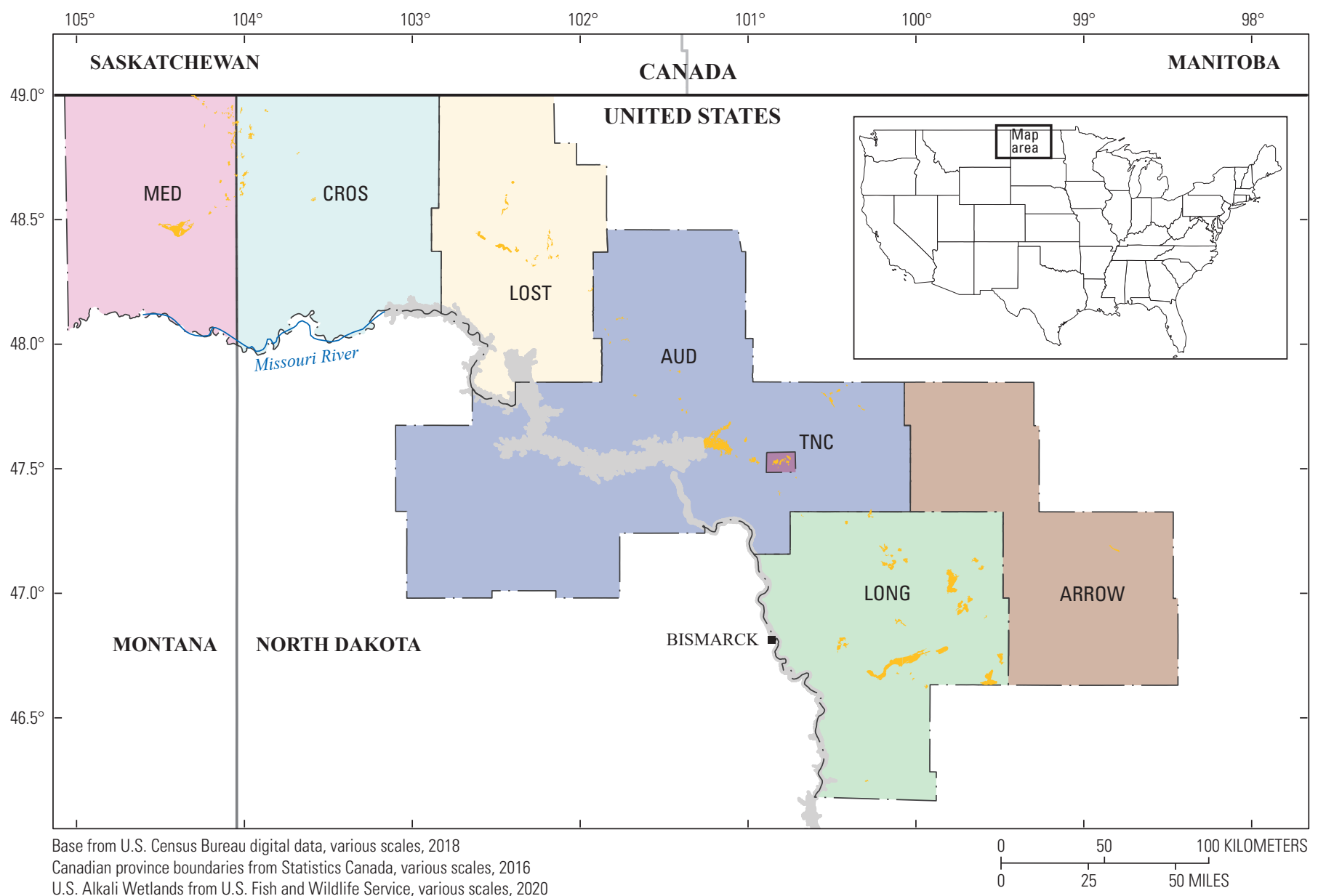

U.S. Alkali Wetlands from U.S. Fish and Wildlife Service, various scales, 2020

Wetland management districts from U.S. Fish and Wildlife Service, various scales, 2018

North American Datum of 1983

\section{EXPLANATION}

Medicine Lake National Wildlife Refuge wetland management district (MED)

Crosby wetland management district (CROS)

Lostwood National Wildlife Refuge wetland management district (LOST)

Audubon National Wildlife Refuge wetland management district (AUD)

John E. Williams Preserve, The Nature Conservancy (TNC)

Long Lake National Wildlife Refuge wetland management district (LONG)

Arrowwood National Wildlife Refuge wetland management district (ARROW)

U.S. Alkali Wetlands

Missouri River management units

Figure 3. Approximate boundaries of the regions based on managers or wetland management districts of the U.S. Alkali Wetlands study area, North Dakota and Montana. 
Table 3. Mean and standard deviation main-stem reservoir pool elevations for May through July for Lake Sakakawea and Lake Oahe in 2014-19 and historical data, North Dakota and South Dakota.

\begin{tabular}{ccc}
\hline \multirow{2}{*}{ Year1 } & \multicolumn{2}{c}{ Reservoir pool elevation, in meters above sea level } \\
\cline { 2 - 3 } & Mean & Standard deviation \\
\hline $1955-2019$ & Lake Sakakawea & \\
2014 & 558.33 & 5.40 \\
2015 & 560.61 & 0.86 \\
2016 & 561.34 & 0.86 \\
2017 & 560.96 & 0.47 \\
2018 & 562.19 & 0.59 \\
2019 & 563.55 & 1.16 \\
& 563.75 & 0.73 \\
\hline $1967-2019$ & Lake 0ahe & 3.59 \\
2014 & 489.35 & 0.88 \\
2015 & 490.74 & 0.67 \\
2016 & 491.00 & 0.29 \\
2017 & 491.16 & 0.22 \\
2018 & 490.66 & 0.74 \\
2019 & 491.63 & 0.24 \\
\hline
\end{tabular}

${ }^{1}$ Year ranges include all historical data to 2019.

Table 4. Total number of segments visited by U.S. Geological Survey crews for each management unit on the Missouri River, North Dakota and South Dakota, 2014-19.

\begin{tabular}{lrrrrrr}
\hline \multirow{2}{*}{ Management unit } & \multicolumn{5}{c}{ Total segments visited per year1 } \\
\cline { 2 - 7 } & $\mathbf{2 0 1 4}$ & $\mathbf{2 0 1 5}$ & $\mathbf{2 0 1 6}$ & $\mathbf{2 0 1 7}$ & $\mathbf{2 0 1 8}$ & $\mathbf{2 0 1 9}$ \\
\hline Lake Sakakawea & 166 & 191 & 159 & 109 & 22 & 18 \\
Garrison Reach of the Missouri River & 104 & 76 & 71 & 43 & 38 & 51 \\
Lake Oahe & 81 & 73 & 81 & 43 & 57 & 45 \\
Total & 351 & 340 & 311 & 195 & 117 & 114 \\
\hline
\end{tabular}

${ }^{1}$ Totals only include segments visited for at least 5 minutes and at least three times per year.

Table 5. Mean and standard deviation main-stem outflow from the Garrison Dam for May through July for the Garrison Reach of the Missouri River, North Dakota, 2014-19.

\begin{tabular}{ccc}
\hline \multirow{2}{*}{ Year } & \multicolumn{2}{c}{ Outflow from Garrison Dam, in cubic feet per second } \\
\cline { 2 - 3 } & Mean & Standard deviation \\
\hline 2014 & $22,640.93$ & $5,043.42$ \\
2015 & $18,751.37$ & $3,677.84$ \\
2016 & $17,065.29$ & $3,084.00$ \\
2017 & $22,897.81$ & $8,499.34$ \\
2018 & $33,920.33$ & $12,028.89$ \\
2019 & $31,644.32$ & $13,652.66$ \\
\hline
\end{tabular}




\section{Lake Oahe}

The OAH study area, a main-stem reservoir of the Missouri River, extended from the headwaters of Lake Oahe, about $30 \mathrm{~km}$ south of Bismarck, N. Dak., to the Oahe Dam. OAH was divided into 1,083 segments consisting of about $2 \mathrm{~km}$ of shoreline based on the average pool elevation from 2004 to 2014 (486 MASL). Maximum pool elevation is 493.8 MASL (elevation of spillway). In 2014, all segments were visited once to assess their potential to provide piping plover nesting habitat. Once most segments containing plover nesting habitat had been visited and identified, crews focused on returning to segments with known nests, broods, and marked adults on a more frequent basis. In subsequent years, crews again used previously known locations of nests and adults to concentrate their efforts and also investigated possible habitats that may have become available or were more suitable as water levels changed within and between seasons (tables 3, 4).

\section{Field Methods}

During all years (2014-19) throughout the full breeding season (late April to early August), crews primarily used spotting scopes and digital cameras to resight uniquely marked adult piping plovers every time crews were present on sandbars or shorelines (see Shaffer and others [2013] and Anteau and others [2019] for more information). Banding efforts for adults and chicks ceased after 2017 (see the "Chicks" and "Adults" sections). Crews attempted to return to each segment with suitable habitat at least three times in a season; however, in general, crews visited segments with high plover densities more frequently.

\section{Nests}

Each year (2014-19), crews searched appropriate habitat or used behavioral observations to locate piping plover nests (table 6). Nest monitoring information from the U.S. Army Corps of Engineers (USACE) real-time database was used to help locate nests for SAK, the GRR, and OAH (Shaffer and others, 2013). A nest was defined as a scrape or depression containing at least one egg. Sandbars and shorelines were searched for nests generally until mid-July, but crews searched for new nests whenever adults were present and exhibited nesting behaviors. In the ALK, joint U.S. Geological Survey (USGS)-USFWS crews were responsible for finding and monitoring nests. Although crews always tried to find nests, as time allowed, the main research priority was resighting marked individuals.

Once a nest was found, researchers floated eggs to determine incubation stage and estimated the hatch date (Liebezeit and others, 2007). Additionally, researchers recorded information on the number of eggs present, the identities of banded adults associated with the nest, and the nest coordinates (see Shaffer and others [2013] and Anteau and others [2019] for more detailed discussions). A small number of nests included from the ALK had predator exclosures for part of incubation (table 7). The estimated date of hatch or failure was the midpoint date between the final two visits, except for known hatch dates when chicks were found in the nest bowl.

The primary objective for nest visits was to identify adults associated with the nest and to band adults and chicks if necessary. From 2014 to 2016, nests were monitored until completion (in other words, until all eggs either hatched or nests failed). Nests were revisited two to three times per week until termination; on the terminal visit, researchers examined evidence around the nest bowl and recorded the fate of the nest. Possible nest fates were successful, probable successful, failed, and unknown. Nests were classified as successful only if at least one live chick was in the nest bowl. Probable successful nests lacked chicks in the nest bowl and therefore required multiple other pieces of evidence of hatching (in other words, eggshells, pipping fragments, and chick droppings or tracks). For these analyses, probable successful nests and successful nests were considered successful (in other words, chicks in the nest had hatched; see Shaffer and others [2013] and Anteau and others [2019] for more detailed discussions). Nests were classified as 'failed' if eggs were found destroyed or were missing but could not have hatched based on the estimated incubation stage. If circumstances around missing eggs were unclear or the nest was not monitored fully, we fated the nest as 'unknown'.

From 2017 to 2019, once the identity of both adults on a nest were known, nest visits were infrequent or ceased unless capture of adults or chicks was necessary (for example, to replace lost or damaged bands). Researchers recorded information on nest fate if it had changed while visiting a nest. Nest fate information was supplemented by ongoing nest monitoring by the USACE where possible for nests on the Missouri River.

\section{Chicks}

From 2014 to 2017, nests near the estimated hatch date were visited frequently to band chicks while in the nest bowl. Crews captured older and more mobile chicks by hand or with butterfly nets. Researchers assigned estimated ages to chicks based on plumage and skeletal development. Researchers attempted to evenly distribute total chicks banded for each study area within a given year while following permit restrictions. However, the distribution of total chicks banded varied among study areas depending on chick availability (table 8).

Piping plover chicks were banded with a single yellow unique alpha-numeric engraved Darvic flag on the upper leg opposite a USGS aluminum band. Sites with uniquely banded chicks were visited one to three times per week by researchers until chicks fledged (in other words, were capable of flight at 
Table 6. Number of piping plover nests found in each management unit, North Dakota, South Dakota, and Montana, 2014-19.

\begin{tabular}{lcccccc}
\hline \multirow{1}{*}{ Management unit } & \multicolumn{5}{c}{ Number of piping plover nests found per year } \\
\cline { 2 - 7 } & $\mathbf{2 0 1 4}$ & $\mathbf{2 0 1 5}$ & $\mathbf{2 0 1 6}$ & $\mathbf{2 0 1 7}$ & $\mathbf{2 0 1 8}$ & $\mathbf{2 0 1 9}$ \\
\hline U.S. Alkali Wetlands & 271 & 251 & 256 & 219 & 186 & 260 \\
Lake Sakakawea & 193 & 258 & 274 & 133 & 48 & 25 \\
Garrison Reach of the Missouri River & 338 & 344 & 317 & 215 & 184 & 163 \\
Lake Oahe & 91 & 117 & 76 & 102 & 67 & 10 \\
Total & 893 & 970 & 923 & 669 & 485 & 458 \\
\hline
\end{tabular}

Table 7. Use of predator exclosures on a subset of piping plover nests in the U.S. Alkali Wetlands study area, North Dakota and Montana, 2014-16.

\begin{tabular}{ccc}
\hline Year & Nests with exclosures & $\begin{array}{c}\text { Nests on alkali wetlands exclosed, } \\
\text { in percent }\end{array}$ \\
\hline 2014 & 33 & 31 \\
2015 & 28 & 18 \\
2016 & 27 & 18 \\
\hline
\end{tabular}

Table 8. Number of uniquely marked piping plover chicks banded, natal recruits observed as adults, and chicks observed during the nonbreeding season hatched on the four management units, North Dakota, South Dakota, and Montana, 2014-17.

\begin{tabular}{|c|c|c|c|}
\hline Year & Number of chicks banded & $\begin{array}{c}\text { Natal recruits observed } \\
\text { as adults }\end{array}$ & $\begin{array}{c}\text { Number of chicks observed } \\
\text { during the nonbreeding } \\
\text { season }\end{array}$ \\
\hline \multicolumn{4}{|c|}{ U.S. Alkali Wetlands } \\
\hline 2014 & 200 & 57 & 23 \\
\hline 2015 & 166 & 32 & 19 \\
\hline 2016 & 202 & 47 & 18 \\
\hline 2017 & 217 & 42 & 32 \\
\hline \multicolumn{4}{|c|}{ Lake Sakakawea } \\
\hline 2014 & 119 & 18 & 5 \\
\hline 2015 & 186 & 31 & 17 \\
\hline 2016 & 259 & 70 & 32 \\
\hline 2017 & 55 & 7 & 4 \\
\hline \multicolumn{4}{|c|}{ Garrison Reach of the Missouri River } \\
\hline 2014 & 305 & 131 & 50 \\
\hline 2015 & 292 & 91 & 47 \\
\hline 2016 & 156 & 53 & 24 \\
\hline 2017 & 276 & 67 & 40 \\
\hline \multicolumn{4}{|c|}{ Lake Oahe } \\
\hline 2014 & 41 & 15 & 6 \\
\hline 2015 & 64 & 17 & 5 \\
\hline 2016 & 74 & 13 & 4 \\
\hline 2017 & 57 & 7 & 6 \\
\hline
\end{tabular}


about 21 days posthatch). Researchers used binoculars, spotting scopes, digital cameras, and opportunistic recaptures to resight uniquely banded chicks (Roche and others, 2014a).

\section{Adults}

Piping plovers were banded with a USGS metal band and unique alpha-numeric engraved flag (table 9). Adults were banded with an aluminum metal band placed above the tibiotarsal joint on one leg and a single yellow alpha-numeric Darvic flag on the upper leg opposite the metal band. In addition, each adult received a unique combination of four plastic color bands (below the tibiotarsal joint; two per leg). Before 2014, plovers were banded on SAK and the GRR. Observations of previously marked adults were included if those individuals were seen between 2014 and 2019. Unbanded adult plovers were trapped on nests during incubation using either a remote-controlled, walk-in trap or bow net through the 2017 breeding season (Roche and others, 2014b). During trapping events, live eggs were replaced with artificial eggs to minimize the potential for egg damage.

Individuals were attributed to nests by capturing individuals on the nest, by observing an identified individual's return to incubate, or by using high-definition video cameras set up near (45-60 centimeters [cm] away) nests for no more than 30 minutes at a time (Toy and others, 2017). In all years, when visiting a site, the crews recorded the band combinations of all birds observed; the degree of completion with which they read the band combination; and the method used to resight the individual. If no adults were observed during a site visit, crews simply recorded the date, time, location, and purpose of the site visit.

\section{Additional Observations}

Anecdotal resightings (non-USGS observations) during the nonbreeding season, migration, and breeding seasons recorded by other Federal and State agencies, nonprofits, and the public were used to supplement observations of individuals collected by USGS researchers (tables 10, 11; fig. 4). Non-USGS observations were collected via a variety of methods including standardized resight surveys and anecdotal observations by individuals. Observations reported directly to the USGS; to the Bird Banding Laboratory (Smith, 2013); and from photographs of banded individuals posted on eBird (https://ebird.org/home; Sullivan and others, 2009), iNaturalist (https://www.inaturalist.org/), and Facebook birding group websites were compiled. USGS crews also resighted many piping plovers not originally banded by the USGS or within the focal study area, which were then reported to the appropriate banders (table 12). 
Table 9. Totals of piping plover adults captured and banded for the first time and unique identifiable resights by management unit, North Dakota, South Dakota, and Montana, 2014-19.

[Individuals may have been observed in multiple management units, and resights include piping plovers banded for the given year]

\begin{tabular}{|c|c|c|}
\hline Year & Adults newly banded & Unique adults resighted \\
\hline \multicolumn{3}{|c|}{ U.S. Alkali Wetlands } \\
\hline 2014 & 147 & 253 \\
\hline 2015 & 121 & 369 \\
\hline 2016 & 81 & 395 \\
\hline 2017 & 74 & 438 \\
\hline 2018 & 0 & 507 \\
\hline 2019 & 0 & 449 \\
\hline \multicolumn{3}{|c|}{ Lake Sakakawea } \\
\hline 2014 & 90 & 198 \\
\hline 2015 & 112 & 390 \\
\hline 2016 & 145 & 524 \\
\hline 2017 & 24 & 317 \\
\hline 2018 & 0 & 120 \\
\hline 2019 & 0 & 43 \\
\hline \multicolumn{3}{|c|}{ Garrison Reach of the Missouri River } \\
\hline 2014 & 161 & 495 \\
\hline 2015 & 121 & 679 \\
\hline 2016 & 59 & 648 \\
\hline 2017 & 33 & 547 \\
\hline 2018 & 0 & 386 \\
\hline 2019 & 0 & 286 \\
\hline \multicolumn{3}{|c|}{ Lake Oahe } \\
\hline 2014 & 87 & 110 \\
\hline 2015 & 69 & 173 \\
\hline 2016 & 38 & 169 \\
\hline 2017 & 28 & 183 \\
\hline 2018 & 0 & 116 \\
\hline 2019 & 0 & 38 \\
\hline
\end{tabular}


Table 10. Unique observations of piping plovers in the management units that were originally banded in other breeding areas, United States and Canada, 2014-19.

\begin{tabular}{|c|c|c|c|c|}
\hline \multirow[b]{2}{*}{ Year } & \multicolumn{4}{|c|}{ Unique piping plovers observed by area originally banded } \\
\hline & $\begin{array}{c}\text { Platte River } \\
\text { and its tributaries }\end{array}$ & Prairie Canada & $\begin{array}{l}\text { Southern Missouri River } \\
\text { and its tributaries }\end{array}$ & Total \\
\hline \multicolumn{5}{|c|}{ U.S. Alkali Wetlands } \\
\hline 2014 & 0 & 5 & 16 & 21 \\
\hline 2015 & 0 & 6 & 11 & 17 \\
\hline 2016 & 1 & 4 & 3 & 8 \\
\hline 2017 & 2 & 3 & 4 & 9 \\
\hline 2018 & 2 & 0 & 3 & 5 \\
\hline 2019 & 2 & 1 & 3 & 6 \\
\hline \multicolumn{5}{|c|}{ Lake Sakakawea } \\
\hline 2014 & 0 & 2 & 8 & 10 \\
\hline 2015 & 1 & 3 & 6 & 10 \\
\hline 2016 & 0 & 4 & 1 & 5 \\
\hline 2017 & 0 & 1 & 0 & 1 \\
\hline 2018 & 0 & 0 & 0 & 0 \\
\hline 2019 & 0 & 1 & 0 & 1 \\
\hline \multicolumn{5}{|c|}{ Garrison Reach of the Missouri River } \\
\hline 2014 & 0 & 2 & 10 & 12 \\
\hline 2015 & 1 & 0 & 4 & 5 \\
\hline 2016 & 1 & 0 & 2 & 3 \\
\hline 2017 & 3 & 0 & 1 & 4 \\
\hline 2018 & 0 & 0 & 1 & 1 \\
\hline 2019 & 0 & 0 & 1 & 1 \\
\hline \multicolumn{5}{|c|}{ Lake Oahe } \\
\hline 2014 & 0 & 2 & 6 & 8 \\
\hline 2015 & 0 & 2 & 2 & 4 \\
\hline 2016 & 0 & 0 & 1 & 1 \\
\hline 2017 & 1 & 1 & 0 & 2 \\
\hline 2018 & 0 & 1 & 0 & 1 \\
\hline 2019 & 0 & 0 & 0 & 0 \\
\hline
\end{tabular}

Table 11. Unique individual piping plover resights and total reported observations per nonbreeding season (0ctober through March), United States, Mexico, and the Caribbean, 2014-20.

\begin{tabular}{ccc}
\hline Nonbreeding season & Unique individuals reported & Total observations reported 1 \\
\hline $2014-15$ & 219 & 813 \\
$2015-16$ & 345 & 1,107 \\
$2016-17$ & 336 & 873 \\
$2017-18$ & 371 & 891 \\
$2018-19$ & 277 & 711 \\
$2019-20$ & 195 & 380 \\
\hline
\end{tabular}

${ }^{1}$ Observations were compiled from reports sent directly to the U.S. Geological Survey, from reports to the Bird Banding Laboratory, and from photographs of banded individuals posted on eBird, iNaturalist, and Facebook birding group websites. 


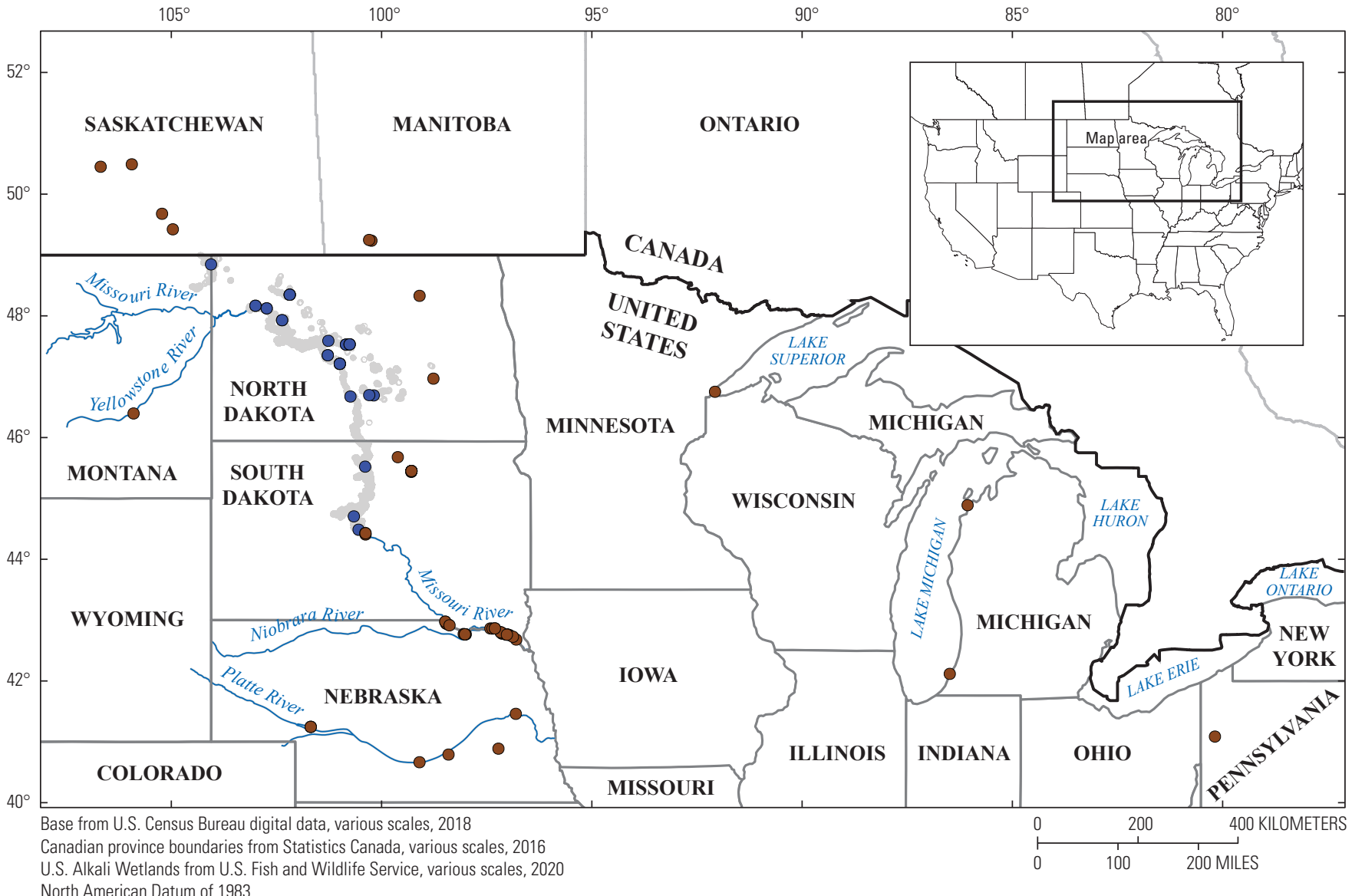

EXPLANATION

Piping plover focal study area

Observations of piping plovers banded by the

U.S. Geological Survey within focal study area (fig. 2)

- Yes

- No

Figure 4. Non-U.S. Geological Survey reported observations of piping plovers banded by the U.S. Geological Survey. 
Table 12. Unique observations of piping plovers reported by non-U.S. Geological Survey observers during the breeding season (May through July), United States and Canada, 2014-19.

\begin{tabular}{|c|c|c|c|c|c|c|}
\hline Year & $\begin{array}{c}\text { Platte River } \\
\text { and its tributaries }\end{array}$ & Prairie Canada & $\begin{array}{l}\text { Southern Missouri River } \\
\text { and its tributaries }\end{array}$ & Other & Focal study area & Tota \\
\hline 2014 & 1 & 0 & 5 & 3 & 1 & 10 \\
\hline 2015 & 2 & 0 & 2 & 2 & 0 & 6 \\
\hline 2016 & 0 & 2 & 7 & 4 & 11 & 24 \\
\hline 2017 & 1 & 2 & 6 & 2 & 2 & 13 \\
\hline 2018 & 0 & 0 & 8 & 7 & 4 & 19 \\
\hline 2019 & 1 & 1 & 9 & 3 & 8 & 22 \\
\hline
\end{tabular}

\section{Data Analysis}

Data generated during this study are available as two USGS data releases (Swift and others, 2019, 2020a)

\section{Individual Covariates}

When appropriate, four classes of variables were examined in each analysis: habitat, reproductive success, social, and individual factors. Each of the covariates used is described in the following subsections followed by the a priori hypotheses for each analysis.

Segments were defined differently for each habitat. For rivers, a segment was a predefined section of equal length (1 river mile or $1.61 \mathrm{~km}$ ) that included stretches of sandbar and shoreline habitat and flowing water. On the reservoirs, previously described segments of roughly $2 \mathrm{~km}$ of reservoir shoreline based on the 2004 pool elevation (Anteau and others, 2012b, 2014b) were re-measured as the perimeter length at the maximum pool elevation of the reservoir shoreline. For alkali wetlands, a segment was the wetland itself derived from the National Wetland Inventory polygons, and its perimeter was calculated using QGIS (version 2.18; https://qgis.org/).

\section{Habitat}

Habitat type was treated as a three-level factor, reservoir, river, or alkali wetland; and landform was treated as a two-level factor, island (including midchannel sandbar) or shoreline. To estimate habitat availability, a standardized index of habitat availability was calculated and derived from either the change in available nesting habitat from the year before or within the year of interest. For alkali wetland basins with water-management systems, the maximum water elevation measured for each month at gages monitored by the USFWS was used. For all other alkali wetlands, variation in climate using an index that was developed specifically for hydrological effects of climate on permanent and semipermanent wetlands of the Prairie Pothole Region (Post van der Burg and others, 2016) was used as a representation of habitat.
This index is based on the Standard Precipitation-Evapotranspiration Index (Beguería and others, 2014) but is calculated using a 72-month average from monthly Parameter-elevation Regressions on Independent Slopes Model (PRISM) data from the PRISM Climate Group (Oregon State University, Corvallis, Oregon) because that time frame has been useful for predicting water-level dynamics in wetlands of similar size and hydroperiod (McCauley and others, 2015; Post van der Burg and others, 2016). A site-specific index of habitat change was calculated by subtracting the index values for May, June, and July and selecting the maximum change from the year before the year of interest. For the GRR, the change in maximum monthly Garrison Dam outflow (1,000 cubic feet per second) between May, June, and July from the prior year to the year of interest was used (USACE, 2020). For reservoirs, a predictive model based on the amount of available piping plover habitat in May developed for SAK (Anteau and others, 2014b) and adapted for use on OAH, which considers eleva-

tion, vegetation growth, and ice scour, was used. For renesting analyses, the index of habitat availability was calculated using the change in values appropriate for each habitat type between May and July within a year. The index of habitat availability was standardized within each study area because of the differences in how each was calculated.

Lastly, a measure of the proximity to other breeding areas for adults to account for the patchy availability of habitat was developed. For each nest location, the Euclidean distance to the three nearest known neighbor nests on three different segments during that year was calculated using the spatstat package (version 1.64; Baddeley and others, 2015) in the program $R$. The mean distance of the three closest active nests on different segments was used as a measure of proximity to alternative nesting areas.

\section{Reproductive Success}

Reproductive success was determined from nest initiation and hatch dates, which were estimated using three methods, depending on the availability of certain types of data. The primary method for determining the nest initiation date was backdating from observed hatch date, if chicks were observed 
in the nest bowl (assuming a laying and incubation period of 35 days). Secondarily, if hatch day was not observed, the nest initiation date $(N I D)$ was estimated from incubation stage using egg floatation (Liebezeit and others, 2007) using the following equation:

$$
N I D=v-([n-1] \times 2)-s,
$$

where

$v \quad$ is the visit date the nest was discovered,

$n \quad$ is the number of eggs at nest discovery, and

$s \quad$ is the incubation stage at nest discovery.

Hatch date was then estimated by adding 35 days to the estimated nest initiation date. Both a linear and a quadratic trend for estimated hatch date was included for natal dispersal distance analysis. Nest initiation date and date of failure were generally correlated (Pearson's correlation coefficient $[r]=0.67)$, so only date of failure was retained for renesting analyses.

For renesting analyses, the cause of reproductive attempt failure was treated as a five-category factor. Researchers were unable to determine causes of brood failures (in other words, predators or flooding), so all reproductive attempts that failed after hatching were treated as one category (hatched), distinct from the causes of nest failures: predation, flooding, severe weather, or abandoned/unknown. Flooding failures were caused by water-level rise on the Missouri River system and were distinguishable from flooding caused by storms (severe weather). Nests that failed because of predation from livestock $(n=5)$ or human trampling $(n=4)$ were included in depredated nests, and abandoned nests $(n=22)$ were included as unknown causes. However, a substantial proportion of nests (about 43 percent) were conservatively placed into the unknown cause category because of a lack of evidence at the time nest fate was determined. Sandbars are dynamic because wind and water can quickly scour away evidence of the cause of nest failure. To avoid falsely attributing nests to alternative causes of failure, crews recorded multiple (two to four) pieces of evidence when fating nests, and if unclear, causes were recorded as unknown.

Annual segment reproductive success (RSseg) was determined based on the proportion of nests that successfully hatched on a segment. A site was then categorized as being below average if its RSseg was less than or equal to the mean RSseg calculated across all segments each year. Alternatively, it was categorized as above average if RSseg was greater than the population mean. RSseg must be predictable from year to year to be used by individuals as an index of a site's reproductive quality based on information recorded the previous year (Danchin and others, 1998). The level of temporal autocorrelation in RSseg across years was estimated based on the working correlation matrix of generalized estimating equations (Agresti, 2002). Specifically, the annual RSseg of sites (above and below average) was modeled as a constant in a generalized estimating equation model with a logit-link function and binomial error structure. Given that RSseg measures were spatially structured and longitudinal, the segment acted as a clustering variable, and the working correlation matrix was autoregressive. The generalized estimating equations were fitted using the geepack package (version 1.1.6; Halekoh and others, 2006) in the program R. Between 2014 and 2019, between 1 (2019) and 7 (2016) percent of segments had an above-average RSseg, and between 27 (2018) to 75 (2016) percent of individuals bred on above-average segments depending on the year. RSseg was positively autocorrelated across years ( $r=0.61$ plus or minus 0.06 ). This positive result supports the assumption that RSseg was predictable in space and time and thus could potentially act as a determinant of dispersal decisions in this system.

For dispersal probabilities, reproductive success was estimated based on nesting success. If the nest an individual was associated with hatched (chicks were found and banded) or was presumed to hatch (multiple lines of evidence that chicks hatched, like pipping fragments and chicks nearby, and near estimated hatch date), the nest was assumed to have hatched; otherwise, the nest was assumed to have failed, and there was no attempt to determine why the nest failed. Prior reproductive success was defined as reproductive success in the previous year.

\section{Social}

The social factors were determined from adult and chick densities. Adult density was calculated as twice the number of nests found on that segment corrected for known renesting probabilities (Swift and others, 2020b) during that breeding season divided by the length of that segment because conspecific abundance can affect nest survival (Swift and others, 2020c). Because nest monitoring efforts varied among years of study, the number of chicks hatched from nests in each year was estimated with a series of assumptions to derive an estimate of chick density per segment. First, if chicks were in the nest bowl, the number of chicks was used. If a nest was presumed successful because of alternate pieces of evidence, the clutch size corrected for the mean hatching rate of eggs (mean $=78.5$ percent) calculated from 129 successful nests closely monitored from 2014 to 2015 was used. Conspecific densities were standardized within each management unit because of the differences in segment length measurement strategies.

\section{Individual}

The individual factor was determined based on an individual's age and previous breeding experiences. For renesting analyses, individuals were categorized into one of four age and experience levels: 2 years old without previous breeding experience, greater than 2 years old without documented previous breeding experience, greater than 2 years old with known previous breeding experience, and individuals of unknown age and experience (newly banded adults). For adults, mate fidelity was categorized as a three-level factor: retained mate from 
previous year (both mates known in both years), divorced mate from previous year (both mates known in both years), and unknown (a mate was unknown or was unbanded in one or both years). Additionally, variables that counted the number of years an individual bred in the management unit they were located in that year, and if the segment they nested on was novel (in other words, they had never been known to nest on it since 2014), were also included.

For each analysis, only covariates were included for which there were formulated a priori hypotheses regarding how each covariate might explain variation in the specific parameter of interest (tables 13, 14, 15, 16).

\section{Renesting Propensity and Reproductive Success}

A renest was defined as an additional reproductive attempt after a failure. Failures occurring in the nesting period (egg laying and incubation until hatching) and the broodrearing period (hatching to 21 days posthatch) were examined. A renesting attempt was assumed to be a continuation nest (in other words, replacement nests of birds that lost a nest during egg laying and renested soon after with no interruption in laying) if nest loss occurred during egg laying and the replacement nest was initiated within 3 days of nest loss; these nests were excluded from analyses related to renesting $(n=3)$.
Apparent renesting propensity was defined as the proportion of individuals that renested after a failed previous reproductive attempt (Arnold, 1993; Claassen and others, 2014). Reproductive failure could occur during either nesting or brood-rearing stages. Reproductive attempts were divided into two categories: first attempts and second or third attempts (Swift and others, 2020b). Because individuals did not always reunite with their former mate for renesting, renesting attempts were analyzed separately for each individual.

Renest reproductive success was defined as a categorical response with reproductive attempts failing during nesting (failed), failing during the brood-rearing period (hatched), or successfully fledging one chick to at least 21 days posthatch (fledged). The number of fledged nests likely represents a minimum estimate because of imperfect detection of older chicks.

Sources of variation in renesting propensity were investigated using generalized linear mixed models using R statistical software (version 3.5.0; R Development Core Team, 2018). For renesting propensity, we used a binomial distribution (package lme4; Bates and others, 2015). Sources of variation in renest reproductive success were investigated using an ordinal multinomial response for the categorical renest reproductive success analysis (package ordinal; Christensen, 2015). Correlations among the independent variables were checked for first, and variables were reduced as needed (if $|r|$ was greater than 0.6; all remaining correlations were below 0.3). To ensure model convergence and interpretability of $\beta$ estimates, all covariates were standardized to a mean of zero and

Table 13. A priori hypotheses about variables affecting renesting propensity and renest reproductive success.

\begin{tabular}{|c|c|c|}
\hline Explanatory variable & Covariate type & A priori hypothesis \\
\hline Failure date & Reproductive success & $\begin{array}{l}\text { Later failure dates for reproductive attempts will decrease adult renest- } \\
\text { ing propensity. }\end{array}$ \\
\hline Cause of failure & Reproductive success & $\begin{array}{l}\text { Renesting propensity will decrease for brood failures and nest depreda- } \\
\text { tion events more than for inundation or severe storms. }\end{array}$ \\
\hline $\begin{array}{l}\text { Index of change in available habitat } \\
\text { from May to July }\end{array}$ & Habitat & $\begin{array}{l}\text { Where less habitat is available later in the breeding season, renesting } \\
\text { propensity will decrease, and renest success will decrease. }\end{array}$ \\
\hline Habitat type & Habitat & $\begin{array}{l}\text { Failed nests on reservoirs will decrease renesting propensity and de- } \\
\text { crease renest success. }\end{array}$ \\
\hline $\begin{array}{l}\text { Interaction between available habitat } \\
\text { index and habitat type }\end{array}$ & Habitat & $\begin{array}{l}\text { Reservoirs with less available habitat in July will decrease renesting } \\
\text { propensity and decrease renest success more than rivers or alkali } \\
\text { wetlands. }\end{array}$ \\
\hline Age and experience of pair & Individual & $\begin{array}{l}\text { 2-year-old individuals and greater than } 2 \text {-year olds without previous } \\
\text { breeding experience will have decreased renesting propensity. }\end{array}$ \\
\hline Mate fidelity & Individual & $\begin{array}{l}\text { Changing mates between consecutive nesting attempts will decrease } \\
\text { renest success. }\end{array}$ \\
\hline Distance between nests & Individual & $\begin{array}{l}\text { Farther distances between consecutive nesting attempts will decrease } \\
\text { renest success. }\end{array}$ \\
\hline
\end{tabular}


Table 14. A priori hypotheses about variables affecting hatch-year annual survival and dispersal probabilities.

\begin{tabular}{|c|c|c|}
\hline Explanatory variable & Covariate type & A priori hypothesis \\
\hline Estimated hatch date & Individual & $\begin{array}{l}\text { Individuals hatched later will have decreased hatch-year survival and decreased } \\
\text { dispersal probabilities. }\end{array}$ \\
\hline Available habitat index at settled site & Habitat & $\begin{array}{l}\text { When more habitat is available at the settling site, individuals will be more likely } \\
\text { to move, and hatch-year survival will increase. }\end{array}$ \\
\hline Adult density at settled site & Social & $\begin{array}{l}\text { Sites with high densities of adults will have increased natal dispersal probabilities } \\
\text { and decreased hatch-year survival. }\end{array}$ \\
\hline Distance between nests & Individual & Individuals that dispersed farther will have decreased hatch-year survival. \\
\hline $\begin{array}{l}\text { Average proximity to other nesting } \\
\text { areas of settled nest }\end{array}$ & Habitat & $\begin{array}{l}\text { Individuals will have increased hatch-year survival and be more likely to disperse } \\
\text { when closer to alternative nesting areas. }\end{array}$ \\
\hline
\end{tabular}

Table 15. A priori hypotheses about variables affecting adult annual survival and dispersal probabilities.

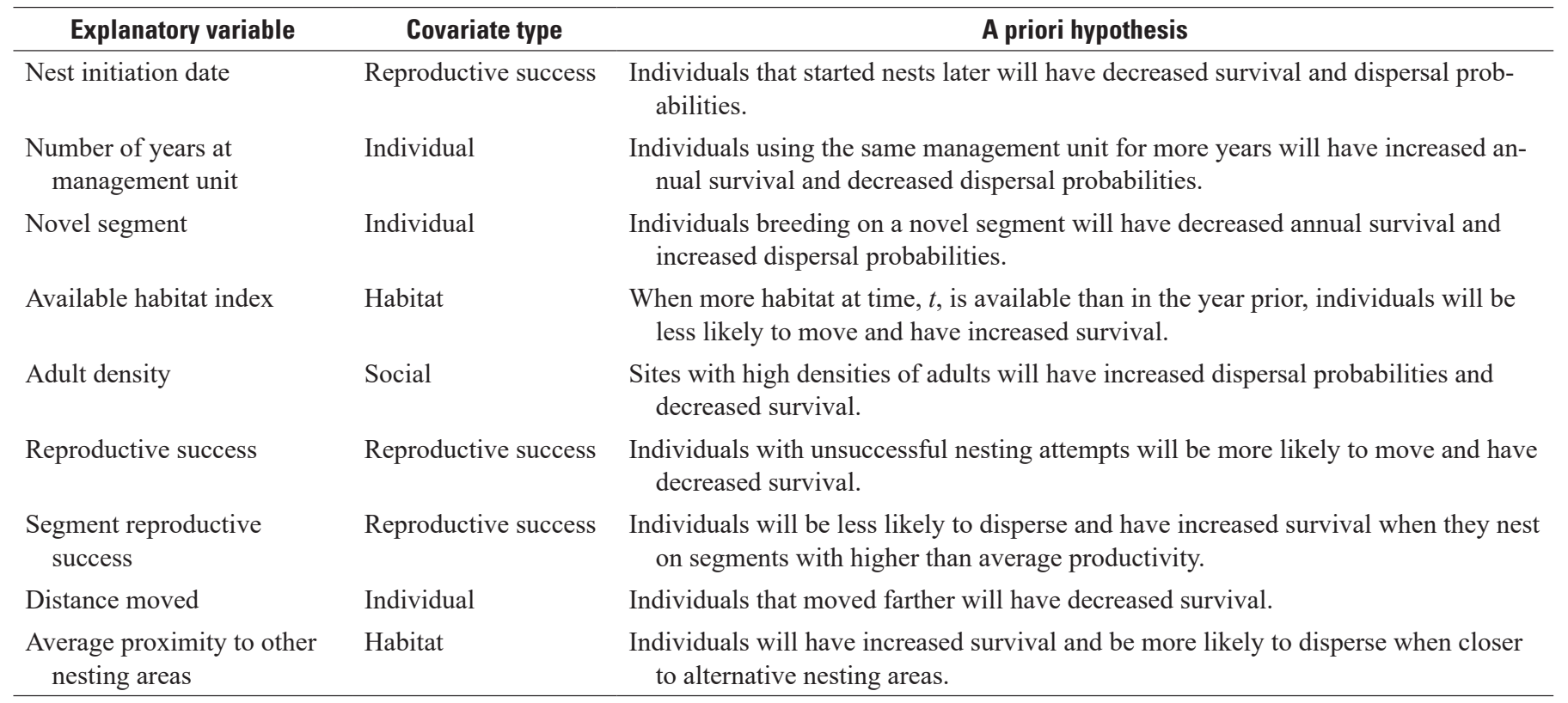

a standard deviation of 1 , except for the categorical covariates. Profile confidence intervals were calculated, and the significance of each parameter of interest in the fitted global generalized linear mixed model was evaluated. Year was included as an additional fixed effect to account for this source of heterogeneity. A random effect of breeding pair was included to account for multiple banded individuals at each nest.

Lastly, daily nest survival during the nesting period (egg laying and incubation) was evaluated for first nests and renests using the nest survival module in program MARK (version 9.0; White and Burnham, 1999; Dinsmore and others, 2002) via $R$ and the contributed $R$ package RMark (version 2.2.5; Laake, 2013). The nest survival module in program MARK uses a generalized linear model with logit-link function and binomial errors to estimate daily nest survival probability as a linear function of the various combinations of the covariates described by the candidate models. All possible combinations of a linear time trend, attempt number of the nest (for example, first attempt or renest), and habitat type of the nest were modeled, and the model with the lowest Akaike's information criterion corrected for small sample size (AICc) was selected (Burnham and Anderson, 2002). Cumulative nest survival to hatch was calculated using daily survival estimates from the top-supported model using an exposure period of 35 days. The $\delta$ method (msm package; Jackson, 2011) was used with daily survival rates generated at mean covariate values, and their associated variance-covariance matrices, to estimate cumulative survival rates and their associated 95-percent confidence intervals. 
Table 16. A priori hypotheses about variables affecting natal dispersal and interannual adult breeding movement distances.

\begin{tabular}{|c|c|c|}
\hline Explanatory variable & Type & A priori hypothesis \\
\hline Estimated hatch date & Individual & Individuals hatched later in the breeding season will disperse shorter distances. \\
\hline $\begin{array}{l}\text { Nest initiation date at settled } \\
\text { site }\end{array}$ & Reproductive success & Individuals will start nests later after longer breeding dispersal movements. \\
\hline Previous or natal habitat type & Habitat & $\begin{array}{l}\text { Individuals hatched on or previously bred on reservoirs will disperse longer dis- } \\
\text { tances. }\end{array}$ \\
\hline Settled habitat type & Habitat & Individuals settling on river habitats will move the shortest distances. \\
\hline $\begin{array}{l}\text { Available habitat index at } \\
\text { settled site }\end{array}$ & Habitat & $\begin{array}{l}\text { When more habitat is available at the settling site, individuals will move farther } \\
\text { distances. }\end{array}$ \\
\hline Chick density & Social & Sites with high densities of chicks will have increased natal dispersal distances. \\
\hline Adult density at previous site & Social & Sites with high densities of adults will have increased movement distances. \\
\hline $\begin{array}{l}\text { Reproductive success at } \\
\text { previous site }\end{array}$ & Reproductive success & Individuals with unsuccessful nesting attempts will move farther between nests. \\
\hline $\begin{array}{l}\text { Reproductive success at } \\
\text { settled nest }\end{array}$ & Reproductive success & $\begin{array}{l}\text { Individuals that moved farther between nest attempts will have better reproductive } \\
\text { success. }\end{array}$ \\
\hline $\begin{array}{l}\text { Average proximity to other } \\
\text { nesting areas of settled nest }\end{array}$ & Habitat & Farther distances between nesting areas will increase breeding movement distances. \\
\hline
\end{tabular}

\section{Natal Survival and Dispersal Probabilities}

Sources of variation in natal dispersal rates, natal survival to adulthood, and natal dispersal distances were investigated. Natal dispersal was defined as the first location where breeding either occurred or was presumed to occur given at least three resightings in the same management unit within a breeding season relative to the natal (hatching) location.

A simplified multievent capture-mark-resight model to estimate survival $(S)$ and transition probabilities $(\Psi)$ from an individual's natal location to their first breeding location state, allowing for uncertainty in an adult's state assignment, was developed (Pradel, 2005). A hierarchical Bayesian multievent model (Kéry and Schaub, 2012; Ranke and others, 2017) based on parametrizing the multievent model by Pradel (2005) was used. The model structure includes four parameters because there was no uncertainty of state assignment at initial capture for hatch-year chicks: $S$ is the probability of survival for individuals in state $i$ from time $t$ to $t+1\left(\mathrm{~S}_{t} i\right) ; \psi$ is the probability of transitioning from state $i$ to state $j$ between times $t$ and $t+1$ given that it survives $\left(\Psi_{t} i\right) ; p$ is the probability of being detected at time $t$ given that it is in state $i$ at time $t\left(p_{t}^{i}\right)$; and $\delta$ is the probability that, given it is encountered, the state is assigned correctly $\left(\delta_{t}^{i \mid i}\right)$.
First, nine states were included in the models that describe the age and location of individuals at time $t$. Age was broken into two distinct stages: hatch year and adults ( 2 years and older). Individuals could occur in one of four locationbased states (the ALK, SAK, the GRR, or OAH) based on the location of their natal nest (for hatch year) or the location of their first known breeding attempt (for adults). Because breeding status could not be determined for all individuals, adults could also be observed in an unknown state. Because the primary interest was in natal dispersal decisions, adult individuals were restricted to retain their first known breeding location state (in other words, once an individual bred in one location, we did not allow them to transition to other locations). The transition probabilities were built to estimate emigration and fidelity from the natal location. Although the models included adult survival estimates, adult survival was not interpreted from these models for two reasons: first, because a much larger dataset of marked adults could be used in the adult-specific analysis below, and second, because the artificial constraint imposed on adult location may create biased location-specific estimates. Second, the three management units that made up the Missouri River (MRS; SAK, the GRR, and OAH) were combined for the two location-based states (the ALK and the MRS), and all models were re-run with five states. Results from models with different state structures will produce similar but incomparable estimates because 
of the different underlying assumptions. For example, models with states for each management unit within the MRS will produce different dispersal estimates than those that combine all the MRS management units.

Individuals that were attributed to a nest (via observation or camera) were assigned the location of their first known nest. Individuals may have nested and failed, without being attributed to that first nest attempt, and then dispersed to renest; however, renesting is relatively rare in this system ( 25 percent of nests that fail are replaced), and only 10 percent of individuals changed habitat types between nest attempts (Swift and others, 2020b). A total of 54 individuals exhibited intra-annual renesting dispersal during the study. Because attribution to nests is imperfect, when individuals were seen in only one location and seen at least three times over the breeding season, they were assigned that location as a breeding state. Individuals that were seen in two management units or seen less than three times in only one management unit were not able to be classified into a state (and were thus given an observation of unknown state). Lastly, observations during the nonbreeding season were included as additional observations of adults in an unknown state if those individuals were not seen during the breeding season. Nonbreeding area location was not incorporated to maintain simplicity in the model because it was not a question of interest.

The models were constrained to preclude biologically infeasible transitions (in other words, decreasing in age). Because individuals automatically aged into the adult age states after their initial capture, detection of $p_{t}{ }^{i}$ for the hatchyear states was fixed. All $\delta_{t}{ }^{i \mid i}$ were fixed for the known hatchyear states because only adult states could be misclassified.

Multievent models were built to estimate factors affecting natal survival $(S)$, and dispersal $(\Psi)$ using the program JAGS (Plummer, 2003) using the package jagsUI (version 1.5.1; Kellner, 2019) in the program R (R Core Development Team, 2018). The aim was to infer only from variables that helped to explain variation in $S$ or $\Psi$. A global model was built using the simplified five-state structure containing all standardized, noncollinear covariates (Pearson's $|r|$ less than 0.7; Dormann and others, 2013) and evaluated if zero fell within the 95-percent credible interval from 5,000 posterior samples. All covariates were standardized (mean $=0$, standard deviation $=1$ ) before analysis, allowing for comparison of relative effect sizes across models of natal and adult survival and dispersal probabilities. All estimated annual vital rates were produced from the basic state- or state- and year-based models, representing the mean rates over all covariates or per year. The tests of the effect of covariates were from the covariate model, which included state-based means for the MRS and the ALK and a random effect of year for each parameter. Posterior means are presented as mean plus or minus 1 standard deviation, unless otherwise indicated. After assessing the performance of a series of exploratory model runs, 3 chains of 50,000 iterations with an adaptive phase of 10,000 iterations and a burn-in period of 10,000 iterations were run. After thinning of chains to account for serial autocorrelation, 5,000 posterior samples remained. Parameter convergence was determined using the Brooks-Gelman-Rubin criterion $(\hat{R}$; Brooks and Gelman, 1998), and models that had $\hat{R}$ less than 1.1 for each parameter node were considered to have reached convergence.

\section{Adult Survival and Breeding Dispersal Probabilities}

A multievent capture-mark-resight model was developed to estimate survival $(S)$ and transition probabilities $(\Psi)$ between breeding location states, allowing for uncertainty in an adult's state assignment (Pradel, 2005). A hierarchical Bayesian multievent model (Kéry and Schaub, 2012; Ranke and others, 2017) based on the parametrization by Pradel (2005) was used. The model structure includes five parameters: $S$ is the probability of survival for individuals in state $i$ from time $t$ to $t+1\left(S_{t} i\right)$, where $t$ represents a year; $\psi$ is the probability of transitioning from state $i$ to state $j$ between times $t$ and $t+1$ given that it survives $\left(\Psi_{t}^{i j}\right) ; p$ is the probability of being detected at time $t$ given that it is in state $i$ at time t $\left(p_{t}^{i}\right) ; \pi$ is the probability that an individual is in state $i$ at time $t$, given that it is released in an unknown state at time $t\left(\pi_{t}^{i}\right)$; and $\delta$ is the probability that, given it is encountered, the state is assigned correctly $\left(\delta_{t}^{i \mid i}\right)$.

First, six states were defined among which individuals could transition in this model. The transition probabilities are built to estimate emigration and fidelity from an individual's previous breeding location. Individuals could occur in one of four location-based breeding states (the ALK, SAK, the GRR, or $\mathrm{OAH})$. In addition, a fifth state (NON) represented individuals seen in multiple locations during a single breeding season; these were defined as transient individuals and assumed to be nonbreeders or early failed breeders. Lastly, a newly dead state was included. To account for uncertainty in state assignment, the observation process was divided into seven categories: seen in one of the four breeding locations (the ALK, SAK, the GRR, or OAH), seen in the transient nonbreeding state (NON), seen but state unknown, and not seen. Second, all models were re-run with a simplified state assignment using only two locations (the ALK and the MRS) with all transient individuals observed in an unknown state. Results from models with different state structures will produce similar but incomparable estimates because of the differing underlying assumptions.

Transient or assumed nonbreeding individuals were defined as those that were seen in at least three management units during the breeding season and were never attributed to a nest. Individuals that were attributed to a nest (via observation or camera) were assigned the location of their first known nest of that year. Individuals may have nested and failed, without being attributed to that first nest attempt, and then dispersed to renest; however, renesting is relatively rare in this system ( 25 percent of nest attempts that fail are replaced), and only 10 percent of individuals changed habitat types between reproductive attempts (Swift and others, 2020b). A total of 
54 individuals exhibited intra-annual renesting dispersal during the study. Because attribution to nests is imperfect, when individuals were seen in only one location and seen at least three times over the breeding season, that location was assigned as a breeding state. Individuals that were seen in two management units or seen less than three times in only one management unit were not able to be classified into a state, and thus their observation was assigned as an unknown state. Lastly, anecdotal resightings during the nonbreeding season between October 1 and March 31 were used to supplement USGS resights. Nonbreeding area location, because it was not a question of interest, was not incorporated to maintain simplicity in the model; instead the model included observations of individuals not seen during the breeding season as being in an unknown state. These supplemental observations contributed to estimation of survival and detection.

The multievent models were built to estimate variables affecting adult survival $(S)$ and dispersal $(\Psi)$ using the program JAGS (Plummer, 2003) using the package jagsUI (version 1.51; Kellner, 2019) in the program R (R Core Development Team, 2018). The aim was to infer from only variables that helped to explain variation in $S$ or $\psi$. A global model for the three-state model containing all standardized, noncollinear covariates (Pearson's $|r|$ less than 0.7; Dormann and others, 2013) was built and if zero fell within the 95-percent credible interval from 5,000 posterior samples was evaluated. All covariates were standardized (mean $=0$, standard deviation=1) before analysis, allowing for comparison of relative effect sizes across variables. All estimated annual vital rates were produced from the basic state-based or state- and year-based models, representing the mean rates over all covariates or per year. The tests of the effect of covariates were from the global covariate model with state-based means for the MRS and the ALK and a random effect of year. Posterior means are presented as mean plus or minus 1 standard deviation unless otherwise indicated. After assessing the performance of a series of exploratory model runs, 3 chains of 50,000 iterations with an adaptive phase of 10,000 and a burn-in period of 10,000 iterations were run for each analysis. After thinning of chains to account for serial autocorrelation, 5,000 posterior samples remained. We determined parameter convergence using $\hat{R}$ (Brooks and Gelman, 1998), and we considered models that had $\hat{R}$ less than 1.1 for each parameter node to have reached convergence.

\section{Dispersal Distances}

Euclidean dispersal distance was calculated as either the distance between the nest a chick was hatched from to the first known nest location of that individual chick or the distance between two successive breeding attempts for adults (package sp; Pebesma and Bivand, 2005). Because piping plovers do not defend stable territories between years, distances shorter than $50 \mathrm{~m}$ were assumed to represent philopatric movements because the adults were likely using the same space in both years and were removed from the analysis. Therefore, all successive breeding attempts greater than 50 meters were included in analyses even when movements were otherwise short for adult breeding dispersal. Thus, breeding dispersal was defined to include all movements greater than 50 meters by individuals between known nesting attempts. Assignment of individuals to a nest is not perfect, and plovers can forgo breeding in some years (Catlin and others, 2019). Therefore, instances where there was a time gap when individuals were not attributed to a nest location were also included.

Sources of variation in dispersal distances were examined using generalized linear models using $\mathrm{R}$ statistical software (3.5.0; R Development Core Team, 2018; package lme4; Bates and others, 2015) and a Y distribution. Correlations among the independent variables were first checked for and variables reduced as needed (if $|r|$ was greater than 0.6; all remaining correlations were below 0.3 ). To ensure model convergence and interpretability of $\beta$ estimates, all covariates were standardized to a mean of zero and a standard deviation of 1 , except for the categorical covariates. The $\alpha$ dispersion coefficient was estimated with the MASS package (Venables and Ripley, 2002) in program R. The dataset for adult dispersal contained multiple dispersals from some individuals; however, models failed to converge when a random effect of individual was included. When only the data for individuals with more than one movement were used, the interclass correlation coefficient for distance was 0.38 (95-percent confidence interval was 0.32 to 0.43 ), indicating low measurement repeatability (Wolak and others, 2012), so all movements were retained in the analyses. Profile confidence intervals were calculated, and the significance of each parameter of interest was evaluated in the fitted global generalized linear model for each response variable. If the 95-percent confidence interval for the parameter coefficient did not include zero, the effect was considered to be strongly supported.

\section{Reproductive Output}

The estimates of adult and hatch-year survival were used to calculate the reproductive output needed to maintain a stable population (in other words, stationarity) as an index of reproductive success for each management unit. The method used by Cohen and Gratto-Trevor (2011) and Catlin and others (2015) was followed to make comparable estimates across studies. The following equation (Cohen and Gratto-Trevor, 2011) was used:

$$
\lambda=S_{A H Y}+R \times P \times B_{t} \times S_{H Y}+R \times(1-P) \times B_{t-1} \times S_{A H Y} \times S_{H Y}
$$

where

$$
\begin{gathered}
\lambda \quad \begin{array}{c}
\text { is the population growth rate from year } \\
t \text { to } t+1,
\end{array} \\
S_{A H Y} \quad \begin{array}{l}
\text { is true survival for adult individuals estimated } \\
\text { in this study, }
\end{array} \\
S_{H Y} \quad \text { is true survival for hatch-year individuals }
\end{gathered}
$$


estimated in this study,

$R$

is the sex ratio at hatch (assumed to be 0.5;

Cohen and Gratto-Trevor, 2011),

$P \quad$ is the probability that a returning hatch-year

individual will breed in its first year (0.68;

Gratto-Trevor and others, 2010; Cohen and

Gratto-Trevor, 2011), and

$B \quad$ is the birth rate defined as fledged chicks produced per pair.

This equation accounts for breeding adults surviving from year $t$ to year $t+1$ and recruiting into the population in year $t+1$.

Following Cohen and Gratto-Trevor (2011) to determine the number of fledged chicks per pair to maintain stationarity, $\lambda$ was set equal to one and, assuming $B_{t}=B_{t-1}, B$ was solved for.

To incorporate variance into the estimate of $B$ following the same procedure as Cohen and Gratto-Trevor (2011), 100,000 values of $S_{A H Y}$ and $S_{H Y}$ were simulated using a multivariate normal distribution. $B$ was then calculated using equation 2 for each of the 100,000 runs and calculated a mean value and the 5 th and 95 th percentiles of those values.

Observed reproductive output was estimated as the number of fledged chicks per pair to compare against the value needed for stationarity using the year and management unit specific estimates of nest and chick survival using the following equation:

$$
C F_{i, t}=C S \times \phi_{N E S T i, t} \times R P_{i, t} \times \phi_{H Y i, \mathrm{t}}
$$

where

$\begin{aligned} C F & \text { is the number of chicks fledged per pair, } \\ i & \text { is the management unit, } \\ t & \text { is the year, } \\ C S & \text { is the mean clutch size of piping plovers in } \\ & \text { this system (3.49), } \\ \phi_{N E S T} & \begin{array}{r}\text { represents the probability that an individual } \\ \text { has a successful nest in a given year } \\ \text { (represented here by cumulative nest }\end{array} \\ & \text { survival), } \\ R P & \text { is the probability an individual replaces a lost } \\ & \text { reproductive attempt, and } \\ \phi_{H Y} & \text { is cumulative survival from hatch to fledge } \\ & \text { (21 days posthatch). }\end{aligned}$

Year and management unit specific estimates of fledged chicks per pair were calculated in the same manner as $\lambda$ above, calculating the mean, 5 th percentile, and 95 th percentile of the 100,000 estimates.

Daily nest survival was estimated during the nesting period (egg laying and incubation) using the nest survival module in program MARK (version 9.0; White and Burnham, 1999; Dinsmore and others, 2002) via the program R and the contributed R package RMark (version 2.2.5; Laake, 2013). The nest survival module in the program MARK uses a generalized linear model with logit-link function and binomial errors to estimate daily nest survival probability as a linear function of the various combinations of the covariates described by the candidate models. The effects of a linear time trend were first modeled against the null model and selected the model with the lowest AICc score (Burnham and Anderson, 2002). All possible combinations of year and management unit effects were then modeled, and the model with lowest AICc after accounting for time was selected. Cumulative nest survival to hatch was calculated using daily survival estimates from the top-supported model using an exposure period of 35 days. The $\delta$ method (msm package; Jackson, 2011) was used with daily survival rates generated from the top model and their associated variance-covariance matrices to estimate cumulative survival rates and their associated 95-percent confidence interval.

Cormack-Jolly-Seber models were built using package RMark in the programs R and MARK (Laake, 2013; White and Burnham, 1999) to estimate the daily probability of apparent survival $(\phi)$ and detection $(p)$ for piping plover chicks. The probability of true survival is generally confounded with the probability of emigration from a site when estimating apparent survival using Cormack-Jolly-Seber models. However, for unfledged chicks, the probability of emigration from a site is essentially zero; thus, all apparent survival estimates made before fledging age can be interpreted as true survival estimates.

Censored age-structured capture histories were created that consisted of 30 occasions (that is, hatch day to age 29 days), were coded based on if the individual was observed or not, and were censored if crews did not visit that site that day (Anteau and others, 2019). The program RELEASE was used to calculate estimates of over-dispersion $(\hat{c})$ for plover capture histories. Because the primary interest was in estimating daily survival probabilities, the first model selection step focused on parameterizing the model of detection probability (Lebreton and others, 1992). In all models of detection, differences in detection based on whether or not a chick was older than the fledge age (21 days posthatch) was accounted for. Models in which detection varied by all combinations of chick age, the year of the study, and the management unit were built. In all cases, management unit, year, and age effects were modeled separately for prefledge and postfledge stages. Models were ranked using Akaike's information criterion corrected for small sample size and overdispersion (QAICc), and the model with the lowest QAICc was selected. This model was then used for detection and first chick age, and then how year and management unit affected chick survival was investigated. Cumulative chick survival to fledging was computed by extrapolating the product of daily chick survival estimates out to 21 days posthatch. Associated standard errors were estimated using the $\delta$ method and the package msm (Jackson, 2011). A logarithmic-odds transformation of the daily survival probability (Armstrong and others, 2002) was used to compute associated 95-percent confidence intervals to ensure estimates were bounded between 0 and 1 . 


\section{References Cited}

Agresti, A., 2002, Categorical data analysis: Hoboken, N.Y., John Wiley and Sons Inc., 710 p. [Also available at https://doi.org/10.1002/0471249688.]

Amarasekare, P., 2004, Spatial variation and densitydependent dispersal in competitive coexistence: Proceedings of the Royal Society of London, v. 271, no. 1547 , p. 1497-1506. [Also available at https://doi.org/ 10.1098/rspb.2004.2696.]

Anteau, M.J., 2012, Do interactions of land use and climate affect productivity of waterbirds and Prairie-Pothole wetlands?: Wetlands, v. 32, no. 1, p. 1-9. [Also available at https://doi.org/10.1007/s13157-011-0206-3.]

Anteau, M.J., Shaffer, T.L., Sherfy, M.H., Sovada, M.A., Stucker, J.H., and Wiltermuth, M.T., 2012a, Nest survival of piping plovers at a dynamic reservoir indicates an ecological trap for a threatened population: Oecologia, v. 170, no. 4, p. 1167-1179. [Also available at https://doi.org/ 10.1007/s00442-012-2384-y.]

Anteau, M.J., Sherfy, M.H., and Wiltermuth, M.T., 2012b, Selection indicates preference in diverse habitats-A ground-nesting bird (Charadrius melodus) using reservoir shoreline: PLoS One, v. 7, no. 1, p. e30347. [Also available at https://doi.org/10.1371/journal.pone.0030347.]

Anteau, M.J., Shaffer, T.L., Wiltermuth, M.T., and Sherfy, M.H., 2014a, Landscape selection by piping plovers has implications for measuring habitat and population size: Landscape Ecology, v. 29, no. 6, p. 1033-1044. [Also available at https://doi.org/10.1007/s10980-014-0041-z.]

Anteau, M.J., Wiltermuth, M.T., Sherfy, M.H., and Shaffer, T.L., 2014b, Measuring and predicting abundance and dynamics of habitat for piping plovers on a large reservoir: Ecological Modelling, v. 272, p. 16-27. [Also available at https://doi.org/10.1016/j.ecolmodel.2013.08.020.]

Anteau, M.J., Sherfy, M.H., Shaffer, T.L., Swift, R.J., Toy, D.L., and Dovichin, C.M., 2019, Demographic responses of least terns and piping plovers to the 2011 Missouri River flood-A large-scale case study: U.S. Geological Survey Open-File Report 2018-1176, 33 p. [Also available at https://doi.org/10.3133/ofr20181176.]

Armstrong, K., Schwartz, J.S., Fitzgerald, G., Putt, M., and Ubel, P.A., 2002, Effect of framing as gain versus loss on understanding and hypothetical treatment choices-Survival and mortality curves: Medical Decision Making, v. 22, no. 1, p. 76-83. [Also available at https://doi.org/10.1177/ 0272989X0202200108.]
Arnold, T.W., 1993, Factors affecting renesting in American Coots: The Condor, v. 95, no. 2, p. 273-281. [Also available at https://doi.org/10.2307/1369349.].

Arnold, T.W., Devries, J.H., and Howerter, D.W., 2010, Factors that affect renesting in mallards (Anas platyrhynchos): The Auk, v. 127, no. 1, p. 212-221. [Also available at https://doi.org/10.1525/auk.2009.09028.]

Baddeley, A., Rubak, E., and Turner, R., 2015, Spatial point patterns-Methodology and applications with R: New York, Chapman and Hall/CRC Press, 828 p. [Also available at https://doi.org/10.1201/b19708.]

Bates, D., Mächler, M., Bolker, B., and Walker, S., 2015, Fitting linear mixed-effects models using lme4: Journal of Statistical Software, v. 67, no. 1, p. 1-48. [Also available at https://doi.org/10.18637/jss.v067.i01.]

Beguería, S., Vicente-Serrano, S.M., Reig, F., and Latorre, B., 2014, Standardized precipitation evapotranspiration index (SPEI) revisited - Parameter fitting, evapotranspiration models, tools, datasets and drought monitoring: International Journal of Climatology, v. 34, no. 10, p. 3001-3023. [Also available at https://doi.org/10.1002/ joc.3887.]

Beissinger, S.R., and Westphal, M.I., 1998, On the use of demographic models of population viability in endangered species management: The Journal of Wildlife Management, v. 62 , no. 3, p. 821-841. [Also available at https://doi.org/ 10.2307/3802534.]

Becker, P.H., and Zhang, H., 2011, Renesting of common terns Sterna hirundo in the life history perspective: Journal of Ornithology, v. 152, S1, p. S213-S225. [Also available at https://doi.org/10.1007/s10336-010-0639-0.]

Blomberg, E., Gibson, D., Atamian, M., and Sedinger, J.S., 2017, Variable drivers of primary versus secondary nesting; density-dependence and drought effects on greater sagegrouse: Journal of Avian Biology, v. 48, no. 6, p. 827-836. [Also available at https://doi.org/10.1111/jav.00988.]

Bowler, D.E., and Benton, T.G., 2005, Causes and consequences of animal dispersal strategies-Relating individual behaviour to spatial dynamics: Biological Reviews of the Cambridge Philosophical Society, v. 80, no. 2, p. 205-225. [Also available at https://doi.org/10.1017/ S1464793104006645.]

Boyce, C.C., and Boyce, J.L., 1988, Population biology of Microtus arvalis. II. Natal and breeding dispersal of females: Journal of Animal Ecology, v. 57, no. 3, p. 723-736. [Also available at https://doi.org/ 10.2307/5089.] 
Brooks, S.P., and Gelman, A., 1998, General methods for monitoring convergence of iterative simulations: Journal of Computational and Graphical Statistics, v. 7, p. 434-455.

Brudney, L.J., Arnold, T.W., Saunders, S.P., and Cuthbert, F.J., 2013, Survival of piping plover (Charadrius melodus) chicks in the Great Lakes region: The Auk, v. 130, no. 1, p. 150-160. [Also available at https://doi.org/10.1525/ auk.2012.12109.]

Burnham, K.P., and Anderson, D.R., 2002, Model selection and multimodel inference ( $2 \mathrm{~d}$ ed.): N.Y., Springer, $488 \mathrm{p}$.

Calvert, A.M., Amirault, D.L., Shaffer, F., Elliot, R., Hanson, A., McKnight, J., and Taylor, P.D., 2006, Population assessment of an endangered shorebird-The piping plover (Charadrius melodus melodus) in eastern Canada: Avian Conservation \& Ecology, v. 1, no. 3, p. art4. [Also available at https://doi.org/10.5751/ACE-00091-010304.]

Catlin, D., Jacobson, R., Sherfy, M., Anteau, M., Felio, J., Fraser, J., Lott, C., Shaffer, T., and Stucker, J., 2010, Discussion of "Natural hydrograph of the Missouri River near Sioux City and the least tern and piping plover" by Donald G. Jorgensen: Journal of Hydrologic Engineering, v. 15, no. 12, p. 1076-1078. [Also available at https://doi.org/10.1061/(ASCE)HE.1943-5584.0000265.]

Catlin, D.H., Fraser, J.D., and Felio, J.H., 2015, Demographic responses of piping plovers to habitat creation on the Missouri River: Wildlife Monographs, v. 192, no. 1, p. 1-42. [Also available at https://doi.org/10.1002/ wmon.1016.]

Catlin, D.H., Zeigler, S.L., Brown, M.B., Dinan, L.R., Fraser, J.D., Hunt, K.L., and Jorgensen, J.G., 2016, Metapopulation viability of an endangered shorebird depends on dispersal and human-created habitats - Piping plovers (Charadrius melodus) and prairie rivers: Movement Ecology, v. 4, no. 1, p. 6. [Also available at https://doi.org/10.1186/s40462016-0072-y.]

Catlin, D.H., Gibson, D., Hunt, K.L., Friedrich, M.J., Weithman, C.E., Karpanty, S.M., and Fraser, J.D., 2019, Direct and indirect effects of nesting density on survival and breeding propensity of an endangered shorebird: Ecosphere, v. 10 , no. 6 , p. e02740. [Also available at https://doi.org/ 10.1002/ecs2.2740.]

Chalfoun, A.D., and Schmidt, K.A., 2012, Adaptive breedinghabitat selection-Is it for the birds?: The Auk, v. 129, no. 4, p. 589-599. [Also available at https://doi.org/10.1525/ auk.2012.129.4.589.]

Christensen, R.H.B., 2015, R package ordinal-Regression models for ordinal data: $\mathrm{R}$ package, digital code, accessed March 2019 at https://github.com/runehaubo/ordinal.
Claassen, A.H., Arnold, T.W., Roche, E.A., Saunders, S.P., and Cuthbert, F.J., 2014, Factors influencing nest survival and renesting by piping plovers in the Great Lakes region: The Condor, v. 116, no. 3, p. 394-407. [Also available at https://doi.org/10.1650/CONDOR-13-146.1.]

Cohen, J.B., and Gratto-Trevor, C., 2011, Survival, site fidelity, and the population dynamics of piping plovers in Saskatchewan: Journal of Field Ornithology, v. 82, no. 4, p. 379-394. [Also available at https://doi.org/10.1111/ j.1557-9263.2011.00341.x.]

Cowardin, L.M., and Johnson, D.H., 1979, Mathematics and mallard management: The Journal of Wildlife Management, v. 43, no. 1, p. 18-35. [Also available at https://doi.org/ 10.2307/3800632.]

Cox, A.S., and Kesler, D.C., 2012, Prospecting behavior and the influence of forest cover on natal dispersal in a resident bird: Behavioral Ecology, v. 23, no. 5, p. 1068-1077. [Also available at https://doi.org/10.1093/beheco/ars076.]

Dail, D., and Madsen, L., 2011, Models for estimating abundance from repeated counts of an open metapopulation: Biometrics, v. 67, no. 2, p. 577-587. [Also available at https://doi.org/10.1111/j.1541-0420.2010.01465.x.]

Danchin, E., Boulinier, T., and Massot, M., 1998, Conspecific reproductive success and breeding habitat selectionImplications for the study of coloniality: Ecology, v. 79, no. 7, p. 2415-2428. [Also available at https://doi.org/ 10.1890/0012-9658(1998)079[2415:CRSABH]2.0.CO;2.]

Danchin, E., Giraldeau, L.A., Valone, T.J., and Wagner, R.H., 2004, Public information-From nosy neighbors to cultural evolution: Science, v. 305, no. 5683, p. 487-491. [Also available at https://doi.org/10.1126/science.1098254.]

Dinsmore, S.J., White, G.C., and Knopf, F.L., 2002, Advanced techniques for modeling avian nest survival: Ecology, v. 83, no. 12, p. 3476-3488. [Also available at https://doi.org/ 10.1890/0012-9658(2002)083[3476:ATFMAN]2.0.CO;2.]

Dormann, C.F., Elith, J., Bacher, S., Buchmann, C., Carl, G., Carré, G., Marquéz, J.R.G., Gruber, B., Lafourcade, B., Leitao, P.J., Münkemüller, T., McClean, C., Osborne, P.E., Reineking, B., Schröder, B., Skidmore, A.K., Zurell, D., and Lautenbach, S., 2013, Collinearity-A review of methods to deal with it and a simulation study evaluating their performance: Ecography, v. 36, no. 1, p. 27-46. [Also available at https://doi.org/10.1111/j.1600-0587.2012.07348.x.]

Euliss, N.H., and Mushet, D.M., 1996, Water-level fluctuation in wetlands as a function of landscape condition in the prairie pothole region: Wetlands, v. 16, no. 4, p. 587-593. [Also available at https://doi.org/10.1007/BF03161350.] 
Euliss, N.H., LaBaugh, J.W., Fredrickson, L.H., Mushet, D.M., Laubhan, M.K., Swanson, G.A., Winter, T.C., Rosenberry, D.O., and Nelson, R.D., 2004, The wetland continuum-A conceptual framework for interpreting biological studies: Wetlands, v. 24, no. 2, p. 448-458. [Also available at https://doi.org/10.1672/02775212(2004)024[0448:TWCACF]2.0.CO;2.]

Forero, M.G., Donázar, J.A., Blas, J., and Hiraldo, F., 1999, Causes and consequences of territory change and breeding dispersal distance in the black kite: Ecology, v. 80, no. 4, p. 1298-1310. [Also available at https://doi.org/10.1890/ 0012-9658(1999)080[1298:CACOTC]2.0.CO;2.]

Gaines, E.P., and Ryan, M.R., 1988, Piping plover habitat use and reproductive success in North Dakota: The Journal of Wildlife Management, v. 52, no. 2, p. 266-273. [Also available at https://doi.org/10.2307/3801233.]

Gill, J.A., Norris, K., Potts, P.M., Gunnarsson, T.G., Atkinson, P.W., and Sutherland, W.J., 2001, The buffer effect and large-scale population regulation in migratory birds: Nature, v. 412, no. 6845, p. 436-438. [Also available at https://doi.org/10.1038/35086568.]

Gratto-Trevor, C.L., Goossen, J.P., and Westworth, S.M., 2010, Identification and breeding of yearling piping plovers: Journal of Field Ornithology, v. 81, no. 4, p. 383-391. [Also available at https://doi.org/10.1111/j.15579263.2010.00294.x.]

Greenwood, P.J., and Harvey, P.H., 1982, The natal and breeding dispersal of birds: Annual Review of Ecology and Systematics, v. 13, no. 1, p. 1-21. [Also available at https://doi.org/10.1146/annurev.es.13.110182.000245.]

Halimubieke, N., Kupán, K., Valdebenito, J.O., Kubelka, V., Carmona-Isunza, M.C., Burgas, D., Catlin, D., St Clair, J.J.H., Cohen, J., Figuerola, J., Yasué, M., Johnson, M., Mencarelli, M., Cruz-López, M., Stantial, M., Weston, M.A., Lloyd, P., Que, P., Montalvo, T., Bansal, U., McDonald, G.C., Liu, Y., Kosztolányi, A., and Székely, T., 2020, Successful breeding predicts divorce in plovers: Scientific Reports, v. 10, no. 1, p. 15576. [Also available at https://doi.org/10.1038/s41598-020-72521-6.]

Hanski, I., 1998, Metapopulation dynamics: Nature, v. 396, no. 6706, p. 41-49. [Also available at https://doi.org/ 10.1038/23876.]

Hanski, I., and Gilpin, M., 1991, Metapopulation dynamicsBrief history and conceptual domain: Biological Journal of the Linnean Society, Linnean Society of London, v. 42, no. 1-2, p. 3-16. [Also available at https://doi.org/10.1111/ j.1095-8312.1991.tb00548.x.]
Halekoh, U., Højsgaard, S., and Yan, J., 2006, The R package geepack for generalized estimating equations: Journal of Statistical Software, v. 15, no. 2, p. 1-11. [Also available at https://doi.org/10.18637/jss.v015.i02.]

Heppell, S.S., Caswell, H., and Crowder, L.B., 2000, Life histories and elasticity patterns_-Perturbation analysis for species with minimal demographic data: Ecology, v. 81, no. 3, p. 654-665. [Also available at https://doi.org/10.1890/00129658(2000)081[0654:LHAEPP]2.0.CO;2.]

Hodgson, D., Townley, S., and McCarthy, D., 2006, Robustness-Predicting the effects of life history perturbations on stage-structured population dynamics: Theoretical Population Biology, v. 70, no. 2, p. 214-224. [Also available at https://doi.org/10.1016/j.tpb.2006.03.004.]

Hoekman, S.T., Mills, L.S., Howerter, D.W., Devries, J.H., and Ball, J., 2002, Sensitivity analyses of the life cycle of midcontinent mallards: The Journal of Wildlife Management, v. 66, no. 3, p. 883-900. [Also available at https://doi.org/ 10.2307/3803153.]

Hunt, K.L., Dinan, L.R., Friedrich, M.J., Brown, M.B., Jorgensen, J.G., Catlin, D.H., and Fraser, J.D., 2015, Density dependent double brooding in piping plovers (Charadrius melodus) in the Northern Great Plains, USA: Waterbirds, v. 38, no. 4, p. 321-329. [Also available at https://doi.org/10.1675/063.038.0409.]

Hunt, K.L., Fraser, J.D., Friedrich, M.J., Karpanty, S.M., and Catlin, D.H., 2018, Demographic response of piping plovers suggests that engineered habitat restoration is no match for natural riverine processes: The Condor, v. 120, p. 149-165. [Also available at https://doi.org/10.1650/CONDOR17-93.1.]

Ivan, J.S., and Murphy, R.K., 2005, What preys on piping plover eggs and chicks?: Wildlife Society Bulletin, v. 33, no. 1, p. 113-119. [Also available at https://doi.org/10.2193/ 0091-7648(2005)33[113:WPOPPE]2.0.CO;2.]

Jackson, C.H., 2011, Multi-state models for panel data-The msm package for R: Journal of Statistical Software, v. 38, no. 8, p. 1-29. [Also available at https://doi.org/10.18637/ jss.v038.i08.]

Kellner, K., 2019, jagsUI-A wrapper around 'rjags' to streamline 'JAGS' analyses (ver. 1.5.1): R package, digital code, accessed July 2020 at https://cran.r-project.org/ package $=$ jagsUI.

Kéry, M., and Schaub, M., 2012, Bayesian population analysis using WinBUGS - A hierarchical perspective: Boston, Academic Press, 554 p. 
Knetter, J.M., Lutz, R.S., Cary, J.R., and Murphy, R.K., 2002, A multi-scale investigation of piping plover productivity on Great Plains alkali lakes, 1994-2000: Wildlife Society Bulletin, v. 30, p. 683-694.

Laake, J.L., 2013, RMark-An R interface for analysis of capture-recapture data with MARK: Seattle, Wash., National Marine Fisheries Service, Alaska Fisheries Science Center, AFSC Processed Report 2013-01, 25 p. [Also available at https://archive.fisheries.noaa.gov/afsc/Publications/ProcRpt/ PR2013-01.pdf.]

Lagrange, P., Gimenez, O., Doligez, B., Pradel, R., Garant, D., Pelletier, F., and Bélisle, M., 2017, Assessment of individual and conspecific reproductive success as determinants of breeding dispersal of female tree swallows - A capturerecapture approach: Ecology and Evolution, v. 7, no. 18, p. 7334-7346. [Also available at https://doi.org/10.1002/ ece3.3241.]

Larson, M.A., Ryan, M.R., and Root, B.G., 2000, Piping plover survival in the Great Plains-An updated analysis: Journal of Field Ornithology, v. 71, no. 4, p. 721-729. [Also available at https://doi.org/10.1648/0273-8570-71.4.721.]

Lebreton, J.D., Burnham, K.P., Clobert, J., and Anderson, D.R., 1992, Modeling survival and testing biological hypotheses using marked animals - A unified approach with case studies: Ecological Monographs, v. 62, no. 1, p. 67-118. [Also available at https://doi.org/10.2307/ 2937171.]

Liebezeit, J.R., Smith, P.A., Lanctot, R.B., Schekkerman, H., Tulp, I., Kendall, S.J., Tracy, D.M., Rodrigues, R.J., Meltofte, H., Robinson, J.A., Gratto-Trevor, C., Mccaffery, B.J., Morse, J., and Zack, S.W., 2007, Assessing the development of shorebird eggs using the flotation methodSpecies-specific and generalized regression models: The Condor, v. 109, no. 1, p. 32-47. [Also available at https://doi.org/10.1093/condor/109.1.32.]

Levins, R., 1969, Some demographic and genetic consequences of environmental heterogeneity for biological control: American Entomologist (Lanham, Md.), v. 15, p. 237-240.

Lishman, C., Nol, E., Abraham, K.F., and Nguyen, L.P., 2010, Behavioral responses to higher predation risk in a subarctic population of the semipalmated plover: The Condor, v. 112, no. 3, p. 499-506. [Also available at https://doi.org/ 10.1525/cond.2010.090059.]

Martin, A.E., and Fahrig, L., 2018, Habitat specialist birds disperse farther and are more migratory than habitat generalist birds: Ecology, v. 99, no. 9, p. 2058-2066. [Also available at https://doi.org/10.1002/ecy.2428.]
Martin, T.E., Scott, J., and Menge, C., 2000, Nest predation increases with parental activity-Separating nest site and parental activity effects: Proceedings. Biological Sciences, v. 267, no. 1459, p. 2287-2293. [Also available at https://doi.org/10.1098/rspb.2000.1281.]

Matthysen, E., 2012, Multicausality of dispersal-A review, chap. 1 of Clobert, J., Baguette, M., Benton, T.G., and Bullock, J.M., eds., Dispersal ecology and evolution: Oxford, Oxford University Press, p. 3-18. [Also available at https://doi.org/10.1093/acprof:oso/ 9780199608898.003.0001.]

McCauley, L.A., Anteau, M.J., Post van der Burg, M., and Wiltermuth, M.T., 2015, Land use and wetland drainage affect water levels and dynamics of remaining wetlands: Ecosphere, v. 6, no. 6, p. 1-22. [Also available at https://doi.org/10.1890/ES14-00494.1.]

McCauley, L.A., Anteau, M.J., and Post van der Burg, M., 2016, Consolidation drainage and climate change may reduce piping plover habitat in the Great Plains: Journal of Fish and Wildlife Management, v. 7, no. 1, p. 4-13. [Also available at https://doi.org/10.3996/072015-JFWM-068.]

McGowan, C.P., Catlin, D.H., Shaffer, T.L., Gratto-Trevor, C.L., and Aron, C., 2014, Establishing endangered species recovery criteria using predictive simulation modeling: Biological Conservation, v. 177, p. 220-229. [Also available at https://doi.org/10.1016/j.biocon.2014.06.018.]

Olivieri, I., Couvet, D., and Gouyon, P.H., 1990, The genetics of transient populations - Research at the metapopulation level: Trends in Ecology \& Evolution, v. 5, no. 7, p. 207-210. [Also available at https://doi.org/10.1016/01695347(90)90132-W.]

Olofsson, H., Ripa, J., and Jonzén, N., 2009, Bet-hedging as an evolutionary game- The trade-off between egg size and number: Proceedings of the Royal Society B, v. 276, no. 1669, p. 2963-2969. [Also available at https://doi.org/ 10.1098/rspb.2009.0500.]

Pakanen, V.M., Rönkä, N., Thomson, R.L., and Koivula, K., 2014, Informed renesting decisions - The effect of nest predation risk: Oecologia, v. 174, no. 4, p. 1159-1167. [Also available at https://doi.org/10.1007/s00442-013-2847-9.]

Pakanen, V., Aikio, S., Luukkonen, A., and Koivula, K., 2016, Grazed wet meadows are sink habitats for the southern dunlin (Calidris alpina schinzii) due to nest trampling by cattle: Ecology and Evolution, v. 6, no. 20, p. 7176-7187. [Also available at https://doi.org/10.1002/ece3.2369.]

Paradis, E., Baillie, S.R., Sutherland, W.J., and Gregory, R.D., 1998, Patterns of natal and breeding dispersal in birds: Journal of Animal Ecology, v. 67, no. 4, p. 518-536. [Also available at https://doi.org/10.1046/j.13652656.1998.00215.x.] 
Pebesma, E.J., and Bivand, R.S., 2005, Classes and methods for spatial data in R: R News, v. 5, p. 9-13.

Plissner, J.H., and Haig, S.M., 2000, Viability of piping plover Charadrius melodus metapopulations: Biological Conservation, v. 92, no. 2, p. 163-173. [Also available at https://doi.org/10.1016/S0006-3207(99)00050-6.]

Plummer, M., 2003, JAGS-A program for analysis of Bayesian graphical models using Gibbs sampling, in Hornik, K., Leisch, F., and Zeileis, A., eds., Proceedings of the 3rd International Workshop on Distributed Statistical Computing (DSC 2003) - International Workshop on Distributed Statistical Computing, 3d, Vienna, Austria, March 20-22, 2003 Proceedings: International Workshop on Distributed Statistical Computing, $10 \mathrm{p}$.

Post van der Burg, M., Anteau, M.J., McCauley, L.A., and Wiltermuth, M.T., 2016, A Bayesian approach for temporally scaling climate for modeling ecological systems: Ecology and Evolution, v. 6, no. 9, p. 2978-2987. [Also available at https://doi.org/10.1002/ece3.2092.]

Pradel, R., 2005, Multievent-An extension of multistate capture-recapture models to uncertain states: Biometrics, v. 61, no. 2, p. 442-447. [Also available at https://doi.org/ 10.1111/j.1541-0420.2005.00318.x.]

Ranke, P.S., Skjelseth, S., Pärn, H., Herfindal, I., Pedersen, Å.A.B., Stokke, B.G., Kvalnes, T., Ringsby, T.H., Sæther, B.E., and Jensen, H., 2017, Demographic influences of translocated individuals on a resident population of house sparrows: Oikos, v. 126, no. 10, p. 1410-1418. [Also available at https://doi.org/10.1111/oik.04065.]

R Development Core Team, 2018, R-A language and environment for statistical computing: Vienna, Austria, R Foundation for Statistical Computing, software, accessed June 2018 at https://www.r-project.org/.

Rioux, S., Amirault-Langlais, D.L., and Shaffer, F., 2011, Piping plovers make decisions regarding dispersal based on personal and public information in a variable coastal ecosystem: Journal of Field Ornithology, v. 82, no. 1, p. 32-43. [Also available at https://doi.org/10.1111/j.15579263.2010.00305.x.]

Roche, E.A., Cohen, J.B., Catlin, D.H., Amirault-Langlais, D.L., Cuthbert, F.J., Gratto-Trevor, C.L., Felio, J., and Fraser, J.D., 2010, Range-wide piping plover survivalCorrelated patterns and temporal declines: The Journal of Wildlife Management, v. 74, no. 8, p. 1784-1791. [Also available at https://doi.org/10.2193/2009-446.]
Roche, E.A., Dovichin, C.M., and Arnold, T.W., 2014b, Field-readable alphanumeric flags are valuable markers for shorebirds - Use of double-marking to identify cases of misidentification: Journal of Field Ornithology, v. 85, no. 3, p. 329-338. [Also available at https://doi.org/10.1111/ jofo.12072.]

Roche, E.A., Gratto-Trevor, C.L., Goossen, J.P., and White, C.L., 2012, Flooding affects dispersal decisions in piping plovers (Charadrius melodus) in Prairie Canada: The Auk, v. 129, no. 2, p. 296-306. [Also available at https://doi.org/ 10.1525/auk.2012.11196.]

Roche, E.A., Shaffer, T.L., Anteau, M.J., Sherfy, M.H., Stucker, J.H., Wiltermuth, M.T., and Dovichin, C.M., 2014a, Detection probability of least tern and piping plover chicks in a large river system: The Journal of Wildlife Management, v. 78, no. 4, p. 709-720. [Also available at https://doi.org/10.1002/jwmg.697.]

Roche, E.A., Shaffer, T.L., Dovichin, C.M., Sherfy, M.H., Anteau, M.J., and Wiltermuth, M.T., 2016, Synchrony of piping plover breeding populations in the U.S. Northern Great Plains: The Condor, v. 118, no. 3, p. 558-570. [Also available at https://doi.org/10.1650/CONDOR-15-195.1.]

Roze, D., and Rousset, F., 2005, Inbreeding depression and the evolution of dispersal rates-A multilocus model: American Naturalist, v. 166 , no. 6, p. 708-721. [Also available at https://doi.org/10.1086/497543.]

Sæther, B.E., and Bakke, Ø., 2000, Avian life history variation and contribution of demographic traits to the population growth rate: Ecology, v. 81, no. 3, p. 642-653. [Also available at https://doi.org/10.1890/00129658(2000)081[0642:ALHVAC]2.0.CO;2.]

Sandercock, B.K., Jensen, W.E., Williams, C.K., and Applegate, R.D., 2008, Demographic sensitivity of population change in northern bobwhite: The Journal of Wildlife Management, v. 72, no. 4, p. 970-982. [Also available at https://doi.org/10.2193/2007-124.]

Sandercock, B.K., Lank, D.B., and Cooke, F., 1999, Seasonal declines in the fecundity of Arctic-breeding sandpipersDifferent tactics in two species with an invariant clutch size: Journal of Avian Biology, v. 30, no. 4, p. 460-468. [Also available at https://doi.org/10.2307/3677018.]

Sandercock, B.K., 2006, Estimation of demographic parameters from live-encounter data-A summary review: The Journal of Wildlife Management, v. 70, no. 6, p. 1504-1520. [Also available at https://doi.org/10.2193/0022541X(2006)70[1504:EODPFL]2.0.CO;2.] 
Schaub, M., and Von Hirschheydt, J., 2009, Effect of current reproduction on apparent survival, breeding dispersal, and future reproduction in barn swallows assessed by multistate capture-recapture models: Journal of Animal Ecology, v. 78, no. 3, p. 625-635. [Also available at https://doi.org/ 10.1111/j.1365-2656.2008.01508.x.]

Sedinger, J.S., Lindberg, M.S., and Chelgren, N.D., 2001, Age-specific breeding probability in black brant-Effects of population density: Journal of Animal Ecology, v. 70, no. 5, p. 798-807. [Also available at https://doi.org/10.1046/ j.0021-8790.2001.00535.x.]

Severinghaus, L.L., 1996, Territory strategy of the migratory brown shrike Lanius cristatus: The Ibis, v. 138, no. 3, p. 460-465. [Also available at https://doi.org/10.1111/ j.1474-919X.1996.tb08065.x.]

Shaffer, T.L., Sherfy, M.H., Anteau, M.J., Stucker, J.H., Sovada, M.A., Roche, E.A., Wiltermuth, M.T., Buhl, T.K., and Dovichin, C.M., 2013, Accuracy of the Missouri River least tern and piping plover monitoring programConsiderations for the future: U.S. Geological Survey Open-File Report 2013-1176, 74 p. [Also available at https://doi.org/10.3133/ofr20131176.]

Sherfy, M.H., Stucker, J.H., and Anteau, M.J., 2008, Missouri River emergent sandbar habitat monitoring plan-A conceptual framework for adaptive management: U.S. Geological Survey Open-File Report 2008-1223, 51 p. [Also available at https://doi.org/10.3133/ofr20081223.]

Smith, G.J., 2013, The U.S. Geological Survey Bird Banding Laboratory-An integrated scientific program supporting research and conservation of North American birds: U.S. Geological Survey Open-File Report 2013-1238, 88 p., [Also available at https://doi.org/10.3133/ofr20131238.]

Stenzel, L.E., Page, G.W., Warriner, J.C., Warriner, J.S., George, D.E., Eyster, C.R., Ramer, B.A., and Neuman, K.K., 2007, Survival and natal dispersal of juvenile snowy plovers (Charadrius alexandrinus) in central coastal California: The Auk, v. 124, no. 3, p. 1023-1036. [Also available at https://doi.org/10.1093/auk/124.3.1023.]

Sullivan, B.L., Wood, C.L., Iliff, M.J., Bonney, R.E., Fink, D., and Kelling, S., 2009, eBird-A citizen-based bird observation network in the biological sciences: Biological Conservation, v. 142 , no. 10, p. 2282-2292. [Also available at https://doi.org/10.1016/j.biocon.2009.05.006.]

Swift, R.J., Rodewald, A.D., and Senner, N.R., 2018, Contextdependent costs and benefits of a heterospecific nesting association: Behavioral Ecology, v. 29, no. 4, p. 974-983. [Also available at https://doi.org/10.1093/beheco/ary042.]
Swift, R.J., Anteau, M.J., Ring, M.M., Toy, D.L., and Sherfy, M.H., 2019, Renesting propensity, intervals, and reproductive success data for the Northern Great Plains Piping Plover, a threatened shorebird species 2014-2016: U.S. Geological Survey data release, https://doi.org/10.5066/ P9VAS8P7.

Swift, R.J., Anteau, M.J., Ellis, K.S., Ring, M.M., Sherfy, M.H., Toy, D.L., and Koons, D.N., 2020a, Spatial variation in population dynamics of Northern Great Plains piping plovers, 2014-2019: U.S. Geological Survey data release, https://doi.org/10.5066/P96PSOBQ.

Swift, R.J., Anteau, M.J., Ring, M.M., Toy, D.L., and Sherfy, M.H., 2020b, Low renesting propensity and reproductive success make renesting unproductive for the threatened piping plover (Charadrius melodus): The Condor, v. 122, no. 2, p. duz066. [Also available at https://doi.org/10.1093/ condor/duz066.]

Swift, R.J., Anteau, M.J., Roche, E.A., Sherfy, M.H., Toy, D.L., and Ring, M.M., 2020c, Asymmetric benefits of a heterospecific breeding association vary with habitat, conspecific abundance, and breeding stage: Oikos, v. 129, no. 10, p. 1504-1520. [Also available at https://doi.org/10.1111/ oik.07256.]

Toy, D.L., Roche, E.A., and Dovichin, C.M., 2017, Small high-definition video cameras as a tool to resight uniquely marked interior least terns: Waterbirds, v. 40, no. 2, p. 180-186. [Also available at https://doi.org/10.1675/ 063.040.0211.]

U.S. Army Corps of Engineers, 2020, Main stem monthly project statistics: U.S. Army Corps of Engineers, digital data, accessed December 2020 at https://www.nwdmr.usace.army.mil/rce/projdata/.

U.S. Fish and Wildlife Service [USFWS], 1985, Determination of endangered and threatened status for the piping plover: Washington, D.C., U.S. Fish and Wildlife Service.

U.S. Fish and Wildlife Service [USFWS], 2003, Supplemental biological opinion on the annual operating plan for the Missouri River main stem reservoir system: Washington, D.C., U.S. Fish and Wildlife Service.

U.S. Fish and Wildlife Service [USFWS], 2009, Piping plover (Charadrius melodus) - 5-year review-Summary and evaluation: Hadley, Mass., U.S. Fish and Wildlife Service, 206 p. [Also available at https://www.fws.gov/northeast/endangered/pdf/piping plover_five_year_review_and_summary.pdf.] 
U.S. Fish and Wildlife Service [USFWS], 2016, Draft revised recovery plan for the northern Great Plains piping plover (Charadrius melodus): Denver, Colo., U.S. Fish and Wildlife Service, 176 p. [Also available at https://www.fws.gov/mountain-prairie/es/species/birds/ pipingplover/2016/Vol\%20I\%20NGP\%20Draft $\% 20$ Revised\%20Breeding\%20Rec\%20Plan.pdf.]

U.S. Fish and Wildlife Service [USFWS], 2018, Biological opinion-Operation of the Missouri River mainstem reservoir system, the operation and maintenance of the bank stabilization and navigation project, the operation of Kansas River reservoir system, and the implementation of the Missouri River recovery management plan: Denver, Colo., U.S. Fish and Wildlife Service, 148 p., TAILS No. 06E00000-2018-F-0001.

Venables, W.N., and Ripley, B.D., 2002, Modern Applied Statistics with S (4th ed.): New York, Springer. [Also available at https://doi.org/10.1007/978-0-387-21706-2.]
Weiser, E.L., Lanctot, R.B., Brown, S.C., Gates, H.R., Bentzen, R.L., Bêty, J., Boldenow, M.L., English, W.B., Franks, S.E., Koloski, L., Kwon, E., Lamarre, J.-F., Lank, D.B., Liebezeit, J.R., McKinnon, L., Nol, E., Rausch, J., Saalfeld, S.T., Senner, N.R., Ward, D.H., Woodard, P.F., and Sandercock, B.K., 2018, Environmental and ecological conditions at Arctic breeding sites have limited effects on true survival rates of adult shorebirds: The Auk, v. 135, no. 1, p. 29-43. [Also available at https://doi.org/10.1642/ AUK-17-107.1.]

Weithman, C.E., Robinson, S.G., Hunt, K.L., Altman, J., Bellman, H.A., DeRose-Wilson, A.L., Walker, K.M., Fraser, J.D., Karpanty, S.M., and Catlin, D.H., 2019, Growth of two Atlantic coast piping plover populations: The Condor, v. 121 , no. 3 , p. $1-14$.

White, G.C., and Burnham, K.P., 1999, Program MARKSurvival estimation from populations of marked animals: Bird Study, v. 46, no. sup1, p. S120-S139. [Also available at https://doi.org/10.1080/00063659909477239.]

Wolak, M.E., Fairbairn, D.J., and Paulsen, Y.R., 2012, Guidelines for estimating repeatability: Methods in Ecology and Evolution, v. 3, no. 1, p. 129-137. [Also available at https://doi.org/10.1111/j.2041-210X.2011.00125.x.] 


\section{Appendix 1. Summary of Piping Plover Demographic Rates}

Piping plovers have been widely studied throughout their range since they were listed under the Endangered Species Act of 1973 (16 U.S.C. ch. $35 \S 1531$ et seq.; U.S. Fish and Wildlife Service, 1985). Vital rates collected on reproductive rates (table 1.1), survival (table 1.2), site fidelity (table 1.3), and dispersal distances (table 1.4) are summarized. 
Table 1.1. Piping plover reproductive rates and estimated reproductive output needed for a stable population (stationarity), $1959-2020$.

[Mean values are presented when available; otherwise, ranges of means are presented. Hatch, hatching success expressed as a proportion of eggs hatched; $S_{N E S T}$, proportion of nests in which at least one egg hatched or estimated nest survival; $S_{C H I C K}$, survival of chicks from hatch to fledging (fledging age was variously defined); $R_{O}$, number of fledged chicks per pair; $R_{O}$ needed, fledged chicks per pair needed for a stationary population; --, no data]

\begin{tabular}{|c|c|c|c|c|c|c|c|}
\hline Hatch & $S_{N E S T}$ & $S_{\text {CHICK }}$ & $R_{0}$ & $R_{0}$ needed & Location & Years & Source \\
\hline 0.91 & -- & -- & -- & -- & Long Island, New York & $1937-58$ & Wilcox (1959) \\
\hline $0.72-0.79$ & -- & -- & $1.3-2.1$ & -- & Nova Scotia & $1975-76$ & Cairns (1982) \\
\hline $0.44-0.75$ & $0.19-0.44$ & -- & $0.6-2.1$ & -- & Lake of the Woods, Minnesota & $1982-84$ & $\begin{array}{l}\text { Wiens (1986); Wiens and Cuthbert } \\
\text { (1988) }\end{array}$ \\
\hline-- & -- & -- & $0.7-1.1$ & -- & Saskatchewan & $1980-81$ & Whyte (1985) \\
\hline-- & -- & -- & $0.2-1.6$ & -- & Manitoba & $1982-85$ & Haig (1987) \\
\hline 0.79 & -- & -- & $0.4-2.3$ & -- & Various areas & -- & U.S. Fish and Wildlife Service (1988) \\
\hline $0.33-0.34$ & $0.41-0.42$ & $0.65-0.77$ & $1.0-1.5$ & $1.2-1.4$ & $\begin{array}{l}\text { The Nature Conservancy's John E. Williams } \\
\text { Preserve }\end{array}$ & $1984-85$ & Gaines and Ryan (1988) \\
\hline-- & $0.09-0.84$ & $0.08-0.60$ & $0.2-1.5$ & -- & Assateague Island, Maryland and Virginia & $1984-85$ & Patterson and others (1991) \\
\hline-- & $0.26-0.48$ & 0.33 & 0.71 & $1.4-1.6$ & Assateague Island, National Seashore, Maryland & $1988-90$ & $\begin{array}{l}\text { Loegering (1992); Loegering and Fraser } \\
\text { (1995) }\end{array}$ \\
\hline-- & -- & -- & -- & 1.13 & Great Plains & -- & Ryan and others (1993) \\
\hline-- & -- & -- & 1.34 & -- & Atlantic coast & $1988-95$ & U.S. Fish and Wildlife Service (1996) \\
\hline-- & -- & -- & 1.21 & 1.25 & Atlantic coast, United States & 1989-93 & Melvin and Gibbs (1996) \\
\hline-- & -- & 0.51 & 1.04 & -- & Long Island, New York & $1992-93$ & Elias and others (2000) \\
\hline-- & -- & -- & -- & $1.3-1.7$ & All populations & -- & Plissner and Haig (2000) \\
\hline-- & 0.46 & -- & 0.33 & -- & Gavins Point Reach and Fort Randall Reach & $1991-92$ & Kruse and others (2001) \\
\hline 0.5 & -- & -- & 0.8 & -- & Long Island, New York & $1988-96$ & Lauro and Tanacredi (2002) \\
\hline-- & $0.32-0.73$ & -- & $1.4-1.6$ & -- & U.S. Alkali Wetlands & $1994-2002$ & Ivan and Murphy (2005) \\
\hline $0.46-0.51$ & -- & $0.62-0.70$ & -- & $1.1-1.6$ & Atlantic Canada & $1998-2003$ & Calvert and others (2006) \\
\hline-- & -- & $0.02-0.69$ a & -- & -- & $\begin{array}{l}\text { Lake Sakakawea, the Garrison Reach of the } \\
\text { Missouri River, Gavins Point Reach }\end{array}$ & $2001-3$ & Lefer and others (2008a) \\
\hline-- & -- & -- & 1.31 & -- & Atlantic coast & $1986-2006$ & Hecht and Melvin (2009) \\
\hline-- & $0.46-0.61$ & -- & $0.4-2.2$ & -- & Long Island, New York & $1993-2004$ & Cohen and others (2009) \\
\hline-- & $0.47-0.66$ & $0.29-0.67$ & -- & -- & Gavins Point Reach, Lewis and Clark Lake & $2005-9$ & Catlin and others $(2011 \mathrm{a}, \mathrm{b})$ \\
\hline-- & -- & -- & $0.9-1.0$ & $0.8-1.2$ & Saskatchewan & $2002-9$ & Cohen and Gratto-Trevor (2011) \\
\hline-- & $0.03-0.28$ & -- & -- & -- & Lake Sakakawea & $2006-9$ & Anteau and others (2012) \\
\hline-- & -- & -- & 0.56 & -- & Great Lakes & $1992-2011$ & Brudney and others (2013) \\
\hline-- & $0.21-0.78$ & 0.05 & -- & -- & $\begin{array}{l}\text { The Garrison Reach of the Missouri River, Lake } \\
\text { Sakakawea, Gavins Point Reach }\end{array}$ & $2006-9$ & Shaffer and others (2013) \\
\hline-- & 0.76 & -- & -- & -- & Great Lakes & $1993-2010$ & Claassen and others (2014) \\
\hline
\end{tabular}


Table 1.1. Piping plover reproductive rates and estimated reproductive output needed for a stable population (stationarity), 1959-2020.-Continued

[Mean values are presented when available; otherwise, ranges of means are presented. Hatch, hatching success expressed as a proportion of eggs hatched; $S_{N E S T}$ proportion of nests in which at least one egg hatched or estimated nest survival; $S_{\text {CHICK, }}$ survival of chicks from hatch to fledging (fledging age was variously defined); $R_{O}$ number of fledged chicks per pair; $R_{O}$ needed, fledged chicks per pair needed for a stationary population; --, no data]

\begin{tabular}{|c|c|c|c|c|c|c|c|}
\hline Hatch & $S_{N E S T}$ & $S_{\text {CHICK }}$ & $\boldsymbol{R}_{0}$ & $R_{0}$ needed & Location & Years & Source \\
\hline-- & 0.36 & 0.55 & 1.01 & 1.25 & Gavins Point Reach, Lewis and Clark Lake & $2005-11$ & Catlin and others (2015) \\
\hline-- & -- & $0.19-0.82$ & -- & -- & Fire Island and Westhampton Island, New York & $2013-15$ & DeRose-Wilson and others (2018) \\
\hline-- & $0.06-0.71 \mathrm{~b}$ & -- & -- & -- & $\begin{array}{l}\text { Cape Hatteras National Seashore, North } \\
\text { Carolina }\end{array}$ & $2008-15$ & Kwon and others (2018) \\
\hline-- & $0.33-0.80$ & 0.44 & $0.49-1.96$ & 1.10 & Fire Island and Westhampton Island, New York & $2013-17$ & Weithman and others (2019) \\
\hline-- & $0.28-0.62$ & 0.17 & $0.20-0.55$ & 1.08 & North Carolina & 2013-17 & Weithman and others (2019) \\
\hline-- & $0.27-0.46$ & $0.05-0.24 \mathrm{c}$ & -- & -- & $\begin{array}{l}\text { The Garrison Reach of the Missouri River, Lake } \\
\text { Sakakawea, U.S. Alkali Wetlands, Lake Oahe }\end{array}$ & $2014-16$ & Swift and others (2020b) \\
\hline-- & -- & $0.67-0.68^{d}$ & -- & -- & Lewis and Clark Lake & 2010 & Hunt and others (2013) \\
\hline-- & 0.76 & 0.74 & -- & -- & Platte River & $2001-15$ & Farrell and others (2018) \\
\hline-- & -- & 0.34 & -- & -- & $\begin{array}{l}\text { Cape Hatteras National Seashore, North } \\
\text { Carolina }\end{array}$ & $2015-18$ & Weithman and others (2020) \\
\hline-- & 0.45 & 0.39 & $0.36-1.63$ & 1.17 & Gavins Point Reach, Lewis and Clark Lake & $2005-9$ & Hunt and others (2018) \\
\hline-- & 0.74 & 0.16 & $1.78-2.12$ & 1.17 & Gavins Point Reach, Lewis and Clark Lake & $2012-14$ & Hunt and others (2018) \\
\hline-- & $0.5 \mathrm{e}$ & $0.47 \mathrm{~d}$ & -- & -- & Atlantic coast & $2012-15$ & Stantial and others (2018) \\
\hline-- & 0.66 & 0.46 & -- & -- & Platte River & $2009-14$ & Roche and others (2016) \\
\hline-- & $0.34-0.8$ & $0.18-0.72$ & $0.33-1.97$ & -- & Fire Island and Westhampton Island, New York & $2013-18$ & Robinson and others (2020) \\
\hline-- & $0.27-0.85$ & $0.27-0.48$ & -- & -- & $\begin{array}{l}\text { The Garrison Reach of the Missouri River, Lake } \\
\text { Sakakawea, Gavins Point Reach }\end{array}$ & $2007-16$ & Swift and others (2020c) \\
\hline-- & $0.37-0.76$ & -- & -- & -- & Atlantic coast & $2009-12$ & Cohen and others (2016) \\
\hline-- & -- & $0.75-0.83$ & -- & -- & Great Lakes & $2012-14$ & Saunders and Cuthbert (2015) \\
\hline-- & $0.11-0.37$ & $0.17-0.40$ & -- & -- & $\begin{array}{l}\text { The Garrison Reach of the Missouri River, Lake } \\
\text { Sakakawea }\end{array}$ & $2006-9$ & Anteau and others (2019) \\
\hline-- & $0.21-0.50$ & $0.43-0.71$ & -- & -- & $\begin{array}{l}\text { The Garrison Reach of the Missouri River, Lake } \\
\text { Sakakawea }\end{array}$ & $2012-14$ & Anteau and others (2019) \\
\hline-- & -- & -- & $0.09-2.11$ & $1.03-2.76$ & $\begin{array}{l}\text { U.S. Alkali Wetlands, Lake Sakakawea, the } \\
\text { Garrison Reach of the Missouri River, Lake } \\
\text { Oahe }\end{array}$ & $2014-16$ & This study \\
\hline
\end{tabular}

aDerived from daily chick survival estimates $(0.853-0.985)$ for 25 days.

bDerived from daily nest survival estimates (0.92-0.99) for 34 days.

cProportion of nests that fledged at least one chick.

dDerived from daily chick survival estimates (0.97) for 25 days.

eDerived from daily nest survival estimates $(0.98)$ for 34 days. 
Table 1.2. Return rates and survival estimates for piping plovers, 1959-2020.

[Mean values are presented when available; otherwise, ranges of means are presented. AHY, adult birds; HY, hatch-year birds; $\phi_{A H Y}$, apparent annual survival of AHY; $\phi_{H Y}$, apparent annual survival of HY (unless otherwise stated, estimates are from fledging [variously defined] to return); $S_{A H Y}$, AHY true survival (corrected for emigration from the study area); $S_{H Y}$, HY true survival (corrected for emigration from the study area); --, no data]

\begin{tabular}{|c|c|c|c|c|c|c|c|c|}
\hline \multicolumn{2}{|c|}{$\begin{array}{c}\text { Annual return rate to } \\
\text { breeding area (for AHY) or } \\
\text { natal area (for HY) }\end{array}$} & \multirow[t]{2}{*}{$\phi_{A H Y}$} & \multirow[t]{2}{*}{$\phi_{H Y}$} & \multirow[t]{2}{*}{$S_{A H Y}$} & \multirow[t]{2}{*}{$S_{H Y}$} & \multirow[t]{2}{*}{ Location } & \multirow[t]{2}{*}{ Years } & \multirow[t]{2}{*}{ Source } \\
\hline AHY & HY & & & & & & & \\
\hline 0.27 & 0.05 & -- & -- & -- & -- & Long Island, New York & $1937-58$ & Wilcox (1959) \\
\hline 0.69 & 0.25 & -- & -- & -- & -- & Lake of the Woods, Minnesota & $1982-84$ & Wiens (1986) \\
\hline 0.77 & & -- & -- & -- & -- & Manitoba & $1982-85$ & Haig (1987) \\
\hline 0.29 & 0.05 & -- & -- & -- & -- & Manitoba and Minnesota & $1981-87$ & Haig and Oring $(1988 \mathrm{a}, \mathrm{b})$ \\
\hline-- & -- & 0.63 & -- & -- & -- & $\begin{array}{l}\text { The Nature Conservancy's John E. } \\
\text { Williams Preserve }\end{array}$ & $1984-85$ & Gaines and Ryan (1988) \\
\hline 0.47 & 0.14 & 0.66 & -- & -- & -- & $\begin{array}{l}\text { The Nature Conservancy's John E. } \\
\text { Williams Preserve }\end{array}$ & $1984-90$ & Root and others (1992) \\
\hline $0.67-0.72$ & 0.41 & -- & -- & -- & -- & $\begin{array}{l}\text { Assateague Island National Seashore, } \\
\text { Maryland }\end{array}$ & 1988-90 & $\begin{array}{l}\text { Loegering (1992); Loegering and } \\
\quad \text { Fraser (1995) }\end{array}$ \\
\hline-- & -- & 0.74 & 0.48 & -- & -- & Cape Cod, Massachusetts & $1985-88$ & Melvin and Gibbs (1996) \\
\hline-- & -- & 0.74 & 0.32 & -- & -- & U.S. Alkali Wetlands & 1984-94 & Larson and others (2000) \\
\hline-- & -- & 0.73 & $0.34-0.53$ & -- & -- & Atlantic Canada & 1998-2003 & Calvert and others (2006) \\
\hline-- & $0.11-0.13$ & -- & -- & 0.7 & -- & Long Island, New York & $2001-5$ & Cohen and others (2006) \\
\hline-- & -- & -- & -- & 0.76 & -- & Great Lakes & $1998-2008$ & LeDee and others (2010) \\
\hline-- & -- & 0.78 & $0.29 \mathrm{a}$ & -- & -- & Great Lakes & 1998-2008 & Roche and others (2008) \\
\hline-- & -- & $0.56-0.81$ & -- & -- & -- & All populations & 1998-2008 & Roche and others (2010) \\
\hline-- & -- & -- & -- & 0.8 & 0.57 & Saskatchewan & $2002-9$ & Cohen and Gratto-Trevor (2011) \\
\hline-- & -- & 0.73 & $0.33^{b}$ & -- & -- & $\begin{array}{l}\text { Gavins Point Reach, Lewis and Clark } \\
\text { Lake }\end{array}$ & $2005-11$ & Catlin and others (2014) \\
\hline-- & -- & 0.73 & 0.37 & -- & -- & Great Lakes & 1993-2012 & Saunders and others (2014) \\
\hline-- & -- & $0.51-0.79$ & $0.14 \mathrm{c}$ & 0.76 & 0.44 & $\begin{array}{l}\text { Gavins Point Reach, Lewis and Clark } \\
\text { Lake }\end{array}$ & $2005-11$ & Catlin and others (2015) \\
\hline-- & -- & 0.78 & 0.22 & -- & -- & Great Lakes & 1993-2016 & Saunders and others (2018) \\
\hline-- & -- & $0.66-0.76$ & -- & -- & -- & $\begin{array}{l}\text { The Garrison Reach of the Missouri } \\
\text { River, Lake Sakakawea }\end{array}$ & $2007-14$ & Anteau and others (2019) \\
\hline-- & -- & -- & -- & 0.72 & 0.68 & $\begin{array}{l}\text { Fire Island and Westhampton Island, } \\
\text { New York }\end{array}$ & $2013-18$ & Robinson and others (2020) \\
\hline-- & -- & $0.68-0.83$ & $0.06-0.49$ & -- & -- & -- & $2005-14$ & Hunt and others (2018) \\
\hline
\end{tabular}


Table 1.2. Return rates and survival estimates for piping plovers, 1959-2020.-Continued

[Mean values are presented when available; otherwise, ranges of means are presented. AHY, adult birds; HY, hatch-year birds; $\phi_{A H Y}$, apparent annual survival of AHY; $\phi_{H Y}$, apparent annual survival of HY (unless otherwise stated, estimates are from fledging [variously defined] to return); $S_{A H Y}$, AHY true survival (corrected for emigration from the study area); $S_{H Y}$, HY true survival (corrected for emigration from the study area); --, no data]

\begin{tabular}{|c|c|c|c|c|c|c|c|c|}
\hline \multicolumn{2}{|c|}{$\begin{array}{c}\text { Annual return rate to } \\
\text { breeding area (for AHY) or } \\
\text { natal area (for HY) }\end{array}$} & \multirow[t]{2}{*}{$\phi_{A H Y}$} & \multirow[t]{2}{*}{$\phi_{H Y}$} & \multirow[t]{2}{*}{$S_{A H Y}$} & \multirow[t]{2}{*}{$S_{H Y}$} & \multirow[t]{2}{*}{ Location } & \multirow[t]{2}{*}{ Years } & \multirow[t]{2}{*}{ Source } \\
\hline AHY & HY & & & & & & & \\
\hline-- & -- & -- & -- & 0.7 & 0.24 & $\begin{array}{l}\text { Gavins Point Reach, Lewis and Clark } \\
\text { Lake, Platte River }\end{array}$ & $2005-14$ & Catlin and others (2016) \\
\hline-- & -- & 0.76 & 0.2 & -- & -- & Platte River & 2009-14 & Roche and others (2016) \\
\hline-- & -- & -- & -- & 0.73 & 0.23 & $\begin{array}{l}\text { Fire Island and Westhampton Island, } \\
\text { New York }\end{array}$ & $2013-17$ & Weithman and others (2019) \\
\hline-- & -- & -- & -- & 0.69 & 0.08 & North Carolina & 2013-17 & Weithman and others (2019) \\
\hline-- & -- & -- & -- & 0.76 & 0.16 & $\begin{array}{l}\text { Gavins Point Reach, Lewis and Clark } \\
\text { Lake }\end{array}$ & 2005-09 & Hunt and others (2018) \\
\hline-- & -- & -- & -- & 0.76 & 0.46 & $\begin{array}{l}\text { Gavins Point Reach, Lewis and Clark } \\
\text { Lake }\end{array}$ & $2012-14$ & Hunt and others (2018) \\
\hline-- & -- & $0.67-0.76$ & -- & -- & -- & Atlantic coast & $2015-18$ & Stantial and others (2019) \\
\hline-- & -- & -- & -- & $0.58^{\mathrm{d} \_0.80}$ & 0.25 & $\begin{array}{l}\text { Gavins Point Reach, Lewis and Clark } \\
\text { Lake }\end{array}$ & $2005-14$ & Catlin and others (2019) \\
\hline-- & -- & -- & -- & $0.76-0.85$ & $0.19-0.30^{\mathrm{c}}$ & $\begin{array}{l}\text { U.S. Alkali Wetlands, Lake } \\
\text { Sakakawea, the Garrison Reach of } \\
\text { the Missouri River, Lake Oahe }\end{array}$ & 2014-19 & This study \\
\hline
\end{tabular}

aProvided estimates for wild and captive-reared chicks. Only information from wild-reared individuals presented.

bEstimates from a subset of HY birds that were captured and measured before fledging.

cEstimated from hatch to the following year.

dEstimate for nonbreeding individuals. 
Table 1.3. Piping plover site fidelity, 1959-2020.

[Mean values are presented when available; otherwise, ranges of means are presented. $F_{A H Y}$, adult (AHY) fidelity to the study area; $F_{H Y}$, hatch-year (HY) fidelity to the study area; $F_{A H Y}^{\prime}$, return rate of AHY birds that previously emigrated from the study area; $F_{H Y}^{\prime}$, return rate of HY birds that previously emigrated from the study area; --, no data]

\begin{tabular}{|c|c|c|c|c|c|c|}
\hline$F_{A H Y}$ & $F_{H Y}$ & $F_{A H Y}^{\prime}$ & $F_{H Y}^{\prime}$ & Location & Years & Source \\
\hline 0.83 & -- & -- & -- & Long Island, New York & $2002-4$ & Cohen and others (2006) \\
\hline 0.91 & -- & 0.2 & -- & Great Lakes & $1998-2008$ & LeDee and others (2010) \\
\hline 0.86 & 0.46 & 0.15 & 0.19 & Saskatchewan & $2002-9$ & Cohen and Gratto-Trevor (2011) \\
\hline $0.89-0.99$ & & & & Saskatchewan & $2002-9$ & Roche and others (2012) \\
\hline $0.94 \mathrm{a}$ & $0.68^{\mathrm{a}}$ & 0.11 & 0.11 & Gavins Point Reach, Lewis and Clark Lake & $2005-11$ & Catlin and others (2015) \\
\hline $0.91-0.92$ & 0.81 & -- & -- & Fire Island and Westhampton Island, New York & $2013-17$ & Weithman and others (2019) \\
\hline 0.94 & 0.85 & -- & -- & North Carolina & $2013-17$ & Weithman and others (2019) \\
\hline $0.76-0.98$ & $0.52-0.88$ & -- & -- & Gavins Point Reach, Lewis and Clark Lake & $2005-14$ & Hunt and others (2018) \\
\hline 0.74 & 0.39 & -- & -- & Fire Island and Westhampton Island, New York & $2013-18$ & Robinson and others (2020) \\
\hline $0.52-0.75$ & $0.32-0.58$ & -- & -- & $\begin{array}{l}\text { U.S. Alkali Wetlands, Lake Sakakawea, the Garrison Reach of the } \\
\text { Missouri River, Lake Oahe }\end{array}$ & 2014-19 & This study \\
\hline
\end{tabular}

aDefined movements between engineered and natural sandbars within the study area but referred to the probability of remaining within the study area as site fidelity $(F)$. 
Table 1.4. Piping plover dispersal distances, 1959-2020.

[--, no data]

Dispersal distance, in kilometers

\begin{tabular}{|c|c|c|c|c|c|c|}
\hline \multicolumn{4}{|c|}{ Dispersal distance, in kilometers } & \multirow{3}{*}{ Location } & \multirow{3}{*}{ Years } & \multirow{3}{*}{ Source } \\
\hline \multicolumn{2}{|c|}{ Adult (2 years and older) } & \multicolumn{2}{|c|}{ Hatch year } & & & \\
\hline Median & Range & Median & Range & & & \\
\hline-- & -- & -- & $1,200^{\mathrm{a}}$ & Great Lakes & -- & Hillman and others (2012) \\
\hline 0.5 & $0.01-298.6$ & 27.98 & $0.4-306.3$ & Gulf of St. Lawrence & $1998-2003$ & Amirault-Langlais and others (2014) \\
\hline 4 & $0.01-70.7$ & 18.57 & $6.5-74.8$ & Nova Scotia & $1998-2003$ & Amirault-Langlais and others (2014) \\
\hline 153 & $0.01-92.6$ & -- & -- & Gavins Point Reach, Lewis and Clark Lake & $2005-12$ & Friedrich and others (2015) \\
\hline-- & $0.01-217.3$ & -- & -- & Gulf of St. Lawrence & 1998-2006 & Rioux and others (2011) \\
\hline-- & $3-595$ & -- & $5-1,500$ & All populations & $1981-87$ & Haig and Oring (1988a) \\
\hline 11.92 & $0.25-92.6$ & 19.28 & $0.98-91.9$ & Gavins Point Reach, Lewis and Clark Lake & $2005-14$ & Catlin and others (2015) \\
\hline 3.7 & $0.05-816$ & 53.0 & $1-410$ & $\begin{array}{l}\text { U.S. Alkali Wetlands, Lake Sakakawea, the } \\
\text { Garrison Reach of the Missouri River, } \\
\text { Lake Oahe }\end{array}$ & 2014-19 & This study \\
\hline
\end{tabular}

aReport of a single individual's movement between breeding groups. 


\section{References Cited}

Amirault-Langlais, D.L., Imlay, T.L., and Boyne, A.W., 2014, Dispersal patterns suggest two breeding populations of piping plovers in eastern Canada: The Wilson Journal of Ornithology, v. 126, no. 2, p. 352-359. [Also available at https://doi.org/10.1676/13-056.1.]

Anteau, M.J., Shaffer, T.L., Sherfy, M.H., Sovada, M.A., Stucker, J.H., and Wiltermuth, M.T., 2012, Nest survival of piping plovers at a dynamic reservoir indicates an ecological trap for a threatened population: Oecologia, v. 170, no. 4, p. 1167-1179. [Also available at https://doi.org/ 10.1007/s00442-012-2384-y.]

Anteau, M.J., Sherfy, M.H., Shaffer, T.L., Swift, R.J., Toy, D.L., and Dovichin, C.M., 2019, Demographic responses of least terns and piping plovers to the 2011 Missouri River flood-A large-scale case study: U.S. Geological Survey Open-File Report 2018-1176, 33 p. [Also available at https://doi.org/10.3133/ofr20181176.]

Brudney, L.J., Arnold, T.W., Saunders, S.P., and Cuthbert, F.J., 2013, Survival of piping plover (Charadrius melodus) chicks in the Great Lakes region: The Auk, v. 130, no. 1, p. 150-160. [Also available at https://doi.org/10.1525/ auk.2012.12109.]

Cairns, W.E., 1982, Biology and behavior of breeding piping plovers: The Wilson Bulletin, v. 94, p. 531-545.

Calvert, A.M., Amirault, D.L., Shaffer, F., Elliot, R., Hanson, A., McKnight, J., and Taylor, P.D., 2006, Population assessment of an endangered shorebird-The piping plover (Charadrius melodus melodus) in eastern Canada: Avian Conservation \& Ecology, v. 1, no. 3, p. art4. [Also available at https://doi.org/10.5751/ACE-00091-010304.]

Catlin, D.H., Felio, J.H., and Fraser, J.D., 2011a, Effect of great horned owl trapping on chick survival in piping plovers: The Journal of Wildlife Management, v. 75, no. 2, p. 458-462. [Also available at https://doi.org/10.1002/ jwmg.56.]

Catlin, D.H., Fraser, J.D., Felio, J.H., and Cohen, J.B., 2011b, Piping plover habitat selection and nest success on natural, managed, and engineered sandbars: The Journal of Wildlife Management, v. 75 , no. 2, p. 305-310. [Also available at https://doi.org/10.1002/jwmg.46.]

Catlin, D.H., Milenkaya, O., Hunt, K.L., Friedrich, M.J., and Fraser, J.D., 2014, Can river management improve the piping plover's long-term survival on the Missouri River?: Biological Conservation, v. 180, p. 196-205. [Also available at https://doi.org/10.1016/j.biocon.2014.10.004.]
Catlin, D.H., Fraser, J.D., and Felio, J.H., 2015, Demographic responses of piping plovers to habitat creation on the Missouri River: Wildlife Monographs, v. 192, no. 1, p. 1-42. [Also available at https://doi.org/10.1002/ wmon.1016.]

Catlin, D.H., Zeigler, S.L., Brown, M.B., Dinan, L.R., Fraser, J.D., Hunt, K.L., and Jorgensen, J.G., 2016, Metapopulation viability of an endangered shorebird depends on dispersal and human-created habitats-Piping plovers (Charadrius melodus) and prairie rivers: Movement Ecology, v. 4, no. 1, p. 6. [Also available at https://doi.org/10.1186/s40462016-0072-y.]

Catlin, D.H., Gibson, D., Hunt, K.L., Friedrich, M.J., Weithman, C.E., Karpanty, S.M., and Fraser, J.D., 2019, Direct and indirect effects of nesting density on survival and breeding propensity of an endangered shorebird: Ecosphere, v. 10, no. 6, p. e02740. [Also available at https://doi.org/ $10.1002 /$ ecs2.2740.]

Claassen, A.H., Arnold, T.W., Roche, E.A., Saunders, S.P., and Cuthbert, F.J., 2014, Factors influencing nest survival and renesting by piping plovers in the Great Lakes region: The Condor, v. 116, p. 394-407. [Also available at https://doi.org/10.1650/CONDOR-13-146.1.]

Cohen, J.B., Fraser, J.D., and Catlin, D.H., 2006, Survival and site fidelity of piping plovers on Long Island, New York: Journal of Field Ornithology, v. 77, no. 4, p. 409-417. [Also available at https://doi.org/10.1111/j.15579263.2006.00072.x.]

Cohen, J.B., and Gratto-Trevor, C., 2011, Survival, site fidelity, and the population dynamics of piping plovers in Saskatchewan: Journal of Field Ornithology, v. 82, no. 4, p. 379-394. [Also available at https://doi.org/10.1111/ j.1557-9263.2011.00341.x.]

Cohen, J.B., Houghton, L.M., and Fraser, J.D., 2009, Nesting density and reproductive success of piping plovers in response to storm- and human-created habitat changes: Wildlife Monographs, v. 173, p. 1-24. [Also available at https://doi.org/10.2193/2007-553.]

Cohen, J.B., Hecht, A., Robinson, K.F., Osnas, E.E., Tyre, A.J., Davis, C., Kocek, A., Maslo, B., and Melvin, S.M., 2016, To exclose nests or not-Structured decision making for the conservation of a threatened species: Ecosphere, v. 7, no. 10, p. e01499. [Also available at https://doi.org/10.1002/ ecs2.1499.]

DeRose-Wilson, A.L., Hunt, K.L., Monk, J.D., Catlin, D.H., Karpanty, S.M., and Fraser, J.D., 2018, Piping plover chick survival negatively correlated with beach recreation: The Journal of Wildlife Management, v. 82, no. 8, p. 1608-1616. [Also available at https://doi.org/10.1002/jwmg.21552] 
Elias, S.P., Fraser, J.D., and Buckley, P.A., 2000, Piping plover brood foraging ecology on New York barrier islands: The Journal of Wildlife Management, v. 64, no. 2, p. 346-354. [Also available at https://doi.org/10.2307/3803232.]

Farrell, P., Baasch, D., Farnsworth, J., and Smith, C., 2018, Interior least tern and piping plover nest and brood survival at managed, off-channel sites along the central Platte River, Nebraska, USA 2001-2015: Avian Conservation \& Ecology, v. 13, no. 1, p. art1. [Also available at https://doi.org/ 10.5751/ACE-01133-130101.]

Friedrich, M.J., Hunt, K.L., Catlin, D.H., and Fraser, J.D., 2015, The importance of site to mate choice-Mate and site fidelity in piping plovers: The Auk, v. 132, no. 1, p. 265-276. [Also available at https://doi.org/10.1642/ AUK-14-100.1.]

Gaines, E.P., and Ryan, M.R., 1988, Piping plover habitat use and reproductive success in North Dakota: The Journal of Wildlife Management, v. 52, no. 2, p. 266-273. [Also available at https://doi.org/10.2307/3801233.]

Haig, S.M., 1987, The population biology and life history patterns of the piping plover: Grand Forks, University of North Dakota, Ph.D. dissertation.

Haig, S.M., and Oring, L.W., 1988a, Distribution and dispersal in the piping plover: The Auk, v. 105, no. 4, p. 630-638. [Also available at https://doi.org/10.1093/auk/105.4.630.]

Haig, S.M., and Oring, L.W., 1988b, Mate, site, and territory fidelity in piping plovers: The Auk, v. 105, no. 2, p. 268-277. [Also available at https://doi.org/10.2307/ 4087489.]

Hecht, A., and Melvin, S.M., 2009, Population trends of Atlantic coast piping plovers, 1986-2006: Waterbirds, v. 32, no. 1, p. 64-72. [Also available at https://doi.org/10.1675/ 063.032.0107.]

Hillman, M.D., Karpanty, S.M., Fraser, J.D., Cuthbert, F.J., Altman, J.M., Borneman, T.E., and DeRose-Wilson, A., 2012, Evidence for long-distance dispersal and successful interpopulation breeding of the endangered piping plover: Waterbirds, v. 35, no. 4, p. 642-644. [Also available at https://doi.org/10.1675/063.035.0414.]

Hunt, K.L., Catlin, D.H., Felio, J.H., and Fraser, J.D., 2013, Effect of capture frequency on the survival of piping plover chicks: Journal of Field Ornithology, v. 84, no. 3, p. 299-303. [Also available at https://doi.org/10.1111/ jofo.12028.]
Hunt, K.L., Fraser, J.D., Friedrich, M.J., Karpanty, S.M., and Catlin, D.H., 2018, Demographic response of piping plovers suggests that engineered habitat restoration is no match for natural riverine processes: The Condor, v. 120, p. 149-165. [Also available at https://doi.org/10.1650/CONDOR17-93.1.]

Ivan, J.S., and Murphy, R.K., 2005, What preys on piping plover eggs and chicks?: Wildlife Society Bulletin, v. 33, no. 1, p. 113-119. [Also available at https://doi.org/10.2193/ 0091-7648(2005)33[113:WPOPPE]2.0.CO;2.]

Kruse, C.D., Higgins, K.F., and Lee, B.A.V., 2001, Influence of predation on piping plover, Charadrius melodus, and least tern, Sterna antillarum, productivity along the Missouri River in South Dakota: Canadian Field Naturalist, v. 115 , p. $480-486$.

Kwon, E., Fraser, J.D., Catlin, D.H., Karpanty, S.M., Weithman, C.E., and Muiznieks, B., 2018, Presence of ghost crabs and piping plover nesting success: The Journal of Wildlife Management, v. 82, no. 4, p. 850-856. [Also available at https://doi.org/10.1002/jwmg.21422.]

Larson, M.A., Ryan, M.R., and Root, B.G., 2000, Piping plover survival in the Great Plains - An updated analysis: Journal of Field Ornithology, v. 71, no. 4, p. 721-729. [Also available at https://doi.org/10.1648/0273-8570-71.4.721.]

Lauro, B., and Tanacredi, J., 2002, An examination of predatory pressures on piping plovers nesting at Breezy Point, New York: Waterbirds, v. 25, no. 4, p. 401-409. [Also available at https://doi.org/10.1675/15244695(2002)025[0401:AEOPPO]2.0.CO;2.]

Le Fer, D., Fraser, J.D., and Kruse, C.D., 2008a, Piping plover chick foraging, growth, and survival in the Great Plains: The Journal of Wildlife Management, v. 72, no. 3, p. 682-687. [Also available at https://doi.org/10.2193/ 2007-097.]

LeDee, O.E., Arnold, T.W., Roche, E.A., and Cuthbert, F.J., 2010, Use of breeding and nonbreeding encounters to estimate survival and breeding-site fidelity of the piping plover at the Great Lakes: The Condor, v. 112, no. 4, p. 637-643. [Also available at https://doi.org/10.1525/ cond.2010.100017.]

Loegering, J.P., 1992, Piping plover breeding biology, foraging ecology and behavior on Assateague Island National Seashore, Maryland: Blacksburg, Virginia Polytechnic Institute and State University, Ph.D. dissertation, 248 p. [Also available at https://vtechworks.lib.vt.edu/handle/10919/44548.] 
Loegering, J.P., and Fraser, J.D., 1995, Factors affecting piping plover chick survival in different brood-rearing habitats: The Journal of Wildlife Management, v. 59, no. 4, p. 646-655. [Also available at https://doi.org/10.2307/ 3801940.]

Melvin, S.M., and Gibbs, J.P., 1996, Viability analysis for the Atlantic coast population of piping plovers, in Piping plover (Charadrius melodus) Atlantic coast population-Revised recovery plan: Hadley, Mass., U.S. Fish and Wildlife Service, p. 175-186. [Also available at https://www.fws.gov/northeast/pipingplover/pdf/entire plan.pdf.]

Patterson, M.E., Fraser, J.D., and Roggenbuck, J.W., 1991, Factors affecting piping plover productivity on Assateague Island: The Journal of Wildlife Management, v. 55, no. 3, p. 525-531. [Also available at https://doi.org/10.2307/ 3808985.]

Plissner, J.H., and Haig, S.M., 2000, Viability of piping plover Charadrius melodus metapopulations: Biological Conservation, v. 92, no. 2, p. 163-173. [Also available at https://doi.org/10.1016/S0006-3207(99)00050-6.]

Rioux, S., Amirault-Langlais, D.L., and Shaffer, F., 2011, Piping plovers make decisions regarding dispersal based on personal and public information in a variable coastal ecosystem: Journal of Field Ornithology, v. 82, no. 1, p. 32-43. [Also available at https://doi.org/10.1111/j.15579263.2010.00305.x.]

Robinson, S.G., Gibson, D., Riecke, T.V., Fraser, J.D., Bellman, H.A., DeRose-Wilson, A., Karpanty, S.M., Walker, K.M., and Catlin, D.H., 2020, Piping plover population increase after Hurricane Sandy mediated by immigration and reproductive output: The Condor, p. duaa041. [Also available at https://doi.org/10.1093/condor/duaa041.]

Roche, E.A., Cohen, J.B., Catlin, D.H., Amirault-Langlais, D.L., Cuthbert, F.J., Gratto-Trevor, C.L., Felio, J., and Fraser, J.D., 2010, Range-wide piping plover survivalCorrelated patterns and temporal declines: The Journal of Wildlife Management, v. 74, no. 8, p. 1784-1791. [Also available at https://doi.org/10.2193/2009-446.]

Roche, E.A., Cuthbert, F.J., and Arnold, T.W., 2008, Relative fitness of wild and captive-reared piping plovers-Does egg salvage contribute to recovery of the endangered Great Lakes population?: Biological Conservation, v. 141, no. 12, p. 3079-3088. [Also available at https://doi.org/10.1016/ j.biocon.2008.09.014.]

Roche, E.A., Gratto-Trevor, C.L., Goossen, J.P., and White, C.L., 2012, Flooding affects dispersal decisions in piping plovers (Charadrius melodus) in prairie Canada: The Auk, v. 129, no. 2, p. 296-306. [Also available at https://doi.org/ 10.1525/auk.2012.11196.]
Roche, E.A., Shaffer, T.L., Dovichin, C.M., Sherfy, M.H., Anteau, M.J., and Wiltermuth, M.T., 2016, Synchrony of piping plover breeding populations in the U.S. Northern Great Plains: The Condor, v. 118, no. 3, p. 558-570. [Also available at https://doi.org/10.1650/CONDOR-15-195.1.]

Root, B.G., Ryan, M.R., and Mayer, P.M., 1992, Piping plover survival in the Great Plains: Journal of Field Ornithology, v. 63 , p. $10-15$.

Ryan, M.R., Root, B.G., and Mayer, P.M., 1993, Status of piping plovers in the Great-Plains of North-America-A demographic simulation model: Conservation Biology, v. 7, no. 3, p. 581-585. [Also available at https://doi.org/ 10.1046/j.1523-1739.1993.07030581.x.]

Saunders, S.P., Arnold, T.W., Roche, E.A., and Cuthbert, F.J., 2014, Age-specific survival and recruitment of piping plovers Charadrius melodus in the Great Lakes region: Journal of Avian Biology, v. 45, no. 5, p. 437-449. [Also available at https://doi.org/10.1111/jav.00319.]

Saunders, S.P., and Cuthbert, F.J., 2015, Chick mortality leads to male-biased sex ratios in endangered Great Lakes piping plovers: Journal of Field Ornithology, v. 86, no. 2, p. 103-114. [Also available at https://doi.org/10.1111/ jofo.12094.]

Saunders, S.P., Cuthbert, F.J., and Zipkin, E.F., 2018, Evaluating population viability and efficacy of conservation management using integrated population models: Journal of Applied Ecology, v. 55, no. 3, p. 1380-1392. [Also available at https://doi.org/10.1111/1365-2664.13080.]

Shaffer, T.L., Sherfy, M.H., Anteau, M.J., Stucker, J.H., Sovada, M.A., Roche, E.A., Wiltermuth, M.T., Buhl, T.K., and Dovichin, C.M., 2013, Accuracy of the Missouri River least tern and piping plover monitoring programConsiderations for the future: U.S. Geological Survey Open-File Report 2013-1176, 74 p. [Also available at https://doi.org/10.3133/ofr20131176.]

Stantial, M.L., Cohen, J.B., Darrah, A.J., Iaquinto, K.E., Loring, P.H., and Paton, P.W., 2018, Radio transmitters did not affect daily nest and chick survival of piping plovers (Charadrius melodus): The Wilson Journal of Ornithology, v. 130 , no. 2, p. 518-524. [Also available at https://doi.org/ 10.1676/16-214.1.]

Stantial, M.L., Cohen, J.B., Loring, P.H., and Paton, P.W., 2019, Radio transmitters did not affect apparent survival rates of adult piping plovers (Charadrius melodus): Waterbirds, v. 42, no. 2, p. 205-209. [Also available at https://doi.org/10.1675/063.042.0207.] 
Swift, R.J., Anteau, M.J., Ring, M.M., Toy, D.L., and Sherfy, M.H., 2020b, Low renesting propensity and reproductive success make renesting unproductive for the threatened piping plover (Charadrius melodus): The Condor, v. 122, no. 2, duz066. [Also available at https://doi.org/10.1093/ condor/duz066.]

Swift, R.J., Anteau, M.J., Roche, E.A., Sherfy, M.H., Toy, D.L., and Ring, M.M., 2020c, Asymmetric benefits of a heterospecific breeding association vary with habitat, conspecific abundance, and breeding stage: Oikos, v. 129, no. 10, p. 1504-1520. [Also available at https://doi.org/10.1111/ oik.07256.]

U.S. Fish and Wildlife Service [USFWS], 1985, Determination of endangered and threatened status for the piping plover: Washington, D.C., U.S. Fish and Wildlife Service.

U.S. Fish and Wildlife Service [USFWS], 1988, Atlantic coast piping plover recovery plan: Newton Corner, Mass., U.S. Fish and Wildlife Service.

U.S. Fish and Wildlife Service [USFWS], 1996, Piping plover (Charadrius melodus) Atlantic coast population-Revised recovery plan: Hadley, Mass., U.S. Fish and Wildlife Service, 245 p. [Also available at https://www.fws.gov/ northeast/pipingplover/pdf/entire_plan.pdf.]
Weithman, C.E., Robinson, S.G., Hunt, K.L., Altman, J., Bellman, H.A., DeRose-Wilson, A.L., Walker, K.M., Fraser, J.D., Karpanty, S.M., and Catlin, D.H., 2019, Growth of two Atlantic Coast piping plover populations: The Condor, v. 121 , no. 3 , p. $1-14$.

Weithman, C.E., Fraser, J.D., Karpanty, S.M., and Catlin, D.H., 2020, Relationship of current management practices to movements of piping plover broods in an Atlantic Coast population: Journal of Field Ornithology, v. 91, no. 2, p. 170-188. [Also available at https://doi.org/10.1111/ jofo.12333.]

Whyte, A.J., 1985, Breeding ecology of the piping plover (Charadrius melodus) in central Saskatchewan: Saskatoon, Canada, University of Saskatchewan, Ph.D. dissertation.

Wiens, T.P., and Cuthbert, F.J., 1988, Nest-site tenacity and mate retention of the piping plover: The Wilson Bulletin, v. 100, p. 545-553.

Wiens, T.P., 1986, Nest-site tenacity and mate retention in the piping plover (Charadrius melodus): Minneapolis, University of Minnesota, Ph.D. dissertation.

Wilcox, L.R., 1959, A twenty year banding study of the piping plover: The Auk, v. 76, no. 2, p. 129-152. [Also available at https://doi.org/10.2307/4081772.] 
For more information about this publication, contact: Director, USGS Northern Prairie Wildlife Research Center 8711 37th Street Southeast

Jamestown, ND 58401

701-253-5500

For additional information, visit: https://www.usgs.gov/centers/npwrc

Publishing support provided by the

Rolla Publishing Service Center 


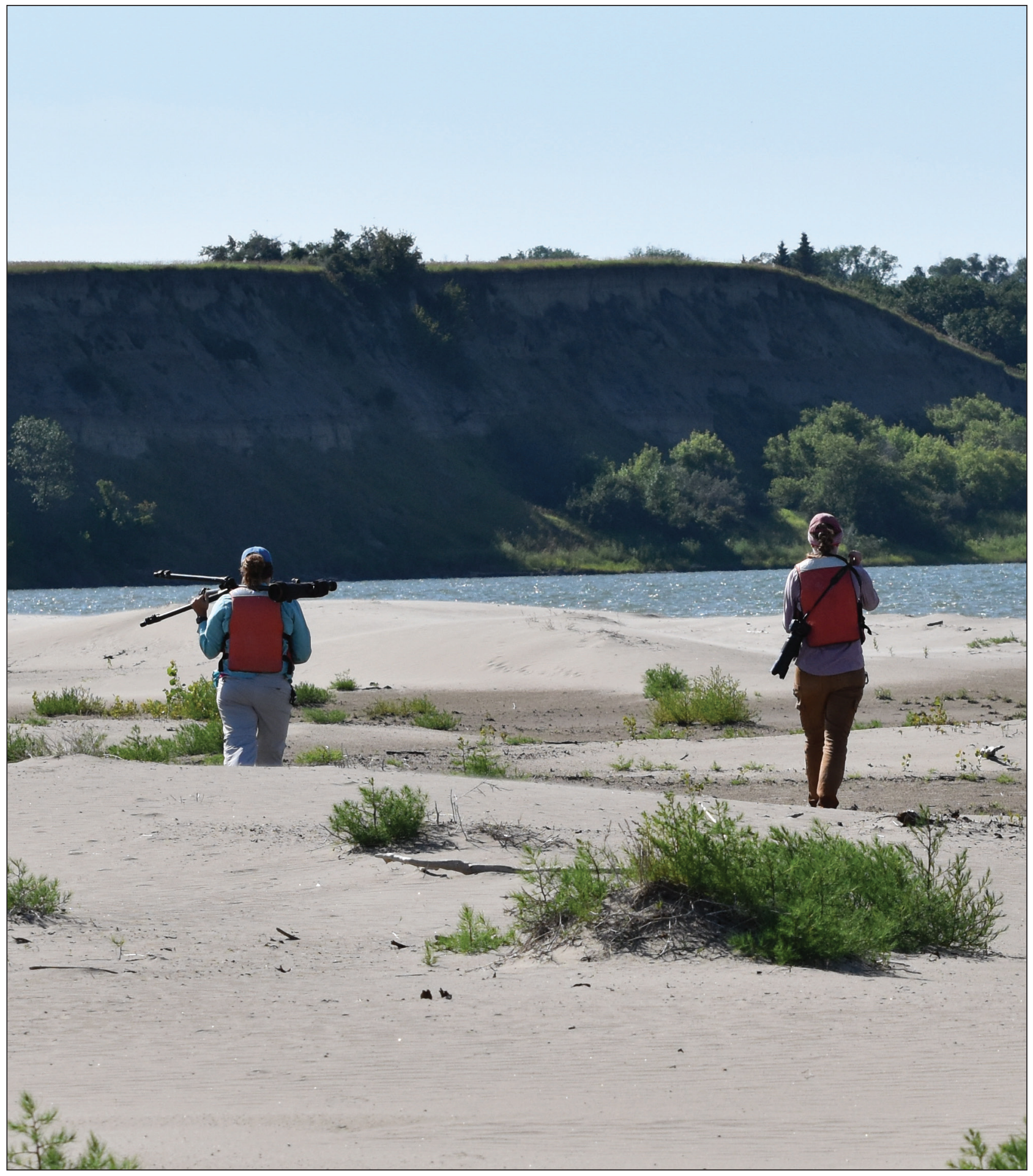

